Literatura latinoamericana mundial 


\section{Latin American Literatures in the World}

\section{Literaturas Latinoamericanas en el Mundo}

Edited by / Editado por Gesine Müller

Volume 5 / Volumen 5 


\section{Literatura}

latinoamericana mundial

Dispositivos y disidencias

Editado por / Edited by

Gustavo Guerrero, Jorge J. Locane, Benjamin Loy y Gesine Müller 
This project has received funding from the European Research Council (ERC) under the European Union's Horizon 2020 Research and Innovation programme - Grant Agreement Number 646714
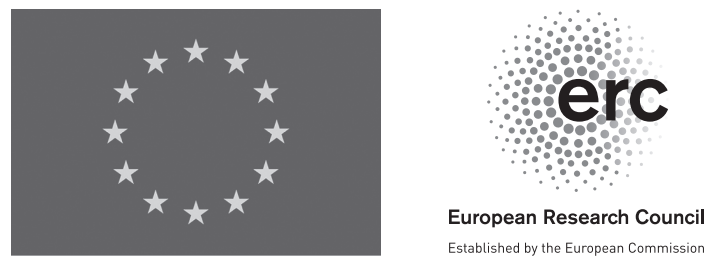

ISBN 978-3-11-067365-4

e-ISBN (PDF) 978-3-11-067367-8

e-ISBN (EPUB) 978-3-11-067379-1

ISSN 2513-0757

e-ISSN 2513-0765

\section{(cc) BY-NC-ND}

This work is licensed under a Creative Commons Attribution-NonCommercial-NoDerivatives 4.0 International License. For details go to: https://creativecommons.org/licenses/by-nc-nd/4.0/.

\section{Library of Congress Control Number: 2019949720}

\section{Bibliographic information published by the Deutsche Nationalbibliothek}

The Deutsche Nationalbibliothek lists this publication in the Deutsche Nationalbibliografie; detailed bibliographic data are available on the Internet at http://dnb.dnb.de.

(C) 2020 Gustavo Guerrero, Jorge J. Locane, Benjamin Loy and Gesine Müller, published by Walter de Gruyter GmbH, Berlin/Boston

The book is published with open access at www.degruyter.com.

Typesetting: Integra Software Services Pvt. Ltd.

Printing and binding: CPI books $\mathrm{GmbH}$, Leck

www.degruyter.com 


\section{Contenidos}

Gustavo Guerrero, Jorge J. Locane, Benjamin Loy, Gesine Müller A modo de introducción. Literatura latinoamericana: inflexiones de un término - 1

\section{Gatekeepers}

Gesine Müller

Gatekeeping and the Conceptualization of World Literature in the Publishing Industry. The Case of Siegfried Unseld and Octavio Paz -17

Judith Illerhaus

Premios porteros. La función del Premio Biblioteca Breve con base en números - 33

Maarten Steenmeijer

Ascenso y ocaso de una marca: la literatura hispanoamericana en Holanda -49

Gustavo Guerrero

José Lezama Lima en Francia: apuntes sobre la mediación editorial, la traducción y la recepción de Paradiso — 61

Ana Gallego Cuiñas

Feminismo y literatura (argentina) mundial: Selva Almada, Mariana Enríquez y Samanta Schweblin — 71

Idun Heir Senstad Literary Diversity through Translation: The Role of Independent Cultural Mediators in the Selection of Cuban Literature in Norway — 97

\section{Traducción}

Annick Louis

El Aleph de Roger Caillois en Gallimard o de cómo salir del laberinto - 125 
VI Contenidos

Liset Díaz Martínez

Gabriel García Márquez traducido: observaciones sobre la variación — 147

Yehua Chen

Traitors or Traders? A Brief Analysis of Chinese Translations of

Latin American Boom Writers — 173

Sara Carini

"Tante cose venivano pubblicate ma hanno dovuto aspettare un altro

momento": la literatura latinoamericana y sus re-traducciones — 191

Ilse Logie

¿Escritos en la traducción y para la traducción? Dos ejemplos:

Valeria Luiselli y Mario Bellatin — 207

Cecilia Alvstad

Anthropology over Aesthetics: On the Poetics of Movement and

Multilingualism in Three Translations of Yuri Herrera's

Señales que precederán al fin del mundo - 223

Benjamin Loy

Glotopolíticas literarias entre resistencia y mercado:

Bolaño en traducción, la traducción en Bolaño — 243

\section{Literaturas locales}

Ignacio M. Sánchez Prado

Cosmopolitismo copyleft. Tumbona Ediciones, autonomía y localidad -267

Silja Helber

¿Cuanto más marginal, más central? - La escritura de Rita Indiana — 279

Matías Moscardi

Audiometrías contemporáneas. La escucha como modo de circulación en la poesía argentina actual -291 
Jorge J. Locane

“Los últimos centímetros de un lápiz de grafito".

Mercado, (neo)autonomía y la 'operación Mike Wilson' — 305

Autores - 319 

Gustavo Guerrero, Jorge J. Locane, Benjamin Loy, Gesine Müller

\section{A modo de introducción. Literatura latinoamericana: inflexiones de un término}

La literatura latinoamericana es un constructo cuya gestación se puede fechar en los años 60 del siglo pasado. Después de la Revolución Cubana, el territorio al sur del Río Bravo termina por recortarse y ganar visibilidad para el resto del mundo como una unidad geocultural en efecto existente y más o menos homogénea. Si se le da crédito a los postulados de José Donoso en su Historia personal del "boom" (1972), es en estos años que la literatura latinoamericana comienza a proyectarse programáticamente y con altura hacia el mundo, y a ser percibida como expresión de "grandes símbolos identitarios" asociados con la región (Avelar 23; cf. también Müller). Pero también habría que anotar que, como efecto de la Revolución Cubana, por aquel entonces se acentuó en América Latina un esfuerzo crítico por aislar -o, acaso, inventar- las especificidades que harían de la literatura del subcontinente algo relativamente homogéneo y diferenciado de las literaturas de otras regiones del mundo. Junto con este proceso vernáculo, además, habría que mencionar la propagación de los estudios areales en los centros de poder mundial comprometidos en la así denominada Guerra Fría. Varias publicaciones de la época, cuyo fundamento suele retrotraerse hasta "Nuestra América” (1891), de José Martí, son testimonio del Zeitgeist que dominaba la región en dicha coyuntura. La literatura latinoamericana como proceso (1985), una de las varias compilaciones de Ana Pizarro; La novela en América Latina (1982), de Ángel Rama; Literatura y conciencia política en América Latina (1969), de Alejo Carpentier; o América Latina en su literatura (1972), editado por César Fernández Moreno y financiado por la UNESCO, valen como ejemplos.

De este último, que surgió de un encuentro y debate entre algunos de los críticos más reconocidos del momento en San José de Costa Rica en 1968, interesa un pasaje de la "Introducción”, redactada por César Fernández Moreno, que condensa varios de los factores mencionados arriba y permite ilustrar de manera gráfica cuál era espíritu de la época. Dice así:

el mundo contemporáneo redescubre con nuevo deslumbramiento este complejo que insiste en llamarse América Latina, entidad todavía no definida, pero que presenta a simple vista la consistencia de lo real. Si profundizáramos en busca de las raíces de esta ostensible unidad, su historia suministra esta primera nota: sucesiva dependencia del conjunto respecto de una potencia exterior. [...]

Ә Open Access. () 2020 Gustavo Guerrero et al., published by De Gruyter. (cc) By-NC-ND This work is licensed under a Creative Commons Attribution-NonCommercial-NoDerivatives 4.0 International License.

https://doi.org/10.1515/9783110673678-001 
Esta nota de dependencia sería, acaso, la primera a considerar para determinar el fugitivo concepto de América Latina. Y, la segunda, su inmersión en la más fuerte polaridad histórica de la actualidad: el abismo que se abre entre los países ricos y los pobres; oposición más vasta que la anterior, pero no contradictoria con ella, ya que se ilustra en el conjunto de las Américas, donde la anglosajona es la rica y la latina es la pobre. Estos dos criterios se complementan y confirman por un tercero más elemental: el geográfico, en que se apoyan, expresa o tácitamente, todos los que hasta ahora hemos compulsado. América Latina sería toda aquella tierra americana que queda al sur del río Grande o Bravo (que marca el límite de Estados Unidos con México). La habitualidad de esta expresión (al sur del río Grande, o Bravo) sería prueba de su veracidad: al sur de este río existe cierta homogeneidad cultural, política, social, lingüística, religiosa. (9)

Y unas páginas más adelante, agrega que "El rumbo no podía ser más acertado: los escritores de esta región, por así decirlo, no tienen más remedio que expresar el mundo que los circunda y se les impone, creciente y bullente, mundo de contradicciones y desgarramientos, de contemplación y acción aniquiladoras” (13). Así, para uno de los observadores de la época, la literatura latinoamericana se manifestaba signada por el estigma de una opresión geopolítica histórica anclada a una geografía concreta y claramente delimitada. "Los escritores de la región", sostenía Fernández Moreno, estarían destinados a dar cuenta de la "realidad" distintiva de América Latina.

En el mismo contexto y bajo el mismo signo ontológico latinoamericanista, hizo sus contribuciones Roberto Fernández Retamar. En su ensayo de 1975 "Para una teoría de la literatura hispanoamericana” argumentaba que, puesto que el mundo lejos está de ser homogéneo, no sería posible identificar una literatura mundial y que, por tal razón, la crítica latinoamericana debía fundar convenciones de abordaje específicas para lo que él consideraba su objeto natural:

Las teorías de la literatura hispanoamericana, pues, no podrían forjarse trasladándole e imponiéndole en bloque criterios que fueron forjados en relación con otras literaturas, las literaturas metropolitanas. Tales criterios, como sabemos, han sido propuestos -e introyectados por nosotros- como de validez universal. Pero también sabemos que ello, en conjunto, es falso, y no representa sino otra manifestación del colonialismo cultural que hemos sufrido, y no hemos dejado enteramente de sufrir, como secuela del colonialismo político y económico. Frente a esa seudouniversalidad, tenemos que proclamar la simple y necesaria verdad de que una teoría de la literatura es la teoría de una literatura. (82)

De modo que, durante el período -en lo que va de mediados de siglo hasta la Caída del Muro de Berlín-, cierta crítica cultural se dio a la tarea de establecer criterios geográficos, políticos y culturales para delimitar América Latina, de identificar rasgos distintivos para su literatura $y$, finalmente, también de exhibir ante el mundo ese objeto como patrimonio singular y bien de consumo con algunas trazas de exotismo. Esta labor crítica correspondía al discurso sostenido por 
el grupo de escritores que bajo el lema del boom se constituyeron en los creadores literarios principales de estas operaciones identitarias y mercantiles. La fórmula de una nueva unidad latinoamericana en términos literario-culturales inauguraba un nuevo discurso universalista nutrido por la posibilidad "de hablar con rigor de la contemporaneidad del escritor latinoamericano, quien súbitamente es parte de un presente cultural común: [. . . ] nuestros escritores pueden dirigir sus preguntas no sólo al presente latinoamericano sino también a un futuro que, cada vez más, también será común al nivel de la cultura y de la condición espiritual de todos los hombres" (Fuentes 35). Frente a un presunto agotamiento de la literatura europea y su poder denominador en tanto "meridiano de Greenwich" de la república mundial de las letras, para usar el término de Pascale Casanova, la literatura latinoamericana se inscribe con una fuerza renovada en el campo literario global formulando de manera ostentativa su nuevo estatus, como cuando Mario Vargas Llosa afirma que "cuando tenían a Proust y Joyce, los europeos se interesaban apenas o nada por Santos Chocano o Eustasio Rivera. Pero ahora que sólo tienen a Robbe-Grillet, Nathalie Sarraute o Giorgio Bassani, ¿cómo no volverán los ojos fuera de sus fronteras en busca de escritores más interesantes, menos letárgicos y más vivos?” (cit. en Avelar 45) ${ }^{1}$.

Con la Caída del Muro, el desmoronamiento de los proyectos comunistas y la fractura del orden bipolar, no obstante, el armado latinoamericanista comienza a resquebrajarse. Sucede que, en la nueva fase de la globalización, al mismo tiempo que algunas instituciones y organismos privados logran ganar cobertura global, los flujos económicos y culturales entre las diferentes regiones del mundo se incentivan a un nivel sin precedentes. Mediante mecanismos como el Consenso de Washington, el proyecto neoliberal se consolida a escala mundial y transforma, aceleradamente, los paisajes culturales al punto de que la singularidad y los recortes identitarios se difuminan y pierden sustento o, como anota María Eugenia Mudrovcic, “si en los '70 'todo era política', a partir de los '90 la economía del mercado pasa a ser el organizador transnacional de la cultura. Al cambiar las reglas de circulación y gestión cultural con miras a lograr una rápida escalada en

1 Al mismo tiempo y más allá de la exhibición de ese optimismo se encuentran, sin embargo, también posiciones más críticas como cuando Julio Cortázar, en una de sus cartas, formula severas dudas con respecto a la profundidad y perdurabilidad de la nueva presencia internacional de la región al sostener que "la opinión corriente sobre nuestra influencia en su literatura me parece más un deseo que una realidad; no basta un boom, no bastan tan pocas décadas para incidir decisivamente en estructuras que para bien y para mal se cierran sobre sí mismas a la vez que coquetean con los recién llegados, vengan de Europa oriental, del Japón, de Estados Unidos, de Australia o de América Latina. Los europeos dialogan ya con nosotros en el plano literario, pero de alguna manera lo hacen todavía acariciándonos la cabeza como cuando se le habla a un niño" (284-285). 
la rentabilidad y la eficiencia, el nuevo modelo de desarrollo económico cambia también el lugar que ocupa la cultura en la sociedad" (756). Los emblemas del capitalismo cruzan fronteras, colonizan la apariencia urbana en todo el mundo y dan paso a procesos de subjetivación posnacionales y posidentitarios. El mundo, así, se comprime y adquiere una apariencia relativamente uniforme, hilvanada por el discurso del capitalismo global. El mundo -ahora sí- puede ser considerado uno, y, en consecuencia, los recortes que se habían aplicado a la literatura pierden credibilidad. En 1999 aparece el ya citado La république mondiale des lettres, de Casanova, y, con él, queda inaugurado oficialmente el hoy ya frondoso debate sobre literatura mundial que tiende a reconsiderar los fenómenos literarios que habían sido adjetivados con algún gentilicio particularista como parte de un sistema global.

Desde entonces, en lo que respecta más concretamente a América Latina, tanto una zona importante de la crítica literaria especializada como un grupo nutrido de escritores con presencia y voz en el mercado internacional van a comenzar a borronear los contornos que las operaciones críticas de las décadas anteriores habían delineado para las literaturas vernáculas. Así, ese corpus, que había sido minuciosa y exitosamente construido, va a tender a diluirse en el corpus mayor de la literatura mundial. Sin atributos distintivos no hay objeto; y, si no hay objeto, tampoco puede haber estudios especializados. Estamos en el reino de McOndo y de El crack, y también en el de algunos estudios literarios que creen ver en la globalización cultural una herramienta para combatir los vetustos nacionalismos y las proclamas nativistas.

Así, en 1999, Carlos Cortés publica el artículo "La literatura latinoamericana (ya) no existe”. En el 2003 el grupo Planeta reúne un grupo de escritores en Sevilla donde se suceden los alegatos cosmopolitas y las descalificaciones de cualquier esencialismo latinoamericanista. En el volumen que reúne las intervenciones, $\mathrm{Pa}$ labra de América, del 2004, aparece la contribución de Volpi "El fin de la narrativa latinoamericana" que se prolongará en el posterior libro El insomnio de Bolivar (2009). Del 2007 es "Y finalmente, ¿existe una literatura latinoamericana?", de Jorge Fornet, formulado en la misma sintonía. También se podrían mencionar textos de Gioconda Marún o Catalina Quesada Gómez. ${ }^{2}$

En "Crítica del panorama” (2009), Gustavo Guerrero recorre algunas de estas intervenciones previas y anota:

2 Habría que aclarar que, si bien la mayoría de estos aportes intenta reinscribir la producción literaria latinoamericana en el marco mayor de la literatura mundial, algunos apuntan más bien a señalar la atomización, la dispersión y las relocalizaciones. 
el fin de los metarrelatos modernos no sólo ha llevado en América Latina a [una] irreprensible diversificación de la producción literaria y las maneras de leerla. Al suscitar vivas tensiones entre las identidades locales y globales, ha dado pie también a un cuestionamiento del concepto mismo de literatura latinoamericana en tanto categoría supranacional y denominador común. $(26)^{3}$

El acta de defunción ha sido, pues, expedida, y los modelos teóricos que habían sido elaborados en el mundo fragmentado anterior a la Caída del Muro para explicar las literaturas regionales parecieran ahora definitivamente incapaces de dar cuenta de los productos culturales elaborados en el marco del actual diseño global.

Este libro intenta reflexionar sobre las tensiones que se dan en los procesos de inscripción de lo que fue delimitado como literatura latinoamericana en dinámicas de circulación internacional. Sin dar necesariamente por supuesto que la literatura latinoamericana, en tanto construcción, se haya desintegrado en el corpus mayor de la literatura mundial, procura examinar mecanismos mediante los cuales parte de la primera se abre paso e integra en la segunda. La literatura latinoamericana mundial sería, pues, una que se halla en tránsito entre un dominio y el otro, sería la literatura que con algún tipo de impronta identificable como latinoamericana encuentra una recepción en horizontes de mayor o menor alcance global ${ }^{4}$. Antes que celebrar o enjuiciar el proceso de proyección hacia el mundo, este volumen intenta analizar los dispositivos que lo propulsan y lo convierten en algo en efecto posible. Interesa, ante todo, la traducción y también los gatekeepers, es decir, los mediadores con poder suficiente como para abrir canales de circulación en el dominio internacional (cf. Marling). Sin traducción -con todo lo que ella implica en términos de pérdida y de ganancia, con sus límites y posibilidades- y sin gatekeepers, lo que incluye determinadas "instituciones" (cf. Helgesson/Vermeulen), no hay literatura mundial. Pero también interesa el negativo de la literatura latinoamericana mundial, esto es, las literaturas que presentan fuertes resistencias al ingreso en flujos internacionales o que permanecen enraizadas en configuraciones geoculturales del continente y que, por tal razón y porque no imperiosamente

3 Véase también su Paisajes en movimiento (2018).

4 Mayores precisiones sobre el término se pueden encontrar en las monografías Beyond Bolaño (2015), de Héctor Hoyos, Strategic Occidentalism (2018), de Ignacio M. Sánchez Prado, quien examina la "literatura mexicana mundial", y De la literatura latinoamericana a la literatura (latinoamericana) mundial (2019), de Jorge J. Locane. El cambio de enfoque hacia nuevas relaciones globales de la literatura latinoamericana se expresa en publicaciones recientes como Re-mapping World Literature. Writing, Book Markets and Epistemologies between Latin America and the Global South (2018), editado por Gesine Müller, Jorge J. Locane y Benjamin Loy. 
responden a horizontes de recepción nacionales, pueden ser denominadas literaturas locales. Estos son, pues, los tres articuladores que, respectivamente, organizan este libro: 1. gatekeepers, 2. traducción y 3. literaturas locales.

Con contribuciones de Gesine Müller, Judith Illerhaus, Marteen Steenmeijer, Gustavo Guerrero, Ana Gallego Cuiñas e Idun Heir Senstad, el primer bloque examina el accionar de diferentes gatekeepers -editores, traductores, premios y festivales- en espacios nacionales de recepción como Alemania, Holanda, Francia y Noruega, en lo que va de los años 60, cuando la literatura latinoamericana adquiere estatus orgánico y delimitado, hasta el presente, cuando, al menos en algunos de sus segmentos, comienza a desdibujarse como un componente más de la literatura mundial. El artículo de Müller, "Gatekeeping and the Conceptualization of World Literature in the Publishing Industry. The Case of Siegfried Unseld and Octavio Paz", se centra en la labor de Siegfried Unseld, en tanto editor general de la editorial Suhrkamp, para la inserción de Octavio Paz en el mercado germanohablante desde fines de los años 70. De acuerdo con sus argumentos, Unseld habría elaborado una imagen de Paz que permitía asimilarlo tanto a los postulados ideológicos de una izquierda europea no dogmática como a fórmulas que le asignan al sistema sociocultural latinoamericano un carácter exótico y lo convierten, según palabras de Unseld, en una suerte de far west. Por su parte, Illerhaus, con la contribución "Premios porteros. La función del Premio Biblioteca Breve con base en números”, enfoca la atención en el impacto del premio otorgado por la casa editorial Seix Barral en la producción de literatura latinoamericana mundial. Su estudio ensaya un examen comparativo entre las dos etapas del premio, la de los años 60 y la que se inaugura a fines de los 90, a partir de indicadores que informan acerca de la cantidad y celeridad de las traducciones de los títulos reconocidos con el galardón. El texto de Steenmeijer, "Ascenso y ocaso de una marca: la literatura hispanoamericana en Holanda”, ofrece un recorrido por la recepción de la literatura latinoamericana en los Países Bajos durante los últimos cincuenta años, precisamente, como "marca” que se inaugura con la figura de Jorge Luis Borges y con el boom para, luego, volver a perder ese estatus. A través de un análisis de numerosos paratextos, críticas de prensa o la caracterización en festivales de literatura, Steenmeijer retrata, con base en ejemplos tan diferentes como Isabel Allende, Roberto Bolaño o César Aira, el progresivo proceso de disolución del consenso sobre las pautas que servían de marco para los escritores latinoamericanos en busca de un público holandés, hecho que interpreta como una especie de "descontinentalización” de la literatura latinoamericana y una forma específica de conversión en "literatura mundial”. En su aporte "José Lezama Lima en Francia: apuntes sobre la mediación editorial, la traducción y la recepción de Paradiso”, Guerrero examina el complejo proceso que, por mediación de Julio Cortázar y Severo Sarduy, 
condujo a la publicación de la novela de José Lezama Lima en Francia en 1971. En el contexto de la Guerra Fría, la publicación de Paradiso no estuvo exenta te tensiones determinadas por la política internacional y también por las dificultades técnicas que condujo a un relevo en el trabajo de traducción, primero, encargado a Claude Couffon y, luego, a Didier Coste. No obstante estas "interferencias", que informan sobre los numerosos factores que afectan la producción de literatura mundial, Paradiso fue publicada por Seuil con un significativo éxito de ventas que, a su vez, se tradujo en la consagración de la editorial y en la posterior traducción de la novela a otras lenguas hegemónicas. Gallego Cuiñas, con su artículo "Feminismo y literatura (argentina) mundial: Selva Almada, Mariana Enríquez y Samanta Schweblin”, argumenta que uno de los grandes recortes que permite pensar la actual propagación de literatura argentina por el mundo estaría delimitado por la impronta femenina. De acuerdo con sus planteos, escritoras como Almada, Enríquez y Schweblin habrían pasado por un proceso de reconocimiento nacional, fundado en la plataforma de asignación de valor simbólico que constituye la red local de editoriales independientes, para, luego, insertarse exitosamente en los catálogos de la industria literaria transnacional. Su conclusión es que la literatura mundial se apropia de estos nuevos modos de significar la experiencia femenina convirtiéndolos "en una mercancía feminista", exportable en virtud de un castellano neutro, de la apelación a subjetividades globales y a una poética general no contrahegemónica -decolonial- sino, antes, confirmatoria del orden mundial. Por último, con "Literary Diversity through Translation: The Role of Independent Cultural Mediators in the Selection of Cuban Literature in Norway", Senstad examina el papel de los traductores, presentados como mediadores culturales independientes, en la selección de la literatura cubana traducida al noruego entre 1990 y 2014. Explora cómo y por qué estos sugieren títulos a los editores y cómo, a través de sus elecciones, contribuyen a la diversidad literaria. Los editores, argumenta Senstad, son quienes tienen la última palabra, ya que son ellos quienes toman la decisión final sobre si encargar o no una traducción; sin embargo, sus decisiones siempre están integradas en redes transnacionales de determinación más amplias que incluyen a los traductores. Su conclusión es que, frente a la selección determinada más directamente por editores y agentes, centrada en textos escritos en inglés por escritores de la diáspora cubana, los traductores abogaron por e introdujeron literatura cubana canonizada del siglo XX o textos de escritores cubanos contemporáneos con residencia en Cuba, originalmente escritos en español.

El bloque dedicado a la traducción incluye artículos de Annick Louis, Liset Díaz Martínez, Yehua Chen, Sara Carini, Ilse Logie, Cecilia Alvstad y Benjamin Loy. También acá se examinan diferentes itinerarios y coyunturas: desde la 
temprana traducción de Jorge Luis Borges al francés y la de Mario Vargas Llosa al chino mandarín hasta la de las nuevas generaciones de escritores, como la de Valeria Luiselli al inglés y la de Yuri Herrera al noruego. Lejos de abordar la traducción a partir de la premisa de la transparencia, estos estudios la piensan como dificultad y desafío. Tratan de analizar sus efectos secundarios y sus límites: los desplazamientos, las asperezas y lo intransferible. Otra línea de análisis que exploran es la que refiere a la tensión entre la literatura más aferrada a formas verbales vernáculas y, por lo tanto, resistente a la circulación internacional vía traducción y la que, desde su origen, se la concibe orientada al mercado internacional o, vale decir, pretraducida. El artículo de Louis, "El Aleph de Roger Caillois en Gallimard o de cómo salir del laberinto”, examina el volumen Labyrinthes, atribuido a Borges y publicado y traducido por Roger Caillois en 1953 como volumen inaugural de la colección "La Cruz del Sur” de la editorial Gallimard. Según informa Louis, este volumen es una fabricación de Caillois, que responde a su lectura de la obra de Borges presentada en el prefacio. El laberinto como supuesto tema fundamental del universo borgeano se impone a partir de esta publicación, que, a su vez, va a dar lugar a numerosas traducciones a diferentes idiomas (inglés y alemán, en particular). Esta operación crítica de traducción, cuyo éxito resulta evidente, no solo construye un Borges para el mundo, sensiblemente distinto del que circula en versión original, sino que también tendrá el efecto inesperado de atrasar la publicación del libro El Aleph, que va a aparecer en Francia recién en 1967. El texto de Díaz Martínez, “Gabriel García Márquez traducido: observaciones sobre la variación”, desarrolla un estudio comparativo de las traducciones al francés del escritor colombiano desde un enfoque lexicológico. Focalizándose en la variación diatópica y en el nivel léxico, propone un estudio interdisciplinario de la realidad lingüística de Colombia plasmada en textos de García Márquez que demuestra que las versiones francesas difícilmente presentan valores equivalentes en relación con la variedad contenida en los textos fuente. Estos fenómenos -que, desde luego, pueden reclamar una representatividad dentro de los complejos procesos de traducción en la literatura latinoamericana mundial- adquieren una importancia particular en su tendencia a reducir sistemáticamente la riqueza léxico-cultural que un autor como García Márquez vuelca en su escritura y que ha sido atendida por los traductores franceses solamente de manera muy parcial. Chen, por su parte, en su contribución titulada "Traitors or Traders? A Brief Analysis of Chinese Translations of Latin American Boom Writers", ofrece un close reading de las traducciones al chino mandarín de textos del boom como Conversación en La Catedral, de Mario Vargas Llosa, y El lugar sin límites, de José Donoso. A partir de la observación de que diferentes traductores chinos, a pesar de que poseían un bagaje similar y de que publicaron sus 
textos en un mismo contexto histórico, desplegaron diferentes estrategias de traducción para conseguir un cierto estilo narrativo, Chen sostiene que lo que está en juego en el acto de traducir son, antes, decisiones que "errores" o "malas interpretaciones" de los textos fuente. Concluye, finalmente, con la idea de que, puesto que, detrás de cada traducción, hay una persona viva que trabaja a conciencia durante largos períodos, y que, detrás de cada elección, hay una razón, no sería adecuado equiparar la práctica con la "traición”. Carini, a su vez, con su artículo “"Tante cose venivano pubblicate ma hanno dovuto aspettare un altro momento': la literatura latinoamericana y sus re-traducciones”, dirige la atención a las nuevas traducciones de literatura latinoamericana que fueron publicadas en Italia desde el año 2000 en adelante. El estudio se detiene, particularmente, en los casos de Paradiso, de Lezama Lima, y Farabeuf, de Salvador Elizondo, para examinar los cambios que ha habido entre la primera salida al mercado de ambas novelas y su nueva versión. Carini subraya cuáles han sido las modificaciones de las perspectivas de la crítica, pero también cuáles han sido las palabras clave utilizadas por las editoriales para difundir y presentar estas obras al público. Este procedimiento le permite a Carini identificar qué clima y qué interés subyace a la recepción de la literatura latinoamericana hoy con respecto a los años 60 y 70 y cómo se filtra la literatura latinoamericana en esta nueva fase de difusión en la que, según argumenta, la escritura de Roberto Bolaño domina el escenario literario tanto por éxito de público como de crítica. El estudio de Logie, “¿Escritos en la traducción y para la traducción? Dos ejemplos: Valeria Luiselli y Mario Bellatin”, retoma los planteos de Rebecca Walkowitz, en su libro Born Translated (2015), para examinar Los ingrávidos, de Valeria Luiselli, y Jacobo el mutante, de Mario Bellatin. Según propone, el carácter translaticio de estos textos se prolonga en sus traducciones, lo que se manifiesta en algunos cambios notables en las traducciones al inglés de ambos. Pero la traducción, sostiene a continuación, puede llegar a generar algo nuevo, una especie de textualidad expandida. Así, a raíz de una carta que recibió de su traductor inglés, Bellatin escribió una nueva versión de su texto, Jacobo reloaded, que posteriormente llegó a ser la fuente de Jacob the Mutant. Logie concluye con una reflexión sobre la dificultad para evaluar este tipo de literatura ya que, según sus detractores (como Tim Parks o Brian Lennon), la circulación global y la preocupación por la traducibilidad llevan a una creciente homogeneidad, mientras que otros estudiosos (como Walkowitz) consideran que se trata de una nueva modalidad de difusión que no está reñida con una crítica a la industria editorial transnacional. La contribución de Alvstad, “Anthropology over Aesthetics: On the Poetics of Movement and Multilingualism in Three Translations of Yuri Herrera's Señales que precederán al fin del mundo", ofrece un estudio comparativo de traducciones al 
noruego, al sueco y al inglés de la novela del escritor mexicano. Según argumenta, la literatura que suele ingresar en el mercado de los países nórdicos enfatiza información antropológica antes que el valor literario. La literatura de las regiones del sur del mundo que, bajo estas premisas se difunde en los países nórdicos, es la que suele ser caracterizada como "literatura mundial”. El análisis minucioso de las traducciones, sin considerar la información paratextual, le permite proponer que varios dispositivos poéticos del original, como los neologismos y los silencios léxicos, que rodean los temas del movimiento y el multilingüismo, fueron burlados en las traducciones. Desde el punto de vista técnico, sostiene, los traductores normalizaron, explicitaron y simplificaron, es decir, crearon características lingüísticas en las traducciones que respetan patrones de recepción estandarizados. Alvstad concluye que los efectos de estos procesos de normalización, explicitación y simplificación debilitan importantes capas estéticas del texto de Herrera, a la vez que refuerzan el marco antropológico asociado con México, Estados Unidos y la frontera entre ambos países. La contribución de Loy que cierra el bloque, "Glotopolíticas literarias entre resistencia y mercado: Bolaño en traducción, la traducción en Bolaño”, también ofrece un estudio comparativo de diferentes traducciones. El artículo parte de una crítica de un aspecto paradójico en cuanto al estatus de la traducción en el contexto de los debates teóricos actuales sobre una literatura mundial: si bien la traducción es valorada porque el acto de traducir como tal forma parte del discurso y de las prácticas cosmopolitas contemporáneos, la gran mayoría de los estudios dedicados al tema -observa Loy- no indagan realmente en las dimensiones concretas de las traducciones en cuanto práctica translaticia. Ante ese panorama, elabora un estudio de caso a partir de la obra de Bolaño y el análisis comparativo de las traducciones de su novela Estrella distante al inglés, alemán y francés. El estudio sostiene la paradójica hipótesis de que, por una parte, la idea de la traducción y de la traducibilidad es fundamental en la obra de Bolaño, pero que, por el otro, posee solamente una importancia secundaria para la obra en cuanto texto traducido en circulación internacional y como parte de una literatura mundial contemporánea.

El tercer y último bloque reúne los aportes de Ignacio Sánchez M. Prado, Silja Helber, Matías Moscardi y Jorge J. Locane. Con un recorte temporal más circunscripto al presente y al marco general de la actual fase de la globalización, estos estudios abordan proyectos, ya sea editoriales o literarios, que de diferentes modos interfieren la lógica de la literatura latinoamericana mundial y se mantienen arraigados a dinámicas de circulación y recepción locales. Ante un panorama de publicación, circulación y consumo de la literatura latinoamericana que ha sido objeto de transformaciones infraestructurales profundas, el artículo de 
Sánchez Prado, “Cosmopolitismo copyleft. Tumbona Ediciones, autonomía y localidad”, examina el rol de las literaturas locales como resistencia a la hegemonización de la "literatura mundial", poniendo especial atención a la materialidad infraestructural de la producción literaria, y la relación tensional y paradójica de la forma literaria respecto a esa materialidad. Sánchez Prado reflexiona sobre este problema a partir del proyecto Tumbona Ediciones, una editorial independiente fundada en principios de autonomía, colectivismo y copyleft en México en 2005, y sus estrategias de construcción de una literatura mundial desde abajo, desde espacios alternativos y a contrapelo de la literatura mundial impuesta desde arriba a través de circuitos hegemónicos de circulación transnacional. El desarrollo de sus observaciones se asienta en una acepción particular del concepto de "hospitalidad" (acuñado por Jacques Derrida) que, según sostiene, se encuentra realizado en la política y el catálogo editorial de Tumbona como una lógica de la circulación que abre, incondicionalmente, las puertas de una tradición a una serie de libros y bienes culturales mundiales y que posee una dialéctica específica: abre un espacio para dar la bienvenida a escrituras nómadas que no entrarían de manera clara en la tradición mexicana, y a una tradición mexicana cuya relación material con el mundo y la literatura sale de los parámetros de los cosmopolitismos hegemónicos, tanto del mercado como del campo de producción cultural del siglo XX. En su artículo “¿Cuanto más marginal, más central? - La escritura de Rita Indiana”, Helber analiza la trayectoria literaria de la figura polifacética que representa la escritora dominicana Rita Indiana, concediendo prioridad a su entrada en el campo literario, primero, nacional y, luego, internacional por la publicación en una editorial española y la traducción al inglés de su novela Papi. Mediante un breve análisis de esta última, Helber indaga si con la inserción en un campo editorial transnacional Indiana deja de formar parte de la "escritura local” y se convierte en lo que se podría llamar literatura con potencial exportable. Como conclusión sostiene que, aunque Papi bien puede ser caracterizada como literatura local, se presta también para una lectura, recepción y circulación a nivel global, y que, por consiguiente, Indiana no es una escritora mundial, en el sentido más estricto, sino una escritora glocal, ya que conecta y reúne temas y elementos globales y locales en su escritura. La pregunta por el género literario y en cómo esta variable afecta la circulación (internacional) es de central importancia tanto en la contribución de Sánchez Prado como en la de Moscardi, “Audiometrías contemporáneas. La escucha como modo de circulación en la poesía argentina actual”. En su artículo, Moscardi examina la puesta en voz de la poesía argentina actual en tanto práctica poética que desborda o elude el formato del libro como soporte privilegiado -y con ello la industria editorial-, para intervenir más allá de él y de sus canales de circulación 
concomitantes. De acuerdo con sus argumentos, en el corpus analizado, de Alfonsina Brión, de Milton López, no parecería existir un "legible" sin un "audible" asociado. De esta manera, concluye, la voz y la escucha parecieran imponer nuevos desafíos para la circulación, la recepción y el abordaje de los textos poéticos; constituirían, además, una dimensión de la literatura intransferible al circuito internacional, pero, en contrapartida, capaz de producir enlaces y generar comunidad a escala local. Como cierre, el texto de Locane, "Los últimos centímetros de un lápiz de grafito’. Mercado, (neo)autonomía y la ‘operación Mike Wilson’”, propone, a partir de una revisión crítica del término "posautonomía” de Josefina Ludmer, un examen de estrategias editoriales autogestivas que cuestionan la lógica de gestión de la industria editorial transnacional y su régimen de heteronomía. Junto con el examen de una imagen extraída de Leñador o ruinas continentales, de Wilson, donde un personaje produce escritura fuera de todo marco posible de recepción, Locane desarrolla una lectura del acto concreto de Wilson de haber autopublicado, después de haber incursionado en el circuito de la literatura mundial, un relato en formato booklet que se entregaba gratuitamente en algunas librerías de Santiago de Chile. Como conclusión, sostiene que esta reinscripción del artefacto literario en un régimen de (neo)autonomía supondría un necesario desprendimiento del circuito internacional y de la literatura mundial: un rechazo de la industria transnacional para pasar a la edición independiente radical o, más aún, a la autoedición.

Hecha esta introducción, esperamos que el volumen acá presentado encuentre sus lectores y contribuya a enriquecer los actuales debates sobre literatura latinoamericana, literatura mundial y globalización. Por lo demás, no queremos cerrar esta introducción sin hacer público nuestro agradecimiento al European Research Council por el apoyo económico a nuestras actividades de investigación y el financiamiento de esta publicación.

\section{Bibliografía}

Avelar, Idelber. Alegorías de la derrota: la ficción postdictatorial y el trabajo del duelo. Cuarto propio, 2000.

Bolaño, Roberto et al. Palabra de América. Seix Barral, 2004.

Carpentier, Alejo. Literatura y conciencia política en América Latina. Alberto Corazón Editor, 1969.

Casanova, Pascale. La republique mondiale des lettres. Seuil, 1999.

Cortázar, Julio. Obra crítica 3. Ed. Saúl Sosnowski. Alfaguara, 1994.

Cortés, Carlos. "La literatura latinoamericana (ya) no existe”. Cuadernos Hispanoamericanos, 592, 1999, pp. 59-67.

Donoso, José. Historia personal del “boom”. Anagrama, 1972. 
Fernández Moreno, César (coord.). América Latina en su literatura. Siglo XXI/UNESCO, 1972.

---. "Introducción”. América Latina en su literatura. Coord. César Fernández Moreno. Siglo XXI/ UNESCO, 1972, pp. 5-18.

Fernández Retamar, Roberto. "Para una teoría de la literatura hispanoamericana”. Para una teoría de la literatura hispanoamericana. Publicaciones del Instituto Caro y Cuervo, 1995 [1975], pp. 74-87.

Fornet, Jorge. "Y finalmente, ¿existe una literatura latinoamericana?”. La jiribilla. Revista de cultura cubana, 9-15 de junio 2007. http://epoca2.lajiribilla.cu/2007/n318_06/318_01. html, consultado 1 de marzo 2019.

Fuentes, Carlos. La nueva novela latinoamericana. Joaquín Mortiz, 1969.

Guerrero, Gustavo. Paisajes en movimiento. Literatura y cambio social entre dos siglos. Eterna Cadencia, 2018.

Guerrero, Gustavo. “Crítica del panorama”. Letras libres, 93, 2009, pp. 24-28.

Helgesson, Stefan/Pieter Vermeulen (eds.). Institutions of World Literature: Writing, Translation, Markets. Routledge, 2016.

Hoyos, Héctor. Beyond Bolaño. The Global Latin American Novel. Columbia University Press, 2015.

Locane, Jorge J. De la literatura latinoamericana a la literatura (latinoamericana) mundial. Condiciones materiales, procesos y actores. De Gruyter, 2019.

Marling, William. Gatekeepers. The Emergence of World Literature \& the 1960s.

Oxford University Press, 2016.

Marún, Gioconda. Latinoamérica y la literatura mundial. Dunken, 2013.

Mudrovcic, María Eugenia. "Políticas culturales en los procesos de integración regional: el sector editorial en el Mercosur”. Revista Iberoamericana LXVII, 197, 2001, pp. 755-766.

Müller, Gesine. Die Boom-Autoren heute: García Márquez, Fuentes, Vargas Llosa, Donoso und ihr Abschied von den großen identitätsstiftenden Entwürfen. Vervuert, 2004.

Müller, Gesine /Jorge J. Locane/Benjamin Loy (eds.). Re-mapping World Literature. Writing, Book Markets, and Epistemologies between Latin America and the Global South. De Gruyter, 2018.

Pizarro, Ana (coord.). La literatura latinoamericana como proceso. Centro Editor de América Latina, 1985.

Quesada Gómez, Catalina. Literatura y globalización: la narrativa hispanoamericana en el siglo XXI (espacio, tiempos y géneros). Universidad de Antioquia, 2014.

Rama, Ángel. La novela en América Latina. Panoramas 1920-1980. Colcultura, 1982.

Sánchez Prado, Ignacio M. Strategic Occidentalism. On Mexican Fiction, the Neoliberal Book Market, and the Question of World Literature. Northwestern University Press, 2018.

Volpi, Jorge. El insomnio de Bolivar. Cuatro consideraciones intempestivas sobre América Latina en el siglo XXI. Debate, 2009.

---. "El fin de la narrativa latinoamericana". Palabra de América. Roberto Bolaño et al. Seix Barral, 2004, pp. 206-223. 



\section{Gatekeepers}





\section{Gatekeeping and the Conceptualization of World Literature in the Publishing Industry. The Case of Siegfried Unseld and Octavio Paz}

The history of the reception of Latin American literatures in Germany cannot be understood without reference to Suhrkamp Verlag's publishing program in international literature. Siegfried Unseld, the head of the publishing house, who died in 2002, shaped the company's history for more than forty years and became the most important 'gatekeeper' (Marling) for Latin American authors in the Germanspeaking world over the course of that time. In establishing the selection criteria for his publishing program in international literature, Unseld followed the motto of the founder of the former Insel Verlag, Anton Kippenberg, understanding world literature as a biblioteca mundi, based on universal categories. A closer examination of the gatekeeping relationship between Siegfried Unseld and the Mexican writer Octavio Paz will allow us to see the degree to which this selection criterion of the universal, an idea that is hard to grasp within reception theory, was combined with the idea of the exotic in the context of the publishing house's Latin American program, which was developed starting in the late 1960s.

\section{The Material Foundation}

In December 2009, almost exactly thirty years after the first meeting between Paz and Unseld in May 1979, the entire estate of the Suhrkamp Verlag was transferred to the German Literary Archive (Deutsches Literaturarchiv, DLA) in Marbach, thereby increasing the total holdings of the Marbach archive by a quarter (Bürger 20). This Suhrkamp estate, in the words of George Steiner, constituted something akin to an international Suhrkamp culture, functioning as a seal of approval for world literature. The relocation of the company to Berlin from Frankfurt am Main was the occasion for the sale of the documents from the Frankfurt "vault"-as the Suhrkamp's basement room on Frankfurt's Lindenstraße, where

Gesine Müller, Universität zu Köln

Ә Open Access. () 2020 Gesine Müller, published by De Gruyter. (cc)BY-NC-ND This work is licensed under a Creative Commons Attribution-NonCommercial-NoDerivatives 4.0 International License. 
business documents and important correspondence with authors were stored, was called. In the winter of 2009/2010, therefore, large quantities of inventory were transported to Marbach. The number of moving boxes was listed as 2100; counting documents from the publisher's villa as well, the estate included more than twenty thousand binders and more than twenty-five thousand books from the Suhrkamp Verlag and the Insel Verlag.

The acquisition of the Siegfried Unseld estate by the DLA was the most valuable purchase the DLA archive had ever made; until then, the heart of the archive had been the collection of the Cotta Verlag, which was Goethe's and Schiller's publishing home. Since the acquisition, the Siegfried Unseld archive (Siegfried Unseld Archiv, SUA) in Marbach has gradually been made accessible for research. Speaking to the press, Ulrich Raulff, the director of the DLA, called it a stroke of luck that "only happens once in a hundred years" (Cammann). In addition to correspondence with Suhrkamp authors including Beckett, Habermas, Paz, and Cortázar, the estate also includes internal reports and editorial reports, minutes of the editorial meetings, enlightening travel reports (including some by Unseld himself), files from the advertising, licensing, and accounting departments, and much more. In spite of the limitations that one necessarily encounters when working in this archive, the material to be found here is exceptionally valuable, and that is also and especially true from a Latin American perspective. There are two reasons for this: first, because the Suhrkamp Verlag played such a decisive role in the international publishing world with respect to Latin American literature, and secondly, because the publishing house kept such unusually extensive and careful records. This means that now, for the first time in Germany, there is very comprehensive material available that can be used to examine a time period before the work of Latin American authors had been translated and published in Germany. Thus, such things as the selection processes of German publishing houses with respect to Latin American literatures can be studied very concretely, in a way that was previously not at all possible.

So much for the institutional preconditions for the material foundation of this study. But how do the publishing house's international selection mechanisms relate to Siegfried Unseld's gatekeeping strategies and possible conception of world literature? 


\section{The Selection of International Literatures at Suhrkamp}

When we look at the history of Suhrkamp's success in the field of world literature, the first phase in the establishment of its international catalogue took place from the early 1950s to the mid-1960s ${ }^{1}$. Here the work of Samuel Beckett, more than any other writer's work, stands out as of extraterritoriality that George Steiner coined in 1973 to describe a constitutive element of the Suhrkamp culture. There is a well-known passage in Beckett's Molloy that employs what critics have often drawn attention to as a "double voice", which can never be clearly traced back to one speaker and about which even the first-person narrator is not clear (Weber 110): "I had forgotten who I was (excusably) and spoken of myself as I would have of another, if I had been compelled to speak of another. Yes it sometimes happens and will sometimes happen again that I forget who I am and strut before my eyes, like a stranger" (Beckett 56) ${ }^{2}$.

For Unseld, the radicalization of extraterritoriality offered itself as a way of speaking another language, on a literary level, through an exophonic materialization: he made the particularity of the literary, as opposed to all other discourses, into the starting point for his publishing activity. On 1 June, 1962, Unseld writes to Beckett: "I would therefore like to publish an edition in three languages [...]. What do you think of this project? Of the project of an edition of your dramatic works, as well as of the 'triglot' project?"3

However, although the success stories of such writers as Samuel Beckett or Marguerite Duras at Suhrkamp cannot be denied, neither French literature nor any other international literature experienced the kind of sweeping reception that can be seen in the history of Latin American literature at Suhrkamp. The expectations of extraterritoriality move away from the intellectual imprint of the language philosophy of someone like Samuel Beckett and towards a concrete place named Macondo. What could be the reason for this?

1 With respect to the following discussion, see also Müller "Literaturen der Amerikas ...," "¿Literatura mundial ...," and "Konstruktion ..."

2 "J’avais oublié qui j'étais (il y avait de quoi) et parlé de moi comme j'aurais parlé d'un autre, s'il m'avait fallu absolument parler d'un autre. Oui, cela m'arrive et cela m'arrivera encore d'oublier qui je suis et d'évoluer devant moi à la manière d'un étranger" (Beckett, 1982: 55).

3 "J'aimerais donc publier une édition en trois langues [...]. Que pensez-vous de ce projet? Du projet d'une édition de vos œuvres dramatiques ainsi que du projet 'triglotte'?" Correspondence between Unseld and Beckett, September 1, 1969, SUA Marbach. I thank the DLA in Marbach, the heirs of Siegfried Unseld, and Michi Strausfeld for their kind permission to quote from the materials from the Siegfried Unseld archive in this article. 


\section{The Selection of Latin American Authors at Suhrkamp. Between Universalism and Exoticism}

Beginning with the first edition of Vallejo in 1963, Suhrkamp Verlag's Latin American program grew steadily and has been consistently expanded-leading to the peak in sales represented by Isabel Allende's House of the Spirits (in German, Geisterhaus) in the 1980s, with 7 million copies sold. While the 1980s and 1990s were characterized by this kind of success, the program has stagnated, relatively speaking, since the year 2000. Between 2000 and 2010, Suhrkamp only published 34 titles from Latin America. This is in sharp contrast with the numbers from 1976, when Latin America was the focus of the Frankfurt Book Fair and Suhrkamp released 17 Latin American titles in that year alone.

How can we write the history of the reception of Latin American literature in Germany-a history in which the Suhrkamp Verlag continues to play the leading role in the publishing world to this day? My thesis, as I have outlined above, is that Suhrkamp's publishing program is based on an unspoken conception of world literature that shapes the criteria for the selection of foreignlanguage literatures. The great and successful Latin American novels were absolutely exemplary cases of these European-defined criteria of world literature. By looking at Octavio Paz, it will be possible to demonstrate how Unseld, as the gatekeeper, made this concept of world literature into a central foundation of his publishing work with Latin American writers.

First of all, let us briefly review the history of Latin American literary production. The so-called 1960s boom in Latin American literature, during which the novels of such writers as García Márquez, Vargas Llosa, Fuentes, and Cortázar quickly became best-selling sensations, was the result of a number of different circumstances. The Cuban revolution can be seen as the beginning of this process, although the word boom certainly refers to the purely economic successes of this literature, which was mostly due to the work of the Barcelona publishing house Seix Barral. But how are the texts of the boom related in terms of content? Julio Cortázar probably best expresses what it is that they have in common: "What is the boom if not the Latin American people's most extraordinary achievement of consciousness of its own identity?” (cited in Avelar 28) ${ }^{4}$. It does not matter whether this consciousness was achieved through the use of pre-Columbian myths, cyclical structures of time, or experimental narrative methods.

4 “¿[...] qué es el boom sino la más extraordinaria toma de conciencia por parte del pueblo latinoamericano de una parte de su propia identidad?” (cited in Rama 244). 
How, then, was this literature received in Germany? If we cast even a cursory look at the reviews that followed the publication of, for example, Gabriel García Márquez's One Hundred Years of Solitude (which appeared in Germany as Hundert Jahre Einsamkeit in 1967) or Mario Vargas Llosa's The Green House (Das grüne Haus, 1965), it quickly becomes clear that the unspoken yardstick is the concept of world literature. Vittoria Borsò has keenly detailed the connections between world literature as a selection criterion and the publishers' reception of these works. That which she was able to establish for García Márquez's Hundert Jahre Einsamkeit, which was published by Kiepenheuer \& Witsch, also applies to Suhrkamp's authors, including Vargas Llosa, namely that what the literary critics stressed as indicators for membership in the canon of world literature were both the assimilation of European and international traditions and, at the same time, the integration of oral narrative strands from pre-Columbian cultures. The writers of the boom were described as having enriched the European and Western traditions with the lavish colors of the tropical world (Borsò 236).

Another feature of these novels that raised them to the level of world literature, following Borsò's argument, is the fact that in (for instance) the mythical Amazonian spot on the Marañón River, which is comparable to García Márquez's Macondo, not only the history of Latin America, but in fact the history of the world takes place. This is suggested by the rich and plentiful allusions to the Book of Genesis and to archetypal myths of origin. In summary, then, we can say that the reception of these Latin American writers by literary critics and literary theorists mostly stressed their ability to connect to modern world literature, while highlighting the combination of representations of alterity that were as exotic as possible with the postmodern narrative processes that had been established in Europe. The paradigm of identity, and concretely the search for a specifically Latin American identity, was the decisive criterion for justifying the novels as belonging to world literature (cf. Borsò 236).

How do the positions expressed by the publishing industry compare to this? We can find strong and vivid material with which to address this question in the archival holdings of Suhrkamp Verlag, mostly in Unseld's correspondence with the various authors, but also in his exchanges with his closest Latin America consultants, Michi Strausfeld and Wolfgang Eitel. We also find evidence of Unseld's encounters with leading Latin Americanists such as Klaus Meyer Minnemann, Dieter Janik, and Karsten Garscha. In May 1979, Unseld wrote in his journal: "Octavio Paz made a strong impression on me. A disposition in whom poetry and erudition, wisdom and knowledge are united. I invited Paz, as 


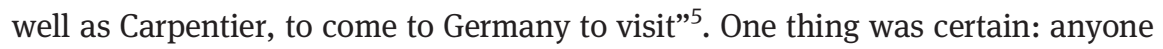
who was part of the illustrious circle of non-German Suhrkamp authors had to be considered as potentially a part of world literature. It seems unquestionable that Suhrkamp's publishing program was to be equated with world literature. The fact that Octavio Paz, in particular, fulfilled this function exceptionally well may also have to do with his affirmatory understanding of a genuinely European modernity.

\section{The Publisher Siegfried Unseld as Octavio Paz's Gatekeeper}

The condolence letter that Unseld wrote to Octavio Paz's widow, María-José, on 30 April, 1998 (ten days after Paz's death on April 20th of that year), is a telling document in our examination of Unseld's gatekeeper function towards Paz ${ }^{6}$. The following lines provide a striking description of the two broad dimensions of the relationship between Paz and Unseld: "For all of us Octavio is the great author. We are proud to have taken care of his work. And you can be sure that we will continue to work for him and his work, to have his books in print and to publish new ones, so that his ideas can continue to irradiate and illuminate the German public"7. We hear two voices of Unseld here. First is the voice of the resourceful, successful businessman, with foresight and mercantile flair, who years earlier, in a strategic move for his publishing agenda, had taken Paz on as part of his Latin American program and who was then retroactively "paid back" for his investment and confirmed in his trust in the Mexican author when Paz was awarded, most notably, the Cervantes Prize in 1981 and the Nobel Prize in 1990. But we also hear another voice here, which speaks of Unseld's image of (or perhaps more strongly put, his projection onto) Paz the literary writer as the 20th-century Latin American Enlightenment thinker whose ideas-marked by their progressive nature, their vision, their educational nature, and, not least, their standing as part of world literature-must not be allowed to dry up. By way of illustration of the public image of Paz in the 1980s, let me cite the former German Federal President Richard von Weizsäcker, who in 1984 gave

\footnotetext{
5 "Octavio Paz hinterließ mir einen großen Eindruck. Eine Persönlichkeit, in der sich Poesie und Gelehrsamkeit, Weisheit und Wissenschaft vereinen. Ich habe Paz und auch Carpentier zu einem Besuch nach Deutschland eingeladen.” Unseld's travel report, Paris, 20-22 May, 1979, SUA Marbach.

6 I rely in this chapter on Müller and Bubel.

7 SUA Marbach.
} 
the speech celebrating the winner of the peace prize awarded by the German book industry: "Octavio Paz is on his way to becoming the defining voice of Latin American culture, in fact its conscience” (Suhrkamp Verlag 22).

Unseld's programmatic understanding of what constituted a "publicationworthy" and potentially successful Suhrkamp author on the Latin America list can only be grasped against the background of the classically established and primarily German-language poetics of authorship within the Suhrkamp universe, as well as in the context of the West German cultural bourgeoisie (professionals who prized education and culture) of the 1970s and 1980s, as we can see from a closer examination of Octavio Paz's poetic, existential, religious, and sociopolitical ideas and beliefs, which made him interesting and relevant to Unseld and to Suhrkamp's Latin America program. These are operational, poetological parameters that were essentially able to function as a master key allowing entry into the Latin America list in the German-language market according to the guidelines set out by Unseld and Suhrkamp. When we look closely at the supposedly exemplary nature of Paz's work, what becomes clear is not only the degree to which Unseld promoted the reception of the Mexican writer in Germany through the influential gatekeeping of his publishing decisions, but also the way in which Unseld's concrete interests shaped his work, particularly his attempts to group Paz among the kaleidoscope of European poets and thinkers that Unseld represented in his publishing program.

In his report on the meeting he had with Paz in Paris in May 1979 (probably their first meeting), Unseld describes how impressed he was at the Mexican author's demeanor and depth of knowledge. He writes: “An impressive presence, poet and scientist, wise man and man of knowledge. One has the impression that the experiences of long periods of social and literary revolutions have

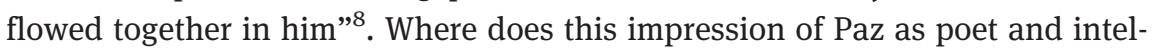
lectual come from? The obvious question arises as to whether and to what extent Paz's work in fact merits this (projected) point of view, or whether Unseld is not, for pragmatic reasons related to the politics of publishing, simply superimposing Suhrkamp's categories onto Paz's person and oeuvre. What are the substantive and formal aspects and means with which the "wise and knowledgeable" Paz was able to cement his status as a Latin American polymath and Enlightenment figure in Unseld's perception? To understand this connection better, we need to outline a short and partial description of Unseld's understanding

8 "Eine imponierende Erscheinung, Poet und Wissenschaftler, Weiser und Wissender. Man hat den Eindruck, in ihm seien Erfahrungen langer Zeiten von sozialen und literarischen Revolutionen zusammengeflossen.” Unseld's travel report, Paris, 20-22 May, 1979, SUA Marbach. 
of a world-class "Enlightenment figure" or "man of knowledge". This can be demonstrated in particular through the comparative categories that Unseld used in order to try to make Paz comprehensible within Unseld's own understanding of art. Thus, Unseld sees the triad of Cortázar, Paz, and Carpentier as the "greats of Latin American literature. All three of them impressive, because in themselves they reflect not only that which is their own, and their own continent, but also the others"'. Thus, Unseld classifies Paz as a universalist author, as it were, one who can transcend his own national and ethnic limitations and constraints to grapple with the-supposedly-higher existential questions in his work, a "world traveler"10 who oscillates between the reference points of Latin America and Europe in his thinking. Behind this intellectual elevation of Paz to the status of grand old man of Latin American literature-along with Cortázar and Carpentier, the "Thomas Mann of Latin America"11_however, we might also guess that there is a trick involving editorial politics: these writers represented Cuba, Mexico, and Argentina, and thus Unseld was able to give a face to the most politically interesting regions of Latin America and make them concrete for the postwar German bourgeoisie.

In addition to these considerations of editorial politics, Unseld's reception of Paz's poetics was, on the one hand, particularly colored by the "Enlightenment" model mentioned above; on the other hand, Unseld was also deeply impressed by a lecture that Paz gave in Frankfurt in the summer of 1980. From the Mexican writer's various aesthetic and poetological comments in that lecture, Unseld extracts what he considered to be the central message: "Yes, it is true: 'América Latina es una cultura'-'Latin America is one culture"”12. In spite of its very great diversity in terms of politics, culture, ethnicity, language, and, ultimately, literature, Unseld would like for Latin America to be understood as a homogeneous whole whose political individuation process is not only reflected in the contemporary literature that accompanies it, but is in fact actively guided and propelled by that literature. Thus, Suhrkamp often advertises its Latin American literature using the word "existentialist" and characterizes Latin America as a kind of "unspoiled" emotional (continental) space that is under construction. It should

9 "Großen der lateinamerikanischen Literatur. Alle drei beeindruckend, weil sie nicht nur das Eigene, den eigenen Kontinent, sondern auch die anderen in sich reflektieren.” Unseld's travel report, Paris, 20-22 May, 1979, SUA Marbach.

10 As Michi Strausfeld puts it in a draft of a Suhrkamp report, probably dating from 1980 (esNF-Lateinamerika, 1980 (?), SUA Marbach).

11 Unseld's travel report, Paris, 20-22 May, 1979, SUA Marbach.

12 “Ja, es ist wahr: 'América Latina es una cultura'-'Lateinamerika ist eine Kultur.”' Siegfried Unseld, Letter to O. Paz, 4 July, 1980, SUA Marbach. 
therefore not be surprising that in 1979, Suhrkamp Verlag's Latin America list was promoted under the title 17 Authors Are Writing the Novel of the Latin American Continent (17 Autoren schreiben am Roman des lateinamerikanischen Kontinents), and that in that document, Unseld notes pithily that:

Of all the contemporary non-German literatures, it is Latin American literature that seems to me to be the most important one for the coming decade. It is a particular kind of existentialist literature that in other countries can now, for whatever reasons, only be written in individual cases. This literature encourages a new kind of education in feelings, and its characters, who are so very real, are not afraid of naming the values of life and assigning to them their relative positions ${ }^{13}$.

This kind of "existential" Latin American literature, one that is able to "name the values of life" and even to kindle a new sort of sentimental education, nevertheless, in Unseld's understanding, continues to operate according to known coordinates. Writing about Octavio Paz's poem "Piedra de Sol” ("Sunstone”), which had what he called a "hunger for being"14 (Hunger nach Sein) that deeply impressed him, Unseld noted that it was the way the poem ended that particularly fascinated him, the "symbol of the river 'that goes curving, / advances and retreats, goes roundabout, / arriving forever,' the soft water in motion"15. It would not seem to be a coincidence that Unseld valued the metaphors, images, and tropes in Paz's work that are topically charged in literary and philosophical history, including such tropes as Heraclitus's panta rhei, invoked here. Given the orientation of the Latin America program and the publishing house's strategy of a "Latin American awakening", such universally interpretable and historically freighted metaphors would in fact be required in order to help the

13 "Von allen außerdeutschen zeitgenössischen Literaturen scheint mir die lateinamerikanische sicherlich für das nächste Jahrzehnt die wichtigste zu sein. Es ist eine besondere Art existentieller Literatur, wie sie in anderen Ländern, aus welchen Gründen auch immer, nur noch in einzelnen Fällen geschrieben werden kann. Diese Literatur macht Mut zu einer neuen Erziehung zu Gefühlen und ihre so realen Gestalten scheuen sich nicht, Werte des Lebens zu benennen und in ihrem Rang zu bestimmen.” Suhrkamp catalogue for the 1979 Frankfurt Book Fair, SUA Marbach.

14 Unseld's travel report, Paris, 20 May, 1979, SUA Marbach.

15 "Piedra de Sol" is one of Octavio Paz's major works, which Unseld is known to have read. It was published in German by Suhrkamp in 1977 in the volume Octavio Paz. Gedichte (Octavio Paz. Poems) and again in 1979 in the volume Suche nach einer Mitte. Die großen Gedichte (Search for a Center. The Great Poems). Unseld's original comment is "Symbol des Flusses, als der, 'der sich windet, verdrängt, zurückweicht, einen Umweg wandelt und immer ankommt', das weiche Wasser in Bewegung”. Unseld's travel report, Paris, 20 May, 1979, SUA Marbach. Paz's lines are "[un caminar de río] que se curva, / avanza, retrocede, da un rodeo / y llega siempre” (Paz, Piedra 1). 
German-speaking public, which had almost no knowledge of Latin America, to gain a more concrete understanding of the region. In addition, such rhetorical devices qualified Paz, a Mexican author who therefore still seemed "exotic" at that time in the German-speaking world, to be incorporated into the group of historically significant Suhrkamp authors. We should not forget that it was not Unseld's ambition to publish "the excavations of odd esoteric documents" in his now-celebrated Library of Modern Classics (Bibliothek der Klassiker der Moderne), "but rather [to strive for] a unity of purpose in spite of the most divergent themes, in order to justify the claim that here, literature becomes an escape into life" (Unseld 9) ${ }^{16}$.

This “escape into life” appears to be, in Unseld's conception, something specifically modernist, shaped by Nietzsche’s emphatic “yes to life” (Ja zum Leben) and Bergson's “vital force” (élan vital), as well as by the politically committed literature of the Weimar Republic (including Hesse and Brecht) and by modernity's existentialist manifestations (including Sartre and Camus). The more points of connection and overlap that could be found between these literary greats and the aesthetics of the Latin Americans, the more valuable their work seemed to Unseld. The fact that, for Unseld, literature could not be separated from social engagement and sociopolitical action is demonstrated not only by the programmatic direction taken by the Suhrkamp Library after the Second World War, but also by Unseld's highly positive assessment of socially engaged literary figures who did not simply loiter in the ivory tower of art for art's sake. Paz's aesthetic is distinct from such artistic escapism (the kind that we see in symbolism), without however allowing itself to be made into a literary mouthpiece for political and social positions. It is namely all too often impossible to separate politically engaged literature from the teleological thought patterns of bourgeois rationalism, and the task of the poet is to create a protected space through poetry in which ideas and knowledge that transcend their times and are unaffected by the zeitgeist can survive, freed of any appropriation by bourgeois categories of thought. Thus, in Sor Juana or, The Traps of Faith, Paz writes:

Bourgeois rationalism is, in a manner of speaking, constitutionally averse to poetry. Hence poetry, from the beginnings of the modern era-that is, since the last years of the eighteenth century-has been a form of rebellion. Poetry is not a genre in harmony with the modern world; its innermost nature is hostile or indifferent to the dogmas of modern times, progress and the cult of the future. [...] Poetry, whatever the manifest content of the poem, is always

16 "keine Ausgrabungen abseitiger Gelegenheitsarbeiten [zu publizieren], vielmehr trotz divergierendster Themen eine Geschlossenheit im Ziel [anzustreben], die die Behauptung rechtfertigt: Hier wird Literatur zur Flucht in das Leben.” 
a violation of the rationalism and morality of bourgeois society. Our society believes in history: newspapers, radio, television, the now; poetry, by its very nature, is atemporal. $(5)^{17}$

Paz here refuses to allow bourgeois categories of value to politicize, appropriate, or impose their influence on literary production, assigning a unique rebellious power to poetry and the poet, a power that has the ability to produce a genuinely other epistemology: a timeless practical knowledge that generates a morality beyond positivism, rationalism, or empiricism. It is through this characteristic kind of literary politicization that the poet fulfills his responsibility to society, as Paz stresses in his "La letra y el cetro" ("The Letter and the Scepter"): "But we cannot renounce politics: that would be worse than spitting at the sky-it would be spitting at our own selves" $(754-755)^{18}$. What Unseld so values in Paz's work is also that very creative, rebellious force that the Mexican writer sees in the medium of literature and poetry. This establishment of poetry as a separate, independent, epistemological category can be found in many of the modernist poets connected with Suhrkamp Verlag, for instance in the work of Hugo von Hofmannsthal, whom Unseld greatly esteemed and whose 1907 essay "The Poet and Our Time" ("Der Dichter und diese Zeit") displays striking similarities with Paz's thinking:

He [the poet] may not shrink from any thought that presses itself on him as if he were from a different order of things. For each thing must fit into his order of things. In him everything has to and wants to come together. He is the one who joins the elements of the age in himself. In him or nowhere is the present [...]. As the most inward sense of all human beings creates time and space and the world of things around them, so does he create out of past and present, from animal and human being and dream and thing, from large and small, from sublime and worthless, the world of relationships ${ }^{19}$. (Hofmannsthal 42)

17 "El racionalismo burgués es, por decirlo así, constitucionalmente adverso a la poesía. De ahí que la poesía, desde los orígenes de la era moderna-o sea: desde las postrimerías del siglo XVIII-se haya manifestado como rebelión. La poesía no es género moderno; su naturaleza profunda es hostil o indiferente a los dogmas de la modernidad: el progreso y la sobrevaloración del futuro [...]. La poesía, cualquiera que sea el contenido manifiesto del poema, es siempre una transgresión de la racionalidad y la moralidad de la sociedad burguesa. Nuestra sociedad cree en la historia-periódico, radio, televisión: el ahora-y la poesía es, por naturaleza, extemporánea” (Paz, Sor Juana 16).

18 "Pero no podemos renegar de la política; sería peor que escupir contra el cielo: escupir contra nosotros mismos."

19 "Keinen Gedanken der sich an ihn [den Dichter] drängt, darf er von sich scheuchen, als sei er aus einer anderen Ordnung der Dinge. Denn in seine Ordnung der Dinge muß jedes Ding hineinpassen. In ihm muß und will alles zusammenkommen. Er ist es, der in sich die Elemente der Zeit verknüpft. In ihm oder nirgends ist Gegenwart [...]. Wie der innerste Sinn aller Menschen Zeit 
For Unseld, Hofmannsthal certainly represented one of the most important points of comparison for evaluating Paz's work. Thus, a letter from Unseld to Paz, dated 4 July, 1980, in which Unseld reviews Paz's weeklong visit to Germany with his wife, María-José, is a testament to Unseld's drive, as Paz's gatekeeper, to position Paz within the tradition of Suhrkamp's established writers and German-language intellectual giants. During Paz' journey through West Germany (visiting Bonn, Frankfurt, and Heidelberg), not only was a visit to the Goethe-Haus "a matter of course", but they were also shown the "Hofmannsthal treasures" in the Goethe library, because, according to Unseld, "Hofmannsthal was, after all, one of the few German poets who had mastered Spanish" ${ }^{20}$. Against the backdrop of this comparison to Hofmannsthal, the following passage from Unseld's 1979 travel journal, already cited above, becomes even more significant:

In these times, when the belief in progress and the historical process seems to be waning, he $[\mathrm{O} . \mathrm{Paz}]$ is an important person for me. His experience, from a half-century of upheavals is this: no one knows what the future looks like, we must be vigilant and watchful, we must be skeptical, but we should also hope. And for him, the most important thing is that the highest value is not the future, but rather the present. "The future is not the time of love: what a person truly wants, he wants now. He who is building the house of future bliss is erecting the prison of the present time". And his verdict on progress is this: "It has peopled history with the wonders and monstrosities of technology, but it has depopulated the lives of human beings: it has given us more things, but not more being" ${ }^{21}$.

Here, Unseld is once again critiquing the bourgeois belief in progress and the dichotomous relationship between what Erich Fromm calls the "being and having" of bourgeois categories of value. In the 1996 interview Octavio Paz: El poeta en su tierra (Octavio Paz: The Poet in His Land), Paz expresses that ambivalence like

und Raum und die Welt der Dinge um sie her schafft, so schafft er aus Vergangenheit und Gegenwart, aus Tier und Mensch und Traum und Ding, aus Groß und Klein, aus Erhabenem und Nichtigem, die Welt der Bezüge” (Hofmannsthal, “Der Dichter” 244-245).

20 "Hofmannsthal war ja einer der wenigen deutschen Dichter, die des Spanischen mächtig waren.” Siegfried Unseld, letter to O. Paz, 4 July, 1980, SUA Marbach.

21 "Für mich ist er [O. Paz] in unserer Zeit, wo der Fortschrittsglaube und Glaube an den historischen Prozess zu verdämmern scheint, eine wichtige Persönlichkeit. Seine Erfahrung aus einem halben Jahrhundert der Umstürze: niemand weiß, wie die Zukunft aussieht, wir müssen wachsam sein und aufpassen, skeptisch sein, aber wir sollten doch auch hoffen. Und für ihn ist das Wichtigste: der höchste Wert ist nicht die Zukunft, sondern die Gegenwart. 'Die Zukunft ist nicht die Zeit der Liebe: was der Mensch in Wahrheit will, das will er jetzt. Derjenige, der das Haus der künftigen Glückseligkeit konstruiert, errichtet das Gefängnis der Gegenwart.' Und das Urteil über den Fortschritt lautet: 'Er hat die Geschichte mit den Wundern und Monstren der Technik bevölkert, aber er hat das Leben der Menschen entvölkert, er hat uns mehr Dinge gegeben, nicht mehr Sein."” Unseld's travel report, Paris, 20-22 May, 1979, SUA Marbach. 
this: "there is a radical opposition between the values of modern society and poetry. The culture of capitalist society is fundamentally grounded in the moral value of utility. And poetry is always an expense, a waste. There is an incompatibility between bourgeois morality-which is the morality of thrift and frugality-and poetic morality, which is the morality of giving, of wastefulness" 22 . This fundamental discrepancy in human nature results, says Paz, in a disregard of the present. Here we can recognize echoes of the radical Sartrean existentialism of the 1950s and thus, too, of a further European intellectual tradition that even more strongly underscores Unseld's endeavor to incorporate Paz into his kaleidoscope of influential (European) thinkers and writers.

\section{Conclusion}

While it is the classic writers of German modernism, such as Hugo von Hofmannsthal or Thomas Mann, who are referenced as yardsticks, in another context Siegfried Unseld, Paz's gatekeeper, draws comparisons to contemporary leftleaning cultural theorists such as Herbert Marcuse. In his May 1979 travel journal, Unseld writes: "Then Octavio Paz comes into the hotel with his wife and we drive to the Grand Vefour to eat [...]. He modifies what Marcuse had said not long before about the zest for life"23. The Suhrkamp Verlag as the "theory forge" of the non-dogmatic left of the 1960s to the 1980s, the sociopolitical activism of the publishing house in general and of Unseld in particular, and the role that the reception of Octavio Paz took on for Unseld in this context have a direct connection with the level of political interest in Latin America: in the 1960s and 1970s, Latin America becomes a kind of sociopolitical laboratory or great new hope for the Western European and especially the German left, and later, with its military dictatorships, served as a legitimation of the critique of capitalism using dependence theory. The literary interest in Latin America, then, should be seen as the flip side of this political interest and of the political engagement for a more socially just world, in addition to providing a fictional underpinning for the theoretical critique

22 "hay una oposición radical entre los valores de la sociedad moderna y la poesía. La cultura de la sociedad capitalista está basada fundamentalmente en la moral de la utilidad. Y la poesía siempre es un gasto, un desperdicio. Hay incompatibilidad entre la moral burguesa-que es la moral del ahorro-y la moral poética, que es la moral del dar, del despilfarro" (Paz and Peralta). 23 "Dann kommt Octavio Paz mit seiner Frau ins Hotel, wir fahren zum Essen ins Grand Vefour [...]. Dann variierte er für sich das, was ein paar Tage vorher Marcuse in den Römerberggesprächen zum Thema 'Lebenslust' ausgeführt hatte.” Unseld's travel report, Paris, 20-22 May, 1979, SUA Marbach. 
of capitalism. What is considered a question of identity from the Latin American point of view is understood as a demand for social justice and cultural acknowledgment from the European or, more specifically, the German perspective.

Unseld's quest for legitimation is noteworthy. He wants Latin American literature to be taken seriously enough that it will be able to find justified admission into the world literary canon: "I must add that Latin American literature is a newcomer. It is the youngest of all Western literatures. [.. .] Latin America is a Far West" ${ }^{24}$. The criterion of operating as a Far West is a way of shifting the established category of an affirmative Orientalism-likewise an indicator of world literature-to a transatlantic sphere and thus taking on existing measures of value for the literary staging of the Other as the exotic. The double criterion of the ability to be integrated into the German cultural tradition (in the form of highly canonical authors) and a left-leaning theoretical formation created a reception filter that served the company well, pragmatically connecting some of the central themes of the "Suhrkamp culture": religion, ethics, and existentialism.

\section{Works cited}

Avelar, Idelber. The Untimely Present: Postdictatorial Latin American Fiction and the Task of Mourning. Duke University Press, 1999.

Beckett, Samuel. Molloy: A Novel. Trans. Patrick Bowles in collaboration with the author. Grove Press, 1955.

---. Molloy. Éditions de Minuit, 1982.

Borsò, Vittoria. "Europäische Literaturen versus Weltliteratur-Zur Zukunft von Nationalliteratur." Jahrbuch der Heinrich-Heine-Universität Düsseldorf. Ed. Alfons Labisch. Heinrich-Heine-Universität Düsseldorf, 2004, pp. 233-250. http://www.uniduesseldorf.de/Jahrbuch/2003/PDF/Borso.pdf, last visit 18/09/18.

Bürger, Jan. “Aber unsere große Entdeckung. . . war Siegfried Unseld.” Jahrbuch der Deutschen Schillergesellschaft, 54, 2010, pp. 13-20.

Cammann, Alexander. “Im Papier-Gebirge.” Die Zeit, 11 Feb. 2010, p. 7.

Hofmannsthal, Hugo von. "The Poet and Our Time." Hugo von Hofmannsthal and the Austrian Idea: Selected Essays and Addresses, 1906-1927. Ed. and trans. David S. Luft. Purdue University Press, 2011, pp. 33-51.

--.. "Der Dichter und diese Zeit." Gesammelte Werke in zehn Einzelbänden. Vol. 8: Reden und Aufsätze I (1891-1913). Ed. Bernd Schoeller. S. Fischer, 1979 [1907], pp. 229-258.

Marling, William. Gatekeepers. The Emergence of World Literature and the 1960 s. Oxford University Press, 2016.

24 "Ich muß hinzufügen, daß die lateinamerikanische Literatur ein Neuankömmling ist. Sie ist die jüngste aller westlichen Literaturen. [.. . ] Lateinamerika ist ein Ferner Westen.” Unseld's travel report, Paris, 20-22 May, 1979, SUA Marbach. 
Müller, Gesine. “¿Literatura mundial o literaturas mundiales? Un estudio de caso de las letras latinoamericanas en la editorial Suhrkamp." América Latina y la Literatura Mundial: mercado editorial, redes globales y la invención de un continente. Eds. Gesine Müller and Dunia Gras. Iberoamericana/Vervuert, 2015, pp. 81-98.

---. "Konstruktion von Weltliteratur und Verlagspolitiken. Der Lateinamerika-Nachlass des Suhrkampverlags." Buchmarkt, Buchindustrie und Buchmessen in Deutschland, Spanien und Lateinamerika. Ed. Marco Thomas Bosshard. LIT, 2015, pp. 147-160.

--.. "Literaturen der Amerikas und ihre Rezeption in Deutschland." Verlag Macht Weltliteratur. Lateinamerikanisch-deutsche Kulturtransfers zwischen internationalem Literaturbetrieb und Übersetzungspolitik. Ed. Gesine Müller. tranvía, 2014, pp. 117-132.

Müller, Gesine, and Sylvester Bubel. "Entre estética y política. Ideas de una literatura mundial en la correspondencia Unseld-Paz." iMex. México Interdisciplinario. Interdisciplinary Mexico, vol. 5, no. 10, 2016, pp. 108-117.

Paz, Octavio. "La letra y el cetro." Obras completas. Vol. 5: El peregrino en su patria: Historia y política de México. Galaxia Gutenberg/Círculo de Lectores, 2002, pp. 751-755.

--.. "The Sunstone." The Collected Poems of Octavio Paz, 1957-1987. Trans. Eliot Weinberger, New Directions Books, 1991, p. 1.

---. Sor Juana or, The Traps of Faith. Trans. Margaret Sayers Peden. Harvard University Press, 1988.

---. Sor Juana Inés de la Cruz o Las trampas de la fe. Fondo de Cultura Económica, 1985.

---. "Alrededores de la literatura hispanoamericana" [Lecture given at Yale University in 1976]. In/Mediaciones. Seix Barral, 1979, pp. 25-37. Also appeared in: Vuelta, vol. 1, no. 5, 1977.

---. Piedra de sol. Tezontle, 1957.

Paz, Octavio, and Braulio Peralta. "Esa parte irracional del hombre, la poesía." El poeta en su tierra: Diálogos con Octavio Paz. Ed. Pámpano Servicios Editoriales S.A. de C.V./H. Cámara de Diputados, LXII Legislatura, 2014, pp. 39-47. http://biblioteca.diputados. gob.mx/janium/bv/md/LXII/poet_tierr.pdf, last visit 14/12/18.

Rama, Ángel. La novela latinoamericana 1920-1980. Procultura, 1982.

Siegfried Unseld archive (SUA) at the German Literary Archive (Deutsches Literaturarchiv) in Marbach.

Suhrkamp Verlag. Suhrkamp Verlagsgeschichte 1950-1990. 40 Jahre Suhrkampverlag. Suhrkamp, 1990.

Unseld, Siegfried. "Kleine Geschichte der Bibliothek Suhrkamp." Klassiker der Moderne-Ein Lesebuch. Ed. Hans-Ulrich Müller Schwefe. Suhrkamp, 1989, pp. 7-23.

Weber, Julia. Das multiple Subjekt. Randgänge ästhetischer Subjektivität bei Fernando Pessoa, Samuel Beckett und Friederike Mayröcker. Fink, 2010. 



\title{
Premios porteros. La función del Premio Biblioteca Breve con base en números
}

\begin{abstract}
Success in World Literature is about gatekeeping. [... . I mean scouts and literary entrepreneurs, some of whom are translators. I mean small publishers and agents. [...]. When we look at contemporary World Literature, however, we can see that gatekeeping must be understood as dimensioned in two or more national or linguistic cultures. (Marling 2, 7)
\end{abstract}

Esta es la definición de gatekeeping que provee William Marling y la que debe ser entendida como tópico orientador para algunos de los aportes en este trabajo. Marling empieza con la afirmación de que los gatekeepers han adquirido los recursos culturales como para estar al tanto de las posibilidades que posee el artefacto literario más allá de su propio campo. Esto implica que hay dos conjuntos de "reglas del juego" que se aplican en cada situación de control: aquellos en la cultura de origen y aquellos otros en la de la recepción. Marling también remite a que los agentes y editores se arriesgan económicamente cuando mueven un texto hacia una circulación internacional. Los editores, esos participantes cruciales en lo que James English denomina "the economy of prestige", han desarrollado premios y distinciones mediante los cuales tasan la comerciabilidad de nuevos autores para luego promover sus mejores apuestas. Para convertir el Premio Biblioteca Breve (PBB) en el objeto de mi investigación y, de cierto modo, en un fenotipo de los gatekeepers, me orientan estos dos conceptos que acabo de mencionar: la circulación de libros y los posibles impactos de los premios literarios. Pero antes que nada hay que aclarar lo que se entiende por circulación en este contexto. La circulación se visibiliza tras las traducciones de la obra original y resulta en un índice de circulación respectivamente más o menos elevado, según la cantidad y la velocidad con que se efectuaron dichas traducciones, o no.

\section{El papel del Biblioteca Breve}

Los premios literarios representan un tema aún poco teorizado que también toca la discusión acerca del valor literario. Ignacio Sánchez Prado en su aporte "Más allá del mercado" constata: "En el vasto mapa de los estudios literarios latinoamericanos, resulta difícil encontrar un punto tan controversial y pobremente

Judith Illerhaus, Universität zu Köln

Ә Open Access. () 2020 Judith Illerhaus, published by De Gruyter. (cc) BY-NC-ND This work is licensed under a Creative Commons Attribution-NonCommercial-NoDerivatives 4.0 International License.

https://doi.org/10.1515/9783110673678-003 
teorizado como la relación sistemática entre mercado editorial y estética literaria" (15). Los dos casos que voy a presentar fueron decisivos y sirven para analizar la sistemática del PBB: el primero será el de Mario Vargas Llosa en el año 1962. Como segundo, se tratará el de Jorge Volpi que ganó la primera distinción de la nueva edición del premio en 1999. Con esta operación, Seix-Barral establece, de cierta forma, un puente literario transatlántico. Sin duda alguna, el premio contribuyó, principalmente en su primera etapa, a la difusión de literatura latinoamericana en Europa. La trayectoria del premio se puede subdividir en 4 etapas:

1. La etapa constituyente en la que cae el primer caso a analizar: para Burkhard Pohl (123), los premios literarios Destino, Planeta y Janés funcionaron como precursores del PBB en el ámbito español, mientras que el Premio Goncourt en Francia sirve como referencia del campo internacional. Herrero-Olaizola (329) localiza el establecimiento del PBB en conexión directa con los premios Formentor y el Premio Internacional de Literatura, que también fueron fundados por Barral. El hecho de que estos dos también ostentaran una alta proporción de autores latinoamericanos entre los ganadores ayudó a fomentar una cierta preparación del campo de literatura latinoamericana en España. A continuación, Herrero-Olaizola sigue describiendo la idea principal detrás de los premios del siguiente modo: "The idea. . . had to do not only with consecration, but also with the internationalization of the publishing house and the reinforcement of its avant-garde readership" (329). El mismo Carlos Barral, iniciador principal del premio, describió el carácter de la distinción con mucho acierto, diciendo:

comenzó siendo un instrumento de maniobra editorial y terminó en maravilloso juguete de la cultura. [...] Muy deprisa, aquel premio de café literario, de amiguetes de café, se fue cargando de prestigio, sobre todo a lo ancho de las Américas; se fue convirtiendo [...] en el eje de una política literaria posible, una política de verdadero descubrimiento de la literatura americana. (79-84)

Aunque la designación específica del premio como parte de una estrategia editorial indica, por un lado, que este fue creado en primer lugar con el fin de ampliar el repertorio de la editorial con nuevos escritores latinoamericanos, la declaración del galardón como "juguete de la cultura" indica que el mismo superó, claramente, las expectativas de los iniciadores y que la dinámica se independizó de cierta manera en el campo literario.

2. La etapa de establecimiento: esta fase describe el periodo de la primera entrega del premio en 1958 al español Luis Goytisolo, por Las Afueras, hasta el último premio, por el momento, para José Leyva en 1972 por La circuncisión del señor solo. Este período comprende catorce momentos de consagración en los cuales un total de nueve latinoamericanos terminaron siendo posibles laureados. Sin embargo, no siempre se llegó a un acuerdo, como pasó en los años 1960, 1966 y 1970. Los 
acontecimientos en torno a la ceremonia así como la comercialización y el marketing del galardón en estos años ayudaron a fomentar el carácter elitista y artístico del premio al que habían aspirado los iniciadores ${ }^{1}$. Durante este tiempo, Carlos Barral consiguió mantener su posición como editor de vanguardia y experto en literaturas latinoamericanas. Además, fue capaz de convertir este capital simbólico en un éxito económico dentro de muy poco tiempo puesto que, a pesar de su reputación elitista y de la estética de alta calidad de las novelas premiadas, esas mismas consiguieron unas cifras de circulación sin precedentes: Herrero-Olaizola (330) se refiere al ejemplo clásico, a la comercialización de La ciudad y los perros. La novela se agotó en muy poco tiempo y después de solo ocho años ya se habían vendido 135000 ejemplares. En comparación con cifras de hoy, este número puede parecer poco llamativo. Pero en su momento de referencia y especialmente formando parte de las editoriales de vanguardia, sí vale la pena mencionarlo, ya que en general se calculaba con una venta de un promedio de 3000 ejemplares.

Aunque los dos primeros ganadores hayan sido los españoles Luis Goytisolo (1958) y Juan García Hortelano (1959), se sabe del hecho que hubo participación latinoamericana en estos dos primeros momentos de consagración (Pohl 127). Por lo tanto, se puede decir que el puente hacia América Latina había sido establecido desde el principio. Aunque el premio fue declarado desierto en 1960 y, al año siguiente, José Manuel Caballero Bonald, otra vez un escritor español, fue anunciado como ganador, a partir del año 1962, con la consagración de Mario Vargas Llosa, los autores latinoamericanos se volvieron serios competidores. Con Vicente Leñero (1963), de México, y Guillermo Cabrera Infante (1964), de Cuba, tres latinoamericanos fueron consagrados consecutivamente. Entre los demás galardonados, se encuentran Carlos Fuentes (1967), José Donoso (1970), aunque a él no le concedieron el premio, y, finalmente, Nivaria Tejera (1971). Con esa cantidad de premiados, la participación de América Latina entre los finalistas (que aquí no fueron mencionados) y ganadores llegó a un 64\% durante la primera fase de adjudicación.

3. Una etapa de pausa entre 1973 y 1998: con la última entrega del premio por el momento en 1972, el PBB cae en un período de pausa por veintiséis años. Los posibles efectos de esta interrupción a largo plazo raramente son nombrados o investigados en la literatura especializada. La primera pregunta que ahora surge para un observador es, por supuesto, la cuestión por la razón de esa pausa y, por otro lado, por las consecuencias. Ya en 1970, Barral renuncia a sus

1 Al respecto, Burkhard Pohl ser refiere al contenido de una entrevista con Jaime Salinas. En esa ocasión, Salinas afirma que, por ejemplo, la selección de Sitges como sitio de entrega del PBB fue elegido estratégicamente para distinguirse conscientemente de Barcelona como metrópolis cultural. Más allá, Pohl cita a un periodista que en su tiempo comentó el trabajo de prensa de Seix Barral con las palabras “qué servicio de información, santo Dios!” (Pohl 124-125). 
actividades en el marco de la casa matriz Seix Barral para asumir el desarrollo de Barral Editores. Algunos autores denominan este período como la "crisis" en la editorial Seix Barral (ver, por ejemplo, Pohl o Herrero-Olaizola); se comenzó a vislumbrar en particular con la muerte de Víctor Seix en el año 1967 y los desacuerdos posteriores entre ambas familias (Seix y Barral). Algunos de los intelectuales y autores se sentían obligados a seguirle el camino a Barral, pero su plan de posicionarse como un serio competidor de Seix Barral en el mercado fracasa pronto. La evaluación de José Luis de Diego es la siguiente: "Es un lugar común afirmar que Barral, respaldado por una sólida cultura cosmopolita, encarnó la vanguardia literaria de aquellos años y fue maestro y guía de editores más jóvenes; es también un lugar común escuchar que era un mal administrador y que confiaba demasiado en sus intuiciones" (“Algunas hipótesis" 4).

La conversión de capital simbólico en una política editorial, en particular en el marco de un mercado profesionalizado de literatura, no pudo sostenerse. Tampoco la iniciación de otro premio literario, el Premio Barral, “... que pretendió ser lo mismo" (Barral 79), no pudo contrarrestar este desarrollo. Como razón del fracaso del premio, Pohl (319) describe la relación inconsistente entre textos experimentales y el potencial comercial del premio. El incidente más relevante durante esa pausa del premio fue la adquisición de un $70 \%$ de la editorial por el grupo Planeta en el 1982. Según de Diego (“Concentración económica” 139), ese acontecimiento define el comienzo de la estrategia de expansión de Planeta y la editorial se posiciona como líder en el mercado hispanohablante.

4. El retorno al campo literario, correspondiente con la premiación de Jorge Volpi: finalmente, después de veintiséis años, el PBB vuelve al escenario en 1998 en forma de una convocatoria. Ante la reaparición de un premio, surgen diferentes interrogantes: uno de ellos sería en qué medida cambió la sistemática de adjudicación de premios y menciones. También la imagen del premio, comunicado por diferentes medios de comunicación, diverge en su presentación. Mientras $E l$ Tiempo remite explícitamente al carácter identitario latinoamericano del premio, El País, por ejemplo, se enfoca en una representación de España como origen del premio. Las siguientes citas así lo demuestran: "Hoy sabemos que solo fue un adiós temporal, explica el director editorial de Seix Barral, Basilio Baltasar. Temporal, porque el premio que tiempo atrás recibieron Carlos Fuentes, Mario Vargas Llosa o Guillermo Cabrera Infante, se volverá a entregar en 1999" (Redacción El Tiempo) [las cursivas son mías]. Y:

El Premio Biblioteca Breve de Seix Barral [. . . vuelve a convocarse. El premio, fundado en 1958 y desaparecido en 1972, constituyó una garantía de calidad y de renovación de la literatura española, sin concesiones a la comercialidad y en tensas relaciones con la censura. El primer jurado... [premió] Las afueras de Luis Goytisolo. Era el primero de una larga lista de novelistas, entonces desconocidos (Vargas Llosa, Caballero Bonald, 
Marsé, Benet, García Hortelano), que son ahora clásicos de la narrativa española de la posguerra. (Vidal-Folch en El País) [las cursivas son mías]

La lista de los galardonados aparentemente representativos del PBB muestra con claridad la diferente percepción del premio. A pesar de que Jorge Volpi como primer ganador procede nuevamente del campo latinoamericano, la excesiva presencia de América Latina durante la primera fase del premio no se vuelve a repetir en la actualidad. Hasta el día de hoy, el premio ha sido otorgado veinte veces. Entre los galardonados hay un total de siete latinoamericanos, lo que corresponde a un 35\%. A cambio, esto significa que, inicialmente, no hubo ni un año sin premio durante esta segunda fase de adjudicación, al contrario de la primera. Ahora bien, uno se podría preguntar si esto representa un jurado con más unanimidad que durante la primera fase, o si la pretensión del premio simplemente ha cambiado. Al menos en este punto parece haber habido una asimilación objetivamente evaluable de la antigua editorial independiente Seix Barral hacia la gran corporación Planeta, y eso a expensas de la calidad estética, así como una no-adjudicación antes se consideraba explícitamente posible, pues, las bases actuales dictan que el premio no puede ser declarado vacante: "El Premio no podrá ser declarado desierto" (Las bases del PBB). En los siguientes apartados se presentarán algunos recortes de unos análisis de las dos obras de Mario Vargas Llosa y Jorge Volpi, o sea, el proceso de consagración y los impactos que ha tenido el premio en ambos casos.

\section{El papel clave de Mario Vargas Llosa}

El ejemplo de Vargas Llosa puede definitivamente valer como confirmación de la tesis de que entre consagraciones literarias y los autores premiados suele existir una influencia recíproca. Sobre todo hablando de premios comerciales. En el marco del caso aquí analizado, se cita a José Donoso que en sus memorias recuerda: “así como el Premio Biblioteca Breve de Novela de 1962 'lanzó' a Mario Vargas Llosa, es igualmente lícito decir que Mario Vargas Llosa 'lanzó' a Seix Barral” (84). En 1962, Mario Vargas Llosa recibió como primer latinoamericano ese premio por su novela La ciudad y los perros, lo que catapultó al parqué literario a nivel internacional. Después de haber fallado con varios intentos de colocar la novela en editoriales como Juillard o Ruedo Ibérico, Vargas Llosa recorrió sus numerosos contactos del campo literario que, a su vez, remitían el manuscrito a sus contactos hasta que llegó al primer ganador del PBB del año 1958, el español Luis Goytisolo. Aunque el juicio de Goytisolo parece no del todo aclarado, Barral también se decidió de leer el manuscrito y quedó deslumbrado con él. De ahí 
resultó una larga e intensa conversación entre el editor y Vargas Llosa de la cual existen muchas evidencias en el archivo de Princeton. Por razones de espacio, no se pueden presentar en el marco de este artículo todos los diálogos que valdrían ciertamente la pena ser presentadas, pero sí conviene citar la siguiente declaración de Vargas Llosa a su amigo Abelardo Oquendo del 15 de setiembre del 1962:

Me dijo [Barral] que le van a dar [a Los impostores] el premio 'Biblioteca Breve', lo que es completamente inmoral, porque yo no me he presentado al concurso, porque las inscripciones ya están cerradas. Además, me joden los concursos. [. . .] Le dije que estaba en comité de lectura en Julliard y me exigió que la retirara porque dice estar seguro de colocarla en Gallimard, en mejores condiciones, y también de vender los derechos al inglés, al alemán y al italiano. [...] Le propuse que me pagara ahora mismo el precio de un pasaje en avión ida y vuelta Lima-París y que a cambio de eso le cedía los derechos y ha aceptado. [...] Todavía no estoy muy convencido de lo que ocurre, pero si me manda el medio millón de francos, firmaré el contrato. (Archivo de Princeton, citado en Aguirre 91)

De este tipo de cartas hay muchas y resulta que, aunque darle el premio a Vargas Llosa hubiese sido un acto estratégico, planificado en detalle por Barral y por eso también un momento decisorio en la carrera del autor, las condiciones comerciales para su éxito que habría de exceder las fronteras de la península, fueron planificadas y creadas anteriormente. Lo que revelan las numerosas correspondencias es que el propio editor propone al autor como participante del concurso y que ese mismo, al final, resulta como ganador. El mismo Barral describe el sector editorial de la siguiente manera: "La política editorial no se caracteriza propiamente por su claridad” (citado en Aguirre 87).

\section{Marketing de la primera edición española}

Como condición para la publicación en el ámbito literario español se requería en aquel momento la aprobación por parte de la censura franquista. Los documentos muestran que la novela de Vargas Llosa en ese momento ya tenía el título final La ciudad y los perros; con respecto al cambio en el título, hay varios puntos de vista, que también resume Aguirre en su estudio (160-162). El procedimiento de la censura se aplazó hasta finales de 1963. Ese hecho significó una oportunidad adicional para la comercialización de la novela por parte de Barral: la presentación al concurso del Prix Formentor, que fue concedido en 1963. A pesar de sus esfuerzos por generar una vez más publicidad para Vargas Llosa, el escritor español Jorge Semprún recibió el premio. Sin embargo, ya el hecho de haber sido candidato al premio sirvió para “comercializar” una vez más a Vargas Llosa, que en ese momento tenía el estado de un newcomer en el mercado del libro europeo. Mientras que la referencia de haber ganado el PBB en 1962 se encontraba en la 
cubierta exterior del libro, la parte interior se refería al haber sido finalista en el concurso del Prix Formentor. La primera edición de La ciudad y los perros incluye un prólogo excepcionalmente amplio, escrito por José María Valverde, también miembro del jurado del PBB, quien justificó aquel prólogo de ocho páginas en una carta informal de la siguiente manera: "para amortiguar la posible reacción escandalosa de ciertas personas y ciertos ambientes, en España, que podían impedir la difusión de la novela" (citado en Aguirre 175). Esta particularidad extraliteraria como parte del proceso de la comercialización de la obra constituye una prueba del interés especial de la editorial por publicar ese libro, a pesar de las circunstancias difíciles, debido en particular a la censura franquista. La primera edición de La ciudad y los perros sale a la venta en octubre de 1963 en Barcelona y solo once meses después, en septiembre de 1964, la novela se publica ya en su cuarta edición y registra tirajes de 12000 a 16000 ejemplares. La sexta edición, impresa en enero de 1966, supuestamente comprendía de 21000 a 25000 ejemplares $^{2}$. En cuanto a la comercialización regular de la primera novela de Vargas Llosa, se puede afirmar que entre 1963-1966 alrededor de 55000 ejemplares de La ciudad y los perros fueron vendidos en español.

\title{
Circulación y recepción
}

Lo que realmente debe de haber ayudado a la fuerte circulación fueron las numerosas reseñas que salieron en muchos países traductores. Aguirre también remite a los elogios excepcionales, difundidos por críticos allegados como Sebastián Salazar Bondy o Carlos Germán Belli en línea directa con el premio. Belli, por ejemplo, escribe el 29 de diciembre de 1962:

\begin{abstract}
Seguro ya estás enterado de la sensación que causó en Lima la noticia de tu premio. Todos los diarios la publicaron en sus primeras páginas. [...] Tu caso es admirable, pues has creado, en plena juventud, una obra perdurable y merecedora de un galardón tan ilustre [...]. Tu justo lauro nos enaltece a todos los americanos. Pues ha tenido la virtud de sacarnos de esta penumbra provincial, en que solemos quedar casi siempre cuando se hacen cotejos con nuestros hermanos españoles. (Archivo de Princeton, citado en Aguirre 102) [las cursivas son mías]
\end{abstract}

Las palabras de Belli explicitan la discrepancia de percepción propia y la visibilidad de las literaturas latinoamericanas en ese momento. Da la impresión de

2 Ya la quinta edición que había sido publicada solo un mes después de la cuarta edición en octubre 1964, comprendía de 17000 a 21000 ejemplares, las indicaciones sobre la sexta edición obviamente contienen errores. 
que Vargas Llosa ganó el PBB no solo en nombre de su propio país, sino en el de todo el continente latinoamericano. Por otra parte, el premio serviría para promover la escena literaria de América Latina de la "penumbra provincial". También el folletín peruano trató el tema y tematizó las referencias reales de la novela: “Quienes en 1952, o antes, o después cursaron estudios secundarios en ese colegio, tal vez habrán de identificarse como protagonistas de la novela, o identificar a más de un muchacho que vivió la experiencia que ellos, como muchos, vivieron" (Aguirre 103). El enfoque claramente antimilitarista de la novela en conexión con aspectos históricos relativos al Colegio Militar Leoncio Prado (CMLP) no fue recibido con mucha euforia por los militares peruanos que solo un año antes habían asumido el poder en el Perú: "El director del CMLP llamó al librero Juan Mejía Baca pocos días después del anuncio del premio para pedirle un ejemplar de Los impostores" (Aguire 105). Mientras su amigo Abelardo Oquendo informa a Vargas Llosa sobre los eventos en Lima y añade una reunión con el director del CMLP, que le dijo "tengo un resumen extenso, un informe completo sobre el asunto. Es un libro marxista” (Aguirre 105). El rechazo se constata, finalmente, con la quema de 1000 ejemplares de la novela en la explanada del CMLP en septiembre y octubre de 1964 por miembros del colegio militar. Sin embargo, este evento es considerado como una leyenda urbana, de la cual no hay evidencia sustancial, porque incluso con el intento

de reconstruir la cronología de los hechos utilizando la correspondencia de algunos de los personajes vinculados con esta historia y las informaciones periodísticas de esos días (,) (l)as evidencias sobre la supuesta quema son bastante endebles, por no decir, inexistentes, y hace falta decir que, [...] no he podido identificar pruebas concluyentes de que ello haya tenido lugar. (Aguirre 223)

Al margen de esto, la discusión de la novela fue casi omnipresente, tanto en España como en los países de América Latina, sobre todo, por supuesto, en Perú. Todos los periódicos trataron tanto la primera novela de Vargas Llosa como también la consagración gracias al $\mathrm{PBB}$. El rechazo público del régimen de Castro por parte de Vargas Llosa llevó a que sus libros, como en el caso de La ciudad y los perros, terminaron siendo parte de la lista de la censura y ya no circulaban más, al menos oficialmente. Aunque el PBB ha sido utilizado también en otros países con el fin de darle un sello adicional de predicado a Vargas Llosa, una imagen de la revista New York Times del 11 de septiembre de 1966, ilustrando la supuesta quema de los libros en Lima, demuestra la priorización de aquel incidente ante la mención de un premio literario como el PBB.

Según la agente del autor, Carmen Balcells, La ciudad y los perros fue traducido a veintisiete lenguas. La siguiente tabla demuestra un recorte de esas traducciones: 
Tabla 1: Recorte de la cronología de traducciones, Vargas Llosa.

\begin{tabular}{llll}
\hline Año & País & Título & Editorial \\
\hline 1963 & España & La ciudad y los perros & Seix Barral \\
1964 & Perú & La ciudad y los perros & Populibros \\
1964 & Países Bajos & De Stad en de Honden & Meulenhoff \\
1965 & Rusia & Город и псы & La Jeune Garde \\
1966 & Inglaterra & The Time of the Hero & Grove Press \\
1966 & Francia & La ville et les chiens & Gallimard \\
1966 & República Checa & Město a psi & Belles Lettres, Mlada Fronta \\
1966 & Alemania & Die Stadt und die Hunde & Rowohlt \\
1966 & Finlandia & Kaupungin koirat & Otava \\
1966 & Suecia & Staden och hundarna & Bonnier \\
1967 & Italia & La Città e i cani & Feltrinelli \\
1967 & Argentina & La ciudad y los perros & Sudamericana \\
1967 & Dinamarca & Byen og hundene & Samlerens \\
1977 & Portugal & A cidade e os cães & Europa-América \\
1981 & China & 城市與狗 (Chéngshì yǔ gǒu) & Editorial de Literatura Extranjera \\
1984 & Turquía & Kent ve Köpekler & Can Yayınları \\
\hline
\end{tabular}

Es interesante notar que la traducción al holandés fue la primera. Maarten Steenmeijer ha escrito varios artículos sobre la recepción de la literatura latinoamericana en los Países Bajos. En uno se refiere explícitamente a la recepción de De Stad en de honden y las muy escasas críticas que salieron en relación con esta novela. Debido a ello, las reacciones del campo literario holandés fueron mínimas. Steenmeijer compara la presencia de Vargas Llosa con los escritores latinoamericanos ya establecidos, como Borges, Cortázar o Neruda. La explicación de Steenmeijer (104) se basa en el hecho de que la recepción de un nuevo autor en el momento era proporcional con su capital literario, que había acumulado hasta el momento en otros países como Francia, Inglaterra, los EE.UU. o Alemania. Lo que sí es reseñable aquí son los textos de presentación de la versión holandesa. En la contracubierta se encuentran las siguientes referencias bibliográficas y biográficas del autor:

Mario Vargas Llosa werd in 1936 geboren in Arequipa (Peru). Hij studeerde wijsbegeerte en letteren in Lima en in Madrid en woont sedert vijf jaren in Parijs, waar hij werkzaam is bij de Franse Radio-omroep en Televisie. In 1958 publiceerde hij een verhalenbundel (Los]efes) en onder de candidaten voor de Prix Formentor 1963 trok hij sterk de aandacht met zijn romanmanuscript LA CIUDAD Y LOS PERROS.

(Mario Vargas Llosa nació en 1936 en Arequipa (Perú). Estudió filosofía y letras en Lima y en Madrid y vive desde hace cinco años en París, donde trabaja en la radio y televisión 
francesas. En 1958 publicó un libro de relatos (Los ]efes) y entre los candidatos del Premio Formentor 1963 llamó mucho la atención el manuscrito de su novela LA CIUDAD Y LOS PERROS.) [Traducción de Maarten Steenmeijer (99)]

El texto, como se observa, refiere a la nominación en el marco del Prix Formentor, pero haber sido el ganador del $\mathrm{PBB}$, al no haber referencia, pareciera desempeñar un menor o, mejor dicho, ningún papel.

De modo que y en contra del criterio corriente, La ciudad y los perros no necesitó de la lingua franca (de la actualidad que viene a ser el inglés) del mercado global de la literatura mundial para ser traducido a varias lenguas más. De hecho, en el mismo año en que salió la primera versión inglesa, salieron las ediciones francesa, checa, alemana, finlandesa y sueca. A excepción de noruego, que según el index translationum de las Naciones Unidas se posiciona como número diecisiete entre las lenguas de destino de traducciones, La ciudad $y$ los perros fue traducido a las veinte lenguas de destino de mayor frecuencia. Junto con esto, las traducciones se efectuaron con una velocidad impresionante como también demuestra la tabla. En menos de diez años fue traducido ya a diez idiomas, descontando las ediciones peruana y argentina. De esa tabla se deduce un índice de circulación que, después, me servirá para comparar diferentes casos de estudio a un nivel numérico.

Tabla 2: Îndice de circulación, Vargas Llosa.

\begin{tabular}{lrrrr}
\hline & Frecuencia & Velocidad & Distancia & Total \\
\hline La ciudad y los perros (1962), Mario Vargas Llosa & 19 & 12 & 6 & $\mathbf{3 7}$ \\
\hline
\end{tabular}

\section{El intento de un revivir con la consagración de Jorge Volpi}

Cuando en el año 1998 el PBB vuelve a la escena literaria en forma de una convocatoria, ya no se trata de la misma distinción, con la misma fama que solía poseer en las décadas de los 60 y 70 aunque eso haya sido lo presentado en anuncios en diarios y en la comunicación externa de la editorial.

Jorge Volpi de cierta manera representa el equivalente de la etapa actual a Mario Vargas Llosa en la primera fase del premio; otra vez se trata de un latinoamericano y otra vez recibe mucha atención por reseñas y, enseguida, numerosas traducciones. En una entrevista, Volpi mismo declara: “Otra de las cosas 
que tiene el Premio, y no lo digo por haberlo ganado yo, sino porque esto es objetivo, es que es uno de esos pocos literarios españoles importantes en el que hay un jurado dispuesto verdaderamente a arriesgar... A mí no me conocía nadie en España...” (Aguirre y Delgado). De hecho eso es cierto; Volpi no había publicado nada anteriormente en España. Pero sí había publicado cinco novelas en México. Como figura central de la generación de El crack $^{3}$, Volpi también se deja posicionar, parecido a los comienzos de Vargas Llosa, en un lugar político. También como Vargas Llosa recibió su grado de doctorado de una universidad española e igual al primer ganador latinoamericano, Volpi, ya anteriormente, había sido consagrado por premios en su país de origen, México. Por ejemplo, ocho años antes de su consagración por la aún prestigiosa editorial española, Volpi recibió el galardón mexicano Premio Latinoamericano de Plural de ensayo por su trabajo El magisterio de Jorge Cuesta.

\section{Circulación y recepción}

La primera traducción de En busca de Klingsor siguió un año después de la primera publicación de la edición original en el entonces sello editor italiano Mondadori. Las siguientes traducciones fueron las correspondientes al francés, griego, portugués (de Brasil), alemán y húngaro. Todas salieron en el 2001. En el 2002 salieron entonces las siguientes cuatro traducciones, entre ellas la estadounidense; otra vez, el inglés aparentemente no fue necesario para fortalecer la circulación. La siguiente tabla representa las traducciones que se pueden localizar según la base de datos de Naciones Unidas, a las que habría que añadir informaciones aportadas por la agencia Kerrigan que incluyen traducciones al croata, holandés, coreano, portugués de Portugal, serbio, turco y la edición inglesa ${ }^{4}$.

3 Jorge Volpi, junto con sus amigos Ignacio Padilla y Eloy Urroz, forman el grupo literario El crack. En un aporte del 2004, Luis García Jambrina (104) señala explícitamente que la creación de este movimiento debe distinguirse claramente de consideraciones estratégicas en un marco editorial: "Acostumbrados como estamos al empleo de todo tipo de estrategias de mercado y reclamos publicitarios dentro del mundo del libro, muchos podrían pensar que el Grupo del Crack es una mera argucia de algunos editores... para lanzar en España a estos nuevos narradores mexicanos [...]. Y, sin embargo, nada más lejos de la realidad".

4 Al terminar este aporte, la autora aún no dispone de las fechas concretas de las publicaciones en traducción que no se encuentran listadas por las Naciones Unidas. 
Tabla 3: Cronología de traducciones, Volpi.

\begin{tabular}{llll}
\hline Año & País & Título & Editorial \\
\hline 1999 & España & En busca de Klingsor & Seix-Barral \\
2000 & Italia & In cerca di Klingsor & Mondadori \\
2001 & Grecia & Anazitontas ton Klingksor & Okeanida \\
2001 & Francia & À la recherche de Klingsor & Plon \\
2001 & Brasil & Em busca de Klingsor & Companhia das Letras \\
2001 & Hungría & Klingsor nyomában & Európa \\
2001 & Alemania & Das Klingsor-Paradox & Klett-Cotta \\
2002 & Israel & Ha-hippus ahar Klingsor & Kinneret \\
2002 & Polonia & Na tropie Klingsora & Muza \\
2002 & EEUU & In search of Klingsor & Scribner \\
2002 & Finlandia & Klingsoria etsimässä & WSOY \\
2003 & Inglaterra & In search of Klingsor & Fourth Estate \\
2004 & China & Zhuixun kelinsuo’er & Yilin chubanshe \\
2005 & Taiwán & Xunzhao kelin suo & Huangguan wenhua chuban youxiangongsi \\
2006 & Russia & V poiskah Klingzora & Tranzitkniga \\
2007 & Bulgaria & V tărsene na Klingsor & Kolibri \\
\hline
\end{tabular}

De esa tabla entonces se deduce, como en el caso anterior pero bajo reserva por algunos datos faltantes, un índice de circulación:

Tabla 4: Índice de circulación, Volpi.

\begin{tabular}{lrrrr}
\hline & Frecuencia & Velocidad & Distancia & Total \\
\hline En busca de Klingsor (1999), Jorge Volpi & 15 & $15^{5}$ & 6 & 36 \\
\hline
\end{tabular}

La similar cantidad total de puntos de las dos obras es llamativa. Mientras la obra de Vargas Llosa cuenta con 37 puntos en total, En busca de Klingsor llega a $36^{6}$.

5 Como se señaló anteriormente, la autora en este momento aún no dispone de las informaciones completas de algunas traducciones; no obstante, el índice únicamente puede divergir en cuanto a la velocidad lo que podría sumar cinco puntos más.

6 Claramente, la cantidad de puntos gana en valor informativo en la comparación con más obras. Este trabajo como también la sistemática de la distribución de los puntos se desarrolla en un trabajo más amplio que se publicará en 2019. 
José Manuel López de Abiada y Daniel Leuenberger describen con mucho acierto, aunque no hubiese sido la intención de su aporte, de qué forma había cambiado el campo literario en los años noventa en comparación con los del "boom". Para ellos, una nueva consagración acrecida de autores latinoamericanos a partir de los últimos años de la década de los noventa, encima viniendo acompañados de buenas cifras de ventas, fue prueba de "que los hispanoamericanos volvían 'a marcar el ritmo”' (356). Pero, al contrario de los sesenta y setenta que se dejaban marcar por una cierta dimensión universalizadora, esa nueva corriente literaria latinoamericana a partir de la segunda mitad de los noventa, según ellos, se caracterizaba más por sus aspectos individuales y posmodernos, y porque escribir para un cierto público se había vuelto más común que otrora. Y como Jorge Volpi ocupa el centro de esta dinámica, usan la obra del mexicano como punto de partida para un análisis de la recepción en el ámbito alemán después de haber sido consagrado con el PBB. Después de escrutar varios medios de comunicación, incluyendo programas de radio e informes de diferentes medios de prensa locales y nacionales, llegan a la conclusión de que la recepción ha sido sumamente positiva en el ámbito alemán. También señalan algunas excepciones en cuanto a la crítica positiva, que en la mayoría de los casos critican la mención de la relación amorosa que no tenía necesidad de entrar en la narración. Pero, a final de cuentas, la consagración de Volpi y la siguiente recepción y circulación de su obra parecen caber muy bien en la estrategia de Seix Barral, preparando la reedición de un instrumento editorial tan exitoso de tiempos pasados.

\section{Síntesis}

Los dos casos aquí presentados deben ser considerados ejemplos para un premio en función de un así llamado gatekeeper. En ambos casos, gracias al galardón, las obras premiadas recibieron mucha atención por parte de críticos y circularon a gran distancia. Pero, y esto es muy importante de recordar, las circunstancias generales de los dos momentos de consagración que al mismo tiempo contextualizan de cierta manera a los autores, también tienen que entrar en la evaluación. Por ejemplo, el hecho de que los dos autores aquí presentados hayan sido los "primeros" -uno, el primer latinoamericano en recibir el galardón, acompañando de cierta manera un tiempo de numerosos cambios en el campo literario a escala mundial, y el otro el primero en haberlo ganado después de una larga pausa y entrando a una nueva etapa fuertemente prometedora- y encima proviniendo del continente latinoamericano. No obstante, como se advirtió, tanto la sistemática de la adjudicación cambió como también el porcentaje de las obras 
ganadoras de autores latinoamericanos decreció claramente en comparación con la primera fase del premio, y los impactos del PBB de la actualidad al menos no se manifestaron en un revivir del latinoamericanismo literario.

En la larga historia del premio también hubo casos que servirían como contraejemplo; uno sería el caso de Vicente Leñero ${ }^{7}$. La recepción de su novela premiada no tuvo ni remotamente el éxito de su antecesor Vargas Llosa o su compatriota Volpi treinta y seis años más tarde. Pero incluso así se puede recurrir a la antigua declaración de Cicerón para asegurarse de la veracidad de las suposiciones aquí formuladas; según él, vale asumir: exceptio probat regulam in casibus non exceptis.

\section{Bibliografía}

Aguirre, Carlos. La ciudad y los perros. Biografía de una novela. Fondo Editorial de la Pontificia Universidad Católica del Perú, 2015.

Aguirre Romero, Joaquín y Yolanda Delgado Batista. “Jorge Volpi. 'Las respuestas absolutas siempre son mentiras”. https://pendientedemigracion.ucm.es/info/especulo/nu mero11/volpi.html, consultado 15 de junio 2018.

Barral, Carlos. Cuando las horas veloces. Tusquets Editores, 1988.

De Diego, José Luis. “Concentración económica, nuevos editores, nuevos agentes”. Primer Coloquio Argentino de Estudios sobre el libro y la Edición, 31 de octubre, 1 y 2 de noviembre 2012, La Plata, Argentina. http://www.memoria.fahce.unlp.edu.ar/trab_even tos/ev.1930/ev.1930.pdf, consultado 15 de junio 2018.

---. "Algunas hipótesis sobre la edición de literatura en la España democrática". ${ }^{\circ}$ Congreso Internacional de Literatura y Cultura Españolas Contemporáneas, 1 al 3 de octubre de 2008, La Plata, Argentina. http://www.memoria.fahce.unlp.edu.ar/trab_eventos/ev.307/ ev.307.pdf, consultado 15 de junio 2018.

Donoso, José. Historia personal del boom. Alfaguara, 1999.

English, James. The Economy of Prestige. Prizes, Awards, and the Circulation of Cultural Value. Harvard University Press, 2005.

García Jambrina, Luis. “En busca de Jorge Volpi”. En busca de Jorge Volpi. Ensayos sobre su obra. Eds. José Manuel López de Abiada et al. Verbum, 2004, pp. 104-111.

Herrero-Olaizola, Alejandro. "Consuming Aesthetics: Seix Barral and José Donoso in the Field of Latin American Literary Production”. MLN, Vol. 115, Nr. 2, 2000, pp. 323-339.

Las Bases del Premio Biblioteca Breve. https://staticoplanetadelibroscom.cdnstatics.com/ usuaris/premios/arxius/1/5_1_Bases_PBB_2018.pdf, consultado 15 de junio 2018.

López de Abiada, José Manuel et al. En busca de Jorge Volpi. Ensayos sobre su obra. Verbum, 2004.

7 En un estudio más amplio cuya publicación está prevista para 2020, el análisis del impacto del PBB en la recepción y circulación de la obra premiada de Vicente Leñero, Los Albañiles, del año 1963, resultó en un total de 9 puntos como índice de circulación y se diferencia, entonces, muy claramente de los dos autores aquí presentados. 
López de Abiada, José Manuel y Daniel Leuenberger. "La recepción de En busca de Klingsor en el ámbito de cultura alemana”. En busca de Jorge Volpi. Ensayos sobre su obra. Eds. José Manuel López de Abiada et al. Verbum, 2004, pp. 355-370.

Marling, William. Gatekeepers: the Emergence of World Literature and the $1960 \mathrm{~s}$. Oxford University Press, 2016.

Pohl, Burkhard. Bücher ohne Grenzen. Der Verlag Seix Barral und die Vermittlung lateinamerikanischer Erzählliteratur im Spanien des Franquismus. Vervuert, 2003.

Redacción El Tiempo. “Una larga ausencia de la Biblioteca Breve”. El Tiempo, 1 de diciembre 1998. http://www.eltiempo.com/archivo/documento/MAM-822320, consultado 15 de junio 2018.

Sánchez Prado, Ignacio M. "Más allá del mercado. Los usos de la literatura latinoamericana en la era neoliberal”. Libro mercado. Literatura y neoliberalismo. Coord. José Ramón Ruisánchez Serra. Universidad Iberoamericana, 2015, pp. 15-40.

Steenmeijer, Maarteen. "Los pasos perdidos: la primera presencia de la literatura hispanoamericana en Holanda”. América Latina y la literatura mundial. Mercado editorial, redes globales y la invención de un continente. Eds. Gesine Müller y Dunia Gras. Iberoamericana/Vervuert, 2015, pp. 99-127.

Vidal-Folch, Ignacio. "Vuelve el Premio Biblioteca Breve, de la editorial Seix Barral”. El País, 2 de octubre 1998. https://elpais.com/diario/1998/10/02/cultura/907279207_850215. html, consultado 15 de junio 2018. 



\section{Ascenso y ocaso de una marca: la literatura hispanoamericana en Holanda}

\section{Borges y la literatura latinoamericana}

¿Quién es Jorge Luis Borges? Con estas palabras arranca el largo texto de la contracubierta de De Aleph ${ }^{1}$, el primer libro del escritor argentino traducido al holandés, una selección de los cuentos en Ficciones y El Aleph. De Aleph fue publicado en 1964 por De Bezige Bij, una de las editoriales literarias más importantes de los Paises Bajos. Se diría y esperaría que las palabras que siguen a esta pregunta introdujeran a un autor desconocido que requiere una identidad que posibilite pasar el umbral y llegar a una nueva entidad de lectores. Esta expectativa, sin embargo, no se cumple. El texto que sigue sostiene que Borges ya tenía cierta fama antes de que aparecieran las primeras traducciones en el Viejo Mundo:

En Europa occidental [Borges era] un gran nombre y nada más: era un gran misterio y no se lo leía. Por fin podemos comprobar en Holanda si es justificada esta fama, después de las traducciones de su obra publicadas en Francia, Alemania e Italia, donde se convirtió en uno de los grandes descubrimientos de la literatura de la posguerra.

La contextualización se continúa en el resto del texto que llena la contracubierta. Así, el siguiente párrafo caracteriza a Borges como un escritor argentino genial e ingenioso que maneja un estilo riguroso y, además, califica su obra como laberíntica, fantástica y muy imaginativa. El tercer párrafo es una pequeña biografía que destaca la estancia de Borges en Europa, la diversidad de su obra (poesía, cuentos, ensayos, críticas de cine, traducciones), su trabajo como director de la Biblioteca Nacional de Argentina y como catedrático de literatura inglesa y norteamericana en la Universidad de Buenos Aires. Luego, se menciona el Premio Formentor que el escritor argentino compartió en 1961 con Samuel Beckett y, después, se afirma que, según el semanario francés Arts, Borges es uno de los escritores más importantes del mundo y que Le Figaro lo ha calificado como uno de los grandes maestros de la literatura.

De un lado, queda claro que esta contextualización de Borges por De Bezige Bij se singulariza por su volumen y diversidad: incluye aspectos geográficos, literarios,

1 Todas las traducciones de los paratextos son del autor de este artículo.

Maarten Steenmeijer, Radboud University Nijmegen

Ә Open Access. ( 2020 Maarten Steenmeijer, published by De Gruyter. (cc)BY-NC-ND This work is licensed under a Creative Commons Attribution-NonCommercial-NoDerivatives 4.0 International License.

https://doi.org/10.1515/9783110673678-004 
profesionales, institucionales y mediáticos. Del otro, llama la atención que brille por su ausencia la etiqueta "hispanoamericano" o variantes de la misma como "latinoamericano" o "suramericano”. No es difícil de explicar: a principios de los años sesenta la literatura hispanoamericana todavía no fue percibida como tal en Holanda. Es cierto que en años anteriores a la aparición de De Aleph se habían publicado traducciones de Los pasos perdidos (Alejo Carpentier), de Hombres de maíz (Miguel Ángel Asturias) y Pedro Páramo (Juan Rulfo), pero estas fueron lanzadas por distintas editoriales, ninguna de las cuales presentó a estos nuevos autores como un conjunto. Este patrón se consolidó en los años posteriores:

[E]n Holanda la nueva novela hispanoamericana todavía no existía en los años 60. Solo había traducciones dispersas que apenas acumularon capital económico y literario, y que no habían conseguido que la literatura hispanoamericana llegara a formar parte del repertorio o la memoria colectiva de los lectores profesionales, por no hablar de los lectores comunes y corrientes. (Steenmeijer 117)

Para resumir: la literatura hispanoamericana distaba mucho de ser una marca, es decir “[a] unique design, sign, symbol, words, or a combination of these, employed in creating an image that identifies a product and differentiates it from its competitors” (“[a] unique design”). Sí que hubo dos autores cuyas obras echaron raíces en el sistema literario holandés en el curso de los años sesenta, como atestigua el número de libros traducidos, su excelente y amplia recepción crítica y, asimismo, las reediciones de algunos de ellos: Jorge Luis Borges y Julio Cortázar. De este modo, los dos escritores argentinos no tardaron en convertirse en marcas pero -importa recalcarlo- no en el marco de la literatura latinoamericana sino como autores idiosincráticos o mundiales.

Es en los años setenta cuando la literatura latinoamericana se canoniza como una marca en el campo literario holandés gracias, ante todo, a los esfuerzos de la editorial Meulenhoff, que en poco tiempo publicó, entre otras, todas las obras narrativas de García Márquez y Vargas Llosa, y gran parte de la obra de Carpentier y Cortázar (y luego también de Fuentes). Mientras tanto, De Bezige Bij siguió lanzando nuevos títulos de Borges al mercado holandés: libros de cuentos pero también de ensayos y de poesía. De esta manera, se desarrolló y potenció la marca Borges que, como tal, llegó a representar "certain benefits and values” y a ser asociada "with a level of credibility, quality, and satisfaction in the consumer's mind (...)” (“[a] unique design”).

No sería exagerado afirmar que a lo largo de los años Borges se convirtió en un clásico en Holanda y, de esta manera, llegó a formar parte del repertorio que los críticos y los lectores manejan para contextualizar (la obra de) otros autores. 
Es por ende muy curioso e interesante el anuncio publicado en abril de 1977 por De Bezige Bij para promocionar la obra del escritor argentino. El anuncio incluye una lista de las obras de Borges publicadas por su editorial holandesa y, además, una foto y el nombre del autor. Sorprendentemente, el conjunto queda encabezado por un prominente titular que reza "Zuidamerikaan" (Suramericano), epíteto que en este contexto ejemplifica la potencia de la literatura suramericana (o latinoamericana o hispanoamericana) como marca en aquellos años.

\section{La literatura escrita por mujeres}

Con el lanzamiento de la versión holandesa de La casa de los espíritus en 1985 por la editorial Wereldbibliotheek se introdujo una nueva vertiente de la literatura hispanoamericana en Holanda: la literatura escrita por mujeres, notoriamente ausente en el boom de los años anteriores. El texto en la contracubierta de Het huis met de geesten -el título de la versión neerlandesa- tiene tres partes. La primera refiere al golpe de estado de 1973 en Chile, un acontecimiento histórico que en aquel entonces formaba parte de la memoria colectiva de Holanda:

Het huis met de geesten es una crónica familiar que abarca cuatro generaciones desde principios del siglo veinte hasta los años setenta, cuando la dictadura terminó con el gobierno socialista de Salvador Allende.

La segunda parte (la más larga) ofrece un adecuado resumen de la trama. En la tercera parte se caracteriza la novela en las siguientes palabras:

En Het huis met de geesten Isabel Allende retrata la sociedad suramericana en todas sus formas heterogéneas y, muchas veces, también místicas y fantásticas. Con este libro Isabel Allende muestra que no solo es una escritora excepcionalmente dotada sino también y sobre todo una narradora de pura cepa.

Llama la atención que los paratextos de Het huis met de geesten no hagan ninguna referencia explícita a la literatura latinoamericana y tampoco a los autores que en los años anteriores habían reunido mucho capital literario y no poco capital económico en el sistema literario holandés: ni en la cubierta (donde solo se mencionan el nombre de la editorial, el de la autora, el título y el género del libro) ni en la contracubierta ni en la minibiografía en la primera página del libro, en la que, dicho sea de paso, también se menciona el golpe militar de $1973 \mathrm{y}$ donde se añade que Salvador Allende es el hermano del padre de la autora. La estrategia es otra: se ubica Het huis met de geesten en un contexto histórico concreto y conocido, se menciona, casi sobre la marcha, el lazo familiar entre la 
autora y Salvador Allende, se presenta la novela como una fiel representación de "la sociedad suramericana" (una significativa generalización, por cierto) y se alaban las capacidades narrativas de la autora. Es decir, por un lado la editorial vincula a la escritora y su novela al continente que se había puesto de moda en los años anteriores pero, por el otro, Wereldbibliotheek elude cualquier asociación con los autores latinoamericanos ya establecidos, representando a Isabel Allende como una escritora literariamente soberana pero arraigada en un espacio histórico y cultural que les era familiar a los lectores holandeses.

La crítica literaria, sin embargo, no dejó de señalar importantes parentescos con Cien años de soledad, y ello casi siempre en detrimento de la novela de Allende. Tampoco dejó de destacar ciertos estereotipos. Pero esto no impidió que la estrategia de Wereldbibliotheek - no aludir a (o competir con) los valores consagrados masculinos de la literatura latinoamericana sino destacar las propias calidades de la obra de Allende- funcionara magníficamente. Isabel Allende encontró su propio lugar en el mercado holandés: ha vendido (y sigue vendiendo) muchísimos libros (Het huis met de geesten ya lleva cuarenta y ocho ediciones y cada uno de los numerosos libros posteriores le siguieron las huellas), tiene un gran aprecio entre sus numerosos lectores (lectoras, sobre todo) mientras que tampoco le falta cierto prestigio literario institucional ${ }^{2}$. En resumidas cuentas: la escritora chilena se convirtió en una marca que se iba constituyendo fuera del contexto de la literatura latinoamericana establecida, monopolizada por discursos masculinos. Lo hizo, además, en base a un contexto histórico-cultural que en un principio era predominantemente local (Latinoamérica), pero que luego se iría globalizando debido a la hibridación de sus temáticas y personajes en novelas como El plan infinito (1991), El amante japonés (2015) y Mas allá del invierno (2017), vertebrada esta última en torno a una chilena de origen croata que va a trabajar en Nueva York, una guatemalteca sin papeles que se busca la vida en los Estados Unidos y un judío neoyorquino de origen europeo que se casó con una brasileña.

Siguiendo el camino de Isabel Allende, en los años noventa del siglo pasado las obras de autoras como Laura Esquivel y Gioconda Belli entraron en el mercado holandés. La primera lo hizo de forma espectacular con la versión holandesa de Como agua para chocolate (lanzada en 1991 bajo el curioso título de

2 Así, en 2001 la escritora chilena dio la Van der Leeuw-lezing (Conferencia Van der Leeuw) en Groningen, compartiendo este honor con Barbara Tuchman, Amos Oz, Simon Schama, Hans Magnus Enzensberger, Carlos Fuentes, Ben Okri, Ian McEwan y muchos otros prominentes escritores y pensadores. 
Rode rozen en tortilla's, es decir "Rosas rojas y tortillas”). Así como los paratextos de Het huis met de geesten, los de Rode rozen en tortilla's no vinculan la novela a la narrativa latinoamericana. Las únicas referencias al subcontinente en la contracubierta son el dato de que Laura Esquivel nació en México y el nombre de la autora de la cita que forma parte de los paratextos en la contracubierta: Elena Poniatowska (aunque es más que probable que los lectores holandeses no la asocien con México por su apellido ya que Poniatowska es una autora desconocida en Holanda). A diferencia de los de Het huis met de geesten, los paratextos de Rode rozen en tortilla's no destacan las capacidades narrativas de la autora, restringiéndose a resaltar la temática culinaria, sentimental, erótica y mágica de la novela. La frase que domina la cubierta refuerza la idea de que se trata de una novela exótica y sentimental: "En Méjico una mujer le prepara platos tradicionales a su amor inalcanzable” (Esquivel).

Rode rozen en tortilla's fue, además de un best seller, un long seller: en 2017 apareció la trigésima tercera edición. Las novelas de Esquivel que luego se publicaron (traducciones de La ley del amor, Tan veloz como el deseo, Malinche), empero, ni por asomo lograron tener el éxito que tuvo Como agua para chocolate. Como consecuencia y a diferencia de Isabel Allende, la autora se quedó en la sombra de la novela con la que debutó. Pero lo que importa aquí es comprobar que, igual que en el caso de la escritora chilena, ninguna de las dos -autora y novela- fue vinculada a la marca establecida de la literatura latinoamericana. Lo mismo vale para Gioconda Belli, otra autora del subcontinente que en Holanda debutó como novelista a principios de los años noventa. La editorial De Geus lanzó De bewoonde vrouw (1992, La mujer habitada) como una novela arraigada en la cultura y la historia de Latinoamérica (dictadura; guerrillas; machismo; indios) sin referir al boom, a la nueva novela o alguno de los autores consagrados como Gabriel García Márquez, Mario Vargas Llosa o Carlos Fuentes. A ello es importante añadir que en Holanda, curiosa y significativamente, las editoriales no aprovecharon la oportunidad de crear una nueva marca: no se empeñaron en lanzar a autoras como Isabel Allende, Laura Esquivel y Gioconda Belli como una nueva tendencia de la literatura latinoamericana, es decir, la literatura escrita por mujeres. Con ello, el concepto "literatura latinoamericana” seguía siendo monopolizado por los viejos valores masculinos del boom de la nueva novela. Como tal, estaba en vías de perder rigor y vigor, como se detallará más abajo. 


\section{Eterno El Dorado}

Desde 1932 en Holanda se organiza cada año con bombo y platillo La Semana del Libro (De Boekenweek). En 1996 el tema del evento fue la literatura latinoamericana (y la caribeña, para incluir y resaltar las literaturas de Surinam y las Antillas Holandesas). La relevancia o urgencia del tema -lanzado bajo el lema de "Eterno El Dorado" - no era evidente para todos, como atestiguan las siguientes palabras del crítico literario Willem Kuipers vertidas en el largo artículo que escribió con motivo del evento en de Volkskrant, uno de los periódicos nacionales más importantes de Holanda:

¿Por qué? ¿Por qué era tan atractiva la literatura de Latinoamérica y del Caribe y por qué se acabó? ¿Por qué se organiza ahora esta revitalización? ¿Algo que estaba atrofiándose tiene que ser reanimado con una última transfusión de sangre?

Luego, Kuipers pasa revista a algunos de los libros que se publicarían en el marco de "Eterno El Dorado" y ensalza a autores como Jorge Luis Borges, Mario Vargas Llosa, Gabriel García Márquez, Julio Cortázar, Carlos Fuentes, Juan Carlos Onetti y Homero Aridjis (así como a algunos escritores brasileños, que quedan fuera del marco de este artículo). Llama la atención que no figure ninguna escritora entre los autores comentados por Kuipers. Es sintomática, asimismo, la ausencia de escritores más jóvenes como Luis Sepúlveda, el chileno que con tres novelas ya estaba bien representado en el prestigioso catálogo de Meulenhoff: Un viejo que leía novelas de amor (1993), Mundo del fin del mundo (1994) y Nombre de torero (1995). Con todo, tanto las presencias como las ausencias en el artículo de Kuipers tienden a constituir una respuesta afirmativa a las preguntas planteadas por el crítico: pues no, no tenía mucho sentido organizar la Semana del Libro en torno a una literatura que ya había alcanzado su cénit y estaba perdiendo importancia e interés.

Esta misma idea predomina en los comentarios de algunos expertos entrevistados sobre el tema de la Semana del Libro de 1996. Reinjan Mulder, crítico literario del diario nacional NRC Handelsblad, sostuvo que "En primer lugar, se trata de un tema que no corresponde con la actualidad literaria. En segundo lugar, los editores podrían haber buscado de forma más activa a nuevos autores. Los libros que ahora están promocionando son todos reediciones” (De Vries). Igual de categóricas son las palabras de la celebrada traductora Barber van de Pol: "La literatura latinoamericana no está en su mejor momento, recientemente no se ha descubierto ningún magnífico escritor. Hay interés, pero la euforia de hace quince años se ha debilitado" (De Vries). 


\section{4 ¿Un boom Bolaño?}

Roberto Bolaño (Santiago, Chile, 1953) es considerado como uno de los mayores talentos de la literatura latinoamericana. Publicó algunas novelas y un libro de cuentos, y fue galardonado con varios premios, entre ellos el Premio Rómulo Gallegos, que antes había sido otorgado a, entre otros, Gabriel García Márquez y Mario Vargas Llosa. (De woeste zoekers)

Esta minibiografía es el texto con el que la editorial Meulenhoff introdujo a Roberto Bolaño en la contracubierta de De wilde zoekers (Los detectives salvajes), el primer libro del escritor chileno traducido al holandés. Hay más paratextos en la contracubierta que revelan los esfuerzos de Meulenhoff de vincular a Bolaño a la gran narrativa latinoamericana que hacía unas décadas había tenido un gran impacto en Holanda. Así, figura una cita de El País que vincula Los detectives salvajes a Borges: "El tipo de novela que Borges hubiera aceptado escribir. . Un libro original y hermosísimo, divertido, conmovedor, importante” (De woeste zoekers). También vale la pena mencionar la cita del semanario alemán Der Spiegel que forma parte de los paratextos de la contracubierta de De wilde zoekers y que califica a Bolaño "como probablemente lo más original que la literatura escrita en español hoy en día nos ofrece”.

Estos paratextos vuelven en las contracubiertas de Het lichtende kwaad (la versión holandesa de Estrella distante que vio la luz en 2002) y de Chileense nocturne (Nocturno de Chile, 2004) aunque, igual que en el caso de De wilde zoekers, no surtieron el efecto deseado. No es que faltaran críticas positivas sobre estas tres novelas de Bolaño, pero eran pocas. Demasiado pocas como para conseguir que la obra de Bolaño echara raíces en Holanda. Otra suerte tuvo la versión holandesa de 2666, publicada en 2009 por Meulenhoff. Una baza a su favor o incluso decisiva fue la recepción espectacular de 2666 en los Estados Unidos en 2008, que fue motivo de varios artículos en la prensa holandesa y que de este modo creó ciertas expectativas. El gran eco de la novela en los Estados Unidos es el origen, asimismo, del eslogan "La sensación internacional por antonomasia" que, junto con una foto de Bolaño y una cita de Susan Sontag ("The most influential and admired novelist of his generation in the Spanish-speaking world"), constituye el conjunto paratextual que luce en la contracubierta de la edición holandesa (2666).

Todos los periódicos y semanarios importantes publicaron largas y positivas reseñas sobre 2666 y Bolaño se convirtió en the talk of the town. Pero si hubo un boom Bolaño en Holanda, este duró poco. A diferencia de Borges, García Márquez, Vargas Llosa e Isabel Allende, Roberto Bolaño apenas transcendió el estatus de one hit wonder: todos los demás libros del escritor chileno 
lanzados al mercado holandés después de 2666 (nuevas ediciones de las obras traducidas ya; nuevas traducciones) tuvieron una recepción efímera o rotundamente pobre, tanto en la prensa como entre los lectores. Incluso para 2666 la fiesta terminó pronto: la novela solo tuvo cuatro ediciones, todas en 2009. No es de sorprender, pues, que después de algunos años Meulenhoff, que se había comprometido a publicar toda la obra de Bolaño en Holanda, interrumpiera este proyecto. Después, el escritor chileno tuvo una segunda oportunidad en Lebowski, una editorial con una atinada sensibilidad publicitaria. Pero Lebowski tampoco fue capaz de encontrar un público para Bolaño. Por consiguiente, el autor que no pocos celebran como el nuevo Borges, carece ahora de casa editorial en Holanda. Es aguda la diferencia con el maestro argentino, cuya obra desde hace más de medio siglo sigue funcionando muy bien en De Bezige Bij.

\section{Desde Borges hasta García Márquez: César Aira}

Como hemos visto, no fue el marco de la narrativa latinoamericana el que contribuyó a catapultar a Bolaño a cierta fama en Holanda sino el éxito espectacular en los Estados Unidos de 2666. El dato no es azaroso sino que subraya que a lo largo de los años la literatura latinoamericana y sus valores más consagrados habían perdido en importancia y relevancia en su capacidad de marca y marco. Es inevitable, pues, la siguiente pregunta: ¿cómo se lanza a los nuevos valores del subcontinente en el nuevo milenio? ¿Cuáles son los contextos o marcos identitarios manejados por las editoriales en sus intentos de despertar la curiosidad y el interés de los lectores y, asimismo, el compromiso de importantes intermediarios como son los libreros y críticos? Por varias razones el caso de César Aira puede verse como representativo. La primera es que han sido varios los intentos de lanzar al autor en el mercado holandés. La segunda es que hay llamativas diferencias entre ellos. La tercera es que todos estos intentos han fracasado. Con todo, nos pueden dar una pista, ofreciéndonos una idea que está lejos de ser exhaustiva pero que es reveladora de la actual praxis editorial a la hora de introducir a nuevos valores literarios hispanoamericanos en el campo literario holandés.

La editorial De Geus lo tenía muy claro cuando en 2007 publicó la versión holandesa de Varamo, la novela con la que Aira debutó en los Países Bajos: lanzó a Aira como "el único verdadero alumno de Jorge Luis Borges - y el más talentoso", como reza la cita de un artículo publicado en el periódico alemán 
Frankfurter Allgemeine Zeitung que encabeza la cubierta del libro (De nachtelijke invallen). En la contracubierta figuran cinco citas de un variopinto abanico de fuentes: The Barcelona Review, Die Zeit, Inrockuptibles, Livres Hebdo y TagesAnzeiger. En ellas no se menciona a Borges, pero de forma implícita se refuerza el vínculo con el maestro argentino: en dos de ellas se destaca la nacionalidad del escritor (como se sabe, Aira es compatriota de Borges) y cuatro de ellas resaltan estrategias o rasgos literarios como la ironía, la ambigüedad, la ilusión, la originalidad, lo absurdo y la fantasía.

De nachtelijke invallen van ambtenaar Varamo, como reza el título de la versión holandesa, fue poco menos que negado en la prensa holandesa y tuvo tan pocas ventas que De Geus, una editorial que suele mantener una política de autor, dejó de invertir en Aira. En 2013 Meulenhoff le tomó relevo y publicó otra novela corta de Aira, De schimmen (Los fantasmas). Como en el caso de Varamo, hay una sola cita en la cubierta, que en este caso representa a Aira como un autor afín a Bolaño en base a una cita del autor chileno que no abarca más que una palabra: "Engancha”. En la contracubierta figuran citas de The New York Times, Der Spiegel y La Vanguardia, respectivamente, que no elaboran el presunto parentesco con Bolaño sino la originalidad de Aira: "Aira is one of the most provocative and idiosyncratic novelists working in Spanish today, and should not be missed” (The New York Times); "Aira hace una grotesca acrobacia literaria entre realismo y fantasía” (Der Spiegel); "Una y otra vez César Aira sorprende al lector con su rara genialidad" (La Vanguardia) ${ }^{3}$. En la minibiografía que figura en la contracubierta se vuelve a destacar la singularidad de Aira, esta vez en un marco más específico: "Se lo considera como uno de los autores más originales de América del Sur".

De schimmen no pasó desapercibida en la prensa. Los críticos no ponían en entredicho la originalidad de la novela. Tampoco discrepaban sobre la arduidad de la prosa de Aira aunque la apreciaban de distintos modos. En su reseña para el semanario De Groene que tiene como titular "Oda a lo inacabado" el joven escritor Christian Weijts formuló sus ideas encontradas sobre De schimmen de la siguiente manera: "Si entregara estas 99 páginas a mi editor este me diría: Estupendo borrador. Vamos a convertirlo en un libro fantástico”.

De schimmen fue un fracaso en ventas, pero no cabe duda de que el capital simbólico de Aira -acumulado gracias a las reseñas en la prensa holandesa, a la acogida en los Estados Unidos (donde en los años anteriores Aira se había convertido en un mini hype) y a los rumores sobre su candidatura para

3 Se trata de una versión muy libre del original: "César Aira es un escritor sorprendente cuyas obras de rara genialidad, se transmiten como un secreto entre una secta de entusiastas cada vez más amplia”. 
el premio Nobel- motivó a Meulenhoff a seguir con Aira. En 2016 la editorial publicó Hoe ik een non werd (Cómo me hice monja) en una edición atiborrada de citas paratextuales -De schimmen tiene cuatro, Hoe ik een non werd diez- que ensalzan la obra del escritor argentino desde distintas perspectivas, por distintos motivos y recurriendo a fuentes muy diversas. Parafraseando y resumiendo, rezan así: Aira sabe exactamente cómo seducir al lector (de Volkskrant), Aira es un autor excéntrico que engancha (Roberto Bolaño), Aira podrá ser el primer escritor argentino galardonado con el premio Nobel (Carlos Fuentes), Aira es uno de los autores más provocativos e idiosincrásicos en español (The New York Times), Por favor, dame otro libro de César Aira (Tubantia), César Aira sorprende al lector con su rara genialidad y tiene más y más aficionados (La Vanguardia), Aira hace una grotesca acrobacia literaria entre realismo y fantasía (Der Spiegel), Aira es un gran artesano que engancha (Die Zeit), Aira es uno de los autores más chocantes, excitantes y subversivos del mundo hispanohablante (El País), Aira escribe como un García Márquez que ha tomado drogas (Tages-Anzeiger). En su conjunto estos paratextos representan a Aira como un autor singular que engancha a sus lectores. Al mismo tiempo, camuflan la arduidad de su narrativa. Esta intrincada representación se condensa en la última cita, prominentemente presente en la contracubierta: "Aira escribe como un García Márquez que ha tomado drogas"4.

El lugar privilegiado de este último paratexto no deja de ser significativo: vincular a Aira al autor paradigmático de la nueva novela hispanoamericana no es evidente, pero aquí tiene todas las pintas de servir de último (y casi se diría desesperado) recurso manejado por Meulenhoff para "vender" a Aira a los lectores holandeses. No lo consiguió. Es más: Hoe ik een non werd ni siquiera fue señalada en la prensa.

\section{Conclusión}

En varios sentidos el caso de Aira es paradigmático. En primer lugar, cabe destacar que los paratextos de los libros de los nuevos valores del subcontinente que procuran encontrar un lugar en el campo literario holandés apenas refieren a la marca (y marco) "literatura latinoamericana" y sus variantes ("hispanoamericana", "suramericana") o a los autores asociados con la misma, algunos de los

\footnotetext{
4 Otra versión muy libre del original, que reza así: "Sein soeben auf Deutsch erschienener Roman "Die Mestizin” liest sich, als habe Gabriel García Márquez im LSD-Rausch die Hölle zum Paradies verklärt” (Blank).
} 
cuales -García Márquez, Vargas Llosa- en el curso de los años se convirtieron en marcas soberanas. En segundo lugar, Borges sigue siendo una firme referencia. En tercer lugar, se puede constatar que la marca Bolaño no tiene la presencia y potencia que tenían la literatura latinoamericana y sus valores más destacados en su momento. En cuarto lugar, se podrían interpretar el gran número y la llamativa diversidad de los paratextos en los libros de los nuevos valores como sintomáticos: no hay consenso sobre las marcas que podrían servir de marcos para los escritores latinoamericanos en busca de un público. Por un lado, es problemática esta ausencia. Por otro lado, empero, este estado de las cosas -que, si no me equivoco, no solo vale para Holanda- podría interpretarse como una emancipación, como una señal de que la literatura latinoamericana se está descontinentalizando, de que se está convirtiendo en literatura mundial.

\section{Bibliografía}

Aira, César. Hoe ik een non werd. Trad. Adri Boon. Meulenhoff, 2016.

--.. De schimmen. Trad. Adri Boon. Meulenhoff, 2013.

--.. De nachtelijke invallen van ambtenaar Varamo. Trad. Adri Boon. De Geus, 2007.

Allende, Isabel. Het huis met de geesten. Trad. Saskia Otter. Wereldbibliotheek, 1985.

“[a] unique design.” "Brand.” Business Dictionary. www.businessdictionary.com/definition/ brand.html, consultado 9 de julio 2018.

Blank, Gunter. “Wie Marquez auf LSD”. Sonntags Zeitung, 31 de octubre 2004, p. 53.

Bolaño, Roberto. 2666. Trad. Aline Glastra van Loon y Arie van der Wal. J.M. Meulenhoff, 2009.

---. De woeste zoekers. Trad. Aline Glastra van Loon. Meulenhoff, 2000.

Borges, Jorge Luis. De Aleph. Trad. A. Sillevis. De Bezige Bij, 1964.

De Vries, Corine. “Boekenweek?” de Volkskrant, 14 de marzo 1996, p. 15.

Esquivel, Laura. Rode rozen en tortilla's. Trad. Francine Mendelaar. Arena, 1991.

Kuipers, Willem. “Grootscheeps komt het Zuiden binnenzeilen”. de Volkskrant, 14 de febrero 1996, p. 4.

Steenmeijer, Maarten. "Los pasos perdidos: la primera presencia de la literatura hispanoamericana en Holanda”. América Latina y la literatura mundial: mercado editorial, redes globales y la invención de un continente. Ed. Gesine Müller y Dunia Gras, Iberoamericana/Vervuert, 2015, pp. 99-127.

Weijts, Christiaan. “Ode aan het onaffe”. De Groene Amsterdammer, 26 de noviembre 2013. 

Gustavo Guerrero

\section{José Lezama Lima en Francia:} apuntes sobre la mediación editorial, la traducción y la recepción de Paradiso

La traducción francesa de Paradiso, que sale a la luz en París el 1 de marzo de 1971 bajo el sello de las ediciones du Seuil, marca sin lugar a dudas un hito no solo en la historia de la difusión internacional de la literatura latinoamericana durante los años del boom, sino también en el proceso mismo de internacionalización de la obra de José Lezama Lima (1914-1976). Recordemos que, conocido inicialmente como poeta y ensayista en ciertos círculos literarios de la lengua española, el cubano gana renombre y lectores en su propia isla y en todo el continente con la aparición de esta novela en 1966. Gracias a ella, se le empieza a traducir asimismo a otros idiomas y se amplía y diversifica el ámbito de circulación de sus libros, con la consecuente creación de valor que ello comporta. La traducción francesa es la primera de las varias que se publican en Europa y Estados Unidos, y constituye, como tal, una experiencia piloto cuya influencia resulta en más de un sentido decisiva para la fortuna ulterior del autor y de su novela, tanto dentro como fuera de América Latina.

No dispongo sino de unas pocas páginas para resumir una narrativa compleja y bastante accidentada, en la que abundan todavía lagunas e importantes zonas de sombra. La edición parisina de Paradiso posee una historia propia y peculiar que la vincula, en primer término, a los contextos políticos, editoriales y literarios de la Francia de aquellos años, un horizonte de recepción cuya comprensión es indispensable para interpretar la acogida que se le da a la novela. Pero, además, y en segundo lugar, la mediación editorial francesa no puede dejar de tener en cuenta por ese entonces los escenarios internacionales de la república de las letras y opera en el marco de las fuertes tensiones ideológicas suscitadas y alimentadas por la Guerra Fría. Para tratar de abarcar estos distintos aspectos siendo lo más claro y conciso posible, mi exposición va a organizarse como una suerte de bookpic repartido en cinco momentos de la historia de la edición gala de Paradiso: el primero responde a la pregunta de cómo se establece la relación entre la casa editorial parisina y el autor habanero; el segundo es el momento de la contratación de la novela; el tercero, el de la traducción; el cuarto, el de la elaboración de una

Gustavo Guerrero, Université de Cergy-Pontoise//Paris Seine, Institut d’Etudes Politiques de Saint-Germain-en-Laye

Ә Open Access. (C) 2020 Gustavo Guerrero, published by De Gruyter. (cc)BY-NC-ND This work is licensed under a Creative Commons Attribution-NonCommercial-NoDerivatives 4.0 International License.

https://doi.org/10.1515/9783110673678-005 
propuesta de lectura y promoción; y el último, el del lanzamiento y sus efectos nacionales e internacionales.

Empiezo por el primero y por la primera característica que hace del caso de Lezama Lima un caso especial. A diferencia de otros escritores latinoamericanos que se traducen y se editan en Francia en aquellos años, el cubano cuenta desde un principio con dos influyentes padrinos -o dos gatekeepers, como diría William Marling (1-9)- que se mueven holgadamente entre el campo cultural latinoamericano y el campo francés, abriendo canales de comunicación entre uno y otro, tejiendo redes de intercambio y circulación de libros, debates e ideas. Se trata, como muchos habrán adivinado, de Julio Cortázar (1914-1984) y de Severo Sarduy (1937-1993). Ambos van a actuar simultánea y paralelamente (no hubo en un principio ni cercanía ni coordinación entre ellos) para dar a conocer Paradiso en Francia y preparar la recepción francesa mucho antes de que Seuil publique la novela en 1971.

En efecto, Cortázar, que, según declarara en varias ocasiones, descubre a Lezama Lima gracias a una recomendación de su amigo Ricardo Vigón en 1957, no solo pone a circular su ensayo "Para llegar a Lezama Lima” por toda América Latina en 1966 a través de la revista Unión, sino que difunde también el nombre del cubano y su lectura entusiasta de la novela entre sus amigos y allegados galos (Cortázar, "Para llegar" 36-60). Hacia mediados de los años sesenta, en el momento en que Paradiso sale a la luz en La Habana, el argentino disponía en París de una red intelectual lo suficientemente extendida y poderosa como para promover un cierto interés por Lezama Lima y su Paradiso. En la galaxia francesa de Cortázar se encuentran a la sazón, como lo muestra su correspondencia, figuras como Laure Bataillon, Monique Lange, Claude Couffon, Roger Caillois, Claude Roy, Roger Grenier y hasta el propio Claude Gallimard, con quien mantiene una relación bastante cercana (Cortázar, Cartas 1 y 2). Tanto es así que, en unos de sus viajes a la isla, en 1976, Cortázar arrastra consigo a Claude Gallimard y organiza en La Habana una cena para presentarle personalmente a Lezama Lima, según cuenta el maestro en una de las últimas cartas que le envía a su hermana (Lezama Lima, Cartas 207). De ahí una pregunta que ya se ha hecho en otras ocasiones y que es legítimo hacerse aunque la respuesta no sea tan simple como parece. Sabemos que pocos escritores latinoamericanos se implicaron tanto en la edición y la traducción de Paradiso como lo hizo Cortázar. Y es que no solo releyó y corrigió el manuscrito de la edición mexicana de la editorial Era, sino que también releyó la traducción francesa de Didier Coste y más tarde recomendó a Gregory Rabassa para la traducción inglesa siguiendo paso a paso su trabajo (Cortázar, Cartas 2 68; Lezama Lima, Cartas 377). La pregunta es por qué habiendo sido uno de los primeros lectores de la novela, uno de los principales 
editores de su texto en varias lenguas y uno de los más apasionados valedores de Lezama Lima en la escena internacional, por qué no trata de hacer traducir y editar la novela a través de su propia casa francesa, Gallimard, y deja que Paradiso acabe apareciendo bajo el sello de las ediciones du Seuil. No estoy haciendo una pregunta retórica ni tampoco, insisto, una pregunta que tenga una respuesta simple, tanto menos cuanto consta que Ugné Karvelis, la secretaria privada de Claude Gallimard, que será luego la segunda esposa de Cortázar y la editora del área hispanoamericana de la colección Du Monde Entier, viaja a La Habana y visita a Lezama Lima unos meses después de la aparición de la novela, en 1966 (Lezama Lima, Cartas 346).

Una parte de la respuesta a esta pregunta está en una remota y curiosa carta del 29 de mayo de 1963 que le envía la entonces directora de derechos internacionales de las ediciones du Seuil, Jacqueline Trabuc, al maestro habanero y en la cual sorprendentemente le pide que le reserve los derechos de traducción al francés de la novela que está escribiendo (IMEC, SEL, dossier Paradiso). Algo perplejo, Lezama Lima le contesta con elegancia el 18 de julio de 1963:

\footnotetext{
Estimada amiga:

En respuesta a la carta que usted me escribió, en relación con mi novela Paradiso, me es grato informarle que dicha novela todavía no se ha publicado, espero a fines de este año haberla terminado, entonces le escribiré a usted para darle noticias sobre los extremos que señala en su carta.

Hace años se publicaron en la revista Orígenes los cinco primeros números de Paradiso, pero, en años posteriores, seguí trabajando en su continuación, esperando en fecha muy próxima poderla terminar.

Su carta me ha alegrado, pues con las noticias que me da, será un motivo de más para trabajar hasta llegar al final.

Hasta entonces,

JLL (IMEC, SEL, dossier Paradiso)
}

Pero el asunto no para allí. Existe una segunda carta del 4 de septiembre de 1963 en la que Trabuc le reitera su interés y le pide a Lezama Lima que le envíe los cinco capítulos publicados en Orígenes, así como también todo los que haya escrito hasta la fecha (IMEC, SEL, dossier Paradiso). Algo incómodo, el escritor le contesta el 24 de octubre de 1963:

\section{Estimada amiga:}

Recibí su carta última en la que me manifiesta sus deseos de conocer los capítulos publicados de mi novela Paradiso. No me parece que tendría objeto publicar aislados del resto de la novela esos cinco capítulos. Ya a la novela le falta muy poco para su terminación y creo que debemos esperar su publicación entre nosotros, para que apareciese la edición 
francesa; también podrían aparecer simultáneamente, todo eso puede ser objeto de posteriores conversaciones.

Le envía un saludo muy cordial, JLL (IMEC, SEL, dossier Paradiso)

Más allá o más acá del intercambio de cortesías, no se puede menos que comprobar cómo el proyecto de una edición francesa se inscribe así desde muy temprano en la génesis misma de la novela como parte de su horizonte editorial, antes incluso de que se haya terminado el proceso de escritura. Lezama Lima llega hasta imaginar la posibilidad de que se publiquen al mismo tiempo la edición original en La Habana y su traducción en París. Y es en este capítulo de la historia donde aparece Severo Sarduy. Porque la carta mecanografiada de Lezama Lima, que se conserva en el IMEC, lleva al margen unas líneas manuscritas probablemente de la propia Trabuc y en las que se lee con claridad: "Sarduy réponds lui", o sea, "Sarduy contéstale”. No sé si lo habrá hecho entonces o si la carta de respuesta se habrá perdido porque no aparece en el dossier ni en las correspondencias de Lezama Lima que conozco. Lo cierto es que, muchos años más tarde, ya editada la novela en París, Lezama Lima le recuerda a Sarduy: "Antes de la publicación en libro, por el conocimiento de los capítulos publicados en Orígenes, ya Usted intuía la posibilidad de la obra. Me estimulaba, me hablaba de su traducción al francés” (Lezama Lima, Cartas 341). Es imposible por ahora saber cuál habrá sido el tenor del intercambio entre ambos en esos últimos años de redacción de la novela, pero parece bastante verosímil que hubo una correspondencia sobre el asunto y es seguro que el seguimiento del proceso de escritura de la novela continúa, como lo muestra otra carta de Trabuc fechada el 15 de junio de 1965:

Cher Monsieur,

Nous avons appris par S. Sarduy que votre livre était maintenant à l'imprimerie.

Pourriez-vous nous envoyer les épreuves dès qu'elles seront prêtes ? Nous sommes très impatients de lire cet ouvrage dans sa totalité.

Cordialement,

JT (IMEC, SEL, dossier Paradiso)

A todas luces, Le Seuil no quiere esperar hasta la aparición del libro para leerlo y para hacer una oferta por los derechos de traducción, como es de usanza; ocho meses antes de que salga, piden las galeradas y preparan la solicitud de una opción exclusiva sobre los derechos de traducción al francés. De ahí que el proceso de contratación sea muy rápido: apenas unas semanas después de que Paradiso se publique en La Habana, el 26 de marzo de 1966, ya la opción ha sido formalizada y el contrato definitivo, tras una breve negociación con el autor, se firma el 25 de julio: Le Seuil se compromete a editar la traducción en dos años y paga 
cinco mil francos por los derechos exclusivos de traducción y edición en Francia (IMEC, SEL, dossier Paradiso). Huelga subrayar que estamos ante una política editorial voluntarista, diligente y asombrosamente rápida, que apuesta por la anticipación para adelantarse a cualquier competencia y para quedarse con el libro. Ninguna otra editorial francesa tuvo en realidad alternativa alguna en aquel momento, ni siquiera Gallimard. O para decirlo de otra manera: cuando Cortázar se pone a leer la novela en su casa de Provenza en julio de 1966, ya el contrato está firmado (Cortázar, Cartas 4 161). Detrás de esta estrategia de captación, esta evidentemente Severo Sarduy, que se había incorporado a la editorial en 1962 y que, según recuerda François Wahl, había llegado a París a principios de esa década con la idea de dar a conocer a Lezama Lima (Wahl, 2 1448). Su red francesa no es por entonces menos amplia e influyente que la de Cortázar: los jóvenes de Tel Quel, el grupo estructuralista (con Roland Barthes a la cabeza) y el activo círculo de la casita de rue Jacob, les Editions du Seuil, componen la galaxia de Sarduy, sin mencionar a los escritores e intelectuales latinoamericanos que gravitan alrededor de Emir Rodríguez Monegal y la revista Mundo Nuevo donde Lezama Lima es por entonces objeto de homenajes y polémicas (Wahl, 2 1449-1451; Guerrero 348-350).

Pero Sarduy no es el único artífice de esta política de captación y contratación que se parece a una guerra relámpago: junto a él, hay que colocar a Claude Durand, que se incorpora a la editorial en 1958 y se convierte en una de las figuras de más peso del equipo, hasta el punto de que algunos lo llaman, entre bromas y veras, el Emperador Claudio (Dosse 75-81). Claude Durand se había casado con una traductora habanera, Carmen Perea Jiménez, y conocía la literatura de la isla y también la del continente. Recordemos que Le Seuil publica Cien años de soledad en 1968 justamente en una traducción de Durand y de Perea Jiménez, uno de los primeros grandes éxitos de su nuevo catálogo latinoamericano. Porque se trata de una aventura reciente: a mediados de los sesenta, cuando despunta el boom, Durand se lanza con Sarduy a la busca y la contratación de autores de América Latina y juntos deciden crear una colección cuyo objetivo manifiesto era competir, en este terreno específico y prometedor, con la Cruz del Sur de Roger Caillois. Ambos quieren imponer otra idea de la literatura latinoamericana, más vanguardista y contemporánea, a la imagen de Le Seuil. Además, Durand es un hombre fuertemente comprometido desde su juventud con la defensa de los derechos humanos y la autonomía de la creación artística y literaria, lo que le lleva a fundar, en 1968, la colección Combats en las ediciones du Seuil y a inaugurarla con el libro Les droits de l'écrivain, de Alexander Soljenitsyne.

Detrás de la edición francesa de Paradiso, no está, pues, solo Severo Sarduy sino también Claude Durand y Carmen Perea Jiménez. A diferencia de lo que 
ocurre en otras editoriales en aquel momento de efervescencia en torno a los autores latinoamericanos, en Le Seuil son conscientes desde un comienzo de la importancia del autor y del libro que tienen entre las manos. Severo Sarduy escribe en su informe de lectura: "En Amérique latine, Lezama Lima est sans équivalent. Du point de vue de la rigueur littéraire et de l'étendue de la culture, la seule comparaison possible est Borges” (IMEC, SEL, dossier Paradiso). Por su parte, Claude Durand señala en una nota sin fecha para el departamento comercial: "Ce livre est tout aussi important que Cent ans de solitude, voire d'avantage encore sur le plan de l'histoire littéraire” (IMEC, SEL, dossier Paradiso).

Le Seuil va a tener, sin embargo, serias dificultades para sacar adelante esta edición, ya el proceso de traducción de la novela pasa por momentos muy delicados, que casi dan al traste con todo, por problemas no solo con la traducción misma sino con los propios traductores. Originalmente, la tarea se le encomienda a Claude Couffon, un reconocido hispanista y una de las figuras mayores de la crítica y la traducción de autores españoles y latinoamericanos en Francia (recordemos que es el traductor de García Lorca, Alberti, Neruda, Asturias y muchos otros). En 1966, Couffon se compromete a entregar la versión francesa de Paradiso al cabo de dos años y a principios de 1968 llega incluso a anunciar que ya ha traducido 400 páginas (Lezama Lima, Cartas 372-73). Pero, en realidad, y aunque publicó un avance de la novela en 1968, en Les Lettres Nouvelles (Lezama Lima, Cartas 25-36), nunca entregó la traducción y Lezama Lima y la editorial lo cesan de común acuerdo en agosto de ese año (IMEC, SEL, dossier Paradiso). Una de las preguntas que deja este episodio es por qué abandona Couffon la traducción de Paradiso. Quizás lo sepamos cuando se puedan estudiar los archivos del crítico y traductor normando. El nuevo traductor, Didier Coste, firma su contrato en septiembre y se compromete a entregar la traducción completa a mediados de 1969 (IMEC, SEL, dossier Paradiso). Pero pronto se hace evidente que tampoco podrá terminar a tiempo. Esto crea una situación bastante tensa que se refleja en la correspondencia entre Lezama Lima y Durand. En enero de 1970 aquel le escribe malhumorado a este:

Supongo, de acuerdo con lo que Usted me prometió, que ya estarán las vidrieras de las librerías de París mostrando el Paradiso. Si así no fuera, le rogaría me informase cómo va la traducción de Didier Coste, cuántas páginas lleva ya traducidas y para cuándo promete tenerla terminada, pues ya han pasado tres años desde que se comenzó a hacer la versión. (Lezama Lima, Cartas 388-89)

Los últimos meses de la traducción, como atesta el propio Didier Coste, serán muy intensos y arduos, con listas de preguntas que cruzan el Atlántico sin obtener muchas veces respuesta, y largas jornadas de relectura y corrección con Sarduy y Durand. Una advertencia entre los preliminares de la edición lo recuerda: 


\begin{abstract}
Avis du traducteur
Au moment de voir paraître l'édition française de Paradiso et à l'issue de près d'un millier et demi d'heures consacrées à cet ouvrage, nous ne prétendons pas avoir pu résoudre tous les problèmes tant de fidélité que de lisibilité posés par sa traduction. Nous tenons à remercier ici de leur contribution Severo Sarduy et l'auteur pour les éclaircissements qu'ils ont bien voulu nous apporter en de nombreux endroits, ainsi que Claude Durand pour sa si attentive lecture des états successifs de notre manuscrit. DC (Lezama Lima, Paradiso)
\end{abstract}

Parte de la correspondencia de Coste con Lezama Lima y Sarduy, que da cuenta de la importancia de los intercambios entre los tres, se encuentra hoy en los Archivos de Escritores e Intelectuales Latinoamericanos en la División de Manuscritos de la Biblioteca de Universidad de Princeton, como parte del legado de Liliane Hasson. A partir de 1970, cuando ya la traducción entra en su fase final, Durand y Sarduy trabajan en el plan de promoción de la obra y en la propuesta de lectura que conlleva. La idea central es que no se trata de descubrir a un nuevo escritor latinoamericano, como está ocurriendo a la sazón con los autores del boom en casi toda Europa, sino de editar a un clásico y compensar una falla en la visión francesa del paisaje literario cubano y latinoamericano. Para Durand y Sarduy, la introducción de Lezama Lima dentro del campo literario francés debe hacerse así por una puerta canónica que sitúe al cubano, desde un comienzo, en una lista donde figuran nombres como el de Proust, Joyce o Valéry. Como instancia privilegiada del paratexto, que preside al primer encuentro entre el lector y la novela, la contraportada da fe del esfuerzo por esbozar un horizonte de escucha específico que debería orientar la recepción del autor y de su obra. No en vano en ella se lo presenta como a un "Proust del Caribe" (Lezama Lima, Paradiso), una etiqueta que tendrá bastante éxito entre la crítica francesa (Valdéz 67-72).

Hay que agregar, sin embargo, una dificultad suplementaria a la hora del lanzamiento. Descartada la perspectiva de un viaje a París de Lezama Lima, que ha sido explorada a través de la UNESCO y del Ministerio de Asuntos Exteriores, Quai d'Orsay (IMEC, SEL, dossier Paradiso), Durand tiene claro que la suerte del libro va depender esencialmente de la reacción de la crítica: "C'est un livre à imposer par la critique", escribe en una nota interna sin fecha (IMEC, SEL, dossier Paradiso). De ahí el cuidado que se pondrá en ofrecerle a los críticos franceses toda la información necesaria para que se hagan una idea de la importancia del autor y de la dimensión de su obra. Junto a las pruebas del libro, que se envían a los principales medios y a los críticos más prescriptores (Waegener, Le Clerc, Nadeau, entre otros) a principios de 1971, va un dossier que contiene, traducidas al francés, una entrevista inédita de Ciro Bianchi con Lezama Lima, otra de Armando Álvarez Bravo que se publica en Arca de Montevideo, una selección de diez frases de Lezama Lima sobre la creación y la poesía sacadas de sus ensayos 
y un prefacio de Julio Ramón Ribeyro a una futura edición peruana de Paradiso (IMEC, SEL, dossier Paradiso).

La edición francesa sale finalmente de la imprenta el 1 de marzo de 1971. Los principales tenores de la crítica literaria acogen el libro como uno de los grandes eventos literarios del año y al cabo de un mes, la novela ya es candidata al premio del mejor libro extranjero. Una primera edición de 5000 ejemplares se agota a finales de abril y es seguida por una segunda edición de 3000 más en mayo (IMEC, SEL, dossier Paradiso). Con el éxito de Paradiso, le Seuil consolida su lugar como una editorial de referencia para la literatura latinoamericana en Francia y destrona a la Cruz del Sur, que no por casualidad, cierra unos meses antes, pero no sin dar una última batalla.

En efecto, el último libro traducido y editado por Roger Caillois es nada menos que Los nuestros, la famosa selección de entrevistas de escritores latinoamericanos realizada por Luis Harss y Barbara Dohmann, que sale con el título de Portraits et propos en París a fines de 1970, justo unos meses antes de la publicación de la traducción francesa de Paradiso. Caillois agrega a su edición un postfacio de los dos autores (que algunos críticos atribuyen erradamente al editor francés porque no va firmado) donde estos hacen un balance bastante duro de las últimas novedades latinoamericanas y no dudan en calificar la novela de Lezama Lima de libro "bilioso", cargado con "una prosa onanista de adolescente tropical” (Harss y Dohmann 264). Por supuesto, para los dos editores de Seuil que están preparando el lanzamiento de la novela en Francia, tamaño juicio no podía caer peor, tanto más cuanto que Le Monde se hace eco de él en una reseña de Portraits et propos firmada por Claude Couffon (13). ¿Qué hacer? En vez de ignorarlo, la contraportada de la traducción francesa de Paradiso recoge el guante y cita, desautorizándolas, las opiniones de Harss y Dolmann, como para poner de relieve el carácter polémico de la obra de Lezama Lima y darle otra vuelta a una propuesta de lectura que permita situar a Paradiso entre los libros censurados o perseguidos por el poder, uno de los grandes temas de Durand.

Como puede adivinarse, el debate sobre el caso Padilla, que estalla en los meses que siguen al lanzamiento, no dejará de incidir en este horizonte de recepción de la obra en Francia y de replantear de otra manera el tema de situación de Lezama Lima en Cuba. También incidirá en las orientaciones de la colección latinoamericana de Seuil y en la manera como se lee su lista de autores. Recordemos que Le Seuil fue el editor francés del propio Padilla. Pero este es un asunto que exigiría muchas más páginas de las que disponemos y una investigación bastante más detallada. Acaso sea más apropiado concluir señalando que la recepción de la edición francesa parece jugar, asimismo, un papel determinante en la difusión internacional de la obra de Lezama Lima y muestra 
la por entonces acusada influencia que ejerce el campo literario y editorial parisino en la circulación internacional de las literaturas extranjeras a nivel global. Un futuro estudio de la internacionalización de Paradiso tendría que tomar en cuenta este hecho y debería reconstruir la cartografía de las redes que vinculan a los distintos centros editoriales y literarios donde se traduce y edita la novela tras el lanzamiento parisino, entre Milán (Edizione Il Saggiatore, 1971), Nueva York (Farrar, Strauss and Giroux, 1974) y Frankfurt (Surhkamp, 1979). Quizás nada asienta mejor este protagonismo de la edición francesa en dicho proceso que la carta que le envía Durand a Lezama Lima el 3 de noviembre de 1971 y que aquí nos sirve de provisorio punto final:

J'espère d'autre part que les nombreux éditeurs étrangers qui nous ont exprimé le désir de traduire Paradiso en diverses langues ont pu vous joindre directement. Si, de quelque manière, nous pouvons vous être utiles en ce domaine, n'hésitez pas à me l'écrire. (IMEC, SEL, dossier Paradiso)

\section{Bibliografía}

Cortázar, Julio. Cartas (1937-1984). 5 vol. Eds. Aurora Bernárdez y Carles Álvarez. Alfaguara, 2012.

--.. “Para llegar a Lezama Lima”. Unión, 5, 4, 1966, pp. 36-60.

Couffon, Claude. "Portraits et propos". Le Monde, 25 de julio 1970, p. 13.

Dosso, François. Les hommes de l'ombre, portraits d'éditeurs. Perrin, 2014.

Guerrero Gustavo. "Rectificaciones, barroquismos y neobarroquismos: José Lezama Lima, una posteridad disputada”. Gravitaciones en torno a la obra poética de Lezama Lima. Actes du Colloque International José Lezama Lima. Dir. Laurence Breyse-Chanet e Ina Salazar. Editions Le Manuscrit, 2011, pp. 347-355.

Harss, Luis y Barbara Dohmann. Portraits et propos. Gallimard, 1970.

IMEC (Institut Mémoire de l'Edition Contemporaine). Archive Editeurs, Fonds Le Seuil (cote SEL), dossier José Lezama Lima, Paradiso.

Lezama Lima, José. Cartas a Eloísa y otra correspondencia. Ed. José Triana. Verbum, 1998.

---. Paradiso. Trad. Didier Coste. Editions du Seuil, 1971.

---. “Paradiso”. Trad. Claude Couffon, Les Lettres Nouvelles, numéro spécial, enero 1968, pp. 25-36.

Marling, William. Gatekeepers, the Emergence of World Literature \& the 1960's. Oxford University Press, 2016.

Valdés, Armando. "El enigma Lezama, la crítica francesa y el autor de Paradiso". Revista Hispano-cubana, 8, 2000, pp. 67-72.

Wahl, François. "Severo de la rue Jacob”. Severo Sarduy, Obra completa. 2 vol. Eds. Gustavo Guerrero y Francois Wahl. Unesco, Colección Archivos, 1999, pp. 1447-1547. 



\title{
Feminismo y literatura (argentina) mundial: Selva Almada, Mariana Enríquez y Samanta Schweblin
}

\author{
"El lugar más sombrío está siempre debajo de la lámpara” \\ Proverbio chino
}

\section{Introducción}

La literatura escrita por mujeres argentinas ha adquirido un protagonismo insólito en el siglo XXI: nunca antes habían publicado tantas escritoras ni habían alcanzado tal nivel de legitimidad, en la academia y en el mercado, en el circuito nacional y en el transnacional. Por supuesto, este hecho no sucede in promtu sino que es consecuencia de la articulación de un discurso literario de raigambre feminista que se ha venido gestando desde los años setenta y ochenta (v.g., Sylvia Molloy, Hebe Uhart, Luisa Valenzuela, Angélica Gorodischer, Claudia Piñeiro, Ana María Shua, Diana Bellesi, Tununa Mercado, María Moreno, etc.), y que alcanza su periodo de mayor eclosión y desarrollo en los últimos lustros (v.g., Gabriela Cabezón Cámara, Fernanda García Lao, Mariana Dimópulos, Jimena Néspolo, Gabriela Bejerman, Selva Almada, Romina Paula, Inés Acevedo, Patricia Ratto, Florencia Abbate, Pola Oloixarac, Samanta Schweblin, Ariana Harwicz, Mariana Enríquez, María Gainza, Lola Copacabana, etc.). Pero, ¿qué factores han contribuido a esta efervescencia feminista en la literatura argentina actual?

Por un lado, esta escritura de mujeres se enmarca en la "nueva” (Drucaroff Los prisioneros) o "novísima” novela argentina (Gallego Cuiñas “Comienzos. ..”), que ha tenido gran protagonismo en la escena cultural latinoamericana, mediante el cultivo de temas como el trauma del pasado dictatorial, la memoria falsa, los fantasmas y/o desaparecidos, el cuerpo, la preocupación por el lenguaje, el diálogo con los medios de comunicación, la civilibarbarie, etc. (Drucaroff Los prisioneros). Aunque lo más significativo de la narrativa argentina del siglo XXI, en mi

Nota: Este trabajo se encuadra dentro del proyecto I+D LETRAL “Comienzos de la novísima literatura latinoamericana (2001-2015)" del Ministerio de Economía Competitividad de España (ref. FFI2016-79025- P); y de la Unidad de Excelencia IBERLAB de la Universidad de Granada.

Ana Gallego Cuiñas, Universidad de Granada

Ә Open Access. (C) 2020 Ana Gallego Cuiñas, published by De Gruyter. (cc) BY-NC-ND This work is licensed under a Creative Commons Attribution-NonCommercial-NoDerivatives 4.0 International License.

https://doi.org/10.1515/9783110673678-006 
opinión, no es el tratamiento de estas problemáticas o el uso de ciertas formas literarias, sino justamente la irrupción, masiva y reveladora, de mujeres escritoras y de poéticas feministas. Esta circunstancia no se ha destacado lo suficiente en importantes estudios sobre la materia: Josefina Ludmer en Aquí América Latina (2010) habla de un sistema literario hecho de "escritores jóvenes y mujeres", pero solo menciona a cinco escritoras ${ }^{1}$, que comparten en la nueva centuria "temporalidades globales"2, que están fuera de la nación o en una "no nación" (89) ${ }^{3}$. Por su parte, Elsa Drucaroff en Los prisioneros de la torre (2011) contempla a treinta mujeres en su nómina de setenta y dos escritores pertenecientes a lo que llama “segunda generación postdictadura” (213-215), nacida entre los setenta y principios de los ochenta; toda vez que dedica un tema a la "mirada femenina”, donde realiza una fecunda lectura de género, aunque no aplica una perspectiva netamente feminista ${ }^{4}$. Y, por último, Beatriz Sarlo en Ficciones argentinas. 33 ensayos (2012) atiende solo a cinco mujeres: Mariana Enríquez, Matilde Sánchez, Mariana Dimópulos, Selva Almada y Laura Alcoba ${ }^{5}$. Asimismo en listas como la que configuró la revista Granta en 2010 o la reciente Bogotá39 del Hay Festival en 2017, donde se eligieron a los treinta y nueve mejores escritores en lengua castellana menores de 39 años y tan solo hallamos trece mujeres. No llega ni a la mitad, algo que llama mucho la atención, habida cuenta de la notable -calidad de la- producción actual de mujeres escritoras ${ }^{6}$.

Pareciera entonces que buena parte de los académicos más consagrados no se ha hecho eco suficiente del extraordinario calibre de esta novísima escritura de mujeres, que no ha conseguido el mismo tratamiento y circulación que la de sus pares hombres. Sin embargo, han proliferado sobremanera en la última década

1 Tampoco se detiene en el análisis de ningún texto de mujeres escritoras, a excepción de unas pocas: Matilde Sánchez, Clara Obligado, María Moreno e Inés Fernández Moreno, entre otras.

2 Yo hablaría más bien de "subjetividades globales", donde está implícita la temporalidad.

3 Ludmer incluye en este apartado los ejemplos de Aira, Libertella y Chejfec.

4 Sí encontramos varios apartados en los que transita cuestiones de género: "Nueva mirada masculina y femenina: 'loquitas' y 'locas”' (274-281); “Madres filicidas: el lado oscuro de un orden simbólico negado" (351-364); "Mirada femenina: una breve introducción” (454-476).

5 Tampoco lo hacen libros de ensayos menos académicos que abordan la narrativa argentina actual, como los de los escritores Juan Terranova, que en Los gauchos irónicos (2013) se centra en ocho jóvenes, entre los cuales solo hay una mujer (Pola Oloixarac); y Maximiliano Crespi que en su agudo y controvertido Los infames (2015) únicamente recala en Selva Almada y María Pía López, entre una decena de autores.

6 El hecho solo puede explicarse por la pervivencia de un sustrato ideológico machista que sigue invisibilizando a la mujer, desvalorizándola, y relegándola a un segundo lugar con respecto al hombre/escritor. 
los estudios de caso aplicados a escritoras y textos en el ámbito de la crítica argentina, por parte de los investigadores más jóvenes, muchos de ellos mujeres. La perspectiva feminista se aplica cada vez más al análisis de la literatura actual, al socaire de las políticas institucionales que promueven la igualdad de género y el feminismo como área de conocimiento propia. A esto hay que sumar que las mujeres han ido ocupando nuevos espacios públicos de legitimidad en la Argentina; un factor social que ha contribuido a ensanchar su presencia también en el discurso literario:

la política argentina posterior al retorno de la institucionalidad democrática, desde 1983, está atravesada por la presencia de las mujeres: la lucha por los derechos humanos de las Madres y Abuelas de Plaza de Mayo, el asesinato en 1997 -aún impune- de la trabajadora Teresa Rodríguez en las primeras manifestaciones sociales en Cutral-có (Neuquén), que la transforman en un símbolo del movimiento piquetero, y la visibilidad de los cuerpos configurados por el género, desde 2015, a partir de las convocatorias " $\mathrm{Ni}$ Una Menos"7. (Angilletta 96)

De otro lado, si hacemos una lectura materialista del objeto literatura feminista argentina es fácil comprobar que el crecimiento de su visibilidad en el campo literario también viene acompañado del auge de las editoriales independientes, que, aunque tienen un radio de acción local/nacional, funcionan como gatekeepers de la literatura (argentina) mundial. La expansión de la industria editorial, es decir, las mejoras de las condiciones materiales del sector, ha favorecido, a todas luces, a las escritoras. Para muchos de estos sellos la apuesta por sectores de mercado tan valorados en la actualidad como el de las mujeres y el de los autores emergentes es fundamental para la configuración de sus catálogos. Sin embargo, cuando ponemos el foco en una escala mayor, en las llamadas literaturas mundiales, la escritura de mujeres sigue invisibilizada. De tal manera que, si las mujeres ocupan un lugar menor en la circulación trasnacional de la literatura latinoamericana, su condición es doblemente subalterna en el espacio de la literatura mundial: por ser latinoamericanas y por ser mujeres. La explicación puede encontrarse en el hecho de que las escritoras más ensalzadas y consagradas en el sistema global han sido, hasta fines de siglo XX, aquellas en que no se vislumbra tanto la diferencia genérica, es decir: su literatura está más asimilada a la canónica, de corte patriarcal ${ }^{8}$.

7 Hay que mencionar también el gobierno de la presidenta de la República Argentina Cristina Kitchner, entre 2007 y 2015, periodo en que se aprobó el matrimonio igualitario (2010) y la identidad de género (2012). Sin embargo, no ha conseguido aprobarse la ley del aborto: el senado argentino volvió a mostrar su negativa en agosto de 2018. El cuerpo de la mujer sigue estando "en disputa".

8 Hagamos un repaso a los temas que han hecho destacar a las últimas mujeres que han ganado el Premio Nobel de Literatura: Svetlana Alexiévich (conflicto bélico); Herta Müller 
$\mathrm{O}$ aquellas en que la diferencia genérica es un producto en sí mismo, ora por el relato de asuntos femeninos ora por su lucha abiertamente feminista ${ }^{9}$, traducida en la narración de situaciones de abuso, violencia y opresión.

A la vista de lo expuesto, he seleccionado una nómina de tres escritoras mujeres nacidas en la Argentina en las década de los setenta (Selva Almada, Mariana Enríquez y Samanta Schweblin), y un corpus de tres novelas que pueden ser leídas como feministas: Distancia de rescate (2014), Chicas muertas (2014) y Éste es el mar (2017). Las tres obras han sido editadas por un gran grupo editorial, Literatura Random House, que desde 2015 acoge en su catálogo a cada vez más jóvenes latinoamericanas, labor mercadotécnica -lo joven es una cuota de mercado muy bien definida- orientada a poner en circulación el fetiche de lo nuevo ${ }^{10}$, que incita a la deseabilidad y al consumo neoliberal, como ya hicieran Planeta y Alfaguara en los noventa. No obstante, en el siglo XXI los grandes sellos actúan con menor margen de riesgo y la mayoría de las veces editan a novelistas emergentes cuando atesoran cierto reconocimiento previo (periodistas, dramaturgos, músicos, cuentistas o poetas). Sucedió con Selva Almada, que después de publicar varias obras en editoriales independientes (v.g., Mardulce que sacó a la luz El viento que arrasa en 2012) y conseguir el beneplácito de una de las gatekeepers más relevantes de la crítica argentina, Beatriz Sarlo, publicó Ladrilleros en 2013 en Lumen (Random House, España) ${ }^{11}$ con la que fue finalista del Premio Tigre Juan. En 2014 la crónica Chicas muertas apareció en Literatura Random House directamente y ahí comenzó su mundialización: fue finalista del Premio Rodolfo Walsh, traducida al francés, al portugués y al turco; y se vendieron sus derechos a la televisión. En 2017 se tradujo El viento que arrasa al inglés, y, desde entonces, su circulación es mayor, aunque su proyección internacional es menos prominente que la de Enríquez y Schweblin, como comprobaremos a continuación.

Mariana Enríquez, la más precoz de esta tríada, comienza publicando su primera novela, Bajar es lo peor (1995), en una gran editorial, Espasa-Calpe ${ }^{12}$, Luego saca en Emecé Cómo desaparecer completamente (2004) y Los peligros de fumar en la cama (2009). Pero será en 2016 cuando Anagrama apueste por Las

(totalitarismos); Doris Lessing (conflictos raciales); Wislawa Szymborska (memoria); Nadine Gordimer (economía y corrupción). Desde la década de los noventa hasta hoy, solo encontramos a tres escritoras feministas: Toni Morrison, Elfriede Jelinek y Alice Munro.

9 Basta pensar en el bestseller de Margaret Atwood, El cuento de la criada.

10 Se trata, además, de la primera novela de Samanta Schweblin y de la primera crónica de Selva Almada.

11 En la Argentina salió en Mardulce Editora.

12 El hecho es insólito, pero también se trataba de la década de los noventa, donde el panorama editorial estaba en plena efervescencia y los catálogos de las grandes editoriales aún publicaban a bastantes autores jóvenes y noveles. 
cosas que perdimos en el fuego y Enríquez comience su andadura mundial: el mismo libro de cuentos será publicado por Vintage Español (Random House), y traducido al inglés por Megan McDowell al año siguiente ${ }^{13}$, Fue incluido en The New Yorker y nombrado libro del año por Boston Globe, PASTE Magazine, Words Without Borders, Grub Street, Remezcla y Entropy Magazine. También en 2017 Literatura Random House sacará a la luz Éste es el mar en Buenos Aires, y en 2018 en España. Otro dato interesante que no hay que soslayar en esta breve semblanza de la trayectoria en el mercado (editoriales, traducciones, premios) de nuestras escritoras es que tanto Selva Almada como Mariana Enríquez, con Chicas muertas y Éste es el mar han entrado a formar parte de la iniciativa Mapa de las lenguas, que lanzaron Alfaguara y Literatura Random House en 2015 para fomentar la circulación transnacional de determinadas obras de sus catálogos $^{14}$. Ambas obras fueron publicadas en España: la primera en 2015 y la segunda en 2018, operación de selección, producción, circulación y recepción que de alguna manera (pre)supone la (pre)figuración de un futuro canon "latinoamericano" 15 .

Por último, queda por abordar a la más mundializada de nuestras escritoras argentinas y latinoamericanas: Samanta Schweblin, que ganó en 2001 el Premio Nacional de las Artes en Argentina con su libro de relatos El núcleo del disturbio, que fue editado por Destino. En 2008 se hizo con el Premio Casa de las Américas por Pájaros en la boca, que salió en Lumen un año después; y en 2010 fue escogida por la revista Granta como una de las mejores voces de la literatura en lengua castellana. A partir de ahí, consigue el premio Juan Rulfo

13 Sin dudarlo, también influye el hecho de pertenecer a la nómina latinoamericana que representa la agencia catalana Casanovas \& Lynch, en la que también encontramos a reconocidos autores como Rodrigo Fresán, Juan Gabriel Vásquez, Fernando Vallejo, Carlos Franz, etc. Llama la atención el elevado número de latinoamericanos jóvenes -nacidos a partir de la década del setenta- que son representados por esta agencia, entre los que destacan los argentinos: María Gainza, Roque Larraquy y Pola Oloixarac. Véase: http://www.casanovaslynch.com/ authors.html.

14 La iniciativa consistió al principio en publicar en España dos obras de escritores latinoamericanos cada mes -que elige cada filial de América Latina, una de Alfaguara y una de Random House- con una tirada de 500 ejemplares. Al año siguiente, en 2016, comenzó la labor de promoción inversa: de escritores españoles en cada filial latinoamericana, y entre filiales latinoamericanas (v.g., escritores mexicanos, chilenos, etc., que se dan a conocer en Argentina, y viceversa). Véase: https://www.megustaleer.com.ar/noticias/mapa-de-las-lenguas/430\&pre view=S.

15 La circulación transnacional -de facto- en Alfaguara o Literatura Random House se produce en contadas ocasiones (entre ellas, el Premio Internacional Alfaguara de Novela inaugurado en 1998, porque tampoco funcionó “Alfaguara Global”), en que el rédito económico es incontestable. 
en 2012 y en 2014 Literatura Random House la ficha -cuando su capital simbólico está asentado y es sólido- para publicar su primera novela: Distancia de rescate, que la hace ingresar directamente en la literatura mundial. Es traducida al inglés por Megan McDowell ${ }^{16}$, seleccionada por Man Booker International Prize en 2017, y merecedora de los premios Tournament of books al mejor libro publicado en USA y Nouvelle Shirley Jackson Award ${ }^{17}$. Ha sido reseñada en The New Yorker, Vanity Fair, The Guardian y Washington Post, entre otros. Hay que subrayar que no se ha incorporado al catálogo de Mapa de las lenguas porque directamente el grupo editorial decidió publicar Distancia de rescate, y el resto de novelas posteriores, en España. Schweblin no ha necesitado de ese filtro para potenciar su circulación transnacional porque su figura, simbólica y económica, es la de mayor trascendencia internacional, entre las escritoras latinoamericanas de su generación.

En definitiva, las tres autoras de nuestro estudio han publicado en el conglomerado editorial más potente en lengua castellana, Bertelsmann, dentro de Literatura Random House, que se consolida como el sello de los emergentes en vías de consagración. Han sido traducidas a varios idiomas, entre ellos el inglés, y cuentan con potentes agentes literarios y premios (españoles e ingleses) que las avalan. Incluso las tres pueden definirse como escritoras profesionales no solo porque vivan de este trabajo -o de desempeños afines- sino porque se han formado en célebres talleres literarios en Buenos Aires ${ }^{18}$ : Almada en el de Alberto Laiseca, Enríquez en el de Tomás Eloy Martínez y Schweblin en el de Liliana Heker; eventualidad no baladí para entender la manera en que se ha profesionalizado el oficio de escritor en el siglo XXI, cuya aura romántica se ha terminado de diluir casi por completo, si es que quedaba algo (véase Riveiro). Además, otro factor que las une es la naturaleza de sus propuestas estéticas, que contemplan un manejo subversivo -feminista- del lenguaje, de temas y problemas -globales- que apuntan a la deconstrucción de categorías genéricas binarias y de ciertos imaginarios heteronormativos diseminados por la ideología patriarcal en relación con las ideas de maternidad, la sexualidad, el amor romántico y la violencia machista. En efecto,

16 Podríamos decir que esta traductora es la Gregory Rabassa del siglo XXI, toda una gatekeeper de la literatura latinoamericana mundial en la actualidad: ha traducido a Zambra, Enríquez, Meruane, Zúñiga, Fonseca, etc.

17 Además de que forma parte de la nómina de una de las agencias literarias más potentes del mundo hispano: Carmen Barcells, lo que sin duda ha contribuido a la mundialización de su literatura.

18 Otra hipótesis de trabajo sería considerar los talleres literarios no solo como síntoma de la profesionalización extrema de la escritura como oficio y de la taylorización -y estandarizació $\mathrm{n}$ - de poéticas en la actualidad, sino como un gatekeeper de la literatura latinoamericana mundial. 
en el campo cultural argentino que impulsó en 2015 el movimiento feminista de alcance mundial Ni una menos, se están produciendo en la última década nuevas formas de empoderamiento literarias que merecen un espacio propio para la reflexión crítica, como se podrá comprobar en el análisis que llevaré a cabo en las siguientes páginas.

\section{Una lectura materialista: la literatura (argentina) mundial}

Agentes y editoriales (v.g., Carmen Balcells, CBQ, Random House y Anagrama en las autoras que nos ocupan) son engranajes cardinales de la maquinaria que activa el mercado literario, determinantes en los modos de circulación y recepción de una obra. La dinámica globalizadora que pusieron en marcha los grandes grupos en los noventa supuso una tendencia al centralismo, la polarización y la homogeneización de productos, que quedaron en manos de oligopolios como Planeta y Bertelsmann -propietarios de Penguin Random House- para la literatura en lengua castellana. Estos conglomerados son los que ponen en la órbita mundial a la literatura latinoamericana actual, cuya marca de identidad más reconocida es la lengua castellana. En rigor, el sistema literario en los últimos años se ha expandido, como el mercado, ferozmente fuera de las fronteras nacionales, hasta el punto que ciertas narrativas se han desterritorializado amén de la globalización capitalista y tecnológica, la mundialización de la cultura, la movilidad, la digitalización, el imperialismo de ciertas lenguas y los flujos de intercambio transnacionales. Pero el marbete literatura mundial no se aviene a la autonomía que predicaban Bourdieu y Casanova, sino a una categoría neutralizadora que asimila el objeto literario a un modelo de consumo dominante -anglosajón- basado en la categoría de autor (que funcionan como marcas) - no en la de obra o en estéticas-, que es lo que permite que se lean novelas concretas como mundiales/del mundo. Así, la circulación global se ha impuesto como forma hegemónica de consagración: los libros con más valor simbólico y económico son lo más visibles, los que más se traducen. Entonces, sobreviene otra vez la misma pregunta (a la que los críticos no paramos de darle vueltas, como ratones en una rueda giratoria): ¿qué es la "literatura mundial”? ¿Un modo de producción (tipo de escritura), un tipo de circulación de texto (trasnacional) o una forma de recepción (marco de lectura)?

Las últimas teorías que han dirimido esta problemática responden y ponen el acento en la circulación global de libros, como argumenta Pheng Cheah en What is a World? (5). Para el reconocido crítico de Berkeley, el hecho de que la 
categoría “mundial” se asocie a la circulación transnacional de bienes y al mercado global es un error, porque sería considerar que la globalización tiene un sesgo imperialista, occidental y anglocéntrico ${ }^{19}$. Sin embargo, desde una perspectiva materialista, la lectura neocolonial -la superproducción de objetos y la estandarización de culturas- es innegable; aunque, como defiende Cheah, también haya que atender a las estéticas mundiales, no solo a los aspectos económicos, sociológicos y políticos que implica la globalización ${ }^{20}$. Mi postura crítica en este ensayo abarca sendos aspectos, el económico y el estético, político, ya que las novelas escogidas albergan principios literarios mundiales como “el presente, la experimentación, lo relativo, lo fluido” (Bourriaud 15), y sus tres autoras tienen una proyección global y una circulación internacional.

Siguiendo este eje de pensamiento, habría que tener en consideración que la globalización de la economía ha cambiado la cadena de producción del libro en virtud de dos procedimientos concretos: la racionalización y la concentración de editoriales. A esto se suman otras variables que determinan la circulación del libro: “aires linguistiques, territoires géographiques de distribution, frontiéres nationales qui circonscrivent des espaces juridiques et des politiques publiques, territoires imaginaires qui asoscient des identiés à des lieux et dessinen un horizon d'attente" (Sapiro 7). Para la socióloga francesa, la "mundialización" o "globalización" se manifiesta en el espacio editorial cuando cae el muro de Berlín, los regímenes dictatoriales de España y América Latina, y se intensifica la circulación internacional de libros (7). Aunque este hecho no sea algo novedoso, sí lo es la aceleración y el cambio en los modos de producción, ahora en manos occidentales, debido a las fusiones de los grandes grupos (e.g., Bertelsmann, Rizzoli o Planeta), que han encastrado progresivamente a los mercados nacionales en América Latina (Sapiro 9-10) ${ }^{21}$.

19 Para Cheah la literatura mundial debería explorar cómo determinados textos literarios contribuyen a la comprensión del mundo, a su cambio -a la "mundialización del mundo"- desde una perspectiva normativa, temporal y no espacial.

20 Véanse las últimas monografías coordinadas por Gesine Müller sobre la literatura latinoamericana mundial, el libro reciente de Ignacio M. Sánchez Prado y el de Jorge J. Locane.

21 No obstante, y sorprendentemente, Gisèle Sapiro insiste -con Bourdieu- en que el mercado de bienes culturales tiene una jerarquización y economía propias, autónomas. Para Jorge J. Locane, la autonomía es inviable porque la literatura (latinoamericana) mundial depende fuertemente de proveedores de capital, aunque no ocurriría lo mismo a una escala localizada (véase Locane). Coincido con este argumento aunque considero que la heteronomía permea también los circuitos locales del libro: siempre que haya publicación -siempre que haya un interlocutor, diría Libertella-, siempre que haya producción, y por tanto circulación, por pequeña que sea, hay un mercado de capitales e intereses (creados). 
En segundo lugar, la globalización del mercado editorial no es un proceso uniforme, sino diverso y contradictorio. Por un lado, se han concentrado los modos de gestión de la producción y la distribución en las regiones centrales (Nueva York, Londres, Frankfurt, París, Barcelona, Madrid) ${ }^{22}$, pero a la vez ha aumentado la producción de libros (más escritores y títulos) y ha disminuido la oferta (menos tirada), lo que trae como consecuencia el conocido fenómeno de los libros que nacen muertos. Esto perjudica a los autores noveles, y a géneros menores como el teatro y la poesía; aunque beneficia al más comercial, la novela, que se aviene a la política del best seller y a la rentabilidad a corto plazo (Sapiro 12-13).

Las nuevas reglas del mercado global -que sustituye a la categoría de campo nacional (véase Gallego Cuiñas "Poéticas...")- conllevan la producción y circulación de las literaturas mundiales, o lo que Tim Parks denomina "New Global Novel” en Where I'm Reading. The Changing World of Books (2014), que ha afectado al oficio literario, en cuanto a la percepción que tienen los autores de quién es su audiencia: "There is a growing sense that for an author to be considered 'great' he or she must be an international rather than a national phenomenon" (Parks s.p.). Y eso implica orientar su producto al mundo anglosajón, motor del mercado internacional, que pondera la legibilidad, lo fácilmente traducible, lo que circula y no se resiste. El sentido estético es abandonado en pos del comercial -la calidad literaria se mide desde hace tiempo por la circulación transnacional de un autor- y la especificidad es desdeñada en beneficio del objeto estandarizado, que propicia un mayor número de traducciones y de ventas.

En lo que respecta al lugar que ocupa el dispositivo literatura latinoamericana en el sistema mundial del siglo XXI, hay que tener en cuenta dos variables: que la novela en lengua castellana tiene una condición menor (se traduce y circula menos) que la de lenguas hegemónicas como el inglés, el francés y el alemán; y que la industria editorial latinoamericana sigue dependiendo de la supremacía -económica- que ha ejercido España, desde los años ochenta, sobre este sector. Hasta el punto que, en la mayoría de ocasiones, un escritor de América Latina ha de ser publicado por un gran grupo editorial en España para ser traducido y entrar en el circuito internacional, que sigue ejerciendo así de gatekeeper de la literatura latinoamericana mundial.

Por último habría que precisar que una vez fabricado ese producto, el de la literatura latinoamericana mundial, es recibido, leído, desde la lógica hegemónica de la tradición occidental. Y en esta predomina una bolsa de valores eurocéntricos, universalizantes y totalitarios que privilegian la alta literatura y la

22 Aunque la industria dominante es la anglosajona. 
forma novelística, el género dominante, el que nace con el capitalismo, el más legible y consumible. Teniendo en cuenta estos factores, las obras de nuestro corpus encajan a la perfección en el cerco mundial: se trata de novelas (y una crónica), abordan temas globales (el feminismo, la ecología y el mercado de la música) y sus autoras son jóvenes y argentinas, otros dos valores que cotizan a la alza. ¿Por qué? El campo nacional argentino -que no deja de ser un "artefacto cultural" (Blanco et al. 13) al que dicen pertenecer las autoras- es el que goza de un alcance superior, simbólico y económico, dentro del circuito mundial de las letras latinoamericanas. Basta pensar en la feria internacional del libro de Frankfurt que tuvo a Argentina como país invitado en 2010, y que originó el Programa Sur para favorecer la traducción de obras argentinas a otras lenguas; hecho que ha contribuido a la mundialización de esta literatura sobre otras de Latinoamérica. También el salón internacional del libro de París se dedicó a Buenos Aires en 2011, y a la Argentina como país de honor en 2014: ambos acontecimientos impulsaron la circulación europea de sus escritores, sobre todo de los emergentes. "Sin pasar por alto que su presencia es profusa en listas como las de Granta o Bogotá39. Con lo anterior queda claro que existen nacionalidades latinoamericanas, como la argentina, que se han fetichizado en el mercado global, habida cuenta de su nutrido capital simbólico y desarrollo económico” (Gallego Cuiñas, “Las narrativas...” 11).

\section{Lecturas feministas de las narrativas argentinas del siglo XXI}

Como es sabido, las teorías feministas tuvieron especial calado en el campo literario latinoamericano a partir de la década de los ochenta, cuando se deconstruyen los modelos de la cultura heteropatriarcal y la mujer se vuelve agente de cambio en virtud de un feminismo de la diferencia (Cixous, Irigaray o Kristeva). Justo en ese momento estalla el llamado Boom de la narrativa escrita por mujeres $^{23}$, que catapulta internacionalmente a una serie de escritoras que orientan sus publicaciones a una lectora femenina a través de temas como: el (des)amor romántico, la cocina, y el erotismo. En realidad, las autoras que se mundializaron más (v.g., Isabel Allende, Laura Esquivel, Ángeles

23 El solo hecho de que exista esta categoría en el mercado "narrativa de/para mujeres" (frente al escritura producida por hombres que no se define sino por su universalidad) es un síntoma de su subalternidad en el sistema literario. 
Mastretta) de algún modo reproducían en sus poéticas “sentimentales” roles de la ideología patriarcal, aunque su objetivo fuera dar visibilidad a una voz propia de las mujeres -el célebre "hablar en femenino"-, que había quedado orillada por el discurso literario masculino. Sin embargo, sus poéticas no terminan de discutir el esencialismo de la categoría de género y siguen vinculando, aunque sea desde una mirada propia, el espacio doméstico de la casa y la labor reproductiva con la mujer, con lo femenino, y con la familia.

En cambio, otras autoras del mismo periodo, Rosario Castellanos y Elena Poniatowska, decidieron apropiarse de los grandes temas de la escritura masculina -la Historia, la Política, la Filosofía- con el fin de armar un discurso otro capaz de subvertir la versión oficial de la Historia e incorporar a los oprimidos y excluidos del centro de poder, generando relatos contrahegemónicos que ponían sobre las cuerdas la ideología patriarcal: no solo en el plano temático sino también formal ${ }^{24}$. A esta línea se adscribieron después las argentinas Hebe Uhart, Luisa Valenzuela y Angélica Gorodischer que fueron más allá: deslegitimaron en sus poéticas al "Sujeto Fundador" -Foucault dixit- de los grandes relatos de la nación argentina, y vindicaron socialmente a la mujer marginada para elaborar una imagen pluridentitaria, que escapa a los roles sexuales impuestos por la heteronormatividad. Y lo hicieron desde un discurso, y una estética, diferente.

Ya a partir de fines del siglo XX, y hasta hoy día, el feminismo ha ido abriéndose a otros enfoques como la teoría queer ${ }^{25}$ (Butler y la performatividad del género y la identidad), el postfeminismo (Haraway), los nuevos materialismos (el posthumanismo y el "thing power" de Jane Bennett o el feminismo materialista de Elizabeth Gross), la pospornografía (que predica Paul B. Preciado) o el feminismo latinoamericano de Marcela Lagarde, focalizado en la violencia y en los procesos de subjetivación -subalternos- de las mujeres latinoamericanas (véase MedeirosLichem). En cuanto a Argentina, además de la reconocida filósofa María Luisa Femenías, que defendía un lugar alternativo para el feminismo latinoamericano, tenemos a la socióloga Karina Bidaseca que aboga por un "feminismo decolonial" que visibiliza a las "otras" del "feminismo hegemónico" (Audran 93), aunque ninguno de estos últimos ha tenido gran calado en el discurso literario argentino.

En este horizonte de feminismos, se ha ido desarrollando una narrativa argentina que hace "trizas el viejo cliché sobre lo que debería ser la escritura de

24 Nótese que estas escritoras son de las más consagradas por la crítica mundial, habida cuenta del tratamiento en sus narrativas de temas "masculinos", aunque la mirada sea "feminista".

25 Véase a este respecto el volumen editado por Falconí en 2016: Resentir lo queer en América Latina: diálogos desde/con el Sur. 
mujeres” (Drucaroff, Los prisioneros 462). ¿De qué modo? Se pueden distinguir al menos dos mecanismos claros: primero, la reapropiación de recursos como el humor negro y la violencia, que eran ínsitos a la escritura masculina y al papel social del hombre. Segundo, la deconstrucción y reconstrucción de los procesos de subjetivación femenina. Ya no se trata de narrar lo que dicen las mujeres, sino lo que no dicen. El objetivo no es solo tener acceso a la palabra sino descorrer el velo ideológico que el discurso hegemónico patriarcal ha extendido sobre el cuerpo de la mujer y sus funciones: como madre, como amante, como víctima de la violencia. Así, esta novísima narrativa feminista muestra, en un acto político, los límites, los agujeros, las sombras (Ludmer, Clases 98) de la feminidad, aunque sin adoptar una postura decolonial para la subjetividad - subalterna- argentina. El punto de partida de las propuestas narrativas de las argentinas Almada, Enríquez y Schweblin es un feminismo hegemónico, que desafía tanto la ideología patriarcal como la literatura femenina, poniendo en jaque la institución del matrimonio, los roles de esposa y madre, la familia y la misma identidad -en devenir y performática- de la mujer mundial (no específicamente latinoamericana). ¿Cómo lo logran? Representando zonas de debate "mundiales", muy productivas desde los enfoques feministas actuales, que son deconstruidas y resignificadas: la maternidad, el amor romántico, y la violencia machista; los topoi de la escritura de mujeres que más y mejor- circulan en la literatura mundial. Sin duda, la resistencia feminista es hoy un mercado en expansión, valga el oxímoron. La literatura mundial, constituida en/por/para el mercado global, pone a circular textualidades disidentes - ma non troppo- cuando hay una oferta y una demanda crecientes. Y la narrativa argentina escrita por mujeres en el siglo XXI se ha convertido en uno de los centros mundiales ${ }^{26}$ de producción literaria feminista (desde el costado hegemónico), cuya naturaleza desentrañaremos a continuación sobre la base de sus principales problemáticas ${ }^{27}$.

26 El policentrismo y la multiterritorialidad son consustanciales a la producción de literatura mundial.

27 Hay detalles no baladíes en las portadas de estas tres obras que hacen alusión inequívoca a la naturaleza, que se ha vinculado con la mujer. En Schweblin hay un pájaro (que está sobre granadas, imagen masculina); en Enríquez, un rielo de luna sobre un mar de plumas (en alusión "femenina" a la magia de las hadas); y en Almada, un río de lodo entre arbustos (una imagen "femenina" en descomposición, como los cuerpos de las chicas muertas). El análisis paratextual de estas publicaciones excede el espacio de este artículo, pero merecería una exégesis más desarrollada. 


\subsection{La maternidad}

Desde el ecuador de la segunda mitad del siglo XX, la escritura feminista argentina bascula entre el afán de construir subjetividades públicas fuera de lo maternal o plantear la maternidad desde la compleja relación con el hijo/hija. Nora Domínguez en De dónde vienen los niños. Maternidad y escritura en la cultura argentina (2007) hace un nutrido recorrido por las diferentes representaciones literarias de la maternidad en la Argentina del siglo XX y concluye que la madre ha sido fagocitada por el hijo en el discurso literario, sin lograr subvertir esa relación de dominación (Maradei 3). Sin embargo, en el siglo XXI las escritoras argentinas atienden a aspectos de la maternidad que han estado excluidos tanto del marco de lo social como del marco literario: el parto, la lactancia, la menstruación, las relaciones sexuales de la mujer/madre, etc. (Rowinsky 429). Incluso han puesto a circular un relato de la maternidad "resistida, denegada o impuesta" (Maradei 3-4) que desestabiliza la normatividad "procreativa" como significante político conservador, ya que promueve la institución familiar y la propiedad privada: “Al emitir este discurso regenerador con respecto a la mujer por medio de la literatura, se logran crear nuevos parámetros de acción y reacción ante las premisas de lo que 'debe ser/ser' la mujer, para volcarlo a un campo mucho más amplio, el de 'querer ser/ser”' (Rowinsky 428).

En rigor, desde la etapa Postfordista o la Nueva Economía que supuso la incorporación masiva de mujeres al trabajo -sobre todo a partir de la década de los ochenta/noventa- el discurso literario de la maternidad se abre a nuevos planteamientos -políticos- disímiles: desde la negativa a la procreación (v.g., Lina Meruane); a la figura de la mala madre (v.g., Dimópulos o Harwicz); o la defensa del aborto ${ }^{28}$ (v.g., Shua o Piñeiro) ${ }^{29}$. Como diría Cixous, el significante unívoco mujer/madre se auto(de)construye en la segunda década del siglo XXI con una narrativa propia que revela más sombras que luces, en el intento de dinamitar el mito y estereotipo - patriarcal- de la experiencia maternal, teñida antaño de un idealismo casi místico. Una de las pioneras en este rubro deconstructor, en el campo literario argentino, es Ana María Shua. En su cuento “Como una buena

28 Este continúa siendo uno de los grandes tabúes en la literatura y sociedad argentinas (e hispánicas en general).

29 Dentro del feminismo hay distintas posiciones: las que abogan por una maternidad/paternidad igualitaria, y las que defienden el reconocimiento de la "diferencia": solo una madre puede embarazarse, parir, amamantar. En este sector, hay incluso una línea más extremista que defiende lo que podríamos llamar una "maternidad ecológica”: partos no intervenidos quirúrgicamente, lactancia a tiempo completo, pañales libres de plástico, no vacunación de hijos/as, etc. 
madre", "trabaja la maternidad desde las pulsiones monstruosas y el humor negro” (Drucaroff, Los prisioneros 364). A partir de ese momento, no ha hecho sino aumentar el número de mujeres escritoras que exponen el lado sombrío de la maternidad desde un punto de vista feminista, subversivo. Los cuentos de Mariana Enríquez, Alejandra Laurencich, Gabriela Bejerman; la poesía de Fernanda Laguna y Marina Yuszczuk; o las novelas de Inés Acevedo, Ariana Harwicz, Mariana Dimópulos y Samanta Schweblin plantan cara al ideario dulce y gratificante de la experiencia maternal desde el tabú del filicidio, mostrando sin ambages la parte negativa de esta imposición social: la asfixia de la dependencia madre-hija, la colisión con la subjetividad, la resemantización del sexo y de las relaciones de pareja.

Y la novela que mejor ilustra esta zona temática es Distancia de rescate. El relato se compone de dos voces - la de David y Amanda- que arman un diálogo trufado de imágenes ${ }^{30}$, fragmentos, silencios y ambigüedades, abierto a interpretaciones que se instalan en el suspense narrativo y la "reflexión metaficcional” (De Leone 66). Amanda es una madre que se marcha sola con su hija Nina de vacaciones al campo y que expone desde el comienzo su relación maternofilial en términos conflictivos: la dependencia, el miedo, la preocupación, la falta de libertad ${ }^{31}$ y la problemática de la identidad. En un contexto rural donde se cultiva soja contaminada -el campo ha pasado de ser sueño a pesadilla ${ }^{32}$ por la explotación del capitalismo global- la lectura ecológica se trenza con la fantasía y lo siniestro, cuando se aborda el tema de la transmigración de almas en los hijos. Le sucede a David, que bebe agua contaminada por un descuido materno (una mala madre), y se transforma en un niño-monstruo, un niño otro que tiene otra alma, pero el mismo cuerpo (gracias a una curandera) ${ }^{33}$; un hijo que su madre rechaza en una pulsión filicida (Drucaroff, "La cicatriz. ..” 4): “Te llamó 'monstruo', y me quedé pensando también en eso. Debe ser muy triste ser lo que sea que sos ahora, y que además tu madre te llame "monstruo"” (Schweblin 35). Luego Nina, la hija de Amanda, también se contamina, y la culpa vuelve a recaer en la figura materna: “¿Se trata entonces de otra cosa? ¿Es porque hice algo mal? ¿Fui una mala madre?” (116). Nos encontramos con

30 La crítica ha resaltado la huella de David Lynch en su poética (De Leone 72).

31 El hilo invisible que mida la "distancia de rescate" también es una atadura que impide la libertad de movimiento de la madre. Y lo peor, es que -como refiere la novela- es algo que se hereda, forma parte de la tradición.

32 Drucaroff habla de civilibarbarie por la fusión de campo y contaminación ("La cicatriz...” 3). 33 No hay un hospital cercano, y la madre tiene que recurrir a la santería, seudociencia común en el campo argentino. 
un grupo de niños-monstruos (véase González Dinamarca) que tienen el cuerpo mutilado, deforme por la contaminación de los campos y el desarrollo de los transgénicos: marginados en el margen (rural) por la política neoliberal sus cuerpos se transforman. Son sus almas pero no son sus cuerpos. Son a medias, como David. Es decir: no son. O son otros.

Pero la verdadera tragedia reside en que Amanda no puede hacer nada para impedirlo: falla como madre, en su rol normativo, y se convierte en mala madre. La identidad pues se separa de lo material y se entiende como disidente, del mismo modo que la sexualidad, que se cristaliza en la tensión erótica entre Carla -la vecina- y Amanda. Así, Samanta Schweblin desactiva el dispositivo de identidad genérica que contienen los cuerpos: su hija Nina pasa a habitar el cuerpo de David, el hijo de Carla; el objeto de deseo de Amanda. Como indica Drucaroff: en "Distancia de rescate el deseo de la madre es deseo de persona y eso se pone en juego: Amanda ama a su hija pero también desea -casi imperceptiblemente- a otra mujer. Su mirada/voz narra a Carla con un erotismo intenso, velado y sutil" ("La cicatriz. .." 5). La escritora argentina reemplaza la noción de sujeto por la de agente social, de ahí que la identidad subjetiva de la narradora sea performática, como la de los hijos. Sin embargo, Amanda es castigada cuando desea a otra persona, porque al final su hija muere justo cuando la madre imagina/desea una vida con Carla. El deseo en la madre es reprimido y negado por el orden patriarcal heteronormativo, máxime cuando se trata del mismo sexo, de los mismos cuerpos. La imagen de la mujer se delinea en el texto como fuera de la norma, aunque ambas mujeres intenten cumplir con sus papeles de esposas y madres, en los que terminan fracasando. De hecho, la figura masculina en la novela está prácticamente ausente, encarnada en los maridos de Carla y Amanda. El primero es comparado con un animal y el segundo, cuando llega después de la muerte de su mujer, no se da cuenta de "lo importante": no ve ninguna transformación ni en el alma de David -que es la de Nina- ni ve la plaga oculta de los campos (Schlickers 14).

Al final Distancia de rescate demuestra que el género es una forma más de ideología, ya que Samanta Schweblin presenta un cuerpo y una escritura que se unen configurando una materia que se transforma, fuera de la norma, un lugar intermedio, ambiguo y plural, como la identidad genérica. Se impone pues una lectura del texto desde el feminismo queer, desplazado al lugar de enunciación de Donna Haraway y a su idea de lo monstruoso. Como hace notar Audran, en el siglo XXI hay una proliferación de cuerpos-monstruos en la literatura argentina que se conciben como "espacio de resistencia y de supervivencia, se hace lugar de enunciación y de transformación performativo” (81). Estos personajes mutantes -como madre/hija- cristalizan una posición crítica, tanto feminista (en contra de la idea de rescate maternal) como ecologista (en contra 
de los transgénico), que circula muy bien por la agenda de la literatura mundial (en su costado más alternativo).

\subsection{El amor romántico}

Ya he hecho alusión en el epígrafe anterior a la actitud subversiva en el tratamiento del amor romántico que lleva a cabo Samanta Schweblin. Pero será Mariana Enríquez la que profundice más en las raíces patriarcales del amor en Éste es el mar, novela en la que confronta estereotipos femeninos como el amor platónico, la mitomanía, la idea de comunidad femenina, y la crueldad para activar un dispositivo de empoderamiento que pasa por la disolución de códigos binarios: amor carnal/amor ideal; eros/tanatos; cultura de masas/educación sentimental, etc.

El argumento de esta novela fantástica es sencillo: las "Luminosas" son seres sobrenaturales, un "Enjambre" de mujeres adolescentes que actúan como fans, musas y asesinas monstruosas, que confabulan entre sí para hacer que famosos músicos rockeros como Kurt Kobain, John Lennon o Jim Morrison se conviertan en dioses de leyenda a través de una muerte repentina y trágica. La Luminosa Helena es la protagonista y con ella vemos el lado sombrío del fanatismo, la titánica fuerza de una comunidad de mujeres jóvenes, alocadas y empoderadas, hiperconscientes de que sin ellas no existirían los mitos del rock. De nuevo, en esta obra de Enríquez los sujetos activos son mujeres y los pasivos como sucedía en Schweblin- son hombres, que no se enteran de nada, que ahora están al margen, que son cuerpos y víctimas (de la seducción, de su vanidad), que mueren. Porque en el orden patriarcal, tal y como describió Bourdieu, el imaginario del amor, y la pasión, aparece bajo la dominación "femenina”:

Las fuerzas que se sospecha que actúan en la oscuridad y el secreto de las relaciones íntimas ("encima de la almohada") y que retienen a los hombres por la magia de las ataduras de la pasión puede hacer olvidar las obligaciones derivadas de su dignidad social, que determinan una inversión de la relación de dominación que, ruptura fatal del orden corriente, normal y natural, está condenada como un fallo contra natura, idóneo para reforzar la cultura androcéntrica. (133-134)

Es más, las letras de las canciones de rock -cantadas por hombres- ${ }^{34}$ redundan en la misma idea: el desamor, el abandono de la mujer, la pérdida. Ya lo enunció Fernández Porta: "La cultura musical gira alrededor de dos temas: la ruptura

34 Leemos: “También le explicaron por qué nunca elegían a mujeres para ser Estrellas: habías otras Hermanas que se ocupaban de eso. Y también de hacer otro tipo de Estrellas. Las del 
sentimental y la dinámica entre independencia y mercado” (308). Las letras de estas canciones tienen un sustrato literario y un mercado en la industria cultural, así como un grupo musical es un producto -una imagen, un estilo, un relato, un cuerpo- que consumen con voracidad las fans, en un acto casi performativo. La seducción que unos y otras ejercen en este intercambio simbólico y económico de experiencias, en esa relación misteriosa entre sujetos, se aviene a la destrucción, como advertía Ovidio. "Siempre que seducimos lo hacemos en el espectáculo y nos hacemos espectáculo” sostiene Fernández Porta (288). Los conciertos, hoy día más espectacularizados que nunca, no son otra cosa que un gran espacio público donde circula el deseo y la violencia, fuerzas que siempre actúan en el mercado neoliberal y que permean en la educación sentimental y en los procesos de subjetivación. Las Luminosas son parte sustancial de ese espectáculo que "ilumina” nuestras experiencias: mujeres que desean y agreden al mismo tiempo, consumidoras y productoras (i.e, ellas son las verdaderas hacedoras de leyendas masculinas); constructoras y destructoras, víctimas y victimarias, fanáticas y $\operatorname{asesinas}^{35}$ :

Cuando recordaba esa noche en una playa con el chico que le había metido arena en la vagina para que le raspara, para que doliera y gritara, escuchaba una canción de Fallen, cantaba I fell apart lloraba y terminaba parada sobre la cama, con los brazos extendidos, sintiendo que alguna vez iba a olvidar ese aliento a alcohol y olor a sangre. (Enríquez 56)

El asunto del cuerpo es central en esta ficción, que no solo refiere a la mujer, sino al hombre, objeto también de actos violentos. En un giro feminista, la misión de las Luminarias -mujeres sin cuerpo- es "Afectar el cuerpo del artista, enfermarlo y darle intenso dolor [que] resulta una estrategia fundamental de las Luminosas para forjar el camino de leyenda, el sufrimiento resulta constitutivo de su camino a la inmortalidad" (Pizarro Silva 51). Se aprovechan de la invisibilización -son fantasmas, hadas- que les otorga el ser mujeres, jóvenes, asimiladas a una masa (todas las fans son iguales) para acabar con la materialidad del mito -el cuerpo- que ellas mismas han construido y perpetuarlo en la tragedia, de la que se benefician materialmente ${ }^{36}$. La metáfora reproductiva del capitalismo y el no-lugar que ocupan las mujeres -sin cuerpo- es evidente, así como la crítica social y (post)feminista que destila el texto, desde una mirada

cine, por ejemplo. El territorio de las Luminosas era sólo el de los chicos y la música” (Enríquez 25).

35 La novela se inscribe a su vez en una tradición muy argentina: la genealogía literaria de mujeres asesinas de la que hablaba Josefina Ludmer en su célebre ensayo El cuerpo del delito.

36 Por supuesto, el final de estas estrellas del rock es de naturaleza romántica, para poder alcanzar el grado de leyenda: la enfermedad, el trauma, la pérdida. 
materialista que no solo cuestiona la categoría de género ${ }^{37}$ como modo de percepción del mundo, sino que revierte la materialidad de la dialéctica masculino/femenino.

Asimismo, podemos leer esta novela a partir de la psicopolítica, como síntoma del capitalismo emocional -"la emoción es dinámica, situacional y performativa" (Han 268)-, efecto de un marketing neoliberal basado en el constante consumo de sexualidad -de iconos e imágenes sexuales- que trae aparejada la erotización de cualquier producto, incluido el sujeto (hombre). Este es el caso del fenómeno de las mujeres fans -una figura tradicionalmente femenina- de estrellas del rock masculinas, que se mueven por la pura deseabilidad (Simmel) y la capitalización de emociones (Han). El artista, como sujeto neoliberal espectacularizado, se autoexplota y se autoagrede en virtud del capital y de la optimización personal (Han 19 y 51). Las fans entonces son una suerte de consumidoras autosometidas por la subjetividad/productividad del ídolo, y de su cuerpo, hasta el punto que ejercen de "panópticos" que controlan, y persiguen, la vida de los famosos. Sucede lo mismo con la religión, no en vano Benjamin concebía el capitalismo como una devoción sacramental (Han 20):

Lo sobrenatural de Este es el mar resulta así una alegoría de la condición religiosa del capitalismo, en el que las criaturas espectrales hacen de las fuerzas invisibles y metafísicas del capital y la mercancía, manipulando las relaciones humanas de acuerdo a sus intereses, produciendo y manteniendo el sentido cultual del consumo fetichista a través de su existencia mística. (Pizarro Silva 70-71)

En la misma órbita, habríamos de pensar la sobreexcitación que conlleva la imagen -el cuerpo- del ídolo como parte de la producción "farmacopornográfica", que diría Paul B. Preciado, propia de "un 'capitalismo caliente' bien distinto del sistema industrial, que generaba productos pero refrenaba las pasiones” (Fernández Porta 33). En este sentido hay una crítica a la fetichización de subjetividades y cuerpos en la sociedad global, a la (sobre)exposición que impone el mercado de la fama, muy similar a lo que sucede en la industria editorial. Los grandes grupos también explotan hasta la saciedad la imagen de los escritores -más aún de los jóvenes, de los nuevos- en actos públicos, que se han multiplicado en el siglo XXI (presentaciones, firmas, festivales, talleres, mesas redondas, entrevistas, etc.), al albur del consumo masivo de celebridades en directo. El escritor reemplaza a la obra, que ha devenido en un proyecto, casi en una "narración en directo", que debe hacerse presente in continuum en el mercado -en disputa- globalizado. Aquí

37 Huelga especificar que el género no es solo una articulación formal sino material. 
los hombres-estrella de la escritura ${ }^{38}$-si seguimos el símil, también ellos habrían conseguido el éxito por las mujeres- son reemplazados por una miríada de figuras (de éxito fugaz) entre las que encontramos, cada vez más, a mujeres escritoras. ¿Luminarias iluminadas?

\subsection{El feminicidio}

“Visibilizar, nombrar, catalogar es el primer paso para modificar”, afirma Ainhoa Vásquez Mejías (14) en un libro que analiza la ficcionalización de los feminicidios en el campo cultural chileno. Como demuestra en su estudio, este topos ha ido ganando protagonismo en la literatura latinoamericana del siglo XXI, después de que Bolaño publicara 2666 -que trata los feminicidios de Ciudad Juárez- ${ }^{39}$ en 2004. En el siglo anterior, este problema político estaba muy invisibilizado en la producción cultural mundial, considerado -incluso a día de hoy- como la "repetición constante del mito victimológico que circunscribe a la mujer en el terreno de la pasividad y al hombre en el espacio de la enfermedad" (Vásquez Mejías 18). Sin embargo, en la última década, el discurso literario ha desplazado este cliché y ha abierto nuevas ventanas a la reflexión de la violencia machista y de la responsabilidad del Estado ${ }^{40}$ que no pone freno -ideológico- a este "terrorismo institucionalizado", a las prácticas sociales que permiten los continuos abusos y agresiones que sufren las mujeres, desprotegidas dentro de la sociedad civil:

cada treinta horas ocurre un femicidio -según distintas estadísticas no oficiales, como las de la organización Mumalá (Vivanco - Mumalá, 2018)-, el aborto es la principal causa de muerte materna y continúa la lucha por la legislación del trabajo sexual. En marzo de 2015 se lleva a cabo la primera maratón de lecturas contra los femicidios, con la coordinación de María Pía López -ensayista, narradora y directora, entre 2011 y 2015, del Museo del Libro y de la Lengua, dependiente de la Biblioteca Nacional-. Tres meses después, tras el femicidio de Chiara Páez, es la primera convocatoria “Ni Una Menos”. (Angiletta 101)

38 ¿Los varones del Boom latinoamericano?

39 Aunque ya antes había representado en su literatura los crímenes de género, como en Estrella distante (1996) (Vásquez Mejías 17). Desde luego, él fue uno de los precursores del tratamiento literario de la violencia machista en el espacio literario chileno. Le siguieron más tarde Diamela Eltit que saca en 2007 Jamás el fuego nunca, Rodrigo Ramos Bañados con Alto hospicio (2008), Juan Poblete con No me ignores (2010) o Diego Zúñiga con Racimo (2015).

40 Por esta razón, se empezó a extender el término "feminicidio", que reemplaza al de femicidio en los años 90, empleado por Lagarde (2009), para visibilizar la responsabilidad -e impunidad- del Estado en los asesinatos de mujeres. De hecho, en Chile se tipificó el "femicidio" como delito punible en el Código Penal en 2010, y en 2012 se incluyó en la Argentina una modificación a su Código Penal en que se contempla el “femicidio” (Vásquez Mejías 28). 
Desde los albores del siglo XXI, la muerte de mujeres, los cuerpos desaparecidos, la violencia y el abuso son instancias literarias en el campo narrativo argentino: valgan como ejemplo, Boca de lobo (2000), de Sergio Chejfec, Chicos que vuelven (2010), de Mariana Enríquez, Beya (2013), de Gabriela Cabezón Cámara, Chicas muertas (2014), de Selva Almada o Aparecida (2015), de Marta Dillon; y en todas se concibe lo corpopolítico como corpoética de la resistencia (Audran 80). En rigor, la sexualidad es política porque lo íntimo es político y porque el cuerpo es político. Por ello en la escritura de mujeres el cuerpo como materia ha ocupado siempre un lugar cardinal, desde que el feminismo de la diferencia estableciera la analogía texto-cuerpo (véase Palaisi-Robert y Torras Francés). Es claro: el cuerpo de la mujer ha sido considerado tradicionalmente propiedad del hombre, mercancía y producto para el patriarcado, que la cosifica y somete a través de la violencia/violación: "hablamos de feminicidio justo por la inoperancia del gobierno a la hora de proteger a las mujeres en peligro y resolver los crímenes, porque su condición social precaria las hace mayormente susceptibles de transformarse en víctimas y, luego, en un número más, contenidas en hojas burocráticas” (Vásquez Mejías 164).

Esto es lo que pone de manifiesto Chicas muertas, de Selva Almada, que cuenta los feminicidios de tres jóvenes ${ }^{41}$ : Andrea Danne, María Luisa Quevedo y Sarita Mundín, acaecidos en la provincia de Entre Ríos en los ochenta. Las tres tienen en común ser víctimas de violencia machista y haberse convertido en un caso más sin resolver. La imposibilidad de darle un final al relato de sus vidas ( un libro de no ficción sin final, en el que funge de investigadora (accede a los archivos de los casos), de víctima de violencia de género, de coleccionista de versiones, de entrevistadora, y de cronista que construye una historia alternativa a la policial, y mediática, que circuló en la época. Y eso es lo importante en el texto: la construcción del relato. Digna heredera de Walsh, y del periodismo comprometido, se vale de la crónica para armar una obra de no ficción que bascula entre lo literario y el reportaje (Falbo 10). Este formato, netamente latinoamericano y vinculado desde la época colonial con lo masculino ${ }^{42}$, ha vuelto a ser muy cultivado -después del Boom- en el campo cultural argentino del siglo XXI, también por mujeres (v.g., María Moreno), donde adquiere fuertes connotaciones políticas al concebirse como un arma contra los medios hegemónicos de comunicación en manos de oligopolios

41 Las mujeres jóvenes son abordadas desde un doble cariz: la fuerza en Mariana Enríquez, y la vulnerabilidad en Selva Almada.

42 Uno de sus insignes cultivadores es José Martí. 
neoliberales. El resurgir del género tiene que ver por igual con el "retorno a lo Real" y con la pulsión de "realidad real”, tal y como sugiere Žižek, que aparece ahora -dado el mundo artificial y virtualizado en que vivimos- como una pesadilla: “a causa de su carácter traumático/excesivo, somos incapaces de integrarlo en (lo que experimentamos como) nuestra realidad" (20). La sociedad por tanto aparta/olvida los crímenes después de un periodo de morbo mediático, mientras la literatura visibiliza esta violencia machista leyendo los cuerpos -asesinados- desde otro lugar. No juzga, expone: "En once capítulos y un epílogo, Almada no sólo reconstruye las vidas de Andrea, María Luisa y Sarita, sino que también evidencia la trama de impunidad, corrupción y violencia que sostiene la sociedad patriarcal” (Elizondo Oviedo 3).

Como Diamela Eltit en Jamás el fuego nunca, Selva Almada establece una “estrecha relación" - no evidente- "entre patriarcado, ideología política y feminicidio” (Vásquez Mejías 153). De esta manera, el vínculo entre sexualidad y violencia reproduce "oposiciones fundadoras del orden simbólico" tales como activo/pasivo y dominante/dominada, que propician la violencia simbólica y física sobre la mujer:

\footnotetext{
El mundo social construye el cuerpo como realidad sexuada y como depositario de principios de visión y de división sexuantes. El programa social de percepción incorporado se aplica a todas las cosas del mundo, y en primer lugar al cuerpo en sí, en su realidad biológica: es el que construye la diferencia entre los sexos biológicos de acuerdo con los principios de una visión mítica del mundo arraigada en la relación arbitraria de dominación de los hombres sobre las mujeres. (Bourdieu 22-24)
}

Si el cuerpo es la única certeza -material- en el capitalismo neoliberal, tal y como ilustra la novísima narrativa argentina (Drucaroff, Los prisioneros 469), la agresión ejercida al cuerpo de la mujer es una forma de negarle su materialidad; una subjetividad propia. Chicas muertas va más allá y presenta cuerpos muertos de mujeres adolescentes en un contexto rural, provinciano, que se yergue como un no-centro, un espacio marginal, propicio para el secreto, el ocultamiento, el asesinato y la violación. La idea del asesino ligado a la barbarie vuelve, pero también se asocia al Estado, a los policías e investigadores que no han sabido detener a los culpables. E incluso la barbarie salpica a la ciudadanía, a la opinión pública más preocupada por el relato, por el morbo, que por los cuerpos.

En definitiva, Almada huye de lo simbólico, de la alta cultura y de la retórica, para trabajar con lo real mediante significantes de la educación social del patriarcado, la cultura de masas y la subjetivación de las mujeres, entremezclando múltiples puntos de vista: medios de comunicación, testigos, amigos, familiares, informes policiales, tarotistas, y el de ella misma: 
A mis doce años esa noticia me había impactado muchísimo. ¿Cómo podía ser que el marido la violara? Los violadores siempre eran hombres desconocidos que agarraban a una mujer y se la llevaban a algún descampado o que entraban a su casa forzando una puerta. Desde chicas nos enseñaban que no debíamos hablar con extraños y que debíamos cuidarnos del Sátiro. El Sátiro era una entidad tan mágica como, en los primeros años de la infancia, la Solapa o el Viejo de la Bolsa. Era el que podía violarte si andabas sola a deshora o si te aventurabas por sitios desolados. El que podía aparecer de golpe y arrastrarte hasta alguna obra en construcción. Nunca nos dijeron que podía violarte tu marido, tu papá, tu hermano, tu primo, tu vecino, tu abuelo, tu maestro. Un varón en el que depositaras toda tu confianza. (Almada 54-55)

Estas revelaciones íntimas son abordadas con crudeza y nitidez en una composición narrativa que lleva al lector/a a la emancipación y al empoderamiento, mediante la visibilidad y la exposición de parcialidades. Así, la fragmentación y la proliferación de versiones pueden ser interpretadas como una ruptura de la unidad patriarcal, o como "resistencia a la significación”. Si "la cultura nos hace construir totalidades homogéneas, imaginarios” (Padilla 19) machistas, producir un texto sobre la base de imágenes parciales, relatos a medias y diálogos interrumpidos, es una manera -feminista- de desestabilizar el discurso hegemónico: literario y social.

\section{Conclusiones}

Al comienzo de este artículo señalaba que lo que verdaderamente nuevo de la literatura argentina del siglo XXI es el destacado lugar que ocupan las escrituras de mujeres, caracterizadas por la radicalidad de sus propuestas y por el tratamiento postfeminista de temas como la maternidad, el amor romántico o la violencia. El género funciona en sus poéticas como un molde sobre el que se construye cada una de las obras, un filtro entre el texto y lo político. En el epicentro, estaría la cuestión de la materialidad de los cuerpos de las mujeres, que es problematizada desde diversos feminismos ${ }^{43}$ y materias: el cuerpo de una madre, el de un niño, el de un hombre, y el de las víctimas de violencia machista:

La violencia contra la mujer no es sólo física parecen decir estos textos cuando refractan el escenario de una sociedad que a través de la institución familiar reprime deseos, naturaliza roles y abandona a subjetividades adscriptas al género femenino atravesadas o interpeladas por la experiencia de la maternidad, que intentan resistir los mandatos y ensayar formas de empoderamiento en los bordes de la animalidad, la locura o la enfermedad. (Maradei 27)

43 Opuesto al cuerpo femenino por antonomasia, que en la literatura argentina habría de encarnarlo Eva Perón (véase Coria). 
Pero no se trata de una generación de mujeres, sino más bien de un núcleo de escritoras que entienden el feminismo como un proceso de construcción de la identidad; como la narración material de la complejidad de los cuerpos; como un relato plural (global); como un trabajo con lo factual y lo documental (que pone en cuestión las formas hegemónicas de dar cuenta de lo real); como la práctica de ciertos géneros menores o "masculinos” (lo fantástico en Schweblin y Enríquez, y la crónica en Almada); como el uso de un lenguaje crudo, directo y procaz, desliteraturizado; como un modo de visibilización y resistencia frente a la univocidad del discurso patriarcal.

En las tres novelas argentinas que componen nuestro archivo no encontramos nuevas técnicas o temas literarios, sino nuevas actitudes o posturas feministas, que operan como un dispositivo a partir del cual se discuten los procesos de subjetivación de (todas) las mujeres -ambiguos, performáticos y monstruosos- y se resignifica -desde lo sombrío, lo siniestro- la construcción masculina de lo femenino. Esto evidencia cómo la literatura mundial se apropia de estas literaturas latinoamericanas que devienen instancias de lucha contra la experiencia patriarcal y la (re)producción de subjetividades feministas, convirtiéndose en una mercancía feminista -del feminismo hegemónico- en sí. No hay que soslayar que nuestro corpus se ha editado en un mismo sello -Literatura Random House, que pertenece a un gran conglomerado-, diseñado a tenor de una política acumulativa de capital simbólico y económico, que ha ido integrando en los últimos años a más mujeres en su catálogo. Mujeres profesionales que han asistido a talleres de escritura, mujeres que publican y viven de sus novelas, mujeres representadas por reputados agentes literarios, mujeres que circulan en el ámbito transnacional del hispanismo, mujeres que se traducen al inglés, mujeres que narran a otras mujeres ${ }^{44}$. Mujeres que comparten no solo una temporalidad o un sensorium -el feminismo globalizado del siglo XXI- sino un espacio internacional en que priman la materialidad de una lengua castellana neutra, la subjetividades globales y las poéticas feministas no contrahegemónicas -decoloniales, latinoamericanas- sino mundiales.

Al cabo, estas obras de Schweblin, Enríquez y Almada no solo representan experiencias de mujeres -maternidad, amor y violencia- sino que son consecuencia de una postura feminista adoptada por una miríada de escritoras del mundo. Escritoras que actúan en ese mundo iluminando las condiciones falologocéntricas en que se han (re)producido los sujetos femeninos, que circulan en el siglo XXI como feministas. Escritoras que han decidido situarse ahora en el lugar más sombrío, debajo de la lámpara.

44 Y no solo a sí mismas, es decir, relatos que se ubican afuera del intimismo propio del discurso femenino y de la literatura del siglo XXI, muy autorreferencial y anclada en el yo. 


\section{Bibliografía}

Almada, Selva. Chicas muertas. Literatura Random House, 2015.

Angilletta, Florencia. "Ficciones argentinas desde el género: un archivo vivo". Tropelías.

Revistas de Teoría de la Literatura y Literatura Comparada, 3, 2018, pp. 95-103.

Audran, Marie. "Resistencias corpopolíticas en Argentina: monstruos femeninos levantándose contra la desaparición". Revell, 17, 2017, pp. 76-96.

Blanco, Fernando A. et al. (eds.). Políticas del amor: derechos sexuales y escrituras disidentes en el Cono Sur. Cuarto Propio, 2018.

Bourdieu, Pierre. La dominación masculina. Anagrama, 2000.

Bourriaud, Nicolas. Radicante. Adriana Hidalgo, 2009.

Cheah, Pheng. What is a World? Duke University Press, 2016.

De Leone, Lucía. “Campos que matan. Espacios, tiempos y narración en Distancia de rescate de Samanta Schweblin”. 452 ${ }^{\circ} F, 16,2017$, pp. 62-76.

Crespi, Maximiliano. Los infames. La literatura de derecha explicada a los niños. Momofuku, 2015.

Domínguez, Nora. De donde vienen los niños. Maternidad y escritura en la cultura argentina. Beatriz Viterbo, 2007.

Drucaroff, Elsa. "La cicatriz de lo que no se pronuncia (Apuntes sobre Distancia de rescate, de Samanta Schweblin)”. XXX Jornadas de Investigación del Instituto de Literatura Hispanoamericana Facultad de Filosofía y Letras. Universidad de Buenos Aires, 2018.

---. Los prisioneros de la torre. Política, relatos y jóvenes en la postdictadura. Emecé, 2011.

Elizondo Oviedo, María Verónica. "Femicidio y exhumación del archivo en Chicas muertas de Selva Almada”. IV Congreso Internacional de Cuestiones Críticas del CELARG. Universidad Nacional de Rosario, 2015. http://www.celarg.org/int/arch_publi/elizondooviedocc2015. pdf, consultado 20 de julio 2018.

Enríquez, Mariana. Éste es el mar. Literatura Random House, 2018.

Falbo, Graciela. "Periodismo y escritura: las discípulas de Walsh”. Trampas de la comunicación y la cultura, 80, 2017, pp. 1-13. http://sedici.unlp.edu.ar/bitstream/han dle/10915/64584/Documento_completo.pdf-PDFA.pdf?sequence=1\&isAllowed=y, consultado 13 de julio 2018.

Falconí Trávez, Diego et al. (eds.). Resentir lo queer en América Latina: diálogos desde/con el Sur. Egales, 2016.

Femenías, María Luisa y Paula Soza Rossi. Saberes situados, teorías trashumantes. Editorial CINIG-IdIHCS, 2011.

Fernández Porta, Eloy. €RO\$. La superproducción de los afectos. Anagrama, 2010.

Gallego Cuiñas, Ana. "Poéticas del mercado global en América Latina". Eds. O. Estrada y E.Valero. Literatura y globalización. Latinoamérica en el nuevo milenio. Anthropos, 2019. En prensa.

--.. "Las narrativas del siglo XXI en el Cono Sur: estéticas alternativas, mediadores independientes”. Ínsula, 859-860, 2018, pp. 9-13.

--.. “Comienzos de la novísima novela argentina (2001-2011)”. Hispamérica, 130, 2015, pp. 3-14.

González Dinamarca, Rodrigo Ignacio. “Los niños monstruosos en El orfanato de Juan Antonio Bayona y Distancia de rescate de Samanta Schweblin”. Brumal. Revista de investigación sobre lo fantástico, III, 2, 2015, pp. 89-106. 
Han, Byung-Chul. Psicopolítica. Neoliberalismo y nuevas técnicas de poder. Herder, 2015. Lagarde, Marcela. "Claves feministas en torno al feminicidio". Nuevas líneas de investigación en género y desarrollo. Coords. Estefanía Molina y Nava San Miguel. Universidad Autónoma de Madrid, 2009, pp. 211-233.

Locane, Jorge J. De la literatura latinoamericana a la literatura (latinoamericana) mundial. Condiciones materiales, procesos y actores. De Gruyter, 2019.

Ludmer, Josefina. Aquí América Latina. Una especulación. Eterna Cadencia. 2010.

--.. Clases 1985. Algunos problemas de teoría literaria. Paidós, 2015.

Maradei, Gudalupe (2016): “Cuerpos que insisten: familia, matrimonio y maternidad en la literatura argentina de la última década”. Chasqui, 45, 2016, pp. 1-31. https://www.aca demia.edu/25412680/Cuerpos_que_insisten_familia_matrimonio_y_maternidad_en_la_ literatura_argentina_de_la_\%C3\%BAltima_d\%C3\%A9cada, consultado 5 de julio 2018.

Medeiros-Lichem, Maria Teresa. Reading the Feminine Voice in Latin American Women's Fiction: From Teresa de la Farra to Elena Poniatowska and Luisa Valenzuela. Peter Lang, 2002.

Marazzi, Christian. Capital and Language. From the New Economy to the War Economy. Semiotext(e), 2008.

Müller, Gesine y Dunia Gras (eds.). América Latina y la literatura mundial. Mercado editorial, redes globales y la invención de un continente. Iberoamericana/Vervuert,2015.

Müller, Gesine, Jorge J. Locane y Benjamin Loy (eds.). Re-mapping World Literature: Writing, Book Markets and Epistemologies between Latin American and the Global South. De Gruyter, 2018.

Orechia Havas, María Teresa. "Cruzando límites: cuestiones críticas y formas actuales de la narrativa escrita por mujeres”. Pasavento, 2, 2014, pp. 407-431. https://ebuah.uah.es/ dspace/bitstream/handle/10017/23903/cruzando_orecchia_PASAVENTO_2014_V2_N2. pdf? sequence=1\&isAllowed=y, consultado 20 de diciembre 2018.

Padilla, José Ignacio. El terreno en disputa es el lenguaje. Ensayos sobre poesía latinoamericana. Iberoamericana/Vervuert, 2014.

Palaisi-Robert, Marie-Agnès y Meri Torras Francés (eds.). El cuerpo en juego: cartografía conceptual y representaciones en las producciones culturales latinoamericanas. Mare \& Martin, 2014.

Parks, Tim. Where l'm Reading. The Changing World of Books. Harvill Secker, 2014 [versión ebook].

Pizarro Silva, Felipe. El espectáculo que nos afecta. La vida en las ventanas (2002) de Andrés Neuman y Éste es el mar (2017) de Mariana Enríquez, Universidad de Chile, 2017, pp. 1-94. http://repositorio.uchile.cl/bitstream/handle/2250/146995/El-espectaculoque-nos-afecta.pdf?sequence=1\&isAllowed=y, consultado 10 de julio 2018.

Poblete, Juan. “Globalización, mediación cultural y literatura nacional”. América Latina en la literatura mundial. Ed. Ignacio M. Sánchez Prado. Instituto Internacional de Literatura Iberoamericana, 2006, pp. 271-306.

Riveiro, María Belén. "Los talleres literarios: el caso de los escritores de narrativa en la Ciudad de Buenos Aires". XI Jornadas de Sociología. Facultad de Ciencias Sociales. Universidad de Buenos Aires, 2015, pp. 1-13. http://www.aacademica.org/000-061/249, consultado 9 de julio 2018. 
Rowinsky, Mercedes. "Super-mujer: estrategias femeninas ante la maternidad en el discurso literario del siglo XX". Actas del XIV Congreso de la Asociación Internacional de Hispanistas, 2014, pp. 425-432. https://cvc.cervantes.es/literatura/aih/pdf/14/aih_14_ 1_049.pdf, consultado 19 de julio 2018.

Sánchez Prado, Ignacio M. Strategic Occidentalism. On Mexican Fiction, the Neoliberal Book Market and the Question of World Literature. Northwestern University Press, 2018.

Sapiro, Gisèle (ed.). Les contradictions de la globalisation éditoriale. Nouveau Monde, 2009. Sarlo, Beatriz. Ficciones argentinas. 33 ensayos. Mardulce, 2012.

Schlickers, Sabine. "La mujer trastornada en la literatura del siglo XXI: La fiesta del chivo (2000) de Mario Vargas Llosa, Letargo (2000/2014) de Perla Suez, Distancia de rescate (2014) de Samanta Schweblin y ‘El último día de las vacaciones’ (2008) de Inés Garland”. Revista Estudios, 31, 2015, pp. 1-17.

Schweblin, Samanta. Distancia de rescate. Literatura Random House, 2015.

Soria, Claudia. Los cuerpos de Eva. Anatomía del deseo femenino. Beatriz Viterbo, 2005.

Terranova, Juan. Los gauchos irónicos. milena caserola, 2013.

Vásquez Mejías, Ainhoa Montserrat. Feminicidio en Chile. Una realidad ficcionada. Cuarto Propio, 2015.

Žižek, Slavoj. Bienvenidos al desierto de lo real. Akal, 2008. 
Idun Heir Senstad

\section{Literary Diversity through Translation: The Role of Independent Cultural Mediators in the Selection of Cuban Literature in Norway}

\section{Introduction}

This article examines the role of independent cultural mediators-such as translators-in the selection of literary works for translation. It explores how and why they suggest titles to publishers, and by extension how, through their choices, they contribute to literary diversity. Publishers are the final gatekeepers of translation selection since they make the final decision as to whether or not to commission a translation; however, their decisions are always embedded in wider, transnational gatekeeping networks (Franssen and Kuipers 49). Translators and other independent cultural mediators form part of these networks, but they normally play a minor role. For most publishers, agents employed in the publishing industry-such as literary scouts, literary agents and publisher colleagues in other countries-are particularly important sources of relevant titles and advice (Franssen and Kuipers 57; Senstad, "Norwegian Publishers' Views”), and most titles are selected via this central network of publishing professionals.

Translators and other independent cultural mediators form an alternative source of manuscripts or books worthy of translation. Whereas the predominant structures of the international translation field favor translations from central languages and regions, particularly English and the Anglo-American area, translators are often mentioned as important sources of titles from so-called peripheral literatures (Bourdieu 147-148; Franssen and Kuipers 57), i.e., from languages that editors do not read, or geographical areas that are underrepresented in a certain literary field. However, few studies examine translators' impact on selection, and the present article addresses this gap. More specifically, it focuses on the independent cultural mediators who participated in the selection of Cuban literature for translation from Spanish into Norwegian between 1990 and 2014. From a world-system perspective on translation, both Cuba and Norway are peripheries. Spanish is normally considered a semi-peripheral language, accounting for

Idun Heir Senstad, OsloMet - Oslo Metropolitan University

Ә Open Access. (C) 2020 Idun Heir Senstad, published by De Gruyter. (cc) BY-NC-ND This work is licensed under a Creative Commons Attribution-NonCommercial-NoDerivatives 4.0 International License. 
somewhere between $1 \%$ and $3 \%$ of all book translations worldwide (Heilbron 434). Given the large number of Spanish language writers from Spain, Latin America, the US, and the Caribbean, translations of Cuban literature only account for a fraction of this. In Norway, numbers for the years 2011-2016 show that only around $1 \%$ of literary translations -58 of 4579 translated fiction titlesoriginated from Spanish ${ }^{1}$. At the same time, translated literature has a strong position in the Norwegian literary field (a typical trait of peripheral literatures). Official statistics demonstrate that between 29\% and 34\% of books published in Norway between 1991 and 2009² were translations (Kulturstatistikk 2000 101; Kulturstatistikk 2016 154). The publishing statistics do not single out fiction as a category of its own, but sales figures show that the total number of sold copies of translated fiction roughly equaled sold copies of original Norwegian fiction (Kulturstatistikk 2000 106; Kulturstatistikk 2016 157), which is indicative of the strong position of translated literature in the Norwegian market. A diverse representation of different literatures through translation is an ideal for many Norwegian publishers (Senstad, "Norwegian Publishers' Views"); nevertheless, English dominated as a source language from 1991 to 2014, accounting for between $60 \%$ and $73 \%$ of all translated books (Kulturstatistikk 2000 103; Kulturstatistikk 2016 155). By paying close attention to the selection of literature from one periphery, Cuba, in another, Norway, this article highlights how invested cultural mediators can make essential contributions to literary diversity.

Following Roig-Sanz and Meylaerts, a cultural mediator is "a cultural actor active across linguistic, cultural and geographical borders, occupying strategic positions within large networks and being the carrier of cultural transfer" (3). According to this definition, publishers, literary scouts and literary agents may also be cultural mediators. The present study focuses on agents working largely outside the central networks of publishing professionals. I therefore suggest the term independent cultural mediator and use this throughout. Independent cultural mediators are translators or other agents who advocate for and are personally invested in the translation of particular titles and/or literature from particular geographical areas; these works are often originally written in languages that are not common as source languages for literary translation in the given culture. These works would not normally gain publishers' attention through the typical channels.

\footnotetext{
1 Numbers from Den norske Bokdatabasen. Between 2011 and 2016, 5409 translated titles (for adults and children) were published, but only 4579 titles have information on source language in the database. Nummedal, Mona. "RE: Opplysninger til forskningsprosjekt." Received by Idun Heir Senstad, 29 Nov. 2018.

2 The data source changed in 2010, and numbers from this year onward are therefore not directly comparable to preceding years.
} 
Independent cultural mediators are often freelancers and are not formally employed in the publishing sector, even though they are part of it. The rules of the transnational translation market are not irrelevant to the independent cultural mediators, since publishers are the ones who make the final decisions on which titles to publish. However, these agents tend to act largely independently of the overarching structures of the international translation market. Their agency is instead enacted through alternative networks and is often manifested in a multiple mediatorship (Schwartz) through which various independent cultural mediators influence the selection process.

In this article, I study the selection processes surrounding nine Cuban fictional works published in Norwegian between 1990 and 2014. Through dynamic searches in Norwegian online library catalogues, reviews of different Norwegian publishers' websites, and interviews with Norwegian translators and publishers, I uncovered a total of 28 Cuban fictional works published in Norwegian during this period. Independent cultural mediators (the translators of the works, or in one case an independent series editor) suggested nine of these works, which form the basis for the study in this article. The nine works were translated by four different translators-Kjell Risvik, Tove Bakke, Kari Näumann, and Hege Hammer-and include novels by the contemporary Cuban writers Wendy Guerra, Pedro Juan Gutiérrez, and Leonardo Padura, as well as canonized classics of $20^{\text {th }}$ century Cuban literature, namely poems and short stories by Virgilio Piñera, poems by Dulce María Loynaz and Ángel Escobar, and finally, José Lezama Lima’s novel Paradiso. The main material for this study consists of interviews with the four translators as well as the prefaces and epilogues (where these exist) printed in the Norwegian translations. This material enabled me to study different contextual voices (Alvstad et al.)-the oral and written manifestations of different agents' involvement in the selection processes-surrounding the Norwegian translations of the nine Cuban works.

There are at least four reasons why the chosen material-the selection of nine Cuban fictional works in Norway-and the period-1990 to 2014-are particularly fitting for a study of the role and impact of independent cultural mediators. Firstly, the Norwegian book market is small, automatically limited by the fact that Norway has only approximately five million inhabitants. This makes it feasible to include all Cuban fictional works introduced by independent cultural mediators throughout a relatively long period of 25 years. Secondly, a small "corpus" of nine translated books allows me to combine micro-, meso- and macrolevel approaches to selection. In the first part of the analysis, I study single actors involved in the translation and selection processes (micro-level), and I address the role that state cultural policies played in the work of these individuals (mesolevel). In the second part, I present the cultural mediators' choices in light of the 
regional and international consecration of the nine Cuban works (macro-level), and I relate this to a study of Spanish Caribbean literature in Sweden for the same period (Lindqvist, "Bibliomigrationsmönster").

The year 1990 is a natural starting point for this study from both a Cuban and a Norwegian perspective. The third reason why the material in this article constitutes a fruitful case is that the 1990s brought important changes to the international circulation of Cuban literature and, by extension, brought a considerable increase in Cuban literature published in Norway. The fourth reason is that a successful state funding program for translation in Norway, namely, the purchasing scheme for translated literature, was established in 1990. Together, these factors set the stage for a dynamic analysis that can demonstrate ways in which independent cultural mediators' activities and choices are entangled in multi-level contexts.

Through focusing on the independent cultural mediators who introduced Cuban literature to Norwegian readers between 1990 and 2014, the present study asks: Who are the independent cultural mediators? What motivated them to suggest particular titles to the publishing houses? What kinds of books did they suggest, and what was the impact of their choices on the general availability of different literatures in a given book market? What was the role of state funding in the work of these independent cultural mediators? In what ways do their choices relate to literary consecration processes?

\section{Background}

\section{Cuban literature and its international circulation since the 1990s}

Prior to 1990, the only Cuban literary works published in Norwegian translation were four novels by Alejo Carpentier (published in Norwegian in 1958, 1965, 1976 and 1978), one novel by Luis Rogelio Nogueras (1984), a poetry anthology (1973), and a few more poems and short stories in anthologies on Latin American literature (Izquierdo). The period from the 1990s onwards saw an upsurge in Cuban literature in Norway, with 28 titles published between 1990 and 2014. This upsurge should be understood in the light of more general developments in the international circulation of Cuban literature and other cultural expressions from the 1990s, often referred to as a "Cuban boom" (Whitfield 10-15; see also Senstad, "Bokomslag" 175-177; "The Making of a Bestseller-inTranslation" 66-68). Editors and other cultural producers in Europe, the United 
States, and elsewhere took an interest in Cuba when the socialist island opened up to more contact with capitalist countries due to changing realities after the disintegration of the Soviet Union and the fall of communism in Europe. Without Soviet trade, Cuba entered a severe economic crisis, affecting all sectors of society. The state-run literary industry faced wide-ranging problems with technical equipment and paper supplies, and it was obliged to keep book production to an absolute minimum (Kumaraswami and Kapcia 132-135). In 1993, Cuban authorities issued a decree that allowed writers, for the first time since the 1959 socialist revolution, to sign contracts with publishers abroad without state involvement. For Cuban writers, this meant enhanced possibilities of being published in times of crisis, and it even carried prospects of economic gain (nearly inexistent in a state-run Cuban literary industry devoid of any market concerns) and censorship circumvention. As the world followed the Cuban developments and waited for the socialist regime to either collapse or survive, foreign editors started looking for literary talent on the island. Travels to Cuba became easier-opening to tourism was one of the Cuban authorities' main strategies to cope with the economic crisis-and many editors and other cultural producers (filmmakers, documentarians, and journalists, etc.) travelled there. Pedro Juan Gutiérrez's Trilogia sucia de La Habana-one of the nine works studied in this article-is one of the most successful literary examples from this period. Gutiérrez's first contact with the international publishing industry was a visiting French publisher who later passed the manuscript to a Spanish agent (Gutiérrez, Diálogo 122-123). The prestigious Spanish publishing house Anagrama published the book in 1998, and to date the book has been translated into 21 languages (Gutiérrez, Todo).

\section{State funding for literary translation in Cuba and Norway}

State funding programs in source or target cultures guide translation flows, and they may be of particular importance for the circulation of peripheral literatures beyond national borders (Heilbron and Sapiro 185). Various analyses demonstrate how translations from peripheral languages such as Hebrew and Dutch depended largely on translation subsidies and promotional activities from state institutions in the source culture (Hacohen; Heilbron and Sapiro; van Es and Heilbron). In the receiving culture, states can, for example, "support translation in order to maintain a level of quality that cannot be sustained by their national market (like in France and the Netherlands)" (Heilbron and Sapiro 184-185).

The availability of state funding is one of the factors that influence the decision-making processes of Norwegian editors when they select literary titles for 
translation (Senstad, “Norwegian Publishers' Views”). Throughout the period in focus (1990-2014), there was no source culture funding available from Cuba, and the state-run Cuban literary industry did not have any coherent strategy for promoting Cuban literature internationally. The Agencia Literaria Latinoamericana (ALL), a governmental rights agency established in 1986, was the only entity in Cuba legally in charge of promoting and selling Cuban literature abroad; however, it is illustrative that the agency did not play any important part in the Norwegian selection of the nine works under scrutiny. The poor economy as well as what Kumaraswami and Kapcia describe as a "cclash of cultures' between market-driven global publishing systems and the subsidized Cuban system” (166) contributed to the inefficiency of the state agency. Many Cuban writers refuse to be represented by the ALL. For example, Wendy Guerra, one of the writers in the present study, is represented by the Spanish Antonia Kerrigan Literary Agencyquite a paradox, since the Norwegian selection of the work happened through the translator rather than the agency.

From the Norwegian (receiving) side, the state provides important funding through the Purchasing Schemes for Literature, or Innkjøpsordningene for litteratur in Norwegian. Managed by the Arts Council Norway, the purchasing schemes are widely regarded as a cornerstone of Norwegian literary policy and an important constituting actor in the Norwegian literary field. While the scheme for literature originally written in Norwegian dates back to 1965 , the scheme for translated literature was established in 1990. This coincides with the start of the period studied in the present article, meaning that the possibility of receiving funding through the scheme was a potential influencing factor in the selection process of the nine Cuban works in question. Through the scheme, the Arts Council Norway purchases 500 copies of selected translated titles to be distributed to Norwegian libraries. In an international context, this funding model is unique in that it explicitly emphasizes literary circulation and reading, making high quality literature available at no cost for library users nationwide. It benefits libraries (which are provided with "free" books), publishers (through improved sales), and translators (since 1995, the funding has included extra payments for translators as a means to improve their economic standing). The funding is intended to contribute to translations into Norwegian from as many languages as possible; in other words, it is intended to contribute to diversity in the Norwegian literary landscape. The funding was initially limited to 50 translated titles yearly. This number increased throughout the 2000s, and in 2014, the Arts Council purchased 120 titles (Årsmelding 2014). The publisher must apply for funding prior to the publication of the translation, but after agreeing on a binding contract with the translator, as a means to make sure the book will be translated and published independently of the outcome of the funding application. A 
considerable number of applications for the scheme are refused-this happened to around half of the applications in 2012, 2013, and 2014 (Arsmelding 2014; Årsmelding 2013).

\section{Theoretical framework}

This article takes an agent-oriented approach to the study of literary exchanges between peripheries. The independent cultural mediators in focus are agents who actively suggest or advocate particular titles or writers, thereby aiming to influence publishers' decisions regarding which translations to publish-in other words, they act in the social world to bring about change. In doing so, they enact agency. Agency is here understood as the "willingness and ability to act" (Kinnunen and Koskinen 6). Whereas willingness implies a "particular internal state and disposition" (6), ability relates to power and choice. This means that agency can be closely connected to professional and social status (7). Publishers will normally only take suggestions from translators or other individuals that they know and trust. A certain degree of symbolic capital in the Norwegian literary field thus seems to be a necessary precondition for cultural mediators' agency in translation selection processes.

As elaborated upon in the introduction, in this study I apply the term independent cultural mediator. Roig-Sanz and Meylaerts argue that, in the sociologically-oriented field of translation studies, the preference to study translators may be conceptually problematic because the agents involved in intercultural mediation often assume various roles (such as translator, writer, art and literary critic, journalist, etc.) $(6,8)$. They furthermore suggest that cultural mediators involved in periphery-to-periphery exchanges are either "smugglers" or "customs officers." While the customs officer "hinders exchange” (3), smugglers are agents who "promote exchanges and often create their own norms, circuits, channels and forms" (14). A thorough understanding of mediation processes should take into account this variety. The concept of independent cultural mediator as applied in the present study allows for the study of mediators other than translators, while at the same time highlighting that these mediators work largely independently of the established transnational networks of the publishing industry.

The object of study in the present article-the selection processes leading to the Norwegian translation of Cuban literary works-furthermore requires an emphasis on networks. Cultural mediators operate in the social world, and multiple agents influence the final selection of works. Schwartz employs the term 
multiple mediatorship to study "the combined contributions of several mediators as members of interconnected networks" (527) at work in literary exchanges between semi-peripheries (in Schwartz's article, Italy and Sweden). The term is a modification of multiple translatorship (Jansen and Wegener), which focuses on how different actors, apart from the translator, are involved in and influence translations; the term is employed in the study of agents such as copy editors (Solum, "The Tacit Influence") or literary critics (Solum, “Translators, Editors, Publishers, and Critics"). The focus of the present article is on the processes leading up to the commissioning of a translation, and it ends when the textual translation starts, so to speak. Multiple mediatorship helps emphasize this. I also find the term particularly useful because it explicitly allows for the inclusion of mediators who are not translators, and in this way, it fits neatly with the notion of the cultural mediator (as elaborated above).

Finally, this article draws on macro-oriented approaches to literary circulation and consecration. Of particular relevance to the present study is a theoretical framework developed by Lindqvist to understand, precisely, the "bibliomigrancy patterns of Caribbean and Scandinavian literature during the period 1990-2010” (“The Scandinavian Literary Translation Field” 174). This framework builds on Bourdieu and Casanova, and it proposes two central hypotheses: (1) that "double consecration"-first in a regional context, and then in the Anglo-American culture-is a necessary condition for translation between peripheries (Lindqvist, "Bibliomigrationsmönster”, "Dubbel konsekration"); and (2) that Sweden functions as the center of a peripheral, autonomous Scandinavian subfield within the global translation field (Lindqvist, "The Scandinavian"). Following Lindqvist, a precondition for the Norwegian translation of Cuban works would be a "triple" consecration-first in the Hispanic world, then in the Anglo-American area through translation into English, and finally by translation into Swedish and further consecration by agents and institutions in the Swedish field ("The Scandinavian Literary Translation Field" 185). In my analysis, I test this idea on the material of the present study.

\section{Materials and methods}

\section{Nine translations}

Table 1 presents the details of the Cuban works that entered the Norwegian literary system via independent cultural mediators between 1990 and 2014. Apart from these nine books, 19 additional translations of Cuban fictional works were 
Table 1: Norwegian Translations of Cuban Literary Works Selected by Independent Cultural Mediators, 1990-2014.

\begin{tabular}{|c|c|c|c|c|c|}
\hline No. & $\begin{array}{l}\text { Norwegian title } \\
\text { (year, publisher) }\end{array}$ & $\begin{array}{l}\text { Genre, } \\
\text { Source } \\
\text { language }\end{array}$ & Author & Translator & Original title (year) \\
\hline 1 & $\begin{array}{l}\text { Svart vin } \\
\text { (Cappelen, 1999) }\end{array}$ & $\begin{array}{l}\text { Poetry, } \\
\text { Spanish }\end{array}$ & $\begin{array}{l}\text { Dulce María } \\
\text { Loynaz } \\
(1902-1997)\end{array}$ & $\begin{array}{l}\text { Tove } \\
\text { Bakke } \\
\text { (b. 1954) }\end{array}$ & $\begin{array}{l}\text { Selected poems from } \\
\text { Versos (1950), Juegos de } \\
\text { agua (1951), Poemas sin } \\
\text { nombre (1953) and } \\
\text { Bestiarium (1991) }\end{array}$ \\
\hline 2 & $\begin{array}{l}\text { To cubanske: } \\
\text { Virgilio Piñera og } \\
\text { Ángel Escobar i utval } \\
\text { (Samlaget, 2001) }\end{array}$ & $\begin{array}{l}\text { Poetry, } \\
\text { Spanish }\end{array}$ & $\begin{array}{l}\text { Virgilio Piñera } \\
(1912-1979) \\
\text { and Ángel } \\
\text { Escobar } \\
(1957-1997)\end{array}$ & $\begin{array}{l}\text { Tove } \\
\text { Bakke }\end{array}$ & $\begin{array}{l}\text { Selected poems from } \\
\text { Virgilio Piñera: } \\
\text { La isla en peso } \\
\text { (1943/1998) } \\
\text { Ángel Escobar: } \\
\text { Abuso de confianza } \\
\text { (1992), Cuando salí de La } \\
\text { Habana (1996/1997), El } \\
\text { examen no ha terminado } \\
\text { (1997/1999), La sombra } \\
\text { del decir (1997) }\end{array}$ \\
\hline 3 & $\begin{array}{l}\text { Paradiso } \\
\text { (Pax, 2002) }\end{array}$ & $\begin{array}{l}\text { Novel, } \\
\text { Spanish }\end{array}$ & $\begin{array}{l}\text { José Lezama } \\
\text { Lima } \\
(1910-1976)\end{array}$ & $\begin{array}{l}\text { Kjell } \\
\text { Risvik } \\
\text { (b. 1941) }\end{array}$ & Paradiso (1966) \\
\hline 4 & $\begin{array}{l}\text { Kaldt fortalt } \\
\text { (Samlaget, 2004) }\end{array}$ & $\begin{array}{l}\text { Short } \\
\text { stories, } \\
\text { Spanish }\end{array}$ & Virgilio Piñera & $\begin{array}{l}\text { Tove } \\
\text { Bakke }\end{array}$ & $\begin{array}{l}\text { Selected short stories } \\
\text { from Cuentos fríos (1956) }\end{array}$ \\
\hline 5 & $\begin{array}{l}\text { Den skitne Havanna- } \\
\text { trilogien (Gyldendal, } \\
\text { 2005) }\end{array}$ & $\begin{array}{l}\text { Novel, } \\
\text { Spanish }\end{array}$ & $\begin{array}{l}\text { Pedro Juan } \\
\text { Gutiérrez (b. } \\
\text { 1950) }\end{array}$ & $\begin{array}{l}\text { Hege } \\
\text { Hammer } \\
\text { (b. 1966) }\end{array}$ & $\begin{array}{l}\text { Trilogía sucia de La } \\
\text { Habana (1998) }\end{array}$ \\
\hline 6 & $\begin{array}{l}\text { Alle drar sin vei } \\
\text { (Bokvennen, 2011) }\end{array}$ & $\begin{array}{l}\text { Novel, } \\
\text { Spanish }\end{array}$ & $\begin{array}{l}\text { Wendy Guerra } \\
\text { (b. 1970) }\end{array}$ & $\begin{array}{l}\text { Kari } \\
\text { Näumann } \\
\text { (b. 1928) }\end{array}$ & Todos se van (2006) \\
\hline 7 & $\begin{array}{l}\text { Jeg var aldri } \\
\text { førstedame } \\
\text { (Bokvennen, 2012) }\end{array}$ & $\begin{array}{l}\text { Novel, } \\
\text { Spanish }\end{array}$ & Wendy Guerra & $\begin{array}{l}\text { Kari } \\
\text { Näumann }\end{array}$ & $\begin{array}{l}\text { Nunca fui primera dama } \\
\text { (2008) }\end{array}$ \\
\hline 8 & $\begin{array}{l}\text { Vinter i Havana } \\
\text { (Bokvennen, 2012) }\end{array}$ & $\begin{array}{l}\text { Novel, } \\
\text { Spanish }\end{array}$ & $\begin{array}{l}\text { Leonardo Padura } \\
\text { (b. 1955) }\end{array}$ & $\begin{array}{l}\text { Kari } \\
\text { Näumann }\end{array}$ & $\begin{array}{l}\text { Pasado perfecto } \\
(1991 / 2000)\end{array}$ \\
\hline 9 & $\begin{array}{l}\text { Storm i Havana } \\
\text { (Bokvennen, 2014) }\end{array}$ & $\begin{array}{l}\text { Novel, } \\
\text { Spanish }\end{array}$ & $\begin{array}{l}\text { Leonardo } \\
\text { Padura }\end{array}$ & $\begin{array}{l}\text { Kari } \\
\text { Näumann }\end{array}$ & $\begin{array}{l}\text { Vientos de cuaresma } \\
(1994 / 2001)\end{array}$ \\
\hline
\end{tabular}


published in the same period. Most of these remaining works were originally written in English by Cuban-American writers ${ }^{3}$, and gained the attention of Norwegian publishers through networks of publishing professionals (literary scouts, literary agents and editors). These 19 works are therefore discussed in a separate article (Senstad, “Norwegian Publishers’ Views”).

\section{Interviews with translators, prefaces, and epilogues}

Interviews with the four translators, Bakke, Hammer, Näumann (qualitative indepth interviews) and Risvik (brief email interview), comprise the main material for the analysis in this article, combined with readings of the preface and epilogue in the translated books. These two categories of data, interviews and prefaces/epilogues, complement each other in that they represent researchgenerated and naturally occurring data, respectively.

Six of the nine translations are accompanied by a preface or epilogue written by the translator (for Tove Bakke's translations of Dulce María Loynaz, Virgilio Piñera and Ángel Escobar) or by other central mediators (the literary critic and translator Kjell Olaf Jensen for Kjell Risvik’s Lezama Lima translation, and literary scholar Hans Jacob Ohldieck for Kari Näumann's translations of Wendy Guerra). The prefaces/epilogues present and contextualize the authors and works for Norwegian readers, and they include information related to the selection of the works. Prefaces and epilogues are valuable material for translation research (Buendia; Dimitriu; Tahir-Gürcaglar), however they are not common in contemporary Scandinavian literary translations. The inclusion of prefaces/epilogues for the Cuban works adds symbolic value to the translations, and the fact that they were written by agents central to the selection of the works is important because it makes these mediators' agency textually manifest.

Whereas the prefaces and epilogues were produced at the time of translation, interviews conducted various years later are necessarily based on the translators' recollections of events. There are obvious reasons why interviews can be an unstable source of factual information-memories might be blurred and shaped by the time that has passed since the translation took place. Interviewees may have agendas that are unknown to the researcher, and each

3 Fourteen of the 19 titles were written by Cuban-Americans and translated from English; five were written by writers who migrated from Cuba and were translated from Spanish. 
interviewee represents only one of the multiple agents possibly involved in the selection of a particular translation. Yet I consider that interviews with translators, such as the ones conducted for the present study, provide valuable data to the selection process. In this article, I therefore choose to give the stage to the interviewed translators and to trust their accounts. Still, whenever possible, I corroborated the translators' information with data from interviews with eight publishing editors; these interviews were conducted in 2017 and analyzed in Senstad (“Norwegian Publishers' Views”).

\section{Results and discussion}

Here, I will present the selection processes that led to the Norwegian translation and publication of the nine Cuban works in question. I will then sum up these observations and subsequently present a brief analysis of the consecration processes pertaining to the nine works.

\section{Jensen and Risvik introduce Lezama Lima}

José Lezama Lima's major work, Paradiso (1966), was published in Norwegian by the small independent publisher Pax in 2002. The driving force behind this translation was Kjell Olaf Jensen (1946-2016), a respected literary critic and translator (from French and German, not Spanish), who was also a trusted adviser at Pax. Paradiso was published in the relatively short-lived series Pax Sargasso, which, according to the translated book's dust jacket, focused on "modern classics from the third world" (my trans.). Jensen edited the series. In the epilogue, he writes:

I read Paradiso in French many years ago, in a brilliant translation by Didier Coste with support from Lezama Lima's apprentice Severo Sarduy [. . . ]. Kjell Risvik has now [. . .] substantiated what has been my dream ever since I discovered José Lezama Lima as a young man in France, but that I did not dare to hope would be possible: to see this swarming world rendered in Norwegian. For that, he deserves at least my heartfelt gratitude (Jensen 558, my trans.).

It is clear that Paradiso was important to Jensen, and he was personally invested in a Norwegian translation of the work. The French translation (already published in 1971) allowed him access to a work he could not read in its original language, and thus laid the grounds for the future mediation of Lezama in Norway. 
Among the nine works under scrutiny in the present study, the Lezama translation is the only one for which rights were acquired from the aforementioned Cuban state literary agency, the ALL. Unfortunately, potential documentation of this contact was lost from Pax' archives in $2011^{4}$. However, the sum of available information about this translation indicates that the rights arrangements were a formality and that the ALL did not play any significant role in the Norwegian selection of Paradiso. From the Norwegian side, the novel was purchased by the Arts Council Norway (in other words, it received funding through the purchasing scheme for translated literature).

Pax chose to commission the translation of Paradiso from Kjell Risvik (b. 1941), one of Norway's most renowned and experienced translators. Risvik has translated widely from Spanish, but also from Portuguese, Catalan, Italian, French, German, English, and Hebrew (Lomheim)-often together with his wife, translator Kari Risvik. Separately or together, they have received important Norwegian literary prizes, such as the Norwegian Association of Literary Translators' Bastian Prize in 1975, the Norwegian Ministry of Culture's prize for literary translation in 1985, and The Brage Prize Honorary Award in 2006. By 2001, the couple reported having translated around 400 titles ("Med andre ord"), including major works by Gabriel García Márquez, Jorge Luis Borges, Mario Vargas Llosa, and other writers from the so-called Latin American boom. Kjell Risvik reports that he tried to initiate translations of central Cuban writers such as Guillermo Cabrera Infante, Heberto Padilla, Severo Sarduy, and Reinaldo Arenas $^{5}$, but none of these writers had been translated into Norwegian at the time this article was written. This demonstrates how publishers are the final gatekeepers of selection-even suggestions from highly respected translators and literary specialists might not be taken into account.

\section{The agency of Tove Bakke. Loynaz, Piñera and Escobar}

Translator Tove Bakke (b. 1954) stands out as a particularly active and enthusiastic mediator of Cuban literature in Norway. Her translation of a selection of Dulce María Loynaz's poetry was published in 1999 by Cappelen, a traditional publishing house that was Norway's third largest at the time ("Cappelen Damms historie”). Bakke was still in her early translation career. "One of her

4 Nordseth, Linn Kristin. “SV: Arkivspørsmål.” Received by Idun Heir Senstad, 14 Aug. 2018. 5 Risvik, Kjell. “SV: Oversettelser fra Cuba.” Received by Idun Heir Senstad, 29 July 2018. 
collections incidentally ended up on my table without me having any particular interest in either Cuba or Cuban poetry," Bakke wrote in the translation's epilogue (85, my trans.). In the interview, she added that this collection was actually a Spanish-English bilingual edition, which Sigurd Allern-a friend and a known Norwegian politician and academic who did not read or speak Spanish-had picked up while traveling in $\mathrm{Cuba}^{6}$. Bakke wrote, "The poems were written on the other side of the world, and mostly before my time, but I was immediately taken by them" (85, my trans.). She was already involved in another poetry translation for Cappelen and suggested to them that she could translate selected poems by Loynaz instead. The publisher agreed.

Bakke later travelled to Cuba on numerous occasions, often to attend the yearly Havana International Book Fair, which is organized by the Cuban state and is relatively disconnected from the international publishing industry. Her first trip was in 1999, at a time characterized by a renewed interest in Cuban literature (the "Cuban boom"), and the island attracted editors and cultural producers from all over the world who wanted to discover literary and artistic talent. Bakke originally wanted to create a varied collection of Cuban contemporary poetry, modeled upon an Austrian-Cuban bilingual volume from 1998 (Bakke 141). In Cuba, Bakke sought advice from "all the book people” (141, my trans.) she met and finally decided on two (not contemporary) poets: Ángel Escobar (1957-1997) and Virgilio Piñera (1912-1979). Piñera became particularly important to the translator. The now well-known Cuban poet and writer was marginalized during his life because of his homosexuality and critical attitudes towards the development of the Cuban revolutionary project. In Cuba, Bakke developed close relationships with important figures who formed part of both Escobar and Piñera's social circles. These experiences resulted in the translation of selected poems in the collection To cubanske: Virgilio Piñera og Ángel Escobar $i$ utval (Samlaget, 2001). Later she translated a selection of Virgilio Piñera's short stories, entitled Kaldt fortalt in Norwegian (Samlaget, 2004). Both translations are accompanied by Bakke's personalized essays-an epilogue in To cubanske and a preface in Kaldt fortalt-where she presents the authors and her own work with the selection and translation. It is telling of Bakke's enthusiasm and involvement that she personally negotiated the translation rights directly with Piñera's heirs in Cuba. In subsequent travels to the island, she brought the royalties-in cash-that accrued to the heirs of both Piñera and Dulce María Loynaz.

6 Unless otherwise stated, the source of information in this section is Bakke, Tove. Personal interview. 24 Feb. 2016. 
Bakke translated her first book in 1977. She translates widely from mainly Spanish and French (Lauritsen), and is a member of the Norwegian Association of Literary Translators. In 2003 she was awarded the association's annual Bastian Prize, and in 2008 she received Samlagetprisen, the annual prize awarded by the publisher Samlaget. Bakke writes and translates into Nynorsk, one of the two official written variants of Norwegian, which is presumed to be employed by $10-15 \%$ of the population (Vikør and Jahr). Samlaget is a small publisher and the only one that exclusively publishes books in Nynorsk. Other Norwegian publishers usually prefer translations into Bokmål, the more common written variant of Norwegian, but they sometimes accept poetry translations into Nynorsk. Nynorsk is often regarded as more "poetic" than Bokmål, but another important reason why many publishers accept poetry translations into Nynorsk is that poetry translations are considered original works by the Arts Council Norway, and they are funded through the purchasing scheme for new Norwegian literature, rather than through the scheme for translated literature. There is one important difference between the two schemes: whereas the scheme for translated literature has a fixed budget and supports a limited number of titles each year, the scheme for new Norwegian literature is a so-called "automatic" scheme, based uniquely on quality criteria". This scheme funds more titles, and it is generally much easier for the publisher to predict if a particular title will be included in the purchasing scheme for new Norwegian literature than in the scheme for translated literature. A translation of a work by a recognized poet done by a recognized translator will most likely receive funding, which makes it easier for the publishing houses to commission these types of translations (even though most poetry translations will have minimal sales in the general market).

Bakke's two poetry translations, the collection of poems by Dulce María Loynaz in 1999 and by Ángel Escobar and Virgilio Piñera in 2001, were both purchased through the scheme for new Norwegian literature ${ }^{8}$. Piñera's short story collection Kaldt fortalt (Samlaget, 2004) was funded through the scheme for translated literature (Årsmelding 2003 47). Bakke reports that she worked

7 Publishers apply for funding, deliver the given number of copies of the title in question, and usually get their payment from the Arts Council prior to the work of the evaluation committee. If the evaluation committee do not consider the title to be of sufficient quality, the publisher should return the payment (but the Arts Council keeps the books).

8 Information on the title by Dulce María Loynaz in Årsmelding 1999 48. Note: Listed with the title Ei øy på ei øy. Information on the title by Escobar and Piñera in Fossanger, Hilde Fjærtoft. “SV: Opplysninger til forskningsprosjekt.” Received by Idun Heir Senstad, 23 Nov. 2018. 
extensively with various Norwegian publishers to carry out Norwegian translations of more Cuban prose, such as novels by the contemporary writers Ena Lucía Portela, Wendy Guerra, and Leonardo Padura. According to Bakke, the fact that she translates into Nynorsk meant that these initiatives were unsuccessful ${ }^{9}$.

\section{Näumann's translations of Guerra and Padura}

Kari Näumann (b. 1928) ended up translating novels by two of the writers that Bakke initially worked towards translating, namely Wendy Guerra and Leonardo Padura. Like Bakke, Näumann is a member of The Norwegian Association of Literary Translators. Her translator career started relatively late in life, as she started learning Spanish in her fifties ${ }^{10}$. Näumann's first translation came in 1993, an anthology of Spanish Golden Age poetry. Later she published acclaimed translations of Spanish classics such as Tirso de Molina, Pedro Calderón de la Barca, Lope de Vega, and Federico García Lorca. The first Cuban title, Guerra's Todos se van (Bruguera, 2006), was published in Norwegian (Bokmål) as Alle drar sin vei in 2011 through Bokvennen, a small independent publisher. Näumann travelled to Cuba on various occasions; her first trip was in 2002. She often encountered Tove Bakke in Havana, Näumann reports. During one of their stays in Cuba, the two translators went to visit a Norwegian literary scholar who lived in Havana at the time, Hans Jacob Ohldieck (who now holds a PhD with a thesis on José Lezama Lima and another classic author of Cuban literature, Severo Sarduy). Näumann recalls that she spotted Guerra's novel at Ohldieck's home. He warmly recommended the novel, and since Näumann was looking for a new translation project, she suggested the book to Bokvennen, the Norwegian publisher with which she had worked the most. "I believe that more or less everything that I have translated, I have suggested myself to the publisher," Näumann explained in the interview. Later she suggested Nunca fui primera dama (Bruguera, 2008), which was published in Näumann's translation in 2012. The Arts Council Norway supported both these novels through the purchasing

\footnotetext{
9 Parallel to building her translation career, Bakke worked part-time in administration at the Arts Council Norway (1995-2008). This means that she was particularly well informed about the possibilities for translation funding through the purchasing scheme. She would, however, not handle funding applications that she was involved in herself.

10 Unless otherwise stated, the source of information in this section is Näumann, Kari. Personal interview. 16 June 2015.
} 
scheme for translated literature ${ }^{11}$. Näumann also considered Guerra's subsequent novel, entitled Negra (Anagrama, 2014), but concluded that this novel would be too complicated to translate because of the centrality of the Spanish word "negra" (black, referring to race) in the narrative ${ }^{12}$.

After finishing the Guerra novels, Näumann again turned to Hans Jacob Ohldieck for advice on possible Cuban titles to translate. He suggested various writers, and Näumann chose to proceed with Leonardo Padura, probably the best-known contemporary Cuban writer today. Padura's most famous works are the four crime novels in the so-called "Havana Quartet," originally published in the 1990s in Cuba and later picked up by the Spanish publisher Tusquets, which published Máscaras, originally the third book in the series, in 1997. A miniseries based on the novels premiered on Netflix in 2016. Näumann translated all four novels for Bokvennen ${ }^{13}$. The novels did not receive the expected funding through the purchasing scheme for translated literature. This postponed the publication dates for the books.

What emerges from the above accounts is a multiple mediatorship that made the Norwegian translations of Wendy Guerra and Leonardo Padura possible. Näumann suggested the writers and their novels to the publisher; these suggestions, coming from an experienced and trusted translator with whom they had previously worked, were accepted. Both Bakke and Ohldieck are, however, co-mediators of these novels. In Norwegian translation circles, Bakke is known for her long-running engagement with Cuba and Cuban literature, and Näumann and/or the publisher most likely knew about Bakke's prior attempts to suggest Guerra and Padura to Norwegian publishers. Ohldieck, in addition to suggesting the writers to Näumann, is also the author of an epilogue printed in Alle drar sin vei (Ohldieck), in the form of a personal essay constructed around Ohldieck's own email correspondence with Wendy Guerra. In the essay, Ohldieck analyses Guerra's authorship and draws lines to central, but often marginalized, Cuban writers, such as Leonardo Padura, Dulce María Loynaz and José Lezama Lima, and the contemporary Pedro Juan Gutiérrez.

11 Both translations' colophon pages state "Innkjøpt av Norsk Kulturråd” (Purchased by Arts Council Norway).

12 A fourth Guerra novel, Revolusjonssøndag (orig. Domingo de Revolución, Anagrama, 2016), was published by Bokvennen in Näumann's translation in 2017.

13 Only two of the translations, Vinter i Havana (2012) and Storm i Havana (2014) appear in the material of the present investigation. The translation of the third novel in the series, Maskespill i Havana, came in 2015 (orig. Máscaras, Tusquets 1997). The fourth and last translation, of Paisaje de otoño (Tusquets 1998), had not yet been published at the time this article was written. 


\section{The multiple mediatorship behind Gutiérrez's Trilogía sucia de La Habana}

The Norwegian translation of Gutiérrez's Trilogía sucia de La Habana (Anagrama, 1998) was published in 2005, by the large, traditional publishing house Gyldendal. The translator, Hege Hammer, described the novel as "the apple of her eye"-the one translation that she initiated herself and that also brought her many new experiences $^{14}$. In 2005, Hammer had translated 12 fictional works from Spanish and English, and she was a member of the Norwegian Association of Literary Translators. Her first reading of Gutiérrez's work occurred because her mother gave her one of his books as a gift. Soon after, she talked to the publishing house, which agreed to commission two reader's reports-one for Trilogía sucia de La Habana, and another for a second Gutiérrez novel, El rey de La Habana. Hammer wrote the reports, and recommended Trilogía. The translation eventually came out in 2005; Hammer had, however, already signed the contract with the publisher in 2002, at a time when there were still few translations of Trilogía available. Hammer explained that prior to the agreement with the publisher, she had travelled to Cuba together with Tove Bakke and the Norwegian writer Ragnar Hovland to attend the Havana book fair. Bente Lodgaard-a manuscript editor at Gyldendal at the time, who was later the corresponding editor for Hammer's translationalso attended the book fair. Lodgaard has extensive knowledge of the Spanish language and the Hispanic world, and she is now a translator from Spanish and English and a member of the Norwegian Association of Literary Translators. Another editor who worked at Gyldendal at the time recalls that various persons from the "Spanish translation environment" were particularly enthusiastic about the novel, and that "they" advocated for this novel over a period of time ${ }^{15}$. In sum, all this clearly testifies to a multiple mediatorship in which the translator played a central role and which involved other actors and partial overlaps with the multiple mediatorship described for the Guerra and Padura translations.

\section{Discussion of the independent cultural mediators' agency}

The independent cultural mediators that worked with Cuban literature between 1990 and 2014 were all agents with considerable symbolic capital in the

14 Unless otherwise stated, the source of information in this section is Hammer, Hege. Personal interview. 18 June 2015.

15 Anonymous. Personal interview. 23 March 2017. 
Norwegian literary field. All the translators were widely experienced and had been recognized for their work through important Norwegian literary prizes (Risvik, Bakke) or by membership in the Norwegian Association of Literary Translators (Bakke, Näumann, Hammer). Apart from the translators-who in the cases of Bakke, Näumann and Hammer assumed mediating roles far beyond the textual translation activity-the other two most central cultural mediators were Kjell Olaf Jensen and Hans Jacob Ohldieck. Both had favorable positions in the field: Jensen was a well-known literary critic and translator from French and German, and Ohldieck was an academic who specialized in Cuban literature. Even agents who had a minor (or even coincidental) role in the selection of these works-such as the academic who happened to bring back Dulce María Loynaz' poetry from a vacation in Cuba, or the Spanish-speaking manuscript editor who was part of the multiple mediatorship behind Pedro Juan Gutiérrez' book-held some level of symbolic capital in the Norwegian literary field.

Most agents in the multiple mediatorships operating in the selection processes pertaining to the different Cuban works were Spanish-language specialists and experts (or aspiring experts) on Cuban literature or culture. Most of them travelled repeatedly to Cuba, and two of the translators (Bakke and Näumann) reported having discovered the writers that they finally translated on trips to Cuba. The case of Guerra's Todos se van, which caught Näumann's attention while visiting Hans Jacob Ohldieck in Havana, is particularly intriguing. Even though Guerra lives and writes in Cuba, the majority of her work has not been published there. Todos se van was published in Spain by Bruguera in 2006, and it is not generally available in Cuban bookstores, since the state is the only actor authorized to publish and sell new books. Ohldieck must have brought the book to Cuba, a fact that adds an extra layer to the analysis and certainly problematizes the idea that literature can travel directly between peripheries.

That said, an important result of this analysis is that the nine Cuban works selected by independent cultural mediators are either canonized classics of 20th century Cuban literature (Lezama Lima, Loynaz, Piñera, and Escobar), or internationally recognized works by contemporary Cuban writers based in Cuba (Guerra, Padura, and Gutiérrez). Cuban-American writers (writing in English) or other Cuban writers that permanently reside outside of Cuba (often writing in Spanish) dominated the selection of Cuban works in Norway throughout the years 1990-2014, however none of these diaspora works were selected or otherwise advocated for by independent cultural mediators. Instead, the selection of these works was embedded in central structures of the international translation market (Senstad, "Norwegian Publishers' Views"). This example of Cuban literature in Norway demonstrate how the dominant mechanisms that govern the international literary trade favor central literatures over peripheral ones: the diaspora 
writers' geographical and cultural proximity to centers of the international publishing industry clearly facilitated their wider circulation. In light of this, the activities of the independent cultural mediators that are the focus of the present article gain an ethical dimension; their agency emerges as essential for the inclusion of non-diaspora Cuban writers within Norwegian translated literature.

Six of the nine translations were funded by the Arts Council Norway through the purchasing scheme for literature. This funding economically benefits both the involved publisher and the translator, and thus directly supported the work of the independent cultural mediators in this study. The funding is explicitly aimed at supporting literary diversity, and it is clear that this strong state funding program provided favorable conditions for the translation of Cuban literature throughout the studied period (1990-2014).

\section{Agency in context-consecration mechanisms at play}

The Norwegian translation and publication of the nine works in question were the result of independent cultural mediators' personal initiative and interest, and individual tastes and preferences played important roles. However, such con amore projects are also embedded within the power relations of the international literary field. All the writers and the works enjoyed some level of regional and international consecration prior to the Norwegian translation-publication by Spanish publishing houses, literary prizes, translations, academic scholarship, etc. Even if the cultural mediators themselves did not always recognize this as a direct influence on their choices, a closer look at the circulation patterns of the writers and works demonstrate that Hispanic and Anglo-American consecration was a precondition of the translation of classic and contemporary Cuban literature into Norwegian (see Table 2).

Table 2 shows that editions of all the translated works-possibly with the exception of Escobar's work, and Piñera's Cuentos frios-had been published in Spain prior to the Norwegian translations. In itself, this is indicative of consecration in the Hispanic world, since Spanish publishers market their books in Spain and elsewhere in the Spanish-speaking world (but not in Cuba). Several of the writers had also received important Spanish-language literary prizes.

English translations of most of the works were also available prior to the Norwegian translations. The exceptions are Dulce Maria Loynaz and Virgilio Piñera, for whom important English translations were published after the Norwegian translation. Another exception is Wendy Guerra; the Norwegian translation of Todos se van was published in 2011, and the English translation 
Table 2: Cuban Writers in Norwegian Translation (1990-2014): Examples of Consecration in the Hispanic and Anglo-American Fields.

\begin{tabular}{|c|c|c|c|}
\hline $\begin{array}{l}\text { Year of } \\
\text { Norwegian } \\
\text { translation }\end{array}$ & Author & $\begin{array}{l}\text { Consecration examples: } \\
\text { Hispanic world }\end{array}$ & $\begin{array}{l}\text { Consecration examples: } \\
\text { Anglo-American }\end{array}$ \\
\hline 1999 & $\begin{array}{l}\text { Dulce María } \\
\text { Loynaz }\end{array}$ & $\begin{array}{l}\text { Most of her poetry collections } \\
\text { were published in Spain in the } \\
1940 \text { s and 1950s (Behar): } \\
\text { Juegos de agua. Madrid, Editora } \\
\text { Nacional, } 1947 . \\
\text { Poemas sin nombre, Madrid, } \\
\text { Aguilar, } 1953 . \\
\text { Premio Cervantes, } 1992 .\end{array}$ & $\begin{array}{l}\text { The poet caught the attention of } \\
\text { the Norwegian translator Tove } \\
\text { Bakke through a bilingual edition } \\
\text { (English-Spanish), probably: } \\
\text { Poems Without Name. Trans. } \\
\text { Harriet de Onís, Havana, Editorial } \\
\text { José Martí, } 1993 \text { (translated in } \\
\text { 1958). } \\
\text { Later poetry collections include } \\
\text { Dulce María Loynaz: A Woman in } \\
\text { Her Garden. Trans. Judith } \\
\text { Kerman, Buffalo, NY, White Pine } \\
\text { Press, } 2002 \text {. } \\
\text { Absolute Solitude. Trans. James } \\
\text { O’Connor, Brooklyn, NY, } \\
\text { Archipelago books, } 2016 .\end{array}$ \\
\hline $\begin{array}{l}2001 \\
2004\end{array}$ & $\begin{array}{l}\text { Virgilio } \\
\text { Piñera and } \\
\text { Ángel } \\
\text { Escobar } \\
\text { Virgilio } \\
\text { Piñera }\end{array}$ & $\begin{array}{l}\text { Virgilio Piñera. La isla en peso. } \\
\text { Barcelona, Tusquets, } 2000 . \\
\text { Cuentos fríos. Buenos Aires, } \\
\text { Losada, } 1956 .\end{array}$ & $\begin{array}{l}\text { Sporadic translations of single } \\
\text { poems. } \\
\text { The Weight of the Island: } \\
\text { Selected Poems of Virgilio } \\
\text { Piñera. Trans. Pablo Medina, } \\
\text { Diálogos, } 2014 . \\
\text { Cold Tales. Trans. Mark Schafer, } \\
\text { Hygiene, Colorado, Eridanos } \\
\text { Press, } 1988 .\end{array}$ \\
\hline 2002 & $\begin{array}{l}\text { José } \\
\text { Lezama } \\
\text { Lima }\end{array}$ & $\begin{array}{l}\text { Paradiso. Mexico, Ediciones } \\
\text { Era, } 1968 . \\
\text { Paradiso. Madrid, Ediciones } \\
\text { Cátedra, } 1980 .\end{array}$ & $\begin{array}{l}\text { Paradiso. } 1974 . \text { Trans. Gregory } \\
\text { Rabassa, New York, Farrar, } \\
\text { Strauss \& Giroux, } 2000 .\end{array}$ \\
\hline 2005 & $\begin{array}{l}\text { Pedro Juan } \\
\text { Gutiérrez }\end{array}$ & $\begin{array}{l}\text { Trilogía sucia de La Habana. } \\
\text { Barcelona, Anagrama, } 1998 . \\
\text { Subsequent books published by } \\
\text { Anagrama. } \\
\text { Premio Alfonso García-Ramos } \\
\text { de Novela, } 2000 . \\
\text { Premio Narrativa Sur del } \\
\text { Mundo, } 2003 .\end{array}$ & $\begin{array}{l}\text { Dirty Havana Trilogy. Trans. } \\
\text { Natasha Wimmer. London, Faber } \\
\text { and Faber, } 2001 .\end{array}$ \\
\hline
\end{tabular}


Table 2 (continued)

\begin{tabular}{|c|c|c|c|}
\hline $\begin{array}{l}\text { Year of } \\
\text { Norwegian } \\
\text { translation }\end{array}$ & Author & $\begin{array}{l}\text { Consecration examples: } \\
\text { Hispanic world }\end{array}$ & $\begin{array}{l}\text { Consecration examples: } \\
\text { Anglo-American }\end{array}$ \\
\hline $\begin{array}{l}2011 \\
2012\end{array}$ & $\begin{array}{l}\text { Wendy } \\
\text { Guerra }\end{array}$ & $\begin{array}{l}\text { Todos se van. Barcelona, } \\
\text { Bruguera, } 2006 . \\
\text { Nunca fui primera dama. } \\
\text { Barcelona, Bruguera, } 2008 . \\
\text { Subsequent books published by } \\
\text { Anagrama (Barcelona) and } \\
\text { Alfaguara (Barcelona). } \\
\text { Premio Bruguera (2006). }\end{array}$ & $\begin{array}{l}\text { Everyone leaves. Trans. Achy } \\
\text { Obejas, AmazonCrossing, } 2012 .\end{array}$ \\
\hline $\begin{array}{l}2012 \\
2014\end{array}$ & $\begin{array}{l}\text { Leonardo } \\
\text { Padura }\end{array}$ & $\begin{array}{l}\text { Máscaras. Barcelona, Tusquets, } \\
1997 . \\
\text { Subsequent books published by } \\
\text { Tusquets. } \\
\text { Several prizes, for example } \\
\text { Premio Hammett, } 2006 . \\
\text { Premio Princesa de Asturias de } \\
\text { las Letras, } 2015 \text {. }\end{array}$ & $\begin{array}{l}\text { Havana Blue. Trans. Peter Bush, } \\
\text { London, Bitter Lemon Press, } \\
2007 . \\
\text { Havana Gold. Trans. Peter Bush, } \\
\text { London, Bitter Lemon Press, } \\
2008 .\end{array}$ \\
\hline
\end{tabular}

was published in 2012. The second novel, Nunca fui primera dama, has not yet been translated into English.

Despite these exceptions, the data presented in the table largely confirm the double consecration hypothesis (Lindqvist, "Bibliomigrationsmönster," "Dubbel konsekration"): the writers and works enjoyed some level of consecration both in the Hispanic and Anglo-American fields prior to the Norwegian translations. It is complicated to evaluate the extent to which this directly influenced the independent cultural mediators' work. However, it is interesting to note that none of the interviewed translators reported that the English translation was a factor in their selection processes. At least two of the mediators were directly inspired by prior translations into languages other than English: an Austrian poetry collection inspired Bakke's translations of Piñera and Escobar's poetry, and the French translation of Paradiso caused Jensen's interest in Lezama Lima. Such instances demonstrate how micro-perspectives serve to lend nuance to macro-perspectives on how literature travels, and they highlight the complexities of literary circulation.

The arguments presented in this article largely dispute the idea of Swedish consecration as a necessary precondition for Norwegian translations of Spanish Caribbean literature, and thus they contradict the claim regarding the centrality 
of Swedish made by Lindqvist ("The Scandinavian”). To test Lindqvist's hypothesis of Sweden as a center for Scandinavian literary translation, I performed searches in the online database världslitteratur.se (Sweden's most complete thematic overview of literary translations from Africa, Asia and Latin America) ${ }^{16}$ and in the National Library of Sweden's online database (www.libris.kb.se) (conducted 1 November 2018). The results are presented below (Table 3).

Table 3: Cuban Writers in Norwegian Translation (1990-2014): Status in Sweden.

\begin{tabular}{|c|c|c|c|}
\hline Author & $\begin{array}{l}\text { Norwegian } \\
\text { title(s), } \\
\text { Year of } \\
\text { translation(s) }\end{array}$ & www.varldslitteratur.se & $\begin{array}{l}\text { National Library of } \\
\text { Sweden } \\
\text { (www.libris.kb.se): } \\
\text { Books in Sweden by } \\
\text { the writer }\end{array}$ \\
\hline $\begin{array}{l}\text { Dulce María } \\
\text { Loynaz }\end{array}$ & Svart vin, 1999 & $\begin{array}{l}\text { Entry on Dulce María Loynaz, } \\
\text { but no translations. }\end{array}$ & None \\
\hline $\begin{array}{l}\text { Virgilio Piñera } \\
\text { and Ángel } \\
\text { Escobar } \\
\text { Virgilio Piñera }\end{array}$ & $\begin{array}{l}\text { To cubanske, } 2001 \\
\text { Kaldt fortalt, } 2004\end{array}$ & $\begin{array}{l}\text { No entries on Piñera and } \\
\text { Escobar in varldslitteratur.se }\end{array}$ & $\begin{array}{l}\text { None } \\
\text { None }\end{array}$ \\
\hline José Lezama Lima & Paradiso, 2002 & $\begin{array}{l}\text { Entry on Lezama Lima, but no } \\
\text { translations. }\end{array}$ & $\begin{array}{l}\text { Poems included in an } \\
\text { anthology: } \\
\text { Kubas poeter } \\
\text { drömmer inte mer, } \\
1969\end{array}$ \\
\hline $\begin{array}{l}\text { Pedro Juan } \\
\text { Gutiérrez }\end{array}$ & $\begin{array}{l}\text { Den skitne } \\
\text { Havanna-trilogien, } \\
2005\end{array}$ & $\begin{array}{l}\text { Entry on Gutiérrez. One } \\
\text { translation. } \\
\text { Dirty Havanna-Havanna- } \\
\text { trilogin, } 2010\end{array}$ & $\begin{array}{l}\text { Dirty Havanna- } \\
\text { Havanna-trilogin, } \\
2010\end{array}$ \\
\hline Wendy Guerra & $\begin{array}{l}\text { Alle drar sin vei, } \\
2011 \\
\text { Jeg var aldri } \\
\text { førstedame, } 2012\end{array}$ & $\begin{array}{l}\text { Entry on Wendy Guerra. One } \\
\text { book translation. } \\
\text { Alla ger sig av, } 2012\end{array}$ & Alla ger sig av, 2012 \\
\hline Leonardo Padura & $\begin{array}{l}\text { Vinter i Havana, } \\
2012 \\
\text { Storm i Havana, } \\
2014\end{array}$ & $\begin{array}{l}\text { No entry on Padura in } \\
\text { varldslitteratur.se }\end{array}$ & None \\
\hline
\end{tabular}

16 Lindqvist ("Bibliomigrationsmönster") uses the same database to confirm the double consecration hypothesis for Spanish Caribbean-mostly Cuban-literature translated into Swedish between 1990 and 2015. This study does not explore Sweden as a Scandinavian center. 
Table 3 demonstrates that none of the nine works were published in Swedish at the time of publication of the Norwegian translation. Two works were later published in Swedish, Gutiérrez' Trilogía sucia de La Habana and Guerra's Todos se van. There are entries on Dulce María Loynaz and Lezama Lima in världslitteratur.se, but no listed translations. Piñera, Escobar and Padura do not have entries in the database. The National Library's catalogue confirms that there are no Swedish translations of any works by these writers, except the inclusion of poems by Lezama Lima in an anthology from 1969.

\section{Concluding remarks}

An important finding of this study is that the studied independent cultural mediators advocated for canonized $20^{\text {th }}$-century Cuban literature or works by contemporary Cuban writers based in Cuba, originally written in Spanish. In doing so, they significantly contributed to a diverse representation of Cuban literature in Norway, since the Cuban fictional works that entered Norway through the publishers' established networks were written mostly in English by Cuban diaspora writers.

The independent mediators enacted their agency in and through alternative networks, which kept their distance from the central networks of publishing professionals (such as literary scouts and literary agents) and the workings of the international translation market. In a sense, they were smugglers (RoigSanz and Meylaerts) who created their own information sources and selection principles. These mediators of the Cuban works were motivated and driven by a personal interest in Spanish and/or Cuban literature, and in the case of the translators, a personal interest combined with the prospect of work. The Arts Council Norway provided funding for six of the nine translations, which makes it an important facilitator of Norwegian translations of Cuban literature throughout the studied period.

The survey of the nine works' regional and international consecration clearly demonstrated how close attention to particular bodies of works can lend nuance to macro-perspectives on literary circulation. The independent cultural mediators' choices were most likely influenced by Hispanic and Anglo-American consecration of the writers and works, but the link is not always very clear, and translations into other languages also inspired some of the agents. The survey furthermore questions the idea of Sweden as a consecrating center for translation in Scandinavia, since none of the nine works were published in Swedish prior to the Norwegian translation. 
In more general terms, the results of the present study highlight how the agency of independent cultural mediators may be vital to promoting literary voices from the Global South. Many peripheral literatures fall beneath the radar of the international translation market's central mechanisms, and the work of invested cultural mediators can provide an alternative means of selection for translation. The absence of a coherent strategy for international literary promotion and state funding from the source culture is, for example, not unique to Cuba-other peripheral literatures from the Global South face similar problems. Uneven power structures between countries and cultures favor some literatures over others in the international marketplace, and in this landscape, cultural mediators such as the ones studied in the present article can assume key roles as promoters of literary diversity.

\section{Works Cited}

Alvstad, Cecilia et al. (eds.). Textual and Contextual Voices of Translation. John Benjamins, 2017.

Bakke, Tove. “Etterord.” Svart vin. Dulce María Loynaz. Trans. Tove Bakke. Cappelen, 1999, pp. 83-91.

--.. "Etterord." To cubanske. Virgilio Piñera og Ángel Escobar i utval. Virgilio Piñera and Ángel Escobar. Trans. Tove Bakke. Samlaget, 2001, pp. 140-163.

Behar, Ruth. "Dulce Maria Loynaz: A Woman Who No Longer Exists.” Michigan Quarterly Review, vol. 36, no. 4, 1997, http://hdl.handle.net/2027/spo.act2080.0036.401, last visit 10/01/19.

Bourdieu, Pierre. "A Conservative Revolution in Publishing." Translation Studies, vol. 1, no. 2, 2008, pp. 123-153.

Bourdieu, Pierre. The Rules of Art: Genesis and Structure of the Literary Field. Trans. Susan Emanuel, Polity Press, 1996.

Bourdieu, Pierre. The Field of Cultural Production: Essays on Art and Literature. Ed. Randal Johnson. Polity Press, 1993.

Buendia, Carmen Toledano. "Listening to the Voice of the Translator: A Description of Translator's Notes as Paratextual Elements.” Translation \& Interpreting, vol. 5, no. 2, 2013, pp. 149-162.

“Cappelen Damms historie." Cappelen Damm. www.cappelendamm.no/cappelendamm/omforlaget/article.action?contentld=39309, last visit 25/11/18.

Casanova, Pascale. "Literature as a World." New Left Review, no. 31, 2005, pp. 71-90.

--.. The World Republic of Letters. Trans. M.B. DeBevoise. Harvard University Press, 2004.

Dimitriu, Rodica. “Translators' Prefaces as Documentary Sources for Translation Studies." Perspectives, vol. 17, no. 3, 2009, pp. 193-206.

Franssen, Thomas and Giselinde Kuipers. "Coping with Uncertainty, Abundance and Strife: Decision-Making Processes of Dutch Acquisition Editors in the Global Market for Translations." Poetics, vol. 41, no. 1, 2013, pp. 48-74.

Gutiérrez, Pedro Juan. Diálogo con mi sombra. Ediciones Unión, 2015. 
--. Todo sobre Pedro Juan. www.pedrojuangutierrez.com, last visit 20/10/18.

Hacohen, Ran. "Literary Transfer between Peripheral Languages: A Production of Culture Perspective.” Meta, vol. 59, no. 2, 2014, pp. 297-309.

Heilbron, Johan. "Towards a Sociology of Translation: Book Translations as a Cultural WorldSystem." European Journal of Social Theory, vol. 2, no. 4, 1999, pp. 429-444.

Heilbron, Johan and Gisèle Sapiro. "Politics of Translation: How States Shape Cultural Transfers." Literary Translation and Cultural Mediators in 'Peripheral' Cultures. Eds. Diana Roig-Sanz and Reine Meylaerts. Palgrave Macmillan, 2018, pp. 183-208.

Izquierdo, José María. LETRAS. University of Oslo, Oct. 2018. ub-fmserver.uio.no/letras/home. php, last visit 18/10/18.

Jansen, Hanne and Anna Wegener (eds.). Authorial and Editorial Voices in Translation, vol. 1. Éditions québécoises de l'œuvre, 2013.

Jensen, Kjell Olaf. “Etterord.” Paradiso. José Lezama Lima. Trans. Kjell Risvik. Pax, 2002, pp. 555-559.

Kinnunen, Tuija and Kaisa Koskinen, editors. Translators' Agency. Tampere University Press, 2010.

Kulturstatistikk 2000. Statistics Norway, Jan. 2002.

Kulturstatistikk 2016. Statistics Norway, 13 Dec. 2017.

Kumaraswami, Par and Antoni Kapcia. Literary Culture in Cuba: Revolution, Nation-Building and the Book. Manchester University Press, 2012.

Lauritsen, Vibeke. “Tove Bakke.” Allkunne - levande leksikon, 11 Apr. 2018. www.allkunne.no/ framside/biografiar/b/tove-bakke/85/1543/, last visit 10/09/18.

Lindqvist, Yvonne. "Bibliomigrationsmönster från periferi till semiperiferi: Om den samtida spanskkaribiska litteraturen i svensk översättning." Tidskrift för litteraturvetenskap, vol. 1, no. 2, 2018, pp. 90-104.

--.. "Dubbel konsekration-en förutsättning för svensk översättning av utomeuropeisk litteratur? Maryse Condé som exempel." Språk \& stil, vol. 21, 2011, pp. 140-170.

---. "The Scandinavian Literary Translation Field from a Global Point of View. A Peripheral (Sub)Field?" Institutions of World Literature: Writing, Translation, Markets. Eds. Stefan Helgesson and Pieter Vermeulen. Routledge, 2018, pp. 174-187.

Lomheim, Sylfest. "Kjell Risvik." Store norske leksikon, 17 Mar. 2009. www.snl.no/ Kjell_Risvik, last visit 25/09/18.

“Med andre ord." Universitas, 25 Apr. 2001. www.universitas.no/kultur/659/med-andre-ord/, last visit 25/09/18.

Ohldieck, Hans Jacob. “Det hvite arket. Om Wendy Guerra i Havanna.” Alle drar sin vei. Wendy Guerra. Trans. Kari Näumann. Bokvennen, 2011, pp. 269-280.

Roig-Sanz, Diana and Reine Meylaerts. "General Introduction. Literary Translation and Cultural Mediators. Toward an Agent and Process-Oriented Approach." Literary Translation and Cultural Mediators in 'Peripheral' Cultures. Customs Officers or Smugglers? Eds. Diana Roig-Sanz and Reine Meylaerts. Palgrave Macmillan, 2018, pp. 1-37.

Schwartz, Cecilia. "From Nuoro to Nobel: The Impact of Multiple Mediatorship on Grazia Deledda's Movement within the Literary Semi-Periphery." Perspectives, vol. 26, no. 4, 2018, pp. 526-542.

Senstad, Idun Heir. "Bokomslag som formidling. Cubanske romaner i norsk innpakning." Litteratur- og kulturformidling. Nye analyser og perspektiver. Eds. Helge Ridderstrøm and Tonje Vold. Pax, 2015, pp. 166-188. 
-.-. "The Making of a Bestseller-in-Translation. Cecilia Samartin as the Voice of Cuba." Textual and Contextual Voices of Translation. Eds. Cecilia Alvstad et al. John Benjamins, 2017, pp. 61-79.

--.. “Norwegian Publishers' Views on Selecting Peripheral Literature for Translation.” Manuscript in preparation.

Solum, Kristina. "The Tacit Influence of the Copy-Editor in Literary Translation.” Perspectives, vol. 26, no. 4, 2018, pp. 543-559.

-.-. "Translators, Editors, Publishers, and Critics. Multiple Translatorship in the Public Sphere." Textual and Contextual Voices of Translation. Eds. Cecilia Alvstad et al. John Benjamins, 2017, pp. 39-60.

Tahir-Gürcaglar, Sehnaz. "Agency in Allographic Prefaces in Translated Works: An Initial Exploration of the Turkish Context." Authorial and Editorial Voices in Translation 2. Editorial and Publishing Practices. Eds. Hanne Jansen and Anna Wegener. Éditions québécoises de l'œuvre, 2013.

van Es, Nicky and Johan Heilbron. "Fiction from the Periphery: How Dutch Writers Enter the Field of English-Language Literature.” Cultural Sociology, vol. 9, no. 3, 2015, pp. 296-319.

Vikør, Lars, S, and Ernst Håkon Jahr. "Språk i Norge.” Store norske leksikon, 12 Nov. 2018. www.snl.no/språk_i_Norge, last visit 25/09/18.

Whitfield, Esther. Cuban Currency: The Dollar and "Special Period" Fiction. University of Minnesota Press, 2008.

Årsmelding 1999. Arts Council Norway, 1999.

Årsmelding 2003. Arts Council Norway, 2003.

Årsmelding 2013. Arts Council Norway, 2013.

Årsmelding 2014. Arts Council Norway, 2014. 
2 Traducción 



\section{El Aleph de Roger Caillois en Gallimard o de cómo salir del laberinto}

\section{Introducción}

La difusión de la obra de Borges en Francia es un caso paradigmático para analizar los procesos de traducción en el marco de la literatura mundial. En este artículo nos proponemos estudiar el contexto de publicación de los volúmenes Labyrinthes y El Aleph en francés, a partir de la hipótesis de que la operación de traducción y montaje realizada por Caillois modifica la obra de Borges y crea un corpus nuevo, a través del cual su recepción adquiere rasgos específicos: se construye en Francia, y a través de Francia, una obra que difiere de la que encontramos en español.

Fictions en la traducción de Paul Verdevoye y Néstor Ibarra inaugura la colección La Cruz del Sur en 1951, dirigida por Roger Caillois en Gallimard, así como la difusión de la obra de Borges en forma de volumen en lengua francesa; en 1953, el mismo Caillois traduce y publica un conjunto de cuentos de Borges, Labyrinthes. Si el primero retoma el contenido de la versión española de Ficciones según su edición de 1944, el segundo es una construcción realizada por Caillois, y contiene relatos provenientes de El Aleph (1949): "L'immortel", "Histoire du guerrier et de la captive", "L'écriture du Dieu”, "La quête d'Averroès". Labyrinthes tuvo un éxito considerable y fue traducido a varios idiomas (al inglés y al alemán en 1961), por lo que se lo considera una exitosa operación crítica de traducción. Si partimos del principio borgeano que una literatura difiere de otra menos por sus textos que por el modo en que es leída, tal como lo expresa en "Nota sobre (hacia) Bernard Shaw" (192), podemos decir que Labyrinthes pertenece a la literatura francesa y no a la argentina, porque este libro va a adquirir rápidamente el valor de obra autónoma. Recordemos también que Fictions y Labyrinthes son objetos de aspecto diferente: Labyrinthes es un pequeño volumen lujoso, con una tapa particularmente trabajada, y una disposición del texto elegante y espaciada (en-16), mientras Fictions toma la forma de la colección La Croix du Sud, más económica, destinada a una difusión vasta. Una tercera etapa

1 "L’immortel" había sido publicado en La Nouvelle Revue Française, el 1ero de septiembre de 1953.

Annick Louis, CRAL (EHESS-CNRS), Universidad de Reims-CRIMEL

¿ Open Access. (C) 2020 Annick Louis, published by De Gruyter. (cc) BY-NC-ND This work is licensed under a Creative Commons Attribution-NonCommercial-NoDerivatives 4.0 International License.

https://doi.org/10.1515/9783110673678-008 
en la edición francesa de la literatura de Borges es la publicación por Caillois de otro conjunto de textos de Borges en enero de 1957, bajo el título de "Trois labyrinthes", en la revista Preuves ${ }^{2}$, número 71 (38-43), que comprende "La demeure d’Astérion” (proveniente también de El Aleph), "Les précurseurs de Kafka”, "La création et P. H. Gosse” (Otras inquisiciones, 1952) ${ }^{3}$.

El "desmantelamiento" al que Caillois somete el volumen El Aleph ha intrigado a lectores e investigadores. Entre los argumentos que se han propuesto para justificarlo se encuentran el supuesto desinterés de los lectores franceses por la forma cuento; el eclecticismo de la producción de Borges; el intento de aprovechar un cambio en el lectorado, que se produce a comienzos de los años 1950 en Francia, cuando el interés por la literatura testimonial y realista comienza a ceder en favor de la de imaginación. Sin embargo, comprender las razones que llevaron a Caillois a realizar este montaje en vez de publicar El Aleph resulta menos interesante que constatar los efectos del volumen en la cultura francesa e internacional. Por un lado, el libro se volvió esencial al conocimiento de Borges, proponiendo el laberinto como un prisma interpretativo a través del cual será percibida y comprendida su obra. Su otro efecto inesperado fue atrasar la publicación de El Aleph hasta $1967^{4}$, y posicionar esta obra de Borges igualmente bajo el signo del laberinto, puesto que Caillois retoma en este volumen su prefacio a Labyrinthes, con ligeras modificaciones. Recordemos también que cuando se publica la versión francesa, ha habido ya tres ediciones de $E l$ Aleph: la de 1949 en la editorial Losada, la primera; la de 1952 en la misma editorial, en la cual Borges agrega los relatos: “Abenjacán el bojarí, muerto en su laberinto”, "Los dos reyes y los dos laberintos”, "La espera”, "El hombre en el umbral” (y un postfacio); la de Emecé de 1957, en el marco de las primeras Obras completas.

Fuera de los que ya figuraban en Labyrinthes, en L'Aleph, Caillois elige traducir "La casa de Asterión”, “Abenjacán el Bojarí, muerto en su laberinto” e "Historia de los dos reyes y los dos laberintos”, todos cuentos en los que encontramos el

2 Preuves (1951-1969) [1era serie]. Revue mensuelle littéraire et politique. Cahiers mensuels du Congrès pour la liberté de la culture. Sous les auspices du Congrès pour la liberté de la culture, Paris. Dirigida por François Bondy. Se publicaron 220 números.

3 Como lo señala Molloy, el caso de Borges es paradójico porque, contrariamente a otros escritores hispanoamericanos, no hizo nada para ser descubierto y difundido en Francia, y porque sus relaciones con la cultura francesa no son privilegiadas (195).

4 Caillois pide a Victoria Ocampo en una carta cuya datación no es certera que le envíe un ejemplar de El Aleph, Carta de Caillois a Victoria Ocampo, fechada tentativamente el 19 janvier [1953] (Caillois y Ocampo 332). Si la fecha fuera correcta, esto significaría que Caillois no empieza a interesarse en El Aleph sino después de la publicación de Fictions en francés y en el momento en que monta Labyrinthes, lo cual resulta algo sorprendente. 
tema del laberinto (los demás fueron traducidos por René L.-F. Durand). Entre la publicación de Labyrinthes y la de El Aleph se editan varios libros de Borges en francés, se difunde vastamente su obra y se asienta su fama en Francia y en el mundo: Enquêtes 1937-1952 en "La Croix du Sud”, Gallimard en 1957; Histoire de l'infamie. Histoire de l'éternité en 1958; La Bibliothèque de Babel en 1963; L'Auteur et autres textes en "La Croix du Sud", Gallimard en 1965; Manuel de zoologie fantastique en 1965; Discussion también en "La Croix du Sud” en 1966; Essai sur les anciennes littératures germaniques en 1966.

En este trabajo queremos proponer una reflexión sobre las causas y los efectos de la operación mediante la cual, como se ha dicho a menudo, Caillois reescribe a Borges en sus ediciones y traducciones, otorgando una identidad específica a su obra y dejando de lado numerosas facetas de la literatura de Borges, que el público francés conocerá recién gracias a los dos tomos de las Obras completas de La Pléiade publicados en 1993 y 1999. Nos concentramos aquí en la relación entre la fabricación del tema del laberinto como eje de la obra de Borges y la publicación de L'Aleph.

\section{Los laberintos de Roger Caillois}

Si la verdadera difusión de la literatura de Borges en Francia comienza con Fictions $^{5}$, antes de la Segunda Guerra Mundial, es decir, en la época en que Borges es esencialmente poeta y ensayista, y hace sus primeros pasos como narrador, solamente dos textos habían sido publicados gracias a la intervención de Ricardo Güiraldes, Valéry Larbaud y Néstor Ibarra: "Paul Groussac" en La Revue Argentine; "L'approche du caché” en traducción de Néstor Ibarra en Mesures en $1939^{6}$. Durante la guerra, dos relatos se editaron en Argentina en francés, en la revista fundada y dirigida por Roger Caillois, Lettres françaises: “Assyriennes”, "La loterie de Babylone” y "La bibliothèque de Babel”, traducidos y presentados por Néstor Ibarra; luego del retorno de Caillois, varios cuentos aparecen en diferentes revistas, gracias a su iniciativa, lo cual traduce la intención de preparar el terreno para la publicación de los volúmenes: “Les Assyriennes: La loterie

5 Respecto de Caillois, su regreso a Francia y la colección La Croix du Sud, ver Felgine; Río de la Plata 1992.

6 Recordemos la evaluación negativa de Caillois al respecto en una carta dirigida a Paulhan del 26 de julio de 1939, donde, a propósito de "El acercamiento a Almotasim" afirma que Borges no se expresa seriamente (Caillois y Paulhan 118). 
de Babylone; Les ruines circulaires", traducción de Paul Verdevoye, en Confluences en 1946; "Fictions", traducción del mismo Paul Verdevoye en La Licorne en 1947; "Histoire du guerrier et de la captive”, traducción de Roger Caillois, en Cahiers de la Pléiade, en $1949^{7}$. Si el proyecto de crear una colección destinada a difundir la literatura hispano-americana surge rápidamente una vez Caillois está de regreso en Francia (Caillois y Ocampo 226), como hemos podido demostrarlo, no existe una continuidad entre sus proyectos desarrollados en Argentina, y la creación de esta colección, puesto que en la revista Lettres françaises, no encontramos una política de difusión de literaturas traducidas, aunque sí se presenta como el refugio de "la otra Francia”, exilada y censurada bajo la ocupación, identificada con la alta cultura y con valores humanistas (Louis, "Étoiles”, “La traduction”).

La operación cultural realizada por Caillois debe en parte su éxito a los diferentes niveles en que interviene: sus ediciones y traducciones se acompañan de un aparato crítico, una serie de prefacios y ensayos, donde sistematiza su lectura, presentando al laberinto como un tema y como una suerte de "inspiración” común de la obra de Borges. Así, en su "Avertissement” en Labyrinthes afirma: "Le thème du labyrinthe n'y est pas toujours explicitement évoqué. En revanche, plusieurs contes du même recueil, que pourtant je n'ai pas cru devoir retenir, se passent dans des labyrinthes mais ceux-ci ne sont que des décors, c'est-à-dire des labyrinthes réels, où s'égare cette fois le corps, non la pensée du héros" (Labyrinthes 9$)^{8}$. El laberinto se presenta, entonces, como una figura mental, no necesariamente geográfica, y se erige en matriz que permite explicar el funcionamiento de la obra de Borges, integrando géneros y diferentes períodos de su producción; porque los cambios de orientación y de referencias literarias, los desplazamientos genéricos pueden verse como una dificultad a la hora de presentar a Borges, autor cuyo recorrido podía parecer incoherente o, al menos, difícil de comprender. La noción de laberinto como representación del universo, por otro lado, permite la apertura hacia una visión filosófica, metafísica, de la obra de Borges, que se convirtió rápidamente en una suerte de doxa interpretativa: "Le labyrinthe fournit ainsi le constant et naturel symbole de l'intuition fondamentale qui fait l'unité des quatre apologues contenus dans ce petit livre et de nombreux autres textes - prose ou vers- de Jorge Luis Borges”

\footnotetext{
7 "Histoire du guerrier et de la captive", había sido publicado en Cahiers de la Pléiade, en el otoño de 1949, pp. 159-164.

8 "El tema del laberinto no es siempre evocado explícitamente. En cambio, varios cuentos del volumen, que sin embargo no creí bueno retener, se desarrollan en laberintos, pero éstos no son más que un decorado, es decir laberintos reales, donde esta vez se pierde el cuerpo no el pensamiento del héroe".
} 
(Labyrinthes 10; L'Aleph 10) ${ }^{9}$. En la breve introducción que acompaña la publicación de Preuves en 1957, Caillois cita su propio prólogo de Labyrinthes (10-11), afirmando la figura del laberinto como una simetría abstracta que permite una síntesis de lo antinómico (en acuerdo con su visión de América Latina $)^{10}$, y agrega la idea de que esta figura rige también su producción crítica porque, en ella, "Borges apparaît également obsédé par les rapports du fini et de l'infini"11 (38).

Caillois explicará su posición y sus elecciones en el ensayo del número de L'Herne dedicado a Borges (1964), "Les thèmes fondamentaux de Jorge Luis Borges”, donde afirma que el principal "thème-clé” (tema-clave) de su obra es el tiempo circular, y que este "en entraîne deux autres qui en représentent comme les projections dans les domaines de l'espace et de la causalité : celui du labyrinthe et celui de la création recurrente" (Labyrinthes 211) ${ }^{12}$. A partir de ahí, da una explicación de lo que llama "l'arrière-plan métaphysique de l'univers de Jorge Luis Borges” (Labyrinthes 214) ${ }^{13}$ :

Borges se trouva contraint de faire correspondre à la durée circulaire une étendue également circulaire. Ce fut le labyrinthe, lequel acquit chez lui une valeur obsédante. Réel ou métaphorique, matériel, moral ou intellectuel, il procure le lieu privilégié de nombreux récits, non seulement de ceux que j'ai réunis et traduits sous ce titre même de Labyrinthes, mais encore de La demeure d'Astérion, d'Abenhakan el Bokhari mort dans son labyrinthe, et d'autres. La loterie de Babylone, La bibliothèque de Babel, sont, à leur manière, des labyrinthes, et naturellement aussi Le jardin aux sentiers qui bifurquent. (Labyrinthes 214) ${ }^{14}$

Notemos la curiosa expresión "se encontró obligado" que atribuye una intención autorial a Borges que en verdad responde a la interpretación del crítico, y

9 "El laberinto provee así el símbolo constante y natural de la intuición fundamental que hace la unidad de los cuatro apólogos contenidos en ese pequeño libro y numerosos otros textos -en prosa o en verso- de Jorge Luis Borges".

10 Tal como lo afirma en su "Poètes d'Amérique. Note".

11 "Borges aparece también obsesionado por las relaciones de lo finito y lo infinito".

12 "arrastra dos otros que representan como las proyecciones en los dominios del espacio y de la causalidad: el del laberinto y el de la creación recurrente".

13 "el trasfondo metafísico del universo de Jorge Luis Borges".

14 "Borges se encontró entonces en la obligación de hacer corresponder a la duración circular una extensión también circular. Fue el laberinto, que adquirió en él un valor obsesivo. Real o metafórico, material, moral o intelectual, procura el espacio privilegiado de numerosos relatos, no solamente de los que he reunido y traducido bajo este título mismo de Labyrinthes, sino también La casa de Asterión, Abenjacán el bojarí muerto en su laberinto, y otros. La lotería en Babilonia, La biblioteca de Babel son, a su manera, laberintos y, naturalmente también El jardín de senderos que se bifurcan”. 
no a la lógica de la obra literaria. Al final de este ensayo, Caillois vincula la obra de Borges con la de otros autores (Jules Vernes, Arnold Toynbee, SaintJohn Perse) para afirmar el lugar de Borges en el Panteón europeo, considerado universal, puesto que estos autores "n'acceptent pour absolu aucun centre de références particulier, ni local, ni temporel” y "se veulent bénéficiaires de la totalité du monde, héritiers d'un humanisme universal” (Labyrinthes 217) ${ }^{15}$. El objetivo de la operación es, en parte, desarraigar a Borges de su propio contexto, así como de toda forma de exotismo y de localismo a partir de los cuales se perciben a menudo las literaturas extranjeras en Europa; y también inscribir a Borges en un canon de la literatura occidental, lo cual solamente puede hacerse, según Caillois, a partir de un intemporal, postulando la existencia de temas tradicionales de la cultura occidental como universales. Esta visión de la obra de Borges permite también explicar por qué Caillois adopta la presentación de Borges hecha por Ibarra en Lettres françaises en su edición de Fictions, gesto que ha desconcertado a la crítica latinoamericana (Molloy 206).

En L'Aleph, Caillois retoma el prefacio de Labyrinthes, completándolo con una justificación de sus elecciones, mientras recuerda sus diferentes compilaciones; dos frases nuevas son particularmente llamativas. La que encabeza el ensayo: "La traduction du recueil El Aleph a subi de nombreux et imprévisibles retards" (El Aleph 7) ${ }^{16}$; y la última: “Aujourd'hui que la traduction des dix autres contes du recueil est menée à bien par M. René L.-F. Durand, les récits que j'avais d'abord publiés à part reprennent la place qu'ils occupaient dans le recueil original et Labyrinthes disparaît, afin que la traduction française de l'ouvrage de J. L. Borges ne se trouve [sic] par répartie en deux volumes inégaux" (El Aleph 11) ${ }^{17}$. Como vemos, Caillois invierte aquí la relación causa-efecto, puesto que presenta sus propias compilaciones como una consecuencia de la falta de traducción de El Aleph, subrayando su origen. En cuanto a la frase final, notamos la idea de la "desaparición” del volumen Labyrinthes, así como la de dos volúmenes "desiguales" (o desparejos) en caso de que se conservara esa primera edición. Es evidente que más de diez años después, la exitosa recepción de Borges impone la publicación del volumen en su totalidad, pero el

15 "no aceptan como absoluto ningún centro de referencias particular, ni local, ni temporal"; "se vuelven beneficiarios de la totalidad del mundo, herederos de un humanismo universal".

16 "La traducción del volumen El Aleph sufrió numerosos e imprevistos retrasos".

17 "Hoy, cuando la traducción de los otros diez cuentos del volumen ha sido realizada por René L.-F. Durand, los relatos que había publicado primero aparte retoman el lugar que ocupaban en el volumen original y Labyrinthes desaparece, para evitar que la traducción francesa del libro de J. L. Borges esté repartida en dos volúmenes desiguales”. 
prefacio muestra claramente que Caillois defiende su lectura, y su interpretación de la obra del escritor, así como el montaje que había realizado.

\section{Historia del laberinto}

Para comprender la operación cultural realizada por Caillois es necesario reconstruir la presencia del laberinto en la obra de Borges en tanto tema, que permite percibir lo que su lectura oculta. Una tarea, sin embargo, de un alcance relativo, puesto que, como el mismo Caillois lo afirma, para él el laberinto es un tema, pero no en el sentido clásico, aunque es evidente que su concepción responde a la tradición de los estudios literarios franceses (Schaeffer). Sin embargo, la producción borgeana, en lengua original, en orden cronológico, en sus medios de publicación primeros, permite afirmar que el laberinto no tiene una presencia dominante, siquiera privilegiada, ni como espacio geográfico ni bajo la forma en que lo entiende Caillois: no aparece como un articulador privilegiado de sus ficciones, pero sí como como tema, como trama y como procedimiento; sus referencias y ocurrencias temáticas y explícitas son poco numerosas, y el lector no necesariamente les atribuye el valor que Caillois les otorga.

La aparición del laberinto se produce en los años 1935-1936; Borges lo asocia entonces a elementos muy distintos de aquellos que propone Caillois, y en particular a la trama policial; es en la nota bibliográfica sobre The Scandal of Father Brown de G. K. Chesterton (1935), "Los laberintos policiales y Chesterton”, donde el laberinto aparece de modo explícito; en ese texto Borges retoma parcialmente "Leyes de la narración policial", su primer ensayo sobre el género policial, donde no se menciona al laberinto. En el segundo artículo la idea aparece solamente en el título, pero al final del artículo se insinúa la orientación que toma: “¿Ha denunciado alguien la afinidad entre el Londres fantástico de Stevenson y el de Chesterton, entre los enlutados caballeros y jardines nocturnos del Suicide Club y los de la ahora quíntuple Saga del Padre Brown?" La ciudad en el cruce de lo fantástico y lo policial, como la literatura de Chesterton según Borges, la ciudad que se transforma en la encrucijada narrativa de un crimen, son elementos excluidos de la selección de Caillois.

La aparición siguiente del laberinto se da en 1936 y se encuentra en una nota publicada bajo el seudónimo de Daniel Haslam, "Laberintos”, en la revista Obra (revista del metro de Buenos Aires) ${ }^{18}$, nota bibliográfica sobre un libro

18 Obra. Revista Mensual Ilustrada. Borges fue secretario de redacción entre 1935 y 1936; en los números 3, 5 y 6 publica bajo el seudónimo de Daniel Haslam. 
imaginario: A General History of Labyrinths, Londres 1932, de Thomas Ingram, libro citado más tarde en “Tlön, Uqbar, Orbis Tertius”. En esta nota apócrifa, la reflexión gira alrededor de dos cuestiones esenciales, saber si el laberinto imita fenómenos naturales, y llegar a comprender si su efecto, perder a los hombres, resulta de una construcción arquitectural o si responde a otros factores (el alcohol, la distracción, la psicología). Cuando considera, a partir de Plinio, que es el autor de referencia del libro inexistente, el laberinto de Creta, anuncia lo que se volverá una interpretación constante del fenómeno: la identidad entre un lugar monstruoso y un habitante monstruoso, que encontramos en "La casa de Asterión”. Presenta luego su "Historia de los dos reyes y los dos laberintos", donde se pone en escena una oposición entre un laberinto construido por el hombre y uno natural (el desierto, obra de Dios en el texto).

Esta presentación traduce el desplazamiento entre el ensayo sobre el género policial y el relato, marcado por este género; al mismo tiempo se manifiesta una asociación entre la ciudad y el laberinto, mientras que este se desprende del espacio físico. El laberinto reaparece como se sabe en El jardín de senderos que se bifurcan (1941), y por tanto en Ficciones (1944), en textos como "La biblioteca de Babel”, y el mismo "Jardín de senderos que se bifurcan”; en El Aleph (1949), lo encontramos en "Los inmortales”, "La casa de Asterión”, y en la edición de 1952, se incorporan "Abenjacán el Bojarí, muerto en su laberinto" y el ya mencionado "Los dos reyes y los dos laberintos”. Varios de estos relatos combinan la trama policial con la ciudad, que se transforma en un laberinto, subrayando así la importancia del policial en la espacialización de la trama en Borges, elemento ajeno a la lectura de Caillois que otorga mayor importancia a la perspectiva filosófica del tema del laberinto, y privilegia textos que no ocurren en Buenos Aires (Louis, Borges).

Al transformar al laberinto en un tema, en la mejor tradición de los estudios literarios franceses, Caillois ignora deliberadamente la función del laberinto en Borges en tanto trama y procedimiento narrativo; inscribe así una impronta metafísica en los textos, que ignora otro componente de la escritura de Borges: el humor, que desaparece en sus traducciones. Al mismo tiempo el reenvío a un mundo urbano y porteño son ocultados, y los espacios, temas y personajes pertenecientes a la tradición occidental ensalzados. Los relatos agregados a la edición de El Aleph de 1952, permiten pensar que Borges despliega el tema del laberinto a partir de la recepción de Labyrinthes, en direcciones diferentes de las propuestas por Caillois, en un gesto que caracteriza su literatura, y que consiste en volver productiva la recepción de su obra, y explotar sus condiciones de recepción para producir literatura. 


\section{Quién habla a través de la lengua del traductor}

Como es sabido, Caillois va a Argentina a dictar una serie de conferencias, en julio de 1939, pero el advenimiento de la Segunda Guerra Mundial determina que se quede hasta 1945. Varios testimonios sugieren que no aprende español, puesto que se mueve en la comunidad de relaciones y amistades de Victoria Ocampo, donde prácticamente todo el mundo habla francés. Los datos de los que disponemos sugieren que cuando vuelve a Francia sigue sin dominar la lengua; incluso en 1946 cuando traduce a Gabriela Mistral, su conocimiento del idioma es relativo, como podemos deducirlo de sus traducciones y su postfacio ${ }^{19}$. Agreguemos que quien sí aprende rápidamente español es su primera esposa, Yvette Billod Caillois (1914-2008), que llega a Argentina en 1940, gracias también a la ayuda de Victoria, para casarse con Roger, luego de haber dado nacimiento a la hija de ambos en Francia; a su regreso, Yvette obtiene la agregación de español, y colabora con su marido en diferentes empresas intelectuales, como lo había hecho en Argentina. El aprendizaje de Caillois del español, por tanto, se realiza en la práctica misma de la traducción, primero traduciendo a Gabriela Mistral, luego a Borges, y más tarde a otros autores, como Cortázar y Octavio Paz; la falta de dominio del idioma representa sin duda un obstáculo técnico, pero a ello viene a sumarse la consciencia (o falta de) que el traductor tiene de sus propios límites. Agreguemos a esto una cuestión esencial para toda traducción literaria, Caillois ignora las tradiciones literarias hispanoamericanas, lo que vuelve imposible toda contextualización de la lengua: traduce como si no fuera necesario conocer la tradición literaria para realizar una traducción de calidad.

Gracias a su correspondencia y a sus escritos podemos intentar comprender la concepción de la lengua y de la tarea de la traducción de Caillois, estrechamente vinculadas a sus ideas sobre la literatura, que conviene resumir rápidamente; es necesario aclarar, sin embargo, que sus decisiones y actitudes resultan a menudo contradictorias, a pesar de su intensa reivindicación de la racionalidad. Como ha sido señalado, las posiciones de Caillois sobre la literatura estuvieron marcadas por su adhesión al surrealismo primero, por su toma de distancia respecto del movimiento en un segundo momento, y luego por su

19 Varios testimonios y su propia correspondencia permiten comprobarlo, como por ejemplo las declaraciones de Jean José Marchand (Felgine 211). Ver también el informe del embajador de Francia en Cuba así como la carta de protesta de un guatemalteco del 20 de marzo de 1946, dirigida al director del servicio de propaganda del Ministerio de Relaciones exteriores, a propósito de la conferencia que Caillois dio el 12 de marzo sobre Lautréamont (Felgine 291; fuente Ministerio de Relaciones Extranjeras, Relaciones culturales 1945-1947, dossier "Affaire Caillois”, Carta del 20 de marzo de 1947). 
ferviente animosidad hacia este ${ }^{20}$. Los años pasados en Buenos Aires también contribuyen a dar una nueva orientación a sus concepciones, que se expresan entonces en la revista Lettres françaises ${ }^{21}$; como para muchos exilados, la lengua materna funcionó para él como un refugio, lo cual modificó su concepción de la lengua, y de la literatura, y, probablemente, lo llevó a resistirse a aprender el español ${ }^{22}$. En cuanto a la literatura, si el joven Caillois había expresado su desconfianza hacia la poesía y la ficción, pronunciándose en favor del ensayo, en su "Manifeste pour une Littérature édifiante" (1944) define la política de la revista, a partir de una oposición entre lo que llama "literatura edificante" y "literatura recreativa" ("de divertissement"), donde lo edificante se sitúa en el estilo (2). Todo indica que esta oposición organiza todavía las concepciones de Caillois en los años 1950 y 1960, aunque sin duda la dimensión filosófica que otorga al laberinto desprende la literatura de Borges de lo meramente recreativo, conservando sin embargo su aspecto imaginativo. Podemos, por tanto, concluir que la importancia de Borges en la obra de Caillois viene en parte del hecho que le permite realizar una síntesis de su concepción que oponía hasta entonces dos tipos de literatura. La marca de la literatura edificante (una preferencia que compartía con Victoria Ocampo) impone una serie de elecciones en el momento de traducir. Agreguemos unas palabras acerca su concepción de la lengua, que se presenta como un medio, o un prisma: un modo de "expresión" de algo otro -la identidad cultural, por ejemplo-. La ficción y la poesía son, así, consideradas como instrumentos de conocimiento, como lo ha señalado ya Roger Bastide.

En las traducciones de Caillois otro aspecto de sus concepciones entra en juego, determinante en su producción ensayística global, que es uno de los elementos que organizaron su epistemología: la idea que existen estructuras comunes a la naturaleza y a las producciones de los hombres, artísticas en particular. Llamamos a este movimiento la "ausencia de arbitrariedad", expresión que designa una suerte de coherencia del mundo, que podemos pensar a partir del libro de Caillois Approches de la poésie, donde retoma su definición de la poesía como el lugar de la metáfora y de la analogía por excelencia, que

20 Así puede verse ya en una carta de Jules Supervielle a Jean Paulhan del 29 de junio de 1945. Archives Paulhan, citado por Felgine (271).

21 Veinte números fueron publicados en Buenos Aires entre julio de 1941 y junio de 1947; la revista estaba dirigida por Caillois, et financiada por Victoria Ocampo.

22 Existen testimonios que indican que Caillois era muy crítico respecto de la calidad de la lengua francesa hablada por las personas que encuentra en Argentina, e incluso que emprende una suerte de cruzada para salvar el francés en las regiones perdidas de América Latina. Ver Felgine (218-219). 
se integran en un movimiento más vasto: reflejan las posibilidades combinatorias de los fenómenos físicos y de los elementos (en el sentido científico del término), más allá del lenguaje y del hombre que lo habla. Se definiría de este modo una "razón poética" que se opone a la imagen poética de los surrealistas que, según Caillois, pone de relieve una relación gratuita y mística, que es lo que llama la "impostura de la poesía”. El objetivo entonces es acceder a imágenes que no sean fortuitas, ni arbitrarias, que no son inimaginables, y que no estén comprometidas con el azar y la gratuidad (Caillois, "Approches" 225-228). En otras palabras, no existiría una arbitrariedad ni del lenguaje ni de la literatura, sino un intento de aprehender estructuras existentes en el mundo, que se manifiestan bajo diferentes formas. No cabe duda de que esta concepción va a jugar un papel determinante no solamente en su interpretación de Borges, sino también en el modo en que lo editará, y lo traducirá -y más generalmente en su práctica de la traducción-. En efecto, se resignifica, así, la relación entre dos idiomas, puesto que el eje determinante se encuentra en la aptitud de cada uno de ellos a conectarse con esas estructuras no arbitrarias.

\section{Espacios de inscripción del traductor}

A partir de estas consideraciones, quisiera proponer algunas observaciones sobre las traducciones hechas por Caillois de los textos de El Aleph, que pueden encontrarse también en sus traducciones de otros autores como Cortázar u Octavio Paz (Taminiaux; Dulou). He aquí los tres tipos de fenómenos que hemos establecido hasta el momento, para señalar los modos en que la traducción de Caillois se aleja del texto en español, basándonos en una comparación de los textos de Borges traducidos por Caillois en El Aleph; por falta de espacio no podemos reproducir todos los ejemplos en su totalidad ${ }^{23}$. Esta propuesta parte del presupuesto que la traducción no es meramente un problema lingüístico, por lo que evito una categorización a partir de parámetros tradicionales -sintácticos, semánticos, léxicos-.

Una primera categoría la constituyen los contrasentidos, es decir aquello que solemos llamar "errores de traducción”, entre los cuales se encuentran los problemas debidos al descuido, o a un conocimiento defectuoso del español

23 En esta etapa del trabajo, comparo El Aleph de 1952 con L'Aleph de 1967, pero es evidente que sería interesante comparar todas las publicaciones de cada cuento. 
(de Argentina, en el caso de Borges) ${ }^{24}$. En general, suponemos que estos contrasentidos son involuntarios, y que no responden a una elección deliberada o meditada del traductor; pero en verdad hay dos casos dentro de esta categoría: a veces el traductor sabe que ignora el sentido de una palabra o expresión, o que no la conoce sino de modo aproximado; en otros casos, el traductor ignora que desconoce el significado de una palabra o de una expresión, y traduce de un modo que supone correcto. El caso de Caillois es particularmente interesante en este sentido, porque, a menudo, ignora su propia ignorancia. Como ejemplo de estos dos tipos de traducciones podemos citar los siguientes: entre los contrasentidos probablemente involuntarios, el comienzo de la frase "Hacia la medianoche, pisé, erizada de formas idolátricas en la arena amarilla, la negra sombra de sus muros" ("El inmortal", 1952: 12), en la cual Caillois traduce “Jusqu’à minuit. ..” (1967: 20) en vez de “Aux alentours de minuit”, lo que sugiere que ignora simplemente el matiz, o padece de distracción. Más interesante tal vez es el caso del contrasentido absoluto: "En tierra alguna es desconocido mi nombre..." (“Abenjacán el bojarí, muerto en su laberinto”, 1952: 116) traducido como: "Il existe une contrée où mon nom est inconnu" (1967: 157). En cuanto a los contrasentidos que se pueden considerar voluntarios, mencionemos, la traducción de “saber” por “décider” en la frase: “. . no puedo ya saber si tal o cual rasgo es una transcripción de la realidad o de las formas que desatinaron mis noches.” (“El inmortal” 1952: 15, 1967: 24), porque pensamos que el matiz entre "saber" y "decidir” no pudo escapar a Caillois, por lo cual se trata de una elección que inscribe un sentido otro en el texto.

Una segunda categoría es la de lo que podemos llamar libertades o desvíos, que pertenecen también a varios tipos distintos y suelen ser voluntarios; generalmente responden al objetivo de adaptar al gusto francés, o a lo que el traductor considera el gusto francés, es decir a la alta literatura francesa; en el caso de Caillois, se ha señalado el fenómeno particularmente en los títulos, pero a esta categoría pertenecerían también las modificaciones de la estructura de las frases y de la puntuación, así como las omisiones (fenómenos frecuentes en sus traducciones). Aunque no se puede hablar de una coherencia absoluta de los casos pertenecientes a esta categoría, en general responden a un parti pris del traductor acerca de la relación entre las lenguas literarias concernidas por la traducción, en varios niveles - puntuación, estructura de las frases, ritmo, registro, vocabulario. Notemos que Caillois exagera a menudo el gesto de adaptación a la

24 María Moliner define el contrasentido como una "interpretación contraria al sentido natural de las palabras o expresiones”, "deducción opuesta a la que es natural dados los antecedentes"; “acción, actitud, comportamiento en el que falta la correspondencia lógica” (753). Mi elección del término se debe a esta idea de la ruptura de un vínculo lógico. 
tradición literaria francesa, por ignorancia de la hispanoamericana, como hemos señalado; pero es evidente que frecuentemente en sus traducciones no ha podido discriminar lo que pertenece a la lengua y lo que pertenece al escritor (como sugiere Borges en "Las versiones homéricas”, 1932: 142). Por tanto, en esta categoría ubicamos también las traducciones que no dan cuenta de los giros, vocabulario y expresiones típicamente borgeanos del período.

El desvío más frecuente de Caillois consiste en modificar la puntuación; recurrentes son el reemplazo de comas por puntos, y de punto y coma por punto, prácticamente sistemáticos; encontramos numerosos casos de reemplazo de punto y como por coma o por punto; numerosos son los reemplazos de la conjunción “y” por punto y coma, por punto, por dos puntos, o por el relativo “où"; también frecuentes son los cambios de coma por dos puntos o por punto y coma, y los puntos por dos puntos. De un modo general, podemos afirmar que las modificaciones de puntuación responden a la intención de fragmentar el texto, y de crear un vínculo entre diferentes partes de frases o entre frases; esta fragmentación tiene como efecto alterar radicalmente el ritmo del relato, $\mathrm{y}$ borronear ciertas ambivalencias del texto borgeano; otro efecto es modificar la estructura, simplificando el texto, como por ejemplo en la primera frase de "La escritura del Dios”: "La cárcel es profunda y de piedra; su forma, la de un hemisferio casi perfecto, si bien el piso (que también es de piedra) es algo menor que un círculo máximo, hecho que agrava de algún modo los sentimientos de opresión y de vastedad" (1952: 106); he aquí la traducción de Caillois: "La prison est profonde. Elle est en Pierre. Sa forme est celle d'une demi-sphère presque parfaite ; le sol, qui est aussi en pierre, l'arrête un peu avant le plus grand cercle, ce qui accentue de quelque manière les sentiments d'oppression et d'espace" (1967 :145). De este modo, la introducción del relato presenta, en español, no solamente la cárcel, sino también el sentimiento, contradictorio, que provoca en quien la habita, en un mismo movimiento; en francés, en cambio, la división de la primera parte de la frase en dos, modifica radicalmente el efecto del texto, al tiempo que la relación concesiva es escamoteada.

Tal vez los casos más extremos de modificación en la puntuación los constituyen los momentos de transformación del estilo directo en estilo indirecto (“Abenjacán el Bojarí, muerto en su laberinto”, 1952: 116-117, 1957: 157, 161), que altera radicalmente el texto; pero podemos mencionar también la introducción de un signo de interrogación en "Historia del guerrero y la cautiva", al final de una frase cuya puntuación altera también por otros medios: "Ni siquiera sé en qué tiempo ocurrió: si al promediar el siglo VI, cuando los longobardos desolaron las llanuras de Italia; si en el VIII, antes de la rendición de Ravena." (1952: 44-45), que Caillois traduce como: "Je ne sais même pas la date des faits. Faut-il les situer vers le milieu du Ve siècle, quand les 
Longobards dévastèrent les plaines italiennes, ou dans le VIIIe siècle, avant la reddition de Ravenne ?” (1967: 64) Como vemos, aquí la frase es cortada en dos, los dos puntos se vuelven un punto, se desarma el paralelismo sintáctico entre las dos partes que siguen los dos puntos, y se introduce una interrogación explícita. En otras palabras, el planteo de ignorancia del narrador y la presentación en paralelo de dos posibilidades son escamoteados por el traductor.

Una tercera categoría es la inscripción de la interpretación del traductor en el texto traducido; esta interpretación puede ser relativa a un relato, un género, un autor. Partimos de la idea que es generalmente voluntaria, aunque es evidente que algunos de sus aspectos pueden no responder a una intención enteramente deliberada. En el caso de Caillois, hemos visto la inscripción de su interpretación de la literatura de Borges en el nivel de la edición, pero esta visión se manifiesta también en el plano de la traducción, al punto de modificar la obra de Borges. Un ejemplo evidente lo constituye el reemplazo de la palabra "red” por "labyrinthe” en "Abejacén el Bojarí, muerto en su laberinto" (1952: 114, 1967: 155), en la frase: "Dunraven dijo que en el interior de la casa había muchas encrucijadas, pero que, doblando siempre a la izquierda, llegarían en poco más de una hora al centro de la red" (114). Pero podemos también reenviar a la introducción de la palabra "race" (17) para traducir "nación" en la frase: "De lejos divisé la montaña que dio nombre al Oceáno: en sus laderas crece el euforbio, que anula los venenos; en la cumbre habitan los sátiros, nación de hombres ferales y rústicos, inclinados a la lujuria” (1952: 9-10). Caillois había introducido esta palabra también en su traducción de un poema de Gabriela Mistral publicado en la Lettres françaises en 1944, "Beber”, para reemplazar la palabra “casta” (Lettres françaises 12, 10); también la podemos relacionar con las concepciones de Caillois sobre la cultura, y la polémica que mantiene con Claude Lévi-Strauss cuando este publica Race et histoire en 1952 (Felgine 321-322; Panoff). La traducción de la frase siguiente a la que ya hemos citado de "Historia del guerrero y la cautiva", presenta un ejemplo de inscripción de la interpretación del traductor en el texto: "Imaginemos (éste no es un trabajo histórico) lo primero" (1952: 45), traducido por: "Choisissons (ceci n'est pas un travail historique) la première hypothèse” (1967: 64), donde el reemplazo de "Imaginemos" por "Choisissons" y la introducción de la palabra científica "hypothèse" desplaza el texto del terreno de la literatura y la imaginación hacia el de la reflexión científica ${ }^{25}$.

25 El párrafo siguiente retoma la idea de imaginación ("Imaginemos, sub specie aeternitatis, a Droctulft, no al individuo Droctulft, que sin duda fue único e insondable...” (1952: 45)), Caillois pasa por alto el paralelismo de las dos frases, pero traduce en esta frase por "Imaginons" (1967: 64). 
La clasificación propuesta presenta dos problemas. Por un lado, no es exclusiva de Caillois, es decir que podemos encontrar estas tendencias en otros traductores, aunque muchos traductores intentan reducir ya sea los contrasentidos, las libertades o la inscripción de la propia interpretación. Si es cierto que Caillois está atento a los primeros, no podemos decir lo mismo de las otras categorías: tanto las libertades como la inscripción de la concepción del traductor en su caso son conscientes, deliberadas y están particularmente desarrolladas, en razón de sus concepción de la lengua francesa y porque se consideraba él mismo como una autoridad suficiente para cuestionar las elecciones del autor (tal como lo muestran los testimonios de Ibarra y de Cortázar, y lo confirman su escritura y su práctica de las traducciones) ${ }^{26}$. El otro problema que presenta esta categorización es que no es siempre posible diferenciar el tipo de intervención del traductor; de un modo general, podemos concluir que prácticamente todos los desvíos pueden también considerarse como modos de inscripción de la interpretación del traductor, cuando no responden a un desconocimiento del lenguaje o de sus connotaciones; lo interesante es estudiar cada caso y sus implicaciones. Como ejemplo, podemos examinar el título de uno de los relatos publicados primero en Labyrinthes y después en El Aleph, "La busca de Averroes" traducido por Caillois como "La quête d'Averroès". Como es sabido, en el cuento de Borges, Averroes intenta comprender el sentido de las palabras

26 Según Ibarra: “Tout bonnement je me demande si lui [Bénichou] et Caillois ne se souviennent pas trop de leurs années de professorat secondaire. Ils sont peut-être marqués à jamais par la version latine. Ils savent trop que Amat janua limen ne doit pas être traduit par la porte aime le seuil, parce que l'élève qui traduit ainsi ne fait pas comprendre qu'il a compris, montre plutôt qu'il n'a pas compris (il s'agit d'une porte qui ne quitte plus le seuil, que personne n'ouvre plus, celle d'une vieille courtisane désaffectée)." ("Me pregunto simplemente si él [Bénichou] y Caillois no recuerdan demasiado sus años de profesores de la secundaria. Están marcados para siempre por la versión latina. Saben demasiado bien que Amat janua limen no debe ser traducido por la puerta ama al umbral, porque el alumno que traduce de este modo no da a entender que ha entendido, sino que muestra más bien que no ha comprendido (se trata de una puerta que no abandona el umbral, que nadie abre ya, la de una vieja cortesana olvidada”) (151-152)). Y Cortázar, en carta a Jean Barnabé, del 8 de mayo de 1957: "Creo haberle dicho en mi carta anterior - anterior a mi partida a la India - que le llevé Bestiaire a Caillois. Me lo devolvió diciéndome que las traducciones le parecían 'demasiado apegadas al original' (sic.). Cuando le pedí que me aclarara lo que quería decir sostuvo que usted había sido 'demasiado fiel' en algunas cosas, alejándose del francés para mantenerse más cerca del giro español, del ritmo de la frase, etc. Creo que fue en ese momento que comprendí por fin por qué las traducciones al francés me parecen casi siempre demasiado alejadas del original; evidentemente la gente como Caillois considera que el autor no interesa gran cosa: lo único que cuenta es salvar a toda costa el GRRRAANNN estilo francés, la manera francesa de decir las cosas. . . aun a riesgo de cualquier traición” (125). 
“tragedia” y “comedia” en Aristóteles, viniendo de una cultura que no conoce el teatro. Para Néstor Ibarra, la traducción del título que propone Caillois es un error: "Caillois préfère La quête d'Averroès, je ne sais pourquoi. Il s'agit d'une recherche littéraire...On ne fait pas de quêtes à la Nationale que je sache ?” $(441)^{27}$. La elección de Caillois, sin embargo, puede explicarse por dos razones; por un lado, el uso poco común de la palabra "busca” (pareciera que para Borges "búsqueda" era una palabra vulgar), que puede haber percibido como un término literario e incluso antiguo; por otro lado, la noción de "quête" introduce una dimensión metafísica que corresponde perfectamente a su lectura de Borges (e introduce también una connotación espiritual); notemos que la palabra se traduce en español por "búsqueda”, pero en esta traducción se pierde la dimensión espiritual y metafísica, razón por la cual tal vez Caillois considera que es un equivalente de "busca". Podemos entonces preguntarnos si se trata de una libertad tomada por razones lingüísticas o de una introducción de la interpretación del traductor, y responder que ambas se combinan en este caso ${ }^{28}$.

A la intención y voluntad de inscribir su lectura de la obra de Borges, se suma otra cuestión, que encontramos también en sus traducciones y ediciones de Julio Cortázar, pero que ya se manifiesta en los años 1940, en el momento en que Borges, Bioy y Silvina Ocampo publican la Antología de la literatura fantástica $^{29}$ : Caillois suele considerar el género fantástico a partir de su vertiente europea, y su concepción no corresponde a la naciente práctica del género en América Latina, por lo cual sus traducciones atenúan ciertos efectos, e introducen cierto grado de explicación en un universo fantástico que suele rechazar toda explicitación ${ }^{30}$. En sus traducciones y ediciones va a inscribir su propia

27 "Caillois prefiere La quête d'Averroès, no sé por qué. Se trata de una investigación literaria... No se hacen « quêtes » en la nacional que yo sepa?”.

28 Un fenómeno similar se observa en la traducción del título "La casa de Asterión”, que Caillois traduce pour "La demeure d'Astérion", que por falta de espacio no podemos analizar aquí, pero señalemos que "demeure" es una palabra que no reenvía necesariamente al mundo humano, por lo cual se borra así parte del proceso de humanización del Minotauro, y disminuye el suspenso del texto.

29 En una carta del 7 de abril de 1941, Roger Caillois le escribe a Victoria Ocampo acerca de la Antología de la literatura fantástica, criticando las elecciones hechas por los compiladores, y el hecho de haber incluido un texto de Borges (Felgine 114-115).

30 La misma carta a Jean Barnabé del 8 de mayo de 1957, donde Julio Cortázar le cuenta su entrevista con Caillois y su discusión a propósito del cuento "La noche boca arriba", permite comprender su concepción: "Una semana más tarde Caillois me dijo que había elegido un cuento para incluirlo en una antología de contes d'épouvante (!) que va a editar Gallimard. Eligió "La noche boca arriba", que tradujo enseguida un señor Durand. Para darle una idea de la mentalidad de Caillois, le regalo esta pequeña anécdota. "El peligro de su cuento" (es él quien habla) "está en que el lector francés pueda pensar que se trata simplemente de una 
concepción, de modo en parte deliberado, modificando el significado de los textos, o intentando modificarlo; no se trata, como se ha pretendido a menudo, de una falta de comprensión de parte de Caillois de la literatura latinoamericana, sino de una concepción otra, que entra en competencia con la de Borges, Bioy, Cortázar, y con algunos principios del género hispanoamericano. Desde su lugar de traductor y editor, inscribe su propia concepción, usando la práctica de la traducción, así como la de la antología y del ensayo, para enfrentar las teorías a las que no adhiere, como podemos verlo en su Anthologie de la littérature fantastique (1966). Caillois no ganó esta batalla (por suerte), la literatura fantástica latinoamericana se impuso con sus peculiaridades, pero en los años 1950, 1960 el enfrentamiento de estas concepciones no permite aún saber cuál de estas estéticas se impondrá, y en la batalla librada por Caillois la traducción juega un papel preponderante $\mathrm{e}^{31}$.

Esta competencia de tendencias estéticas se manifiesta en particular en la dificultad que manifiesta Caillois para dejar las interpretaciones libradas al lector, principio que responde a una concepción pedagógica de la literatura y del lenguaje, destinada a construir y confirmar el lugar privilegiado que ocupa el escritor (cercana a la de Victoria Ocampo); por ello, sus traducciones y ediciones muestran una tendencia a explicitar, a resolver las ambivalencias (línea continuada en relación con lo fantástico por Todorov 1970). Cuando se trabaja con la lengua, estas concepciones se manifiestan de modo voluntario, pero se inscriben también de modo involuntario en numerosas elecciones y decisiones de traducción. En este sentido hemos señalado la fuerte tendencia a la explicación, explicitación e interpretación en las traducciones de Caillois, mediante, como vimos, agregados, supresiones, modificaciones de la puntuación, introducción de bastardilla, y desvíos en el nivel semántico.

Tal vez haya sido Ibarra quien mejor expresó el problema que plantean las traducciones de Borges hechas por Caillois (y otros traductores franceses): “Ils veulent, eux, traducteurs de Borges, laisser trace qu'ils l'ont bien interprété; mais voilà, en l'interprétant, ils privent le lecteur de la joie de l'inter-

alucinación del hombre a quien ha operado... ¿No le parece que convendría agregar una frase final, por ejemplo que a la mañana siguiente los enfermeros encontraron muerto al enfermo, y al mirarlos con atención se dieron cuenta de que tenía una herida en el pecho y que le faltaba el corazón?” (!!!) Yo me quedé mirándolo como si me estuviera tomando el pelo, pero hablaba con toda seriedad" (126). Notemos que, si Cortázar reproduce fielmente las palabras de Caillois, este dice "el lector francés", lo que significa que la ambigüedad del final del texto le parece un problema solamente para este lectorado.

31 Es evidente, por otra parte, que la publicación de la Introduction à la littérature fantastique de Todorov en 1970 va a modificar la historia literaria. Ver Louis, "Del rol de la delimitación". 
préter”(152) ${ }^{32}$. Y agrega, subrayando el papel de intérprete que se otorga de este modo el traductor: "La littéralité, notamment, inspire à ses traducteurs de la méfiance, sinon de l'horreur. Ils voient partout des "faux amis"; les "faux amis" les détournent des vrais. Et Nous aboutissons à ce paradoxe qu'en lisant Borges en espagnol, Nous le sentons s'adresser à des lecteurs beaucoup plus fins, plus lettrés, plus "artistes" qu'en le lisant dans ses traductions françaises !" $(152-153)^{33}$. La escritura de Borges abre, en efecto, un espacio al lector para que interprete, rechazando deliberadamente toda explicitación y a menudo toda explicación - un procedimiento particularmente importante en el género fantástico. Es la razón por la cual Enrique Pezzoni consideraba su literatura como antipedagógica, porque demanda un lector activo, dispuesto a socavar las bases del pensamiento occidental (45). Traducir da la posibilidad al traductor de llenar ese espacio de la escritura, de inscribir un "rastro" en ella, marcándola con la propia concepción, en este caso: explicitando, simplificando, explicando aquello deliberadamente dejado en suspenso por el autor. Y tal vez el modo en que se ocupa ese espacio es parte del éxito de una traducción en un momento determinado y en una cultura específica, porque inscribe la imaginación del traductor, y toda imaginación es social.

\section{Traductores, agentes, autores}

Introducir un autor extranjero en una cultura (lo que se suele llamar transferencia cultural) es necesariamente una operación cargada de sentido, y de consecuencias, puesto que toda interpretación de una obra lleva a un montaje editorial particular. El rasgo más llamativo del caso de Borges es el hecho que la obra haya sido presentada y organizada a partir de un tema, que funciona a la vez como un articulador como un unificador, y que es propuesto simultáneamente como universal y como específico a la cultura occidental: el

32 "Ellos, los traductores de Borges, quieren dejar una huella que muestre que lo han interpretado bien; pero al interpretarlo, privan al lector de la alegría de hacerlo ellos”. También según Ibarra: "Labyrinthes est une sorte de jugement porté sur Borges, une définition de Borges par Caillois" (92) (“Labyrinthe es una suerte de juicio sobre Borges, una definición de Borges por Caillois").

33 "La literalidad, en particular, inspira desconfianza a sus traductores, y a veces horror. Ven en todas partes 'falsos amigos'; los 'falsos amigos' los alejan de los verdaderos. Y llegamos asî a esa paradoja, que cuando leemos a Borges en español, sentimos que se dirige a lectores mucho más finos, más letrados, más ‘artistas', ique al leer sus traducciones francesas!”. 
laberinto, inscripto en una red de motivos (el tiempo, la biblioteca, el tigre). Edición y traducción son puestas al servicio de este objetivo, aunque en el caso de las traducciones otros factores también contribuyen a otorgarles una identidad.

Contrariamente a lo que se suele creer, y a lo que se ha sostenido a menudo, Roger Caillois no inventó la idea de difundir la obra de Borges a partir de un tema; pero al poner en evidencia el del laberinto, fue uno de los agentes de su difusión, quizás el principal (pero otros factores quedan por estudiar). Si hizo posible la articulación de la literatura de Borges a la cultura francesa, la asociación entre Borges y una serie de temas universales, extranjero a su contexto de producción había nacido en Buenos Aires, en el comienzo de los años 1940, en el momento de la primera recepción de sus cuentos en su propio medio cultural. Esta lectura se explicitó durante el discreto escándalo provocado por el Premio Nacional de Literatura en 1942, que llevó a los enemigos y a los defensores de su estética a expresar sus posiciones (Louis, Borges 95-104); lecturas que probablemente influyeron en la presentación de Ibarra para las “Assyriennes”. Todos acontecimientos que se producen mientras Caillois está todavía en Buenos Aires.

La creación de Labyrinthes por Caillois extendió el automatismo que consiste en asociar a Borges al laberinto más allá del ámbito de la literatura; la lista es larga de todo aquello que aparece como laberíntico y borgeano -el libro, la biblioteca, los barrios de Buenos Aires, el tiempo, el jardín; la cultura es un laberinto, como el universo y la paradoja de Zenón; la web y el internet-. Uno de los problemas que debe enfrentar la interpretación temática es cómo lograr hablar de temas o ideas en literatura sin reducir su especificidad, es decir, sin hacer de la literatura un simple sistema de traducción. Aquí, nos encontramos con el caso opuesto: la obra de Borges se impuso sobre el tema del laberinto, y se lo apropió ${ }^{34}$. El tema no traduce (ni reduce) la obra de Borges: la obra de Borges encarna el tema, y se impone en toda ocurrencia de laberinto, expandiéndose de este modo más allá de su textualidad.

34 En otras palabras, se trata del movimiento opuesto al que se produjo en el comienzo, lanzado por Caillois, que había sido definido del siguiente modo por Ibarra: "Un peu partout dans son œuvre, Borges imagine, dénonce, divers labyrinthes; Caillois les ramasse tous en un seul et y enferme Borges" (93) ("En varios momentos en su obra, Borges imagina, denuncia, diferentes laberintos; Caillois los junta todos en uno solo y encierra adentro a Borges”). 


\section{Bibliografía}

Bastide, Roger. "Sous 'La Croix du Sud': l'Amérique latine dans le miroir de sa littérature”. Annales a 13, no. 1, 1958, pp. 30-46.

Borges, Jorge Luis. Euvres Complètes. Tome 1. Gallimard/NRF/La Pléiade, 1993. Édition établie, présentée et annotée par Jean-Pierre Bernès. Tome 2. Gallimard/NRF/La Pléiade, 1999.

---. L'Aleph. Trad. Roger Caillois y René L.-F. Durand. Gallimard, colección “Du monde entier”, 1967.

---. Essai sur les anciennes littératures germaniques (en collaboration avec María Esther Vázquez). Trad. Michel Maxence. Christian Bourgois, 1966.

--.. Discussion. Gallimard, collection “La Croix du Sud”, 1966.

--.. Manuel de zoologie fantastique. (en collaboration avec Margarita Guerrero). Trad. Roger Caillois. Lettres Nouvelles, 1965.

-.-. L'Auteur et autres textes. Trad. Roger Caillois. Gallimard, colección “La Croix du Sud”, 1965.

--.. La Bibliothèque de Babel. Trad. Nestor Ibarra. R. Gid, 1963.

--.. Labyrinths. Selected Stories and Other Writings. Trad. James E. Irby et al. Ed. Donald

A. Yates y James E. Irby. Prefacio de André Maurois. New Directions, 1961.

---. Labyrinthe. Erzählungen. Trad. Karl August Horst. Carl Hanser Verlag, 1961.

---. Histoire de l'infamie. Histoire de l'éternité. Trad. Roger Caillois y Laure Guille (con la ayuda de Julio Cortázar). Editions du Rocher, 1958; Union générale des éditeurs, colección “Le Monde" en 10/18, 1964.

---. Enquêtes 1937-1952. Trad. Paul y Sylvia Bénichou. Gallimard, colección “La Croix du Sud", 1957.

--.. “L'immortel”. Trad. Roger Caillois. La Nouvelle Revue Française, 1/09/1953, a. 1, no. 9, pp. 422-439.

--.. "Nota sobre (hacia) Bernard Shaw". Otras inquisiciones. Sur, 1952, pp. 193-196.

---. “El hombre en el umbral”. La Nación 2e, 20/04/1952: 1, 2da sección, ilustración de Alejandro Sirio. El Aleph. Losada, 1952, pp. 131-137.

--.. “Abenjacán el Bojarí, muerto en su laberinto”. Sur, no. 202, 08/1951, pp. 1-8./El Aleph. Losada, 1952, pp. 113-123.

---. “La espera”. La Nación 27/08/1950: 1, 2da. Sección, ilustración de Alejandro Sirio. El Aleph. Losada, 1952, pp. 123-130.

---. Fictions. Trad. Paul Verdevoye y Néstor Ibarra. Prólogo de Néstor Ibarra. Gallimard, colección "La Croix du Sud”, 1951.

-.-. "Histoire du guerrier et de la captive". Trad. Roger Caillois. Cahiers de la Pléiade, Otoño de 1949, pp. 159-164.

---. “La casa de Asterión”. Los Anales de Buenos Aires a. 2, no. 15-16, 05/1947, pp. 47-49; El Aleph. Losada, 1949, pp. 69-72.

---. "Los inmortales”. Anales de Buenos Aires a.2, no.12, 02/1947, pp. 29-39, ilustración de Amanda Molina Vedia. Bajo el título de "El inmortal”, El Aleph. Losada, 1949, pp. 7-28.

---. "Fictions". Trad. Paul Verdevoye. La Licorne. no. 1, primavera de 1947, pp. 13-26.

--.. "Les ruines circulaires". Trad. Paul Verdevoye. Confluences (nueva serie), año 6 ${ }^{\mathrm{e}}$, no. 11, abril de 1946, pp. 131-135. 
--.. “Assyriennes”. Trad. Néstor Ibarra. Lettres françaises, no. 14, Buenos Aires, 01/10/1944, pp. 9-26.

--.. "Historia de los dos reyes y los dos laberintos". El Hogar, vol. 35, no. 1548, 16/06/1939, p. 25 (bajo el título de "Una leyenda arábiga (Historia de los dos reyes y los dos laberintos, como nota de Burton)"; bajo el título de "Historia de los dos reyes y los dos laberintos", en Los Anales de Buenos Aires vol. 1, no. 5, mayo de 1946, p. 51, sección "Museo", compuesta en colaboración con Bioy Casares y publicada bajo el seudónimo de B. Suárez Lynch. El Aleph, Losada, 1952, p. 51.

---. “L’approche du caché”. Trad. Néstor Ibarra. Mesures, 1939, pp. 115-122.

--. "Laberintos". Obra a.1, no. 3, 01/1936, pp. 38-39. Bajo el seudónimo de Daniel Haslam.

--.. “Nota sobre la 4ta dimensión”. Obra 1, no. 5, 04/1936, pp. 38-39. Bajo el seudónimo de Daniel Haslam. Publicado antes en la Revista Multicolor de los Sábados. Crítica 1, no. 51, 28/07/1934, p. 4.

--. “Un infinito problema. El mentiroso. El cocodrilo. El puente. El adivinador”. Obra 1, no. 6, 05/1936, p. 38. Bajo el seudónimo de Daniel Haslam. (Habían ya sido publicados en la Revista Multicolor de los Sábados. Crítica, bajo el título de "Dos antiguos problemas"1, no. $40,12 / 05 / 1934$, p. 5.)

--.. "Paul Groussac". La Revue Argentine, dic.-enero 1936, p. 33-36.

--.. “Los laberintos policiales y Chesterton”. Sur, no. 10, mayo 1935, pp. 92-94.

---. "Leyes de la narración policial”. Hoy Argentina, vol. 1, no. 2, abril 1933, pp. 48-49.

---. “Las versiones homéricas”. Discusión. Manuel Gleizer, 1932, pp. 13-150.

Caillois, Roger. Approches de la poésie. Gallimard, 1978.

--.. Anthologie du fantastique. Gallimard/NRF, 1966.

--.. "Les thèmes fondamentaux de Jorge Luis Borges". Jorge Luis Borges. Ed. Dominique de Roux y Jean de Milleret. L'Herne, 1964, p. 211-217.

--.. “Poètes d’Amérique. Note”. Lettres françaises, no. 12, 01/04/1944, pp. 7-8.

--.. “Manifeste pour une littérature édifiante”. Lettres Françaises, no. 13, 1/07/1944, pp. 1-5.

---. Les impostures de la poésie. Sur, 1944.

Caillois, Roger y Paulhan, Jean. Correspondance. (1934-1967). Cahiers Jean Paulhan, no. 6. Presentación y anotaciones de Odile Felgine y de Claude-Pierre Perez, con la colaboración de Jacqueline Paulhan, prefacio de Laurent Jenny. Gallimard, 1991.

Caillois, Roger. y Victoria Ocampo Correspondance. Stock, 1997.

Cortázar, Julio. Cartas. 5 vol. Eds. Aurora Bernárdez y Carles Álvarez Garriga. Alfaguara, 2012. Dulou, Jérôme. “Julio Cortázar et Roger Caillois: du rêve au fantastique”. Tesis de doctorado Nouveau Régime. Paris IV, 30/05/2018.

Felgine, Odile. Roger Caillois (biographie). Stock, 1994.

Ibarra, Néstor. Borges et Borges. L'Herne/Glose, 1969.

Louis, Annick. "La traduction dans la revue Lettres françaises (1941-1947) de Roger Caillois". Scènes de la traduction France/Argentine. Ed. Gersende Camenen. Editions Rue d’Ulm, 2019. (en prensa)

---. “Étoiles d'un ciel étranger. Roger Caillois et l'Amérique Latine”. Littérature. Roger Caillois, no. 170 , junio 2013 , pp. $71-81$.

---. "Del rol de la delimitación del corpus en la teoría literaria. A propósito de la Introducción a la literatura fantástica de Tzvetan Todorov y de la crítica literaria hispanoamericana". Badebec, vol. 2, no. 3, septiembre 2012, pp. 118-142.

---. Borges ante el fascismo. Peter Lang, 2007.

Mistral, Gabriela. Poèmes. Trad. Roger Caillois. Gallimard, 1946. 
Moliner, Maria. Diccionario de uso del español. Gredos, 1986.

Molloy, Sylvia. La diffusion de la littérature en France au xx ${ }^{e}$ siècle. PUF, 1972.

Panoff, Michel. Les frères ennemis. Roger Caillois et Claude Lévi-Strauss. Editions Payot et Rivages, 1993.

Pezzoni, Enrique. Enrique Pezzoni lector de Borges. Lecciones de literatura 1984-1988. Edición y prefacio de Annick Louis. Sudamericana, 1999.

Río de la Plata, números 13-14, 1992.

Schaeffer, Jean-Marie. "Thématique". Nouveau Dictionnaire encyclopédique des sciences $d u$ langage. Ed. Oswald Ducrot y Jean-Marie Schaeffer. Seuil, 1995, pp. 530-532.

Taminiaux, Pierre. "Roger Caillois et l'expérience de la traduction". Revue des lettres et des traductions, no. 9, 2003, pp. 39-51.

Todorov, Tzvetan. Introduction à la littérature fantastique. Seuil, 1970. 


\section{Gabriel García Márquez traducido: observaciones sobre la variación}

\section{Introducción}

Cuando el gran filólogo colombiano Rufino José Cuervo, padre de la dialectología hispanoamericana, evocaba su concepción sobre la lengua, ya podíamos percibir en sus escritos una visión muy clara de la importancia de la variación: “cada lengua varía más o menos según las comarcas en que domina, y en cada una de ellas sigue su evolución propia: en la Península, no habla el natural de Castilla como el aragonés o el andaluz; ni, en América, el chileno como el mexicano o el colombiano" (Cuervo 3). Focalizándonos en la variación diatópica y en el nivel léxico, proponemos un estudio multidisciplinario de la realidad lingüística de Colombia a través de las obras literarias de Gabriel García Márquez, escritor emblemático colombiano y de la literatura hispanoamericana, digno representante de la literatura mundial gracias al universalismo y al exotismo de su obra.

Elementos diatópicos presentes en tres novelas del autor: Cien años de soledad, Crónica de una muerte anunciada y El amor en los tiempos del cólera, nos han permitido constituir un corpus lexicográfico diferencial con el fin de observar la variación diatópica en el léxico. También hemos conformado un segundo corpus en el que se puede observar con precisión la traducción al francés de estas formas y apreciar la manera como los traductores de las obras interpretan la variación. La traducción, pilar de la literatura mundial, nos permite acceder a una obra literaria mediada por un traductor. Pensamos que el análisis sistemático que proponemos, integrando la variación como eje del estudio, posibilita observar este proceso de "transcripción" a una lengua diferente que posee una variación diatópica con valores y matices propios.

\section{Marco teórico}

Este trabajo se enmarca en el campo de la lexicografía dialectal definida por Manuel Alvar Ezquerra y el de la metalexicografía fundada por el francés Bernard Quemada, aplicadas al estudio de obras literarias. Nos focalizamos en el

Liset Díaz Martínez, Université de Cergy-Pontoise

Ә Open Access. (C) 2020 Liset Díaz Martínez, published by De Gruyter. (c) BY-NC-ND This work is licensed under a Creative Commons Attribution-NonCommercial-NoDerivatives 4.0 International License.

https://doi.org/10.1515/9783110673678-009 
análisis de las voces marcadas en obras lexicográficas como colombianismos observando como esta variación es percibida e interpretada por los traductores y luego restituida en el texto traducido. Es decir que nuestro estudio hace también parte de la traductología. Nuestro material de trabajo está constituido por elementos diatópicos presentes en nuestro corpus, incluyendo igualmente como objeto de estudio las obras lexicográficas utilizadas en nuestros análisis.

La primera cuestión que abordaremos concierne a la diferencia entre español de Colombia y colombianismo. El español de Colombia es un dialecto historicoestructural que pertenece al complejo lingüístico del español panhispánico. Definir un dialecto es bastante difícil porque tradicionalmente ha sido asociado a una variedad informal o poco desarrollada de la lengua, la subordinación hace también parte del concepto y puede darle una connotación negativa. Pero podemos decir que un dialecto es equivalente a una lengua porque sus normas se realizan efectivamente en el habla. Un dialecto es, entonces, un sistema dependiente o subordinado de un complejo lingüístico, un resultado histórico de procesos convergentes o divergentes. Ese complejo lingüístico como lo conceptualiza José Juaquín Montes Giraldo, es una "lengua histórica" y lo consideramos como autónomo, unitario y social por naturaleza. El dialecto comparte con otros, entonces, una base estructural común y posee igualmente características diferenciales. En el caso del español, existe un complejo lingüístico que poco a poco se define y hacen parte de este todas las variantes nacionales autónomas de la lengua. Estas variantes son subsistemas diferenciados que cuentan con elementos comunes que permiten la comunicación entre hispanohablantes y también con particularidades regionales y locales que conocemos como diatopismos o "ismos". Muchas veces estos elementos son percibidos como marginales o vulgares del acervo lingüístico, pero, en realidad, no se definen por el nivel de lengua sino por la extensión geográfica de su uso.

En cada variante encontramos normas cultas, y el objetivo es estudiarlas y caracterizarlas saliendo de las barreras prescriptivas que pueden causar problemas de identidad y que niegan la riqueza de la lengua. Las normas cultas de cada país deben por lo tanto ser aceptadas y descritas en todos los niveles de la lengua. En este trabajo nos ocuparemos del nivel léxico, puesto que nos interesa su dinamismo y su tratamiento en las obras lexicográficas.

Los colombianismos son, entonces, fenómenos lingüísticos propios del español de Colombia, utilizados e identificados por los locutores nativos de esta variante del español. Esto significa que en el conjunto dialectal conformado por el español panhispánico, encontramos colombianismos, chilenismos, mexicanismos, argentinismos, españolismos, etc. También americanismos y, en este caso, estamos considerando fenómenos pertenecientes al español de América; sin embargo, definir el americanismo y el español de América es, en realidad, una tarea ardua. En efecto, estos conceptos que parecen tan simples y que se utilizan con tanta 
naturalidad no han podido ser definidos precisamente y pueden ser fuente de conflicto entre investigadores. La noción de español americano fue creada en oposición a otra llamada español peninsular a partir de elementos extralingüísticos y bajo una concepción de supuesta homogeneidad entre las variantes de América. Pero los estudios de estas variantes, todavía bastante fragmentados, no nos permiten promulgar científicamente esta homogeneidad lingüística y, por el momento, debemos mejor hablar de variantes hispanoamericanas y no de español americano. Algunos investigadores como José Pedro Rona nos explican también que este español no existe en sincronía porque no podemos encontrar fenómenos lingüísticos compartidos por todos los países de América y, al mismo tiempo, ausentes en todo el territorio español. El concepto de americanismo es igualmente problemático porque en sentido estricto representa rasgos lingüísticos usados en todo el territorio americano, pero, en realidad, se aplica a una cantidad enorme de rasgos que tienen una extensión geográfica muy variada. Si observamos la definición del diccionario de la Real Academia Española, esta extensión puede reducirse incluso a un solo país. Es decir que términos que tienen un uso bastante restringido también son considerados como americanismos y que una diferencia entre colombianismo, por ejemplo, y americanismo no sería bien marcada. Este concepto ha sido tratado por muchos lingüistas, mencionemos a Ambrosio Rabanales y de nuevo a José Pedro Rona, reconocidos como autores clásicos en el estudio del americanismo, quienes enuncian criterios de origen y de difusión geográfica para caracterizarlo.

En cuanto al americanismo en el nivel léxico, Jesús Gútemberg Bohórquez nos explica tres criterios principales de definición y de clasificación de estas palabras. Primero, el criterio de origen que incluye las palabras que nacieron en alguno de los países de América ya sea desde las lenguas indígenas, o creados en el territorio americano por los locutores hispanohablantes. El segundo criterio es enciclopédico e incluye términos que designan conceptos o realidades típicas del continente americano, como la fauna, la flora, por ejemplo. El último criterio es de uso y designa los términos que se utilizan en América, puede ser de forma global o contrastiva. Huguette Pottier-Navarro va más allá de de estos criterios y propone combinarlos con otros elementos como, por ejemplo, la extensión geográfica e integra igualmente una diferenciación de clasificación definiendo criterios intralingüísticos y extralingüísticos. Como vemos, muchas propuestas han explorado la definición de esta noción, y actualmente todas son válidas en los estudios lexicográficos.

Ahora vamos a focalizarnos en los diccionarios y estudiaremos como estas obras manejan el léxico definido como americano. Hablemos primero de dos tipos de diccionarios que tratan este léxico, los globales que utilizan el método global en la elección de su nomenclatura, y los contrastivos que se basan en 
el método diferencial. Es decir que eligen sus entradas comparándolas con otras obras lexicográficas, en cambio los globales no hacen ninguna comparación e incluyen directamente el léxico que desean definir. En el caso del español, los dos métodos se han utilizado, pero de manera muy particular. Generalmente, cuando un diccionario presenta el léxico de un país americano, las entradas se eligen usando el método diferencial. Es por esto que la mayoría de los diccionarios de las variantes americanas son diccionarios de "ismos" y no diccionarios globales. Los únicos diccionarios de este tipo corresponden a las variantes argentina y mexicana. De hecho, el Colegio de México milita por este tipo de diccionario y lo ha ya informatizado para proponer su uso libre en la web, se trata del Diccionario del Español de México o DEM (http://dem.colmex.mx/).

El tratamiento del léxico español de España se basa tradicionalmente en el método global. Muchas de las obras clásicas, académicas o no académicas, se han convertido en "diccionarios generales" que han poco a poco incluido una gran cantidad de léxico americano, sobre todo a partir del siglo XIX cuando las colonias americanas se emanciparon y la cuestión de la inclusión de los diatopismos en las obras lexicográficas se volvió argumento político, económico y sobre todo comercial. Siempre han existido voces americanas en los diccionarios globales del español de España, pero el siglo XIX aportó la inclusión de las marcas diatópicas americanas en estos diccionarios, con la obra pionera de Vicente de Salvá, publicada en 1846. Estas marcas han sido alabadas y también criticadas, su uso se generaliza pero parece todavía muy intuitivo y sin bases teóricas bien afincadas.

En cuanto a la metodología de los diccionarios diferenciales de las variedades americanas, hemos dicho que se basan en el contraste con otras obras lexicográficas. Estas corresponden tradicionalmente a diccionarios del español de España y sobre todo al diccionario académico. Estos diccionarios diferenciales aparecen al final del siglo XIX y representan una evolución importante de la lexicografía americana que producía sobre todo vocabularios y diccionarios de voces provinciales o provincialismos, que presentaban generalmente elementos exóticos del léxico americano con algunos apuntes enciclopédicos. También existían vocabularios o diccionarios de barbarismos o de voces corrompidas que mostraban el léxico americano como una desviación de la norma culta, es decir la norma de España, y que "ayudaban" a identificar estas voces americanas para corregirlas dando la equivalencia española correspondiente. En el siglo XX, gracias a los avances de la teoría lingüística, se comprende que la variación es inherente a la lengua, que las variantes americanas no son una corrupción y que cada una de ellas presenta normas cultas que pueden ser descritas y analizadas cualitativa o cuantitativamente. También un avance teórico importante es la concepción del español de España como variante de la lengua y no como núcleo prestigioso del complejo dialectal del español. En 
realidad, esta concepción es la que interviene en la realización de diccionarios diferenciales de variantes americanas y designa al español de España como modelo de comparación.

Hemos dicho que observaremos la variación diatópica en las obras literarias estudiadas para luego analizar cómo esta variación es tomada en cuenta por los traductores y cuáles estrategias son utilizadas para reconstituir el mensaje del autor. La lexicultura o cultura que se moviliza y se actualiza por las palabras, concepto presentado por Galisson, juega aquí un papel importante porque pensamos que cada lexema posee valores implícitos que son marcados por la pertenencia a una cultura particular. La dificultad de la traducción se presenta al intentar adaptarse a otra lengua que posee una variación como existe en todas las lenguas, pero con valores y cargas culturales diferentes. El léxico colombiano utilizado por Gabriel García Márquez es frecuentemente marcado y posee valores culturales de su caribe natal, describe particularidades lingüísticas de esa zona colombiana, costumbres, incluso olores, comidas típicas, etc. Es por eso que ese léxico debe ser tratado con mucha atención para tratar de conservar esos valores lexiculturales tan representativos de la variante descrita. Sin embargo, el autor de un texto traducido, como el de cualquier otro texto, tiene que también pensar en el público al cual va dirigido su traducción y a los valores lexiculturales de las palabras en el texto meta. Es por eso que la variación es un reto para el traductor.

\section{Obras lexicográficas utilizadas}

Nuestras observaciones sobre el léxico colombiano se fundamentan en obras lexicográficas diferenciales y globales, tres diccionarios de colombianismos y dos generales de la lengua española. El primer diccionario diferencial es el Nuevo diccionario de colombianismos publicado por el ICC en Bogotá en 1993. Este diccionario es una obra de referencia del léxico colombiano que hace parte del proyecto Nuevo diccionario de americanismos iniciado y dirigido por Günter Haensch y Reinhold Werner de la Universidad de Augsburgo. Es también la primera obra publicada de este proyecto cuya idea era producir diccionarios diferenciales en todos los países de América para ayudar al conocimiento léxico de todas variantes del continente. Se han publicado hasta ahora cinco diccionarios contrastivos y se preparan todavía tres, pero desafortunadamente el fallecimiento de los dos directores del proyecto y la falta de patrocinio para las últimas obras deja un panorama incierto para la finalización y publicación de estos trabajos. 
En el Nuevo diccionario de colombianismos, cada entrada se analiza de manera minuciosa y se describe con un juego de marcas gramaticales y sociolingüísticas bastante interesantes. Se mencionan igualmente marcas regionales, sinónimos y equivalencias, incluso en el español de España. En el prólogo de la obra se encuentran igualmente varios elementos y explicaciones lingüísticas de gran interés para los que estudian el léxico colombiano y para los que usan el diccionario. También al final de la obra, encontramos tres índices, el primero, muy extenso, presenta palabras del léxico de España y su equivalente en el léxico colombiano; los dos siguientes indican elementos enciclopédicos sobre la botánica y la zoología.

La segunda obra lexicográfica diferencial es el Breve diccionario de colombianismos de la Academia Colombiana de la Lengua que ha sido editado cuatro veces, publicado por primera vez en 1975 bajo la coordinación de José Antonio León, director de la Comisión de Lexicografía en esa fecha. La última edición revisada ha sido presentada en el año 2012 por la Comisión de Lingüística de esa Academia. Como su título lo indica es un trabajo poco extenso, pero de una gran calidad de redacción, coordinado por Carlos Patiño Rosselli, quien presenta la obra y explica lo que se entiende por colombianismo en el diccionario, es decir las palabras del léxico colombiano que no pertenecen a la lengua general. Pero ¿dónde se encuentra ese léxico general? Según el coordinador de la obra, en el diccionario de la Real Academia Española, que es la base de comparación del Breve diccionario de colombianismos. También se presentan las diferentes marcas gramaticales y sociolingüísticas, marcas regionales, y en algunas entradas además de la definición hay ejemplos tomados de obras literarias o forjados por los lexicógrafos. Las fuentes aparecen al final de la obra, asimismo una bibliografía del léxico colombiano y un anexo con los gentilicios de los diferentes departamentos del país. Esta obra se adquiere gratuitamente en la página de la Academia Colombiana.

El último diccionario diferencial es el Diccionario comentado del español actual en Colombia de Ramiro Montoya, tercera edición publicada en Madrid en 2006 por la editorial Vison Net, Colección Diccionarios. En la presentación de la obra se habla del español colombiano como variedad lingüística y en la introducción el autor explica las claves de lectura del diccionario. Las definiciones son redactadas de forma simple pero clara, sin embargo, hay marcas gramaticales que no se usan sistemáticamente en las acepciones. Encontramos igualmente marcas sociolingüísticas y regionales, ejemplos forjados en algunas entradas y notas de uso o de pronunciación. Esta tercera edición incluye dos suplementos léxicos, uno sobre el parlache o jerga que tiene sus raíces en las pandillas de jóvenes de Medellín, otro que compila léxico o expresiones que 
se usan principalmente en Madrid y no en Colombia, y algunas expresiones colombianas que no se usan en Madrid.

En cuanto a los diccionarios generales, empleamos el Diccionario de la lengua española (DLE a partir de aquí) de la Real Academia publicado en $2014 \mathrm{y}$ actualizado regularmente en la página Internet de esta institución. Corresponde a la vigesimotercera edición o edición del tricentenario. Es interesante anotar que en el preámbulo de la obra se señala la colaboración con las academias de América y de Filipinas y se evoca la unidad de la lengua española. Además, se presenta de manera muy general el trabajo de las Academias Americanas en cuanto a la inclusión de americanismos en el DLE. Este diccionario es un resultado histórico y cultural de una Academia que se funda en 1713 y que produce una serie de obras prescriptivas que comienzan con la publicación del primer tomo del Diccionario de autoridades en 1726. Actualmente, el titulo de la obra ha evolucionado y el diccionario se presenta como "general", descriptivo y sincrónico, con aproximadamente 93000 entradas y 195000 acepciones. Después del preámbulo, encontramos una serie de páginas que nos explican la forma de usar el diccionario, la estructura de los artículos lexicográficos, un juego de marcas complejo que incluye variedades americanas y regionales de España. Las marcas americanas, además de nombrar países, designan zonas más extensas como por ejemplo América Central o América. Un artículo puede ser muy complejo con información etimológica, varias acepciones y diferentes tipos de marcas.

El Pequeño Larousse ilustrado de 2012 hace también parte de los diccionarios generales utilizados. Esta obra es particular porque es un diccionario de lengua que presenta a la vez elementos enciclopédicos, en el artículo lexicográfico vemos las marcas, las informaciones etimológicas y la definición, a veces acompañados de ilustraciones, mapas, tablas o fotos. Esta edición es interesante porque corresponde a la del centenario puesto que la edición española del Petit Larousse illustré aparece en 1912 y es una adaptación hecha por Miguel de Toro y Gisbert. En esa época la obra seguía la nomenclatura de la Real Academia Española y contenía más de 10000 americanismos. En cuanto a las marcas del léxico de las variedades americanas, encontramos todos los países del continente y algunas con zonas más extensas como América, América Central o América Meridional. Para la lengua francesa, utilizamos las definiciones dadas por el Centro Nacional de Recursos Textuales y Lexicales o CNRTL. Este gran centro de lingüística asociado a laboratorios de investigación franceses agrupa diferentes obras lexicográficas en un portal léxico de acceso libre (http://www. cnrtl.fr/). 


\section{Novelas y traductores}

Como lo hemos ya mencionado, nuestro trabajo se focaliza en tres obras del escritor colombiano Gabriel García Márquez: Cien años de soledad, Crónica de una muerte anunciada y El amor en los tiempos del cólera. Consideramos que estas poseen elementos léxicos propios de la variedad colombiana que nos han servido para constituir un corpus léxico de colombianismos. Cien años de soledad, obra maestra del autor, fue publicada en 1967 en Argentina por la editorial Sudamericana y se ha convertido en clásico de la literatura mundial con más de 50 millones de ejemplares vendidos en todo el mundo. Gracias a esta obra, como lo evoca Ospina, Colombia, un país que resultaba olvidado, lejano, incluso "inquietante y paradójico", aparece de repente en la escena mundial. La historia de su redacción es apasionante y ampliamente conocida, Gabriel García Márquez explicaba que vivía modestamente en México con su esposa y que su situación económica era difícil, incluso no pudo enviarle a su editor Francisco Porrúa la totalidad del manuscrito porque no tenía los medios financieros para hacerlo. La obra fue un éxito inmediato y a pesar de que el autor no tenía un reconocimiento internacional fuera del ámbito latinoamericano, las traducciones de la obra aparecen rápidamente y se convierten a su vez en éxitos literarios. Como lo explica Marling, esta notoriedad es en gran parte ganada gracias a sus "gatekeepers" (guardianes): amigos, escritores, agentes, traductores, editores, etc., que a su modo contribuyeron al renombre del autor y ayudaron a moldear su imagen, primero en Colombia y luego a nivel internacional.

En Francia la situación fue diferente, la editorial Seuil tenía una colección conocida como "Cadre vert" en donde se publicaba la literatura extranjera traducida. Esta colección (que todavía existe) se focalizaba al principio en obras alemanas, pero fue poco a poco abriéndose a otras lenguas como el inglés y el español. Claude Durand, director de colección en esa editorial, conoce la novela de Gabriel García Márquez, según Dosse, gracias a Severo Sarduy que trabajaba allí como responsable de la sección española. Durand decide comprar los derechos de la traducción al francés y traducir la obra con la ayuda de su esposa Carmen; la novela traducida aparece en 1968 en Francia. La respuesta del público francés, como lo comenta Dosse, es muy matizada, las ventas de la obra son relativamente bajas aunque la crítica es buena. A principios de los años 70 la situación cambia y las ventas aumentan, la obra se convierte en un éxito para la casa editora pasando rápidamente a un millón de ejemplares vendidos. La reputación internacional del autor aumenta y los lectores franceses comienzan a apreciar profundamente al escritor colombiano. La colaboración entre Gabriel García Márquez y la casa editora Seuil se acaba rápidamente 
puesto que Claude Durand no puede adquirir los derechos de la traducción de las otras obras del autor porque que su precio había aumentado considerablemente. Claude Durand toma esto como un engaño imperdonable que modifica su percepción del escritor colombiano. Jean-Claude Fasquelle adquiere los derechos para la editorial Grasset y publica El otoño del patriarca y Crónica de una muerte anunciada.

Claude Couffon traduce estas obras y evoca su trabajo con la obra Crónica de una muerte anunciada que pudo traducir sin muchas dificultades puesto que el texto le parece muy claro y eficaz, es por esto que en Francia la obra fue publicada en 1981, es decir en el mismo año de la publicación en español. Claude Couffon es un hispanista reconocido que tradujo varias obras del autor colombiano. Un año después de esta publicación, Gabriel García Márquez recibe el premio Nobel de literatura y es aclamado mundialmente. Pero en Francia algunos periodistas lo atacan públicamente y artículos difamatorios son publicados en revistas como el Figaro magazine. Grasset continúa a publicar las novelas del autor; El amor en los tiempos del cólera aparece en Francia en 1987, dos años después de la publicación en español. Annie Morvan, traductora de la obra, conoce a Gabriel García Márquez en 1981 y el autor la cautiva inmediatamente. En esa época Le Nouvel Observateur le propone traducir un cuento del autor al francés y puesto que este se encontraba en París pudieron conocerse para trabajar en ese proyecto. Así se inicia una colaboración activa y una amistad inquebrantable. Gabriel García Márquez establecía generalmente lazos fuertes con sus traductores y los incitaba a crear porque le interesaba que su universo fuera comprendido por el lector en cualquier idioma.

\section{Corpus}

\subsection{Constitución del corpus}

Gracias al estudio de las obras en español y en francés constituimos un corpus inicial de trabajo en español. Luego, un estudio diccionárico nos permitió pulir el corpus inicial integrando o suprimiendo entradas. Paralelamente construimos un corpus en francés que contiene las traducciones del corpus español. Seguir el rastro de estas traducciones fue algunas veces complejo y necesitaba una atención particular. Actualmente contamos con dos bases de datos paralelas que contienen 800 palabras cada una, este número no es fijo y puede modificarse por varias razones. Primero, porque la nomenclatura de los diccionarios de colombianismos es bastante restringida y también porque en los diccionarios generales el léxico de 
las variantes americanas no aparece siempre con una marca diatópica. Algunas veces, una investigación diacrónica es necesaria para conocer el origen de la palabra y para identificar el uso colombiano. También, la forma de definir un colombianismo, es decir un "ismo" como lo hemos indicado en el marco teórico, entra en juego porque podemos caracterizarlo de una manera restrictiva o de forma amplia. No hemos incluido en el corpus expresiones fijas, pero las hemos identificado y en cambio, si hemos incluido palabras compuestas. Veamos, entonces, algunas observaciones sobre los datos obtenidos.

\subsection{Observaciones sobre el corpus}

Una vez creados los corpus paralelos en español y en francés, podemos compararlos y forjarnos una idea de la variación en general y de la traducción de la variación en el caso francés. Comentaremos algunos aspectos que nos parecen interesantes desde el punto de vista lexicultural.

Para empezar, queremos mencionar las voces de la fauna y de la flora que son americanismos de origen según la tipología definida por Jesús Gútemberg Bohórquez. Sin embargo, no podemos decir que la procedencia de estas palabras sea colombiana, pero las encontramos en los diccionarios diferenciales de nuestro estudio y por lo tanto las hemos incluido en nuestro trabajo. Además, pensamos que la definición de los “ismos" (colombianismos) no debe ser restrictiva, entonces, estas voces ganan su lugar en nuestro corpus sin problema alguno. Generalmente, éstas no presentan ninguna dificultad para traducirlas porque muchas de ellas han pasado al léxico francés como extranjerismos, a veces de forma directa. En los diccionarios generales, la marca americana no aparece en este tipo de palabras y solo podemos fiarnos en la etimología puesto que el origen de la lengua amerindia sí se explicita. Algunas veces, la definición del término también incluye indicaciones sobre su procedencia, usando frases como “originario/a de América”. Veamos algunos ejemplos (Imágenes 1 a 6) con las entradas "yuca” y "guayaba” que se encuentran en los dos diccionarios generales y en los diccionarios de colombianismos. En el Pequeño Larousse ilustrado algunas imágenes o fotos pueden acompañar la definición, siendo esto una característica de ese diccionario.

Finalmente, el Diccionario comentado del español en Colombia (que llamaremos DC), presenta una definición que ya hace parte del universo de García Márquez (ver Imágen 7).

Como lo explicamos anteriormente, estos términos no poseen marca diatópica en los diccionarios generales y se conserva únicamente la etimología de la lengua indígena, a veces con indicaciones del origen en la definición. En el corpus francés 
YUCA s.f. (voz taína). Planta liliácea de origen americano parecida al áloe, aclimatada en los países templados y con cuya raíz se elabora una harina alimenticia.

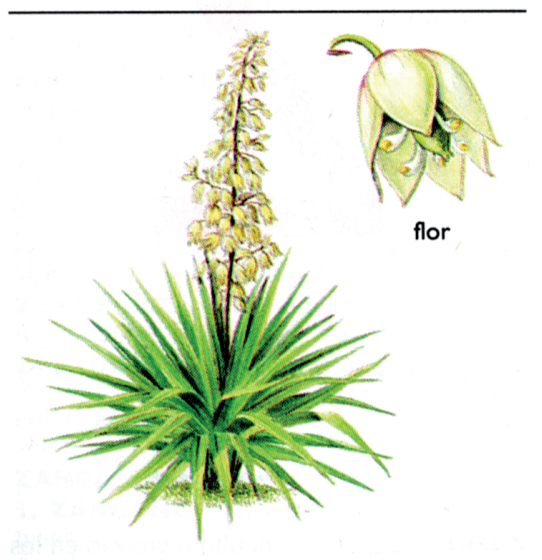

YUCA

Imagen 1: Pequeño Larousse ilustrado ("Yuca 1053").

GUAYABA s.f. Fruto del guayabo. 2. Antillas, Colomb., Nicar., Salv. y Urug. Fig. y fam. Mentira, embuste.

Imagen 2: Pequeño Larousse ilustrado (“Guayaba 504”).

encontramos todas las ocurrencias de la palabra "yuca" (6) traducidas como "manioc", palabra de origen tupí que entra directamente al francés (sin pasar por el español) a partir del siglo XVI. Las del término "guayaba" (3) se traducen "goyave", término que entra al francés en el siglo XVI por medio de una traducción de una obra del historiador español Gonzalo Fernandez de Oviedo y Valdés. Observamos, entonces, que la traducción de estas palabras es bastante simple y el término traducido conserva valores diatópicos americanos. Sin embargo, algunos americanismos de origen causan dificultades al traductor. Consideremos el caso del término "guacamaya" (ave) que tiene 11 ocurrencias en nuestro corpus y que aparece en los diccionarios que hemos venido mencionando. En España el término "guacamayo" tiene uso preferencial, como lo indica en el NDC la abreviación "E”: [E: guacamayo]. Pero en Colombia "guacamayo" designa un árbol (ver Imágenes 8 a 10).

El término se encuentra en el corpus francés traducido como "perroquet" con 8 ocurrencias y "cacatoès" con 3 ocurrencias. Pero usar "perroquet" despoja a esta realidad, que correspondería a "ara" en francés, de varias de sus características distintivas como sus colores típicos, su tamaño y su cola con plumaje largo. Si observamos la definición de "ara" en el CNRTL, encontramos 
yuca

De or. taíno.

1. f.. Planta de América tropical, de la familia de las liliáceas, con tallo arborescente, cilíndrico, lleno de cicatrices, de hasta dos metros de altura, coronado por un penacho de hojas largas, gruesas, rígidas y ensiformes, que tiene flores blancas, casi globosas, colgantes de un escapo largo y central, y raíz gruesa, de la que se saca harina alimenticia, y que se cultiva en Europa como planta de adorno.

2. f. Especie de mandioca.

3. f. colog. C. Rica. embuste (\| mentira).

4. f. Cuba, El Salv. y Nic. Raíz de la yuca que se come cocida en diversos platos típicos.

5. f. El Salv..... deuda (\| obligación de pagar).

6. f. El $\mathrm{S}$ al.... Cosa muy difícil de hacer.

andar de yuca un militar

1. loc. verb. $R . D o m$. Vestirse de paisano con fines particulares.

como yuca para mi guayo

1. loc. adv. colog. P. Rico. Con cuidado y esmero.

dar alguien yuca

1. loc. verb. colog. EC. Hacer un corte de mangas.

hacer alguien yuca

1. loc. verb. colog. Ec. Hacer un corte de mangas.

2. loc. verb. $R, D o m$. Cortejar a la enamorada.

meter una yuca

1. loc. verb. Nic. Amenazar con un daño.

ser alguien de yuca y ñame

1. loc. verb. Cuba. Ser severo, riguroso e intransigente.

bobo de la yuca

Imagen 3: DLE (“Yuca”).

\section{guayaba}

Voz arahuaca.

1. f... Fruto del guayabo, que es de forma aovada, del tamaño de una pera mediana, de varios colores, y más o menos dulce, con la carne llena de unos granillos o semillas pequeñas.

2. f. Conserva o jalea hecha con guayaba.

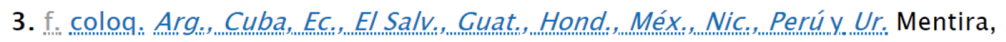
embuste.

4. f. El Salv. retentiva.

Imagen 4: DLE (“Guayaba”). 
estas características reconocidas igualmente en la cultura francesa. La traducción “cacatoès", utilizada una vez por los esposos Durand y dos veces por Annie Morvan, se aleja aún más del texto español porque representa un tipo de ave que no es originario de América, y un término que no es por lo tanto un americanismo de origen.

yuca $f$ tamb bot Planta de la familia de las euforbiáceas que alcanza hasta $2 \mathrm{~m}$ de alto. Tiene hojas palmeadas, de lóbulos profundos y flores pequeñas, poco vistosas. Su raíz tuberosa forma parte de la alimentación básica de los colombianos. Se cultivan numerosas variedades en climas cálidos y templados (Manihot esculenta) [cient: mandioca, tapioca]. | Tubérculo comestible de esta planta. * conseguir / ganarse la $\sim$ E- coloq Trabajar para conseguir los medios neccsarios de subsistencia $[E$, Col $+:$ ganarse el pan; $\mathrm{Col}+$ : conseguir / ganarse la papa]. I| sacar las s E-Boy, Cund, Huila, Llanos, NStder, Tol, Valle coloq Hacer sonar las articulaciones de los dedos de una mano, tirando de ellos con la otra $[E, A n t$, Risar: sacar (las) novias].

Imagen 5: Nuevo diccionario de colombianismos que llamaremos NDC ("Yuca 421-422").

guayaba $f E$ - Fruto del $\rightarrow$ guayabo, con el cual se preparan dulces, jaleas y el $\rightarrow$ bocadillo. | Grano de café, de mala calidad, por haberse secado en el cafeto antes de la cosecha. * palo de $\sim E$ - bot Árbol de la familia de las mirtáceas, de hasta $7 \mathrm{~m}$ de alto, de flores blancas, pequeñas, y frutos amarillos y globosos, comestibles ( $\rightarrow$ guayaba), de pulpa de color blanco o rosado, con numerosas semillas. La corteza de su tronco es de color café rojizo. El árbol crece silvestre o cultivado en climas cálido y templado (Psidium guayaba) [Col $+:$ guayabo]. $\| \sim$ agria $E$ - bot Fruto del $\rightarrow$ guayabo agrio.

Imagen 6: NDC (“Guayaba 210”).

Guayaba s. Fruta de muy delicioso sabor y olor.

(Se toma como fruta, en mermeladas o jalea, en jugo. Su consumo es tan extendido que García Márquez define "el olor de la guayaba" como la nostalgia del colombiano por su país). Véase bocadillo de guayaba.

Imagen 7: DC (“Guayaba 143”). 


\section{guacamayo}

\section{Del taíno huacamayo.}

1. m. Ave de América, especie de papagayo, del tamaño de la gallina, con el pico blanco por encima, negro por debajo, las sienes blancas, el cuerpo rojo sanguíneo, el pecho variado de azul y verde, las plumas grandes exteriores de las alas muy azules, los encuentros amarillos, y la cola muy larga y roja, con las plumas de los lados azules.

Imagen 8: DLE (“Guacamayo”).

GUACAMAYO s.m. (voz arauaca). Ave de América del Sur parecida al papagayo, de unos $90 \mathrm{~cm}$ de long., cola larga y plumaje de colores vivos.

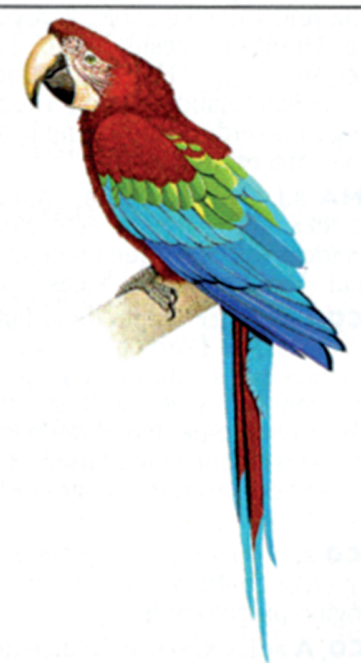

Imagen 9: Pequeño Larousse ilustrado (“Guacamayo 501”).

Veamos también el caso de algunas plantas cuyo origen no es americano, pero llegaron a América desde la época colonial y actualmente su cultura está extendida y arraigada en el continente americano. Es el caso del término "plátano" que aparece en nuestro corpus 10 veces, 9 para evocar el fruto que se come cocinado y una para designar la planta. Veamos la definición muy completa que presenta el NDC (ver Imagen 11).

Este término se traduce sistemáticamente como "banane", pero sabemos que "banane" designa en Colombia el "banano", fruto que se come crudo. Es una realidad del "plátano" que correspondería en francés a "plantain", "banane plantain" o "banane légume". La carga cultural de esa palabra solo se puede observar en el NDC y no en los diccionarios generales. En el caso del DLE, vemos que la tercera 
guacamaya $f E$ - zool Nombre de varias especies de grandes papagayos que habitan las selvas de las tierras cálidas. Alcanzan, en general, hasta $60 \mathrm{~cm}$ de largo y se diferencian entre sí sobre todo por el color de su plumaje (Ara spp.) [E: guacamayo] $* \sim$ bandera $E$ - zool Especie de $\rightarrow$ guacamaya, en su mayor parte de color escarlata. La parte baja del lomo, la rabadilla y las coberteras supracaudales son de color azul claro, las coberteras medias de las alas, amarillas, y el resto de las plumas, azules (Ara macao). $\| \sim$ azul y amarilla $E$ - zool Especie de $\rightarrow$ guacamaya de color azul brillante en la parte de arriba y amarillo encendido en la de abajo (Ara ararauna). $\| \sim$ roja y azul $E$ zool Especie de $\rightarrow$ guacamaya que presenta un plumaje llamativo en el que alternan los colores escarlata, azul y verde. De la punta de la cola al pico puede llegar a los $90 \mathrm{~cm}$ (Ara chloroptera). $\| \sim$ verde $E$ - zool Especie de $\rightarrow$ guacamaya de plumaje mayormente verde, con la frente escarlata y la parte baja del lomo, la rabadilla y las coberteras supracaudales de color azul (Ara militaris).

Imagen 10: NDC (“Guacamaya 202”).

acepción del término "plátano" corresponde al fruto, pero al leer la definición observamos que se trata de lo que en Colombia se llama "banano", es decir la baya que se come cruda y no a la baya que se come cocida. Puesto que este diccionario (DLE) recoge primordialmente el uso de España, concluimos que en ese país "plátano" designa lo que en Colombia se llama "banano". Y en este caso es a partir de esa realidad española que han trabajado los traductores (ver Imagen 12).

Esta observación es igualmente válida para el otro diccionario general de nuestro estudio (ver Imagen 13).

Los traductores no toman en cuenta la lexicultura de este término ni de la diferencia marcada entre "plátano" y "banano" en Colombia. En el caso de la frase "patacones de plátano verde" que aparece en la novela El amor en los tiempos del cólera, Annie Morvan propone la traducción "rondelles de bananes vertes". Esta frase en español es interesante porque presenta dos colombianismos: "patacón” y “plátano”. Un “patacón”, en la Costa Atlántica colombiana, corresponde a una rebanada gruesa de plátano que se aplasta y que luego se frita para acompañar las comidas. Es muy raro usar el banano para hacer este tipo de preparación. Estos elementos lexiculturales se encuentran bien descritos en los diccionarios de colombianismos de nuestro corpus, aquí presentamos las definiciones, por eso estas obras son de gran utilidad para el traductor (ver Imágenes 14 y 15). 
plátano $m$ tamb bot Planta de la familia de las musáceas que alcanza de 3 a $5 \mathrm{~m}$ de altura. Tiene hojas grandes, alargadas, de color verde claro y brillantes. Sus flores crecen en grandes racimos colgantes. El fruto, alargado, de cáscara verde y pulpa amarilla, es parecido al $\rightarrow$ banano, pero, a diferencia de éste, sólo puede ser consumido una vez sometido a cocción (ya sea frito, hervido o asado). Es planta de climas cálidos y templados; se cultivan numerosas variedades (Musa paradisiaca). | Fruto de la planta del $\rightarrow$ plátano [Col +: (plátano) hartón]. | Cund coloq Abultamiento grasoso que se forma en la cintura de las personas por falta de ejercicios y exceso de comida [ $E$ : michelín; Col: llanta; Valle: banano]. $*(\sim)$ amarillo $E$ Costa atl Fruto maduro de la planta de $\rightarrow$ plátano. Se lo llama así cuando, a diferencia del $\rightarrow$ (plátano) verde, ha madurado por completo y su cáscara se ha puesto de color amarillo [Col: (plátano) maduro]. $\|(\sim)$ banano $E$ - Fruta de una planta parecida al $\rightarrow$ plátano (Musa sapientum). A diferencia del fruto de éste, se puede comer crudo $[E$, Col +: plátano; Costa atl: (plátano) guineo; Cund: habano]. $\|(\sim)$ bocadillo E-Fruto de una planta parecida al $\rightarrow$ plátano (Musa acuminata). Se caracteriza por su tamaño pequeño y sabor dulce. $\|(\sim)$ cachaco $E$ Tol, Valle Fruto de una planta parecida al $\rightarrow$ plátano (Musa balbisiana). Se caracteriza por ser muy grueso y pequeño y se come cocido o frito [Cund: (plátano) popocho; Cund, Llanos: (plátano) topocho; NStder, Stder: mataburros]. $\|(\sim)$ guineo $E$-Costa atl Fruto de una planta parecida al $\rightarrow$ plátano (Musa sapientum). A diferencia del fruto de éste, se puede comer crudo $[E, \mathrm{Col}+$ : plátano; Col: (plátano) banano; Cund: habano]. $\|(\sim)$ hartón $E$-Fruto de la planta de $\rightarrow$ plátano [ $\mathrm{Col}+:$ plátano]. $\|(\sim)$ maduro $E$ - Fruto maduro de la planta de $\rightarrow$ plátano. Se lo llama así cuando, a diferencia del $\rightarrow$ (plátano) verde, ha madurado por completo y su cáscara se ha puesto de color amarillo [Costa atl: (plátano) amarillo]. $\|(\sim)$ manzano $E$ - Fruto de una planta parecida al $\rightarrow$ plátano (Crataegus stipulosa). Se caracteriza por su tamaño pequeño y su sabor semejante al de la manzana. Se puede comer crudo. $\|(\sim)$ popocho, var $(\sim)$ topocho $E$ Cund Fruto de una planta parecida al $\rightarrow$ plátano (Musa balbisiana). Se caracteriza por ser muy grueso y pequeño y se come cocido o frito [Cund +, Llanos: (plátano) topocho; NStder, Stder: mataburros; Tol, Valle: (plátano) cachaco]. $\|(\sim)$ topocho $E$ - Cund, Llanos $\rightarrow$ (plátano) popocho. $\| \sim$ verde $E$ Fruto verde de la planta de $\rightarrow$ plátano. Se lo llama así cuando, a diferencia del $\rightarrow$ (plátano) maduro, ha alcanzado su desarrollo normal, pero conserva aún su cáscara verde.

Imagen 11: NDC (“Plátano 329”).

Otra observación importante concierne los términos "pollera" (2 ocurrencias) y "pollerín" (8 ocurrencias). El primero es un término marcado diatópicamente en Colombia que se usa en la Costa Atlántica y designa un tipo de falda muy particular (falda larga y amplia). "Pollerín" también es un término típico de la Costa Atlántica, utilizado por Gabriel García Márquez en Cien años de soledad y en $E l$ amor en los tiempos del cólera. Estas realidades hacen parte de la cultura del caribe y de su folclor. "Pollera" aparece en los diccionarios generales de nuestro estudio, en el DLE como una acepción marcada diatopicamente con las indicaciones América Meridional, Nicaragua y República Dominicana. En el Pequeño Larousse ilustrado el término (cuarta acepción) está marcado únicamente con América Meridional. En el NDC encontramos la extensión geográfica del uso del término en Colombia (Costa Atlántica) y explicaciones sobre las características de este tipo de falda (ver Imágenes 16 a 19).

Cuando observamos las traducciones, encontramos los términos "jupe", "jupon" et "cotillon". "Jupe” corresponde a un término no marcado, es el hiperónimo "falda". Un "jupon" se pone debajo de una falda, corresponde a una "enagua". Es decir que, la traducción de los colombianismos por términos de nivel estándar hace que una parte del mensaje del autor se pierda puesto que "pollera" 


\section{plátano}

Del lat. platănus, y este del gr. $\pi \lambda$ átavos plátanos.

1. m. Árbol de la familia de las platanáceas, con una altura de 15 a 20 o más metros y amplia copa, tronco cilíndrico, de corteza lisa de tono claro, verde grisáceo, que se renueva anualmente, desprendiéndose en placas irregulares, hojas caedizas y alternas, de limbo amplio, palmeadolobuladas, con pecíolo ensanchado en su base, que recubre la yema subsiguiente. Es árbol de sombra, muy apreciado para plantaciones lineales en calles y paseos. Su madera blanca rosada, de dureza media, ofrece un bello jaspeado y se presta para trabajos de ebanistería.

2. $m$. Planta herbácea de grandes dimensiones, que en algunos países llaman banano. Pertenece a la familia de las musáceas. Alcanza una altura de 2 a $3 \mathrm{~m}$ y un fuste de unos $20 \mathrm{~cm}$ de diámetro, formado por las vainas de las hojas, enrolladas apretadamente unas sobre otras y terminadas en un amplio limbo, de unos $2 \mathrm{~m}$ de longitud y unos $30 \mathrm{~cm}$ de anchura, redondeadas en su ápice. El conjunto de estas hojas forma el penacho o copa de la planta.

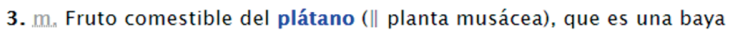
alargada, de diez a quince centímetros de longitud, algo encorvada y de corteza lisa y amarilla.

4. m. Pan, y. P. Rico, plátano grande.

\section{plátano falso}

1. m. Árbol frondoso, botánicamente incluido en los llamados arces, cuyas hojas, amplias y palmeado-lobuladas, recuerdan las del verdadero plátano de sombra.

\section{plátano fruta}

1. m. Cuban plátano que se puede comer crudo.

\section{plátano grande}

1. m. Fruto comestible de una planta musácea de origen indo-malayo, llamada higuera de Adán y muy cultivada hoy en el África tropical, que es mucho más grande, encorvado y verde al exterior que el plátano común.

\section{plátano guineo}

1. m. Fruto de una planta musácea del mismo género que la higuera de Adán, procedente de una especie originaria de la India y muy cultivada en América Central y las Antillas.

\section{plátano manzano}

1. m. . Cupa, Méx. y Perún Variedad de plátano cuyo sabor recuerda al de la manzana.

\section{plátano roatán}

1. m. Méx plátano grande.

\section{plátano verde}

1. m. Cuba.. Y Pan. plátano grande.

estar alguien más pelado que un plátano

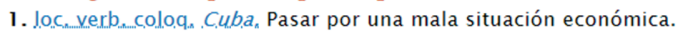

no comer plátano por no botar la cáscara

1. loc. verb, Perú Ser tacaño y cicatero.

mancha de plátano

Imagen 12: DLE (“Plátano”). 
PLÁtANO s.m. (lat. platanus, del gr. plátanos). Banano, planta y fruto. 2. Árbol platanáceo de hasta 3 o $4 \mathrm{~m}$. de alt., gran longevidad (de 500 a 2000 años), fruto en nuececilla,cuya corteza se desprende por placas y que suele plantarse en plazas y paseos. $\diamond$ Plátano falso Árbol de corteza lisa,con hojas de color verde oscuro por el haz y amarillo azulado por el envés.

Imagen 13: Pequeño Larousse ilustrado (“Plátano 806”).

patacón m. Rebanada frita de plátano ver-

de. $\| \sim$ pisao. Variedad de patacón.

Imagen 14: Breve diccionario de colombianismos (“Patacón 82”).

patacón $m \neq$ Rebanada de $\rightarrow$ plátano ver-

de cortada a lo ancho, despachurrada y frita

en aceite.

Imagen 15: NDC (“Patacón 307”).

\section{pollero, ra}

Del lat. pullarius.

1. m.... y. Persona que tiene por oficio criar y vender pollos.

2. m. y. . Méx. Persona que transporta trabajadores indocumentados a los Estados Unidos de América.

3. m. Lugar en que se crían pollos.

4. m. El. Salk. Hombre que transporta trabajadores indocumentados a los Estados Unidos de América.

5. f. pollero (II lugar en que se crían pollos).

6. f. Especie de cesto de mimbres o red, angosto de arriba y ancho de abajo, que sirve para criar los pollos y tenerlos guardados.

7. f. Andador en forma de campana, hecho de mimbres, que se pone a los niños para que aprendan a andar sin caerse.

8. $f$ Falda que las mujeres se ponían sobre el guardainfante y encima de la cual se asentaba la basquiña o la saya.

9. f. Am. Mer...Nic....y. R. Dom. Falda externa del vestido femenino.

10. f. Col. y Pan. Traje típico femenino de Panamá y de la costa norte de Colombia, que consta de una blusa y una falda de amplio vuelo, finamente bordadas.

Imagen 16: DLE (“Pollero, ra”).

y "pollerín" corresponden a una realidad cultural muy precisa y a unos valores que el escritor quiere hacer llegar al lector. El término "cotillon" que aparece marcado en el CNRTL como "vielli" ("anticuado") representa un tipo de falda usado sobre todo por las mujeres del campo. El uso de este término implica una 
Pollera s.f. Sitio en que se crían los pollos. 2. Cesto estrecho de boca y ancho de base que sirve para criar y tener pollos. 3. Utensilio de mimbre acampanado en que se ponía a los niños que todavía no sabían andar. 4. Amér. Merid. Falda de mujer.

Imagen 17: Pequeño Larousse ilustrado (“Pollera 813”).

pollera $f \neq z$ ool $\rightarrow$ (araña) pollera. Costa atl Prenda del vestido femenino consistente en una tela suelta, de diferentes hechuras, que se sujeta en la cintura y cubre la mitad inferior del cuerpo hasta las rodillas o más abajo [E, Col: falda; Ant: funda].

Imagen 18: NDC (“Pollera 332-333”).

pollerín $m E$ - Costa atl Falda interior de mujer [E, Col +: enagua].

Imagen 19: NDC (“Pollerín 333”).

indicación geográfica (el campo) y puede mostrar de alguna forma un tipo de variación diatópica.

Ahora veamos el término "sancocho" que aparece 7 veces en nuestro corpus y que representa un tipo de sopa muy consumido en Colombia que se prepara con carne, plátano y papas. Se traduce sistemáticamente por “pot-au-feu”, es decir por un término no marcado que no incluye en sus valores un uso regional particular. Aparece en los diccionarios generales y en el NDC (ver Imágenes 20 a 22).

SANCOCHO s.m. Amér. Cocido a base de carne,yuca, banano y otros ingredientes.

Imagen 20: Pequeño Larousse ilustrado (“Sancocho 908”).

\section{sancocho}

1. m. Alimento a medio cocer.

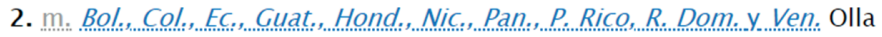
compuesta de carne, yuca, plátano y otros ingredientes, y que se toma en el almuerzo.

3. $m$. Bol., C. Ricay. $R$. Dom, revoltijo (\| conjunto de cosas sin orden).

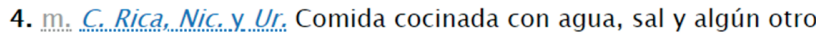
condimento.

5. m. despect. colog. Cubay. Ur. Comida mal preparada, insulsa, pobre en ingredientes.

6. m. Cuba. Resto de comida que se utiliza como alimento para los cerdos.

Imagen 21: DLE (“Sancocho"). 
sancocho $m \neq$ Sopa compuesta de carne, verduras, $\rightarrow$ (plátano) verde $\mathrm{y} \rightarrow$ yuca. $O B S$ : Según la región, pueden variar sus ingredientes. | coloq Barullo, mezcla confusa y desordenada de cosas [ $E$ : batiburrillo; $E$, Col +: embrollo].

Imagen 22: NDC (“Sancocho 365”).

“Cachaco/a” aparece igualmente en nuestro corpus 8 veces y representa en la Costa Atlántica una forma de llamar a las personas que vienen del interior del país, con un matiz despectivo. Aquí encontramos una diferencia dialectal marcada entre dos zonas del país en cuanto al uso de este término pues en el interior del país, y particularmente en Cundinamarca, este designa generalmente una persona de buenos modales y bien vestida. El DLE integra este colombianismo, pero recoge únicamente el uso del interior del país y no mencionan el de la Costa Atlántica. El Pequeño Larousse indica (segunda acepción) el matiz negativo que puede tener la palabra para designar una persona que cuida su apariencia de forma extrema, pero no el uso costeño, el cual está bien descrito en los diccionarios de colombianismos (ver Imágenes 23 a 27).

cachaco, ca

1. adj: Col. Dicho de un joven: Elegante, servicial y caballeroso.

2. m. y. . . Col., Persona bien educada.

3. m. y. f. rur. P. Rico, Español de buena posición económica.

4. m. despect. Perú. Miembro del cuerpo de Policía.

5. m. despect. Perú. militar (\| hombre que profesa la milicia).

Imagen 23: DLE (“Cachaco, ca”).

CACHACO, A adj. Colomb. Se dice del joven elegante, servicial y caballeroso. 2. Colomb., Ecuad. y Venez. Lechuguino, petimetre. $\bullet$ s.m. Perú. Desp. Policía. — s. P. Rico. Nombre dado en la zona rural de la isla a los españoles acomodados.

Imagen 24: Pequeño Larousse ilustrado (“Cachaco,a 179”).

Si observamos la traducción de "cachaca", en Cien años de soledad vemos que los esposos Durand escogieron el término "précieuse" que designa a una persona muy refinada, pero llegando a ser muy artificial y un poco pretenciosa, con una marca estilística "peyorativa" según el CNRTL. "Cachaca" es un término marcado geográficamente, que fue traducido por otro que varía únicamente de manera estilística. La traducción de Claude Couffon y de Annie Morvan nos parece más adecuada en este caso porque hay una indicación geográfica: "fille(s) (venues) des Andes". 
cachaco, -a 1. $m / f E$ - Persona bien educada, de buenos modales. | Ant, Cald, Cund Persona de apariencia elegante y bien vestida. OBS: Puede tener, según el contexto, una connotación despectiva, en el sentido de: lechuguino, petimetre. | Costa atl Natural del interior de Colombia [Costa atl $+:$ interiorano]. $O B S$ : Suele tener una connctación despectiva. $\mid 2$ adj $E$ - Bien educado, de buenos modales [E, Col + : correcto]. $A n t$, Cald, Cund Elegante, bien vestido [ $E$ : peripuesto; Col: V. perchudo]. OBS: Puede tener, según el contexto, una connotación despectiva, en el sentido de: lechuguino, petimetre. | Costa atl Relativo o propio del interior de Colombia. OBS: Suele tener una connotación despectiva.

cachaco $m E$ - Tol, Valle $\rightarrow$ (plátano) cachaco.

Imagen 25: NDC (“Cachaco,-a 63”).

Cachaco(a) s. y adj. 1. -Originalmente designaba un Caballero muy bien vestido. "¿Para dónde va tan cachaco?". 2. -Pasó a ser genérico de bogotano y luego de toda persona de la zona andina, calificada así por los costeños: "Cachaco, palomo y gato: tres animales ingratos". (Por esta generalización los colombianos nos dividimos en cachacos y costeños, excepto los cartageneros que son los cachacos de la Costa, por habitar una ciudad señorial).

Imagen 26: DC (“Cachaco(a) 91”).

cachaco, a adj. Bog. Dicho de una persona, de finas maneras, bien educada. Es muy cachaco, siempre atento con sus invitados. U. t. c. s. 2. Elegante en el vestir. 3. Costa Atl. Dicho de una persona, que es del interior del país, especialmente de Bogotá.

Imagen 27: Breve diccionario de colombianismos ("Cachaco,a 27").

Observemos ahora el término "bolillo" que aparece dos veces en Cien años de soledad y que designa en Colombia un tipo de arma generalmente de madera, alargado, usado por las fuerzas policiales. Este término se traduce por "bâton", que no muestra la carga lexicultural de la palabra porque un "bolillo" hace parte del traje de un policía colombiano y su uso está reservado a personas que pertenecen a esta institución o al gremio de los agentes de seguridad. 
Utilizar "bâton", es decir "palo", cambia completamente el mensaje, cualquier persona puede armarse de un palo, lo que equivale a decir que los policías no estaban bien equipados. Encontramos "bolillo" en todos los diccionarios de colombianismos y en los diccionarios generales el término aparece como una acepción que tiene la marca Colombia (ver Imágenes 28 a 32).

\section{bolillo}

\section{Del dim de bolo ${ }^{1}$}

1. m. Palo pequeño y torneado que sirve para hacer encajes y pasamanería. El hilo se arrolla o devana en la mitad superior, que es más delgada, y queda tirante por el peso de la otra mitad, que es más gruesa.

2. $m$. En la mesa de trucos, hierro redondo, de diez a doce centímetros de alto, puesto perpendicularmente en una cabecera, enfrente de la barra.

3. $m$. Horma para aderezar vuelos de gasa o de encaje.

4. $m$. Vuelo de gasa o de encaje.

5. $m$. Hueso a que está unido el casco de las caballerías.

6. $m$. Cols Instrumento cilíndrico, de unos $50 \mathrm{~cm}$ de longitud, que los agentes de la Policía usan como signo de autoridad.

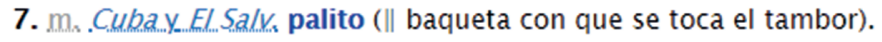

8. $m$. EG, rodillo (II cilindro para estirar la masa).

9. $m$. El Salv. y. Méx Cierto tipo de pan blanco.

10. m. pl. Barritas de masa dulce.

puro bolillo

1. expr... Méx. Nada, en absoluto.

valer alguien o algo bolillo

1. loc. verb. Méx valer muy poco o nada. encaje de bolillos

Imagen 28: DLE (“Bolillo”).

BOLILLO s.m. Palo pequeño cilíndrico al cual se enrollan los hilos para hacer encajes y pasamanería. 2. Hierro redondo colocado perpendicularmente en una cabecera, enfrente de la barra, en la mesa de billar. 3. Hueso al que se une el casco o uña de las caballerías. 4. Colomb. Porra de caucho o madera usada por la policía. 5. C. Rica. Palo pequeño para tocar el tambor. 6. Méx. Pan alargado, esponjoso, de corteza dura y con los extremos rematados con dos bolitas. $<$ bolillos s.m.pl. Barra pequeña de masa dulce.

Imagen 29: Pequeño Larousse ilustrado (“Bolillo 161”). 
bolillo $\mathrm{m}$. Instrumento cilíndrico de madera o goma, de unos cincuenta centímetros de longitud, que usan los agentes de policía y los vigilantes.

Imagen 30: Breve diccionario de colombianismos ("Bolillo 25").

bolillo $m$ tamb Palo grueso y fuerte que usan los agentes de policía como arma [E: porra; Cund: macana]. | Boy, NStder Rebanada de $\rightarrow$ plátano verde cortada de a lo ancho y frita en aceite [Col: patacón; Ant, Cald, Cauca, Valle: tronco].

Imagen 31: NDC (“Bolillo 50").

Bolillo I. -Porra de los agentes de policía. 2. -Rodillo para amasar.

Imagen 32: DC (“Bolillo 87").

Gracias a la marca "E” del NDC, vemos que el término equivalente a "bo lillo” en España es “porra”.

Terminemos está presentación con el término "parranda” que tiene 50 ocurrencias en nuestro corpus, 23 en Cien años de soledad, 16 en Crónica de una muerte anunciada y 11 en El amor en los tiempos del cólera. "Parranda" es una fiesta animada con música y bebidas alcohólicas. En el DLE el término aparece con diferentes marcas diatópicas, pero sin una marca colombiana que debería aparecer puesto que el término es de amplio uso en ese país. En el Pequeño Larousse tampoco aparece esa marca (ver Imágenes 33 y 34).

\section{parranda}

Etim. disc.

1. f.. Cuadrilla de músicos o aficionados que salen de noche tocando instrumentos de música o cantando para divertirse.

2. f. colog. Juerga bulliciosa, especialmente la que se hace yendo de un sitio a otro.

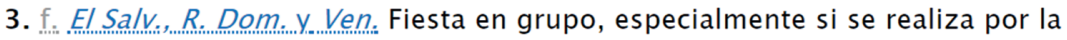
noche y con bebidas alcohólicas.

4. $\mathrm{f} . \mathrm{Ven}$. Manifestación folclórica en la que un grupo de personas canta y baila alrededor de una persona disfrazada, generalmente de animal, que es el tema central de las canciones.

Imagen 33: DLE (“Parranda”).

En los diccionarios de colombianismos, sobre todo en el DC, podemos observar que el uso del término está marcado dentro del país. 
PARRANDA s.f. Juerga, especialmente la que consiste en ir de un lugar a otro: salieron de parranda por los bares de la ciudad.

Imagen 34: Pequeño Larousse ilustrado (“Parranda 769”).

Parranda s. En la Costa, reunión de amigos para celebrar algo, fiesta popular para tomar trago, oír música y bailar. Es famosa la parranda vallenata. Véanse vallenato. Parrandear(se) v. (pronunc. parrandearse) Malgastar.

Imagen 35: DC (“Parranda 179”).

\section{parranda $f$ tamb coloq Muchedumbre o abundancia de personas o cosas.}

Imagen 36: NDC ("Parranda 304").

Es interesante observar que en francés el término se traduce por una gran cantidad de palabras, con estrategias particulares según el traductor. Los esposos Durand escogen sobre todo términos no marcados como "fête", "festin", "festivité", "noce”, "débauche”, “orgie” y "réjouissances". En su traducción vemos solamente un término familiar o anticuado (CNRTL): "ripaille". Claude Couffon decide servirse más de términos marcados diafásicamente en su traducción con palabras como "bombance", "nouba” y “cuite”. Usa además "noce”, "bacchanale”, "festin", "fête” y "beuverie". Annie Morvan también explora la variación estilística con los términos "bombance", "bamboche", "bamboula", pero puede utilizar otros términos no marcados como "fête", "réjouissances" y "festivités".

\section{A modo de conclusión}

De manera general, podemos decir que esta investigación ha permitido crear un corpus de colombianismos léxicos y sus traducciones que deseamos extender a otras obras del autor y a otros autores colombianos con el fin de presentar en libre acceso estos datos para los interesados en la variación en general y en el español de Colombia en particular.

En cuanto a las obras lexicográficas, podemos decir que los diccionarios de colombianismos presentan elementos de gran riqueza lexicultural, su uso es, por lo tanto, indispensable en la traducción de un texto literario colombiano. Los diccionarios generales, como ya lo hemos evocado, incluyen muchos diatopismos hispanoamericanos, Colombia es un país que aparece bien representado 
en cuanto al número de marcas diatópicas en estos diccionarios, pero con gran frecuencia las definiciones no reflejan los valores lexiculturales colombianos. Una tarea pendiente de la lexicografía colombiana es la creación de un diccionario global que sobrepase la tradición contrastiva y que incluya valores lingüísticos y culturales de esta variedad.

Con respecto a las traducciones, hemos observado varias estrategias para aprehender la variación diatópica. Si un término se observa marcado únicamente por esta variación, la estrategia de los esposos Durand es casi sistemática optando por la traducción a un término estándar en la versión francesa. Pero si el término varía además de forma estilística, los traductores prefieren conservar esta variación estilística en el texto en francés. Algunas tentativas de introducir elementos geográficos se observan en las traducciones de Claude Couffon y de Annie Morvan. Pero el único intento de traducir la variación diatópica aparece en el texto de Claude Couffon, con el término "canoa”. Este término es de gran valor simbólico porque es la primera palabra hispanoamericana introducida en un diccionario europeo, el diccionario de Nebrija publicado en 1495.

\section{Canoa nave deun madero, monorylumol.}

Imagen 37: (“Nebrija 38”).

Claude Couffon propone en su traducción “canot”, término marcado geográficamente, puesto que se utiliza sobre todo en el Canadá. En Francia se usa generalmente “canoë” y Annie Morvan así lo tradujo en El amor en los tiempos del cólera.

Terminaremos señalando que desde un punto de vista lingüístico-cultural los textos traducidos de nuestro corpus presentan difícilmente valores equivalentes en cuanto a la variación diatópica del texto origen y no ofrecen la misma riqueza lexicultural que el autor introduce en español. Es decir que los traductores, gracias a sus conocimientos y a su visión de la lengua y de la cultura del texto origen, proponen una nueva visión de ese texto pasando por valores lexiculturales de la lengua meta. Este estudio muestra que la variación diatópica del español se toma muy poco en cuenta en las traducciones y que la intencionalidad del autor en cuanto a esta variación desaparece. Sin embargo, el traductor introduce una idea general de esta variación geográfica, no por medio de valores diatópicos sino generalmente por medio de valores diafásicos de la lengua y de la cultura meta.

\section{Bibliografía}

Alvar Ezquerra, Manuel. “Lexicografía dialectal”. Estudios de Lingüística de la Universidad de Alicante, $\mathrm{n}^{\circ} 11,1996-97, \mathrm{pp} .79-108$. 
Bohorquez, Jesús Gútemberg. Concepto de "americanismo" en la historia del español: punto de vista lexicológico y lexicográfico. ICC, 1984.

Cuervo, Rufino José. Obras inéditas de Rufino J. Cuervo. Ed. José Félix de Restrepo. Ministerio de Educación Nacional, 1944.

Dosse, François. Les hommes de l'ombre. Portraits d'éditeurs. Perrin, 2014.

Galisson Robert. "Cultures et lexicultures. Pour une approche dictionnairique de la culture partagée”. Annexes des Cahiers de linguistique hispanique médiévale, Hommage à Bernard Pottier, vol n 7, 1988, pp. 325-341.

García Márquez, Gabriel. L’Amour aux temps du choléra. Trad. Annie Morvan. Éditions Grasset, 1987.

---. El amor en los tiempos del cólera. Oveja negra, 1985.

--.. Chronique d'une mort annoncée. Trad. Claude Couffon. Éditions Grasset, 1981.

--.. Crónica de una muerte anunciada. Oveja negra, 1981.

--.. Cent ans de solitude. Trad. Claude y Carmen Durand. Éditions du Seuil, 1968.

--.. Cien años de soledad. Sudamericana, 1967.

Marling, William. Gatekeepers: the emergence of World Literature and the 1960s. Oxford University Press, 2016.

Montes Giraldo, José Joaquín. Dialectología general e hispanoamericana: orientación teórica, metodológica y bibliográfica. ICC, 1995.

Montoya, Ramiro. “Guayaba.”/“Cachaco(a).”/“Bolillo.”/“Parranda.” Diccionario comentado del español actual en Colombia, 3a edición. Visión Net, 2006, pp. 143/91/87/179.

Nebrija, Antonio de. "Canoa." Dictionarium ex hispaniensi in latinum sermone o Vocabulario español-latino. 1495 [ ], p. 38.

Ospina, William. Pa que se acabe la vaina. Planeta, 2018.

Otálora de Fernández, Hilda. Léxico del habla culta de Santafé de Bogotá. ICC, 1997.

"Patacón."/“Cachaco, a."/"Bolillo." Breve diccionario de colombianismos. Coord. Carlos Patiño Rosselli, 4a edición. Academia Colombiana de la Lengua, 2012, pp. 82/25/23.

Pottier-Navarro, Huguette. “El concepto de americanismo léxico". Revista de Filología Española, vol. LXXII, n 3-4, 1992, pp. 297-312.

Quemada, Bernard. Les dictionnaires du français moderne 1539-1863. Didier, 1968.

Rabanales, Ambrosio. Introducción al estudio del español de Chile, determinación del concepto de chilenismo. Universidad de Chile, Instituto de Filología, 1953.

Rona, José Pedro. “¿Qué es un americanismo?”. Actas, informes y comunicaciones del Programa Interamericano de Lingüística y Enseñanza de Idiomas. El simposio de México, enero de 1968. Universidad Nacional Autónoma de México, 1969, pp. 135-148.

"Yuca.”/“Guayaba.”/“Guacamaya.”/“Plátano.”/“Patacón.”/“Pollera.”/“Pollerín.”/ "Sancocho."/“Cachaco."/“Bolillo."/“Parranda." Nuevo Diccionario de Americanismos. Tomo I, Nuevo diccionario de colombianismos. Dir. Günter Haensch y Reinhold Werner. ICC, 1993, pp. 421-422/210/202/329/307/332-333/333/365/63/50/304.

"Yuca."/“Guayaba."/“Guacamayo.”/“Plátano.”/“Pollera.”/“Sancocho."/“Cachaco.”/ “Bolillo."/“Parranda.” Pequeño Larousse ilustrado 2012. Larousse editorial, 2011, pp. 1053/504/501/806/813/908/179/161/769.

"Yuca."/“Guayaba."/“Guacamayo.”/“Plátano."/“Pollero-a.”/“Sancocho.”/“Cachaco.”/ “Bolillo."/"Parranda.” Diccionario de la lengua española, 23. a ed., actualización 2017. Real Academia Española. http://dle.rae.es/, consultado el 13 de junio de 2018. 


\title{
Traitors or Traders? A Brief Analysis of Chinese Translations of Latin American Boom Writers
}

In contrast to the abundance of articles on the literary reception of magic realism in contemporary Chinese literature, textual analyses of translation seem to have been neglected. This gap in literary translation research is where my question arises: what are we reading when we read the Chinese translation of Boom writers? Most of the existing studies are centered on the translation of cultural elements ${ }^{1}$. In these discussions, comments are focused on misunderstandings, errors, omissions, imprecisions, suppressions, and the use of domestication or foreignization methods, rather than on a textual analysis of the function of translation strategies. Hence I set out to address the possible difficulties that may emerge during the translation process, and to analyze the functional dimension of the shifts in the translation based on a close reading of texts.

Although many discussions focus their attention on "errors" in literary translation, some researchers have pointed out that translation strategies should not necessarily be considered problematic. Following Lawrence Venuti's opinion in his article entitled "World Literature and Translation Studies," he frames "errors" in literary translation in this way:

\begin{abstract}
It is extremely important that the shifts in the translation not be regarded dismissively as errors in need of correction [... .] the translator has applied his own interpretants in translating the novel, a concept of equivalence [...] and a fictional discourse [...], and these choices result in a nuanced interpretation. To treat a specific verbal choice as incorrect without careful examination of the context risks the unwitting assumption of a different interpretation as a standard of evaluation. (191)
\end{abstract}

\footnotetext{
1 Research papers on this topic include the master's dissertations (some of them not published) of graduate students majoring in Translation Studies, and $\mathrm{PhD}$ theses or monographs on the reception of Latin American writers in China. These Chinese translations of the following books have been studied: El coronel no tiene quien le escriba (Chang, Hsiu-Hui 2003); Cien años de soledad (Wu, Chia-Hua 2003, Zeng, Lijun 2012); El amor en los tiempos del cólera (Zhang, Yanan 2013, Chen, Yehua 2014); Discusión (Chen, Ning 2014); La ciudad y los perros (Chang, Yi-Tzu 2012, Yan, Jia-Yi 2016); Casa verde (Hou, Jian 2017), etc.
}

Yehua Chen, Universität zu Köln

¿ Open Access. () 2020 Yehua Chen, published by De Gruyter. (c) BY-NC-ND This work is licensed under a Creative Commons Attribution-NonCommercial-NoDerivatives 4.0 International License.

https://doi.org/10.1515/9783110673678-010 
Venuti proposes not to treat deviations or transformations in translated texts as "deficiencies", "errors that denaturalize the obsessive images and the effects, or destroy the narrative techniques” (Vázquez-Ayora, "La traducción” 5, my trans.), but as a compromise or negotiation between the translators and the language system and literary conventions of the receiving context. As for the methodology, Munday suggests a reflection on two levels, namely the macro- and micro-levels. On the macro-level, the cultural context related to the predominant ideology of the society is represented through varied registers, and in the text is manifested by the narrative point of view. On the micro-level, the narrative perspective and discourse semantics are realized through the lexico-grammatical choices of the translator (47). When working with translated texts, Munday emphasizes that "the question relates to the micro-features of the style of the translator and many possible macro-factors affecting it” (47). Following these ideas, I combine these aspects in my discussion. The examples quoted and discussed in this article are taken from Chinese translations of Boom writers published from 1980 to 2014.

\section{Typography and punctuation: techniques for both authors and translators}

One of the narrative techniques deployed frequently by Mario Vargas Llosa in his works is telescopic dialogue. In Conversación en La Catedral (1969), this tool is represented in Santiago's conversation with Ambrosio, which is continued throughout the novel and is inserted into multiple dialogues that take place in various situations between different characters. In the original text, this technique works with the change of introductory verbs: when Ambrosio or Santiago speaks, the sentence begins with the present tense "dice" (says), unlike other dialogues interspersed in their conversations, which begin with the past tense "dijo" (said). Native readers can perceive this difference in direct discourse (see examples 1 and 3), as well as in free direct and free indirect discourses (examples 2 and 3). Chinese is a language without variation in verb tenses, which suggests that Chinese texts would fail to reproduce this technique. To narrate a past action in Chinese, one must employ other linguistic elements to complement the context, with auxiliary particles and prepositions. In this case, "decir" (say) works as an introductory verb in a dialogue. "Says" in the present tense can be translated to “说” (shuō), or “说道” (shuōdao), but to express "dijo" (said) in the past, it is not enough to insert an auxiliary particle, such as 说 了/说过 (shuōle/shuōguò), which is more commonly used in the perfect tense. Instead, it is essential to add an exact adverb of time (yesterday, a while ago, etc.) in order to determine the verb tense. When Sun Jiameng's translation of excerpts from 
Conversación en La Catedral was released for the first time in the literary journal World Literature (Shijiè wénxué 世界文学) in 1987, the editor He Rong (it should be noted that it may also have been the translator's own decision) pointed out the untranslatable characteristic of this literary technique ${ }^{2}$ and explained their solution to the problem, which consists in separating the two levels of dialogue through a typographical change. Thus readers can identify the core and recurrent conversation between Santiago and Ambrosio with a variant of Song style that differs from the regular one. In 1993, the People's Publishing House of Yunnan published the first complete translation of the novel by Sun in book format, in which the change in typeface was maintained. Several different publishers have since republished Sun's translation $^{3}$. Whilst reading the 2011 edition, one perceives that it is even easier to distinguish the conversations, because the font difference is more evident (from Song style to Kai style), as we can recognize in the following examples.

Example 1 -Se casó con ese muchacho que iba a la casa -dice Santiago-. Popeye Arévalo. El pecoso Arévalo.

-El flaco no se lleva bien con su viejo porque no tiene las mismas ideas -dijo Popeye. [. . .]

-El coloradito, el de las pecas - dice Ambrosio-. El hijito del senador con don Emilio Arévalo, claro. ¿Se casó con él?

-No me gustan los pecosos ni los pelirrojos- hizo una morisqueta la Teté-. Y él es las dos cosas. Uy, qué asco. (Vargas Llosa 40-43, italics added)

“蒂蒂和那个总到我们家来的小伙子结婚了。”圣地亚哥说道,“他叫波佩

耶. 阿雷瓦洛, 就是那个雀斑脸阿雷瓦洛。”

“瘦子跟他老头子的关系不太好, 两个人的想法不一样。”波佩耶说道。

“她跟女朋友到赛艇俱乐部去了。”圣地亚哥说道, “我说你怎么还不接受 教训?”

“就是红脸膛,有雀斑的那位?”安布罗修说道, “参议员堂埃米略・阿雷瓦

洛的儿子? 我当然知道。蒂蒂小姐跟他结婚了?”

“我不喜欢有雀纴的,也不喜欢红头发的。”蒂蒂做了个怪相, “而他二者兼

备。鸣呵.真叫人恶心。”

2 “本书主要的一组对话, 即圣地亚哥与安布罗修的对话, 西班牙原文作陈述式现在时以示区 别, 但译成中文, 无法表达, 故用异体字排印, 加以标明, 请读者注意” (The main conversation in the book is the one that develops between Santiago and Ambrosio. In the original Spanish text, the present tense is applied to distinguish this conversation from other conversations, however it turned out to be impossible to reproduce this technique in the Chinese translation. Therefore, we decide to use variants of the font to show the difference. We hope readers will take this into account when reading the text) (He 6).

3 These editions include Shidai Wenyi Press, 1996; People's Literature Publishing House/99 Readers, 2011 and 2017; Shanghai Art and Literature Publishing House/99 Readers, 2015. 
(Vargas Llosa, Sun translation 1993: 32-35)

“蒂蒂和那个总到我们家来的小伙子结婚了。”圣地亚哥说, “他叫波佩耶·阿雷瓦洛, 就是那 个雀斑脸阿雷瓦洛。”

“瘦子跟她老头子的关系不太好, 两个人的想法不一样。”波佩耶说道。[......

“就是红脸膛, 有雀斑的那位?”安布罗修说道, “参议员堂埃米略·阿雷瓦洛的儿子 ? 我当然 知道。蒂蒂小姐跟他结婚了?”

“我不喜欢有雀斑的, 也不喜欢红头发的。” 蒂蒂做了个怪相, “而他二者兼备。鸣呵, 真叫 人恶心。”(Vargas Llosa, Sun translation 2011: 22-25)

In the second extract, two discourses with opposite ideas appear one after the other, which creates an ironic effect. A typographical variation thus seems crucial here to reduce possible confusion during reading.

The following case is more interesting as it deals with a conversation between Santiago (S) and Ambrosio (A) including both free direct discourse (first sentence in italics) and free indirect speech (second sentence in italics). Here the S-A conversation is inserted into another one of Santiago's dialogue with Popeye in the same place. The author situates the reader in the bar La Catedral with the changing point of view of the interlocutors and separates scenes by means of two indicators: verbs in the present tense "Ambrosio señala" (Ambrosio points), and different forms of addressing Santiago, “niño” (kid) by Ambrosio or “flaco” (skinny) by Popeye.

Example 2 [.. . ] qué riquita la cholita, flaco. La pareja de la mesa vecina se levantó y Ambrosio señala a la mujer: ésa era una polilla, niño, se pasaba el día en La Catedral buscando clientes. Vieron a la pareja salir a Larco, la vieron cruzar la calle Schell. El paradero estaba ahora desierto, Expreso y colectivos pasaban semivacíos. Llamaron al mozo, dividieron la cuenta, i y por qué sabía que era polilla? Porque, además de bar-restaurante, La Catedral también era jabe, niño, detrás de la cocina había un cuartito y lo alquilaban dos soles la hora. (Vargas Llosa 48, italics added)

看。向下可以看到一个轮廊模糊的人影和一件黑色的浴衣。这乔洛姑娘太够 意思了,瘦子。圣地亚哥和波佩耶旁边桌子上的一对男女站了起来。安布罗修 指着女的说:那是个夜蝴蝶, 成天到“大教堂”来拉客。二人人看到那一对走到拉 尔柯路上,穿过雪尔大街。汽车站上这时已经没有人了, 公共汽车和私人汽车虽 过去,一半都是空的。他们唤来侍者,分推着付了账。你怎么知道那女的是娆 女? “大教堂”是个酒吧、饭馆,还兼曲会旅馆，少爷，府房后面有一间小屋子，种

金是每小时两索尔。圼地亚歌和波佩耶沿拉尔柯路一面走着,一面欣赏着从商 店里出来的姑娘和用车推着嗰呀学语的婴儿的太太。在公园门口,波佩耶买了

(Vargas Llosa, Sun translation 1993: 40)

这乔洛姑娘太够意思了, 瘦子。圣地亚哥和波佩耶旁边桌子上的一对男女站了起来。安布 罗修指着女的说: 那是个夜蝴蝶, 成天到“大教堂”来拉客。二人看到那一对走到拉尔柯路上, 
穿过雪尔大街。汽车站上这时已经没有人了。公共汽车和私人汽车驶过去, 一半都是空的。他 们唤来侍者, 分推着付了账。你怎么知道那个女的是妓女? 大教堂是个酒吧、饭馆, 还兼幽会 旅馆, 少爷, 厨房后面有一间小屋子, 租金是每小时两索尔。(Vargas Llosa, Sun translation 2011: 28)

In example 3, the author manages to merge a discourse of the free direct style into the interior monologue of Santiago. In this paragraph, the appellation "Ambrosio" at the end of the inserted discourse helps to identify the addressee of this sentence, which is not Carlitos, who appears in the principal narration. It is obvious that the translator has sufficient knowledge of Vargas Llosa's literary techniques, which concedes him a certain authority to intervene with indications that are much more explicit than those in the original text.

Example 3 Pero se había emborrachado él, piensa, como ahora tú. Carlitos se levantó, desapareció en las sombras, la risita de la mujer que moría y renacía y el piano monótono: quería emborracharte a ti y el que se ha emborrachado soy yo, Ambrosio. Ahí estaba Carlitos de nuevo: había orinado un litro de cerveza, Zavalita, qué manera de desperdiciar la plata ¿no?

- ¿Y para qué quería emborracharme? -se ríe Ambrosio-. Yo no me emborracho jamás, niño. (Vargas Llosa 437-438, italics added)

圣地亚哥回想:实际上是他先喝醉了, 然后我才醉的。卡利托斯站了起来, 消失在黑暗中,女人哧哧的荡笑断断续续, 钢琴声显得很单调。安布罗修, 我本 想把你淮醉, 可我倒先醉了。卡利托斯又回来了:我尿了一公升的唓酒,小萨,你 瞧,我们这不是在浪费钞票吗?

“您为什么想把我淮醉?”安布罗修笑了,“我从来没喝碎过,少爷。”

(Vargas Llosa, Sun translation 2011: 329)

The intervention or mediation of the translator becomes more evident and direct when they introduce their own interpretation of the original work in the text through a typographical change. At the same time, the translator runs the risk of altering the original idea of the text in the case of a misunderstanding. For instance, in the following paragraph we can observe a small but creative “mistake” of the ingenious translator when transforming Santiago's interior monologue in indirect style into an interrogative speech by Ambrosio. In the Chinese translation, each question ends with "usted", the polite form of "you" in Spanish, as if Ambrosio were asking Santiago, while in the original text it is Santiago himself evaluating his friendship during his university days. 
Example 4 Pero ya sólo se veían porque San Marcos y la política a ratos nos juntaban, piensa, ya sólo por casualidad, ya sólo por obligación. ¿ Se veían ellos solos después de la reunión de su círculo?, ¿paseaban, iban a museos o librerías o cinemas como antes con él?, ¿ lo extrañaban a él, pensaban en él, hablaban de él? (Vargas Llosa 139, italics added)

圣地亚哥回想: 我们三人还继续见面, 那只是因为圣马可和政治把我们联系在一起, 仅仅是偶 然相遇, 仅仅是出于责任感。学习小组开会后他们两人会单独会面吗? 他们还跟以前一样跟您 一起参观博物馆、逛书店、看电影 (iban a museos, librerías o cinemas con usted) 吗? 他们思 念您 (extrañaban a usted) 、想您 (pensaban en usted) 、谈论您 (hablaban de usted) 吗? (Vargas Llosa, Sun translation 2011: 99, italics added)

利维亚和危地马拉的局势。圣地亚哥回想:我们三人还继续见面,那只是因为圣 马可和政治把我们联系在一起, 仅仅是偶然相遇, 仅仅是出于责任感。学习小组 开会后他们两人单独会面吗? 他们还跟以前一样跟您一起参观博物馆、遜书店、 看电影吗? 他们思念您、想您、谈论您吗?

Even so, does this change modify the overall image of the novel or the reading experience for those who have been reading around a hundred pages of the novel and have supposedly already familiarized themselves with the narrative technique of the author? This section of text consists of a series of rhetorical questions that Santiago asks himself reflectively: "Did they take walks or movies the way they did with him before? Did they miss him, think about him, and talk about him?" With the translator's change of personal pronoun from "him" to "you", these sentences appear to be Ambrosio questioning Santiago in a persuasive way that make him reflect on his past. However, this substitution does not necessarily seem odd, or make a big difference from the reader's perspective, since the conversation between Ambrosio and Santiago is embedded in the narration as a connecter of different scenes throughout the whole structure. This intervention is probably unnecessary, but it enriches the interpretation of the novel. The translator, whether consciously or not, starts to imitate the style of the author. This translation, although not in the most expected way, shows the "the gift of mimicry" claimed by Nabokov as one of the abilities that a great literary translator should possess. For the translator, the process of translation is also a process of learning the style of the author and "impersonating his tricks of demeanor and speech, his ways and his mind, with the utmost degree of verisimilitude" (Nabokov).

Pedro Páramo (1955) is another important novel of Latin American literature both in terms of its worldwide circulation and in terms of its Chinese reception. Typographically, the author Juan Rulfo separates different narrators with the use of italics and quotation marks. In the following examples we see that he locates the remembrance of Susana in young Pedro Páramo's conversations with his 
mother and grandmother with a dash. Since the dash is often used in literary texts to indicate the beginning of a dialogue, the author encloses Pedro Páramo's analepsis in Spanish quotation marks («») in an attempt to distinguish them from the principal discourse.

Example 5 -Sí, mamá.

«Pensaba en ti, Susana. En las lomas verdes [...] Tus labios estaban mojados como si los hubiera besado besado el rocío.»

-Te he dicho que te salgas del excusado, muchacho. (Rulfo 74)

“你说得对, 妈妈。”

“我想念你, 苏珊娜。也想念那绿色的山丘。[…. 你的嘴唇十分湿润, 好像经过朝露的亲 吻。”

“我跟你说过, 快从则所里出来, 孩子。” (Rulfo, Tu translation169-170)

-Vete, pues, a limpiar el molino.

«A centenares de metros, encima de todas las nubes, más, mucho más allá de todo, estás escondida tú, Susana. Escondida en la inmensidad de Dios, detrás de su Divina Providencia, donde yo no puedo alcanzarte ni verte y adonde no llegan mis palabras. "

-Abuela, el molino no sirve, tiene el gusano roto. (Rulfo 75)

“那你就快去把磨盘打扫一下。”

“你躲藏在几百公尺的高空里, 躲藏在云端, 躲藏在很远很远的地方, 苏珊娜。你躲在上帝 那无边无际的怀抱里, 躲藏在神灵的身后。我追不上你, 也看不到你, 连我的话语也传不到你 那里。”

“奶奶, 石磨不能用了, 螺丝坏了。” (Rulfo, Tu translation 171)

According to Luraschi (22), these methods are essential in Pedro Páramo, as it is a complex text with extended dialogues, fragmented discourses and omitted introductory words for utterances. Interestingly, the Chinese translation of these fragments reveals that the absence of variation in typography eliminates the indications carefully designed by the author, which creates an unexpected effect. As a result, the text becomes more complex, since it requires the active participation of the reader to identify the romantic memories of Pedro Páramo through the changes in narrator.

In this context, it is interesting to note Sun's strategy (also probably of the editor) to change the typeface of the dialogues in Conversation in the Cathedral, which serves as an auxiliary device to help understand the structure of telescopic dialogues. The indifference of Pedro Páramo's Chinese translator to the use of punctuation nevertheless implies a choice that breaks with the Chinese narrative convention. Often regarded as extra-textual elements, typography and punctuation are easily neglected in translation. In fact, both are part of a text and have semantic and pragmatic functions. The act of modifying them can cause qualitative changes to translated texts when they are linked to the narrative structure of a literary work. In this respect, translators should scrutinize the use of typography and punctuation. 


\section{Different translators, different styles}

As we can notice from the previous examples, free direct and indirect speech, as well as changes of perspective is literary devices that Latin American Boom writers employed frequently, so that different voices and planes of characters are interspersed with each other. For example, José Donoso used a lot of these resources in El lugar sin limites (1966), in which the main narrator, La Manuela, speaks from "yo" (I). This perspective is merged with the simultaneous interventions of actions and discourses of others.

Example 6 Va apurada: tan traicioneros los vinos nuevos. Se encerró en el retrete que cabalga a la acequia del fondo del patio, junto al gallinero. Pero no, no voy a mandar a la Lucy. A la Clotilde sí. (Donoso 13)

她(Ella)忽匀忙忙地走开了 (se fue apurada), 她(ella)把自己关进(se encerró)跨在院内水沟上 的则所里, 则所旁是鸡笼。他想(él piensa)还是算了吧, 别支使露西了(él piensa que mejor no, no mandar a la Lucy), 对, 就让克劳蒂去吧。(Donoso, Duan translation 198)

露茜(Lucy)象没听见似的醉醺醺地向前走去, 新酒的后劲可真不小。她(ella)进了(entró)鸡窝 旁边的则所里, 则所盖在院犄角的下水沟上。不, 我还是不支使露茜的好 (No, mejor que yo no mando a la Lucy)。干脆让克洛蒂尔德去吧。(Donoso, Zhou and Li translation 7)

If we analyze this fragment by focusing on the subjects and introductory verbs, it is clear that the author also opts for the use of the present tense to separate the mental activities of La Manuela from the principal narration:

(La Manuela ve que Lucy) va apurada: (y piensa que son) tan traicioneros los vinos nuevos. (Lucy) Se encerró en el retrete que cabalga a la acequia del fondo del patio, junto al gallinero. (La Mauela piensa/se dice así misma) Pero no, no voy a mandar a la Lucy. A la Clotilde sí.

(La Manuela sees that Lucy) is in a hurry: (and she thinks that) new wines are so treacherous. (Lucy) locked herself in the toilet that sits astride the ditch at the back of the yard, next to the chicken coop. (La Manuela says to herself) But no, I'm not going to send Lucy. But Clotilde. (my translation)

The first quotation is from the translation by Duan Ruochuan (1986), entitled Hell without Boundaries (in Chinese没有界限的地狱méiyǒu jièxiàn dì dìyù). There are two notable changes: firstly, the speaker's first speech about wine is eliminated and instead, La Manuela's viewpoint and the omniscient perspective on Lucy's activities are united in the same sentence; secondly, a free direct discourse in the first person is replaced by a free indirect discourse in the third person. Throughout the novel we can find other similar syntactic adjustments, which verifies the consistency of this strategy (see also example 9). Without direct explanations from the translator or editors, one can suppose, based on the 
translation, that it is a strategy in order to facilitate reading. The second translation with the title Bizarre Woman (in Chinese 奇异的女人 qiyì de nürén) was released one year later. It can be understood that the two translations target the same general reading public. Despite this, the translators of this version, Zhou Yiqin and Li Hongqin, chose precision over syntactic simplification in most cases, which preserves the stylistic features of the literary work.

Gabriel García Márquez goes further in terms of narrative experiments in $\mathrm{El}$ otoño del patriarca (1975). The novel is considered the most complicated work by García Márquez. It was translated for the first time into Chinese from Russian by Yi Xin in 1985. In 2014, Xuan Le accomplished a direct translation from Spanish. The stylistic differences between the two versions have provoked a debate among Chinese readers on the quality of translation. Xuan's translation has been especially criticized for its "lack of respect for the Chinese language" 4 . The controversy motivates me to make a comparison of some fragments that possibly generated difficulties in the translation process. The particular style of syntactic organization, change of point of view, and use of punctuation in this novel constitute a great challenge when it comes to translating it into Chinese. Many obstacles to translation have their origin in the divergences between two linguistic systems. The characteristics of the Spanish language allowed the author to strongly economize the narration with the use of free direct and indirect discourse. Thus, the voices of the characters are embedded in the narrator's speech, without previous indication or introductory verbs, and without punctuation such as colons, dashes, and quotation marks.

Example 7 dicho sea sin el menor respeto mi general, pero a él no le importaba la insolencia sino la ingratitud de Patricio Aragonés a quien puse a vivir como un rey en un palacio y te di lo que nadie le ha dado a nadie en este mundo hasta prestarle mis propias mujeres, aunque mejor no hablemos de eso mi general que vale más estar capado a mazo que andar tumbando madres por el suelo como si fuera cuestión de herrar novillas. (García Márquez 32)

. 请恕我说话直爽, 我的将军! ”然而使他感到受屈辱的与其说是巴特里西奥·阿拉戈内 斯的无礼, 围宁说是他的忘恩负义: “那是你说的话吗? 你, 像国王似的住在这儿。我把自己 生平从来不给别人的东西都给了你。我甚至连自己的娘儿们也奉送给了你！”( i Acaso es algo que tú puedes decir? Tú, vives aquí como un rey. Te he dado lo que jamás he dado a los otros

4 Since the new translation of El otoño del patriarca was released, several discussions have arisen regarding this text in Douban, a virtual online community where users comment and evaluate the books they have read. For instance, one criticism of Xuan's translation is "how can they publish a translation with eight 的in only one sentence, is this even Chinese?" (的 is a structural particle that unites the owner with its property, an adjective with the noun it describes, a subordinate adjective or relative sentence with its antecedent, etc.). See https://book. douban.com/review/6700704/. 
en mi vida. ¡Hasta te regalé mis propias mujeres!) 但这时巴特里西奥·阿拉戈内斯打断了他的 话 (pero en ese momento Patricio Aragonés le interrumpió sus palabras) : “不要谈这个了, 我的将军......按倒这些不幸的妇女、这些受折磨的母亲, 就像把小母牛按倒了打烙印那样按 倒她们......” (García Márquez, Yi translation 26, emphasis added)

请恕我不敬, 将军阁下, 然而他并不在乎帕特里西奥·阿拉贡内斯的无礼却在意他的忘恩负 义, 我让你在这宫殿里过得像个国王, 我给你的没有别人能给, 世上再没有谁能像我这样甚至 连自己的女人们都借给了你, 咱们还是别谈这个了把将军阁下, 我宁愿被阉了也不想把那些做 母亲的推倒在地, 好像她们是需要被烙印的小母牛似的 (García Márquez, Xuan translation 24)

This paragraph contains four levels of discourse: "The voice of the story is that of the basic narrator. Without any indication, space or connector, the Patriarch's words are reproduced first, and then followed by that of Patricio Aragonés, as if the narrator gave them the floor or as if they were snatched from them" (Rodríguez Herrera and Valverde Acosta 45, my trans.). In Yi's translation, there is an obvious transformation from free direct and indirect speech to direct quotation. Not only does he add an indication of the change of narrator, “但这时巴特里西奥.阿拉戈内斯打断了他的话” (but at that moment Patricio Aragonés interrupted his words), an interpolation that does not exist in the source text, but he also encloses each section of speech in quotation marks. Supplementary to this syntactic simplification, the translator divides the speech into shorter sentences with a vigorous tone like “你, 像国王似的 住在这儿” (You, live here like a king) that produces a dramatic effect. This is not an individual case, but is representative of systematic shifts that are maintained throughout Yi's translation. By checking the Russian translation ${ }^{5}$, it was verified that this stylistic transformation came from the Russian. We might hypothesize that all the changes in this Chinese translation derive from the intermediary text. In this regard, Xuan's translation shows closer adherence to the Spanish source text.

In addition, El otoño del patriarca is a text that contains an abundance of Spanish recursive prepositions such as "de" (of, from, by), "por" (for, by, because, through), and "con" (with). The frequent use of these elements enables the texts to gain an "expressive economy" (Vázquez-Ayora, "Estudios estilísticos” 164-165, my trans.). Together with the scarcity of punctuation marks, a particular narrative rhythm is well established, as the following illustration of interrogative parallelism demonstrates:

5 The Russian text “Осень патриарха” is available online: lib.ru/MARKES/patriarh.txt. 
Example 8 preguntándose asustado dónde podías vivir en aquella [...], dónde estará [...] en este trueno de [...], dónde te habrás perdido en la parranda sin término del maranguango y la burundanga y el gordolobo y la manta de bandera y el tremendo salchichón de hoyito y el centavo negro de ñapa en el delirio mítico del Negro Adán y Juancito Trucupey, carajo, cuál es tu casa de vivir de este estruendo de paredes descaradas de color amarillo de ahuyama con cenefas moradas de balandrán de obispo con ventanas de verde cotorra con tabiques de azul de pelotica con pilares rosados de tu rosa en la mano, qué hora será en tu vida si estos desmerecidos [...], cuál eres tú de estas mujeres [...] mientras él preguntaba a través de [...] (García Márquez 84-85, emphasis added)

而自己却心慌意乱地想道: “你怎么能在这里居住[..... 在发臭的水洼中间好像嗅到你像兰 花般香的气息 $[\ldots . .$. 怎样能在 $[\ldots . .$. 找到你 $[\ldots .$. . 怎样找到你在这黑色亚当和 $[\ldots . .$. 怎样找到 你的房子在这贫民窟的杂乱无章的建筑里 [...... 你的钟指在几点钟 [..... 在这些女人中间怎么 样能认出你来 [......] (García Márquez, Yi translation 77)

他惊恐地问自己你能住在这片骚乱中的哪个地方，在这里，拱起的 [....... ], 你气息的甘草 味道会在这里的哪个地方, 在这里, 婊子女儿的 [......], 你会迷失在哪一处无尽的寻欢作乐 中, 在这里, 充斥着[...... 你的家是这糟乱房屋中的哪一个, 在这里, 有你的家是这糟乱房 屋中的哪一个, 在这里, 有葫芦黄的斑驳墙壁主教长袍花边般的紫色纹饰鹦武绿的窗户地球蓝 的隔断以及粉如你手中的玫瑰色立柱, 你生命的时钟究竟走到了哪一刻, 如果在这个 [......], 你究竟是这些女人中的哪一个[......] (García Márquez, Xuan translation 68-69)

In this fragment, the "unpaused accumulation of complementary expansions confers the prose a great speed" (Iglesias 40, my trans.). The phonetic iteration of nouns and adjectives rhymed with "an", "a", and "o" grants a poetic character to the text, an aspect that is regrettably but inevitably lost in the Chinese translation. If we focus on the syntactic reconstruction of this expansive narration in Chinese, the comparison of the two translations seems very interesting. Xuan resorts to syntactic amplification by adding “在这里” (here it is) after each phrase initiated with an interrogative pronoun to convey the sense of "en este trueno" (in this thunder), "de este estruendo" (of this rumble), "esto(a)s" (these). She separates the continuous discourse with more commas than in the original text, thus producing several pauses that interrupt the speech with a deceleration effect, while at the same time presenting a more obvious parallelism. Yi's translation, while supposedly a faithful reproduction of the Russian version, is deprived of punctuation marks. It only includes one colon and two quotes at the beginning to enclose the sentences and also to indicate that it is an internal monologue. Instead of starting the questions with specific interrogative pronouns, Yi extends the sentences by altering the way of asking, with structures such as “怎样 (how) ... . . 找到你 (to find you) . . . . 在这 (in this)”, “怎样 能在这 (how can in this) .... . 找到你 (to find you).” Surprisingly, Yi's translation appears to be less conventional, since it consists of an uninterrupted flow of narration that even accelerates the rhythm of the original text. 
If we only take "domestication" and "foreignization" as analytical parameters, we may be able to ascertain a general tendency in each epoch. In this case, the tension between the two strategies influences the style of the translated text, and the discrepancy in their reception reflects the changes in translation norms in both the Chinese and Russian context. For instance, the reason for making changes that favor easier and more fluid reading partly lies in Chinese translators' "anxiety over lack of readability" because they "regard readability as their highest value" (Sun “(Un) translatability” 243). Shifts motivated by translation norms are perhaps the price that literary works have to pay in order to circulate in different countries and cultures.

\section{Ideology and translation}

There are several studies that show how ideological factors can affect the results of translation. For example, the suppression of the cannibalism scene in the Chinese translation from 1985 of El otoño del patriarca: "entró el egregio general de división Rodrigo de Aguilar en bandeja de plata [. . . coliflores y laureles, macerado en especias, dorado al horno" (141), was probably the result of faithfully following the Russian translation. Zeng Lijun found that in the first Chinese translation of Cien años de soledad by Gao Changrong (1984), translated from Russian and English, the last paragraph of chapter 19 about the aunt-nephew incest was deleted (Amaranta Ursula and Aureliano) (95). After a comparison, Zeng confirmed that the Russian version that was used as a reference retained a small part of the text, and in the English version there were no changes (97), which indicates possible self-censorship by the translator concerning taboo issues of sexuality.

Ideological factors can impact not only the final product of the translation, i.e. the text itself, but also during the whole translation process, including publication. Teng Wei's research (2011) reveals a predilection in the 1950s and 1960s for translating the political and revolutionary poems of Pablo Neruda, rather than his romantic verses. The publication of Octavio Paz's Pasión crítica was put on hold for many years because one of the retired editors, hired by the publisher to review the texts, evaluated the work as "not in accordance with Marx and Lenin's view on art and literature" (98). For similar reasons, Rayuela was criticized with comments such as "an anti-communist and anti-people novel", "inferior artistic techniques" (98), and its Chinese translation took several years to appear, and was finally released in 1996. 
As I stated at the beginning of this essay, there are enough discussions in which suppression and misunderstandings in translation are given greater weight than specific translation choices. The intention of this research is to study the extent to which the translation norms, which are comprised of ideology, social-cultural taboos, the linguistic system, and the literary tradition of a country, among other factors, can affect the translated text. Therefore I am more interested in analyzing small significant shifts on the basis of a close reading. To discuss the topic of ideology and translation, we need to go back to Donoso's El lugar sin límites, which can be considered an experimental novel due to its contents (inversion of gender) and narrative methods (changeable voices), which were notable when it was published in 1966, as well as in terms of the Chinese socio-cultural context of the 1980s (when the translation was published). Both translations contain a translator's preface that reveals different attitudes towards the main character, La Manuela. In one translator's empathic description of her misfortune, she is a transvestite who "wanders in this world of hell" (Donoso, Duan translation 5, my trans.), while in the preface of the other translation, La Manuela is depicted as a "deviator with an abnormal mentality" (Li 3). From these paratextual materials we can glimpse the dominant ideology on sexuality and gender during the period when the translation was produced. However, the following example demonstrates that ideological factors, individual preferences, and stylistic considerations, are all involved in the final translation decisions.

Example $9 \mathrm{Al}$ agacharse sobre el brasero de la Clotilde para tomar el brasero de la Clotilde para tomar carbones con una lata de conservas achatada, a la Manuela le crujió el espinazo. Va a llover. Ya no estoy para estas cosas. Hasta miedo al aire de la mañana le tenía ahora, miedo a la mañana sobre todo cuando le tenía miedo a [...]

Vieja estaría pero se iba a morir cantando y con las plumas puestas. En su maleta, debajo del catre, además de su vestido de española tenía unas plumas lloronas bastante apolilladas. La Ludo se las regaló hacía años para consolarla porque un hombre no le hizo caso...cuál hombre sería, ya no me acuerdo (uno de los tantos que cuando joven me hicieron sufrir). (Donoso $14-15$, italics added)

曼努埃拉用一个扁罐头盒弯腰去克劳蒂的火盆取炭火时, 脊梁骨嘎吱嘎吱响。要下雨了。 他(él)觉得已经干不了多少事了, 现在连早晨的冷空气都怕, 特别是早晨, 有那么多东西使他 (le a él)害怕[......]

他(él)可能老了吧, 可他(él)要唱着歌、头戴着羽毛去死。在他(su masculino)床 底下的手提 箱里, 除了他的(su masculino)西班牙舞服外, 还有一些被虫蛙得很厉害的长羽毛。这些羽毛 是几年前卢多为了安慰他 (para consolarle a él) 而送的, 因为有个男人不理睬他(no le hicieron caso a él)..... 是哪个男人来着, 他(él)已经想不起来了 (年轻时那么多使他 (que le hicieron sufrir a él)受罪的男人中的一个)。(Donoso, Duan translation 199-200, emphasis added)

当她(ella)弯腰从克洛蒂的炉灶里夹出几块红炭, 装到一个已经压扁了的罐头盒里时, 她的 (su femenino)脊椎骨嘎嘎直响。看来要下雨了, 我已经干不了这 些活了。现在我(yo)真怕这早 晨的空气, 尤其是怕那随之而来的一大堆使人不 舒服的感觉 [...... ] 
我(yo)也许已经老了, 可是就是马上会死掉, 也要玩个痛快。在床下的箱子里, 除了那件西 班牙裙子, 还有一些常年搁置、被虫蛙坏了的插在帽子上的羽毛。那是几年前卢多送给我(me regaló Ludo)的, 她是为了安慰我(para consolarme), 因为一个男人抛弃了我(me abandonó)。 哪个男人呢? 现在已经记不清了, 反正是年轻时让我(me hicieron sufrir)吃了苦头的那些小伙 子中的一个。(Donoso, Zhou and Li translation 9-10, emphasis added)

There are transformations in both translations: Duan modifies the internal monologues of La Manuela and changes them into narration in the third person, and in Zhou and Li's translation of the second fragment, we can observe a shift from third person to first person. What interests us most here, rather than the significant syntactic adjustments, is the different selection of the pronouns used to refer to La Manuela: “他” (he) or “她” (she). In the light of the author's choice of word, it is evident that he treats Manuela as female, without uncertainty, using, for example, "vieja" (old) and "consolarla"(comforting her), which are both exclusive determinants regarding gender. Oddly enough, in Chinese translations produced almost in the same year, Duan chose "he", while Zhou and $\mathrm{Li}$, who include some derogatory comments regarding the blurred gender category in the preface, opted for "she." Considering other shifts that occurred in the text, we deduce that they do not belong to the category of "zero grade translation" (Vázquez-Ayora, "La traducción" 8); that is to say, these translations contain several procedures that are not elementary translation strategies. Therefore, to understand the translational decisions, which cannot be reduced to only one factor, a multi-faceted analysis must be conducted of the general context and the translator's personal preoccupations.

The reversal of gender is also notable in El beso de la mujer araña (1976), another important novel for the Chinese reception of Latin American literature. The circulation of this book in China is a very particular case that deserves more discussion not only because of its contents of homosexuality, but also for the numerous re-editions of the translation that exist in the Chinese market, with five reissues since the first release in 1988, and at least two pirated editions. The number of reprints implies that this book is in fact one of the few long-term sellers of Latin American literature in China. In 2001, the novel was even included in a collection of "World Forbidden Books." I do not doubt that it has a wide readership regardless of the limited attention from Chinese literary critics in comparison to other famous works by Boom writers.

The 2004 edition, by Yilin Press, begins with a prologue written by Chen Kaixian. A brief and general introduction about Latin American literature, some biographical information about Manuel Puig, and a synthesis of his representative works is followed by an "anticipated" summary with commentary on the novel. Chen describes homosexuality as a social problem: "Homosexuality is 
analyzed from the social, psychological and physiological aspects, a social problem that increasingly attracts our attention. The author makes a serious analysis about the formation and existence of homosexuality" (6, my trans.). He mentions the sociohistorical meaning of the book, commenting that "not only it reveals the mentality of homosexuals, but also shows an aspect of the revolutionary battle in Latin America." We can see that the nuances have not changed much, even if this is a recent publication, from 2004. The issue of homosexuality is still a sensitive topic and requires a certain level of paratextual mediation. In line with Munday's insights, "shifts on the ideological point of view [...] are more likely to entail shifts in evaluation, or higher level editing, selection and the presentation of the target text. So, evaluation is added through the paratextual commentaries, stereotyping [...]” (89). Especially when it comes to taboo issues, the preventive function of the paratext is notable, as we see in the prologues of El lugar sin limites and El beso de la mujer araña. Rather than avoiding conflict with the censorial institution, the purpose of these prologues is to prevent the public, especially the more conservative part, from being too surprised when reading the stories (Tan 64).

At the textual level, the translator Tu Mengchao also encounters with the dilemma of choosing between "he" and "she" when Molina displays his ambiguous identity:

Example $10-$ Que me dejes un poco que me escape de la realidad, ¿para qué me voy a desesperar más todavía?, ¿querés que me vuelva loco? Porque loca ya soy. (Puig 85 , italics added)

“你应该允许我逃避现实。我为什么还要使自己更加感到绝望呢? 你想我成为疯子吗? 我现 在已经是一个疯女人了啊。”(Rulfo, Tu translation 67-68, emphasis added)

-...Y a la semana siguiente fui sola al restaurant.

- ¿Sola?

-Sí, perdoname, pero cuando hablo de él yo no puedo hablar como hombre, porque no me siento hombre. (Puig 68-69, italics added)

“...... 一个星期后，小女子我就一个人去了(me, a little girl, I went alone)。”

“小女子? (Little girl?)”

“对, 请原谅。每次我讲到他时, 我不能以男人的身分说话, 因为我不觉得自己是男人。” (Rulfo, Tu translation 54, emphasis added)

In Spanish the adjectives must be matched with the form of the noun or pronoun that determines the gender and number, a grammatical rule that does not exist in the Chinese language. In the first case, the translator distinguishes "loco" from "loca", respectively "crazy" in masculine and feminine form, with “疯子” (fēngzi, crazy person, neutral) and “疯女人”(fēng nürén, crazy woman). The difficulty of translating the second dialogue into Chinese lies in the 
repetition of "sola", the feminine form of "alone" with regard to Valentín, which requires the translator to think of a one-word expression that can, ideally, convey both the sense of "alone" and Molina's female identity at the same time. Tu renders “sola” into “小女子” (xiăonứzi), which literally means "little girl", and is a modest appellation in Chinese, normally used by young girls when they refer to themselves to show humility and shyness. The use of this expression places the narrator in the Chinese context, with Molina speaking like a Chinese person, and thus delineates the figure of a delicate woman. Again, the specific translation choices show heterogeneous thinking that differs from what the prologue represents.

\section{Concluding remarks}

As this research is still ongoing, I can only provide some preliminary concluding thoughts. Existing comparative studies on the translation of Latin American works into Chinese emphasize a general trend from domestication to foreignization strategies, especially in retranslations. However, if we reduce ourselves to this conclusion, we will overlook a more diverse panorama, as exemplified in this study. Different translators with a similar background who are publishing their texts around the same time nonetheless select different translation strategies to achieve a certain narrative style. There are also discrepancies in the translation choices made regarding how to translate the same sensitive topic in the same period, revealing that some narrative novelties of the Latin American Boom fiction did not fit well into the Chinese context during the major period of their reception, or even later. Even so, shifts in translation deserve a textual analysis without addressing all the "errors" or "misunderstandings," as they may appear to be, since they imply decisions that were not taken lightly.

Our fascination with the idea of shortening the distance between two cultures, of sharing literature in different languages, of accomplishing a free circulation of literature without borders, and of undermining the Tower of Babel, which symbolizes the limited capacity of human communication, sometimes causes us to forget about the obstacles that literary works have to overcome while traveling the world. Among all these difficulties, perhaps we should employ the term "untranslatability" in a more careful way. I find it inadequate to say that a word, a text, or an author is untranslatable only from the perspective of the original text. Admittedly, there is a certain challenge to translating texts into another language, as the culture, grammar, and vocabulary of that 
language must be considered. But this does not mean that it is "untranslatable," as to translate is to choose and to compensate. As Cees Koster affirms, "it is the translator's task to make choices from the repertoire of possible means to bring about analogous effects and a corresponding narrative” (151). Behind each translation, there is a living person who works months and years, and behind each choice there is a reason. Thus, "translator, trader," proposed by Douglas Hofstadter as an alternative to the famous notion "traduttore, traditore," might be a more suitable approach, according to which we scrutinize and set forth an analysis of translations.

\section{Works cited}

Donoso, José. El lugar sin límites. Joaquín Mortiz, 1971.

--.. "Meiyou jiexian de diyu." Zhoumo yishi. Trans. Ruochuan Duan. North China Literature and Art Publishing House, 1986.

---. Qiyi de nüren. Trans. Yiqin Zhou and Hongqin Li. Culture and Art Publishing House, 1987.

García Márquez, Gabriel. El otoño del patriarca. Penguin Random House, 2014.

--.. Zuzhang de moluo. Trans. Xin Yi. Shandong Art and Literature Press, 1985.

---. Zuzhang de qiutian. Trans. Le Xuan. Nanhai Publishing Company/ Thinkingdom, 2014.

Iglesias, Julio Calviño. "El ritmo prosístico en El otoño del patriarca." Anales de literatura hispanoamericana, no. 12, 1983, pp. 29-50.

Koster, Cees. "Literary translation.” Translation: A Multidisciplinary Approach. Ed. Juliane House. Palgrave Macmillan, 2014, pp.140-157.

Luraschi, Ilse Adriana. "Narradores en la obra de Juan Rulfo: Estudio de sus funciones y efectos." Cuadernos Hispanoamericanos, no. 308, febrero, 1976, pp.5-29. www.cervan tesvirtual.com/nd/ark:/59851/bmc1z4p7, last visit 12/01/19.

Munday, Jeremy. Style and Ideology in Translation: Latin American Writing in English. Routledge, 2008.

Nabokov, Vladimir. "The art of translation.” New Republic, 04/08/1941, https://newrepublic. com/article/62610/the-art-translation, last visit 19/01/19.

Puig, Manuel. El beso de la mujer araña. Seix Barral, 2001.

-. Zhizhunü zhiwen. Trans. Mengchao Tu. Yilin Press, 2008.

Rodríguez Herrera, María Elia, and Carmen María Valverde Acosta. "Los estilos indirecto y directo libres: Un aporte a su definición.” Revista de Filología y Lingüística de la Universidad de Costa Rica, no. 1-2, 1981, pp. 43-48.

Rulfo, Juan. Hu'an lu'erfu zhongduanpian xiaoshuoji. Trans. Mengchao Tu. Foreign Literature Press, 1980.

---. Pedro Páramo. Cátedra, 2010.

Sun, Yifeng. "(Un)translatability and cross-cultural readability." Perspectives. Studies in Translation Theory and Practice, vol. 20, no. 2, 2012, pp. 231-247. doi.org/10.1080/ 0907676X.2012.659746.

Tan, Zaixi. "Censorship in Translation: The Dynamics of Non-, Partial and Full Translations in the Chinese Context." Meta, vol. 62, no. 1, 2017, pp.45-68. doi:10.7202/1040466ar. 
Teng, Wei. Bianjing zhi nan. Ladingmeizhou wenxue hanyi yu zhongguo dangdai wenxue

(1949-1999). Peking University Press, 2011.

Vargas Llosa, Mario. Conversación en La Catedral. Alfaguara, 2004.

---. Jiuba changtan. Trans. Jiameng Sun. People’s Literature Publishing House, 1993.

--.. Jiuba changtan. Trans. Jiameng Sun. People’s Literature Publishing House/99 Readers, 2011.

Vázquez-Ayora, Gerardo. "Estudio estilístico de El otoño del patriarca, de Gabriel

García Márquez.” Dispositio, vol. 2, no. 5/6, 1977, pp. 160-181. www.jstor.org/stable/ 41491118, last visit 12/01/19.

---. “La traducción de la nueva novela latinoamericana al inglés." Babel, vol. 34, no. 1, 1978, pp. 4-18.

Venuti, Lawrence. "World literature and translation studies." The Routledge Companion to World Literature. Eds. Theo D'haen, David Damrosch, and Djelal Kadir. Routledge, 2012, pp. 180-193.

Zeng, Lijun. Ma'erkesi zai Zhongguo. China Social Sciences Press, 2012. 


\section{"Tante cose venivano pubblicate ma hanno dovuto aspettare un altro momento": la literatura latinoamericana y sus re-traducciones}

\section{Introducción}

Los estudios sobre la recepción de la literatura latinoamericana en Italia se han centrado, por lo general, en el análisis de la cantidad de títulos publicados o en la recepción de obras y autores específicos. El ámbito crítico todavía carece de una visión de conjunto en la que el objeto libro se analice en relación con las dinámicas editoriales. A no ser por el trabajo de Stefano Tedeschi All'inseguimento dell'ultima utopia, donde se delinea una historia de la recepción a través del análisis de traducciones y reseñas que el autor interpreta a partir de una perspectiva socio-literaria, los estudios de recepción sobre la difusión de la literatura latinoamericana en Italia no cuentan con un estudio que tome nota de cómo evolucionaron las dinámicas internas al ámbito literario con respecto a las dinámicas editoriales y culturales italianas de 1950 en adelante.

Este tipo de investigación supone repensar el análisis de la recepción a partir del estudio de las modalidades a través de las que se cumple el encuentro entre "mundo del texto" y "mundo del lector" (Ricoeur 228-263) tanto desde un punto de vista socio-literario como desde un punto de vista editorial, incluyendo todas esas praxis que se dan alrededor de un libro y que, cuando se identifican, permiten una visión más amplia del fenómeno receptivo y facilitan la identificación de las modalidades de acceso, incluyendo "los espacios, los gestos y las costumbres” (Chartier 17), que la comunidad de lectores -en este caso italianos- ha utilizado para leer textos procedentes de América Latina.

Tomando como punto de referencia al estudio de Chartier L'ordre du livre, un texto puede aparecer en un contexto cultural en diferentes épocas y bajo diversas modalidades (24-30). Esto comportará una aproximación diferente de la comunidad lectora hacia un determinado libro y, en consecuencia, también un acercamiento distinto a su recepción y a su inclusión en el campo cultural. Sin embargo, la primera recepción no es la del público, sino que se da en primer lugar en los ámbitos editoriales -que supuestamente deciden si apoyar o no

Sara Carini, Università Cattolica del Sacro Cuore

Ә Open Access. (C) 2020 Sara Carini, published by De Gruyter. (c) BY-NC-ND This work is licensed under a Creative Commons Attribution-NonCommercial-NoDerivatives 4.0 International License.

https://doi.org/10.1515/9783110673678-011 
una traducción y establecen el aspecto que tendrá un libro- y, en segundo lugar, en el ámbito cultural especializado, donde trabajan profesionales de la cultura más o menos vinculados con el mundo editorial y literario.

Como afirma Alberto Cadioli, el estudio de la relación entre editoriales y libros editados ayuda a comprender cómo se ha desarrollado la oferta literaria porque permite comprender las razones que conforman la base de una acción editorial (11). Pero la oferta propuesta por una editorial no puede moverse libre dentro del campo cultural y literario, se encuentra bajo el control de las dinámicas que económica, política y literariamente definen las modas y las pautas de la oferta literaria y de la cultural global. A nivel de recepción, aproximarnos al análisis de los fenómenos culturales que se desarrollan alrededor del objeto libro permite valorar los modos de inserción aplicados a un libro en traducción y permite, cuando esto sea posible, considerar la cantidad de recursos que se han invertido en la edición de un libro y también la postura que mantuvieron los medios culturales y literarios. De hecho, conocer el grado de disponibilidad y el tipo de competencias que un campo cultural puso a disposición de una literatura extranjera es el primer dato de interés a la hora de comprender cómo se ha desarrollado su difusión en un campo literario y cultural diferente al original, más allá de la consideración de la simple cuota "virtual” de lectores que el libro puede alcanzar por haber entrado en un catálogo editorial extranjero.

\section{Casos de estudio: Farabeuf y Paradiso en los siglos XX y XXI}

Siguiendo este enfoque, lo que proponemos en este estudio es el análisis de las reseñas a dos ediciones diferentes de las novelas Farabeuf, de Salvador Elizondo, y Paradiso, de José Lezama Lima, editadas en 1970 y 1971 respectivamente por las editoriales il Saggiatore y Feltrinelli y, en 2018 y 2016, por las editoriales LiberAria y SUR. Nuestro objetivo es identificar las dinámicas que entraron en juego a la hora de introducir un texto al público. Con esta aproximación queremos delinear las características del ámbito de recepción en el que tuvieron que insertarse los textos latinoamericanos en traducción y, en particular, nos centraremos en las reseñas que se produjeron tras la primera y la última edición de ambas novelas porque nos interesa comparar la primera recepción, que se dio en los años del primer boom de la narrativa latinoamericana en Italia, con la última, que, en cambio, se dio en un nuevo contexto de 
referencias literarias, en el que predominan la voz de los narradores nacidos alrededor de los 70 y el mito de Roberto Bolaño.

\subsection{Premisas necesarias: el campo literario italiano y la literatura latinoamericana}

La recepción de los latinoamericanos en Italia fue bastante peculiar. Para delinearlo de forma rápida nos parecen esclarecedoras las palabras con las que Italo Calvino describió la importancia de la literatura latinoamericana para Italia en una entrevista de 1984. En esta ocasión, el autor italiano, importantísimo para el contexto de las traducciones de latinoamericanos al italiano debido a su papel de asesor editorial para Einaudi, afirmaba rotundamente que la oficialidad de las palabras de algunos autores latinoamericanos lo fastidiaba, porque detestaba que un escritor se volviera un personaje oficial y a los escritores involucrados en causas políticas prefería aquellos que sabían transmitir un espíritu internacional (Riccio 11). Pero aludiendo todavía más a las dinámicas editoriales que se dieron alrededor de la literatura latinoamericana Calvino admitía, de forma implícita, un desfase entre el campo cultural italiano e hispanoamericano cuando, con respecto a la traducción de la obra de Alejo Carpentier hecha por Longanesi en los años 50, afirmaba que: "Tante cose si pubblicavano ma hanno dovuto aspettare un altro momento" (Riccio 11$)^{2}$.

Aunque se trate de una opinión personal, las palabras de Calvino son muy interesantes por más de un motivo. En primer lugar, su “odio” a los escritores oficiales nos parece representativo de la opinión general que el campo cultural italiano mantuvo hacia la literatura latinoamericana a lo largo de cuatro décadas, entre 1950 y 1990. El estudio de los documentos de archivo editoriales hechos hasta ahora ${ }^{3}$ informa sobre las dificultades que el ámbito editorial italiano enfrentó para incluir en sus catálogos textos demasiado políticos o vinculados con una posición socio-política demasiado evidente, con lo que es posible imaginar cierto recelo hacia la producción literaria latinoamericana, sobre todo a raíz de los enfrentamientos, políticos y sociales, que caracterizaron los años 70 italianos. A lo largo de toda la segunda mitad del siglo XX la recepción editorial de la literatura latinoamericana vivió altibajos constantes: aunque se tradujeran muchísimos títulos el interés del campo cultural y literario se veía influido

1 Como lo explicaremos más adelante: no consideraremos las reseñas a las ediciones Rizzoli y Einaudi de la novela de Lezama Lima.

2 "Muchas cosas se publicaron pero tuvieron que esperar otro momento" [traducción mía].

3 Véase Carini, "Tra mediazione” y "Ciro Alegría”. 
por una lectura política y no literaria de las obras. En nuestra opinión esto causó el encubrimiento de muchas de las calidades literarias de los textos latinoamericanos y, al mismo tiempo, la imposición de estereotipos que facilitaban aquellos textos más fácilmente ubicables en un contexto determinado como lo fue, a partir de 1967 y de la aparición de Cien años de soledad, el del realismo mágico (Carini, “Etiquetas literarias”). De esta forma, la referencia hecha por Calvino a un desfase en el interés que caracterizó la mirada de los italianos hacia la literatura latinoamericana es, quizás, la admisión más sincera de los obstáculos que el campo editorial italiano encontró a la hora de interpretar y trasladar a otro contexto las obras procedentes de América Latina.

\section{2 ¿Por qué las reseñas?}

A partir de estos motivos pensamos que el análisis de las reseñas pueda representar un método adecuado para establecer qué esquemas interpretativos se utilizaron para leer las obras latinoamericanas y, al mismo tiempo, para empezar a tomar nota de cuánta distancia existía entre el campo cultural italiano y las obras latinoamericanas. Desde este punto de vista el análisis de la recepción a través de las reseñas mide las décimas de la acogida reservada a cada literatura en traducción y finalmente ayuda a identificar todos aquellos elementos que, ajenos a la literatura, contribuyeron a la formación del capital literario de los latinoamericanos en Italia (Casanova 31).

Por lo que se refiere a nuestro objeto de estudio, las primeras traducciones de Paradiso y Farabeuf, aparecieron en el mercado italiano en 1971 y fueron recibidas de forma muy distinta por la crítica.

Paradiso fue recibido de forma positiva, sobre todo en relación con la narración pseudo autobiográfica elegida por el autor, considerada estilísticamente óptima y, aunque complicada, fascinante y digna de interés literario. A los elogios se emparejaron algunas polémicas políticas, que sin embargo no perjudicaron el valor de la novela para el público italiano -hecho confirmado tanto por la gran cantidad de reseñas como por el alto número de ediciones que se produjeron a lo largo de los años. Al contrario, la centralidad del sexo y de la tortura en Farabeuf representaron un problema para los reseñistas, que tan solo le dedicaron una veintena de reseñas (incluyendo las entradillas), algunas de ellas totalmente negativas.

Una lectura más atenta del conjunto de reseñas disponibles permite dividirlas según varias tipologías:

- reseñas en revistas literarias,

- reseñas en periódicos, 
- entradillas,

- reseñas de escritores publicadas en periódicos.

Cada una de estas tipologías mantiene las características propias del medio en el que se publica, pero las reseñas en periódicos y las reseñas de escritores permiten una mayor profundización, ya que reflejan, por un lado, la ideología del periódico en el que aparecen y, por otro, el pulso del campo cultural visto desde un protagonista del ámbito creativo. Por consiguiente, es de particular interés el análisis de estas dos categorías, ya que permiten enfrentarse de forma más directa con las dinámicas -tanto políticas como literarias- que rodean el campo literario y que "influyen" en y "deciden” sobre el porvenir de un autor según esquemas jerárquicos predefinidos (Bourdieu 279).

\title{
3 Farabeuf en los años 70: un libro incómodo
}

Por lo que se refiere a Farabeuf, podemos identificar dos tipos de reseñas: las que valoran la novela dentro del conjunto de las obras latinoamericanas y las que valoran la eficacia de su temática. En relación con la primera categoría encontramos juicios positivos, como el de Ignazio Delogu, donde se distingue de forma neta la postura desde la que nacen Farabeuf y Cien años de soledad, la novela latinoamericana sin duda más conocida en el ámbito italiano en esos años. Delogu define el estilo de Elizondo como algo que diferente a las narraciones latinoamericanas más populares:

\begin{abstract}
lontan[o] dalla volontà di creare per comprendere, di forzare, sia pure, la realtà ma per impadronirsi della sua essenza proprie di un García Márquez o di un Vargas Llosa. Elizondo, con la sua dichiarata incapacità e impossibilità di dare un senso alla realtà e all'esperienza, sembra rappresentare l'altra faccia della medaglia, l'alternativa polare a un modo di vedere, di esistere, di raccontare ${ }^{4}$.
\end{abstract}

De la misma forma, el reseñista anónimo de Corriere Ticino identifica Farabeuf con la estética decadente europea y subraya la habilidad con la que Elizondo llega a elaborar su novela a partir de estímulos refinados que prevén una competencia formal elevada: “Elizondo rappresenta nell'ambito della letteratura

4 "Lejos de la voluntad de crear para comprender, de forzar, la realidad para apoderarse de su esencia propia de un García Márquez o de un Vargas Llosa. Elizondo, con su declarada incapacidad e imposibilidad para dar un sentido de realidad a la experiencia, parece representar la otra cara de la medalla, la alternativa polar a una forma de ver, de existir, de contar" [traducción mía]. 
latino-americana, la corrente che mira ad appropriarsi delle esperienze più raffinate della cultura europea in materia di técnica narrativa, di soluzione formale del linguaggio" ("Funambulismo intellettuale") 5 . Ambas reseñas reconocen el valor de la novela comparándola con la producción latinoamericana de la época e insertándolas en un contexto literario específico. Pero existe otro grupo de reseñas, de corte menos literario, que llega a considerar la novela amoral y negativa. En estas reseñas aparece, de forma bastante explítica, la voluntad de alejarse de los temas de Elizondo atribuyendo al libro, al autor y al tema tratado una valoración de tipo moral. En una entradilla de un autor anónimo Farabeuf es definido como "un romanzo macabro, oscuro e ossessivo. Negativo dal lato morale, blasfemo da quello religioso"6 ("Salvador Elizondo. Farabeuf"); en otra reseña es descrita como una "tromperie” literaria, "un vaneggiamento presuntuoso in cui si mescolano, come ingredienti di base, l'erotismo malato alle degeneranti crudezze"7 (Grigliè s.p.) sin que esto pueda tener alguna relación con los méritos del autor o con el papel que este libro puede llegar a tener dentro del ámbito literario. Podría parecer una contraposición bastante típica en referencia a una novela compleja y seguramente difícil, pero en el conjunto de reseñas que se produjeron sobre Farabeuf nos llama la atención la de Mario Luzi, publicada en las columnas del Corriere della Sera en el marco de la actividad como reseñista de latinoamericanos que el poeta italiano desempeñó de 1967 a 1974. Luzi, que a lo largo de sus reseñas traza un panorama bastante completo y coherente de la literatura latinoamericana, dedica a Elizondo una de sus reseñas en 1971; en ella señala los méritos del autor por su habilidad en la construcción formal de la obra, pero en el último párrafo de la reseña parece dar marcha atrás, por lo menos por lo que se refiere al tema, que juzga difícil de tolerar: "I luoghi comuni della letteratura "perversa” e dell'erotismo nero sono i più feroci che ci possano venire imposti. E certo, non basta questo raffinato prodotto di un discepolo di Bataille passato attraverso gli arcanes di André Breton, a farceli tollerare" ("Farabeuf")

5 "Elizondo representa en el ámbito de la literatura latinoamericana, la corriente que apunta a apoderarse de las experiencias más refinadas de la cultura europea en cuanto a la técnica narrativa, de solución formal del lenguaje" [traducción mía].

6 "Una novela macabra, oscura y obsesiva. Negativa desde el punto de vista moral, blasfema desde el religioso” [traducción mía].

7 "Un desvarío presumido en el que se mezclan, como ingredientes básicos, el erotismo enfermo a una depravada crudeza" [traducción mía].

8 "Los clichés de la literatura "perversa” y del erotismo negro son los más duros que puedan ser impuestos. Y por cierto, no basta este refinado producto de un discípulo de Bataille pasado por los arcanes de André Breton para que lo toleremos” [traducción mía]. 


\subsection{Paradiso en los años 70: entre política y literatura}

También en el caso de Lezama Lima es posible identificar dos diferentes categorías de reseñas: las literarias tout court y aquellas que además de lo literario incluyen comentarios políticos o referencias a los mecanismos del campo literario. Lo que más resalta es que para la mayoría de los reseñistas el estilo y la estructura de la novela del escritor cubano apelan a Proust, Joyce y Musil, y lo afirman con un consentimiento casi general. La novela del autor es considerada una obra maestra y la calidad de su literariedad se afianza reseña tras reseña. Pero alrededor de las reseñas a Paradiso surge un fenómeno peculiar, que es la apertura de brechas de debate cultural en las que se discuten dos elementos interesantes para nuestro análisis: la forma con la que la intelectualidad italiana lee las novelas latinoamericanas y su conocimiento de las mismas. En este sentido, una de las reseñas más polémicas es la de Giuseppe Bonura, que se publica bajo el título provocador "Rifugiati nella magia". El tema central es el cuestionamiento del interés hacia la literatura latinoamericana, que para Bonura reside en la similitud de temas y situaciones que son el espejo de lo que el lector italiano vive y ha vivido y no una simple fascinación política:

Può darsi, invece, che le ragioni siano da ricercarsi in altra sede, fuori dal contesto proprio della letteratura. Che siano, ad esempio, ragioni politiche. (Ma i critici qualunquisti ricordano con un sorrisetto ebete i fenomeni d'infatuazione per la narrativa russa e ungherese nell'Italia paleoindustriale, e poi la cotta per la narrativa nordamericana nel dopoguerra. Ebbene, anche in quei casi, l'infatuazione fu "anche" politica) [. . . Questi libri ci parlano di una realtà che, pur appartenendo a un mondo sviluppato, immobile, in cui non si muove foglia che la Cia non voglia [...] in qualche modo ci coinvolge. Anzi ci sembra addirittura emblematica di una situazione universale, planetaria: quella appunto dell'uomo preso tra la morsa del capitalismo colonizzatore perfino delle coscienze e la ribellione anarchica, da apocalisse. Tra la supina accettazione del sistema e l'avventura per l'avventura, è la seconda che dà luogo dal mito, o all'utopia, o al sogno: almeno presso i giovani'

\footnotetext{
9 "Puede ser, en cambio, que las razones tengamos que buscarlas en otra sede, fuera del contexto propio de la literatura. Que sean, por ejemplo, razones políticas. (Pero los críticos recuerdan con una sonrisita tonta los fenómenos de enamoramiento de la literatura rusa y húngara en la Italia paleoindustrial, y además el enamoramiento de la narrativa norteamericana en la posguerra. Pues bien, incluso en aquellos casos, el enamoramiento fue "también” político) [...] Estos libros nos hablan de una realidad que, no obstante pertenezca a un mundo desarrollado, inmóvil, en el que no se mueve hoja que la CIA no quiera [. . . ] de alguna forma nos comprometen. Es más, hasta nos parece emblemático de una situación universal, planetaria: aquella del hombre atrapado entre el capitalismo colonizador hasta en las conciencias y la rebelión anárquica, de apocalipsis. Entre la aceptación del sistema y la aventura por la aventura, es la segunda que da lugar al mito, a la utopía, o al sueño: por lo menos entre los jóvenes” [traducción mía].
} 
La referencia no puede ser que una politización de la recepción de la literatura latinoamericana -debido también a la acción, totalmente política, de editores como Feltrinelli- que pudo caracterizar el mercado editorial italiano de los años 70. De hecho, en aquellos años la cultura italiana empezó a escindirse en una confrontación entre cultura baja y alta/cultura revolucionaria y conservadora (Ferretti) que inevitablemente recaía también en la recepción de los productos editoriales. Pero analizando el extracto de la reseña de Bonura percibimos que su cuestionamiento no es solo el resultado de una problematización política, sino que tiene que ver también con la disponibilidad que el campo cultural demuestra hacia esta literatura. En particular, nos interesa la primera parte de la cita, porque ahí Bonura parece hacer referencia a cierto esnobismo que circulaba en los ambientes editoriales y literarios italianos y que iba en descrédito de las obras procedentes de América Latina. El reproche a una pasión literaria que se ve impulsada por la política sugiere que la calidad de la literatura latinoamericana se viera anulada por su vinculación con la política y la reivindicación. Por esto no nos sorprende que, a unos meses de salir Paradiso, Dario Puccini escribiera una reseña que más allá de los contenidos literarios sobre la obra nos interesa por las referencias implícitas a las dinámicas extraliterarias que caracterizaban el ámbito literario italiano.

En primer lugar, Puccini propone una lectura de Paradiso que resalte sus peculiaridades estéticas más allá de la comparación con cualquier autor europeo, oponiéndose, de hecho, al emparejamiento con Musil, Proust y otros que venía haciéndose desde su llegada a las librerías:

quando si sono fatti i nomi di Proust o di Joyce o di Musil, aggiungendo per Lezama Lima soltanto l'aggettivo "tropicale" per poter in qualche modo spiegare la natura conturbante e frenetica di questo viaggio nella memoria [...] si sono soltanto tracciate alcune linee generiche della genealogia di Paradiso: la cui sostanza è un gongorismo a misura oceanica e a fermentazione tropicale [. . . ] la letterarietà di Paradiso è qualcosa di diverso dalla letterarietà nostra, occidentale. Mentre la seconda, infatti, sembra non possa andar disgiunta da concetti come gusto, misura, squisitezza, finitezza, scelta impeccabile delle parole e degli stilemi, la prima appare caotica, smisurata, automatica, visionaria (giustamente si è detto che Paradiso va ricollegato alle forme del tardo surrealismo), e in qualche modo spontanea ed elementare ${ }^{10}$. ("Il Paradiso di Lezama Lima")

10 "Cuando se hicieron los nombres de Proust o de Joyce o de Musil, añadiendo para Lezama Lima solo el adjetivo "tropical” para poder de alguna manera explicar la naturaleza perturbadora y frenética de este viaje en la memoria [. . . s se trazaron solo algunas líneas genéricas de la genealogía de Paradiso, cuya sustancia es un gongorismo oceánico con fermentación tropical [. . . ] la literariedad de Parasido es algo distinto de la literariedad nuestra, occidental. Mientras la segunda, en efecto, parece no poder ir separada de conceptos como gusto, mesura, exquisitez, finitud, elección impecable de las palabras y de los símbolos, la primera parece 
Puccini, que fue uno de los primeros hispanistas italianos en el siglo XX, subraya la necesidad de referirse a Lezama Lima utilizando referencias menos europeas y sí más tradicionalmente relacionadas con la literatura latinoamericana- para conseguir una comparación más adecuada tanto desde el punto de vista estilístico como del temático. En efecto, los autores que propone como referencias son Melville, Faulkner, el primer Neruda, el primer Asturias, Guimarães Rosa y el García Márquez de Cien años de soledad, más en línea con el punto de vista del que comienza el relato autobiográfico. Puccini, además, distingue de forma evidente el origen de la literariedad latinoamericana, dirigiéndose de forma implícita a aquellos que dentro del campo cultural se obstinaban a leer a las obras procedentes de América Latina simplificando y juzgando el texto desde un punto de vista "europeo". Lo mismo haría Luzi desde el Corriere della Sera: sin entrar de algún modo en el tema político cuestionaría la inexactitud de las primeras asociaciones "europeas" con Proust, Musil y Joyce, reivindicando la alteridad de la producción literaria latinoamericana como característica peculiar y valiosa:

La demiurgia di Proust, di Musil e di Joyce nasce da una intuizione primaria sulla natura profonda dell'uomo ma è anche ordinata intorno a un criterio, per così dire, formante. In questi maestri del romanzo europeo moderno la profondità è la dimensione in cui vive l'eroe dissociato dalla normalità del mondo, ma è anche l'origine di un sistema implicito di conoscenza e di relazione con il mondo. [.. .] Sebbene questi autori siano stati tutti invocati per dare una parentela a Lezama Lima, non vedo niente di tutto questo in Paradiso. In primo luogo non c'è qui un retroterra di crisi e di frustrazione, ma siamo anzi nel pieno di un atteggiamento salutare e sapienziale. La tendenza ad ammettere a coinvolgere il mondo nella sua totalità di tempi e di modi non obbedisce a un movimento di recessione vorticosa della coscienza, ma a un naturale movimento di espansione e di conquista verso un'ultima possibile completezza ${ }^{11}$. ("Paradiso")

caótica, desmesurada, automática, visionaria (con razón se ha dicho que Paradiso hay que relacionarlo a las formas del surrealismo tardío), en alguna forma espontánea y elemental” [traducción mía].

11 "La demiurgía de Proust, de Musil y de Joyce nace de una intuición primaria sobre la naturaleza profunda del hombre, pero se ordena alrededor de un criterio, digamos así, que forma. En estos maestros de la novela europea moderna la profundización es la dimensión en la que vive el héroe disociado de la normalidad del mundo, pero es también el origen de un sistema implícito de conocimientos y de relaciones con el mundo. [...] No obstante, estos autores se invoquen para dar familia a Lezama Lima, no veo nada de todo esto en Paradiso. En primer lugar, aquí no hay todo ese bagaje de crisis y frustración, al contrario, estamos en el medio de una actitud saludable y sapiencial. La tendencia a incluir el mundo en su totalidad de tiempos y modos no obedece a un movimiento de recesión de la conciencia, sino a un natural movimiento de expansión y de conquista hacia una última posible situación completa" [traducción mía]. 
Sin embargo, es en el cierre donde Puccini se enfrenta con la cuestión del valor de los latinoamericanos y de cómo leerlos, delatando, una vez más, la distancia que separaba el ámbito italiano del latinoamericano. Es así como en la frase de cierre de su reseña Puccini añade una clara referencia a las múltiples alusiones a la política y a la supuesta cercanía de Lezama Lima que se manifiestan en las reseñas tras el caso Padilla y concluye -aunque con trece años de antelación con respecto a Calvino- señalando la lejanía del campo cultural italiano:

non è senza significato che le due opere maggiori della letteratura cubana contemporanea, Il secolo dei lumi di Alejo Carpentier e Paradiso di Lezama Lima, si riferiscano a un passato remoto e coloniale. La cosa non ci scandalizza, ma neppure ci esalta (vogliamo parlare del caso Padilla?). Del resto personalmente non ho il minimo dubbio (e l'ho in parte dimostrato) che Paradiso sia una opera d'alta civiltà letteraria, e un vero capolavoro della letteratura dell'America Latina. Volutamente lasciando in sospeso ogni altro discorso è questo che qui conta per ora affermare ${ }^{12}$. ("Il Paradiso di Lezama Lima")

Esta última consideración nos llama la atención porque se empareja con una muy similar hecha por Mario Luzi en ocasión de la salida de Raccattacadaveri en 1969:

Il nostro taccuino di appunti latino-americani si infittisce rapidamente di nomi nuovi o che arrivano in Italia per la prima volta. Forse l'ho già scritto, ma è bene ribattere che non si tratta di un fuoco d'artificio editoriale: la letteratura del continente si trova davvero in un periodo di manifesto rigoglio. Non tento neppure di spiegarlo il perché, sapendo quanto il rapporto di causa ed effetto sia aleatorio se applicato a questo argomento. È vero che il forte di alcuni tipi di critica -non più soltanto dello storicismo- è appunto di fornire quelle spiegazioni; ma il fenomeno ricorrente delle stagioni creative rimane, tutto sommato, inesplicabile e perentorio. Mi limito così ad osservare che la letteratura latinoamericana usufruisce di una condizione unica (non del tutto invidiabile, certo, ma indubbiamente vitale) determinata soprattutto dal coesistere di questi fattori: l'aprirsi e l'insorgere della coscienza alla tragedia sociale e politica del continente, la scoperta simultanea della realtà e del mito autoctoni, il trapianto vigoroso di tecniche artistiche europee e nord americane. Per ultimo il più prezioso: l'integrità non corrosa dei sentimenti dell'uomo ${ }^{13}$. ("L'asceta del peccato")

12 "No es sin significado que las dos más grandes obras cubanas contemporáneas, Il secolo dei lumi de Alejo Carpentier y Paradiso de Lezama Lima, se refieran a un pasado remoto y colonial. La cosa no nos indigna, pero tampoco nos exalta (¿queremos hablar del caso Padilla?). En resumidas cuentas, personalmente no tengo la menor duda (y en parte lo demostré) de que Paradiso es una obra de alta civilización literaria, y una verdadera obra maestra de la literatura de América Latina. Dejando cualquier otro discurso a un lado adrede, es esto lo que importa aquî” [traducción mía].

13 "Nuestro cuaderno de apuntes latinoamericano se hace rápidamente más denso de nombres nuevos que llegan a Italia por primera vez. Quizás ya lo escribí, pero es bueno recordar que no se trata de fuegos artificiales de la edición: la literatura del continente se encuentra realmente en un momento de manifiesta plenitud. No intenta ni siquiera explicar el porqué, 
Como es posible deducir, el valor literario de la literatura latinoamericana es reiterado una y otra vez. Esto puede ocurrir porque esta literatura frecuentemente iba acompañada por una ideologización que se relacionaba con el contexto extra literario, pero, de hecho, pensamos que estas frecuentes declaraciones sirvieran como justificación ante esa parte del circuito cultural que no tenía una visión de conjunto lo suficientemente amplia como para comprender el aspecto multifacético de la propuesta literaria procedente del subcontinente. por esto la interpretaba aplicando estereotipos (Carini "Tra mediazione”, "Etiquetas literarias"). Es aquí, entonces, donde podemos empezar a comprender la importancia de una reflexión sobre las consecuencias que los elementos extraliterarios pudieron tener sobre la difusión de la literatura latinoamericana en traducción.

Un grupo de reseñas aluden de forma más precisa a la relación que el autor y la obra tuvieron con el régimen castrista, posiblemente para contextualizar su procedencia y, pensamos, para insertarlos en un contexto editorial y literario específicos dentro del ámbito cultural italiano. Lo que sí se percibe es cierto cuestionamiento sobre la validez de la aproximación apolítica de Lezama Lima después del caso Padilla, pero sin llegar a construir un caso político alrededor del texto literario.

\section{Las re-traducciones en el siglo XXI}

La situación respecto a la segunda ola de reseñas que decidimos analizar es totalmente diferente. Ante todo, es bastante diferente la situación de llegada de estas nuevas ediciones. Mientras Farabeuf no vuelve a ser reeditado hasta 2018, Paradiso lo es en tres diferentes ocasiones entre 1971 y 2016. En 1990, por la editorial Rizzoli, con una traducción que pasa de estar al cargo de Storchi y Riva a ser solo de Valerio Riva, de quien resultan también las notas. En 1992,

sabiendo cuánto la relación entre causa y efecto pueda ser aleatoria si se aplica a este argumento. Es verdad que lo fuerte de cierta crítica - no solo del historicismo es el de dotar aquellas explicaciones, pero el fenómeno cíclico de las estaciones de la creatividad humana, al final, inexplicables y perentorias. Me limito de este modo a observar que la literatura latinoamericana goza de una condición única (no envidiable, por cierto, pero indudablemente vital), determinada sobre todo por el coexistir de estos factores: el abrirse y el insurgir de la conciencia de la tragedia social y política del continente, el descubrimiento simultáneo de la realidad y del mito autóctono, el implante vigoroso de técnicas artísticas europeas y norteamericanas. Por último el más valioso: la integridad no corroída de los sentimientos del hombre" [traducción mía]. 
para la editorial Einaudi, con una re-traducción a cargo de Glauco Felici, a la que se añaden un conjunto de epitextos que complementan la lectura: nota del traductor y un apéndice con trascripciones, glosario de voces cubanas e hispánicas, un repertorio de lugares, cosas y personajes y un apartado titulado "Coordenandas lezamianas" con notas que explican la genealogía de algunos personajes de la novela. En 2001, siempre por la editorial Einaudi, en una edición en la que es añadida una introducción a cargo de Mario Vargas Llosa.

Las ediciones a las que haremos referencia nosotros salen al mercado en noviembre 2016, para Edizioni SUR, y en 2018, para la editorial LiberAria. En la nueva edición de Paradiso se señalan algunos cambios: la traducción es la de Felici, pero se ha reinsertado el texto de Julio Cortázar que había acompañado la primera edición il Saggiatore y un prefacio de Chiara Valerio, escritora y editora italiana y, en 2016, directora cultural de la feria del libro de Milán Tempo di Libri. Farabeuf, en cambio, apareció en marzo de 2018 con una nueva traducción firmada por Giulia Zavagna y una introducción firmada por Alessandro Raveggi. Básicamente, la mayor novedad de las reediciones que interesaron a estas dos novelas es la anexión de nuevos paratextos. Algunos de estos paratextos (Valerio, Raveggi) son guías de lectura actualizadas a la contemporaneidad, en las que protagonistas del panorama literario italiano se dibujan discursos alrededor de la literatura latinoamericana. En otros casos, como los son el de Riccio y Vargas Llosa en las ediciones de 1991 y 2001, los paratextos tienen una faceta más latinoamericana, siendo escritos por una catedrática y un escritor que delinean la figura de Lezama Lima directamente desde un punto de vista latinoamericano.

Por lo que concierne las reseñas a las ediciones más recientes de las novelas -que son las que utilizaremos para este estudio- tenemos que señalar ante todo el formato diferente que las reseñas han adquirido en la práctica editorial. Las reseñas actuales no son simplemente un comentario, sino que se han vuelto verdaderos instrumentos de marketing que en muchas ocasiones funcionan en paralelo, y en acuerdo, con las estrategias editoriales. El primer dato que tenemos a nuestro alcance es que las reseñas son, para ambas novelas, escasas y carecen de una figura predominante en el escenario actual de la comunicación sobre libros: los bookbloggers no aparecen, lo que implica que siendo SUR y LiberAria editoriales independientes que cuentan con una red de distribución propia, la distribución de estas dos novelas se ha estructurado según los mecanismos tradicionales editorial-librería-lector, editorial-revista-lector, sin poder gozar de esa comunicación inmediata y directa que es posible a través de la participación hecha por internet a través de las redes sociales. Las reseñas a ambos libros cuentan con firmas de cierto nivel en el panorama literario actual: tanto Stefano Gallerani, para Paradiso, como Gianni Montieri, para 
Farabeuf, son dos personajes importantes y reconocidos en el ámbito literario italiano. Por lo que se refiere a Paradiso Gallerani actualiza las referencias culturales que se habían indicado en los años 70, añadiendo Pynchon y Roussel a los modelos que pueden ser útiles para acercarse a Lezama Lima. La reseña, que aparece en La Stampa, es a la vez una presentación del autor, una contextualización del mismo y una descripción del argumento de la obra, en la que nos parece faltar, sin embargo, una valoración personal por parte del autor con respecto a la forma de la obra. Más amplia y detenida en el análisis y la explicación de la estructura y de los significados de la obra es otra reseña a Paradiso, la de Francesca Lazzarato aparecida en la revista Alias. Lazzarato, traductora del español, presenta el contexto, el autor y el tema y comenta la estructura utilizando, cuando es necesario, también citas de autoridad -en este caso, Cortázar y Sarduy- que le permiten enmarcar la obra en un ámbito más específico, pero igualmente cercano a los lectores.

Por lo que se refiere a Farabeuf, en cambio, hasta este momento -junio 2018- las reseñas son solo cuatro, de las que solo una, la de Gianni Montieri, llega a profundizar sobre la novela con cierta fluidez. En su texto, publicado en el blog cultural Minima \& Moralia, se detiene en el valor de la memoria como fil rouge para la lectura del texto sin hacer alguna referencia al ámbito latinoamericano, es decir, interpretando la novela a partir de una experiencia totalmente personal y subjetiva de poeta. De hecho, pensamos que la literariedad de ambas novelas ha podido ser un límite en la comunicación directa e instantánea que se necesita en las redes sociales y que hoy predomina en el mundo del marketing editorial. Es quizás por esto que ciertos temas, como la memoria, el renacer, el sexo y, más en general, el replegarse en sí mismo que caracteriza ambas novelas pasa desapercibido y no es transmitido a los lectores italianos a través de estos epitextos. A nuestro parecer la complejidad -y la variedad- que caracterizan el ámbito literario latinoamericano siguen siendo difíciles de resumir y explicar. Este dato nos parece confirmado por la reseña que Goffredo Fofi dedicó a Paradiso en las páginas de la revista Internazionale: "Torna un classico del novecento poco frequentato dall'italica cultura" ${ }^{14}$, lo que confirma -nuevamente- la existencia de cierta dificultad en apoderarse de textos complejos o diferentes a los traducidos de costumbre dentro del marco del exotismo.

14 "Vuelve un clásico de 1900 poco frecuentado por la cultura italiana” [traducción mía]. 


\section{Conclusiones}

En conclusión, los resultados de nuestra investigación convergen hacia algunos elementos que nos parecen de suma importancia para definir la necesidad de ampliar los estudios de recepción, añadiendo a una interpretación estrictamente literaria de los epitextos una investigación a nivel cultural y editorial. Más allá de la valoración de los contenidos de una obra las palabras utilizadas por los reseñistas ayudan a comprender el tono y la predisposición con los que el ámbito cultural y literario está decidido a acoger una obra y un autor, lo que va a determinar su éxito o su fracaso. El análisis de los casos de Paradiso y Farabeuf, por ejemplo, permite individuar un problema común, el de una "literariedad latinoamericana", que impide una recepción "profesional" amplia. A esto añadimos que las reseñas de Bonura, Puccini y Luzi, ahí donde subrayan y distinguen la procedencia y el valor de la literariedad latinoamericana, apelan a un cambio de perspectiva en la mirada de aquellos profesionales y lectores que quieren acercarse a las obras procedentes de América Latina sin tomar nota de cuáles son sus características propias. Por otro lado, las reseñas de Bonura, Puccini y Luzi delatan la frustración que los tres sufren al tener que compartir el espacio literario con interpretaciones políticas sobre las obras latinoamericanas. Esto nos hace pensar que, en realidad, dentro del ámbito cultural italiano el interés en los latinoamericanos se concreta sobre todo en términos de contenidos. Se repite, entonces, la condición que se ha observado en los estudios de archivos sobre la mediación editorial: una porción del campo literario italiano tenía un escaso conocimiento de las características literarias latinoamericanas e interpretó sus productos a través de los estereotipos de la política y del exotismo.

A la hora de valorar la contribución de la literatura latinoamericana al campo literario italiano tendremos que tomar nota de estos elementos aunque no concuerden con la percepción que el número de títulos traducidos puede dar de la difusión de la literatura procedente de América Latina en Italia. Gracias a los resultados conseguidos, podemos afirmar la necesidad de ponderar la valoración de la recepción de las obras latinoamericanas considerando tanto su traducción -con datos numéricos y estadísticas- como los métodos y las dinámicas que se relacionan a esta ${ }^{15}$. En general, para comprender la real

15 Puccini hace referencia a cierto problema de comprensión entre ámbito literario italiano y literatura latinoamericana también en una reseña a Il grande Sertao y Paradiso, publicada por Puccini en la revista Avanti el 25 de julio de 1971: "I più importanti libri latino-americani di questa annata letteraria, tradotti in italiano sono stati Grande Sertao di Joao Guimaraes Rosa (ed. Feltrinelli) e Paradiso di José Lezama Lima (ed. Il Saggiatore). Del primo si è parlato poco, 
configuración de la recepción de la literatura latinoamericana en Italia y, más adelante, anotar cuáles fueron las repercusiones que tuvo sobre la literatura italiana, es necesario considerar cuáles autores han sido traducidos y leídos y cuáles no. Por esto habrá que valorar su inserción o no inserción en el campo cultural desde una perspectiva múltiple, que se proponga comprender qué imagen de América Latina se proporcionó a los lectores y cuáles dinámicas (políticas, económicas, culturales y literarias) la argumentaba. Esto implica que nos preguntemos, por ejemplo, hasta qué punto pudieron comprender la literatura latinoamericana ciertos reseñistas si no conocían la totalidad de la oferta procedente de América Latina. Del mismo modo, es oportuno preguntarse si se puede juzgar o trabajar sobre la literatura latinoamericana prescindiendo de los autores telúricos o políticos, así como si la que se ha traducido ha sido un fiel reflejo de la producción literaria latinoamericana o si tan solo se ha llegado a conocer una pequeña parte de ella. Este enfoque interesa en primer lugar para una profundización del estudio del ámbito literario italiano, pero, en vista de una comunicación más amplia y rápida de los textos, también para el estudio del ámbito literario hispanoamericano y, aún más, de las relaciones entre ámbitos editoriales y de sus consecuentes repercusiones a nivel de producción literaria por parte de autores cuanto más conectados y en relación entre sí incluso desde espacios físicos diferentes.

\section{Bibliografía}

Anónimo. “Funambolismo intelletuale'. Reseña de Farabeuf, de S. Elizondo”. Corriere del Ticino, 27 de marzo 1971.

--.. “'Salvador Elizondo. Farabeuf'. Reseña de Farabeuf, de S. Elizondo”. Libri di ieri e di oggi, enero 1971.

ed è un vero peccato. Del secondo si è parlato molto, ma - a mio modo di vedere - con un'ottica ancora inadeguata. Non credo sia il caso di entrare qui in polemica con la critica europea (non solo italiana), che a tutti i costi ha cercato grandi riferimenti nella letteratura occidentale (ed es. Joyce e Proust) per penetrare nel mondo allucinante e labirintico ed allegorico, di Paradiso. Se a tutt'oggi rimangono misteriosi (anche perché poco noti) fenomeni europei come il barocco di Góngora e di Quevedo, tanto più rimangono misteriosi i loro 'figli' americani, da Sor Juana Inés de la Cruz (contemporanea di Calderón) a José Lezama Lima (contemporaneo si fa per dire - di Carlo Emilio Gadda). Del resto, per scoprire e riconoscere fenomeni che nella letteratura d'oltre oceano appaiono abbastanza "europei” come Borges e Cortázar ci è voluto parecchio tempo, e lo aiuto della pubblicità e del cinema (Blow Up). Per scoprire e riconoscere Lezama Lima e Guimaraes Rosa ci vorrà ancor più tempo" ("Paradiso"). 
Bonura, Giuseppe. “'Rifugiati nella magia’. Reseña de Paradiso, de J. Lezama Lima”. Sette giorni, 23 de mayo 1971, s.p.

Bourdieu, Pierre. Le regole dell'arte. Genesi e struttura del campo letterario. il Saggiatore, 2013 [1992].

Cadioli, Alberto. Le diverse pagine. il Saggiatore, 2012.

Carini, Sara. "Etiquetas literarias y cánones distorsionados: la literatura latinoamericana en Italia entre estereotipos y miradas desenfocadas”. Centroamericana, 26.1, 2016, pp. 27-43.

---. “Ciro Alegría en la 'Medusa' Mondadori: éxitos y problemas de una mediación editorial”, América Latina y la literatura mundial. Mercado editorial, redes globales y la invención de un continente. Eds. Gesine Müller y Dunia Gras. Iberoamericana/Vervuert, 2015, pp. 143-162.

--.. "Tra mediazione e incomprensione: la ricezione editoriale e le letterature straniere. Il caso delle Meduse latinoamericane in Mondadori". Letteratura e archivi editoriali. Nuovi spunti d'autore. Le carte d'archivio strumento di critica letteraria. Eds. Carmela Pierini, Sara Carini, Elisa Bolchi. Aracne editrice, 2014, pp. 75-103.

Casanova, Pascale. La República mundial de las Letras. Anagrama, 2001 [1999].

Chartier, Roger. L'ordine dei libri. il Saggiatore, 1994 [1992].

Delogu, Ignazio. "Salvador Elizondo. Farabeuf”. Rinascita, 1 de enero de 1971, s.p.

Ferretti, Gian Carlo. Il mercado delle lettere. Industria cultural e lavoro critico in Italia dagli anni cinquanta ad oggi. Einaudi, 1979.

Fofi, Goffredo. “'Un classico cubano da riscoprire’. Reseña de Paradiso, de J. Lezama Lima”. Internazionale, 2 de diciembre 2016, p. 100.

Gallerani, Stefano. “'Lezama Lima, il Paradiso dello scandalo’. Reseña de Paradiso, de J. Lezama Lima”. Il Mattino, 30 de diciembre 2016, p. 19.

Grigliè, Remo [Grig. R]. “'Oh che bel piacere la chirurgia erotica!'. Reseña de Farabeuf, de

S. Elizondo". Stampa sera, 2 de octubre 1970.

Lazzarato, Francesca. “'Lezama Lima, una carezza sul caos’. Reseña de Paradiso, de J. Lezama Lima”. Alias, Il Manifesto, 24 de noviembre 2016, p. 1.

Luzi, Mario. “'Paradiso'. Reseña de Paradiso, de J. Lezama Lima”. Corriere letterario, Corriere della Sera, 13 de mayo 1971, p. 12.

---. “'Farabeuf'. Reseña de Farabeuf, de S. Elizondo". Corriere letterario, Corriere della Sera, 24 de diciembre 1970, p. 12.

--.. “'L'asceta del peccato. Reseña de Raccattacadaveri, de J.C. Onetti”. Corriere letterario, Corriere della Sera, 9 de noviembre 1969, p. 13.

Montieri, Gianni. “'Più Tenace della memoria. Farabeuf di Salvador Elizondo'. Reseña de Farabeuf, de S. Elizondo". Minima \& Moralia, 16 de mayo 2018. http://www.minimaetmo ralia.it/wp/memoria-farabeuf-salvador-elizondo/, consultado 3 de junio 2018.

Puccini, Dario. “'Il “Paradiso” di Lezama Lima'. Reseña de Paradiso, de J. Lezama Lima”.

Paese Sera, 18 de junio 1971.

-.-. "Paradiso". Avanti. 25 de julio 1971.

Riccio, Alessandra. “'Scrittori esemplari io vi odio tutti'. Entrevista a Italo Calvino”. l'Unità, 20 de septiembre 1984.

Ricœur, Paul. Tempo e racconto, vol III. Jaka Book, 1988. 


\section{Ilse Logie}

\section{¿Escritos en la traducción y para la traducción? Dos ejemplos: Valeria Luiselli y Mario Bellatin}

\section{Born translated novels}

Según la tesis de Rebecca Walkowitz, formulada en Born Translated. The Contemporary Novel in an Age of World Literature, cada vez más autores contemporáneos escriben obras literarias que nacen "ya traducidas"1; o sea, diseñadas para ser traducidas. En su estudio, Walkowitz examina cómo estas obras imaginan y generan a sus audiencias y cómo cambian la forma tradicional de la novela. Si bien poseen ciertas características que contribuyen a su circulación transnacional, entre otras cosas porque sus autores entienden la traducción como esencia de toda operación literaria o porque ponen en tela de juicio el concepto de originalidad, concibiendo sus textos como copias, versiones o clones, no son necesariamente sinónimo de la estandarización que, según varios estudiosos, sería inherente a la "literatura mundial" 2 . Estos detractores sostienen que, al entrar en el circuito global, los textos literarios son resignificados en términos transnacionales, borrándose sus huellas locales. Para un crítico como Tim Parks, por ejemplo, en Where I'm Reading From, la circulación global y la preocupación por la traducibilidad llevan a una literatura aséptica y homogeneizada (habla de "the dull new global novel"). En la misma línea, el investigador Brian Lennon aboga en In Babel's Shadow. Multilingual Literatures, Monolingual States por obras "no traducibles", o sea, por obras que no se dejen inscribir en esta tendencia. Y, según Vicente Luis Mora, en un dossier de Pasavento dedicado a la globalización en América Latina, empieza a detectarse en la narrativa que nos ocupa en este trabajo, la hispánica, la aparición de lo que

1 La expresión ha sido acuñada por analogía con "born digital", es decir, hecho en la computadora y para la computadora.

2 Entendida aquí de acuerdo a la definición de David Damrosch (4-6): no como un canon de obras, sino como un modelo de circulación y difusión literaria que no se deja reducir a dinámicas de mercado. Damrosch insiste en que, más que un objeto, la literatura mundial es un método de lectura, una manera de comprometerse con la literatura más allá del limitado mundo cultural propio.

Ilse Logie, Universiteit Gent

Ә Open Access. (C) 2020 Ilse Logie, published by De Gruyter. (c) BY-NC-ND This work is licensed under a Creative Commons Attribution-NonCommercial-NoDerivatives 4.0 International License.

https://doi.org/10.1515/9783110673678-012 
llama "panespañol", y que define como "este dialecto literario [que] consist[e] en una especie de castellano estándar mediante el que los escritores van moderando los modismos eliminando las expresiones localistas, para ser más y mejor entendidos, cualquiera que sea el lugar de Hispanoamérica donde sean leídos; especie de lengua posnacional”. Da como ejemplos la prosa de Juan Villoro, Jorge Volpi y Alejandro Zambra. Por su parte, la influyente colección de ensayos compilada por Ignacio M. Sánchez Prado, América Latina en la "literatura mundial", asentó en su día las bases de la recepción generalmente negativa que ha tenido este debate entre los críticos hispanoamericanos.

A Walkowitz esta crítica le parece demasiado simplista. A su modo de ver, las novelas de su corpus obedecen a mecanismos más complejos. Sostiene que las obras de, pongamos por caso, Coetzee o Murakami anticipan distintas culturas literarias al mismo tiempo al dirigirse a través de la traducción a múltiples audiencias locales y no solamente a una única y gran audiencia homogénea ${ }^{3}$. Son textos que no aparecen simplemente "en traducción", sino que incorporan la traducción más que facilitarla. La contienen como condición de producción, como eslabón orgánico en el proceso textual. Walkowitz analiza sobre todo obras escritas en inglés que inventan estrategias para descentralizar esa lengua dotada de elevado capital simbólico a fin de romper su monopolio. Otros ejemplos de autores productores de este tipo de textos que menciona son Teju Cole, Aleksander Hemon, Kazuo Ishiguro, Ben Lerner y -aunque solo aparece aludido- Roberto Bolaño ${ }^{4}$.

En lo que sigue, se presentarán dos textos más recientes con tales características surgidos en el ámbito hispanoamericano: Los ingrávidos (2011), de Valeria Luiselli, y Jacobo el mutante, seguido de su secuela Jacobo reloaded (2002-2014), de Mario Bellatin. Son dos ejemplos que permitirán señalar algunas paradojas que caracterizan esta producción cultural. A pesar de inscribirse en proyectos estéticos divergentes, las obras tienen varios rasgos en común. No solo han sido traducidas a las grandes lenguas internacionales (inglés -que opera como requisito para la inclusión en la literatura mundial-, francés,

3 Walkowitz refuta asimismo el reproche de la falta de compromiso ético o político que se suele achacar a este tipo de obras: "Distance brings neither affective nor ethical detachment [...]. Coetzee rejects both the ideal and the promise: he may be writing for translation, but he is not writing from nowhere; he can't because he associates global invisibility [...] with the very forces he wishes he could disavow" (81).

4 Los detectives salvajes de Bolaño solo es mencionado de paso (17-20) y la inserción del autor en el paradigma de la literatura emergida de la traducción no aparece problematizada, pese a que la obra del chileno se caracteriza por una marcada tensión entre el rechazo del vínculo lengua/territorio por una parte y una tendencia a exhibir el fracaso de lo multilingüe por otra. No sería, por tanto, correcto presentarlo como un representante del discurso de la transparencia en materia de traducción. 
alemán) y han resultado afectadas por este proceso, como veremos a continuación cuando comentemos su afterlife o pervivencia, sino que son libros "ya adaptados", libros que gastan muchas energías escenificando los mecanismos de la escritura y la traducción. Esta última aparece como dispositivo narrativo, al formar parte de la representación que aquellos textos ofrecen de su propia situación enunciativa. Las dos obras proporcionan, asimismo, una reflexión sobre el funcionamiento institucional de la literatura. Son, además, obras globalizadas por varios motivos: por la recepción de la que fueron objeto (sendos autores poseen evidentemente un capital transnacional), pero también por el gesto cosmopolita a través del cual conectan referencias culturales que a primera vista parecen lejanas e incompatibles.

Mi análisis pretende argumentar que Bellatin y Luiselli logran insertarse en este sistema global y hasta adelantarse a la literatura mundial manteniendo una relativa autonomía. Se sostiene en dos ideas: la primera es que la tensión entre lo local y lo mundial constituye el principio generador de sus tramas y que, a través de diferentes procedimientos, logran expandir la noción de literatura latinoamericana al tiempo que subvierten ese mismo ecosistema global del que forman parte. La segunda idea es que su internacionalización es facilitada por la clave vanguardista en que ambos autores conciben el arte. Son autores que retoman -de distintas maneras- la vanguardia histórica en el presente y que incluyen en varios de sus relatos una serie de referentes de ficción que nos remiten a la vanguardia artística de los años 1920-1930. Aun cuando faltan estos referentes, sigue presente el legado vanguardista a través de la fe en el procedimiento como elemento que distingue el arte de lo que no lo es y en el uso de recursos que desestabilizan el concepto tradicional de la literatura (manuscritos apócrifos, técnica de reapropiación de materiales preexistentes...). Su concepción de la traducción se sitúa en la misma línea: rechazan la modalidad de la traducción predominante en Occidente que postula la "invisibilidad" del traductor, según la célebre fórmula con la que Lawrence Venuti rebautizó el tradicional concepto de fidelidad, y tampoco creen en el carácter sagrado del original. Enfocan la traducción como potencialidad transformadora de la escritura, alternativa para reinventar el arte, espacio de innovación formal más que como operación de equivalencia.

\section{Traducciones y desplazamientos: Los ingrávidos de Valeria Luiselli}

Valeria Luiselli es una de las escritoras mexicanas más relevantes de los últimos años. Es autora de cinco libros muy diversos: el ensayo narrativo Papeles falsos 
(2010), las novelas Los ingrávidos (2011), Historia de mis dientes (2014) y Lost Children Archive (2019) y el ensayo-reportaje Los niños perdidos (2016). Su biografía casi la predestinaba a una carrera “global”. Luiselli nació en Ciudad de México en 1983. Hija de padres diplomáticos, antes de cumplir 18 años, ya había vivido en EEUU, Costa Rica, Corea del Sur, Sudáfrica e India. Regresó a México para estudiar en la UNAM y en 2011 se mudó a Nueva York para hacer el doctorado, ciudad donde sigue residiendo. Considera el español su lengua materna, aunque aprendió a leer y a escribir antes en inglés. Escribe alternando sus dos lenguas. Los tres primeros libros que ha publicado han sido escritos en español y luego traducidos al inglés, en estrecha colaboración con la traductora Christina MacSweeney, a la que Luiselli otorga una libertad creativa poco frecuente. Muchas veces los resultados de esta colaboración han producido cambios en el original en español, como se verá de manera más detenida abajo. Por su parte, Los niños perdidos está escrito originalmente en inglés y fue autotraducido por la autora al español, convirtiéndose parcialmente en otro texto. Y para la traducción al español de su última novela, Desierto sonoro, la escritora ha trabajado con Daniel Saldaña París. Luiselli ha publicado todos sus libros en español en la editorial independiente Sexto Piso (México/España), editorial de la que ya formó parte desde su fundación. Sus traducciones al inglés salen en Granta (Londres) y Coffee House Press (Minneapolis).

Los ingrávidos es un relato que emana de dos voces. La primera pertenece a una narradora que escribe sobre la vida cotidiana que lleva en Ciudad de México con su marido y sus dos hijos. Esta misma narradora configura simultáneamente una narración sobre la época en la que vivía en Nueva York y trabajaba como editora para un sello especializado en encontrar autores latinoamericanos no traducidos, que andaba febrilmente en busca del "próximo Bolaño”: “Trabajaba como dictaminadora y traductora en una editorial pequeña que se dedicaba a rescatar 'perlas extranjeras' que nadie compraba -porque al fin y al cabo estaban destinadas a una cultura insular donde la traducción se abomina por impura” (11). La otra voz pertenece a Gilberto Owen, poeta mexicano del grupo de los Contemporáneos. Como diplomático en EEUU en los tiempos del Harlem Renaissance, Owen hizo de mediador entre el mundo anglosajón y el hispanohablante desde su afán de divulgar la estética vanguardista. Durante su estancia en EEUU, la protagonista empieza a seguir obsesivamente los rastros de Owen en diferentes etapas de su vida: el joven que vive en Nueva York y el viejo cónsul en Filadelfia, alcohólico, que está a punto de morir. Owen se vuelve una fascinación para ella, incluso empieza a aparecérsele conforme avanza el texto. El nexo entre las dos historias es una traducción. Para interesar al jefe de la editorial donde trabaja, la narradora decide presentarle la falsa traducción de unos poemas de Owen hecha, supuestamente, por el fundador del objetivismo norteamericano, Louis Zukofsky. La historia desemboca en una estafa literaria: la 
narradora fabrica documentos apócrifos que su editor publica en la prensa. Finalmente, el fraude es desenmascarado y lleva a su dimisión y a su regreso a México. Pero la fijación de la joven mujer por Owen no se acaba allí. Muchos años después, resuelve escribir su biografía novelada a partir de retazos de su investigación, sugiriendo encuentros y amistades que pudieron ser posibles pero de los que no hay constancia.

La crítica ha dicho que la novela debe más a la poesía norteamericana que a la narrativa en español. Nueva York aparece como espacio de la vanguardia cultural: es allí donde Owen puede que hubiera coincidido con íconos del cosmopolitismo internacional de la era moderna: Federico García Lorca, José Limón, Homer Collyer y el ya nombrado Zukofsky, entre otros. Por otra parte, esta biografía imaginaria de Owen ha hecho resurgir el interés en EEUU por la poesía mexicana, suscitando una "Owenomanía"5. Puede decirse, entonces, que a Los ingrávidos se le puede aplicar la "refracción elíptica” de literatura nacional puesta como condición por Damrosch para ingresar en el circuito mundial: la obra sigue teniendo rasgos culturales de su origen mexicano. Muestra también que hay un México que se extiende más allá de las fronteras y que una buena parte de la literatura latinoamericana se produce desde hace tiempo en los EEUU, con frecuencia en español pero también en inglés.

En sus análisis, Walkowitz muestra que las obras "born translated” despliegan la traducción como tema o procedimiento o como vaivén entre lenguas al interior del texto. Sostiene que son novelas que incorporan la traducción al concebirse en diferentes lenguas y cuyos personajes se expresan en múltiples idiomas. El hecho de que hayan sido construidas pensando en el modo en que circularán a través del mundo en diferentes ediciones e idiomas tiene sus consecuencias para el proceso de traducción. A menudo estas novelas cambian de forma y significado cuando se mueven, generan algo nuevo, en una especie de textualidad expandida.

En efecto, Los ingrávidos ha crecido en otras lenguas. Fue traducido al inglés como Faces in the Crowd, título que hace suyo parte de un poema de catorce palabras de Ezra Pound. Pero quien compare las dos versiones notará que no hay un único original. Dice Luiselli a propósito: "There is a section in Faces in the Crowd, for instance, that my Italian translator, Elsa Tramontin, came up with. She produced such a good translation of it in Italian that I changed the original after her input, and so all the other translators followed her version instead of my 'original'” (Reber). Del mismo modo, en la versión en inglés, Luiselli y su traductora al

5 Véase al respecto la columna de Guillermo Sheridan en Letras Libres. 
inglés, Christina MacSweeney convierten al marido, que en Los ingrávidos es un director de cine, en un arquitecto. Otros cambios se deben a dificultades de tipo pragmático. Así, en inglés no aparece Zukovsky sino Zvorsky porque no fue posible conseguir los derechos para reproducir fragmentos de su emblemático poema "A", que se transforma entonces en "That”, una especie de paráfrasis. Por su parte, en Die Schwerelosen 6 , la traductora al alemán, Dagmar Ploetz, se adhiere a la versión inglesa en lo que respecta a Zukovsky, pero en cambio mantiene la profesión de cineasta para el marido. A veces hasta se agregan capítulos, como ha sido el caso de la edición en inglés de otra novela de Luiselli, La historia de mis dientes: a The Story of my Teeth se le añadió un capítulo titulado "The Chronologic", una especie de hoja de ruta para los lectores no familiarizados con la historia ni los referentes literarios mexicanos. Este capítulo fue escrito en su totalidad por MacSweeney, que también ha cambiado los nombres de los personajes y algunos acontecimientos. En una columna harto negativa sobre la recepción de la obra de Luiselli en México, el crítico Jorge Téllez lee esta cronología como una "normalización" del texto porque se adecúa a su público meta. Es una interpretación que parte de la premisa de la intocabilidad del original. Se podría aducir que, al adaptar la novela, Luiselli y su traductora insisten en que el mundo, antes que aparecer como un contenedor homogéneo en el que las obras literarias son "lo mismo" en varias lenguas, es un colectivo polifónico.

Es llamativo que Walkowitz apenas presta atención a la dimensión interlingüística de las traducciones como si, paradójicamente, estas obras de su corpus, que hablan extensamente del multilingüismo, no parecieran plantear importantes dificultades de traducción. Según Walkowitz, esto se debe a que la intraducibilidad de los textos "born translated" no reside en la presencia mimética de la(s) otra(s) lengua(s), sino en la narrativización de los procesos lingüísticos. O sea que no se trata aquí del tipo de intraducibilidad "habitual”, basada en la descripción lingüística - pensemos en el trabajo con ideolectos, particularismos, procedimientos como el cambio de código, juegos de palabras, términos en cursiva que denotan slang, palabras extranjeras, referencias locales etc. presente en autores como (para el ámbito latinoamericano) Cabrera Infante o Junot Díaz. Si hay "intraducibilidad" en los textos "born translated", se entiende en el sentido que Barbara Cassin otorgó al término en su Dictionnaire des intraduisibles, es decir, la traducción no

\footnotetext{
6 Agradezco a Andrea Pagni la información que me proporcionó sobre la traducción alemana de Los ingrávidos, cuando se debatió el tema durante el panel Contemporary Latin America: a Space for Translations del congreso de la American Comparative Literature Association en Utrecht, 6-9 de julio 2017.
} 
como lo que es irreductible en el original, sino como un proceso que nunca termina. Los "intraducibles" son para ella los síntomas de las diferencias entre los idiomas, por lo que nunca se puede dejar de traducir (3).

Aplicando esta idea a Los ingrávidos, cabe decir que no es, efectivamente, un texto que enfatice la particularidad de alguna variante del español, pero que sí evoca la interacción lingüística a través de la presencia diegética (y no tanto mimética). La otra lengua, que es el inglés, aparece reproducida en varias ocasiones bajo la forma de breves ejemplos de poesía citada (a la manera de los objets trouvés) y diferentes propuestas de traducción; por ejemplo, en la escena en la que se barajan diferentes opciones para los versos de San Juan de la Cruz (38-39). Sin embargo, la mayor parte del tiempo la novela lleva a su lector a reflexionar sobre el vaivén entre el español y el inglés que tiene lugar en Nueva York y en Ciudad de México a través de comentarios metalingüísticos como el siguiente: "A diferencia de la mayoría de los editores gringos, White no era monolingüe. Y a diferencia de la mayoría de los gringos que hablan español y han pasado una temporada larga o corta en Latinoamérica y creen que eso les da una especie de fogueo internacional tercermundista que los capacita intelectual y moralmente para -no sé muy bien para qué-, White sí entendía los mecanismos jodidos de la historia literaria latinoamericana" (36). O sobre el aprendizaje de la lengua de su bebé que nació en EEUU y ahora vive en México: "Produce sonidos que difícilmente se incorporarán al español, cuando lo aprenda a hablar. Vocales cerradas, opiniones guturales. Habla algo parecido a lo que hablan los personajes de los dramas de Lars von Trier” (26).

Se podría argumentar que Los ingrávidos presenta una estructura de quiasmo: el texto posee aquella misma traducibilidad que pone en tela de juicio. Se caracteriza por una tensión entre su ansia de plasmar un modus operandi multilingüe, que a fin de cuentas constituye la matriz de su pensamiento y de su afecto, y la necesidad de escribir en una sola lengua para poder publicar. Esta constelación explica por qué el "otro espacio" del texto manifiesto, o hipertexto, existe tan solo como proyección, como concepto, como aporía, como utopía. La otra lengua aparece como residuo que se plasma en escenas que dificultan u obstruyen esta transparencia, en nudos de opacidad. No es casual que se retomen aquí prácticas experimentales de la vanguardia, mecanismos productores de una nueva textualidad. Una de estas prácticas es la homofonía: el sonido de las palabras en inglés evoca acústicamente palabras en castellano similares, pero cuya semejanza fonética implica un desvío completo del sentido. Aparece cuando, en unas páginas muy elocuentes de Los ingrávidos, se narran las peripecias del grupo literario que se supone que Owen había fundado con García Lorca y Zukofsky. Zukofsky no habla español y los dos hispanohablantes hacen traducciones fonéticas de sus 
poemas que García Lorca lee en voz alta en los pasillos del metro. Este juego de transliteración conduce a interpretaciones disparatadas, como cuando el poema "A", que empieza con los versos "These, each in itself is saying, 'behoove us, / Disprove us least as things of love appearing" (108), es parafraseado por Owen como una oda a las aspiradoras Hoover ("These, itching and saying, 'behoover us / Dispose us least as things of love-happy-ring”, 116). En la performance de García Lorca, la traducción se vuelve aún más objeto de reflexión y de ironía, cuando estos mismos versos se transforman en "Aquí le pica y dice, 'hooveréanos, / Despáchanos mica como cosas del amor-alegre-anillo” (116).

Como queda dicho, esta estrategia de traducción puede identificarse como la homofonía. Se relaciona con lo que André Lefevere, tomando como ejemplo las versiones de Catulo en inglés firmadas precisamente por Celia y Louis Zukofsky (22), ha denominado “traducción fonética”, práctica que intenta reproducir en la lengua meta la configuración sonora del texto fuente y cuyo objetivo es crear imágenes nuevas. La homofonía desafía la noción tradicional de la traducción guiada por una idea de equivalencia con respecto a la lengua extranjera, ya que la reproducción es sustituida por una operación remodeladora y da lugar a un nuevo texto que no pretende funcionar como la traducción de un original, sino que se distancia de él. Son estas las escenas cuya traducción diverge considerablemente en las versiones en inglés, alemán, neerlandés, italiano... Algunos traductores continúan el juego fonético, mientras que otros restablecen la normalidad y traducen según el principio de la equivalencia.

Se puede concluir que, más que sacar a la superficie la idiosincrasia fonética/léxica/sintáctica de una lengua determinada, Luiselli muestra las operaciones lingüísticas subyacentes. Sin embargo, a su manera también logra visibilizar el proceso de traducción, la no evidencia de la fluidez, el fenómeno disruptivo de lo intraducible que, según la definición de Cassin, implica que su escritura arroje determinadas consecuencias para el proceso de traducción.

\section{Montajes transnacionales: Jacobo el mutante y Jacobo reloaded de Mario Bellatin}

\section{Jacobo el mutante}

Mario Bellatin es un autor mexicano-peruano, nacido en 1960, que se ha convertido en una de las voces imprescindibles de América Latina. Se perfila como un escritor neovanguardista cuya obra no obedece protocolos de representación o de causalidad, sino que desafía la idea de texto tradicional o de novela total 
latinoamericana ${ }^{7}$. Ha logrado crear un estilo tan lacónico que funciona como una marca. Viene ensayando una escritura modular, en la que cualquiera de sus textos puede replicarse en cualquier parte. La crítica recalca el carácter fragmentario de su escritura y el hecho de que sus libros rechazan toda categorización y rondan siempre otras artes. Salón de belleza (1994) es su novela corta más famosa. Su obra destaca por su prosa minuciosa, la densidad de sus imágenes y los universos inquietantes que evoca. Sus ejes temáticos son la culpa, la belleza, la muerte, la enfermedad y el dolor.

Bellatin se ha convertido en un escritor de culto. Hay un anecdotario alrededor de su figura que, de algún modo, da cuenta de cómo funciona su mundo narrativo que nunca concluye con la escritura, sino que se transforma en instalación, puesta en escena o engaño. Si Bellatin forja su mito personal de autor sobre una serie de hechos -haber nacido con un brazo malformado, pertenecer a una comunidad sufí, haber fundado la Escuela Dinámica de Escritores en el Distrito Federal, en la que se desaconsejaba escribir-, estos gestos extraliterarios no lo definen como un mero artista de happenings, sino que forman parte íntegra de su escritura.

En 2015 se desató una guerra en torno a Salón de belleza que ilustra el posicionamiento de Bellatin frente al mercado del libro. El autor prefiere diversificar su perfil: trabaja con numerosas editoriales, tanto grandes grupos transnacionales como sellos independientes y hasta artesanales y digitales. Como no cree en el concepto de texto definitivo, sus obras dan lugar a una proliferación de ediciones siempre modificadas. En 2015, Bellatin demandó a Planeta-Tusquets, una de las transnacionales literarias más poderosas del mundo, y lo hizo porque no le pagaban derechos de autor ni le permitían utilizar el texto que entonces ya tenía cinco reimpresiones. Habían firmado contrato en 1999 y, pese a su desacuerdo, la empresa lo renovó por otros quince años. Bellatin ganó la batalla y se convirtió en el primer autor a quien devuelven sus derechos ${ }^{8}$.

En 2002 salió una de sus obras más desconcertantes: Jacobo el mutante. Pretende ser la reescritura de una novela inédita del escritor austríaco Joseph Roth (1894-1939), autor de textos famosos como Radetzkymarsch (La marcha de Radetzky), que contiene la historia de una mutación. El tema central es el arte de la transformación. Los personajes se ubican en una serie de espacios en los que los cambios son incesantes y requieren, por tanto, una reflexión sobre la identidad y sobre la experiencia mística. La mutación se incluye desde el título como apuesta

7 Ha expresado sus ideas en el texto programático “Underwood portátil: modelo 1915” (Bellatin, Obra reunida 483-506).

8 Información encontrada en Mónica Felipe. 
a la metamorfosis. Sin embargo, el título ya entra en contradicción con el primer epígrafe que lo niega: "no se produjo ninguna mutación" (259). Existen varias ediciones del texto; trabajaré con la que fue publicada originalmente en México por Alfaguara y recogida posteriormente en Obra reunida (2013). Lleva fotografías de Ximenea Berecochea sobre las que volveré.

En Jacobo el mutante, un investigador literario poco fidedigno trata de reconstruir y analizar esa novela inédita de Roth, titulada Die Grenze (La Frontera), a partir de restos textuales. Narra la historia de Jacobo Pliniak, un rabino que es dueño de una taberna en el límite entre Rusia y Austria-Hungría cuyo nombre también es "La Frontera". Además de atender su negocio e iniciar en su fe a los niños de su comunidad, ayuda de manera semiclandestina a otros judíos de los pogromos rusos. Acosado por el antisemitismo, Jacobo tiene que salir de Polonia y se exilia en la costa oeste de EEUU. La historia experimenta un giro inesperado cuando, ya en el siglo XXI, Jacobo se transforma en una anciana octogenaria que lleva el mismo nombre que su propia hija adoptiva, Rosa Plinianson, una respetable anciana que lucha contra la instalación masiva de academias de baile en una ciudad de California?.

Las partes en cursiva son supuestas citas textuales de los fragmentos rescatados de la novela perdida. En realidad, Jacobo el mutante se presenta como el desvelamiento de un signo que permanece oculto, pues la novela se basa en la falsa recuperación de un texto de Roth, según ha confesado el propio Bellatin. Este texto citado, además, pretende ser una traducción hecha por el narrador, puesto que de la obra mencionada de Roth

[n]o se dispone aún de una traducción en regla, pero han aparecido fragmentos, como el ofrecido líneas antes, en revistas especializadas tanto de París como de la Costa oeste de los EEUU. En Frankfurt, la editorial Stroemfeld posee en sus archivos una antigua edición que se supone íntegra de la obra, y la editorial independiente Kieperheuer \& Witsh [sic] tiene otra versión que para muchos está compuesta sólo por una serie de fragmentos. Nadie sabe por qué, pero hasta ahora no se ha publicado ninguna de las dos. (262)

El texto posee, pues, un fuerte carácter metaficcional, al comentar la génesis de la literatura y de su circulación. Habla extensamente de los mediadores del texto: de la crítica inglesa que vivió con Roth los últimos años, de los lectores, de las dos versiones del manuscrito en manos de sendas editoriales, o sea, del libro como artefacto y de las problemáticas fronteras de lo que el canon entiende por

9 Lourdes Dávila (en untexto inédito que me fue facilitado por la autora) lee esta acumulación vacía de espacios para la danza como metáfora de una honda crisis de la producción cultural en nuestra época contemporánea. 
literatura. Roth no es de ningún modo un escritor desconocido aunque Bellatin, mediante su ficción, reavive el interés por los libros del mencionado escritor.

Según el narrador, algunos "errores" en la novela de Roth serían atribuibles a circunstancias externas: la larga duración de la creación; el hecho de que Roth solo trabajaba en este texto en sus frecuentes momentos de dependencia alcohólica (de allí las incoherencias); el carácter preparatorio del texto que no sería más que un borrador para otras obras; la pérdida de ciertos fragmentos. A estos residuos apócrifos se va superponiendo el relato del investigador literario que involucra elementos de la biografía de Roth, la tradición judía, su propia interpretación, el resultado de sus pesquisas en archivos, pasajes de la Biblia. Lo que leemos es, de hecho, una parodia a propósito de las fórmulas del discurso académico; una impostura de la erudición. Lo que está fuera del texto importa tanto o más de lo que se dice. A fin de cuentas, la obra puede ser leída como una elegía de un mundo destruido por el nazismo, ya que el drama del holocausto es el gran vacío alrededor del cual gira. Una lectura semejante confirma una de las premisas centrales de la obra de Bellatin, la que dice que la literatura no es referencial, sino que crea mundos paralelos que solo de manera oblicua se refieren a lo real.

Jacobo el mutante forma parte de una serie de obras de Bellatin producidas entre 2000 y 2002 que participan en una dinámica de construcciones apócrifas y atribuciones falsas, donde se privilegia el rol de la traducción. Shiki Nagaoka: una nariz de ficción es una biografía apócrifa en la que se instala la traducción como la dimensión más literaria de una obra. Por su parte, El jardín de la señora Murakami hace pasar al autor como el traductor de un texto inexistente. En Jacobo el mutante, además de un pseudotraductor, el narrador es un incompetente investigador literario. Las 33 fotografías de Ximena Berecochea insertadas en el texto de la novela pueden ser interpretadas erróneamente por el lector como traducciones intersemióticas. Miradas con detenimiento, resulta sin embargo que, por su carácter hermético y opaco, no son ilustraciones que revelan el sentido de la obra, sino que llevan a cabo otra mutación, esta vez de lo textual en lo visual. En lugar de reflejar el texto cuentan una segunda historia en la que aparecen, descontextualizadas, ciertas huellas de la presencia humana. Muestran restos de neumáticos en un camino de tierra reseca, botones entre la hierba, rocas en un paisaje de desierto, objetos hundidos en el agua de un lago.

\section{Jacob the Mutant: un remake}

La traducción es una noción clave para el universo narrativo de Bellatin. Muchas de sus obras son "born translated"; o sea, que la traducción se considera 
como un ingrediente necesario de la cadena de transformaciones en la que se apoya el proceso de escritura ya que, para Bellatin, una obra nunca está acabada y continúa desarrollándose cuando se vierte a otra lengua.

La obra de Bellatin ha sido traducida a varias lenguas, entre ellas al francés, al alemán y al inglés. Seis títulos han aparecido en inglés en editoriales independientes. Phoneme Media (Los Ángeles) ha publicado cuatro libros: El Gran Vidrio (The Large Glass), La mirada del pájaro transparente (The Transparent Bird's Gaze) y Nagaoka Shiki: una nariz de ficción (Shiki Nagaoka: a Nose for Fiction) -los tres traducidos por David Shook-, más el que se comentará abajo, Jacobo el mutante. Por su parte, Kurt Hollander tradujo Salón de belleza (Beauty Salon) para City Lights, un sello con sede en San Francisco.

Es particularmente relevante la mutación que sufrió Jacobo el mutante durante el proceso de traducción, mutación que afectó al texto original. Cuando el traductor al inglés y judío ortodoxo Jacobo Steinberg estaba trabajando con el texto, mandó una carta al autor contándole que había descubierto partes reales; a esa carta contestó Bellatin con una explicación en la que un narrador llamado Mario Bellatin recuerda a su abuelo judío y reflexiona sobre su propia conversión al sufismo. Ese comentario terminó siendo tan largo que llevó a reescribir el original y a publicar una versión reelaborada y expandida, Jacobo reloaded (Sexto Piso, 2014) ${ }^{10}$. Jacobo reloaded comienza de la misma manera que Jacobo el mutante: nos reconduce a La Frontera de Roth, pero a partir de este inicio falso Bellatin introduce personajes latinoamericanos, entre los cuales está su abuelo. Más en particular, retoma fragmentos enteros de un texto suyo anterior, Lecciones para una liebre muerta $(2005)^{11}$, que también trata de los recuerdos que un personaje narrador, converso islámico del judaísmo, tiene de su abuelo, que padeció el rechazo social de su lengua quechua. La vida del propio Bellatin, que evoca en Jacobo reloaded, tiene, como la de Roth, un importante "no dicho" aludido elípticamente: es una vida heredera de una lengua proscrita, esta vez el yiddish, que ahora se ha desplazado al Perú de su infancia. En ambos casos, observamos la ausencia de una lengua perdida que retorna constantemente de modo espectral. En su "Nota del Autor", Bellatin remite a este sustrato original desaparecido: "Las posibles contradicciones presentes en el texto anterior pueden haber sido consecuencias de que éste originalmente no fue concebido en el idioma en el que se encuentra plasmado" (81). Este epígrafe, que encabezaba una protoversión de Lecciones para una liebre muerta, titulada "Quechua", pero que había desaparecido de la novela

10 Véase Armento.

11 Texto que a su vez amplía el relato "Quechua”, como ha mostrado Juan Pablo Cuartas en su artículo de crítica genética. 
de 2005 (Cuartas), vuelve a aparecer literalmente en Jacobo reloaded, repitiéndose así un motivo presente en libros anteriores. En su estudio de la danza en Jacobo reloaded, Lourdes Dávila explica que en esta versión ampliada, la expulsión del cuerpo judío del espacio de lo social ya no se remonta a los pogromos rusos, sino a una época anterior, es decir, a la Venecia del siglo XV. Según Dávila, que ha tenido acceso al archivo que Bellatin ha utilizado explícita o implícitamente para la secuela, "[e]s allí donde observa el narrador el germen legal de la prohibición de la danza en los espacios públicos junto con la prohibición de las escuelas de baile o canto judío como forma de regular, controlar y criminalizar la expansión del judaísmo" (8). Este archivo, de donde proviene la mayor parte de las referencias a los bailes judíos que aparecen en Jacobo reloaded, fue creado por Jacob Steinberg, que por lo tanto debe ser considerado coautor de la novela.

La traducción al inglés que finalmente publicó Steinberg, Jacob the Mutant, es de la secuela, no del original. Contiene los paratextos de Jacobo reloaded: "Could There Have Been a Reason for Writing Jacob the Mutant”; "Affairs with Respect to Jacobo reloaded that It Would Be Good Not to Forget”, incluido el epílogo del traductor titulado "The Diary of Rose Eigen: A Translator's Afterword”, que no es lo que se espera de este tipo de texto, sino un testimonio personal en el que el traductor relaciona la novela con su propia vida, declarando que él también vivió una mutación parecida a la de Jacobo Pliniak. En Jacobo reloaded, las ilustraciones de la mexicana Ximena Berecochea han sido reemplazadas por los dibujos de la húngara Zsu Szkurka (que faltan en la traducción; solo han sido reproducidos dos mapas explicativos de la dibujante), que contrariamente a las fotos de Berecochea complementan la historia y ahondan en ella. Cabe decir, entonces, que, del mismo modo en que Jacobo el mutante es presentado como una traducción de un texto perdido de Roth, Jacob the Mutant es una traducción que lleva la propuesta estética de Bellatin a sus últimas consecuencias.

\section{Conclusión}

En lo que precede, he presentado dos novelas latinoamericanas que, según los criterios de Rebecca Walkowitz, nacieron “ya traducidas”. Son textos que no aparecen simplemente en traducción, sino que han sido escritos para ser traducidos, conteniendo la traducción en su génesis. El carácter translaticio de estas obras se prolonga en sus traducciones, lo que se manifiesta en algunos cambios notables en las traducciones al inglés y al alemán de Los ingrávidos y en la traducción sui géneris al inglés de Jacobo el mutante, que, de hecho, consiste en una reescritura desencadenada por la reacción del traductor al original. 
Por otra parte, de lo anteriormente expuesto se desprende que este tipo de textos no necesariamente deben confirmar el horizonte de expectativas del mercado ni llevar a una literatura global desmemoriada. Tanto Los ingrávidos como Jacobo el mutante/Jacobo reloaded confrontan a su manera la estandarización cultural propuesta por la globalización. Son obras que participan en distintas culturas literarias a la vez: la estadounidense y la mexicana en el caso de Luiselli, y la europea y peruana en el de Bellatin. Esta doble pertenencia explica su mayor circulación, el factor sine qua non de la literatura mundial, aunque hay que reconocer que el hecho de trascender el medio local para entrar en el escenario global no constituye un mérito literario en sí y que existen también muchas formas ultralocales de lo contemporáneo que no podrían ni tendrían por qué formar parte de este corpus.

Si estos dos autores escapan a los parámetros comerciales impuestos por la cultura global y logran integrarse en ella de manera original, poniendo de relieve elementos de la cultura latinoamericana, esto se debe en parte a su apuesta por una literatura que trabaja con el legado de la vanguardia (Luiselli) o, directamente, con los principios de la literatura experimental (Bellatin). Luiselli retrocede hasta principios del siglo XX para convertir en personajes a algunas figuras de la modernidad mexicana, mientras que Bellatin convoca el imaginario del exilio judío para asociarlo, a través de un ingenioso montaje, con la marginalización del yiddish en el Perú. Aunque cabría preguntarse en este contexto si ambos autores no "copian" de manera inteligente ciertos conceptos que han probado su éxito internacional: Luiselli el modelo Detectives salvajes, usando las vanguardias como ancla de una lectura "globalizada"; Bellatin el "modelo judío" que también un autor como Eduardo Halfon a estas alturas ha "usado" para generar un éxito internacional considerable ${ }^{12}$. En Luiselli la traducción aparece por doquier, pero funciona más como un tropo que como una práctica vinculada a la especificidad de una lengua determinada. Bellatin, que quiere purgar sus textos de todo origen, maneja un estilo deliberadamente neutro y, por tanto, eminentemente traducible. Vuelve a la vanguardia para tensar la relación entre la escritura y la circulación del texto en el mercado editorial. En los dos casos, las historias, independientemente del aspecto lingüístico, siguen siendo narrables para una audiencia de monolingües cosmopolitas.

El resultado de estas operaciones es que ya nada se considera local porque no hay extranjería y nada está al margen porque no hay centro. De acuerdo con la tesis defendida por Héctor Hoyos en Beyond Bolaño (en cuyo último capítulo, "Duchamp and Beuys as Latin American Writers", se aborda la obra de Bellatin)

12 Debo este comentario a Benjamin Loy. 
estos autores buscan claves para entender la forma en que la literatura latinoamericana representa al mundo globalizado y se ve representada en él. Hoyos apuesta por una multipolaridad en el campo cultural, en la que la noción de novela global latinoamericana sería un polo constitutivo. Los proyectos de Luiselli y de Bellatin contribuyen activamente a descentrar ciertos imaginarios y a colocar en el centro otros. Sin embargo, es legítimo preguntarse si, a la larga, la experimentación en la que se apoyan no corre el riesgo de terminar ofreciendo una propuesta estandarizada en sí misma. Sea como fuere, los dos estudios de caso dejan bien a las claras que usar el paradigma de la literatura mundial resulta provechoso, ya que la producción latinoamericana está irremediable y plenamente inscrita en los flujos transnacionales.

\section{Bibliografía}

Armenta, Carlos. “Jacobo reloaded, nuevo libro de Mario Bellatin”. El informador, 03/12/2014. www.informador.mx/Cultura/Jacobo-Reloaded-nuevo-libro-de-Mario-Bellatin-201412030061.html, consultado 6 de mayo 2018.

Bellatin, Mario. Jacob the Mutant. Trad. Jacob Steinberg. Phoneme Media, 2015.

--.. Jacobo reloaded. Sexto Piso, 2014.

--.. Jacobo el mutante. En: Obra reunida. Alfaguara, 2013 [2002], pp. 257-290.

--.. Obra reunida. Alfaguara, 2013.

Cassin, Barbara. Le vocabulaire européen des philosophies: Dictionnaire des intraduisibles. Du Seuil/Le Robert, 2004.

Cuartas, Juan Pablo. "Mario Bellatin, ¿Qué clase de espanto puede generar una escritura semejante?”. VI Jornadas Internacionales de Filología y Lingüística. I Jornada de Crítica Genética "Las lenguas del archivo". Universidad Nacional de La Plata, 2013. sedici.unlp. edu.ar/bitstream/handle/10915/42252/Documento_completo.pdf?sequence=1, consultado 5 de mayo 2018.

Damrosch, David. What Is World Literature? Princeton University Press, 2003.

Dávila, Lourdes. "Jacobo Reloaded: El movimiento hacia el fin de la cultura”. Ponencia inédita leída en el IXL Congreso IILI 2018, Pontificia Universidad Javeriana de Bogotá, 13 junio 2018.

Hoyos, Héctor. Beyond Bolaño: The Global Latin American Novel. Columbia University Press, 2015.

Lefevere, André. Translating Poetry: Seven Strategies and a Blueprint. Van Gorcum, 1975.

Lennon, Brian. In Babel's Shadow. Multilingual Literatures, Monolingual States. University of Minnesota Press, 2010.

Luiselli, Valeria. The Story of My Teeth. Trad. Christina MacSweeney. Coffee House Press, 2015 [2015].

--.. Faces in the Crowd. Trad. Christina MacSweeney. Coffee House Press, 2014 [2012].

---. La historia de mis dientes. Sexto Piso, 2013.

---. Die Schwerelosen. Trad. Dagmar Ploetz. Verlag Antje Kunstmann, 2013.

---. Los ingrávidos. Sexto Piso, 2011. 
Mónaco Felipe, Paula. “Mario Bellatin, perruno y enfermo de varios malos”. Cartón Piedra, 06/02/2017. www.cartonpiedra.com.ec/noticias/edicion-n-275/1/mario-bellatin-perruno -y-enfermo-de-varios-males, consultado 6 de mayo 2018.

Mora, Vicente Luis. “Globalización y literaturas hispánicas: de lo posnacional a la novela glocal”. Pasavento, vol 2, no 2, 2014. www.pasavento.com/pdf/04_05_mora.pdf, consultado 28 de abril 2018.

Parks, Tim. Where l'm Reading From: the Changing World of Books. Harvill Secker, 2014.

Reber, Nichole. "Writing Yourself into the World. A Conversation with Valeria Luiselli”. World Literature Today 90, 01/01/2016. www.worldliteraturetoday.org/2016/january/writingyourself-world-conversation-valeria-luiselli-nichole-l-reber, consultado 7 de abril 2018.

Sánchez Prado, Ignacio M. (ed.). América Latina en la "literatura mundial”. IILI, 2006.

Sheridan, Guillermo. “Nuevos mensajes de Gilberto". Letras Libres, 07/10/2012. www.letrasli bres.com/mexico-espana/nuevos-mensajes-gilberto, consultado 7 de mayo 2018.

Téllez, Jorge. "La otra historia de mis dientes". Letras Libres, 19/02/2016. www.letraslibres. com/mexico-espana/la-otra-historia-mis-dientes, consultado 7 de mayo 2018.

Walkowitz, Rebecca L. Born Translated. The Contemporary Novel in an Age of World Literature. Columbia University Press, 2015. 


\section{Anthropology over Aesthetics: On the Poetics of Movement and Multilingualism in Three Translations of Yuri Herrera's Señales que precederán al fin del mundo}

\section{Introduction}

When Latin American literature is translated into Scandinavian languages, book covers and reviews often stress anthropological values over aesthetic ones, typically highlighting both where the author comes from and where the book is set (Alvstad, "Strategic Moves"). Books from Latin America are thus mainly made relevant because of their origin rather than their aesthetic value or literary innovativeness. In general, this anthropological highlighting invites readers to expect that fictional texts from Latin America and other former European colonies would provide facts, information and insight into geographic, cultural and social conditions, that is, to values associated with non-fiction rather than fiction.

The Scandinavian emphasis on anthropology takes place in the paratextual packaging of the books, both on the covers and in forewords, epilogues, advertisements and reviews, at times neutrally, at times with travel metaphors and cover illustrations reminiscent of holiday brochures, at times in exoticizing ways evocative of the discourse identified by Said some forty years ago as orientalism (Alvstad, “Antologizing," "Arguing," "Strategic Moves”; Refsdal; Senstad). Since this emphasis on anthropology is characteristic also of literature translated from Africa and Asia, it plays a role in bringing these rather diverse literatures from the Global South together into a genre that in Sweden is sometimes referred to as world literature (Alvstad, "Strategic Moves" 81). It is a conception of world literature that stresses origin rather than "circulation" (cfr. Damrosch 4) and that clearly appeals to a certain section of the marketplace and its associated demands for the postcolonial to be exotic (Brouillete; Huggan). When the seemingly factual and/or the exotic (however invented) is given priority over aesthetic singularity, the immense literary diversity within each of these huge continents runs the risk of being homogenized (Alvstad, "Arguing," "Strategic Moves").

Cecilia Alvstad, Stockholm University

๑ Open Access. () 2020 Cecilia Alvstad, published by De Gruyter. (cc) BY-NC-ND This work is licensed under a Creative Commons Attribution-NonCommercial-NoDerivatives 4.0 International License.

https://doi.org/10.1515/9783110673678-013 
The present essay will explore more deeply the issue of emphasizing anthropology over aesthetics through a contrastive textual study of a Latin American novel by the Mexican writer Yuri Herrera and three of its translations. The aim is to shed light on whether the translated text itself-that is, the literary text seen in isolation from its paratextual surroundings-also can be shown to prioritize anthropological (geographic, cultural, social, etc.) values over aesthetic values. The focus of the analysis is on how formal poetic features, such as neologisms, direct the readers' attention to two of the novel's dominant topics, the interconnected issues of movement and multilingualism. The method of analysis is closely related to Boehmer's concept of reception-based or readerly pragmatics, in which critical reading means to pay close attention to how specific literary structures shape the cognitive processes that direct our perceptions while reading (2-3).

Boehmer claims that literary texts in postcolonial studies have "tended to be read illustratively or symptomatically, as an instantiation of paradigms drawn from a range of extra-literary studies-such as cultural studies, diaspora studies, anthropology" (3). In order to examine how the translators dealt with some of the text's aesthetic layers that shape the literary exploration of specific topics, the present essay will compare poetic features of the original to those of three of its translations. An underlying assumption is that the poetics of the texts is what allows the readers to work with these topics in specific ways. Just like in Boehmer's recent Postcolonial Poetics, the focus is on

the text as something that is read, and on the heuristic power of literature as literature; specifically, on the verbal and structural dynamics, the poetics, through which our understanding of the particular postcolonial condition being represented (race, resistance, liberation, reconciliation, precarity, and so on) may be shaped and sharpened. (3, Boehmer's italics)

The present essay will thus pay close attention to aesthetic elements such as neologisms that are likely to cognitively structure readers' attention toward certain passages.

The analysis will refer to three linguistic traits that typically appear in translations when compared to their source texts, namely, simplification, explicitation and normalization. Some scholars have even suggested that these three phenomena are universal linguistic traits of all translations (Laviosa-Braithwaite 288). Simplification may be lexical, syntactic and stylistic, for example when a more general word is used instead of a more specific one. Explicitation means that the translated text is more explicit than the source text, as when it adds background information, repeats information and clears up ambiguities. Normalization refers to a standardization of the text into a more conventional form (288-290). 
The novel under scrutiny here is Yuri Herrera's Señales que precederán al fin del mundo (2010) (SP) and its translations into Norwegian (Tegn forut for verdens ende, 2016) (NO), Swedish (Tecken som föregår jordens undergång, 2016) (SW) and English (Signs Preceding the End of the World, 2015) (EN). There are three reasons for choosing precisely Señales, the first of which is its highly innovative style. Lisa Dillman, the English-language translator of Herrera's book, portrays this style in the following manner:

Yuri Herrera's prose ... exhibits a multitude of distinct characteristics, displaying great variations in what is always creative and often non-standard language: its rhythm and orality; a style that is elegantly spare; striking metaphors, which are often unusual but rarely jarring: a mix of registers both low and high-slang and colloquial-but also lyrical and eloquent, some rural and others urban and both often very Mexican (or very much of its border); and neologism, to name just some. (Dillman 109-110)

The present essay focuses on a few of the stylistic traits mentioned by Dillman, more precisely the ones that in one way or another have to do with creative and non-standard language and how they call the readers' attention to the topics of movement and multilingualism. As it is impossible to include and focus on every poetic trait, the analysis risks coming across as unfair to the translators. However, the idea of this essay is not to evaluate the work of the three translators, but rather to point out some of the effects that translation decisions might have for how the book, the author, the source literature and source culture may be perceived/shaped by readers of the translations. The essay thus inscribes itself within the cultural turn in translation studies (Bassnett and Lefevere).

Second, the three translators work for different publishers in different target cultures and hence face very different expectations when translating a text. Target culture expectations delimit the translator's range of action. Other factors that may affect how translators carry out their task include the strength of their position in the field, if they translate in order to make a living or if it is a hobby, and so forth. This essay will not dwell long upon such issues, since the focus is neither on the quality of the translations nor on explaining the choices made by the translators/publishers. For the same reason, this essay will not examine the possible influence of the English translation, which was published first, on the Swedish and Norwegian translations.

The third reason for choosing this particular novel is that it resists a factual anthropological reading. References to languages and the people who speak them are associative, as when the languages being spoken are variously referred to as las lenguas de acá (SP 19), lengua (SP 19) lengua latina (SP 19, 115), lengua gabacha (SP 39) and gabacho (SP 73). Although it is possible to argue that these names allude to real languages such as Spanish and English, the names of these 
languages are never spelled out. Likewise, rather than providing a completely realistic account of Mexico peppered with Mexican names of towns and villages, the novel creates a mythological space, as described in the blurb of the Spanish edition:

Yuri Herrera no escribe "simplemente" sobre México y la frontera, sino que crea su México a través de historias y leyendas del pasado y del presente. Y traza con exactitud el mapa de un territorio que es aún más gigantesco, hecho tanto de lo que está sobre la tierra y en lo real como de lo que está bajo ella y pertenece a lo mitológico, a las culturas precolombinas.

[Yuri Herrera does not "simply" write about Mexico and the border but rather creates his Mexico through stories and legends of the past and the present. And with exactness, he draws the map of an even more gigantic territory, which is made up of both what is above the earth and real, and of what is below it and belongs to the mythological, to the preColumbian cultures]. (Herrera, Señales blurb, my translation)

In other words, this is a novel that might have a lot to do with Mexican society and culture, but there are few, if any, explicit references to Mexico itself ${ }^{1}$. All places are referred to in vague terms as el Pueblo (SP 19), Ciudadcita (SP 12) and Gran Chilango (SP 27), which means that the setting does not clearly play into a segment of a country that exists outside of the fiction. Likewise, when the protagonist Makina crosses a river on an "enormous inner tube, like from a tractor" (EN 37), this crossing may be reminiscent of what a crossing of Mexico's northern border might look like, but the river is never named, the border is not explicitly mentioned, and there are no explicit references to the United States after she arrives on the other side. There are some implicit references, however, for example to an army base that could be a United States army base (SP 79, 89, 95-104). There is also a stadium in which a game is played that seems to be baseball. In Dillman's translation the description of the game reads:

1 A word explicitly referring to Mexico only occurs once: Toda la cocina es cocina mexicana (SP 64, “All cooking is Mexican cooking,” EN 58). It is a complex reference to foreign kitchens, suggesting that the food from all restaurants smells familiar, and that this is because the people preparing the food, just like the people working as dishwashers, builders, florists, loaders, etc., are "countrymen" (paisanaje, SP 63). It is thus hinted that Makina is Mexican or at least that she knows Mexico well. This hint is made more explicit in the English translation since paisanaje-which in Spanish bears the two meanings of "countrymen", as either someone from a rural area or someone from the same country-is translated into "compatriots" (EN 57), which unambiguously bears only the second of these two meanings. Likewise, allá (SP 63), meaning "there", is translated into "back home" (EN 57) which explicitates that "there" is "home." This is made similarly explicit in the Swedish and Norwegian translations of this passage. 
Every week the anglos play a game to celebrate who they are. He stopped, raised his cane and fanned the air. One of them whacks it, then sets off like it was a trip around the world, to every one of the bases out there, you know the anglos have bases all over the world, right? Well the one who whacked it runs from one to the next while the others keep taking swings to distract their enemies, and if he doesn't get caught he makes it home and his people welcome him with open arms and cheering. (EN 59-60)

These descriptions certainly allude to the United States, but the country is not explicitly identified as such. However, although most geographic and cultural references throughout the novel are equally vague, the blurbs of all three translations, as well as Dillman's abovementioned epilogue, explicitly highlight that the plot is set in Mexico and the United States and on the border in between ${ }^{2}$. The novel's geographic setting is thus made much more explicit in the paratexts of the translations than it was in the original. Independently of any textual changes within the literary text itself, these paratexts will most probably prime readers of the translations to read them as a depiction of "reality" rather than mythical allegory. Moreover, the baseball scene excerpted above contains an example of a textual decision that might bring the translated text closer to "reality." The word "anglos" in the quote signals an association to people speaking English. Gabachos, the word Herrera uses in Spanish, is slightly more ambiguous. According to the crowdsourced Urban Dictionary, gabachos in the Mexico-United States context is a "chicano pejorative term for an English-speaking, non-Hispanic," but the word has also other meanings in Spanish. In Spain it is a pejorative way of referring to the French; according to the dictionary of the Royal Spanish Academy, it stems from gavach, which in Occitan refers to someone who does not speak well. The word gabacho thus plays into a scheme of spatio-linguistic ambiguity and vagueness that in the original contributes to a de-geographizing of the setting of the novel, which is neither a complete allegory nor a literary space with a completely clear counterpart in reality. It seems to say simultaneously that the setting is North America (Mexico and the United States) and that it might be elsewhere, thus anchoring the topics of movement of people and multilingualism that the novel explores within a much larger context.

Similarly, although this is clearly a book that features migration, this topic is not referred to with conventional words, such as "migrant," "migration" and "border." It is a literary investigation of the topic that works with neologisms and refrains from stereotypical language and typecast representations. Overall, this novel does not therefore lend itself easily to "strategic exoticism" (Huggan). Thus,

2 The Swedish blurb even mentions Mexican macho culture, which has been shown to already have been textually and paratextually reinforced in translations from the 1960s, that is, in some of the first Scandinavian translations of Latin American literature (Refsdal). 
it is not an immediate example of the anthropological-geographical translation strategies that this essay sets out to examine. Then again, if the target culture strongly expects Latin American literature to be about Latin America in a way that provides factual knowledge and some exotic elements, then it might be that the translators perceive and adapt to such expectations by adding such features.

\section{Movement}

Herrera's novel explores diverse issues related to the movement of people, and it is therefore not surprising that one of the most conspicuous neologisms in the book is a movement verb. An invented word, the meaning of which the reader has to figure out, is a poetic device likely to cognitively call attention to the topic of movement in the novel, thus constituting one of the central themes for the reader. In the Spanish text this invented verb is jarchar as in Jarchó a la calle (SP 38) and apenas jarchó del agua (SP 41). Dillman translates these two examples into "She versed to the street" (EN 36) and "as soon as he was out of the water" (EN 38). In Herrera's Spanish text jarchar is a frequently used verb-it appears on most pages of the book-and as such it will soon establish itself as a verb of movement to the reader.

Dillman generally translates jarchar into her English neologism "to verse." From the context this is clearly also a motion verb in English. The meaning of the word is moreover strengthened by its semantic similarity to the existing verb "reverse," moving backward. Dillman comments on her decision to translate jarchar into "verse" in an epilogue that follows the translated text. She decided on the word since, like jarchar in Spanish, it is a "noun-turned-verb" (113) and since itjust like the Spanish word-has a connection to poetry. As those acquainted with the Spanish literary tradition will be aware, jarchas are the last lines of Arabic or Hebrew poems written in Al-Andalus. Dillman (112) explains that the word comes from the Arabic kharja, which means "exit". In contrast to the rest of the poem, these last lines would be written in Mozarabic, the Romance vernacular spoken at the time in what is now southern Spain.

The Norwegian and Swedish translators, instead of creating a neologism, normalize jarchar into existing movement verbs that are not at all stylistically notable:

NO (29): Hun gikk ut på gata [She went out into the street]

SW (37): Makina gick ut [Makina went out]

NO (31): da han hadde kommet seg opp av vannet [when he had come out of the water]

SW (39): så fort han kommit upp ur vattnet [as soon as he (had) come out of the water] 
The Norwegian and the Swedish translations here simply say that Makina went out (to the street) and that he (Chucho) came out of the water. The deviant language is gone. A reader who only reads the translation and not the Spanish text will not have a chance to know that it was ever there. This normalization of Herrera's neologism means that there is nothing in this part of the text that may draw the readers' attention to the way the translated text has been formulated. A neologism would have involved a higher risk in this sense, since the translator could have been perceived as being too influenced by the source language or, even worse, as not being proficient in the target language. The very fact that Dillman, who chose to translate jarchar as "verse," comments extensively on this decision in the epilogue may be her way of regaining some of the readers' "trust" that she may have lost by using a non-existent verb (Alvstad, "Translation Pact”). In the Norwegian and Swedish translations, although the translators have eliminated one of the most talked about stylistic features of Herrera's novel, there is nothing in the translated text itself that can make the reader suspicious of such a translation loss.

From an ethical perspective and using the terminology established by Andrew Chesterman (175-191), the values of trust and clarity have won over the values of truth and understanding, where truth concerns the relationship to what is actually said in the source text. Although both the Norwegian and Swedish text is clear, the not so "truthful" handling of these and similar instances of the verb jarchar may in fact obfuscate the understanding of the novel as a whole, or at least take this understanding along new routes. Two examples will illustrate this point. As already mentioned, Herrera's novel deals with people on the move, without using words typically related to migration, such as migrante, migrar or frontera. If not immediately conspicuous by their absence, the frequently used neologism jarchar, which precisely indicates movement, may serve to draw attention to this absence. The fact that the word jarchar furthermore has its roots in Al-Andalus, a cultural context well-known for its many coexisting languages and cultures at a time before the Mozarabic language had even developed into Spanish, widens the reader's perspective on the idea of human beings in movement well beyond the Mexico-United States context. The normalization of the verb into standard language is thus not primarily merely a downplaying of a creative word formation. It has much broader implications for the possible interpretations of the novel as a whole, since it also downplays its intertexts and the historic and geographic contexts they bring in. Moreover, by erasing an important pointer to what is absent, it downplays the allegoric and mythological in favor of the immediately understandable. There is of course a limit to what can be achieved in translation, and Dillman's solution using 
"verse" must in this context be considered a relatively fortunate manner of conveying many of the hidden and open meanings of the Spanish neologism, and although Dillman uses "verse" less than Herrera uses jarchar-see for example the above-quoted normalization "as soon as he was out of the water" (EN 38)it succeeds significantly in reproducing the poetic idea of movement that is lost in the Norwegian and Swedish translations.

With regard to the absence of prototypical words related to migration, this absence is not paralleled by a corresponding absence in any of the three translations. In the following example, taken from the English translation, the word "migrants" is used as a counterpart to the more specific and marked transterrados (from trans, meaning "at the other side of" or "through," and tierra, meaning “earth," "region” or "country”):

SP (76): Dos o tres recados les había hecho llegar su carnal con sendos transterrados a su vuelta. [Her relative had caused two or three messages to reach her/them, each by a transplanted person on their return.] (My underlining, here and in subsequent quotes.)

EN (68): Her brother had sent two or three messages back with assorted migrants on their way home.

The rhetorical device of not using certain words is thus eliminated in this translation. Another difference between the two sentences above is that Dillman explicitates that the returning people are "on their way home" when the Spanish only says a su vuelta ("on their return"). Dillman thus emphasizes where these transterrados belong, where their real homes are.

Like Dillman, the two Scandinavian translators use the morpheme "migrant" to translate transterrados as, respectively, the standard Norwegian word emigranter ("emigrants") and the invented Swedish word transmigranter ("trans-migrants"), the latter thus borrowing a word from the title of another of Herrera's books La transmigración de los cuerpos (The Transmigration of Bodies):

NO (59): Broren hennes hadde sendt to eller tre beskjeder med emigranter på vei hjem. [Her brother had sent two or three messages with emigrants on their way home.]

SW (74): Makinas bror hade skickat två eller tre meddelanden till dem med olika hemvändande transmigranter. [Makina's brother had sent them two or three messages with different home-returning trans-migrants.]

All three translations thus explicitate the word "migrant," which is not used in the source text, and furthermore explicitate "home" (Norwegian hjem and Swedish hem in hemvändande, a noun+verb compound meaning something like "home-returning"). 
The word transterrados merits further comment, since its meaning, in fact, is not only that of "migrants." It was coined by the Spanish philosopher José Gaos (1900-1969), who fled to Mexico as an exile in 1939 and remained there for the rest of his life. Gaos' neologism transterrado allowed him to make a distinction between this and the already existing concept of desterrado. While the dictionary definition of desterrados refers to those who have to leave their country for a foreign one, transterrados refers to those who find that they can make the new country their home. The word transterrados has not yet made it all the way to the dictionary of the Royal Spanish Academy, but it is nonetheless used in Spanish, recently as the title of a novel published in Spain by the Colombian author Consuelo Triviño Anzola ${ }^{3}$. The choice of “migrants" normalizes Herrera's choice of word into a more standard form and it is also a simplification, since it uses a more general word for a more specific one. This may make the meaning clear, but it also alters the aesthetics of Herrera's prose, explicitly spelling out a word that is not used in the source text. It further means that the intertextual connection that transterrados has to the philosophical work of José Gao is severed, and since Gao himself was one of many Spanish intellectuals who became exiles in Mexico during the Franco regime, there is also a loss of the connection to this context to Mexico as a host country for political migrants.

A similar example where there is also a loss of intertext is the translation of éxodo multitudinario (SP 36), which Dillman renders as "mass exodus" (EN 34). Exodo and "exodus" both refer to the emigration of a large amount of people, and they are both also the name of the second book of the Old Testament, in which Moses helps his people escape from slavery in Egypt across the Red Sea. The word thus intertextually anchors the idea of people having always been on the move away from unfair living conditions and persecution. In this sense its function is similar to jarcha, which suggests Al-Andalus, and transterrados, which in turn suggests the Spanish anti-Franco intellectuals who fled to Mexico. "Mass exodus" (EN 34) reproduces this intertextual connection and thus the historical dimension, but it interestingly changes multitudinario, which is a neutral or even slightly positive way of denominating a large group of people, whereas "mass" rather is slightly negative, especially when combined with a word related to migration. Although a minor change, it may play into such negative stereotypical preconceptions of migration that Herrera's novel in Spanish seems to question.

3 See https://www.letraslibres.com/mexico-espana/filosofia-la-filosofia and https://elpais. com/diario/1989/08/28/opinion/620258410_850215.html for two examples of the word and a discussion of its origins. See https://www.proceso.com.mx/556604/los-transterrados for a recent example of the word being used in relation to Mexico-United States migration (24/10/ 2018). 
The Norwegian and Swedish translations, however, normalize éxodo multitudinario as masseutvandring ("mass emigration," NO 28) and väldig folkvandring ("enormous migration of people," SW 34), with utvandring and vandring in Norwegian and Swedish being Germanic synonyms of "emigration" and "migration." The most common way of referring to immigrants in Norwegian and Swedish is in fact by the Germanic words innvandrer and invandrare ("immigrant"), respectively, rather than the Latinate immigrant. Thus, although the morpheme migrant is not being used here, the translations certainly involve the most common way of referring to migration in Swedish. The two translations de-historicize Herrera's formulation, since the intertextual link to the movement of people in the Bible is broken. A possible explanation for not using the word "exodus" may be that the translators opted for clarity, since exodus may be a less-established concept in Scandinavia than in North America, given that the Book of Exodus in Norwegian and Swedish is known rather as "the Second Book of Moses" (Andre Mosebok and Andra Moseboken, respectively). The Swedish text also adds folk ("people") to folkvandring, which in Swedish connotes another historical context, namely the turbulent Migration Period of late antiquity, that is the Germanic invasions of around 350-600 CE, potentially therefore priming the idea of "invasion" in the reader rather than the Exodus-related idea of leaving a situation of slavery.

Finally, the Norwegian choice of masse is similar to "mass" in English, although its common usage together with the word innvandring ("immigration") by Norwegian politicians who are hostile to immigration may make its semantic prosody even more negative in Norwegian than in English ${ }^{4}$. Väldig in Swedish, meaning "enormous" or "huge," is in contrast value-neutral.

Returning now to how the seemingly clear handling of the verb jarchar in Norwegian and Swedish may obfuscate the understanding of the novel as a whole, a second example will illustrate this point. This takes us to the end of the novel, its exit, or jarcha, where the word Jarcha, now a noun, appears on a sign over a door, and then twice in the following sentences. In Spanish and English this section reads:

SP (117): Sobre la puerta había un cartel que decía Jarcha. Trató de recordar cómo se decía jarcha en alguna de sus lenguas pero no lo consiguió. Ésta era la única palabra que se le venía a los labios. Jarcha. [Over the door was a sign that said Jarcha. She tried to remember how to say jarcha in any of her languages but couldn't. This was the only word that came to her lips. Jarcha.]

4 Cfr. this usage at https://www.rights.no/tag/masseinnvandring/. 
EN (105): Over the door was a sign that said Verse. She tried to remember how to say verse in any of her tongues but couldn't. This was the only word that came to her lips. Verse.

The verb jarchar has been used throughout the novel, a novel written in Spanish, and this passage clearly indicates that it is not a word that Makina, the multilingual protagonist who speaks and interprets for others between lengua, lengua latina and lengua gabacha, recognizes from any of the languages she knows. There is a twist here that underscores that none of the languages spoken in the novel is Spanish. There are textual features that have invited readers to identify the space of the second part of the book with the United States, but these indices are here followed by a decontextualization from any existing geographic and anthropological "reality." The space is again clearly mythological and not the least socio-realistic.

This is all well-reproduced in Dillman's translation, as is the connection to poetry. Lost, however, are the connections to the multilingual and multicultural Al-Andalus with its multilingual poetry-there are limits to what translation can do. The Norwegian and the Swedish translators, however, run into bigger problems. Since they normalized jarchar into standard Norwegian and Swedish, they have no neologism they can draw upon here. The Swedish translator solves this problem using the foreign word jarcha in italics in her text:

SW (117): Ovanför dörren hängde en skylt där det stod Jarcha, utgång. Makina försökte dra sig till minnes hur man sa jarcha på något av de språk hon talade, men kunde inte. Det enda ord som dök upp på hennes tunga var jarcha. [Over the door hung a sign saying Jarcha, exit. Makina tried to remember how one said jarcha in any of the languages she spoke, but she could not. The only word that appeared on her tongue was jarcha.]

This is a rather verbatim translation from the Spanish, with one exception, the explicitation of the meaning of jarcha the first time it is used. The translator then adds a comma and the word utganng ("exit"). A problem with this translation is that it is rather unclear who the utterer of utgaing is. The seeing of the sign is focalized through Makina, the narrator being responsible for the utterance. But is the narrator also the one who provides the translation of what jarcha means? It comes across as illogical that the narrator suddenly, in a passage focalized through Makina, would provide information to the readers over the head of the character. It would however be even more illogical if Makina would know the meaning of this word since the text clearly says that she cannot remember what it is in any of the languages she speaks. The word could also be attributed to the translator, as a kind of translator's note inserted more or less ostentatiously into the translated text. Or it could be attributed to the author, who in this case would come across as 
a bad writer who did not know how to be consistent with the voices and perspectives he created.

The Norwegian translator opts for another solution:

NO (91): Over døra hang det et skilt. Jarcha, sto det-Utgang. Hun forsøkte å finne et godt ord for jarcha, avferd og endelikt, på språkene hun kunne, men klarte det ikke. [Over the door hung a sign. Jarcha, it said-Exit. She tried to find a good word for jarcha, departure and ending, in the languages she knew, but she did not succeed.]

Utgang means "exit," avferd "departure” and endelikt "ending” or even "death." This means that the translator spells out three of the words that Makina cannot find, but in contrast to the Swedish text, the internal logic of the text in Norwegian still works. This is because the translator changes more details. What the Norwegian text says is that she tried to find a good word for jarcha, but that she did not succeed, so that the three words for jarcha that appear in the text become tentative approximations. Furthermore, the Norwegian translator omits the following two sentences, which say that jarcha was the only word that came to mind ("Ésta era la única palabra que se le venía a los labios. Jarcha.”), and the problem is solved. It is not a truthful representation of what the original says, and it furthermore certainly alters the poetics of the text, but it is a solution that has an internal logic. This warrants the trust the reader has in the translator and also the author, whereas an illogical translation solution would have exposed not only the translator but also the author to potential criticism and distrust.

Before leaving the discussion of jarcha altogether, it may be noted that the fact that this word appears once in the Norwegian and Swedish texts makes the connection to Al-Andalus present in their translations. Very few Norwegian or Swedes would, however, be able to pick up this reference. Not many Scandinavians are acquainted with Mozarabic poetry, and those who are would probably choose to read Herrera's novel in Spanish and not in translation. Although formally retained in the text, this allusion to the final lines of multilingual poetry from the past must therefore be considered more or less lost in translation.

\section{Multilingualism}

The setting of Señales is multilingual, but unlike many recent works of Chicano literature by authors such as Gloria Anzaldúa, Ana Castillo and Sandra Cisneros, there is no English-Spanish hybridity in Herrera's prose. The multilingual setting is instead constructed via other techniques such as a number of reflections on multilingualism and code-switching (e.g. SP 73-74), as well as through the 
constant usage of slightly twisted or invented expressions such as lengua latina (SP 115) and lengua gabacha (SP 39), which, although alluding to a multilingual Mexico-United States setting, does not turn the text into a Spanish-English multilingual text, since it is all written in Spanish. The following is an example of a passage in which multilingualism is brought to the fore in the novel:

SP (74): Al usar en una lengua la palabra que sirve para eso en la otra, resuenan los atributos de una y de la otra: si uno dice Dame fuego cuando ellos dicen Dame una luz ¿qué no se aprende sobre el fuego, la luz y sobre el acto de dar? No es que sea otra manera de hablar de las cosas: son cosas nuevas. Es el mundo sucediendo nuevamente, advierte Makina: prometiendo otras cosas, significando otras cosas, produciendo objetos distintos.

EN (66): Using in one tongue the word for a thing in the other makes the attributes of both resound: if you say Give me fire when they say Give me a light, what is not to be learned about fire, light and the act of giving? It's not another way of saying things: these are new things. The world happening anew, Makina realizes: promising other things, signifying other things, producing different objects.

This section describes one of the other ways in which Herrera creates the multilingual setting, that is, by using calques, also called direct translations, from English in his Spanish, or what in the quote above is described as "using in one tongue the word for a thing in the other."

Dillman's English translation closely follows the Spanish text here, as do the Norwegian and Swedish translations of the same passages. The slightly twisted expressions such as lengua latina and lengua gabacha, conversely, seem to create more of a challenge for the translators. As mentioned in the introduction to this essay, Dillman chooses to translate gabacho with "anglo," as in the following example, which also provides the Norwegian and Swedish translations of the same sequence:

SP (68): y en gabacho decían Frescos. [and in Gabacho they said We're cool]

EN (62): and in anglo said We're cool.

NO (52): og sa på gabacho: We're good. [and said in Gabacho: We're good]

SW (67): och på gabacho konstaterade Det är lugnt. [and in Gabacho said It is cool]

As mentioned before, "anglo" has a narrower meaning in the English language than gabacho has in Spanish, as it only could refer to people speaking English, with the original Spanish meaning of the word gabacho, which refers to the French and Spanish-French border context, being lost. Then again, this original meaning may not be known to Spanish-speakers in Mexico and the United States.

Moreover, in the Spanish original, gabacho, lengua latina and so forth are invented languages, or at least the invented names of languages, i.e., they do exist as languages in the fictional world. From this point of view, they should have been 
capitalized in English, but they are not. They appear in the English translation as "anglo," "anglo tongue" and "latin tongue" and therefore do not seem to be the names of languages, but paraphrases. This interestingly enough contributes to making them more identifiable with English. By not capitalizing the "a," the translation seems to communicate that the language English is referred to in this text with the circumlocution "anglo," rather than Anglo being a language of its own.

The Norwegian and the Swedish keep gabacho, using italics, which at first sight may seem to reproduce the aesthetics of the source text to a higher degree. The opposite may actually be the case, however, since the Norwegian translation uses the English phrase "We're good" to represent what is being said in Gabacho, thus suggesting that Gabacho is English. Since the word gabacho at the same time appears in Spanish, the Norwegian translation thus introduces a multilingual code (Norwegian, English and Spanish) that does not have a counterpart in Herrera's text in Spanish, which consistently makes use of a monolingual and not a bilingual or multilingual code.

There is a similar example further on in the book in which the characters are speaking Gabacho:

SP (102): Primera base, ¿eh? ¡Bien por ti! [First base, huh? Good for you!]

EN (92): First base, huh? Good for you!

NO (78): First base hæ? Bra for deg! [First base huh? Good for you!]

SW (100): First base, va? Du har tur, du! [First base, huh? You are lucky, you!]

In the Spanish text the language Gabacho is always represented in Spanish, possibly with the exception of a "Hey" used to call someone's attention (SP 50). In the above examples, however, the Spanish primera base is a calque of an American conventionalized baseball metaphor for "a preliminary stage of sexual intimacy, typically characterized as kissing" (Oxford Dictionary of English, Apple 2.2.2). The English translation does not in any way represent this, since translated back into English, the Spanish neologism is again conventionalized (a translation challenge indeed difficult to resolve). The Norwegian and the Swedish translations manifest the Englishness of the expression by representing it in English. Thus, they explicitate that Gabacho is English and shift the text from the monolingual to the multilingual. In the above example, they also eliminate Herrera's stylistic device of using a calque from the English, which, as mentioned above, is one of the devices he uses to build up the multilingual setting.

When the Norwegian and Swedish translators introduce a multilingual code into Herrera's novel, they in fact draw on a much-used device in the abovementioned Chicano writing as well as in the fairly recently translated-and much talked about-The Brief Wondrous Life of Oscar Wao by Junot Diaz. This can be 
analyzed as an aesthetic stereotyping in which the singularity of this works gets lost, in favor of what seems to be an expectation of a larger body of works.

Not only gabacho but also lengua latina seems to create problems for the translators. The Norwegian translator faces this challenge by varying the ways he translates it. Among the less fortunate solutions are translating it into spansk ("Spanish," NO 52) and latino ("Latino," NO 74), thus again explicitating realworld correspondences for a fictional language (or, if not an invented language, at least a language with an invented name).

On another occasion, the Norwegian translator opts for hennes eget språk ("her own language," NO 89), thus singling out lengua latina as Makina's own. The original, however, never spells out that lengua latina is Makina's first language. Early on in the Spanish version of the text, it is even possible to infer the opposite, that is, that both lengua latina and lengua gabacha are second languages for Makina. In a sequence that describes Makina's work as an operator of the only telephone in the neighborhood, the three languages are depicted in the following way, suggesting that the language that might be closest to her is the language here referred to as just lengua ("language"):

SP (19): A veces era gente de pueblos de por ahí la que llamaba y ella contestaba en lengua o lengua latina. A veces, cada vez más, llamaban del gabacho; éstos frecuentemente ya se habían olvidado de las hablas de acá y ella les respondía en la suya nueva. Makina hablaba las tres y en las tres sabía callarse. [Sometimes it was people from villages nearby who called and she answered in Language or Latin Language. Sometimes, more and more, they called from the Gabacho, those frequently already had forgotten the ways of speaking from here and she answered them in their own new one. Makina spoke all three and in these three she knew how to keep quiet.]

EN (19): Sometimes they called from nearby villages and she answered them in native

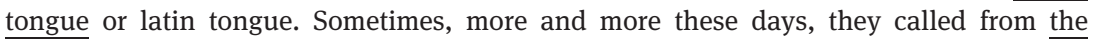
North; these were the ones who'd often already forgotten the local lingo, so she responded to them in their own new tongue. Makina spoke all three, and knew how to keep quiet in all three, too.

NO (15): Iblant ringte det folk fra andre landsbyer, og hun svarte på dialekt eller på vanlig spansk. Iblant, og det skjedde stadig oftere, ringte folk nordfra. Det var dem som hadde glemt den lokale dialekten, så hun svarte på det nye gringospråket deres. Makina snakket alle tre språkene, og kunne også holde munn på alle tre. [Sometimes people called from other villages, and she answered in dialect or in ordinary Spanish. Sometimes, and this happened ever more often, people called from the North. It was they who had forgotten the local dialect, so she answered in their new gringo language. Makina spoke all three languages, and she also knew how to keep her mouth shut in all three].

SW (17): Ibland var det folk från byarna i närheten som ringde och då svarade hon på det egna språket eller på det latinska. Ibland, allt oftare, ringde de norrifrån; och då hade de för det mesta glömt traktens språk, så hon svarade på deras nya. Makina talade alla tre och på alla tre kunde hon hålla tyst. [Sometimes it was people from the villages nearby 
who called and then she answered in the own language or in the Latin one. Sometimes, more and more often, they called from the North; and then they had more often than not forgotten the language(s) of the neighborhood, so she answered them in their new one. Makina spoke all three and in all three she knew how to keep quiet.]

Lengua is just "language" without further definitions and the way it is used here can be considered deviant from a linguistic and stylistic point of view. All three translators, however, normalize this deviant usage of lengua. The English and Norwegian translations, by specifying that it was her "native tongue" or dialekt ("dialect"), respectively, eliminate the possibility of inferring that this is Makina's first language, while the Swedish translation explicitates that this is indeed her first language, or det egna språket (literally, "the own language").

Another important difference between the translations and the original is underlined above. All three translations mention the North (nordfra and norrifrån in Norwegian and Swedish). This again adds a geographic explicitness that may not be as obvious in the Spanish text.

The Norwegian translator in this quote moreover specifies that the people who went to the North speak not only a new language, but det nye gringospråket deres ("their new gringo language"). A similar explicitation appears some pages further on, when gabacho is followed by the addition of gringoenes språk ("the language of the gringos"). This may be a compensation for what is lost in the translation of the word gabacho, since Norwegian readers will not know that gabacho, in the Spanish spoken in the United States and Mexico, is similar to what in Norwegian is referred to as gringo. As a consequence, however, the deviant and innovative language-a building element crucial to Herrera's prose-is compromised.

All three translations make use of Spanish words, for example the word pulque early on in the book when Makina is offered this drink at a bar (SP 17-18), the word jefecita for mother (SP 48) and Doña (SP 83) as a way of addressing a woman. From the context it is quite obvious that pulque is an alcoholic beverage. It is also clear that jefecita is the mother and that Doña is well-known as a form of address-if not understood, it would probably be taken for a proper name. There is in other words no need to provide a translation to improve clarity. Dillman writes in the epilogue to her translation that she retains some words in Spanish as "a linguistic reminder to the reader that this is, in fact, a translated text" (112). This seems clear-cut and is furthermore consistent with the ethical approach to translated texts advocated by, for example, Lawrence Venuti. However, foreign words in translations are not only innocent reminders of the text being translated but would also generally signal a foreign setting. When it comes to the translation of this novel, the words in Spanish specify the geographic-linguistic context as being precisely Spanish-speaking. 
The Norwegian translation uses more expressions in Spanish than the other two. It also explicitates early in the book that the characters are speaking to each other in Spanish by letting the last words of what a character says appear in Spanish in the Norwegian translation:

NO (13): så ber du meg om hjelp, og jeg, jeg sier claro que sí [and you ask me for help, and I, I say claro que sí]

SP (17): me estás pidiendo ayuda y yo, mírame, te digo claro que sí

The Spanish text here is all in Spanish and the other two translations use monolingual English (EN 17) and Swedish (SW15), respectively, without any mixing of two linguistic codes. The device of using Spanish in the Norwegian text here, rather than telling the reader what language the book is translated from, serves to show the reader that the characters are speaking Spanish to each other. However, as has been made clear above, it is in fact not stated in the original that the characters are speaking Spanish. Spanish is used to represent all languages in the original text. In this sequence the characters could be speaking lengua or lengua latina, but neither of these is in fact identified as being Spanish, and in this sense the novel as a whole is in fact a fictional translation.

\section{Conclusion}

Movement and multilingualism are central themes throughout Señales and its translations into English, Norwegian and Swedish. The comparison of the four texts has shown, however, that there are important differences to how these themes are built up in each text. The Spanish text includes a number of neologisms such as jarchar and jarcha that draw attention to the theme of movement. The creative names of languages and the people who speak them (lengua, lengua latina, lengua gabacha, etc.) puts the focus on multilingualism. The words jarcha, gabacho, transterrado and éxodo furthermore place the themes of movement and multilingualism in a wide historic setting that includes the Bible, AlAndalus and the exile of Spaniards in Mexico during the Franco regime. Moreover, there are important absences in the Spanish text, such as stereotypical words referring to migration (migración, migrante, frontera, etc.), which also work as a poetic device to put the theme in focus. In the original there are furthermore very few cues that point particularly to North American historic or cultural circumstances, there being, for example, no names of languages and villages with an exact counterpart in the real world. When cultural phenomena such as baseball are implied, they are generally not mentioned by their names, 
and there is thus a vagueness and ambiguity surrounding even the most obvious references to real-world cultural or geographic circumstances.

In the translations this does not work in the same way, since many of the translation solutions undeniably bring the literary text closer to reality. The fictional language Gabacho is, for instance, made more identifiable with English in all three translations. The English translation does this by naming the fictional language "anglo," while the Swedish and Norwegian translations use English phrases a few times when it is clear from the novel that Gabacho is being spoken. The Norwegian furthermore explicitates that lengua latina is Spanish. The way the neologisms and the concepts they represent are translated thus brings the setting to a North American geographic and cultural context.

The use of pulque, jefecita and other Spanish words in the translations furthermore reinforces this geographical setting. Dillman comments in her epilogue that she left these words in Spanish as a reminder that the text is a translation. This is consistent with the ethical approach to translated texts advocated by, for example, Lawrence Venuti. This essay has, however, shown that the Spanish words in the translations are not innocent reminders of the text's status as a translation, since they also add a specification of the geographic-linguistic context as being precisely Spanish-speaking. The question that arises is therefore whether interweaving words from the source language into the translation, thus anchoring the translated text in its source culture, can be considered ethical when the novel itself so distinctly resists a multilingual linguistic code, when the languages are not identifiable as real languages, and when the cultural and geographic setting is ambiguous.

Various poetic devices, such as neologisms and lexical silences, surround the themes of movement and multilingualism in the original, but were flouted in the translations. From a technical point of view, the translators normalized, explicitated, and simplified, that is, they created linguistic features that are very common in translations. The effects of these processes of normalization, explicitation and simplification were here shown to weaken important aesthetic layers of Herrera's text, while at the same time reinforcing the anthropological setting as being Mexico, the United States and the border between them. While previous studies of Scandinavian translations of Latin American literature have shown that book covers and reviews stress anthropological over aesthetic values, this study has demonstrated that this also takes place in the literary text itself, seen in isolation from its paratextual surrounding. 


\section{Works cited}

Alvstad, Cecilia. "Anthologizing Latin-American Literature: Swedish Translative Reimaginings of Latin America 1954-1998 and Links to Travel Writing.” Anglo-Saxónica, vol. 3, 2012, pp. 39-68.

--.. "Arguing for Indirect Translations in Twenty-First-Century Scandinavia." Translation Studies, vol. 10, no. 2, 2017, pp. 150-165. doi:10.1080/14781700.2017.1286254.

-.-. "The Strategic Moves in Paratexts: World Literature Through Swedish Eyes." Translation Studies, vol. 5, no. 1, 2012, pp. 78-94.

--.. "The Translation Pact." Language and Literature, vol. 23, 2014, pp. 270-284.

Bassnett, Susan, and André Lefevere (eds). Translation, History and Culture. Pinter, 1990.

Boehmer, Elleke. Postcolonial Poetics: 21st-Century Critical Readings. Palgrave Macmillan, 2018.

Brouillete, Sarah. Postcolonial Writers in the Literary Marketplace. Palgrave Macmillan, 2007.

Chesterman, Andrew. Memes of Translation: The Spread of Ideas in Translation Theory. Benjamins, 1997.

Damrosch, David. What Is World Literature? Princeton University Press, 2003.

Dillman, Lisa. "Translator's Note." Signs Preceding the End of the World. Yuri Herrera. And Other Stories, 2015, pp. 109-114.

Herrera, Yuri. Señales que precederán al fin del mundo. 2nd ed. Periférica, 2010.

---. Signs Preceding the End of the World. Trans. Lisa Dillman. And Other Stories. 2015.

--.. Tecken som föregår jordens undergång. Trans. Maria Cederroth. Nilsson, 2016.

--.. Tegn forut for verdens ende. Trans. Christian Rugstad. Cappelen Damm, 2016.

Huggan, Graham. The Postcolonial Exotic: Marketing the Margins. Routledge, 2001.

Laviosa-Braithwaite, Sara. "Universals of Translation." Routledge Encyclopedia of Translation Studies. Ed. Mona Baker. Routledge, 2001, pp. 288-291.

Refsdal, Eva. When "a girl" Becomes "an attractive little number": Stereotyped Representations of Latin America in Literary Translation and Reception in 1960 s Norway. University of Oslo, PhD dissertation, 2016.

Said, Edward, W. Orientalism. Pantheon Books, 1978.

Senstad, Idun Heir. "Bokomslag som formidling: Cubanske romaner i norsk innpakning."

Litteratur-og kulturformidling: Nye analyser og perspektiver. Eds. Helge Ridderstrøm and Tonje Vold. Pax, 2015, pp. 166-188.

Venuti, Lawrence. Translation Changes Everything: Theory and Practice. Routledge, 2013.

--.. The Translator's Invisibility: A History of Translation. 2nd ed. Routledge, 2008. 



\section{Glotopolíticas literarias entre resistencia y mercado: Bolaño en traducción, la traducción en Bolaño}

\section{Literatura mundial y/en traducción: de ganancias, pérdidas y traductores (in-)visibles}

Afirmar que el acto de traducir es el sine qua non de la existencia de la literatura mundial es una evidencia ya destacada por Goethe en uno de sus tantos pasajes acerca del tema, ya que "diga lo que se diga acerca de la insuficiencia de la traducción, es y será uno de los negocios más importantes y dignos del tráfico mundial general" (434) ${ }^{1}$. Al mismo tiempo -y en concordancia con la afirmación del clásico alemán- la traducción ocupa un lugar ambiguo en la amplia tradición de su investigación teórica: es indispensable para la circulación de textos, ideas y como sugiere la dominante metáfora economicista del Verkehr en las nociones de Goethe- de mercancías, sin que por ello pudiese superar el eterno defecto de su propia imperfectibilidad. "Nothing is translatable. [...] Everything is translatable" es la fórmula paradójica que Emily Apter ha usado en los debates contemporáneos para designar los dos "poles of translation theory" (The Tranlation Zone 8), entre los que se podría situar gran parte de los textos teóricos recientes. Uno de los ejemplos más prominentes resulta ser la reconocida (re-)definición de la literatura mundial por parte de David Damrosch, quien postula que esta sería, principalmente, "writing that gains in translation" (281). Si bien, al adherir más bien a un lenguaje metafórico ${ }^{2}$-“works become world literature when they gain

1 Traducción propia del original ("Denn was man auch von der Unzulänglichkeit des Übersetzens sagen mag, so ist und bleibt es doch eines der wichtigsten und würdigsten Geschäfte in dem allgemeinen Weltverkehr"). Acerca del aspecto de la traducción en Goethe, véanse también las reflexiones de Strich (15-30). Sobre la importancia de los estudios de traducción en el debate actual sobre literatura mundial, véase el artículo de Venuti que parte de la afirmación: "World Literature cannot be conceptualized apart from translation" ("World Literature" 180).

2 Véanse al respecto las reflexiones de Harrison y su crítica de que "the fundamental problem with Damrosch's assertion about gains in translation is that it seems to assume arbitrarily that gains outweigh losses” (415).

Benjamin Loy, Universität zu Köln

Ә Open Access. () 2020 Benjamin Loy, published by De Gruyter. (cc) BY-NC-ND This work is licensed under a Creative Commons Attribution-NonCommercial-NoDerivatives 4.0 International License.

https://doi.org/10.1515/9783110673678-014 
on balance in translation, stylistic losses offset by an expansion in depth as they increase their range" (289)-, Damrosch no profundiza realmente en las dimensiones materiales del negocio translaticio, subraya la importancia de la traducibilidad de una obra como factor para su circulación internacional, ya que "some works are not translatable without substantial loss, and so they remain largely within their local or national context, never achieving an effective life as world literature" (288-289). Frente a esa larga lista de posiciones de una Weltliteraturwissenschaft (22) (como la ha llamado Fritz Strich) que explican "why translation matters" (Grossman), siendo la base de una literatura mundial entendida como un conjunto de "multiple windows on the world" (Damrosch 15), el polo opuesto del espectro teórico ha preferido insistir en las dimensiones problemáticas de la traducción: aparte de complejizar la noción del fenómeno en el sentido de una "política de la traducción” (Spivak, “The Politics”), implicando también una problematización del acto de traducir como tal que contribuye -como es el caso en gran parte del mercado literario y universitario global ${ }^{3}$ - a una homogenización lingüística (Spivak, Death of a discipline), esos trabajos han llamado la atención sobre aspectos de "intraducibilidad" como opuesto crítico y productivo ${ }^{4}$ del discurso translaticio afirmativo.

El punto en común de ese tipo de trabajos reside en sus perspectivas teóricas y muchas veces abstractas frente a ejemplos de traducciones literarias concretas. Esto conduce -siguiendo la separación entre traductología y práctica traslaticia establecida por Antoine Berman (69) - a la pregunta por la importancia de una crítica de la traducción enfocada en el texto concreto, es decir en la dimensión filológica y -en el mejor de los sentidos-artesanal que representa el centro imprescindible de cualquier trabajo translaticio como operación textual ${ }^{5}$. La necesidad de semejante trabajo crítico se hace más evidente si se considera, además, el papel que ocupan tanto la traducción como las traductoras en la crítica literaria actual. A diferencia de la "invisibilidad" de la traductora, como lo formuló de manera prominente Lawrence Venuti en sus críticas a la “illusion of transparency” (1)

3 Walkowitz destaca la velocidad y simultaneidad de la circulación internacional contemporánea: "The translation and circulation of literature today is historically unprecedented once we consider how quickly books enter various national markets, small and large, across several continents" (2).

4 Apter hace hincapié en ese aspecto al entender lo intraducible "not as pure difference in opposition to the always translatable (rightly suspect as just another non-coeval form of the romantic Absolute, or fetish of the Other, or myth of hermeneutic inaccessibility) but as a linguistic form of creative failure with homeopathic uses" (Against World Literature 20).

5 , para decirlo en palabras de uno de los precursores de una filología de la literatura mundial, "El arte de la interpretación está perdido si se cree poder descuidar las palabras claras del texto en nombre de una idea poética mayor" (Auerbach 141). 
que ha imperado tradicionalmente en el mercado literario anglo-americano, en los últimos años una nueva tendencia (sobre cuya magnitud ciertamente se puede discutir) parece haber surgido en las editoriales y en los suplementos culturales de los principales medios para hacer frente al trato y la presencia de las traducciones y las traductoras: así como (al menos algunas de) las editoriales optan por una nueva visibilidad de las autoras de la traducción de una obra (a través de su presencia en las portadas de los libros, por ejemplo), así también cada día son más numerosas las reseñas literarias de obras traducidas que -en una especie de acto de political correctness literaria prácticamente internalizado- reservan una frase obligatoria para expresar la calidad (casi siempre positiva) de la labor translaticia en cuestión. Sin embargo, por más que se quiera valorar esta nueva sensibilidad de la crítica frente al oficio de las traductoras que, por otro lado, siguen siendo (con pocas excepciones) “the literary proletariat” (Apter, The Translation Zone xi), no caben dudas de que dicho discurso reconocedor se reduce en la mayoría de los casos a una fórmula vacía ya que los juicios emitidos sobre la calidad de una traducción no explican ni remotamente sus motivos en concordancia con un conocimiento del original. Como anota Walkowitz, "We think about writing all the time, of course, but whenever we talk about translation we seem to know and to agree what a translator translates from" (173). De esta manera, la supuesta atención lograda por la traducción -al menos con respecto a los medios dominantes en Europa y América ${ }^{6}$ - termina siendo una operación que sustituye la "ilusión de la transparencia” y la negación del carácter translaticio de una obra (en el sentido de Venuti) por una especie de "ilusión de la visibilidad": la traducción es valorada porque el acto de traducir como tal forma parte del discurso y de las prácticas cosmopolitas contemporáneos, sin que eso signifique una reflexión sobre el problema de cómo encontrar en reseñas literarias y otros formatos no-académicos "an intelligent way to review both the original and its translation within the space limitations imposed by the publication" (Grossmann 32). Si Grossman tilda ese tipo de falencias en la prensa cultural como "product of intransigent dilettantism and tenacious amateurism" (32), cabe aquí subrayar el hecho de que la vasta producción de trabajos académicos dedicados al paradigma de World Literature (y el papel de la traducción) en su gran mayoría ha omitido la dimensión de una crítica concreta textual y/o comparativa- de obras en su “vida en traducción”. Por tal motivo, en

\footnotetext{
6 En el mundo cibernético la situación -como se verá más adelante- difiere de manera significativa con la de la prensa escrita al existir una multitud de revistas y blogs en línea dedicados a la traducción, la crítica de la traducción, la presentación de traductoras contemporáneas, etc. (véanse también algunos ejemplos en Walkowitz 235-245). De la misma manera habría que diferenciar, sin lugar a dudas, entre la crítica de novelas y de poesía, siendo esta última (y por razones obvias) mucho más sensible frente a las dimensiones concretas de obras en traducción.
} 
lo que sigue este artículo adhiere claramente a la posición (y la metodología) de Venuti con respecto a la relación entre literatura mundial y traducción:

Clearly, the formal and semantic gain that enables translation to define world literature cannot be perceived without close reading, without a detailed analysis that examines shifts between the source and translated texts. "Distant" reading [...] is essential to understanding world literature as an intricate, historically developing ensemble of crosscultural relations among major and minor traditions [...]. Yet allowing the text to disappear as a unit of analysis between these two extremes would be counterproductive: the text not only links the small feature and the large structure, showing how they depend on one another for their literary and cultural significance, but it also makes visible the role of translation in the construction of world literature. ("World Literature" 186)

En este sentido, un ejemplo paradigmático lo constituye la obra de Roberto Bolaño, que, debido a su enorme éxito y circulación mundial, se analizará a continuación como un "estudio de caso" en el contexto de la problemática esbozada hasta aquí. Partiendo de una breve discusión de los trabajos críticos dedicados al aspecto de la traducción y recepción mundial de Bolaño, se discutirá, con base en un análisis comparativo puntualmente de las traducciones de su novela Estrella distante al inglés, alemán y francés, la paradójica hipótesis de que, por una parte, la idea de la traducción y de la traducibilidad es fundamental en la obra de Bolaño pero que posee, al mismo tiempo, solamente una importancia secundaria para la obra en cuanto texto traducido en circulación internacional y como parte de una literatura mundial contemporánea. Metodológicamente el trabajo entonces hace énfasis tanto en la práctica (muchas veces descuidada) de un close reading comparativo de traducciones (siguiendo a Venuti y recurriendo sobre todo a algunos aspectos de los trabajos traductológicos de Berman) como en la dimensión más bien "sociológica” (o de un distant reading) de los distintos factores de recepción y circulación global de la obra de Bolaño para desarrollar, de esta manera, una perspectiva más amplia sobre la relación entre traducción y literatura mundial ${ }^{7}$.

7 Retomo parcialmente la propuesta de Walkowitz, quien insiste en una combinación de "close reading, book history, and translation studies" (83) y una renovada atención global "to all aspects of the literary work [...] [to] conceive of details more broadly and more variously as those parts of the text, of potentially any scale or size, that seem prosaic, beneath notice, or simply mechanical" (90). Walkowitz también integra, como una de las pocas críticas del debate actual, un pequeño estudio comparativo de traducciones dedicado a la obra That's how you lose her, de Junot Díaz (35-39). De manera parecida, Venuti sostiene en la necesidad “[to] combine distant and close reading of translation to explore the relations between canons and interpretations" ("World Literature” 191). 


\section{Bolaño en traducción: posiciones y equívocos}

Una prueba del importante lugar que ocupa la obra de Roberto Bolaño dentro de los recientes debates en torno a la literatura mundial ${ }^{8}$ (y el papel de la traducción en especial) es su inserción dentro de algunas de las contribuciones más importantes (y ya nombradas) de la literatura comparada al respecto: así, por ejemplo, Walkowitz incluye Los detectives salvajes en sus reflexiones sobre lo que denomina "born-translated literature" al argüir que "[h]is novels seem translated, in part because they combine several regional idioms and seem to have no one native tongue" (17), mientras que Apter retoma textos, como su cuento "El viaje de Álvaro Rousselot" o el episodio sobre Max Mirebalais en La literatura nazi en América, para discutir la relación entre traducción y autoría (Against World Literature 317-319). Si bien la pregunta por el concepto de la traducción en la obra de Bolaño, al que estos estudios aluden, se discutirá en el tercer y cuarto punto del presente artículo, es necesario, en primer lugar, tratar brevemente algunos de los numerosos estudios (provenientes básicamente del campo latinoamericanista) acerca de la traducción de su obra. El problema que comparten todos esos trabajos reside en el hecho de que el término traducción apunta en realidad a la recepción de sus obras traducidas, es decir que en ninguno de ellos se investiga la traducción como texto sino más bien las lecturas críticas y las reseñas de esas traducciones que como tales se hacen "invisibles". Así, para dar algunos ejemplos, el capítulo de Bielsa dedicado a "Bolaño in translation” en su estudio sobre cosmopolitismo y traducción se limita, básicamente, a una labor recopilatoria de las reseñas en torno a la obra del autor en el ámbito hispanófono y anglófono (90-98). De manera parecida, el temprano y conocido artículo de Pollack ofrece una lectura crítica de los imaginarios estadounidenses en juego en su recepción y mercantilización, mientras que el estudio de Birns enfoca (de manera muy informativa, por cierto) la vida editorial de los textos del autor en Estados Unidos y sus diferentes traductores, pero sin referirse a las traducciones como tales. Otro ejemplo para el fenómeno de la práctica del "elogio no-fundamentado" de las traducciones de Bolaño ofrece Corral en su libro Bolaño traducido ${ }^{10}$ cuando habla, con respecto a Chris Andrews como uno de los tres traductores de Bolaño al inglés, de "las generalmente excelentes traducciones del australiano Andrews"

8 Consultar, por ejemplo, los artículos en Birns/De Castro o mis propias observaciones al respecto en Loy, "Deseos de mundo" y "Mocking World Literature".

9 Véase mi propia interpretación acerca de ese relato en Loy, "Deseos de mundo" y "Fantasmas". 10 Para una crítica más extensa a ese estudio, véanse Echevarría, "Bolaño internacional” y Loy, "Chistes”. 
(139) sin dar alguna explicación de esa presunta excelencia. De la misma manera, no precisa a qué se refiere al sostener que "[e]stá bien que los cuentos de Bolaño sean leídos como si hubieran sido escritos en inglés en vez de español" (140) y prefiere deshacerse de la tarea de una interpretación efectiva de las traducciones con el polémico comentario de que la pregunta por su calidad en realidad solo "ocasionará que algún nacionalista o provinciano latinoamericano quiera reclamar que algo se ha perdido en la presunta apropiación, como si la traducción fuera más que un arma funcional que les permite a los monolingües ampliar sus lecturas” (140). Esta posición parece tanto más equivocada si se tiene en cuenta que la obra de Bolaño por sus características formales -desde la coexistencia o mezcla de las múltiples variedades del español hasta la infinidad de alusiones (trans-)culturales e intertextuales- representa un sinfín de desafíos para cualquier traducción que merecen mayor escrutinio.

El acto de Walkowitz de incluir a Bolaño en su corpus de "born-translated literature" solo se justifica parcialmente, ya que, por un lado, su concepto abarca novelas en las que "translation functions as a thematic, structural, conceptual, and sometimes even typographical device" (4), cosa que, sin lugar a dudas, aplica para los textos del autor chileno; pero, por otra parte, parece difícil sostener con respecto a los libros de Bolaño que estos cumplan también con la segunda (y más prominente) parte de la definición de Walkowitz, es decir de pertenecer a "works [that] are written for translation, in the hope of being translated" (4). Si bien los debates por la "legibilidad" de la obra de Bolaño han sido numerosos ${ }^{11}$, vale señalar que factores como su tardío reconocimiento incluso en español y su temprana muerte difícilmente le hubieran permitido concebir sus obras desde un inicio en función de una futura traducción, o como lo ha formulado Ignacio Sánchez Prado: "Bolaño se destaca por el hecho de que su estética no parece haber cambiado de manera particularmente drástica como resultado del mercado. El trabajo altamente idiosincrático del estilo y su fuerte adherencia a juegos metaficcionales difícilmente podrían considerarse escritura mercantilizada" (29). Esta observación también rige especialmente para el lenguaje de Bolaño y los desafíos en relación a la ya nombrada copresencia múltiple de las variedades del español en su obra un punto que representaba, como han reconocido también sus traductores ${ }^{12}$, una

11 Véanse las observaciones al respecto en Altenberg (218).

12 Claro ejemplo de esto representa el comentario de Natasha Wimmer, quien tradujo al inglés, entre otros, Los detectives salvajes y 2666: "Yes, it was difficult. Idiomatic language is always one of the translator's biggest challenges. Bolaño draws on slang spanning continents and decades, from Mexico in the 1970s to Spain in the 1990s" (Esposito). 
dificultad particular al abordar la traducción de sus obras. Esta "glotopolítica"13 de Bolaño, como se podría llamar también, ha sido considerada por Hoyos como uno de los motivos fundamentales de su éxito mundial, al afirmar que "el escritor chileno se hizo global porque ofrece una escritura de la globalidad" (95). En la mezcla de variedades del habla, como es característica en la obra de Bolaño, Hoyos ve "una exploración de las condiciones de base de la experiencia transnacional, empezando por su registro oral" y no duda de la plena traducibilidad de estas formas de una enunciación híbrida al señalar que "Natasha Wimmer pudo capturar de esa rica textualidad en su traducción inglesa, bastó para causar un efecto potente, y lo mismo puede decirse de las traducciones a las otras lenguas que presiden sobre lo que Pascale Casanova llama république mondiale des lettres: el francés y el alemán” (95). Aparte de sumarse a la mencionada lista de los “elogios no-fundamentados” de las traducciones de Bolaño, la explicación de Hoyos no es convincente porque precisamente la copresencia de las distintas variedades del español, que en su versión original sí crean un efecto inmediato de un espacio narrativo "global" o "transnacional", se pierde irremediablemente en las versiones en inglés y, sobre todo, en francés y en alemán, ya que estos idiomas no disponen de un sistema lingüístico diatópico comparable al castellano. Con esto, la observación equivocada de Hoyos deja en evidencia la necesidad de una mayor atención que una crítica de la traducción de la(s) literatura(s) mundial (es) debería ostentar en sus juicios sobre la calidad y los aspectos de (in-)traducibilidad de este tipo de textos en el sentido de un balance más exacto de las ganancias y pérdidas translaticias ${ }^{14}$. A través de ejemplos puntuales de la novela Estrella distante (1996), a continuación se pretende dar cuenta de semejantes procesos al comparar exactamente las tres traducciones en los idiomas ya mencionados: inglés, francés y alemán.

13 Véase acerca de este concepto el libro de Marcellesi y Guespin, así como, para el contexto del castellano, sobre todo los estudios realizados por José del Valle. Si la noción glotopolítica del lenguaje se centra, como del Valle sostiene, en una "concepción fundamentalmente contextual del lenguaje [. . . ] donde se sitúan, por ejemplo, las distintas encarnaciones de la sociolingüística, que lo conciben como hecho social” (14), entonces no caben dudas de que la obra de Bolaño -y Estrella distante en especial- se inscriben en ese paradigma al considerar el lenguaje como un fenómeno siempre cambiante y dependiente de sus contextos sociales, temporales, geográficos y políticos frente a una noción autoritaria del lenguaje (en ese aspecto reside el motivo clave de la novela de relacionar el lenguaje autoritario de la dictadura de Pinochet con el discurso salvatorio de las vanguardias encarnado por el personaje de Carlos Wieder (véanse al respecto también mis comentarios en Loy, "La ironía”).

14 Locane formula una crítica parecida al concepto de Walkowitz y su interpretación superficial de Bolaño (142-149). 


\section{Las glotopolíticas literarias de Bolaño: tres traducciones de Estrella distante}

Si el aspecto de la traducción puede reclamar una importancia general para la escritura de Roberto Bolaño, es en su novela corta Estrella distante que quizás el lector se enfrenta de manera más intensa con una especie de "meta-novela translaticia”. Sin querer analizar aquí en profundidad la novela ${ }^{15}$, cabe señalar que la historia en torno de la búsqueda del poeta y asesino Carlos Wieder por un narrador alter-ego de Bolaño remite de manera constante y en el sentido más amplio a fenómenos de traducción: así, por ejemplo, aparece una serie de personajes enfrascados en proyectos de traducción, como un profesor chileno llamado Diego Soto sobre el que se dice:

También intentó traducir a Sophie Podolski, la joven poeta belga suicidada a los veintiún años (no pudo), a Pierre Guyotat, el autor de Eden, Eden, Eden y Prostitution (tampoco pudo), y La Disparition, de Georges Perec, novela policíaca escrita sin la letra $e$ y que Soto intentó (y sólo consiguió a medias) trasladar al español aplicándose en lo que Jardiel Poncela había hecho medio siglo antes en un relato en donde la consabida vocal brillaba por su ausencia. Pero una cosa era escribir sin la e y otra muy distinta traducir sin la e. (76)

Ya a partir de este ejemplo se podría desarrollar una serie de reflexiones sobre la importancia de la traducción en la novela: por un lado, destaca la idea de la traducción como esa forma de acceder a otros "textos del mundo"16, que implica siempre preguntas de (in-)visibilidad y del canon, como lo demuestra aquí el comentario irónico acerca del precursor español (prácticamente olvidado) de Perec; por el otro lado, se hace énfasis en una separación de los actos de escribir y de traducir, así como en el hecho de que las traducciones pueden perfectamente fracasar. Cabe destacar, sin embargo, que, más allá de esta presencia explícita de actos translaticios en la novela y los temas de la memoria o de la herencia de las vanguardias, que han dominado las lecturas críticas de la novela, su núcleo, en un sentido más amplio, consiste en una reflexión sobre un mundo dominado por una genuina falta de estabilidad de los signos y, por ende, del lenguaje mismo. Este fenómeno afecta, en primer lugar, la constitución del relato que se presenta, en el prólogo muchas veces citado, como una reescritura del último capítulo de $L a$

15 Para diferentes lecturas de la novela, véanse, por ejemplo, mis propuestas en Loy, "Escritores bárbaros", "De oposiciones" y "The Precarious".

16 Hay que tener en cuenta que una de las primeras apariciones documentadas de Bolaño como autor se efectúa como autor de traducciones de una "nueva poesía francesa" en la revista Plural en 1977. Acerca de la intertextualidad en la novela (y en especial de la antipoesía de Nicanor Parra), véase mi análisis en Loy, “Chistes”. 
literatura nazi en América en forma de "una historia más larga, no espejo ni explosión de otras historias sino espejo y explosión en sí misma” (11). La novela se exhibe como un texto concebido de manera dialógica -entre Bolaño, Belano y "el fantasma cada día más vivo de Pierre Menard" (11) - que rechaza -como subraya la referencia a Borges- la idea del "original" ${ }^{17}$ y la posibilidad de una estabilidad y de un control de los signos y de los significados. En ese sentido, el texto ostenta en todos sus niveles exhibe su carácter "translaticio": la reescritura le confiere un estado de "derivado", todas las identidades de los personajes -empezando por la del criminal buscado- se tornan inciertas porque siempre se basan en testimonios, historias y otras huellas materiales "ambiguas" (como la serie de fotografías presentadas como inciertas y borrosas), que en su conjunto componen un universo sígnico radicalmente inestable ${ }^{18}$. Si Antoine Berman en sus trabajos traductológicos postula que una de las bases metodológicas dentro de la crítica de traducción sea "un patient travail de sélection d'exemples stylistiques (au sens large) pertinents et significatifs dans l'original [...], les zones signifiantes où une œuvre atteint sa propre visée [...] et son propre centre de gravité” (70), entonces el argumento aquí sería que en Estrella distante son precisamente las zonas en las que la inestabilidad del lenguaje como tal se hace más evidente las que habría que investigar con preferencia y desde una perspectiva comparada ${ }^{19}$.

17 Walkowitz subsume también este fenómeno bajo sus "born-translated novels" al advertir que frente a muchos de esos textos "[r]eaders are asked to experience the text as a delayed or detoured object: a book that began somewhere else” (30).

18 Este hecho también conlleva una dimensión ética del texto que se hace visible, para nombrar solamente un ejemplo específico, en el asesinato de Carlos Wieder por parte del detective chileno Abel Romero al final de la novela: no queda claro si Wieder realmente es el autor de todos los crímenes que bajo distintos nombres ha cometido porque Romero en sus investigaciones se basa en una serie de testimonios dudosos como el de Joanna Silvestri, una exactriz porno cuyas declaraciones sobre el caso no aparecen en la novela sino en un cuento de la colección Llamadas telefónicas. El lector de la novela solamente dispone de una "traducción" de esta conversación de Romero y Silvestri que, además, se realiza entre un chileno y una italiana en francés y luego es relatada en castellano a Belano por Romero y, finalmente, resumida por el narrador para el lector real de la novela - una serie que escenifica, otra vez más, el principio fundamental de la cadena de relatos y la inseguridad del significado "real" o "auténtico" de un hecho deformado por la comunicación misma.

19 Véase también el argumento de Berman acerca de la comparación de traducciones: "Les 'solutions' apportées par chaque traducteur à la traduction d'une œuvre [.. .] sont si variées, si inattendues, qu'elles nous introduisent [...] à une double dimension plurielle: celle de la traduction, qui est toujours les traductions [...]. Le lecteur ou l'auditeur [..] est ainsi amené à se libérer de toute naïveté et de tout dogmatisme” (85). 
No resulta difícil reconocer que todas las traducciones de Bolaño generalmente cumplen con la primera pregunta que, según Berman, una crítica de la traducción tiene que aclarar: si la traducción "funciona" ("si le texte traduit 'tient”” (65)). En el caso de los tres idiomas en cuestión acá -inglés, francés y alemán- cabe destacar que Bolaño ha contado con un total de diez traductores diferentes: Chris Andrews y Natasha Wimmer en el caso de los textos narrativos y Laura Healy de la poesía en inglés, Robert Amutio para la obra completa en francés con excepción de Amuleto (traducida por Emile y Nicole Martel para la editorial canadiense Les Allusifs) y Heinrich von Berenberg y Christian Hansen en alemán. Sin indagar profundamente en las biografías profesionales de todos los traductores ${ }^{20}$, se recurrirá a lo largo del análisis a determinados comentarios en relación a sus respectivas percepciones de la obra de Bolaño en traducción.

Si el desafío particular de traducir las obras de Bolaño consiste, como se acaba de mencionar, en la presencia simultánea de las múltiples variedades del español y si el núcleo de Estrella distante representa la inestabilidad de los signos y del lenguaje, entonces resulta lógico enfocar el siguiente análisis en ejemplos que ilustren precisamente el manejo de estos dos aspectos por parte de los traductores de la novela, quienes son Andrews, Amutio y Hansen. Un punto decisivo en cuanto a la forma lingüística de la narración es la alternancia de la variedad chilena y otra "peninsular"/"ibérica” del español, que en el relato biográfico del narrador se superponen continuamente y vuelven borrosas las fronteras espacio-temporales de la historia: esto se hace evidente, por ejemplo, cuando el narrador (chileno) relata un encuentro en los días posteriores al Golpe de Estado de 1973 con dos amigas-poetas de su taller en el sur de Chile con las siguientes palabras: "Me dijeron que se iban, pero no al extranjero sino a Nacimiento, un pueblo a pocos kilómetros de Concepción, a la casa de sus padres. Qué alivio, dije, pensé que os marchabais a Suecia o algo asî” (27). Destaca el hecho de que el narrador usa aquí la segunda persona del plural propia del español peninsular y ausente en la variedad chilena, por lo que resulta altamente inverosímil que el comentario del narrador en su momento se haya hecho literalmente de esta manera. Más bien, la irrupción de la variedad peninsular señala aquí ya al inicio del relato el futuro destino del exilio y el traspaso a España - un indicio dentro

20 Se podría destacar el hecho de que Wimmer, Hansen y Amutio son sobre todo traductores (habiendo Amutio contribuido también de manera decisiva a que se adquirieran los derechos en francés por parte de Christian Bourgois) mientras que el “descubridor” alemán de Bolaño, von Berenberg, ha dedicado su carrera profesional en primer lugar a la edición. Andrews, en cambio, no es solamente traductor sino también poeta y profesor universitario así como autor de una de las obras críticas más logradas que hasta el momento se han publicado sobre Bolaño. 
de la estructura detectivesca de la novela que en las traducciones necesariamente tiene que desaparecer ${ }^{21}$. Mientras que en este ejemplo es fácil de "esconder" ese aspecto en la traducción, hay otro caso que remite a la misma problemática de la copresencia de variedades lingüísticas pero con la diferencia de que se hacen explícitos el traslado del narrador de Chile a España y las consecuencias para su propio uso del lenguaje: "Nosotros casi nunca teníamos plata (es divertido escribir ahora la palabra plata: brilla como un ojo en la noche)" (16). La clave de esta frase es la siguiente: la reacción afectiva que formula el narrador -“es divertido escribir ahora la palabra plata" - surge a raíz de esta diferencia espacio-temporal-lingüística que separa su pasado chileno y el presente español (o más bien: catalán) desde el que escribe. Dicho de otra manera: el uso de la palabra "plata" como expresión corriente (coloquial) de la variedad chilena del español le llama la atención precisamente porque en su entorno ibérico debe haber dejado de usarla, siendo "pasta" el término coloquial correspondiente de la variedad peninsular. El problema para la traducción resulta del hecho que tiene que encontrar una solución para hacer plausible la reacción de asombro del narrador ante una diferencia lingüística que no se puede traducir literalmente a los tres idiomas en cuestión porque desconocen prácticamente esta simultaneidad de variedades diatópicas. En la versión inglesa, Andrews escribe lo siguiente: "We hardly ever had two dimes to rub together (it seems so odd to be writing the word dime. I can see it shining like an eye in the night)" (6). Andrews apela a una expresión idiomática más allá del lexema singular del original que es llamativa porque recurre, en el uso de la palabra "dime”, a una opción que conlleva una marca geográfica clara del inglés estadounidense ${ }^{22}$. Las implicaciones de esta decisión resultan interesantes: si el narrador de Andrews afirma que le parece “odd” el uso de la palabra “dime”, entonces el lector en inglés aquí debe asociar ese asombro del narrador (de igual manera que en su original en español) con el hecho de que el uso del inglés estadounidense para él ha perdido una familiaridad que alguna vez probablemente había tenido para él. Andrews, por lo tanto, opta por la opción "geográfica” porque el inglés es capaz de ofrecerla de manera parecida al español. Esta hipótesis se refuerza probablemente al considerar que la

21 Véanse la versión inglesa ("What a relief, I said, I thought you were going to Sweden or somewhere like that" (17)) y francesa ("Je suis content, dis-je soulagé, je croyais que vous partiez pour la Suède ou un pays de ce genre” (29)). Hansen, en la traducción alemana, comete un error llamativo al confundir Suecia con Suiza cuando escribe: "Na, ein Glück, sagte ich, ich dachte, ihr würdet in die Schweiz gehen oder sonstwohin” (24-25). Aplica para este caso probablemente el comentario lacónico de Berman de que hasta los mejores traductores de repente pueden caer en un "profundo sueño".

22 Véanse, para comprobar esta hipótesis, por ejemplo, los datos históricos acerca del uso de la palabra en los corpus del Corpus of Historical American English y del British National Corpus. 
primera traducción en inglés para New Directions fue publicada efectivamente en Inglaterra $^{23}$, por lo que la presencia de un giro "americano" aquí claramente podría causarle un efecto parecido a un lector inglés en el sentido de percibir el asombro del narrador a raíz de una diferencia de variedades del lenguaje. Si bien Andrews en una entrevista ha señalado lo problemático que resulta el uso de regionalismos en inglés ${ }^{24}$ y la necesidad “[to] rely on other markers of locality in the context” (Wilson), aquí pareciera haber optado igualmente por una variante que en inglés funciona bien, ya que hace plausible la reacción del narrador (aunque resulta más bien curioso si se sigue desarrollando la idea porque, si la variedad estadounidense le resulta extraña al "Bolaño de Andrews", entonces la conclusión tendría que ser que el traslado en la traducción en realidad no fue entre Chile y España sino entre Estados Unidos e Inglaterra o Irlanda o Australia) ${ }^{25}$.

En la versión alemana, en cambio, Christian Hansen opta por la siguiente traducción: "Wir waren fast immer blank (lustig, heute das Wort blank zu benutzen; es leuchtet wie ein Auge in der Nacht)" (13). Hansen sustituye la palabra "plata" por el adjetivo "blank" que forma parte de otro giro idiomático: "blank sein” en alemán significa "no tener dinero", de manera idéntica a la expresión “estar sin blanca” en español. En alemán, el traductor no tiene la posibilidad de recurrir a una marca geográfica, ya que -de una forma mucho más extrema que

23 Véase el comentario de Andrews al respecto: "When the first couple of English translations, By Night in Chile and Distant Star, came out in England, they weren’t published in America straight away" (Heyward). Asimismo, Andrews resalta este aspecto del lugar de la publicación y su uso del lenguaje: "It depends where the commissioning is done, and what's happened with Bolaño has been a little strange because the commissioning shifted from the UK to the US after the first three books. When it has been for an English publisher, I have written, for example, "flat" rather than "apartment." I've never really used many "Australianisms" though. I've tried to smuggle a few in here and there, but it's tricky, and it's hard to get away with! It would be different if you were working for an Australian publisher, publishing for an Australian market. It has occasionally been tempting to use an "Australianism" to translate an expression from Chilean Spanish, but the risk is that it would be merely confusing, even for an Australian reader" (Heyward).

24 "One difficulty that crops up frequently in Bolaño is how to translate regional familiar language: Mexican or Chilean slang, for example. If you use regional terms in English it can be confusing for the reader, because they will hear the Chilean or Mexican character as an Australian, say" (Wilson).

25 Veáse también el comentario de Venuti al respecto de este fenómeno: “[t]he localizing drive of translation can [...] change the very nature of the categories 'foreign' and 'local' as they are understood by readerships in the receiving situation" ("World Literature" 182). Aparte de la dimensión geográfica, se podría argumentar que Andrews también logra incorporar una dimensión temporal ya que los corpus señalan que el uso de ese giro ha ido disminuyendo levemente en las últimas tres décadas, cosa que le confiere más plausibilidad al hecho de que entre el momento de la afirmación del narrador a mediados de los años 90 y su pasado en Chile en los 70 existe igualmente una diferencia de tiempo considerable. 
en inglés- las únicas posibilidades serían el uso de uno de los dialectos regionales alemanes o de un término del alemán suizo o austríaco, todas opciones que tendrían un efecto grotesco porque transformarían al narrador chileno en España fácilmente en un bávaro o berlinés perdido en la Costa Brava ${ }^{26}$. No obstante, el uso de la expresión "blank sein” hace plausible la reacción del narrador también en la traducción porque posee en alemán un carácter algo anticuado ${ }^{27}$ que es capaz de sugerirle al lector alemán una diferencia temporal (en el sentido de una expresión que el narrador usaba en su juventud probablemente) como causa de $\mathrm{su}$ asombro ${ }^{28}$. En la versión francesa, finalmente, Robert Amutio escribe: "Nous n'avions presque jamais d'argent (c'est drôle d'écrire maintenant le mot argent: il luit comme un œil dans la nuit)" (17). A diferencia de Andrews y Hansen, Amutio traduce la frase del original en su sentido literal $-\mathrm{y}$ fracasa con esto porque no logra hacer plausible la reacción del narrador-: "argent” no transporta ningún significado que pudiera justificar su asombro (o más bien: el divertimiento del narrador porque, al igual que Hansen, opta por la traducción en el sentido de “cómico" en vez de "bizarre” o “curieux" que sería probablemente más adecuado). En la simple repetición del lexema no se logra crear ninguna tensión espacio-temporal, el efecto aquí se pierde y hasta queda, para el lector francés, sin sentido (¿por qué debería ser divertido volver a repetir esa palabra? Probablemente también en este caso una solución idiomática como "Nous n’avions presque jamais de sous" hubiera sido preferible $)^{29}$.

26 El efecto inverso y practicado a lo largo de toda la obra de Bolaño se puede observar, por ejemplo, en el caso de su novela póstuma El Tercer Reich en la que un empleado alemán de Stuttgart pasa sus vacaciones en la Costa Brava con su novia y entra en contacto tanto con los locales como con otros turistas alemanes y donde todos conversan, por supuesto, en castellano y sin problemas aparentes de comunicación. El mismo efecto se reproduce en 2666, sobre todo en la parte de los críticos (véase al respecto también el trabajo de Altenberg).

27 Véase también en el diccionario Digitales Wörterbuch der deutschen Sprache que constata una clara caída en desuso después de los años 60.

28 Otro punto interesante al comprar las opciones de Andrews y Hansen es que la palabra "divertido", que en el español chileno se usa más bien en el sentido de "raro", es traducida por Andrews muy adecuadamente con "odd" mientras que Hansen opta por "lustig” que borra la ambigüedad de "divertido" porque en alemán significa solamente "gracioso"/"chistoso" (en cambio, una palabra como "komisch" podría haber conservado ese vaivén entre "raro" y "gracioso" como uno de los principios operantes de la novela con sus pasajes humorísticos y bizarros).

29 Le agradezco al poeta franco-chileno Carles Díaz las intensas discusiones sobre este punto. 
Otros casos que demuestran bien las diferentes estrategias de traducción se refieren, por ejemplo, al grado divergente de los textos con el que exhiben elementos "extraños" del original o aspiran a crear esa "ilusión de transparencia" tan criticada por Venuti. En Estrella distante se encuentran varias menciones en ese sentido. Así, como muestra de lo anterior, dice el narrador en un momento sobre su experiencia en los días después del Golpe de Estado: "Pero yo tenía ganas de cantar y de bailar y las malas noticias (o las elucubraciones sobre malas noticias) sólo contribuían a echarle más leña al fuego de mi alegría, si se me permite la expresión, cursi a más no poder (siútica hubiéramos dicho entonces)" (27-28). Mientras que Andrews opta por una traducción que esta vez usa una marca temporal para expresar la diferencia geográfica del original (siútico es una palabra marcada sobre todo por el registro chileno y no por un desuso en el tiempo $)^{30}$ y la versión de Hansen fracasa en ese ejemplo ${ }^{31}$, Amutio opta simplemente para mantener el término al escribir: "si on me passe l'expression, d'un mauvais goût absolu (nous aurions dit siútica dans l'argot d'alors)" (31). Igualmente interesante en ese sentido es otra frase de la novela en la que el narrador se refiere a un poema llamado "Saranguaco" de Nicanor Parra para burlarse de las incoherencias de la poesía de Carlos Wieder con las palabras: "(Más exactamente: con un inicio que no hubiera desaprobado Isidore Isou y con un final inédito digno de un saranguaco)” (42). Mientras Hansen mantiene la opacidad ${ }^{32}$ (que, sin lugar a dudas, también para un lector común y corriente en español debe resultar oscura si no conoce el texto de Parra) y Amutio hace explícita la referencia intertextual ("et une fin inédite digne du Saranguaco de Nicanor Parra” (48)), Andrews opta por una simplificación radical al poner "(while the unexpected ending would not have been out of place in a Chilean folk song)" (31-32). A pesar de que Andrews en otro momento reconoce que "[j]ust occasionally, I think, the best solution is to leave the word in Spanish, but only very occasionally" (Wilson), se puede observar

30 Andrews escribe: "to use an expression which is, I admit, impossibly trite ('corny' we would have said back then)” (18). "Corny”, según los corpus del inglés, aparece más o menos de manera igual en las variedades de Estados Unidos y de Inglaterra, pero ostenta una leve caída en desuso en las últimas tres décadas.

31 La versión alemana pone: "wenn ich mir diese abgeschmackte Formulierung erlauben darf ("kitschig' hätten wir damals gesagt)" (26). Aquí no hay ninguna lógica de marcar la palabra "kitschig" como presuntamente "pasada de moda" sino que incluso habría que cambiar ambos términos de posición porque "kitschig" experimenta, según las estadísticas del DWDS, un fuerte auge a partir de los años 80 mientras que "abgeschmackt” pierde claramente importancia a partir de los 90 .

32 "(genauer: mit einem Anfang, dem Isidore Isou seine Billigung nicht versagt, und einem unerhörten Schluß, der einem saranguaco gut zu Gesicht gestanden hätte)” (41). 
en su traducción una cierta tendencia a "limar" el texto con respecto a la presencia de palabras españolas y reducir, de esta manera, el grado de "extrañeza” para el lector del texto traducido -un hecho que encuentra probablemente su correspondencia en el diseño de las portadas en la versión inglesa/estadounidense y francesa-: mientras que las primeras optan por una "plasticidad" al enmarcar el título en un paisaje de los Andes con un avión cruzando el cielo y remitiendo básicamente al "plot" del relato con un cierto toque exotizante, la portada francesa muestra un fragmento de la pintura Coigitum, del artista chileno Roberto Matta, cuya biografía y obra permiten en muchos sentidos una relación mucho más compleja frente al relato de Bolaño ${ }^{33}$.

Dos conclusiones pueden extraerse de estas observaciones: la primera es que los textos de Bolaño poseen múltiples dimensiones lingüísticas que se resisten a una traducción sencilla (en el sentido de ser "born-translated novels" concebidas para la traducción) y que las soluciones propuestas por sus traductores en la mayoría de los casos se pueden considerar logradas, y en otros no tanto; la segunda conclusión -paradójica y lógica a la vez- es que estas microresistencias, como las que se han analizado aquí, en los libros de Bolaño influyen poco o nada en la percepción general de sus novelas en traducción y menos aún en su éxito mundial. Este último punto requiere una explicación para el que los comentarios de los traductores de Bolaño bien pueden servir porque confirman de alguna manera esta hipótesis: las obras de Bolaño se resisten parcialmente a la traducción, pero la mayoría -y las más importantes y características- de sus rasgos distintivos, sobre todo sintácticos, se conservan también al traspasar sus textos a otros idiomas. En ese sentido hay que entender el comentario de Chris Andrews cuando afirma en otra entrevista que:

The first thing I should say is that there are always losses and shifts in translation, and Bolaño is no exception. But I do think that his style comes through relatively strongly, whether it's me translating him or someone else. When I read Natasha Wimmer's translations of his other books, I feel like I'm straight back into the world of Bolaño, and I don't feel any resistance or drag or loss. That is partly because some of the key stylistic features in his work are quite large-scale, like the head-long sentence that keeps rolling on via coordination, for example, with, and, and and, and and. (Heyward)

33 La versión alemana simplemente muestra el nombre del autor y el título de la novela en una tapa negra al lado de una representación estilizada del apellido de Bolaño quien, a la fecha de la publicación de esta versión de la traducción en 2010, ya podía funcionar como esa "marca” capaz de atraer a los lectores únicamente a través de su nombre. 
Esto significa que -a pesar de los problemas que el fenómeno de las múltiples variedades diatópicas del español le puede causar a las traducciones en no pocas ocasiones- el rasgo reconocible de la prosa bolañesca, que también se puede conservar sin mayores problemas en otros idiomas, son el ritmo y las estructuras sintácticas de su estilo. De manera muy parecida, Heinrich von Berenberg ha destacado este aspecto al hablar en una entrevista de la "musicalidad" de sus narraciones que, para el traductor de Los detectives salvajes y La literatura nazi al alemán, son "el elemento formal determinante” en Bolaño (Kleinemeier). También Christian Hansen destaca su decepción inicial con la prosa de Bolaño que sentía, en cuanto a su expresividad, como "funcional, de Bauhaus" hasta descubrir que el rasgo distintivo y cautivador se revelaba a nivel estructural de los textos. Hansen habla también del efecto de un "folioscopio" (Mortati 54) y destaca que "[e]n el caso de Bolaño tienes que crear esas configuraciones, esas atmósferas. Hay ciertos cuentos de él que leo con lágrimas en los ojos y si ese efecto no se produce también en la traducción, no me parecería lograda. No se trata de una palabra, ni de una frase, sino que es el conjunto" (Mortati 55). Asimismo, Robert Amutio sostiene:

Chez Bolaño, il y a aussi bien sûr des éléments plus ou moins facilement traduisibles [...]. J'ai rencontré il y a quelques jours les traducteurs vers l'anglais et vers l'allemand de Bolaño, et si je les crois, qu'on lise Bolaño dans une langue ou dans une autre, on reconnaît le « style » bolanien [...]. Ça ne signifie pas évidemment que Bolaño soit un auteur facile à traduire! (Anquetil)

El estilo y el lenguaje figurativo ${ }^{34}$ representan, entonces, mucho más que las dimensiones lingüísticas de su español "híbrido" que se han analizado aquí, los factores decisivos de la traducibilidad de Bolaño. En ese sentido, bien se podría denominar sus obras -tal como lo ha hecho Andrews en repetidas ocasiones- como "quite robust, which is not to say that they're easy to translate" (Wilson). Esta "robusteza" de la obra, que se refiere sobre todo a su capacidad de proteger su "carácter” y sus rasgos distintivos en la traducción, corresponde a la idea de la "obra elástica”, como la he formulado en otro contexto ${ }^{35}$, como un motivo decisivo del éxito mundial de Bolaño: si el autor chileno se caracteriza, en palabras de Echevarría, por una "infrecuente capacidad de conectar con lectores de todo tipo" (176), entonces parece radicar ahí un punto clave de su recepción global y, muy importante también, de su mercantilización radical de los últimos diez años: como en pocos autores, la obra de

34 "Many of the figures and the kind of post-surrealist images that come in strange bursts in his prose are also pretty amenable to translation", afirma Andrews (Heyward).

35 Véase mi artículo sobre la recepción alemana de Bolaño en Loy "Der Teil der Kritiker”. 
Bolaño es capaz de satisfacer tanto las inquietudes de un lector joven y naif, que se identifica con los plots de aventura y viajes en Los detectives salvajes, como las del filólogo versado en las lecturas del canon que saca un placer inmenso al descifrar los crucigramas intertextuales ${ }^{36}$ que caracterizan toda su obra. Es esta posibilidad de ofrecer al mismo tiempo lecturas hípercomplejas y reducciones más bien extremas, de funcionar tanto en el gran canon literario como desde la perspectiva de los lectores aficionados de las buenas historias, la que transformó a Bolaño -junto con su biografía perfectamente "vendible" desde las perspectivas del mercado angloamericano- en un candidato ideal para transformarse en un autor mundial del siglo XXI. Ante ese panorama es importante realzar el hecho de que la glotopolítica de Bolaño refleja esa dialéctica entre resistencia y traducibilidad que abre su obra hacia múltiples lecturas: por un lado, la "variedad de variedades" lingüísticas con sus potenciales resistentes es, como se ha visto, capaz de mantener un grado de "extrañeza" en las traducciones (a diferencia de esas "born-translated novels" limadas desde un inicio para su circulación internacional sin dificultades), por lo que Bolaño se diferencia de lo que Echevarría ha denominado como "estilo internacional” que acompaña las generaciones jóvenes de autores latinoamericanos en su afán de integrarse a un mercado literario global que "incentiva entre los jóvenes escritores una estandarización de la lengua y una estereotipificación de los planteamientos narrativos" ("Lengua", 186). En ese sentido, el lenguaje literario de Bolaño se resiste a una plena recuperación en traducción sin ser por eso "untranslatable”, es más, en la persistencia de ciertos elementos lingüísticos difíciles o imposibles de traducir estos creen lo que Andrews ha llamado "a strong flavor" (Heyward), por lo que se podría decir que es precisamente ese grado limitado de "otredad" lingüística que distingue a Bolaño de buena parte de una prosa "funcional” y le confiere una singularidad que, por otro lado, hace que su capacidad de circulación más bien aumente en vez de disminuir ${ }^{37}$. Lo particular de estos aspectos y de la recepción global de

36 En mi reciente libro (Roberto Bolaños wilde Bibliothek) ofrezco una serie de interpretaciones de esas dimensiones intertextuales de su obra completa en relación a autores tan diversos como Georges Perec y Luis de Góngora, Enrique Lihn y Ernst Jünger, Sor Juana Inés de la Cruz y Charles Baudelaire.

37 Es interesante observar como esta glotopolítica de Bolaño en el sentido de una posición relativa entre resistencia y accesibilidad frente al mercado literario corresponde en muchos sentidos a sus políticas de autoría y su estética en general; véase acerca de ese argumento el artículo de Cobas Carral y Garibotto. Que ese tipo de glotopolíticas es un factor importante sobre todo para la literatura latinoamericana se explica ante el hecho de la dominación española internacional del mercado editorial en castellano (véase, acerca de este aspecto, por ejemplo, el estudio de Yúdice). Sin poder indagar aquí en este aspecto, baste con un testimonio muy ilustrativo que da el autor colombiano Evelio Rosero sobre su novela Juliana los mira 
Bolaño es que -sin querer caer aquí en el género de lo profético- refleja, con una exactitud algo inquietante, precisamente la propia poética (translaticia) como la formuló el autor en diferentes escritos y que se analizará brevemente en la parte final del presente estudio.

\section{4 "La traducción es un yunque": la (in-)traducibilidad en Bolaño}

La traducción y sus frecuentes fracasos en un mundo globalizado ${ }^{38}$ son un tema recurrente en Bolaño. Sin embargo, han sido relativamente escasos los comentarios explícitos del autor sobre el tema, con la importante excepción de un breve texto ensayístico titulado "La traducción es un yunque" e incluido en el volumen Entre paréntesis. En este, Bolaño diferencia en la literatura mundial, en un primer paso, entre "una obra maestra absoluta de una obra maestra a secas, o, si es posible decirlo, una literatura viva, una literatura patrimonio de todos los hombres, de una literatura que sólo es patrimonio de determinada tribu o de un segmento de determinada tribu" (223). Mientras que Cervantes forma parte de la primera categoría, autores como Quevedo y Góngora -debido a su complejidad lingüística prácticamente intraducible de forma "adecuada" a otros idiomas- representan la segunda. El punto clave de las reflexiones de Bolaño consiste en proponer la

y su destino luego de haber sido finalista del Premio Herralde en 1986: "Yo estaba muy contento por el premio Anagrama. Mi agente entonces era Carmen Balcells, una gran señora y una gran lectora que me guió mucho. El problema empezó cuando me llegaron las pruebas del libro para que yo le diera la última leída. Tenía cambios totales. Yo tengo diálogos sin puntuación y ellos los puntuaron. Luego hablé con ellos personalmente y los veía escandalizados: en lugar de escribir matera escribían maceta; yo escribía ‘debe ser que fulanito' y ellos ‘debe de ser’; ese 'debe de’ a mí me parecía cacofónico y se los dije. [.. .] Publicaron mi novela, pero nunca la trajeron a Colombia, nunca la enviaron a un periodista o a un crítico, se quedó encerrada durante diez años en una bodega. Fue una mala jugada por parte de estos editores" (Maldonado Tovar).

38 Sobre todo 2666 exhibe este aspecto en toda una serie de escenas de la novela como, por ejemplo, en el famoso episodio en los que los críticos literarios europeos agreden a un taxista pakistaní en Londres o cuando se describe el viaje de unos antropólogos franceses a Borneo y su contacto con un grupo de indígenas. Con respecto al primer episodio, véase también Altenberg; sobre el problema de la traducción en el contexto de la crisis del cosmopolitismo en 2666 también Loy, "Der Teil der Kritiker". Que sobre todo "La parte de Fate” en 2666 integra estas preguntas también a nivel del lenguaje mismo en forma de un español "mexicano" inventado por Bolaño ha demostrado el estupendo análisis de Levinson. 
traducción de una obra como el método decisivo para "probar" su calidad literaria, es decir como ese "yunque" en el que se revela bajo los golpes del "herrero traductor" el potencial de resistencia de un texto:

¿Cómo reconocer una obra de arte? [...] Es fácil. Hay que traducirla. Que el traductor no sea una lumbrera. Hay que arrancarle páginas al azar. Hay que dejarla tirada en un desván. Si después de todo esto aparece un joven y la lee, y tras leerla la hace suya, y le es fiel (o infiel, qué más da) y la reinterpreta y la acompaña en su viaje a los límites y ambos se enriquecen y el joven añade un gramo de valor a su valor natural, estamos ante algo, una máquina o un libro, capaz de hablar a todos los seres humanos [...]. (223-224)

El hecho de que Bolaño considere que una traducción fracasada -“que el traductor no sea una lumbrera”- es la mejor forma para reconocer si una obra literaria “sobrevive" en la traducción corresponde de manera exacta a los resultados de la breve comparación de las traducciones de su obra realizadas anteriormente: aunque estas -al igual que probablemente todas las traducciones de sus libros- no sean perfectas ni puedan transportar (a pesar de la calidad innegable de sus traductores) todos los matices del original ${ }^{39}$, la literatura de Bolaño es capaz de surtir esos efectos en sus lectores mundiales. El factor de la fidelidad - "fiel (o infiel, qué más da)" - no es de importancia para el texto traducido mientras que la traducción sepa trasladar lo que Bolaño llama, en relación al ejemplo del Quijote, su "razón" (222) que hace que "se imponga o impregne la imaginación de miles de lectores, a quienes no les importa ni el lujo verbal ni el ritmo ni la fuerza de la prosodia cervantina que obviamente cualquier traducción, por buena que sea, desdibuja o disuelve” (222-223). Las modalidades de este proceso, sin embargo, (y aquí nos encontramos en el punto límite de la crítica de la literatura mundial y sus aspiraciones a describir los funcionamientos de su objeto) tienen que sustraerse necesariamente a los intentos de verbalización: son, como lo describe Bolaño a partir del ejemplo de una representación infame de Macbeth visitada por Borges, un efecto que surge cuando el lector -más allá de los contextos de la obra entre las que también contarían la traducción y su calidad- "vuelve a sumergirse en el destino de aquellos seres que atraviesan el tiempo y vuelve a temblar con aquello que a falta de una palabra mejor llamaremos magia” (223).

39 Amutio relata la negación de Bolaño de intervenir en mayor grado en el proceso de traducción aunque sus conocimientos del francés se lo hubieran permitido sin problemas: "Il me laissait la liberté et la responsabilité de faire ce que je croyais être le mieux pour l'œuvre” (223). 


\section{Bibliografía}

Anquetil, Marilyn et al. “Entretien avec Robert Amutio, traducteur”. Littexpress, 2011. http:// littexpress.over-blog.net/article-entretien-avec-robert-amutio-traducteur-65470640.html, consultado 8 de enero 2019.

Altenberg, Tilmann. "Bolaño against Babel: Multilingualism, Translation and Narration in 2666, 'La parte de los críticos'”. Bulletin of Hispanic Studies, vol. 95, no. 2, pp. 217-233.

Amutio, Robert. "Paroles de traducteur”. Les astres noirs de Roberto Bolaño. Eds. Karim Benmiloud y Raphael Estève. Presses Universitaires de Bordeaux, 2007, pp. 219-228.

Andrews, Chris. Roberto Bolaño's Fiction: an Expanding Universe. Columbia University Press, 2014.

Apter, Emily. Against World Literature. On the Politics of Untranslatability. Verso, 2013.

--.. The Translation Zone. A New Comparative Literature. Princeton University Press, 2006.

Auerbach, Erich. Dante als Dichter der irdischen Welt. De Gruyter, 2001.

Berman, Antoine. Pour une critique des traductions: John Donne. Gallimard, 1995.

Bielsa, Esperança. Cosmopolitanism and Translation. Investigations into the experience of the foreign. Routledge, 2016.

Bolaño, Roberto. Stern in der Ferne. Trad. Christian Hansen. Fischer, 2010.

--.. Distant Star. Trad. Chris Andrews. Vintage, 2009.

--.. 2666. Anagrama, 2004.

--.. “La traducción es un yunque”. Entre paréntesis. Anagrama, 2004, pp. 222-224.

---. Étoile distante. Trad. Robert Amutio. Christian Bourgois, 2002.

--.. Estrella distante. Anagrama, 1996.

--.. “El universo hinchado. Nueva poesía francesa”. Plural, 64, 1977, pp. 20-24.

Birns, Nicholas. "The Part about the Critics: the World Reception of Roberto Bolaño". Critical Insights: Roberto Bolaño. Ed. Ignacio López-Calvo. Salem Press, 2015, pp. 50-64.

Birns, Nicholas y Juan De Castro (eds.). Roberto Bolaño as World Literature. Bloomsbury, 2017. Cobas Carral, Andrea y Verónica Garibotto. “Un epitafio en el desierto. Poesía y revolución en Los detectives salvajes”. Bolaño salvaje. Eds. Edmundo Paz Soldán y Gustavo Faverón. Candaya, 2008, pp. 163-189.

Corral, Wilfrido. Bolaño traducido: nueva literatura mundial. Escalera, 2011.

Damrosch, David. What is World Literature? Princeton University Press, 2003.

Echevarría, Ignacio. "Bolaño internacional: algunas reflexiones en torno al éxito internacional de Roberto Bolaño". Estudios Públicos, no. 130, 2013, pp. 175-202.

--.. "Lengua e identidad". Desvíos: un recorrida crítico por la reciente narrativa latinoamericana. Ediciones Universidad Diego Portales, 2007, pp. 185-188.

Esposito, Scott. “The Natasha Wimmer Interview". The Quarterly Conversation, 2008. http:// quarterlyconversation.com/the-natasha-wimmer-interview, consultado 8 de enero 2019.

Goethe, Johann Wolfgang. "German Romance”. Sämtliche Werke, Vol. 22. Eds. Friedmar Apel y Hendrik Birus. Suhrkamp, 1999, pp. 432-434.

Grossman, Edith. Why Translation Matters. Yale University Press, 2010.

Guespin, Louis y Jean-Baptiste Marcellesi. “Pour la glottopolitique”. Langages, no. 83, 1986, pp. 5-34.

Hansen, Christian. “Aus dem Übersetzernähkästchen: Flaulfleisch-Prosa”. Wilde Leser, 2009. http://www.wilde-leser.de/?p=469, consultado 8 de enero 2019. 
Harrison, Nicholas. "World literature: What gets lost in translation?" The Journal of Commonwealth Literature, Vol. 49, no. 3, 2014, pp. 411-426.

Heyward, Will. “Chris Andrews. Interview”. BOMB Magazine, 2012. https://bombmagazine. org/articles/chris-andrews/, consultado 8 de enero 2019.

Hoyos, Héctor. "Bolaño como excusa: contra la representación sinecdótica en la Literatura Mundial”. Letra anexa, no. 1, 2015, pp. 92-106.

Kleinemeier, Marvin. "Ein Interview mit Heinrich von Berenberg”. Wilde Leser, 2009. http://www.wilde-leser.de/?p=1562, consultado 8 de enero 2019.

Locane, Jorge J. De la literatura latinoamericana a la literatura (latinoamericana) mundial. Condiciones materiales, procesos y actores. De Gruyter, 2019.

Loy, Benjamin. "Der Teil der Kritiker: die deutschsprachige Bolaño-Rezeption zwischen Exotismus-Perpetuierung und globaler Prestige-Ökonomie". Roberto Bolaño im deutschsprachigen Kontext. Ed. Stephanie Catani, transcript 2019 (en prensa).

-.-. Roberto Bolaños wilde Bibliothek. Eine Ästhetik und Politik der Lektüre. De Gruyter, 2019.

--.. "The Precarious State of the Art: Writing the Global South and Critical Cosmopolitanism in the Works of J.M. Coetzee and Roberto Bolaño". Re-mapping World Literature. Writing, Book Markets, and Epistemologies between Latin America and the Global South. Eds. Gesine Müller, Jorge J. Locane y Benjamin Loy. De Gruyter, 2018, pp. 91-116.

---. "La ironía como cuestión de Wieder y muerte: Estrella distante de Roberto Bolaño". Ironía y violencia en la literatura latinoamericana. Eds. Brigitte Adriaensen y Carlos van Tongeren. Instituto Internacional de Literatura Iberoamericana, 2018, pp. 189-203.

--.. “Mocking World Literature and Canon Parodies in Roberto Bolaño's Fiction”. Roberto Bolaño as World Literature. Eds. Nicholas Birns y Juan De Castro. Bloomsbury, 2017, pp. 153-166.

--.. "De oposiciones, apropiaciones y traducciones (anti)poéticas: lecturas cruzadas de Nicanor Parra y Roberto Bolaño". La traducción desde, en y hacia Latinoamérica. Perspectivas literarias y lingüísticas. Eds. Silke Jansen y Gesine Müller. Iberoamericana/ Vervuert, 2017, pp. 211-228.

--.. "Chistes par(r)a reordenar el canon - Roberto Bolaño, Nicanor Parra y la poesía chilena”. Romanische Studien, no. 1, 2015, pp. 45-60.

--.. "Deseos de mundo - Roberto Bolaño y la (no tan nueva) literatura mundial”. América Latina y la literatura mundial: mercado editorial, redes globales y la invención de un continente. Eds. Dunia Gras y Gesine Müller. Iberoamericana/Vervuert, 2015, pp. 273-294.

---. “Fantasmas de la periferia o la República Mundial de los Plagios: ‘El viaje de Álvaro Rousselot' de Roberto Bolaño”. Bolaño en sus cuentos. Eds. Paula Aguilar y Teresa Basile. Almenara, 2015, pp. 138-157.

--.. "Escritores bárbaros, detectives distantes y un cura amnésico - escenificaciones de la (post-) dictadura chilena en la obra de Roberto Bolaño". Arpillera sobre Chile. Cine, teatro y literatura antes y después de 1973. Eds. Annette Paatz y Janett Reinstädler. tranvía, 2013, pp. 117-138.

Maldonado Tovar, Juan Camilo. "Escribir a pesar del silencio: una entrevista con Evelio Rosero Diago". El Tiempo, 2017. http://www.eltiempo.com/bocas/una-entrevista-con-el-escritorcolombiano-evelio-rosero-diago-90086, consultado 8 de enero 2019.

Mortati, Julieta. "El actor escondido. Una entrevista con el traductor de Bolaño, Christian Hansen”. alba. lateinamerika lesen, no. 03, 2013, pp. 52-57. 
Pollack, Sarah. “Latin America Translated (Again): Roberto Bolaño’s The Savage Detectives in the United States". Comparative Literature, vol. 61, no. 3, 2009, pp. 346-365.

Sánchez Prado, Ignacio M. “Más allá del mercado. El uso de la literatura latinoamericana en la era neoliberal”. Libro Mercado. Literatura y Neoliberalismo. Ed. José Ramón Ruisánchez Serra. Universidad Iberoamericana, 2015, pp. 15-40.

Spivak, Gayatri Chakravorty. "The Politics of Translation". The Translation Studies Reader. Ed. Lawrence Venuti. Routledge, 2012, pp. 312-330.

---. Death of a Discipline. Columbia University Press, 2003.

Strich, Fritz. Goethe und die Weltliteratur. Francke, 1957.

Valle, José del. "Glotopolítica, ideología y discurso: categorías para el estudio del estatus simbólico del español”. La lengua, ¿patria común? Ideas e ideologías del español. Ed. José del Valle. Iberoamericana/Vervuert, pp. 14-29.

Venuti, Lawrence. "World Literature and Translation Studies". The Routledge Companion to World Literature. Eds. Theo D’haen, David Damrosch y Djelal Kadir. Routledge, 2012, pp. 180-193.

---. The Translator's Invisibility. A History of Translation. Routledge, 2004.

Walkowitz, Rebecca. Born Translated. The Contemporary Novel in an Age of World Literature. Columbia University Press, 2015.

Wilson, Scott Bryan. “The Chris Andrews Interview”. The Quarterly Conversation, 2008. http:// quarterlyconversation.com/the-chris-andrews-interview, consultado 8 de enero 2019. 
3 Literaturas locales 



\section{Cosmopolitismo copyleft. Tumbona Ediciones, autonomía y localidad}

Uno de los problemas centrales en el estudio de la literatura contemporánea radica en su elusiva materialidad como institución y práctica. En el caso latinoamericano, el panorama de publicación, circulación y consumo de la literatura ha sido objeto de transformaciones infraestructurales profundas, cuyos efectos tanto en la idea de la literatura como en las estéticas y políticas que intervienen en su figuración son siempre estudiados en una suerte de time-lag, una aproximación siempre tardía ante la dificultad de acercarse críticamente a la aceleración material de la cultura. A pesar de haber perdido y continuar perdiendo privilegios epistemológicos y críticos en vista tanto de la explosión multimediática de la era del internet como de las metodologías y aproximaciones transdisciplinares de los estudios culturales, la literatura como disciplina y la obra literaria como objeto siguen manteniendo un valor aurático como espacios de resistencia a las hegemonías globalizantes, los flujos del mercado y el arrasamiento necropolítico que han caracterizado la experiencia neoliberal de la región. Si hemos de responder la pregunta respecto al rol de las literaturas locales como resistencia a la hegemonización de la llamada "literatura mundial", la atención a la materialidad infraestructural de la producción literaria, y la relación tensional y paradójica de la forma literaria respecto a esa materialidad requieren ser atendidas.

Este artículo reflexiona sobre este problema a partir del proyecto Tumbona Ediciones, una editorial independiente fundada en principios de autonomía, colectivismo y copyleft en México en 2005 y dirigida por los escritores Luigi Amara y Vivian Abenshushan. Los fundadores describen así el proyecto:

Bajo el lema "El derecho universal a la pereza", Tumbona Ediciones reúne a un grupo de creadores artísticos que desde el 2005 propone un tipo de resistencia creativa frente al progresivo empobrecimiento cultural del país. Nuestra intención es dar hospitalidad y circulación a los géneros más desatendidos por los grandes grupos (ensayo, aforismo, cuento), así como a títulos y apuestas poco frecuentes en nuestro panorama editorial (libros visuales de pequeño formato, flipbooks o cine de dedo). Libros con espíritu heterodoxo e irreverente, libros con vitalidad estética y riesgo intelectual, libros impuros que puedan ir de un lado a otro de las ramificaciones artísticas, esos son los libros que publicamos. (“Sobre la Tumbona” s.f.)

Ignacio M. Sánchez Prado, Washington University in St. Louis 
En esta breve descripción, emerge una terminología que permite entender estrategias de construcción de una "literatura mundial" desde abajo, a contrapelo de la literatura mundial construida desde arriba a través de circuitos hegemónicos de circulación transnacional. Tumbona se erige a sí misma como "resistencia creativa frente al empobrecimiento cultural del país”, sugiriendo una lectura de las condiciones hegemónicas de producción literaria como una gradual erosión de la cultura misma. Ante la “desatención” de los grandes grupos ante géneros nucleares de la tradición literaria mundial que no participan de manera obvia en el mercado (como el aforismo o el ensayo), proponen la idea de la "hospitalidad" y la "circulación” como contraparte. Si bien la idea parece simple (publicar aquello que no se publica en el circuito comercial), el concepto de "hospitalidad" tiene en el contexto de la época actual una serie compleja de implicaciones en la tensión entre lo nacional y lo mundial. En el contexto de los debates sobre inmigración, Jacques Derrida discute la distinción y tensión entre la "hospitalidad incondicional" y "los derechos y deberes que son las condiciones de la hospitalidad”. Según Derrida, la migración (y yo diría aquí la totalidad de circulación de bienes, cuerpos y símbolos en la era contemporánea) se funda en la tensión entre el deseo incondicional y la ley absoluta de la hospitalidad, el deseo de recibir lo forastero en casa, y la ética y política de la hospitalidad, siempre condicional (Doufourmantelle y Derrida 147). Para no caer en una digresión teórica, basta para mis propósitos comprender que el tema que interesa a Derrida es el hecho de que ambas formas de la hospitalidad no se contradicen, sino que "they appeal to each other, in a disconcerting way” (Derrida, "The Principle” 6): por un lado existe una ética en la cual se abren las puertas de un hogar, y por otro existen comunidades lingüísticas, familiares o nacionales que no se suspenden al ejercer la hospitalidad. Por tanto, concluye Derrida, debemos pensar en una "double law of hospitality: to calculate the risks, yes, but without closing the door on the incalculable, that is, on the future and the foreigner" (6).

Si leemos el manifiesto de Tumbona desde esta acepción de hospitalidad, podemos plantear la idea de que el cosmopolitismo y la literatura tanto nacional como mundial a la que apela un proyecto editorial independiente funciona bajo los condicionamientos éticos y culturales de una lógica de la circulación que simultáneamente abre de manera incondicional las puertas de una tradición a una serie de libros y bienes culturales mundiales, a la vez que establece reglas y condicionamientos que permiten definir una ciudadanía cultural propia. Como en Derrida, su hospitalidad se basa en la pregunta sobre la ética y la política de la cultura de la globalización en su encuentro problemático tanto con las culturas nacionales (materializadas en regímenes legislativos y simbólicos de restricción de la circulación) como con la cultura global capitalista (que fomenta una libre circulación de bienes erosionando formas de vida y de pensamiento). En Derrida, tanto 
la hospitalidad como el cosmopolitismo se fundan en la tensión entre una responsabilidad infinita hacia el Otro y el pragmatismo que conlleva dicha responsabilidad en el espacio de lo particular (Derrida, Cosmopolites). Así, proyectos editoriales como Tumbona se basan en el desplazamiento de los dos términos hacia espacios distintos a los promulgados por la libre circulación del capital literario (la literatura que Rebecca Walkowitz llama "born translated” y que está escrita para la circulación sin fricciones a través de espacios culturales y lingüísticos. Por un lado, en vez de apelar a una universalidad pre-establecida por los principios de circulación de la literatura comercial, Tumbona opta por un principio de hospitalidad hacia los géneros "impuros", basado en un "derecho universal a la pereza" que constituye un marco simbólico-legal alterno a las nociones de industria cultural y trabajo cultural que subyacen a las obras literarias que participan de lo que Sarah Brouillette, a partir de una lectura crítica del sociólogo Richard Florida, llama la "economía creativa”. A la vez, al aplicar pragmáticamente esta hospitalidad a su catálogo, Tumbona establece una serie de limitantes y criterios que efectivamente ponen reglas y condicionantes a la literatura que publican, algo necesario para definir su cosmopolitismo opuesto al mercado. Así, términos como "heterodoxo" e "irreverente" reemplazan las condicionantes del mercado ("ligero", "legible”, etc.) como infraestructura estético-legal de la hospitalidad del proyecto. Estructuralmente hablando es un cosmopolitismo que sigue las mismas reglas, discutidas por Derrida, de cualquier otro cosmopolitismo involucrado en la tensión entre lo nacional y lo global, sea este migratorio, económico o simbólico. Pero se trata de un cosmopolitismo, en este caso editorial, que resiste las leyes de circulación (como el "nacer traducido" de Walkowitz o el circuito transnacional de agentes y mediadores) y de restricción (las leyes de copyright, las restricciones del "literatura nacional") del cosmopolitismo comercial a partir del establecimiento de leyes alternas: circulación en libro e internet, establecimiento de un movimiento copyleft, introducción al mercado de géneros no vendibles, etc.

La legibilidad del proyecto de Tumbona ediciones emerge en contraste al cambio de coordenadas de la infraestructura editorial latinoamericana que comienza en los años ochenta y que continúa hasta nuestros días. La cuestión de los realineamientos del mercado es compleja y ha sido discutida en varios textos relevantes (sobre todo Ruisánchez y Guerrero para el tema al que dedico estas páginas), así que no me expandiré en demasía sobre el tema Tumbona nace a contrapelo de fenómenos que han redefinido la publicación en habla hispana. La primera es la fuerte consolidación corporativa de la publicación en la región, que incluye la gradual emergencia de los dos titanes que controlan un porcentaje alto de la publicación de libros: el Grupo Planeta y, sobre todo, Penguin Random House Mondadori, que incluso ha absorbido a Alfaguara, el gigante mayor de la publicación literaria en español de los noventa. La segunda tiene que ver con 
editoriales que, en resistencia a esa consolidación corporativa, han en distintos periodos tratado de posicionarse como editoriales de concepto y hacer competencia a nivel nacional o transnacional a los dos corporativos: estas editoriales incluyen a Anagrama y Periférica en España, Eterna Cadencia y Mardulce en Argentina, LOM en Chile, Era, Sexto Piso y Almadía en México, por mencionar a algunas. Estos dos factores tienen como efecto paradójico una renacionalización de la literatura ya que las primeras suelen segmentar su publicación por países, transnacionalizando solamente autores específicos, mientras que las segundas (sobre todo las latinoamericanas) circulan poco fuera de su ámbito nacional o (en el caso de Anagrama por ejemplo) mantienen filiales locales que diferencian precios de los autores nacionales respecto al resto del catálogo. Como observa atinadamente Gustavo Guerrero,

El recentramiento del negocio en torno a la producción local no sólo trae como consecuencia una acentuación del proceso de balcanización y aislamiento tradicional de las distintas literaturas nacionales sino que acaba convirtiendo a lo nacional en una especie de efecto del mercado cuyo contenido y alcance suscita severas críticas y reservas, sobre todo en lo que toca al rediseño del campo por parte de agentes foráneos y en lo que respecta a la revisión de las jerarquías establecidas en función del nivel de ventas. (105)

Asimismo, continúa Guerrero, este proceso viene acompañado de "una puesta en escena simultánea de su crisis, pues, a todo lo largo de la década, el mercado se segmenta nichos y se convierte en una caja de resonancia social de las diferencias, en una vitrina para la afirmación del multiculturalismo" (106). A esto cabría agregar también que estas cajas de resonancia (una nacional y una serie de cajas identitarias hacia dentro de ellas) no solo han vaciado de sentido la idea de literatura latinoamericana a través de las restricciones en la circulación (algo sobre lo que ha reflexionado de manera radical Jorge Volpi, El insomnio) sino también construyen una literatura mundial cuyos parámetros de canonización están completamente fuera de la práctica literaria latinoamericana, funcionalizados a contratos de edición negociados en mercados como Frankfurt y a la previa canonización en el francés o el inglés. Hay que recordar, por ejemplo, que autores como Sergio Pitol lograron crear un canon de literatura mundial distinto al producido por los circuitos hegemónicos transnacionales precisamente porque la relativa autonomía que gozó la edición en español entre los años sesenta y ochenta, anterior a la consolidación corporativa, permitía a traductores, creadores y críticos publicar constelaciones de autores mundiales distintas a las de otras lenguas ${ }^{1}$. Siguiendo el concepto de hospitalidad, es posible decir que este panorama editorial es inhóspito. Por un lado, restringe significativamente

1 Sobre esto, véase Sánchez Prado, capítulo 1. 
tanto el género de las obras literarias que circulan de tradición en tradición como sus orígenes lingüísticos y estéticos, procesando todo por un sistema comercial que en general es exógeno a las prácticas literarias de base en los países latinoamericanos. A su vez, los sistemas literarios nacionales se vuelven más cerrados de lo que eran antes, pero además son construidos por políticas de edición y de mercado de corporaciones localizadas en espacios geográficos hegemónicos (España, Estados Unidos, etc.) impidiendo a las literatura locales el establecimiento de las reglas y principios de hospitalidad necesarias para la creación y preservación de identidades estéticas e ideológicas de campos literarios específicos.

Tumbona pertenece a un tercer ámbito de editoriales que, ante este desafío, buscan construir procesos de literatura mundial y nacional a partir de desafiar no solo a la hegemonía en las estructuras de publicación y distribución que los corporativos fomentan, sino también al privilegio que formas tradicionales de la escritura -sobre todo la novela, el cuento y las narrativas de no-ficción como la crónica y la memoria- tienen en la canonización literaria del mundo hispanohablante. Conviene recordar que la centralidad de la novela en América Latina es un fenómeno reciente, atado a la inserción misma de América Latina en el mercado transnacional del libro en la era del Boom. La respuesta dada por Tumbona emerge por un cambio tecnológico central a la producción literaria latinoamericana y global. En un ensayo clásico sobre el Boom, Jean Franco propone una historia de la narrativa latinoamericana basada en registrar los tipos de autoría relacionados con avances tecnológicos en el arte de la narración. Así, Franco distingue al "narrador" (en el sentido benjaminiano del término) como un resabio de las tradiciones orales y al autor como la figura que emerge a partir del establecimiento, y ampliación, de las tecnologías de la imprenta (51-53). La novela latinoamericana del nuevo siglo establecería así un modelo distinto al autor europeo, cuya característica es la utilización de la novela como el género del individuo en la sociedad, mientras que el modelo predominante en América Latina sería el autor como "fundador" desde los márgenes (157-159). La entrada al ámbito de la literatura de los medios masivos y electrónicos permite la emergencia del autor "superstar" que asume los principios de la cultura de masas y contribuye a la erosión de ciertas formas tradicioales de la novela ante la primacía de la imagen del autor mismo (166-167). En cierto sentido, la literatura de mercado de hoy en día no es algo nuevo, sino una aceleración y expansión del modelo del superstar: autores como Roberto Bolaño, Orhan Pamuk o Elena Ferrante, pese incluso al hecho de que sus obras ponen elementos de sus precursores en entredicho, son consumidos por el mercado de maneras muy similares a las que fueron desarrolladas alrededor de figuras como Gabriel García Márquez, 
Umberto Eco o Milán Kundera décadas atrás ${ }^{2}$. Las aperturas que se pueden ver en el mercado tienen que ver con las descentralizaciones que cambios tecnológicos recientes (como el blog, las redes sociales y el libro electrónico) han tenido no tanto en la desestabilización del sistema hegenómico (que sigue operando sin novedad) sino en la proliferación de posibilidades alternas a dicho sistema.

Tumbona puede ser ubicada en el cuadrante de lo que Craig Epplin llama, para el caso argentino, "late book culture", un intraducible que busca registrar la existencia de una cultura que no es post-libresca del todo, pero que navega las incertidumbres del futuro del libro como soporte material único de la escritura literaria. El proyecto de Tumbona emerge en un punto en el cual la escritura literaria latinoamericana ha mudado, como explica Epplin, de ecosistemas. En México, esto comenzaba a verse de manera decisiva en la década pasada, ante la emergencia del blog como precursor o complementador de proyectos novelísticos (cabe recordar, por ejemplo, El jardín devastado, de Jorge Volpi (2008), publicado originalmente en blog, o el proyecto de Cristina Rivera Garza, cuyo blog No hay tal lugar dio partida a una constelación de libros interconectados, incluyendo la novela La muerte me da (2008)). Si bien las cartoneras en México no tuvieron, debido al peso institucional del Estado, la relevancia que adquirieron en Argentina, existen ideas comunitarias del libro que operan desde principios parecidos, como la editorial Sur+ de Oaxaca, que se define a sí misma como "editorial colectiva independiente" o Mantarraya Ediciones, un proyecto editorial atado a Hosteria La Bota -restaurante y centro cultural de Antonio Calera Grobet- y La Chula Foro Móvil, una combi de los años setenta que lleva eventos culturales a comunidades marginadas de la Ciudad de México. Lo que se observa en el caso mexicano, y establece diferencias importantes respecto al caso argentino estudiado por Epplin, es que el problema del soporte libro es parte de una constelación mayor de intervenciones. Por un lado, el blog, las redes sociales y las nuevas formas de comunitarismo literario que han propagado autores como Rivera Garza o Alberto Chimal hablan de una noción de la escritura literaria que excede al libro. Pero, en el contexto de una literatura altamente institucionalizada en un sistema de premios, becas y subsidios del Estado en proporciones inexistentes en cualquier otro país latinoamericano, Sur+, Mantarraya y Tumbona piensan la localía y la resistencia a la hegemonía cultural desde la intervención de la infraestructura misma. Así, Mantarraya constituye una edición de libros alrededor de un proyecto gastronómico y un espacio de difusión cultural que dan vuelta y que complementan la materialidad cultural

2 Sobre la forma en que Bolaño repite patrones de García Márquez en su circulación de mercado, véase Pollack. 
de Estado. Tumbona, por su parte, apela a la intervención estética en dos formas: el rechazo del copyright y el valor económico del libro y la consecuente promoción de formas de escritura que solo son pensables desde dicho rechazo.

El catálogo de Tumbona es demasiado complejo y amplio para dar cuenta de él de manera exhaustiva en un estudio como este, así que me enfocaré solamente en libros particulares para plantear algunas ideas centrales cuáles son los espacios de intervención de la editorial en la tensión entre literatura mundial y literatura nacional que subraya la hospitalidad de su proyecto. Destaca, por ejemplo, el volumen colectivo Contra el copyright (Stallman), una reflexión en cinco ensayos que recorre la idea del derecho a la lectura, el problema del copyright, la idea del copyleft y la cuestión del futuro digital. El libro aparece en la serie Versus, un conjunto de breves libros -a veces de un autor, a veces de un conjunto de autores- que entran en polémica contra principios y mecanismos de la era contemporánea en defensa de la filosofía general de la pereza y la hospitalidad de la editorial (hay por ejemplo, un volumen contra la "vida activa” (Lemus) o el conocido ensayo de Lina Meruane contra los hijos). En el volumen contra el copyright se puede ver ya la idea de una literatura mundial que la editorial recibe a través de su hospitalidad, y que se basa en la lectura de una constelación de prácticas y practicantes de la literatura que ponen en entredicho la idea misma de literatura de mercado. Los dos textos sobre copyright y copyleft, por ejemplo, provienen del colectivo Wu Ming, un grupo de autores italianos activo entre el año 2000 y el 2011 que, en el contexto del régimen de Berlusconi, publicaron una serie de novelas bajo licencia Creative Commons. El texto del derecho a la lectura fue escrito por Richard Stallman, el fundador de la idea del software libre y el pionero del concepto mismo de copyleft y de las licencias públicas generales. Un texto sobre el derecho al plagio fue escrito por César Rendueles, un pensador español conocido por su obra sobre los cambios políticos de la era digital, mientras que el del futuro digital es de Kembrew McLeod, un estudioso de la comunicación cuyo reconocimiento viene de su patente de la idea de "libertad de expresión" y su demanda contra la compañía AT\&T por su uso promocional del término, para poner en evidencia los absurdos de la ley de propiedad intelectual.

Destaca de este libro el carácter de manifiesto que la compilación tiene. Uno de los diagnósticos centrales del proyecto de Tumbona radica en "la transición de la censura del Estado a la no menos efectiva del mercado", en la cual "los libros se volvieron mercancías perecederas, que debían venderse en tiempo record" (Loy y Locane 74). En esto, los editores de Tumbona coinciden con diversos diagnósticos de fines de los noventa e inicios del siglo XXI, que veían una suerte de proliferación de la violencia contra la literatura a partir de lo que 
uno podría llamar una nueva microfísica donde el poder centralizado de la censura del Estado comenzaba, particularmente en las sociedades occidentales, a difuminarse en mecanismos de mercado. Esto fue una denuncia que venía tanto de editores como André Schiffrin, cuyo The Business of Books denunciaba la manera en que los conglomerados corporativos reemplazaban a los editores del siglo XX, o críticos como Christian Salmon, quien diagnosticaba en Tumba de la ficción que "las formas tradicionales de censura jurídica e institucional están desapareciendo sustituidas por formas nuevas”, cuyo fin es la instalación del "reino de lo homogéneo y su fobia por el arte y la ficción” (15).

Vivian Abenshushan, una de las fundadoras y editoras de Tumbona, argumenta que el copyright es uno de los mecanismos que permite dicha censura. En un texto sobre el tema, Abenshushan argumenta que la "tiranía del copyright sofoca la cultura" y pone como ejemplo un libro de arte que deja recuadros en blanco porque "no consiguieron los derechos de reproducción de algunas imágenes y el resto resultaba impagable" (Escritos 267). Ante esto, el copyleft es una estrategia que permite la apropiación y recirculación de los objetos culturales, contrastando "la economía del máximo beneficio frente a la economía del regalo” (275-276). Podríamos decir entonces que Tumbona se funda en un cosmopolitismo copyleft, donde la globalización y la mundialización de las culturas no se fundan en la libre circulación de mercancías en el ámbito de lo económico, pero fuertemente controladas por entidades comerciales empoderadas por las leyes del copyright. Eso es lo que permite, por ejemplo, que editoriales como Planeta o Penguin Random House ejerzan un derecho absoluto de publicación sobre un libro de literatura latinoamericana en todos los idiomas, a la vez que decide solo publicarlo en el país de origen de la autora y, de hecho, restringir completamente la producción en otros lugares. Asimismo, Abenshushan arguye, esto no impide la apropiación que la cultura corporativa hace de las culturas marginales. Pone como ejemplo la canción "Waka Waka” de Shakira y Wyclef Jean para hablar de un "plagio imperial" que roba a culturas periféricas para el beneficio comercial de culturas dominantes (Escritos 270). En el contexto de la idea de literatura mundial, creo que esta aseveración, junto al catálogo de Tumbona, puede leerse como un argumento respecto a una forma de ejercerla de manera alternativa a la planteada por los corporativos editoriales. Los críticos de la relación entre cultura poscolonial y literatura mundial (Huggan; Brouillette, Postcolonial) han demostrado con suficiencia que la mera representación de lo marginal puede ser perfectamente compatible con los procesos de hegemonización y homogeneización de la literatura mundial corporativa. Lo que argumenta Abenshushan en sus escritos, y Tumbona en general como proyecto, es que no puede resistirse significativamente al mercado si uno sigue operando dentro de sus términos o si uno simplemente atiende al contenido de las publicaciones. El 
cosmopolitismo copyleft debe comprenderse así como una intervención en la literatura mundial a nivel de infraestructura, cuestionando la materialidad que permite la hegemonización, desde los regímenes jurídicos de propiedad intelectual hasta los calendarios de publicación basados en la maximización del lucro.

Tumbona no es una editorial de tesis, pero sí mantiene un sentido claro del canon, sobre todo de un canon interesado en repensar escrituras que resisten la propiedad, la economización y el trabajo. Con base a esto articula los dos términos de la dialéctica de la hospitalidad: un espacio para dar la bienvenida a escrituras nómadas que no entrarían de manera clara a la tradición mexicana, y una tradición mexicana cuya relación material con el mundo y la literatura sale de los parámetros de los cosmopolitismos hegemónicos tanto del mercado como del campo de producción cultural del siglo XX. Estos archivos nos permiten ver, primero, cómo la intervención en la idea misma del texto canonizable plantea la posibilidad de un "cosmopolitismo copyleft”, que, fuera de la mercancía y objeto del libro y el privilegio capitalista a la novela, permiten recuperar una tradición literaria basada en repertorios, prácticas y formas performativas de la literatura que carecen de fijación en el ámbito de la mercancía. Por otro, es posible ver la forma en la cual se piensa la idea del escritor contemporáneo mexicano y latinoamericano en correlación a formas de ser escritor mundial que no pasan por la validación de las estructuras hegemónicas del mercado. Esto es observable en los dos "Archivos" que, en tres volúmenes cada uno, apuestan a una recuperación precisa del pasado.

El primero de estos archivos es "Archivo Fluxus" (Kaprow; Higgins; Friedman, Smith y Sawchyn), en el cual Tumbona recupera en tres volúmenes textos, imágenes e intervenciones del colectivo artístico neo-dadaísta Fluxus, al que pertenecieron entre otros Allen Kaprow, Joseph Beuys y Yoko Ono, y que buscaron en sus momentos más radicales la construcción de formas de arte que rompieran no solo barreras disciplinares sino también espacios utópicos de ruptura de la relación jerárquica entre creador y espectador. Los tres libros del Archivo Fluxus operan bajo la premisa de un cosmopolitismo literario que deja de estar anclado, como es el caso de mucha de la literatura mundial, en las tradiciones de la novela moderna y del modernismo global, y más bien apela al gesto neovanguardista de cuestionamiento de la institución arte y la institución literatura para reflexionar sobre el posicionamiento mismo de la literatura y el arte contemporáneos en la Latinoamérica contemporánea. Abenshushan lo plantea en estos términos en uno de sus ensayos sobre el Archivo:

Incoercible, antisolemne, abierta a la experimentación, animada por la colaboración y las prácticas colectivas, donde las disciplinas convivieron en promiscuidad fecundante para crear lenguajes inéditos como el happening o el videoarte, la actividad contracultural de 
Fluxus fue a su modo una cristalización del espíritu de la época. "Un modo de vida impregnado de una soberbia libertad de pensar, de expresar y de elegir”, escribió Robert Filliou. Más una zona temporalmente autónoma que una prefiguración del conceptualismo global, como han interpretado algunas versiones momificadoras. Un continente del absurdo (y del sentido del humor y la subversión y la imaginación radical). Un lugar sin lugar, donde Fourier habría vivido plácidamente. ("Fluxus" s.p.)

Esta descripción va directamente al tipo de genealogía que busca construir Tumbona: ante una cultura global definida por el capital y la propiedad intelectual, Tumbona recupera en Fluxus la colaboración y la colectividad, ante el disciplinamiento de las academias y los géneros artísticos, Fluxus representa la promiscuidad estética y la transdisciplinareidad, ante el conceptualismo global y el arte contemporáneo, un performance continuo y utópico de la imaginación radical.

El segundo proyecto es el "Archivo Ulises Carrión”, editado por Juan J. Agius y Heriberto Yépez, que colecciona en tres libros un conjunto de escritos, textos visuales y misceláneas del escritor y artista conceptual mexicano (Carrión, El arte correo; Lilia Prado; El arte nuevo). Carrión ha adquirido recientemente una centralidad considerable, a partir sobre todo de la exhibición de sus obras que, bajo el título de “Querido lector, no lea”, tuvo lugar en el Museo Reina Sofía en Madrid y el Museo Jumex en la Ciudad de México (Schraenen). Al igual que Fluxus, Carrión pertenece a un estilo heterodoxo de escritor que pone al centro de la creación literaria la producción de textos efímeros que impiden su fijación en el espacio de la mercancía o del libro. Carrión opera programáticamente a partir de la disociación entre texto y libro ("Un escritor", dice Carrión en uno de sus manifiestos, "contrariamente a la opinión popular no escribe libros / Un escritor escribe textos" (El arte nuevo 37)). Así, Carrión rechaza una forma del "arte viejo" en el cual el escritor produce un texto y un sistema económico ("los lacayos, los artesanos, los obreros, los otros" (39) producen el objeto libro. A cambio de esto, Carrión propone un "arte nuevo" en el que "el escritor asume la responsabilidad del proceso entero" (39)). Las razones por las cuales el "arte nuevo" de Carrión es el núcleo que permite ver la naturaleza de un proyecto como Tumbona y el replanteamiento de la literatura mundial que lo subyace son evidentes. Primero, es importante señalar que Carrión constituye un modelo único de escritor transnacional que, al disociarse del libro y al operar desde sitios como Ámsterdam, permite pensar una literatura mundial definida por prácticas materiales y para el mercado. Segundo, el arte nuevo de Carrión adelanta formas en las cuales proyectos como Tumbona y escritores como Heriberto Yépez trabajan alrededor de las instituciones literarias para controlar el proceso de producción literaria. La teorización de Carrión antecede la forma en que el blog, la 
publicación en Creative Commons (que Tumbona usa para liberar las versiones electrónicas de algunos de los libros) y el cuestionamiento de la plusvalía cultural operan en el siglo XXI.

\section{Bibliografía}

Abenshushan, Vivian. “Fluxus. Hágalo usted mismo”. Nexos en línea, 14 de junio 2016. https://cultura.nexos.com.mx/?p=10630, consultado 15 de agosto 2018.

---. Escritos para desocupados. Surplus, 2013.

Brouillette, Sarah. Literature and the Creative Economy. Stanford University Press, 2014.

---. Postcolonial Writers in the Global Literary Marketplace. Palgrave Macmillan, 2007.

Carrión, Ulises. El arte nuevo de hacer libros. Archivo Carrión 1. Segunda Edición. Eds. Juan J. Agius y Heriberto Yépez. Tumbona, 2016.

---. Lilia Prado superestrella y otros chismes. Archivo Carrión 3. Eds. Juan J. Agius y Heriberto Yépez. Tumbona, 2014.

---. El arte correo y el gran monstruo. Archivo Carrión 2. Eds. Juan J. Agius y Heriberto Yépez. Tumbona, 2013.

Derrida, Jacques. “The Principle of Hospitality”. Parallax, 11.1, 2005, pp. 6-9.

---. Cosmopolites de tous les pays, encore un effort! Galilée, 1997.

Dufourmantelle, Anne y Derrida, Jacques. Of Hospitality. Anne Duforumantelle invites Jacques Derrida to respond. Trad. Rachel Bowlby. Stanford University Press, 2000.

Epplin, Craig. Late Book Culture in Argentina. Bloomsbury, 2014.

Franco, Jean. Critical Passions. Selected Essays. Duke University Press, 1999.

Friedman, Ken, Owen Smith y Lauren Sawchyn. Cuaderno de ejercicios. Eventos, acciones y performances. Tumbona, 2016.

Guerrero, Gustavo. Paisajes en movimiento. Literatura y cambio cultural entre dos siglos. Eterna Cadencia, 2018.

Higgins, Dick. [Breve] autobiografía de la originalidad. Tumbona, 2015.

Kaprow, Allen. Ensayos sin títulos y otros happenings. Tumbona, 2013.

Lemus, Rafael. Contra la vida activa. Tumbona, 2008.

Loy, Benjamin y Jorge Locane. “'La única manera de sobrevivir para nosotros ha sido apelar a la imaginación'. Una conversación con la cooperativa Tumbona Ediciones”. alba. lateinamerika lesen, 7, 2015, pp. 75-78.

Meruane, Lina. Contra los hijos. Tumbona, 2014.

Pollack, Sarah. “Latin America Translated (Again). Roberto Bolaño's The Savage Detectives in the United States". Comparative Literature, 61.3, 2009, pp. 346-365.

Rivera Garza, Cristina. La muerte me da. Tusquets, 2008.

Ruisánchez, José Ramón. Libro mercado. Literatura y neoliberalismo. Universidad Iberoamericana, 2015.

Salmon, Christian. Tumba de la ficción. Trad. Thomas Kauf. Anagrama, 2001.

Sánchez Prado, Ignacio M. Strategic Occidentalism. On Mexican Fiction, the Neoliberal Book Market and the Question of World Literature. Northwestern University Press, 2018.

Schiffrin, André. The Business of Books. How International Conglomerates Took Over Publishing and Changed the Way We Read. Verso, 2001. 
Schraenen, Guy. Querido lector no lea: Ulises Carrión. Museo Nacional Centro de Arte Reina Sofía, 2016.

"Sobre la Tumbona" (sin fecha). www.tumbonaediciones.com/sitio/sobre-la-tumbona, consultado 13 de agosto 2018.

Stallman, Richard, Wu Ming, César Rendueles y Kembrew McLeod. Contra el copyright. Tumbona, 2008.

Volpi, Jorge. El insomnio de Bolívar. Cuatro consideraciones intempestivas sobre América Latina en el siglo XXI. Debate, 2009.

---. El jardín devastado. Alfaguara, 2008.

Walkowitz, Rebecca L. Born Translated. The Contemporary Novel in the Age of World Literature. Columbia University Press, 2017. 


\section{Silja Helber}

\section{¿Cuanto más marginal, más central? - La escritura de Rita Indiana}

\section{Introducción}

Las representaciones y los imaginarios predominantes a nivel global de la República Dominicana oscilan entre el actual 'paraíso vacacional caribeño' y su pasado oscuro por la 'Era de Trujillo'. Su riqueza literaria, prescindiendo de los textos escritos en inglés desde la diáspora, para la mayoría queda inadvertida. Desde este lado del Atlántico lo "caribeño", o sea, las literaturas caribeñas hispanas quedan reducidas a lo que se escribe en Cuba o en algunos casos en Puerto Rico. En este sentido "la literatura dominicana sería la periferia de la periferia caribeña" (De Maeseneer y Logie 20). Alguien que está cambiando este panorama es la escritora Rita Indiana, galardonada con el Gran Premio de Literatura de la Asociación de Escritores del Caribe 2017 y editada, actualmente, por la editorial española Periférica.

¿Pero, quién es "La Montra”?, como la llaman sus aficionados. ¿Quién es la persona que el periódico español El País nombró en el 2011 como una de las cien latinas más influyentes y a quien al mismo tiempo describió como "uno de los descubrimientos literarios más explosivos"? Cantante, productora de música, creadora publicitaria, escritora, artista de performance, voz crítica de la República Dominicana, columnista, icono queer... Ninguna de las facetas nombradas valora ni describe debidamente lo que representa Rita Indiana, puesto que sus capacidades y aficiones se suelen mezclar y entrecruzar. Indiana lo es todo, es versátil - una artista total en todos los sentidos. Además, encasillarla en uno de estos ámbitos iría en contra de su propia resistencia contra cualquier tipo de categorización o atribución de etiquetas, procesos con los cuales ha sido enfrentada por la crítica durante toda su trayectoria, como dijo en una ocasión: "Labels exist cause they have a function. I'm uncomfortable with them anyways [sic] because I've been dealing with labels all my life. Tomboy, headbanger, weirdo or lesbian, underground, celebrity. Labels are caricatures" (citado en Alamo).

Tan inconstante como sus ocupaciones y múltiple como sus identidades, también lo han sido sus lugares de residencia. Nacida en 1977 en Santo Domingo, República Dominicana, vivió un tiempo en Nueva York para instalarse luego en Puerto Rico, donde reside actualmente. El estilo de vida que Indiana representa,

Silja Helber, Universität zu Köln

Ә Open Access. (C) 2020 Silja Helber, published by De Gruyter. (cc) BY-NC-ND This work is licensed under a Creative Commons Attribution-NonCommercial-NoDerivatives 4.0 International License.

https://doi.org/10.1515/9783110673678-016 
recuerda mucho a la 'condición nomádica', una de las características clave de los escritores latinoamericanos actuales según Fernando Aínsa: "Se exalta así la 'condición nomádica' y la figura del 'fugitivo cultural' como componentes de una identidad que ya no es unívoca - territorio y lengua y menos aún étnica sino múltiple, capaz de esgrimir, según qué circunstancia o conveniencia, uno u otro pasaporte" (80).

Indiana comenzó su carrera literaria escribiendo poesía y narraciones, posteriormente debutó en el género de la novela. Entretanto su obra literaria abarca ya dos libros de relatos, una colección de poemas y performances y cinco novelas. Sus primeros textos literarios fueron difundidos en fotocopias y en un reducido tiraje por vías alternativas, luego publicados en una editorial en República Dominicana. Pero ya con su segunda novela Papi del 2005 abandonó la isla, siendo esta editada por la pequeña editorial Vértigo, de la isla vecina Puerto Rico. Pasaron cinco años más hasta que fue reeditada la versión dominicana, un año antes de que fuera también publicada al otro lado del charco en la editorial española Periférica. Otros cinco años más tarde, en el 2016, fue publicada su primera traducción al inglés por University of Chicago Press. Con la primera traducción, la percepción internacional y el análisis de su obra literaria en países de habla no hispana encontraron su punto de partida. De modo que a la traducción inglesa le siguió la versión italiana en el 2017, publicada en NN Editore, y la versión noruega en la editorial Solum Forlag en el 2018. Después de varias nominaciones, en el 2017 a Indiana le otorgaron el Gran Premio Literario de la Asociación de Escritores del Caribe. Este galardón definitivamente puede considerarse un hito en su carrera literaria internacional, ya que este premio la destacó como una de las voces literarias más importantes de las Antillas en la actualidad (Bustamante).

En vista del itinerario de publicación y reedición transnacional de Papi, novela con la cual Indiana debutó en el campo literario transnacional, desearía plantear la teoría de que ésta fue escrita para un público lector no prioritariamente local, sino dirigida desde un inicio a uno global, y por ende, cosechó mejores críticas en el extranjero y solo posteriormente llamó la atención en su país de origen República Dominicana. Esto significaría también que Indiana con Papi pretendía inscribirse en el corpus de la literatura mundial con potencial exportable cumpliendo con los requisitos de la novela global actualmente en boga, despidiéndose, por lo tanto, de una escritura más local que sería difícilmente inteligible fuera de su contexto de producción. Comprobar la validez de esta hipótesis mediante una lectura y un análisis más detallado de la novela sería el objetivo de mi artículo. 


\section{Literatura global vs. literatura local}

Pero antes de pasar al análisis de texto, quisiera hacer unas observaciones previas en cuanto a los conceptos usados, especialmente la oposición mencionada entre literatura local y literatura global. Este último concepto se aplica según Anadeli Bencomo sobre todo a textos literarios que circulan -supuestamente- a nivel global y con una trama previsible, por no decir trivial o prefabricada, empleando un lenguaje neutro o simple que contribuye, además, a una mayor traducibilidad; se trata, por ende, de textos (y básicamente novelas) que no se arriesgan con experimentos estilísticos, sino que se orientan más bien por las demandas de un mercado global y, por consiguiente, por los parámetros de la literatura bestseller (Bencomo 44). Conforme a Ana Gallego Cuiñas “'lo global’ supone un término 'neutralizador' que asimila el objeto literario a un modelo dominante más 'legible' (vendible)" (3), el cual para poder circular mejor carece de especificaciones y marcas demasiado locales. Entre este tipo de textos literarios figura también la literatura "born translated", término acuñado por Rebecca Walkowitz, que se aplica a textos literarios que nacen traducidos, es decir que ya en el proceso de escritura tienen una traducción posterior “en mente” (5).

Por otra parte existe la tal llamada literatura local que no sigue ni depende de tendencias globales. De acuerdo con Gallego Cuiñas, este tipo de literatura apuesta por tradiciones y tendencias locales así como un lenguaje más experimental con claras marcas locales. Son textos literarios que por su complejidad se dirigen más a los amantes de literatura especializada y no necesariamente a un público lector global que prefiere la literatura amena (Gallego Cuiñas 3). Por eso, la mayoría son textos literarios publicados en editoriales independientes para los cuales una traducción posterior es una posibilidad, pero no una aspiración incondicional.

\section{Análisis de Papi}

A primera vista, la trama de Papi en torno a una niña de ocho años como protagonista-narradora es bastante sencilla. Resumiéndolo en unas pocas palabras, describe y narra la relación compleja entre una hija y su padre ausente cuyo regreso la niña espera con ansias y se imagina vivamente: "[C]uando me dijeron que él iba a volver yo había dejado de esperarlo hacía tiempo y había visto un millón de veces su regreso, la ropa con que papi iba a volver, cómo iba a bajar del avión, oliendo el aire, salado, arrodillándose para lamer el suelo" (11). Parece ser una historia ya mil veces contada y leída, nada fuera de lo común. Incluso se podría 
clasificarla como una novela de aprendizaje porque describe la infancia, la desilusión y maduración de la niña - un tema no particularmente dominicano, sino universal. Lo peculiar es el modo y el tratamiento que Indiana ofrece: Efectivamente, la novela trata solo superficialmente el motivo conocido y casi universal del padre ausente. En lugar de eso, Indiana cuenta una historia de múltiples capas y facetas que temáticamente aborda la cultura popular dominicana y estadounidense, la diáspora dominicana, la crítica del excesivo consumismo de ciertos estratos sociales, del culto a la persona practicado en la historia de la República Dominicana, así como el cuestionamiento de las relaciones sociales patriarcales. Aparte de esto, la obra prescinde de una narración lineal o cronológica como tal sino, se presta para una lectura circular o continua ya que la trama cierra con las mismas palabras de la niña que inicia: "Papi es como Jason, el de Viernes trece.. . .Cuando uno menos lo espera se aparece” (9); "Y por fin comienzo: papi es como Jason... Aplausos, aleluyas, amén. Que cuando uno menos lo espera se aparece" (209). A lo largo de los doce capítulos los lectores por medio de monólogos y flujos de consciencia contados desde la perspectiva de la niña pueden formarse una idea de su fuerza imaginativa y fantasía desbordante que predominan su mente y percepción de la realidad y, por lo tanto, los hechos narrados. Como por ejemplo lo muestra la siguiente cita:

Y papi y yo seguimos subiendo y subiendo y subiendo, ya ni el mar se ve. Y la temperatura comienza a descender y a descender y a descender y papi tiembla y yo tiemblo, y hacemos fogoticos poniendo ambas manos juntas y ahuecando y soplando dentro. Papi enciende la calefacción que lleva el carro con un calor de mentira por el que se cuelan, aún en sus mejores momentos, alfileres de frío. Afuera todo es blanco y le digo a papi que si esto es la nieve, que si ahora por fin vamos a necesitar ropa de invierno. Él me dice que no, que esto son nubes solamente. (32)

Tal y como lo indica ya el título de la novela, todos los episodios narrados giran en torno a la figura del padre, cuyo apodo papi se repite continuamente y a quien la niña idealiza como un superhéroe y adora profundamente a pesar de los negocios ilícitos en los cuales está metido y cuyas dimensiones y consecuencias para ella hasta el final de la novela no parecen posibles de ser valorados. A pesar de su ausencia, el padre, en la fantasía y el mundo infantil de la niña, siempre está presente e intentando compensar su ausencia corporal por una abundancia de regalos materiales: "Papi también me ha comprado botas y crayolas y alphabet stickers, pre tested water colors, flexi foam sheets, pelucas de la Barbie, sweat shirts, halloween decorations (...), leather gloves para el invierno, para cuando vaya a visitarlo, para cuando papi vuelva y me lleve con él” (37).

Mientras como lectores nunca llegamos a saber la identidad completa de la niña, ni siquiera conocemos su nombre, el escenario y el momento en el que 
tiene lugar el argumento -todavía está en el poder el presidente dominicano Joaquín Balaguer (1986-1996) - quedan bastante definidos. El uso de marcas geográficas, tales como lo son nombres de calles, plazas, edificios y barrios (el Aeropuerto Internacional de las Américas, la avenida George Washington, la avenida Independencia, la avenida Abraham Lincoln, la avenida Churchill, la Plaza de la Bandera, San Juan de la Maguana, el estadio Quisqueya, el Country Club, el barrio La Feria, el barrio Centro de los Héroes) posibilita definir bien las coordenadas del argumento dentro de la capital dominicana, Santo Domingo, la cual sirve como escenario principal. Más allá de esto algunos episodios tienen lugar en EE.UU., en ciudades como Nueva York y Miami figurando como escenarios secundarios, donde reside gran parte de la diáspora dominicana y donde la niña se imagina visitando a su padre.

Aunque la novela también trate el tema de la migración (dominicana), la diáspora y las expectativas de las personas que se quedan atrás, Indiana no forma parte de los escritores latinoamericanos que viven ya en EE.UU. y convierten sus (propias) historias migratorias en el motor y tema de sus escrituras (Aínsa 103). Su experiencia de vivir algún tiempo en EE.UU. tampoco la ha hecho cambiar de idioma, o sea, escribir en inglés -lo que suele ser una práctica común en la actualidad-, y de esta forma ingresar directamente en el campo literario estadounidense. Aun así el inglés y la cultura norteamericana han dejado huellas en su escritura. En este contexto cabe mencionar el uso del spanglish que no solo se revela en la presencia de muchos anglicismos, es decir préstamos lingüísticos ("me seca el pelo con el blower en high" (72), "vending machine" (204)), sino sobre todo en la constante alternancia de códigos ("Y a contar hasta twenty" (70), "Y nos quedamos viendo a otra vieja que le habla a las latas de leche en polvo ninety nine cents for christ sake" (70)). Pero la presencia de la cultura anglosajona no se limita solamente al nivel lingüístico. Todo el texto está salpicado por referencias culturales en forma de marcas de bienes de consumo (principalmente artículos de lujo, juguetes y comida: Froot Loops, Coca-Cola, avena Quaker, Paper Mate, Nike, Pontiac, Ray-Ban), estrellas de cine (John Travolta), cantantes (Ozzy Osbourne, Tears for Fears, Alpha Blondie, Metallica), héroes infantiles (ET, Barbie, Winnie Pooh, Bugs Bunny, pato Donald) y personajes cinematográficos (Rocky, Jason, Luke Skywalker, Darth Vader, Doctor Spock). Éstas a la vez penetran la vida cotidiana en la isla, y por consiguiente también el habla de la niña, y se mezclan con las referencias culturales locales tales como lo son la música dominicana (especialmente las canciones y cantantes de merengue) y la gastronomía local (arroz con guandule, Ponche Crema de Oro, helado de champola, mofongo etc.). Al mismo tiempo, las abundantes referencias a la cultura popular estadounidense hacen que el libro sea legible a nivel global, puesto que la mayoría de los lectores en el mundo asocia una $u$ otra experiencia con aquellos 
productos o personajes. El resultado es un texto híbrido con un estilo experimental o más bien un popurrí colorido hecho de una combinación de letras de canciones, escenas cinematográficas de géneros como lo son el horror, la ciencia ficción, la fantasía y la acción, así como escenas de la realidad dominicana.

El tema del lenguaje es clave al momento de analizar la poética de Indiana. A nivel lingüístico en Papi confluyen diversas experiencias e intereses suyos como lo son la música caribeña, la cultura popular y masiva, el cine y la poesía. Indiana misma describió la creación de Papi como la labor de una DJ que aprovecha la variedad que le ofrece su colección de discos, mezclando estilos y ritmos de diferente índole (citado en Cordeu). Al narrar la historia desde la perspectiva de la niña, Indiana reproduce de forma creativa el lenguaje infantil: Abundan las onomatopeyas que recuerdan a los comics (“zum, zum”, “cras, cras”, “claca, claca, claca”, "retetetetetete”, "ratatatatatatata”, "rutututututututu”), los neologismos ("me hacen ba bay" (Indiana 31)) y errores ("Papi y yo andamo loquísimo por la cartera. Carretera!, me corrige papi, carretera!” (103)), así como las exageraciones ("y papi suda, suda, suda, suda, suda, suda muuucho" (24)) e hipérboles típicas del habla y los jugueteos de una niña de ocho años:

Papi tiene más de to que el tuyo, más fuerza que el tuyo, más pelo, más músculo, más dinero y más novias que el tuyo. Papi tiene más carros que el tuyo, más carros que el diablo, tantos carros que tiene que venderlos porque no le caben en su propia marquesina. Papi tiene carros que hablan y te dicen que te pongas el cinturón y que cierres la boca, en inglés, francés y otros idiomas. (18)

A pesar de su temprana edad, la niña es todo menos inocente de modo que el humor predominante se caracteriza por un tono impertinente y descarado, así como por muchos vulgarismos, coloquialismos y jerga callejera. Pero, lo que más llama la atención es el estilo oral que predomina en todo el texto y que se refleja sobre todo a nivel de la sintaxis donde en algunas partes cualquier regla ortográfica o de puntuación pierde su validez. El efecto es que el discurso se vuelve tan inmediato como si la niña se estuviera dirigiendo directamente a los lectores ("búscalo que no lo vas a encontrar" (98), "Primero, debes entender la historia detrás de la aventura. Un buen conocimiento de la historia antes de empezar el juego hará tu aventura más rica” (121)). En este contexto también se deberían mencionar los experimentos lingüísticos y estilísticos que por un lado reflejan el estado de ánimo de la niña que varía de capítulo a capítulo y que por otro lado hacen que la narración aumente de velocidad y cambie de ritmo:

El carro, un carro carro. Un carro carro carro, el carro más carro, car, ataca, atácalo, cógelo, chúbalo, chúbalo, chúbalo. Car, car. Por un carro fue que lo mataron, por un car, un carro carro caro, bien caro. Los carros caros más baratos, los carros caros son raros, uno 
dos, tres carros pasan sin darle, pero el cuarto de lao, le da de lao, lo está majando... (171)

A esto hay que añadir el uso del español dominicano cuya presencia no se nota solamente en el léxico en palabras y expresiones como por ejemplo ser un hijo de machepa, patana, guillo, jipío, suape etc., sino también en la morfología, la sintaxis y la fonética del texto. Para poder valorar debidamente la última, uno debería leer el texto en voz alta. Solo de esta forma resaltarían realmente la reducción fonética, la aspiración de la $h$, el lambdacismo, el rotacismo y muchos otros rasgos característicos del habla dominicana que se reflejan en expresiones como lo son écusenme, vamo, pielna, cambialme, jartar, a to lo que da, dolol etc. De esta manera Indiana logra crear un fiel reflejo de la realidad sociolingüística de República Dominicana que en algunos puntos por sus repentinos cambios de ritmos y velocidad recuerda más a una canción que a una novela. Por otro lado, esta autenticidad lingüística hace que leer la novela sea cualquier cosa menos fácil para quien no esté familiarizado con la variedad dominicana. Esta circunstancia contradice la tesis inicialmente establecida de que la novela está dirigida principalmente a un público internacional. Sin embargo, se debe recordar que estos regionalismos ya no afectan a los lectores que leen la novela en traducción, dado que por lo general es imposible transportarlos al idioma de destino, es decir, mantenerlos, y solo se dará cuenta de éstas quien compara la versión traducida con el original: "The loss in translation remains invisible to any reader who doesn't undertake a careful comparison to the foreign text - i.e., most of us" (Venuti). A pesar de todo, para quienes representan un desafío es para los traductores.

\section{Conclusión}

A partir del análisis resulta que la novela Papi de Indiana de ninguna manera puede ser considerada como una lectura fácilmente legible o traducible. Al contrario, por su estilo, su lenguaje y sus incontables referencias culturales y musicales -de las cuales no me he ocupado en el marco de este artículo- representa un reto para cualquier lector y traductor no familiarizado con el contexto dominicano. Por este motivo, es de suponer que Indiana o bien da por sentado que el lector implícito conoce todas estas referencias, porque el libro no contiene ni un glosario ni notas de pie de página con explicaciones secundarias, o que no hace falta entenderlas todas para poder disfrutar de una buena lectura.

Además, quedó claro que Papi no forma parte de la literatura "born translated”, porque una novela en la que el experimento con el lenguaje y el lenguaje 
mismo representan una parte central del texto literario de ninguna manera anticipa su traducción. Esto tampoco cambia el hecho de que la novela por su uso del spanglish, inglés y español antillano recuerda a la técnica del multilingüismo descrita por Walkowitz como una estrategia para alcanzar y dirigirse a un público multinacional: "Written for multiple audiences, contemporary novels have developed strategies of multilingualism designed for the foreign, nonfluent, and semifluent readers who will encounter them" (44). Detrás de esto, posiblemente también podría esconderse una estrategia de Indiana para dirigirse a los lectores multilingües en la diáspora dominicana.

Al mismo tiempo, la novela Papi también ofrece al lector "multiple windows on the world" (Damrosch 15), es decir, una vista a un mundo desconocido, una característica que de acuerdo con David Damrosch la convertiría en literatura mundial. Pero también se podría objetar que tan 'innovadora' tampoco puede ser la versión del mundo dominicano que Indiana presenta, teniendo en cuenta el hecho de que fue una de las pocas novelas de las que se traducen al inglés anualmente. La razón por la cual se optó por ella podría ser, en referencia al mismo Damrosch, que la novela refleja y confirma las imaginaciones e ideas que los lectores estadounidenses tienen de la isla, o sea, de República Dominicana (18).

No obstante, también se pudo desprender que no es tanto la historia sobre la relación entre padre e hija la cual dificulta la comprensión, puesto que ésta es bastante sencilla, aunque en realidad solo fija el ambiente para un gran espectáculo de la lengua. Tal y como se ha dicho en el El País, "Papi es un tour de force” (Manrique), en el cual el lector al acompañarle a la niña en la espera de su papi se siente como en un viaje vertiginoso de una montaña rusa en el cual nunca sabe lo que sucederá después - solo que papi está “"al doblar la esquina”" (Indiana 59).

Dicho de forma concisa, Papi no pertenece a la literatura global fácilmente consumible y exportable que presenté al principio de mi artículo, puesto que cuesta adentrarse al mundo y la escritura de Indiana, quien no omite esfuerzos estilísticos para crear una literatura distinta - inclasificable - como ella misma.

Si recordamos lo que dijo Sarah Brouillette sobre los obstáculos con los cuales se enfrentan los libros al pasar la frontera entre un país a otro, "books cannot move easily across borders due to linguistic and cultural differences that impede easy dissemination” (49), sorprende todavía más el éxito de Indiana en España, Puerto Rico, Italia y EE.UU. Esto es tanto más notable considerando que Indiana no equipa su versión original con comentarios explicatorios como lo hace por ejemplo el escritor estadounidense-dominicano Junot Díaz en su novela The brief wondrous life of Oscar Wao y con el cual Indiana muchas veces fue comparada. 
No obstante, salta a la vista que en las reseñas en la prensa extranjera las referencias a este escritor son recurrentes, como si por medio de éstas se expresara una recomendación implícita a cierto público destinatario de lector.

El hecho de que existen traducciones de Papi también rebate la hipótesis de Damrosch respecto a la pérdida que representa la traducción para una obra literaria: "A work can hold a prominent place within its own culture but read poorly elsewhere, either because its language doesn't translate well or because its cultural assumptions don't travel” (289). Eso nos hace suponer que Papi a pesar de todo sí "funciona”, es decir, es inteligible fuera de República Dominicana.

En relación a las palabras de Damrosch uno ahora se podría preguntar por qué Indiana con Papi entonces no tuvo el mismo eco en República Dominicana como en el extranjero. Ahí es importante aclarar que la falta de presencia y reconocimiento de Indiana en el campo literario de su país de origen de ninguna manera se deben a la calidad y al valor estético de su obra literaria, sino éstos están relacionados con los mensajes que la escritora transporta en sus textos literarios y los temas que trata:

No resulta difícil relacionar el silencio de la crítica insular sobre la producción de [Indiana] Hernández al hecho de que su obra ejemplifica, acaso más puntualmente que otros textos de la literatura dominicana reciente, el impulso hacia una cartografía subversiva de la identidad dominicana. (Rodríguez)

En consecuencia, la escritura de Indiana se caracteriza por un distanciamiento de los tópicos y temas comunes de la literatura dominicana, que se refieren principalmente al pasado oscuro de la isla (Maeseneer 156). Aun así, las Antillas continúan formando el punto crucial y partida de sus novelas. Lo único distinto son su enfoque y su manejo de temas conocidos de las literaturas caribeñas dado que conecta lo que pasa en el espacio local, el Caribe, con temas de relevancia y alcance global (Maeseneer 158). En este punto se clarifica que ella no abandonó la isla porque quería inscribirse directamente en la República Mundial de las Letras, sino porque su proyecto artístico y su poética no eran compatibles con el sector editorial local.

Llego a la siguiente conclusión: La novela Papi cumple con las expectativas de lectura de un público europeo y norteamericano que asocia con las literaturas latinoamericanas -en este caso caribeñas- temas como la magia, la fantasía, la violencia, el exotismo y el machismo. Y efectivamente todos estos son temas que la novela de una u otra forma aborda. Al mismo tiempo Indiana juega consciente y exageradamente con estos elementos, de modo que su novela, dependiendo de la lectura que se le da, puede ser vista tanto afirmativa 
como subversiva frente a estas imaginaciones. Con respecto a la hipótesis planteada inicialmente se pudo constatar que, aunque Papi tiene más características en común con la literatura local, se presta sin más para una lectura, recepción y circulación a nivel global. En cuanto a Indiana misma, se puede afirmar que no es una escritora mundial, en el sentido más estricto, sino una escritora glocal, ya que conecta y reúne temas y elementos globales y locales en su escritura ${ }^{1}$.

\section{Bibliografía}

Aínsa, Fernando. Palabras nómadas: Nueva cartografía de la pertenencia. Iberoamericana/ Vervuert, 2012.

Alamo, Héctor Luis. "Interview: Rita Indiana Hernández”. Gozamos.com, 22 de diciembre 2013. https://gozamos.com/2013/12/interview-rita-indiana-hernandez/, consultado 12 de abril 2018.

Bencomo, Anadeli. “Geopolíticas de la novela hispanoamericana contemporánea: En la encrucijada entre narrativas extraterritoriales e internacionales". Revista de Crítica Literaria Latinoamericana, vol. 35, no. 69, 2009, pp. 33-50.

Bustamante, Fernanda. "Rita Indiana: escritura y canto desde el Caribe". Vísperas. Revista panhispánica de crítica literaria, 13 de junio 2017. www.revistavisperas.com/ritaindia naescrituraycantodesdeelcaribe/, consultado 14 de abril 2018.

Cordeu, Mora. "Rita Indiana irrumpe en la Argentina con la singularidad de la literatura caribeña”. Télam, 26 de marzo 2015. www.telam.com.ar/notas/201503/99343-culturarita-indiana-literatura-novela.html, consultado 13 de abril 2018.

Damrosch, David. What is World Literature? Princeton University Press, 2003.

Díaz, Junot. The brief Wondrous Life of Oscar Wao. Riverhead Books, 2008.

EL PAÍS, and POP etc. "Rita Indiana vacila a los 'papis' del Caribe”. 21 de septiembre 2011, blogs.elpais.com/pop-etc/2011/09/rita-indiana-contra-el-papi-tropical.html, consultado 11 de abril 2018.

Gallego Cuiñas, Ana. "El valor del objeto literario". Ínsula. Revista de Letras y Ciencias Sociales, no. 814, 2014, pp. 2-5.

Indiana, Rita. Papi. Periférica, 2011.

Maeseneer, Rita de. “Rita Indiana Hernández (Dominican Republic, 1977)”. The contemporary Spanish-American novel: Bolaño and after. Ed. Wilfrido H. Corral. Bloomsbury, 2013, pp. 156-159.

Maeseneer, Rita de e Ilse Logie. “Antologías del cuento dominicano de la última década (2000-2010) y canon”. Confluencia, vol. 31, no. 1, 2015, pp. 17-27.

Manrique, Diego A. "Papi: Crítica: Feria de Guadalajara." El País, 19 de noviembre 2011. https://elpais.com/diario/2011/11/19/babelia/1321665147_850215.html, consultado 7 de mayo 2018.

1 Agradezco sumamente el comentario valioso de Rita de Maeseneer. 
Rodríguez, Néstor E. "Rita Indiana Hernández y la novísima narrativa dominicana”. Letras dominicanas, 2002. www.cielonaranja.com/nestorchochueca.htm, consultado 16 de abril 2018.

Venuti, Lawrence. "How to Read a Translation”. Words Without Borders, 2004. www.wordswit houtborders.org/article/how-to-read-a-translation, consultado 16 de abril 2018.

Walkowitz, Rebecca L. Born Translated. The Contemporary Novel in an Age of World Literature. Columbia University Press, 2015. 

Matías Moscardi

\title{
Audiometrías contemporáneas. La escucha como modo de circulación en la poesía argentina actual
}

\author{
"Lo digo como lo oigo" \\ Samuel Beckett \\ "La escucha habla" \\ Roland Barthes
}

Tanto los festivales internacionales como los recitales emergentes de poesía joven que se organizan regularmente, desde hace más de una década, en la Argentina, conforman un fenómeno visible que destaca por su carácter proliferante: eventos que se multiplican, de manera enfática, cada año ${ }^{1}$. Tal es así que, en un artículo titulado "La poesía como festival" Cristian Molina se refiere a la "festivalización de la poesía argentina" (1) como una estrategia de supervivencia, en el presente, de la poesía contemporánea, que genera transformaciones significativas al nivel de la práctica literaria. De acuerdo con el planteo de Molina, la poesía se festivaliza dado que, en este tipo de contextos, la producción textual no se encontraría orientada simplemente desde y hacia la escritura "sino a múltiples relaciones con su puesta en voz y performatividad" (1).

La hipótesis central del artículo es que estamos ante formas poéticas escritas que exceden el formato del libro como dispositivo privilegiado -y con ello la industria editorial-, para intervenir más allá de él, en sus desafueros, a partir de

1 Cristian Molina consigna varios de ellos: "Pienso en el Festival Sumergible, de San Salvador de Jujuy, que desde el año 2012 se lleva a cabo con una dinámica participación de escritores y artistas visuales emergentes, en La Juntada. Festival de poesía joven de Buenos Aires, que desde 2009 se ha convertido en el principal muestrario de la escritura poética de autores entre 20 y 30 años con alcance federal, en el también reciente Festival Internacional de poesía de Córdoba que irrumpe en 2012, y a su vez, en los históricos FIP de Buenos Aires, que aparece en 2006, y en el Festival Internacional de poesía de Rosario, que, desde 1993, se convirtió no solo el más antiguo sino en el referente pionero dentro de este mapa creciente y en expansión del presente" (2).

Matías Moscardi, Universidad de Mar del Plata

Ә Open Access. (C) 2020 Matías Moscardi, published by De Gruyter. (cc) BY-NC-ND This work is licensed under a Creative Commons Attribution-NonCommercial-NoDerivatives 4.0 International License. https://doi.org/10.1515/9783110673678-017 
diferentes soportes y medios. Para Molina, el auge de los festivales de poesía permite interrogar, por sus características estructurales, "las formas de circulación y de puesta en común de lo poético: ¿qué sería lo que se pone en juego en un Festival en relación con la poesía? [. . . ¿Cómo pensar la relación y las redefiniciones de lo poético/el poema/la poesía que se producen en esta inflexión del presente en Argentina?” (2). Molina señala, como consecuencia, que la producción de los poetas jóvenes y emergentes "tiende cada vez más hacia una poesía escrita en relación con su puesta en voz, con su posibilidad de ser cantada, actuada y exhibida, no ya solo leída en formato libro, sino también oída y vista” (16).

El estado de la cuestión que recorta Molina permite pensar, luego, algunos modos de circulación y producción de las práctica poéticas que no se encuentran centrados en la letra impresa y que, por lo tanto, no responden a categorías escriturarias como las de autor, texto y lectura. En su lugar, encontramos voces articuladas en distintos espacios performáticos audiovisuales -del recital en vivo al video de Youtube- en donde la condición de legibilidad del texto aparece desplazada y subsumida por otro tipo de reorganización sensible centrada en lo auditivo y en lo visual como coordenadas de significación. Esto no conlleva, por supuesto, la afirmación apocalíptica y alarmista de la desaparición del libro: los libros de poesía de autores argentinos, por el contrario, militan la tradición revitalizada, en la década de los noventa, por las editoriales independientes, cuya herencia simbólica parece decisiva en el presente del libro de poesía actual. A pesar del saldo positivo, es innegable que otros modos de circulación se adosan a la letra impresa para generar diálogos, tensiones, yuxtaposiciones y mixturas en las que quisiera detenerme. Algunas de las preguntas que quisiera sondear como inquietudes centrales de este artículo son: ¿cómo se escucha la poesía argentina? ¿Qué lugar ocupa el oído en relación a la mano? Y luego: ¿cuáles son los efectos auditivos que resuenan en la escritura? ¿Cabe pensar en una intervocalidad entendida como repercusión sonora de unas voces en otras a la hora de pensar las relaciones entre distintas poéticas?

\section{2}

En un apartado titulado "Escuchar" del libro La expulsión de lo distinto, el filósofo surcoreano Byung-Chul Han escribe:

En el futuro habrá, posiblemente, una profesión que se llamará oyente. A cambio de pago, el oyente escuchará a otro atendiendo a lo que dice. Acudiremos al oyente porque, aparte de él, apenas quedará nadie más que nos escuche. Hoy perdemos cada vez más la 
capacidad de escuchar. Lo que hace difícil escuchar es sobre todo lacreciente focalización en el ego, el progresivo narcisismo de la sociedad. Narciso no responde a la amorosa voz de la ninfa Eco, que en realidad sería la voz del otro. Así es como se degrada hasta convertirse en repetición de la voz propia. (47)

Es posible imaginar, en el reverso de este presagio negativo, un tipo de escucha resistente: la escucha poética. En este sentido, la escucha poética sería lo opuesto a la sordera narcisista porque implicaría, justamente, la incorporación de la voz del otro en la propia. Como explica Byung-Chul Han, escuchar no puede ser un acto pasivo: "la escucha tiene una dimensión política. Es una acción, una participación activa en la existencia de otros” (49). Podríamos encontrar una posible primera nota para una genealogía de la escucha poética moderna en el ensayo "La música de la poesía”, de T. S. Eliot. En su libro Radical Artifice, Marjorie Perloff subraya, al respecto, el lugar el lugar primordial que Eliot le asigna a la escucha como combustible auditivo de la escritura cuando sostiene que la poesía no debería distanciarse del common speech (Perloff 29). Por el contrario, Eliot parece encontrar una coordenada estética determinante en la atención acústica de las resonancias que pueden oírse, por ejemplo, en una conversación cotidiana. Algunas décadas después, los planteos de Eliot serán retomados por Denise Levertov en su ensayo "Technique and Tune-Up". En la expresión "Tune-Up" -traducida frecuentemente como "entonación", aunque también remite, en términos musicales, a la "afinación" y al ajuste de las clavijas de un instrumento- predomina un marcado acento en las habilidades auditivas del poeta, concretamente en la capacidad de escucha como medio de arreglo fundamental en el verso libre. La escucha aparece, en el artículo de Levertov, como una tónica rectora de referencia insoslayable para la afinación y entonación del poema como instrumento musical.

En la crítica contemporánea de poesía argentina, Jorge Monteleone, en su artículo "Voz en sombras: poesía y oralidad", postula la existencia de una entonación que funciona como dispositivo de la oralidad en la escritura: aquello que, interiorizado por el lector, activa rítmicamente la modulación y acentuación de los vocablos. Según Monteleone, esta dimensión imaginaria de la voz en el poema "se conecta mediante sus articulaciones simbólicas en el ritmo, la prosodia, la sintaxis y el sentido” (150) a la vez que, desde sus modulaciones tonales, establece linajes, parentescos, tradiciones, continuidades y rupturas. En el marco de la tradición argentina, la escucha podría pensarse a partir del "Posfacio con deudas" incluido en La obsesión del espacio, de Ricardo Zelarayán. El texto empieza con una escena de escucha:

No sé cómo empezar esto pero empiezo nomás. Hoy estaba almorzando en una pizzería y oí una conversación telefónica del cajero que estaba detrás del mostrador. "Escúcheme 
don Juan -decía el cajero-, la verdad es que cuando hablo con usted salen cositas. ..”. Se hablaba de comprar muy barato un hotel alojamiento por parte del cajero y de su invisible interlocutor. Hotel alojamiento aparte, lo importante era el cajero hablado. No existen los poetas, existen los hablados por la poesía. (71)

Más allá del famoso aforismo final, lo interesante es que, en el reverso de esta ontología de lo poético, se articula una definición tácita: el poeta es, también, aquel que, como el músico, ostenta un saber de la escucha, un oído afinado en el canto del lenguaje. Si en Levertov se encontraba la dimensión técnica de la escucha como clave compositiva para la ejecución de la partitura textual, en la poesía argentina contemporánea, la escucha aparece, muchas veces, tematizada por los mismos textos poéticos. Algo de lo que se adelanta acá, en Zelarayán y en la idea del poeta como aquel que escucha al hablado por la poesía, reaparece, por ejemplo, como dictum, en este poema de Mariano Blatt:

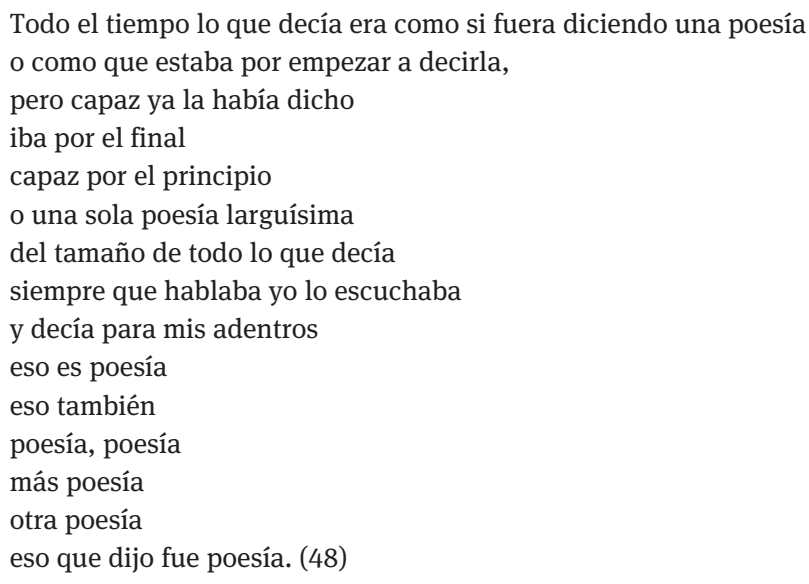

En La interferencia, Michel Serres define a la escucha como "la detección de una señal entre el ruido de fondo" (188). Precisamente, habría algo apuntalado en la concepción de la escucha que encontramos en el poema de Blatt: especie de pinzamiento táctil del oído, de captura acústica. La escucha poética, luego, podría pensarse como punctum auricular. En La cámara lúcida, Roland Barthes define al punctum como un fenómeno carente de organicidad: "ese azar que [en la foto] me despunta" (59). Si el studium está instituido como un saber en tanto "emoción impulsada racionalmente por una cultura" (57), por el contrario, el punctum posee un estatuto distinto: "pinchazo, agujerito, pequeña mancha, pequeño corte, y también casualidad" (59). Si desplazamos el centro visual que vertebra las nociones barthesianas para pensar en términos de escucha, el studium auricular sería, luego, el equivalente de un saber del código -la métrica, pero también los sentidos codificados culturalmente- mientras que el punctum 
auricular, en cambio, sería la percepción punzante de una indeterminación sonora -el ritmo-, de una materia que adviene al oído sin premeditación, que se vuelve audible más allá de su propia racionalidad.

En el caso del citado poema de Mariano Blatt, la escucha aparece como un radar poético: es absolutamente magnética, táctil, deíctica (el oído señala con el dedo: “eso") y se transforma en una metodología distintiva, en una poética que trata de captar la materialidad sonora, verbal, reconocida potencialmente como poesía. El desplazamiento de la escritura a la voz, de la lectura a la escucha, implica un desplazamiento complementario: del ojo al oído, de lo legible a lo audible, de la imagen al sonido, de la escena a la circunferencia, de lo lineal a lo simultáneo. Esto no sucede como exclusión, por supuesto, sino como reorganización de los centros y los márgenes de un régimen sensible. La aproximación a las cosas desde su materialidad acústica implica un estar ahí para ser tocados por el sonido, experimentar su presencia implica estar abierto, disponible, al afecto en tanto contacto con esa materia sonora, con sus reverberaciones.

\section{3}

Para pensar esa relación complementaria en la reorganización simbólica que supone el poema y las figuras compositivas que lo impulsan, habría que revisar teóricamente las posibilidades y proyecciones acústicas de la materialidad textual. En La Galaxia Gutenberg, Marshall McLuhan explica que el "enmudecimiento del lector ha sido un proceso gradual, e incluso la palabra impresa no consiguió silenciar a todos los lectores” (105). En esta dirección, McLuhan se refiere a un énfasis tanto táctil como auditivo en el Finnegans Wake: "el lenguaje de Joyce solo se hace vivo cuando se lee en voz alta, creando una sinestesia o interacción de los sentidos" (105). Luego menciona, como semejantes, los textos de Gertrude Stein, E. E. Cummings, Ezra Pound y T. S. Eliot quienes, en sus poemas, tratan de "poner en acción oral participante al pasivo lector visual" (106): se trata de un tipo de textualidad que debemos "leer con los oídos" (131). Agrega McLuhan: "el Vers libre es tanto para el oído como para el ojo" (106). Incluso en los siglos XVI y XVII, la puntuación tiene como destinatario la audición antes que la visión. En el dato subrayado por McLuhan, aparece esa cercanía entre puntuación y punctum auricular que servía para pensar los rastros auditivos que encontramos como características centrales de algunas escrituras poéticas como la de Mariano Blatt.

Me pregunto, entonces, si esa festivalización que detecta Molina como marca de época no podría pensarse, culturalmente, como una onda expansiva 
tardía de aquel retorno de los espacios acústicos en la cultura letrada del mundo globalizado al que se refería McLuhan de manera incipiente hacia fines de los sesenta, especie de reacustización de una palabra enmudecida históricamente por la escritura. En La palabra muda, Jacques Rancière recupera, como síntoma del mutismo significante, una cita de Marc Fumaroli: "Nuestro concepto de literatura, excesivamente ligado a lo impreso, al texto, deja fuera de su campo lo que el ideal abarcador del orador y de su elocuencia engloba generosamente: el arte de la arenga, el arte de la conversación, sin contar con la tacita significatio del arte del gesto y de las artes plásticas" (citado en Rancière 37). Dicho de otro modo: la palabra impresa parece haber producido un efecto de autonomía y separación casi autotélica de la letra como una entidad desprovista de voz, de gestualidad, de escena, que la escucha poética del presente revitaliza en términos auditivos.

Ezequiel Alemian, en una cobertura periodística para el XVIII Festival Internacional de Poesía de Rosario en Argentina, se pregunta: "Cuando uno escucha leer a un poeta, ¿dónde busca la poesía? ¿En el texto escrito que se escucha pronunciar, o en la pronunciación de ese texto? ¿En la relación dinámica que hay entre el texto escrito y la manera en que se lo pronuncia, o en algo incorpóreo en lo cual texto escrito y manera en que se lo pronuncia se funden por completo?” (1). En este sentido, Alemian percibe que no se trata tanto de un tipo de poesía que se lee en voz alta, "sino de poesía que se escribe para ser leída en voz alta” (1). Esta reorganización de la palabra poética y sus modos de circulación modula un objeto que ya no remitiría exclusiva o estrictamente a lo textual sino a otro tipo de locus donde se aloja lo poético como acontecimiento. El lugar activo de la escucha, luego, permitiría pensar una morada dislocada de la poesía en la lengua, cuya residencia no estaría tanto en los signos de la escritura como en su posibilidad de ser vocalizados y procesados por una sensibilidad audiovisual.

Estamos, entonces, ante poemas construidos entre la escucha y sus objetos: desde los sonidos de la naturaleza hasta las hablas cotidianas, desde los ruidos de la ciudad hasta la escucha misma de las voces de otros poetas, como si la escritura, en todo caso, pudiera captar mejor lo audible que lo visible, como si la escucha poética fuera la respuesta ante un malestar visual. Por ejemplo, en Veriles, de Cristhian Monti, aparece, casi como réplica a las poéticas del objetivismo argentino ${ }^{2}$, la enfermedad del ojo y su intervención quirúrgica: los versos

2 Para una ampliación acerca del diálogo entre el objetivismo norteamericano y la poesía argentina en la década de los noventa se puede consultar: Porrúa, Dobry, García Helder, Prieto, Raimondi, Yuszczuk, Moscardi y Mallol. 
fluctúan entre las imágenes de una mirada defectuosa y su consecuente apoyatura en lo audible casi como tercera dimensión de las composiciones visuales que arman los poemas. En El camino de la liebre, esta impronta aparece condensada en la figura de un animal atravesado por la escucha: "La liebre ya sabía todo al escucharlo" (19). El saber de la escucha, como señala Roland Barthes en "El acto de escuchar", en términos antropológicos, remite de manera directa al sentido del espacio, ya que registra movimientos de alejamiento y retorno: se trata de una concepción territorial de la escucha. De acuerdo con Barthes, también es sonora la apropiación del espacio doméstico, "el de la casa, el del piso (y equivalente aproximado del territorio animal) es el espacio de los ruidos familiares, reconocibles, y su conjunto forma una especie de sinfonía doméstica: los diferentes golpeteos de las puertas, las voces, los ruidos de cocina, de cañerías, los rumores exteriores” (244). La poesía argentina joven, luego, parece abandonar el centro gravitatorio que la generación de los noventa había construido en torno a las poéticas de la mirada, el ojo y lo visual, para reconfigurar un tipo de sensibilidad auditiva en constante interacción con el movimiento y el territorio. Escribe Milton López: "No hay poesía en lo que ves / y si la hubo se diluyó / en el océano de la indefinición” (Borders 34). En la poesía de López, lo audible abre la posibilidad de nuevos imaginarios: "Decían que yo había escrito un poema muy bueno / sobre el ruido que hace un lavarropas / y yo les creí, pero me imaginé mal / me imaginé un ruido más parecido al del secador de pelo. / [...] decían que mi poema había triunfado en Europa / porque allá los lavarropas no hacen ruido / y todos pudieron escuchar un lavarropas de nuevo" (Hablar como los animales 17). De este modo, la escucha, como centro del régimen perceptivo y modo de circulación y vinculación, produce sus efectos desde una reconfiguración fantasmática de la sensibilidad (Nancy 32) ante la frontalidad de la imagen, ante el marco o cuadro que implica toda escena, toda mirada, la escucha desestabiliza el sentido porque pone a disposición un tipo de experiencia que ya no se apoya exclusivamente en la visión.

Otro caso interesante es el de Santiago Pontoni ${ }^{3}$ : cuando recita sus poemas, la flexión vocal propone una escucha declamatoria, casi solemne, paródicamente entonada, que busca el efecto de lo clásico a partir de materiales degradados: "Las crenchas de musgo balanceándose polirrítmicas / como si les hubiesen rallado un remanso encima, / engominadas por el continuum semiótico del meo”. El léxico exógeno a la escena -“polirrítmicas”, "continuum semiótico”- opera como referencia tónica de contraste con lo que se describe: produce, de este modo, una fricción

3 Los poemas a los que me refiero pertenecen a su primer libro y se pueden escuchar acá, leídos por el autor: https://www.youtube.com/watch?v=xs1GdTqHiUo. 
entre tono y sentido, entre lo que el poeta vuelve audible y lo que dice. Al final, incluso, la reescritura de un famoso poema de William Carlos Williams -cuyas lecturas registradas en audio solían ser neutrales, monocordes ${ }^{4}-$ se somete, primero, en una reformulación auditiva que afina ese modo bajo otras coordenadas de pronunciamiento, como si lo dicho fuera estrictamente solemne:

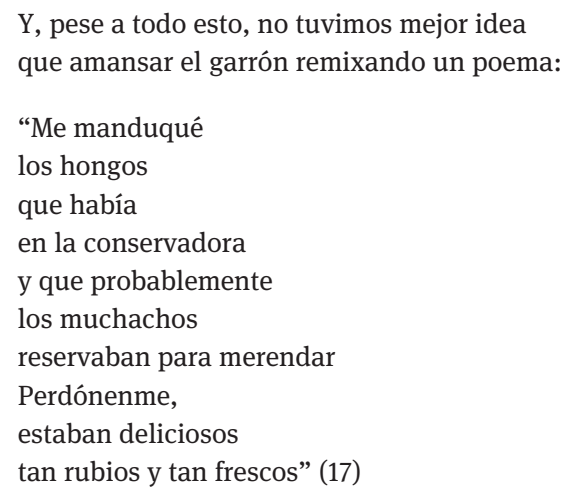

El poema recurre, ahora inversamente, por elecciones léxicas informales o contrastantes - "manducar" en lugar de "comer", "hongos" en lugar de "ciruelas"- que se vuelven risibles al oído bajo el tono grandilocuente en que la voz recalibra la dicción del poema. Y si bien la operatoria de reescritura del poema de Williams puede leerse más allá de su escucha, en términos netamente textuales, es el oído el sensorio que termina de definir la clave fundamental de la parodia: no se trata, en este sentido, de una intertextualidad sino, más bien, de una intervocalidad. Pontoni no reescribe a Williams sino que retoma la poética monocorde del objetivismo norteamericano para remixar su ecualización, para buscar, ya no otro poema, ni otra versión, sino una forma nueva de hacer escuchar ese texto; leer "La carretilla roja”, de William Carlos Williams, como se leería, imaginariamente, un poema de Rubén Darío o incluso -por poner un ejemplo radicalmente opuesto- un poema neobarroco como "Cadáveres", de Néstor Perlongher ${ }^{5}$ : hacer escuchar un poema objetivista en otra escala, decididamente afectada por la declamación, estilizada, incluso exagerada.

La escucha opera, acá, entonces, como un elemento que no puede suprimirse a la hora de pensar la operatoria de reescritura. Quiero decir: por supuesto, no es lo mismo leer el poema de Pontoni que escucharlo. La escucha viene

4 Algunas de las lecturas en vivo de William Carlos Williams se pueden escuchar acá: http:// www.ubu.com/sound/wcw.html.

5 El citado poema de Perlongher se puede escuchar acá, leído por el autor: https://www.you tube.com/watch?v=di_IbckdtHw. 
a acoplarse al poema ya no como una exterioridad o como un suplemento sino como un elemento que define la direccionalidad fundamental de su sentido, una clave sin la cual sería insuficiente leerlo. Dicho de otra manera: la lectura textualista nos dicta que Pontoni reescribe a Williams pero no nos deja oír en qué escala se encuentra exactamente afinada dicha operación. Distinto sería, por ejemplo, si Pontoni reescribiera a Williams y leyera en vivo el poema de un modo monocorde, imitando el mismo estilo Williams. En la versión que escuchamos acá, por el contrario, la reescritura convoca, necesariamente, una revocalización: como si no existiera la posibilidad de una intertextualidad sin su correspondiente correlato vocal. Por otro lado, Pontoni, en efecto, no lee sus poemas sino que los recita ${ }^{6}$ : en el recitado clásico -incluso en los movimientos de la mano de Pontoni- podemos ver el gesto de independizarse de la preponderancia de la letra impresa. La atención es puramente teatral: la escenificación misma del video pone el acento en la escucha y no en la reposición imaginaria de un texto que está siendo leído. Algo en la irrupción excéntrica del viejo recitado genera el efecto de la improvisación: la idea de que el texto, o bien no existe como elemento determinante de lo que escuchamos, o existe de un modo flexible, franqueable.

Ahora bien, si escuchamos leer a Fabián Casas, uno de los poetas argentinos más reconocidos de la actualidad, observamos que ocurre exactamente lo mismo que en el caso de Pontoni, pero en un sentido inverso. Veamos el poema "Después de largo viaje"”:

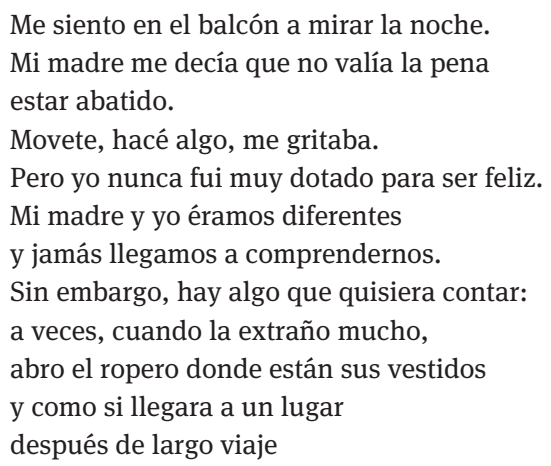

6 Es importante señalar que el recitado de memoria es muy frecuente en las lecturas en vivo de poesía en Argentina: Daiana Henderson, Mariano Blatt, Milton López, Tálata Rodríguez, Alejandra Saguí, Bernardo Orge, entre muchos otros poetas jóvenes, en un momento de la lectura en vivo -o incluso a lo largo de la lectura entera- recitan de memoria uno o más poemas. 7 El poema pertenece al libro El salmón (1996) y se puede escuchar acá, leído por el autor: https://www.youtube.com/watch?v=PUEO0X89kf0. 
me meto adentro.

Parece absurdo: pero a oscuras y con ese olor

tengo la certeza de que nada nos separa. (21)

Se trata, sin dudas, de un poema de duelo, de una voz melancolizada. Y, sin embargo, cuando escuchamos leer a Casas, su voz es el arco que termina de definir eso que nuestra escucha imaginaria anticipa como semiosis textual: se trata de una voz casi sin modulación, sin espectro, de corto alcance, una voz baja que parece pronunciarse desde ese mismo placard, desde el locus que el poema arma como lugar de enunciación. Lo que quiero decir es que la voz monocorde e incluso previsible con que Casas lee el poema no produce el efecto de una tautología, de una reproducción mimética del tono contenido en la escritura: por el contrario, algo se redefine en la escucha. Lo que se redefine, me atrevería a decir, es una imposibilidad tonal: la idea de que el poema suena como suena, efectivamente, y no podría, de ninguna manera, ser escuchado de otro modo.

\section{4}

Alfonsina Brión, en su libro Martes dedo, directamente escribe la escucha, lo que dicen sus interlocutores en sucesivos viajes de ruta, una selección apuntalada de datos auditivos:

Mi nombre es el Rey de la Cumbia.

Tuvo boliche en los 90 .

Trajo cumbieros de todos lados.

Que le ponga azúcar al mate

que para amarga es la vida.

Pinta melanco.

Que lo acompañe el sábado

a escuchar Karina sin El Polaco

que se me va a sanar el corazón.

La Nueva Luna al palo.

Sigue para White.

Me deja en la entrada de Colón.

Hay protesta en Petrobrás.

Se escuchan los bombos. (7)

En los poemas de Brión, la escritura funciona como un aparato de desgrabación selectiva: no hay simple transcripción de esas voces sino síntesis, recortes, ajustes que el registro de la escucha organiza. Si el gesto periodístico de la 
entrevista es la de reconstruir un discurso, el gesto poético de la escucha es doble: pone a resonar una voz en el espacio de la escritura a la vez que intenta producir el efecto de una escucha bífida, como la llama Peter Szendy. “¿Es posible hacer escuchar una escucha?” se pregunta en su libro Escucha. Una historia del oído melómano (22). En este sentido, Szendy sostiene que las escuchas quedan escritas en algún lado: la escucha es, para Szendy, un modo de apropiación tonal que se ejerce sobre la materia sonora. La escritura poética, en el caso de Brión, puede leerse como el dispositivo mismo de registro y reorganización de la materialidad auditiva.

En sus lecturas en vivo, Milton López ${ }^{8}$, por ejemplo, toma un verso muy simple como punto de partida - "te fuiste de casa y te dejaste una caja llena de bufandas"- para luego segmentarlo en todas sus variaciones posibles, en busca de entonaciones diversas como si quisiera volver audible el aparato respiratorio del texto:

Te fuiste de casa y dejaste una caja llena de bufandas

Te fuiste de casa y dejaste

Una caja llena de bufandas

Te fuiste de casa

y dejaste una caja

llena de bufandas

Te fuiste de casa

y dejaste

una caja llena

de bufandas

Te fuiste

de casa

y dejaste

una caja

llena de

bufandas

Te

fuiste

de

casa

$\mathrm{y}$

dejaste

una

caja

llena

de

8 Los poemas seleccionados pertenecen al libro inédito Arroba y se pueden escuchar acá, leídos por el autor: https://www.youtube.com/channel/UCf55u_zOHrzDtlrC7XehODQ. 


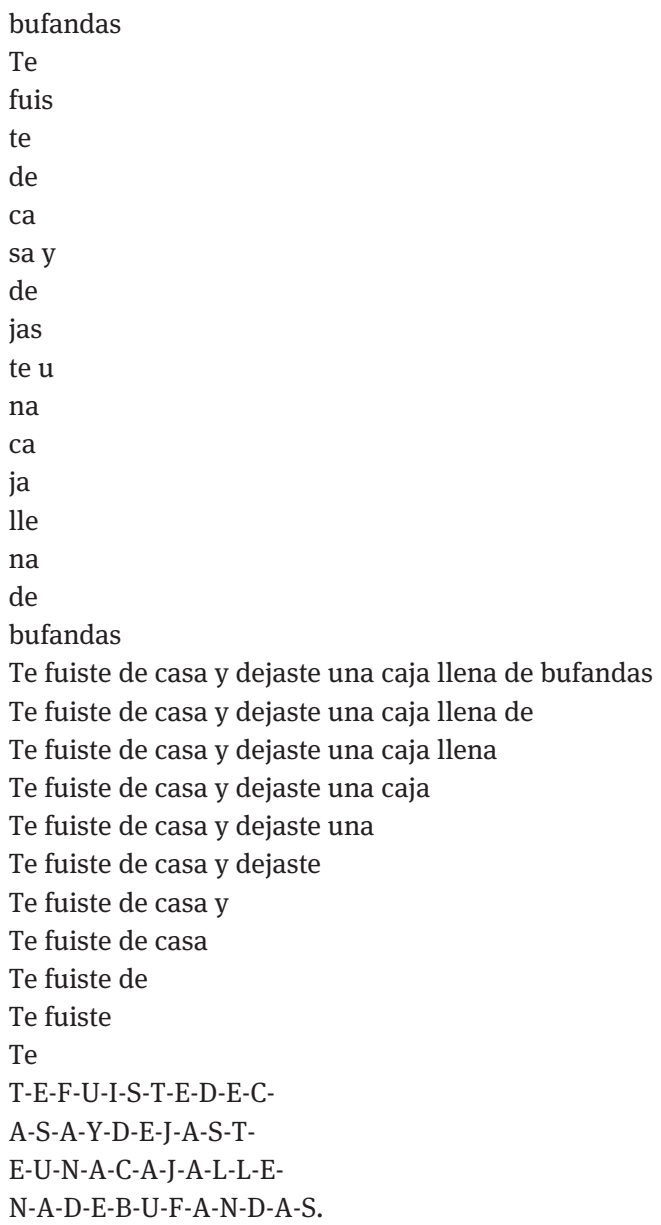

En otras palabras: con el corte de verso lo que se escucha son los procesos de calibración, ajusta y afinación del poema, ese "Tune-Up” del que hablaba Levertov aunque, acá, transformado en objeto mismo del verso. El desarme llega hasta el deletreo: destejer como una bufanda el verso hasta sus unidades constituyentes para dar con la voz, como si debajo de la escritura siempre hubiera un sustrato vocal irreductible; incluso en las letras: porque su pronunciamiento es, en términos vocales, lo que marca una distancia entre la grafía y la voz.

En estas poéticas contemporáneas no parecería haber un legible sin su correspondiente audible. Y más aún: leer a estos y otros poetas argentinos contemporáneos es estar necesariamente $a$ la escucha. Esto quiere decir que el sentido de un poema parece abrirse a su tonalidad, a su ritmo, a su dicción y a 
su timbre: la escucha como aquello que pasa de definir una instancia de producción del poema como el dispositivo clave de su recepción. De este modo, la voz y la escucha, como objetos específicos de la crítica, parecen imponer nuevos desafíos para la circulación, la recepción y el abordaje de los textos poéticos: si los textos impresos ya no resultan la apoyatura exclusiva y privilegiada de la letra, si los soportes audiovisuales y las lecturas en vivo irrumpen en el campo poético con una preponderancia significativa, entonces la crítica tendrá que aguzar su oído para leer a estos poetas.

\section{Bibliografía}

Alemian, Ezequiel. “El nacimiento de la poesía”. Revista Ñ, 11 de octubre 2010. https://www.clarin.com/rn/literatura/poesia/poetica-malestar_0_rk7BEbnaDme.html, consultado 17 de abril 2018.

Barthes, Roland. "El acto de escuchar". Lo obvio y lo obtuso. Imágenes, gestos, voces. Paidós, 1986, pp. 243-257.

---. La cámara lúcida. Nota sobre la fotografía. Paidós, 2004.

Blatt, Mariano. Mi juventud unida. Mansalva, 2015.

Brión, Alfonsina. Martes dedo. Chuy, 2014.

Casas, Fabián. El salmón. Tierra Firme, 1996.

Dobry, Edgardo. “Poesía argentina actual: del neobarroco al objetivismo (y más allá)”. Tres décadas de poesía argentina (1976-2006). Ed. Jorge Fondebrider. Libros del Rojas, 2006, pp. 117-135.

García Helder, Daniel. “Aspectos materialistas en la poesía argentina”. Cahiers de LI.RI.CO, 3, 2007, pp. 131-148.

Han, Byung-Chul. La expulsión de lo distinto. Herder, 2017.

Levertov, Denise. "Technique and Tune-Up”. New and Selected Essays. New Directions, 1992, pp. 93-102.

López, Milton. Hablar como los animales. Eloísa Cartonera, 2014.

---. Borders. La paz: Neutrinos, 2015.

McLuhan, Marshall. La galaxia Gutenberg. Planeta Agostini, 1985.

Molina, Cristian. "La poesía como festival”. El jardín de los poetas, 1, 2016, pp. 223-242.

Mallol, Anahí. “Traducciones y poéticas en Diario de Poesía”. Orbis Tertius, 18:19, 2013, pp. 101-112.

Monti, Cristhian. El camino de la liebre. Iván Rosado, 2014.

---. Veriles. Vox, 2014.

Moscardi, Matías. "Operaciones de traducción en la revista 18 whiskys". Cuaderno del Sur, Letras, 40, 2010, pp. 135-152.

Nancy, Jean-Luc. A la escucha. Amorrortu, 2007.

Perloff, Marjorie. Radical Artifice. Writing Poetry in the Age of Media. University of Chicago Press, 1991.

Pontoni, Santiago. jKowabunga! Diatriba, 2008. 
Porrúa, Ana. "Una polémica a media voz: objetivistas y neobarrocos en Diario de poesía". Boletín del Centro de Estudios de Teoría y Crítica Literaria, 11, 2003. http://www.ce larg.org/int/arch_publi/porrua_una_polemica_a_media_voz.pdf, consultado 19 de octubre 2018.

Prieto, Martín. "Neobarrocos, objetivistas, epifánicos y realistas: nuevos apuntes para la historia de la nueva poesía argentina". Cahiers de LI.RI.CO, 3, 2007, pp. 23-44.

Raimondi, Sergio. “El sistema afecta la lengua (sobre la poesía de Martín Gambarotta)”, Margens/Márgenes, 9/10, 2007, pp. 50-59.

Rancière, Jacques. La palabra muda. Ensayo sobre las contradicciones de la literatura. Eterna Cadencia, 2009.

Serres, Michel. La interferencia. Hermes II. Almagesto, 2000.

Szendy, Peter. Escucha. Una historia del oído melómano. Paidós, 2003.

Toop, David. Resonancia siniestra. El oyente como médium. Caja negra, 2013.

Yucszczuk, Marina. Lecturas de la tradición en la poesía argentina de los noventa. Universidad Nacional de La Plata. Facultad de Humanidades y Ciencias de la Educación, 2011. http:// www.memoria.fahce.unlp.edu.ar/tesis/te.742/te.742.pdf, consultado 6 de junio 2018.

Zelarayán, Ricardo. Ahora o nunca. Poesía reunida. Argonauta, 2009. 


\section{"Los últimos centímetros de un lápiz de grafito". Mercado, (neo)autonomía y la 'operación Mike Wilson'}

\section{I}

El desmantelamiento del orden bipolar que había organizado el mundo durante gran parte del siglo XX y el posterior devenir histórico a partir de los años 90 marcan un quiebre epistémico, político y cultural a escala global. El ingreso en la nueva fase de la globalización se manifiesta asociado de manera indisoluble con una hegemonía del relato (neo)liberal y el consecuente fin de los relatos antagónicos que habían estado vigentes hasta el momento. No se trata, según el tan difundido como desacertado apotegma de Jean-François Lyotard, del fin de los grandes relatos, sino, más bien, de que un relato logra imponerse, aunque sea temporalmente, sobre otros que hasta entonces compartían un significativo poder de interpelación y se presentaban, por consiguiente, como competencias viables. De modo que, a punto de ingresar en la tercera década del siglo XXI, nuestra realidad sigue gobernada por cierto consenso; es una relativamente "estable”, pero también desencantada. Apelando a un eslogan que por un tiempo estuvo en boga en Argentina, se podría decir “cambiamos”. Lo hicimos, y ¿ahora? Simple, la historia apaga su motor para dejarnos suspendidos en un eterno presente. Puesto que las transformaciones radicales en este escenario no configuran ninguna agenda pública, la imaginación (crítica) ya no resulta necesaria. Y por extensión, la literatura, según la concibió el pensamiento occidental moderno, de Immanuel Kant a Theodor Adorno, como el territorio de lo posible, tampoco estaría vigente. Esto ocurre también porque la consolidación y naturalización de la lógica de gestión (neo)liberal, ahora propagada como solución de alcance global, implica una sensible reconceptualización en los modos de producir y concebir la literatura. Desde un cierto punto de vista, con el afianzamiento del mercado como agente regulador privilegiado, estaríamos asistiendo, como anota Gustavo Guerrero, a un resurgimiento del "drama romántico del fin de la literatura y el arte" (83), pues lo que estaría en debate, finalmente, es la autonomía, al menos si se la entiende de acuerdo con los postulados de la modernidad europea.

Jorge J. Locane, Universitat Oberta de Catalunya

Ә Open Access. (c) 2020 Jorge J. Locane, published by De Gruyter. (cc) BY-NC-ND This work is licensed under a Creative Commons Attribution-NonCommercial-NoDerivatives 4.0 International License.

https://doi.org/10.1515/9783110673678-018 


\section{Escribe Guerrero que,}

Aunque es cierto que el debate sobre la cuestión de la autonomía de los campos literarios y artísticos se remonta entre nosotros [latinoamericanos], cuando menos, hasta el movimiento modernista, los niveles de tensión (e incluso de crispación) que adquiere en la última década del siglo XX no tienen precedentes en la historia de nuestra cultura. Escribir, publicar y leer con los telones de fondo de unos volúmenes de sobreproducción [de libros] tan evidentes y asombrosos supone adentrarse en una paisaje bastante conflictivo y donde se han alterado sustancialmente los equilibrios tradicionales que regían las relaciones entre autores y editores, entre críticos y promotores, entre distribuidores y libreros. Pareciera que hay una ruptura, un antes y un después, no solo en lo que concierne al peliagudo asunto de la apreciación o valoración de las obras literarias, sino en lo que toca asimismo a otros aspectos de la mediación editorial y, por tanto, de la imposición de un sentido a través del proceso de transformación de un manuscrito en libro impreso. (81-82)

Para captar la esencia de esta evolución, hace más de diez años Josefina Ludmer introdujo un término que enseguida hizo escuela. Según su fórmula, a nuestro presente le corresponden las 'literaturas posautónomas'. Dos axiomas las sostienen. Uno, el que para los fines de este trabajo interesa, sería "que todo lo cultural (y literario) es económico y todo lo económico es cultural (y literario)" (150-151). Se trata, nuevamente, de que, en este reino gobernado por la lógica de gestión (neo)liberal, no habría existencia fuera del mercado, no habría -dicho de otro modo- producto de la actividad humana que no se realizara como mercancía. Las literaturas posautónomas "representarían a la literatura en el fin del ciclo de la autonomía literaria, en la época de las empresas transnacionales del libro o de las oficinas del libro en las grandes cadenas de diarios, radios, tv y otros medios" (150). Con lo que "Al perder voluntariamente especificidad y atributos literarios, al perder 'el valor literario' (y al perder 'la ficción') la literatura posautónoma perdería el poder crítico, emancipador y hasta subversivo que le asignó la autonomía a la literatura como política propia, específica" $(154)^{1}$. En breve, se trata de que la

1 El segundo postulado que define las literaturas posautónomas sería que en nuestra coyuntura de sobreexposición mediática ya no resultaría posible distinguir entre realidad y ficción, de modo que en estas "el sentido [...] es ocupado totalmente por la ambivalencia: son y no son literatura, son ficción y realidad" (150). No puedo profundizar acá en lo que, desde mi punto de vista, constituiría una serie de complejidades, no exentas de contradicciones y desprolijidades, en los planteos de Ludmer: por un lado, las literaturas posautónomas estarían subordinadas al mercado y, por lo tanto, desprovistas de autonomía, pero, por el otro, al confundirse con "la realidad", se aproximarían a la vida y, por consiguiente, entrarían en sintonía con premisas de las vanguardias históricas. Si se sigue esta lógica, las literaturas posautónomas o, vale decir, "neoancilares”, estarían superando la autonomía artepurista vía reinscripción en el mercado, es decir, que, así como ganarían en poder crítico, por apartarse del artepurismo (cfr. Palmeiro), también lo estarían perdiendo al aceptar prerrogativas de mercado. 
literatura del siglo XXI, al haber aceptado determinaciones de mercado, también habría sacrificando su capacidad de perturbar la gramática del orden establecido.

Hay una serie de problemas con los postulados de Ludmer, ya señalados por varios investigadores. Uno, observa acertadamente Ben Bollig, es que monta sus argumentos sobre una sinécdoque implícita: al tomar la parte (la novela) por el todo (la literatura) y no revelar su operación, evita confrontar su hipótesis con otras "partes", fundamentalmente con la poesía, que posiblemente la obligarían a revisar su planteo. Por lo pronto, "Las oficinas y empresas transnacionales del libro" que menciona Ludmer y que, sin duda, actúan como decisivos agentes reguladores de los flujos y significados de la literatura de nuestra época no suelen ser lugar de acogida para la poesía: si algo caracteriza a los numerosos catálogos del grupo Bertelsmann, a los de las dependencias del grupo Planeta o incluso al de Anagrama es, precisamente, que no reservan espacio para la poesía (cfr. Guerrero 98 y ss., Locane cap. IV.4). Que Ludmer extraiga conclusiones generales a partir de la observación de un único género -hegemónico, pero de todas maneras uno entre otros- solo se puede explicar como una maniobra ideológica condicionada también- por el régimen dominante en la industria editorial a gran escala ${ }^{2}$.

Diría, con todo, que sus argumentos no son ajenos a un Zeitgeist y que, en efecto, auscultan una articulación hoy particularmente sensible. Sin duda, en la actual coyuntura histórica, el enlace entre literatura y mercado se ha tornado en cierto modo inescindible, de manera que las principales categorías -autonomía, valor estético o literario, obra, etc.- que permitían pensar los fenómenos literarios de acuerdo con premisas arraigadas en la modernidad occidental parecen exigir fuertes reconsideraciones. Una de ellas, particularmente desafiante, es la que ofrece Ignacio M. Sánchez Prado en el artículo "Más allá del mercado. Los usos de la literatura latinoamericana en la era neoliberal” (2015). Su propuesta es la siguiente:

2 Ya Pierre Bourdieu, cuando examinó el proceso de autonomización de la literatura durante el siglo XIX francés, daba cuenta de esta distinción entre novela, como género tendiente a la conciliación con el mercado y las determinaciones del poder, y la poesía, en tanto discurso disruptivo y, por lo tanto, sospechoso para las instituciones. De acuerdo con sus planteos, durante la segunda mitad del siglo XIX, "Los gustos de los nuevos ricos instalados en el poder se orienta hacia la novela, en sus formas más asequibles, como los folletines, que se arrancan unos a otros de las manos en la corte y en los ministerios, y que dan lugar a empresas editoriales lucrativas; por el contrario, la poesía, todavía asociada a las grandes batallas románticas, a la bohemia y al compromiso en pro de los menos favorecidos, es objeto de una política deliberadamente hostil, particularmente por parte de la Fiscalía del Estado, asunto del que por ejemplo dan fe los juicios instruidos contra los poetas o el acoso judicial contra los editores como Poulet-Malassis, que había publicado a toda la vanguardia poética, especialmente a Baudelaire, Banville, Gautier, Leconte de Lisle, y que acabó arruinado y encarcelado por deudas” (83). 
en la medida en que en los últimos treinta años las lógicas del mercado literario [...] se han exacerbado en direcciones impredecibles, un modelo basado en la distinción entre una literatura estéticamente autónoma, por un lado, y un mercado que canibaliza sus producciones y las introduce a la lógica de circulación económica, por otro, es inoperante. [. . .] La literatura latinoamericana contemporánea exige, en contra de muchos presupuestos críticos y afinidades ideológicas del legado intelectual latinoamericanista, una comprensión de estética y mercado como parte del mismo sistema de producción cultural. $(19-20)$

Para no abusar del espacio reservado para la introducción, voy a decir que, en principio, coincido en todo -también, aunque abunde en contradicciones, en cierta medida, con Ludmer-, pero que aun así no puedo dejar de escuchar el llamado de una intuición que me sugiere que tal vez haya producciones literarias en su sentido más amplio- que, incluso hoy, en el marco del totalitarismo del mercado, están eludiendo las prescripciones del polo heterónomo y que nosotros, investigadoras e investigadores, -y esto es lo que considero más preocupante- no las estaríamos viendo porque -como Ludmer- fuimos adiestrados para no poder pensar artefactos que no se realizan como mercancía o incluso los que se resisten a tomar su apariencia.

Leñador o ruinas continentales (2013), de Mike Wilson, es un texto ${ }^{3}$ radical no solo en la etiqueta, es decir, de esos que no suelen estar presentes en las estanterías de las librerías y mucho menos en los catálogos de las "empresas transnacionales del libro" que invoca Ludmer. Basta decir que en quinientas páginas apenas hay períodos narrativos y que, en lugar de eso, lo que se encuentra son entradas a manera de una enciclopedia que van dando cuenta del aprendizaje llevado a cabo por el protagonista y narrador homodiegético, un boxeador y excombatiente, acaso de Malvinas, que comienza una nueva vida en una comunidad de leñadores de Yukón. Si el texto puede ser caracterizado de alguna manera es por la postergación indefinida de la acción o, dicho en otros términos, por el detenimiento en el material de la narración, la palabra, antes que en el desarrollo de una trama narrativa. Es uno de esos textos de los que se dice que "no pasa nada", como también sucede en una película -y el paralelismo da para un examen en profundidad- sobre otro

3 La primera edición apareció en la editorial chilena Orjikh editores sin clasificación genérica y sin nombre de autor en la portada. La segunda, aparecida en Fiordo, de Argentina, por el contrario, indica en la tapa no solo el nombre de autor sino también que se trata de una "novela”. Cito de esta última. 
leñador, La libertad (2001), de Lisandro Alonso. Entre los pocos pasajes narrativos del libro, se abre una línea argumentativa muy tangencial y esporádica que tiene como protagonista a un enigmático leñador haitiano. Creo que, a pesar de su carácter en apariencia marginal, esa línea es clave y que merece atención. Cito:

En el centro del campamento hay una cabaña de troncos construida por los leñadores. Adentro hay una estufa a leña, un par de sillas y mesas también hechas por ellos.

Una escala lleva a un altillo estrecho. En él hay una pequeña ventana cuadrada, da a la cordillera. Anoche subí al altillo a ver de qué se trataba. En un rincón se sentaba el leñador haitiano.

Un hombre grande encogido sobre un cuaderno. Entre sus dedos gruesos sostenía los últimos centímetros de un lápiz de grafito. Escribía. (22)

La primera propuesta es que se retenga la imagen de esos "últimos centímetros de un lápiz de grafito” en las manos ásperas de un leñador completamente aislado del mundo: en el rincón de un altillo de una cabaña rústica en un bosque de Yukón. Reténgase también el "escribía”. Se configura, así, una escena en la que una persona dedica su tiempo a la escritura -lo derrocha- sin que, al menos en un principio o como supuesto, se pueda identificar un público receptor/consumidor destinado a ella. El personaje va a reaparecer en unos pocos pasajes más; siempre, sin embargo, en el mismo lugar y las mismas circunstancias. Cito otra vez:

Anoche regresé al altillo. El leñador haitiano seguía en el rincón de siempre, trazando líneas en una libreta. Se escuchaba el ruido seco del grafito contra el papel.

Esta vez me acerqué, me miró de reojo. Le pregunté por qué se aislaba del resto. Al comienzo no respondió. Insistí. Dejó de escribir y alzó la mirada. Tenía ojos grandes, el rostro oculto tras una barba densa y crespa.

Me pidió que lo mirara, que lo mirara bien, que viera su entorno, que de verdad lo viera, no solo como una idea ni como un cuerpo, que me detuviera en él independientemente de todo lo demás, que sólo así entendería por qué se refugiaba en el altillo.

Me senté en el piso y lo observé. Él recogió el lápiz y retomó la escritura. $(37)^{4}$

4 El personaje va a reaparecer esporádicamente en las páginas 118 y 119 y apenas mencionado por el narrador en algunas más. En uno de esos pasajes se lee: "Ya no subo al altillo ni busco al haitiano. No sé bien por qué, pero simplemente no siento la necesidad. Me basta con saber que él sigue allí, sigue escribiendo en su libreta, haciendo cálculos, anotando silogismos, mapeando su entorno. Él ya no baja, vive, come, duerme en el altillo” (212). El narrador, así, pasa de ser el único y circunstancial receptor del mensaje del haitiano al último conocido. Desde ese momento, la escritura del haitiano, aunque él mismo nunca se haya preocupado por ello, no cuenta con ninguna recepción y, sin embargo, no pierde su condición ontológica. La escritura, por lo tanto, sigue su desarrollo aunque no exista instancia receptora. 
Creo que lo más interesante de esta imagen y la serie que conforma es que, con toda su infinita sutileza, contiene el poder inconmensurable de desbaratar el relato -dominante, generalizado y difícil de cuestionar- de que la literatura solo puede adquirir estatus ontológico dentro de los límites del mercado. El leñador haitiano de Wilson, iluminado por determinada operación crítica, desmiente el axioma, compartido por el público amplio y gran parte de los estudios literarios/ culturales, que sostiene que la literatura exige, como condición, la plataforma de difusión que conocemos como mercado para que pueda manifestarse como tal. La literatura -según esta concepción-, antes de pasar por los consabidos mecanismos de la industria editorial, solo sería escritura e intrascendencia. Pero, vale preguntarse, ¿por qué escribe el leñador haitiano? ¿Para quién escribe? ¿Contiene esa escritura la referencia implícita de un consumidor ${ }^{5}$ En breve, ¿es la escritura del leñador haitiano susceptible de ser interpelada como mercancía? La hipótesis que sugiero es que no, que "esos últimos centímetros de un lápiz de grafito" constituirían, acaso, la última encarnación posible -e irreductible- de una cierta autonomía literaria, de una, para responder a Ludmer con otro prefijo, (neo)autonomía ${ }^{6}$. En Yukón, en medio de un bosque, en una comunidad de leñadores, en un altillo. Es decir, radicalmente fuera de los dominios del mercado literario, fuera incluso de los territorios del saber académico, en una circunscripción altamente localizada y replegada sobre sí misma, la literatura -aunque casi invisible- pareciera seguir

5 Del mismo modo, podría hacer la pregunta ¿para quién escribe Mike Wilson?, ¿se orienta su escritura por y hacia la recepción? El paralelismo entre el leñador/escritor de la ficción y el sujeto de la enunciación la establece, a su manera, el mismo Wilson cuando afirma "Para mí escribir representa en muchos sentidos [...] libertad. Me parece lo más natural y lógico. No hay por qué limitarse ni restringirse, nadie es autoridad en esto, no hay que pedirle permiso a nadie ni rendirle homenaje a nadie ni escribir para nadie si uno no quiere. No hay reglas ni fórmulas ni gramáticas que importen. Nada de eso importa, menos aún criterios comerciales o editoriales. Todo eso atenta contra escribir con libertad. Las supuestas aduanas literarias son la invención más dañina que hay para un escritor. Incluso pienso que es maravilloso dejar de considerar al lector" (Ruiz Ortega).

6 La autonomía decimonónica implicó una desvinculación de la literatura de las esferas de los poderes políticos y religiosos. La reinscripción de la literatura en un régimen de neodependecia, ahora del mercado, supondría, por lo tanto, el surgimiento de una nueva autonomía relativa. Como se sabe, las vanguardias y neovanguardias, cuestionaron los postulados del arte por el arte y procuraron estrechar el vínculo entre arte y vida, intentaron poner el primero al servicio de la segunda. La neoautonomía que estoy tratando de conceptualizar se definiría en relación de tensión con las prerrogativas de mercado, implicaría, sí, una autonomía relativa en relación con este, pero, en consonancia con demandas vanguardistas, con el fin no de restaurar algún tipo de solipsismo o tautología, sino como condición, aunque no siempre sea suficiente, para que la literatura pueda sostener su potencial crítico ante todo frente a la lengua y su instrumentalización como herramienta para la producción de sentido común. 
existiendo. ¿Y en qué tipo de autonomía se sostiene? Desde luego no en la del artepurismo, sino en una que procura reservar para la literatura el examen crítico del lenguaje en tanto materialidad y que, por consiguiente, al indagar ese elemento púbico por excelencia, asume también una misión política. Leñador, frente a la literatura mundial (hegemónica), se opone al ‘contenidismo’ (cfr. Guerrero 97 y ss., Locane 42 y ss.), a la literatura al servicio del mensaje útil y de fácil comercialización; incluso como narración, se desliza hacia la poesía para convertir en objeto de análisis al lenguaje y, finalmente, a la literatura misma, sus límites y posibilidades.

Pero ese microlugar extraterritorial, donde la literatura por la literatura misma como garantía para el pensamiento crítico todavía es posible, pertenece -concedo momentáneamente- al orden de la ficción. Un recorrido por la trayectoria del sujeto que asume la autoría del texto -proceso que podría ser denominado 'operación Mike Wilson'- permite vislumbrar, no obstante, que ese lugar de excepción también puede ser creado en este mundo, en el de la realidad empírica. Mike Wilson después de haber publicado un par de novelas en editoriales menores, continúa con el itinerario convencional hasta irrumpir en el campo de la literatura latinoamericana a través de los mecanismos habituales de producción de 'literatura mundial' (cfr. Gallego Cuiñas, Locane): con Guillermo Schavelzon como agente desde Barcelona, publica Zombie (2009) y Rockabilly (2011) en la editorial ahora dependiente del grupo Bertelsmann Alfaguara. Algo, sin embargo, ocurre en ese momento que lo lleva a invertir la lógica e iniciar un proceso de progresiva demarcación de las pautas de mercado y de la circulación internacional: rompe el contrato con su agente, y hace un salto "de retorno" a la publicación en editoriales de escasa cobertura territorial y baja proyección de ventas. Como ya anoté, la primera edición de Leñador (2013) aparece en la editorial Orjikh, la segunda (2016), en Fiordo, y la tercera (2016), en España, en Errata Naturae. Con lo cual, después de pasar por una editorial como Alfaguara y su potencial alcance internacional, opta por una reinserción en circuitos localizados ${ }^{7}$. Consultado sobre ese tránsito, Wilson dijo

7 Las tres ediciones, incluso la española, corresponden a lo que normalmente se conoce como editoriales independientes. Al margen de la discusión que se pueda dar acerca de la adjetivación 'independientes', en los tres casos se trata de editoriales de baja proyección de ventas y escasa cobertura territorial (cfr. Locane). La inserción en el mercado español, y acá le agradezco la observación a César Domínguez, trajo aparejada una (re)semantización de Leñador en clave ecologista, vinculada al mito Henry Thoreau, de buena acogida comercial. En la presentación del libro que ofrece el sitio web de la editorial se pueden constatar la creación de este marco de lectura. Lo mismo se observa en notas publicadas en periódicos españoles, como "Los frutos salvajes: herederos de Thoreau" aparecida en $A B C$. Esto ocurre porque los textos, como se sabe, viajan sin contexto y la circulación internacional conlleva una pérdida de 
Sabía que con Orjikh iba a poder publicar el libro exactamente de la forma que quería. Es una editorial que cuida bien los libros. Además el perfil de Orjikh es más bien de ensayo filosófico y me gusta eso, publicar una novela en un contexto como ese. En parte también quería alejarme un poco del ruido, similar al alejamiento de las redes sociales, publicar la novela en una editorial pequeña, que no es conocida por sacar narrativa. Me pareció un buen refugio. (Salgado Boza)

Me gustaría, entonces, poner en paralelo ese "refugio", que acá representa Orjikh, con el altillo del leñador haitiano: las pequeñas editoriales ancladas a sus contextos serían, así, el refugio de la (neo)autonomía. Y en ese circuito, al menos en relación de tensión con la industria editorial establecida, eventualmente, habría que rastrear indicios de la supervivencia y regeneración de la literatura -por decirlo de algún modo- en el sentido adorniano ${ }^{8}$.

control sobre los significados. Mike Wilson, no obstante, ha tratado de despegar el texto de cualquier lectura en clave ecologista. En una entrevista concedida en 2017 a Joel Vargas, decía: "No tengo una relación especial con la naturaleza, pero me interesan mucho los espacios, los lugares, suelen ser protagónicos en lo que escribo. Creo que el vínculo con Thoreau es válido desde la perspectiva del lector, ellos deciden esas cosas. Pero para mí, al escribir la novela, no era un referente importante, no estaba tan interesado en la naturaleza en sí ni en el oficio de leñador, eso era un pretexto. Me interesaba más el tema del lenguaje. Ese espacio me permitió explorar ciertos límites y ciertas formas de lenguaje, de texto y pensamiento. Fueron otros los referentes, libros como manuales, guías, textos no-narrativos de todo tipo, textos obsoletos, estos jugaron un papel más importante en la novela".

8 También Gustavo Guerrero emplea el término "refugio" para pensar la articulación entre autonomía y edición independiente en el marco de régimen de gestión neoliberal: "En aquel fin de siglo $[\mathrm{XX}]$, y hasta bien entrado el siguiente, el discurso de y sobre la edición independiente se erige en uno de los raros espacios donde se reivindican sin ambages una cierta legitimidad literaria y un valor propio de la literatura. La discusión que Paz y Sarlo habían iniciado a principios de los noventa (y que se echa tanto de menos entre jóvenes generaciones emergentes durante la década) repunta así de una manera radical, inesperada y abierta en las palabras de los editores. Hablar del poder liberador de la escritura, hablar de la importancia de la forma literaria, hablar de la coherencia y la calidad de un catálogo, los convierte en portavoces, garantes y refugio de una autonomía que ahora se defiende no desde fuera sino desde dentro del mismo mercado, en un enfrentamiento claro con los grandes conglomerados y sus expectativas de rentabilidad. La diferencia pasa aquí por la manera de arbitrar y articular las relaciones entre el valor literario que se atribuye a una obra y el valor económico que resulta de la venta de un libro: los independientes reconocen la prioridad de aquel y acusan a los grupos de someterlo todo a los dictados de este. Aún más, los independientes reclaman una cierta idea de legitimidad literaria que se traduciría en la coherencia de la construcción de un catálogo y constituiría así una propuesta estética, crítica y creativa de la cual carecerían los catálogos de los megagrupos” (121-122) (el subrayado es mío). Nótese que el planteo de Guerrero, al sostener que la autonomía se postula necesariamente dentro de los márgenes definidos por el mercado, no se aparta del de Bourdieu (ver nota 10). 
Pero la 'operación Mike Wilson' no concluye ahí, sino que se va a acentuar hasta llegar a la forma más radical de autoedición, autodistribución y descomercialización del producto literario: en 2016, después de Leñador, publicó el relato Scout armado por él mismo como booklet y distribuido gratuitamente en algunas librerías del circuito alternativo de Santiago de Chile. La sentencia "Scout es gratis. No vender" cubre gran parte de la portada y remarca la sustracción del producto al circuito comercial, lo cual -cabe señalar- de ningún modo lo estaría inhibiendo como fenómeno literario. Al respecto de esta política editorial, Wilson declaró: "La gratuidad del texto es una forma de bypasear todo el sistema editorial que tiene que ver con echar a correr un texto literario" (Rozas). Bypasear: el neologismo me parece adecuado. Se trataría de que, mediante este 'puenteo' del régimen heterónomo, que implica ante todo la desmercantilización del texto, el sistema de la literatura todavía seguiría funcionando, es decir que, al contrario de lo que comúnmente se cree, la literatura no necesita del mercado para garantizar su existencia.

A Scout, le siguió Ártico (2016), también publicado, aunque ahora como primera edición, en Fiordo, con lo que, después de la incursión por los extramuros, Wilson parece haber retornado al circuito alternativo pero comercial de las pequeñas editoriales independientes. En este caso, sin embargo, la aclaración genérica desaparece. En el paratexto legal la categoría empleada para clasificarlo es "Literatura”. El subtítulo, que podría arrojar luz al respecto, es "una lista”, de modo que lo que compra el consumidor, al comprar Ártico, en principio, no es ni narrativa ni poesía, sino "una lista”. Al leerlo, sin embargo, se encuentra, sí, con una suerte de narración que reconstruye, en primera persona, el deambular accidentado, físico y psicológico, de un hombre. Lo que interesa, no obstante, es la resolución formal, cercana a la poesía, pero sin llegar a serlo, porque bien podría ser una lista de breves episodios narrativos. $\mathrm{O}$, tal vez, sí se trata de un poema, pero uno despojado de los abusos estilísticos de la poesía manierista. Lo cierto es que, con Ártico, al narrar sin relato, Wilson sigue evadiendo prescripciones de la industria editorial y manteniendo su escritura en un régimen soberano y experimental que difícilmente sería imaginable en el circuito de la gran industria editorial.

\section{III}

Pero la operación Mike Wilson, aunque con sus particularidades, no es exactamente un caso aislado, sino que forma parte una trama algo más compleja donde diferentes formatos, expresiones y proyectos coinciden en rebatir el supuesto de que la intersección entre literatura y mercado resulta hoy en día 
obvia e insoslayable y que, por esa razón, habría que admitir que la primera, aunque sea parcialmente, deba ser regulada por el segundo o que, necesariamente, haya que buscar dentro de los límites más estrechos de este último las soluciones que mejor pueden valer como "literatura"9.

A partir de la imagen del leñador haitiano, me gustaría, entonces, convocar y poner en consideración fórmulas que "bypasean” el régimen heterónomo, que negocian poco o nada con este, es decir, soluciones que, de algún modo, muchas veces se estarían inscribiendo más allá, en un dominio diferenciado, del de la autonomía, según los planteos de Bourdieu ${ }^{10}$, y configurando una suerte de (neo) autonomía crítica. Si esta zona que quiero iluminar -que va desde la edición independiente o autoedición radical y de fanzines hasta la oralidad, la performance y la publicación en internet- no pertenece a la literatura, habría que preguntarse por qué los estudios literarios, de todas maneras, la incluyen dentro de su horizonte de intereses. Me refiero, ante todo, a lo que no se publica, a lo que se publica en los bordes del circuito editorial o a lo que no se publica a través de mecanismos convencionales, a iniciativas que, ante todo, sortean los agentes, las ferias del libro y las grandes librerías y que suelen no trascender fronteras locales. Piénsese, por ejemplo, en Osvaldo Lamborghini encerrado en una habitación de Barcelona

\footnotetext{
9 La propuesta de dar por superada la oposición entre mercado y literatura, que a su modo se encuentra tanto en Sánchez Prado como en Ludmer, aparece sustentada también por José Luis de Diego, quien afirma que "Hace ya varios años, la literatura comercial y la literatura de vanguardia tenían circuitos (y mercados) diferenciados y alternativos, y editoriales especializadas en cada caso; hoy se ha impuesto un criterio midcult en el que el best seller de calidad convive con el best seller abiertamente comercial, con el long seller y con el texto experimental. Pero esto no siempre fue asî” (238). En parcial desacuerdo con estos postulados, mi opinión es que la literatura experimental, la más arriesgada, la que, por lo general, toma distancia crítica de la novela en su formato más convencional, sigue generando, y tal vez hoy más que nunca, sus propios espacios de desarrollo al margen del circuito más comercial. Pensar únicamente dentro de los límites de este último, sería, desde este punto de vista, un recorte centrado en la novela y daría lugar, en cualquier caso, a observaciones parciales.

10 Obsérvese que Bourdieu diseñó su modelo con la mirada puesta en el mercado/campo francés y que el polo heterónomo, guiado por las premisas del desinterés y el rechazo al beneficio económico (a corto plazo), en favor del simbólico, podía estar encarnado por una editorial como Éditions de Minuit (214-221), es decir que la tensión entre ambas lógicas, en su esquema, se da siempre dentro de los límites de la industria editorial convencional. Con la mirada puesta en América Latina, donde la exclusión no solo del orden económico sino también estatal es constitutiva, resulta necesario activar un dispositivo gnoseológico que permita dar cuenta de lo que ocurre -también- fuera del horizonte de las instituciones. Ese territorio, precisamente, es el que en muchos casos tampoco llega a sondear la investigación latinoamericanista.
} 
produciendo ese mítico ejemplar único de Teatro proletario de cámara $(2008)^{11}$, un libro objeto/collage sin rasgos que permitan decir que fue concebido o siquiera identificarlo como un bien de mercado. Recuérdese la revista mural Prisma (1921-1922) publicada y dirigida por Eduardo González Lanuza, Francisco Piñero y Jorge Luis Borges, pegada en la vía pública en Buenos Aires y accesible, por lo tanto, para cualquier pasante. Considérese toda la tradición de literatura oral presente hasta la actualidad en América Latina en la voz de los cuentacuentos y poetas de la oraliteratura como Wiñay Mallki/Fredy Chikangana y Elicura Chihuailaf ${ }^{12}$. Recuérdese la literatura de cordel y la poesía marginal ${ }^{13}$ brasileras en la que funda su estudio Cecilia Palmeiro y que, finalmente, emparenta con proyectos editoriales como Belleza y felicidad y Eloísa cartonera. Piénsese en todas las editoriales cartoneras y la edición artesanal. Incluso en la publicación pirata ampliamente difundida en países de América Latina. Considérese la cita que sigue de Palmeiro acerca del proyecto/galería/lugar de encuentro Tu Rito fundado en 2009 por Fernanda Laguna y Cecilia Pavón en "un local sin terminar de una galería comercial que estaba casi en desuso" (339): "En Tu Rito no hay puertas (unas cortinas de tela cuelgan de lo que sería el frente, y a veces se recogen, como en un escenario); tampoco hay nada a la venta, y salvo algunas noches, nadie atiende o recibe. A Tu Rito puede ir cualquiera, cuando quiera y hacer lo que quiera, incluso robarse las obras, intervenirlas o instalar nuevas" (340). Evalúese toda la autoedición que circula subterráneamente, por lo regular fuera de librerías y bibliotecas, sin registro ISBN $^{14}$, como Scout.

11 Teatro proletario de cámara fue durante mucho tiempo un libro objeto de ejemplar único compuesto por varias carpetas armadas a mano por Lamborghini, y no hay registro de que su proyecto haya sido publicarlo. En el 2008, recién a veintiocho años de la muerte de Lamborghini, apareció una versión facsimilar a cargo de AR Publicaciones, de Santiago de Compostela, con lo que el libro, en un tiraje mínimo, de trescientos ejemplares, ingresó, aunque sea de modo muy marginal y sin que su autor lo hubiera previsto, en el circuito comercial.

12 Para un análisis de las lecturas de poesía como un espacio vital de producción y difusión de literatura irreproducible a través de la industria editorial mainstream y, fundamentalmente, en el circuito mundial, véase Moscardi en este volumen.

13 Sobre la poesía marginal, en la caracterización contenida en $O$ que é poesia marginal, Glauco Mattoso escribió que estos poetas "são desconhecidos do grande público, e produzem e vinculam suas obras por conta própria, com recursos ora precários, ora artesanais, ora técnicos, mas sempre fora do mercado editorial" (20) (el subrayado es mío).

14 Para un estudio en profundidad sobre publicaciones sin ISBN recientes, ver Cella et al. En uno de los artículos que componen el volumen, Lisa Rosenblatt anota: "Para algunas minorías sociales la autoedición representa la posibilidad de articular y difundir sus reclamos y perspectivas sociopolíticas. De este modo, los medios impresos autoeditados constituyen una alternativa a los medios comerciales de la cultura dominante. Muchas autoras y autores pertenecientes a algún grupo desfavorecido o no se sienten representados por estos medios o 
Uno de los problemas, subyacente en varias de estas observaciones, tiene que ver con la asociación mecánica e irreflexiva entre literatura y el soporte libro convencional, como si este objeto fuera el único capaz de contener literatura y como si el libro estuviese predestinado a contener exclusivamente literatura. Pero la pregunta central, para no abundar, sería: ¿Cómo pensar todas estas fórmulas si los límites establecidos para el análisis de los fenómenos estéticos/culturales son los mismos que delimitan el mercado? ¿Cómo pensar, desde ese lugar, al leñador haitiano? ¿Cómo pensar, si el marco de comprensión es la industria mainstream, cualquier proyecto no dispuesto a negociar nada o poco y a regañadientes en el territorio de esta última?

Estas preguntas sirven, ante todo, para problematizar el alineamiento entre mercado y literatura que guía cierta percepción de la crítica y la investigación contemporáneas. En efecto, pienso que la reciente evolución histórica ha dado lugar a una clara hegemonía del polo heterónomo, pero lo que ocurre es que esto vale, principalmente, para el dominio de la literatura mundial, para el circuito donde se resolvió el así llamado boom de la literatura latinoamericana de los años $60 \mathrm{y}$, ahora, la literatura netamente comercial que va de la siempre mentada Isabel Allende a las pseudorevueltas de El crack y compañía. Es decir, el circuito al que Mike Wilson, oportunamente, le sustrajo su producción, de Leñador en adelante. Anota Sánchez Prado que

la interacción entre estética y mercado producida por mecanismos como el premio literario es, de hecho, orgánica al género mismo de la novela y podría decirse que la suspicacia en torno a esta relación es, en buena medida, un producto ideológico de la economía de bienes simbólicos, cuya construcción de capital cultural opera, en parte, a través del ocultamiento de la dimensión puramente económica de la producción cultural. (28)

Es cierto, pero, nuevamente, ¿se reduce la literatura a la novela o, como dejé anotado con Bourdieu, en realidad se trata de que esta constituye el género más condescendiente y acomodaticio a la lógica de mercado? La pregunta, en el fondo y en vista de la 'operación Mike Wilson', extendida, a su vez, a la serie de casos que acabo de mencionar, es si, efectivamente, todo producto cultural es al mismo tiempo una mercancía o si todos lo son de la misma manera. Diría, porque tampoco hay que pecar de inocente y porque el marco general no deja de ser el orden capitalista, que en principio sí, y que Theodor Adorno se equivocaba cuando consideraba a Arnold Schönberg, por ejemplo, expresión radical de la autonomía del arte. Pero esto tampoco debería cegarnos ante fenómenos estéticos/culturales que, incluso hoy, en el contexto del totalitarismo (neo)liberal, no adoptan la forma de

representados en una luz distorsionada que no hace justicia a su propia percepción” (418) (la traducción es mía). 
mercancía o, como dice Wilson, bypasean el sistema editorial. Héctor Hoyos escribe que "La realidad del consumo literario y de la relectura académica es que la oferta con mucho excede la capacidad de asimilación y análisis. No hay tiempo para navegar sin brújula y mapas, por lo cual el Mercado entra a mediar” (93). Tampoco creo que sea conveniente, ni responsable en términos profesionales, dejar en manos del mercado tareas que deberían incumbir a la crítica y la investigación. Quiero decir: para el público en general y ante el exceso de oferta, puede ser coherente, a falta de mejor recurso, que el mercado establezca mecanismos de selección y jerarquización, pero la misma afirmación no valdría para las y los especialistas que deberían actuar como compensación ante las fuerzas que, también para evaluar la literatura, priorizan el rédito económico.

Para cerrar, me permito insistir en que la reinscripción del artefacto estético en algún régimen de (neo)autonomía estaría implicando un necesario desprendimiento del circuito internacional o, valga decir, de la literatura mundial: un abandono de Bertelsmann para pasar a Fiordo o de modo más radical a la autoedición o, valga decir, al altillo. De acá, por lo tanto, que el estudio de una literatura mundial no regulada por pautas exógenas, por principios heterónomos, debería, al contrario de lo que normalmente sucede, concentrar su atención en los dominios locales, en la no-circulación y en la circulación alternativa o subterránea.

\section{Bibliografía}

Bollig, Ben. Activismo poético. Ensayos sobre la poesía argentina contemporánea. Espacio Hudson, 2013.

Bourdieu, Pierre. Las reglas del arte. Génesis y estructura del campo literario. Anagrama, 2015 [1992].

Cella, Bernhard et al. (eds.). NO-ISBN. On Self-publishing. Salon für Kunstbuch/Walther König, 2015.

Cueva, Carmen G. de la. "Los frutos salvajes: herederos de Thoreau”. ABC Culural, 7 de febrero 2017. https://www.abc.es/cultura/cultural/abci-frutos-salvajes-herederosthoreau-201702071128_noticia.html, consultado 16 de enero 2019.

Diego, José Luis de. La otra cara de Jano. Una mirada crítica sobre el libro y la edición. Ampersand, 2015.

Gallego Cuiñas, Ana. "Las narrativas del siglo XXI en el Cono Sur. Estéticas alternativas, mediadores independientes”. Ínsula. Revista de letras y ciencias humanas, 859-860, 2018, pp. 9-13.

Guerrero, Gustavo. Paisajes en movimiento. Literatura y cambio social entre dos siglos. Eterna Cadencia, 2018.

Hoyos, Héctor. "Bolaño como excusa: Contra la representación sinecdótica en la Literatura Mundial”. Letra anexa, 1, 2015, pp. 91-106. 
Locane, Jorge J. De la literatura latinoamericana a la literatura (latinoamericana) mundial.

Condiciones materiales, procesos y actores. De Gruyter, 2019.

Ludmer, Josefina. Aquí América latina. Una especulación. Eterna Cadencia, 2010.

Mattoso, Glauco. O que é poesia marginal. Editora Brasiliense, 1982.

Palmeiro, Cecilia. Desbunde y felicidad. De la cartonera a Perlongher. Título, 2011.

Rozas, Daniel. "Mike Wilson: 'Algunos creen que para escribir Leñador me interné en los bosques con un hacha”. La Segunda, 18 de noviembre 2018. http://impresa.lasegunda. com/2016/11/18/A/7531UVDA, consultado 15 de enero 2019.

Ruiz Ortega, G. “Mike Wilson: ‘Para mí escribir representa en muchos sentidos la libertad’”. Sur Blog, 18 de enero 2017. https://surblogspot.wordpress.com/2017/01/18/mikewilson-para-mi-escribir-representa-en-muchos-sentidos-la-libertad/, consultado $16 \mathrm{de}$ enero 2019.

Salgado Boza, Rodrigo. "Mike Wilson: ‘No me compro el lugar común de que exista una voz generacional”. Lo que leímos, 22 de julio 2015. http://www.loqueleimos.com/2015/07/ mike-wilson-no-me-compro-el-lugar-comun-de-que-exista-una-voz-generacional/, consultado 15 de enero 2019.

Sánchez Prado, Ignacio M. "Más allá del mercado. Los usos de la literatura latinoamericana en la era neoliberal". Libro mercado: literatura y neoliberalismo. Comp. José Ramón Ruisánchez Serra. Universidad Iberoamericana, 2015, pp. 15-40.

Vargas, Joel. “Mike Wilson: 'Leñador no es una novela sobre la naturaleza, sino sobre el lenguaje”.' Artezeta, 2017. http://artezeta.com.ar/mike-wilson-lenador-no-es-una-novela -sobre-la-naturaleza-sino-sobre-el-lenguaje/, consultado 15 de enero 2019.

Wilson, Mike. Ártico. Una lista. Fiordo, 2017.

--.. Leñador o ruinas continentales. Fiordo, 2016 [2013].

---. Scout. Autoedición, 2016. https://issuu.com/mikewilson696/docs/scout, consultado 15 de enero 2019. 


\section{Autores}

Ana Gallego Cuiñas es profesora titular en el Departamento de Literatura Española de la Universidad de Granada. Doctora en Filología Hispánica y licenciada en Antropología Social y Cultural por la Universidad de Granada, ha sido contratada del programa Ramón y Cajal e investigadora visitante en las universidades de California Los Ángeles, Princeton, ParisSorbonne, Buenos Aires y Yale. Numerosos libros, ensayos y artículos de su autoría han aparecido en editoriales y revistas de reconocido prestigio internacional sobre temas dominicanos, narrativa rioplatense contemporánea, escritura autobiográfica, estudios transatlánticos, feminismo, y acerca de la relación entre literatura y economía. Sus publicaciones más destacadas son: Entre la Argentina y España. El espacio transatlántico de la narrativa actual (2012), Queridos todos: el intercambio epistolar entre escritores hispanoamericanos y españoles (2013), Diarios latinoamericanos del siglo XX (2016), A pulmón o sobre cómo editar de forma independiente en español (2017), Las novelas argentinas del siglo 21. Nuevos modos de producción, circulación y recepción (2019) y Otros. Ricardo Piglia y la literatura mundial (2019).

Annick Louis es especialista en literatura argentina e hispanoamericana y en teoría literaria. Actualmente sus trabajos se centran en particular en las relaciones entre ficción, conocimiento e historia. Su trabajo intenta reflexionar también sobre las creencias y los mitos de la crítica, de la historia y de la teoría literaria. Otros centros de interés son: las producciones paratextuales (compilaciones, obras completas, colecciones, antologías, prólogos, escritura en colaboración, compilación en colaboración), las revistas literarias y la enseñanza de la literatura. Fue Visiting Assistant Professor de la Universidad de Yale en 1999-2000 y becaria de la Fundación Alexander von Humboldt (RFA) entre los años 2000 y 2002. Es Maître de Conférences Habilité en la Université de Reims y miembro del Centre des Recherches sur les Arts et le Langage (CRAL, centro de investigación CNRS-EHESS).

Benjamin Loy es profesor asistente en el Departamento de Romanística de la Universidad de Colonia y doctor en Filología Románica por la Universidad de Potsdam. Sus publicaciones e intereses de investigación se centran en las literaturas latinoamericanas y francesa modernas y contemporáneas, teorías y prácticas de la traducción, el cine latinoamericano contemporáneo y las relaciones entre estética y política. Es autor de Roberto Bolaños wilde Bibliothek. Eine Ästhetik und Politik der Lektüre (2019) y ha coeditado colecciones como Re-mapping World Literature. Writing, Book Markets, and Epistemologies between Latin America and the Global South (2018). Su proyecto de investigación actual se ocupa de "narrativas autoritarias" en la literatura e historia de ideas del Siglo XIX y XX en Francia y España. También es traductor y crítico literario y ha traducido al alemán a autores como Juan Villoro, Eduardo Halfon y Eduardo Mendoza.

Cecilia Alvstad es catedrática de los estudios de traducción en la Universidad de Estocolmo. Se especializa en la traducción de la literatura latinoamericana y en la traducción de la literatura infantil y juvenil. Dirigió el proyecto internacional Voices of Translation (2011-2017) y el proyecto interdisciplinario Traveling Texts: Translation and Transnational Reception (2013-2018), ambos en la Universidad de Oslo. Recientemente ha publicado un capítulo sobre traducciones de la obra de Jorge Luis Borges en Translation and World Literature y el capítulo sobre literatura infantil en Routledge Handbook of Literary Translation.

Ә Open Access. (C) 2020 Gustavo Guerrero et al., published by De Gruyter. (c) BY-NC-ND This work is licensed under a Creative Commons Attribution-NonCommercial-NoDerivatives 4.0 International License. https://doi.org/10.1515/9783110673678-019 
Gesine Müller es desde abril de 2013 titular de la cátedra de Romanística de la Universidad de Colonia. Desde 2015 es directora del grupo de investigación Reading Global. Constructions of World Literature and Latin America, fundado por el Consejo de Investigación Europeo. Sus principales focos de interés han sido la literatura romántica en Francia y España, literaturas latinoamericanas contemporáneas y teoría cultural, literaturas caribeñas, procesos de transferencia literaria y transculturalidad. Es autora de libros como Crossroads of Colonial Cultures. Caribbean Literatures in the Age of Revolution (2018) y ha editado más de veinte volúmenes colectivos relativos a cuestiones literarias y culturales del mundo franco e hispanohablante.

Gustavo Guerrero es profesor de literatura y cultura hispanoamericanas contemporáneas en la Universidad de París-Cergy. Paralelamente se desempeña como editor de la casa Gallimard para el área española, portuguesa e iberoamericana. Estudió letras modernas en la Universidad de Paris III y se doctoró en historia y teoría literarias en la Escuela de Altos Estudios en Ciencias Sociales (EHESS) de París. Editó, junto a François Wahl, las Obras completas (Madrid 1999) del cubano Severo Sarduy en la colección Archivos-Unesco. Como ensayista, ha publicado La estrategia neobarroca (Barcelona, 1987), Itinerarios (Caracas 1997), Teorías de la Lírica (México, 1998), La religión del vacío y otros ensayos (México, 2002), Historia de un encargo: La catira de Camilo José Cela (2008), con la que obtuvo el XXXVI Premio Anagrama de Ensayo, y Paisajes en movimiento, literatura y cambio cultural entre dos siglos (Buenos Aires, 2018). Fue profesor invitado en las universidades de Princeton, Cornell y Berna. Actualmente dirige el proyecto interuniversitario Mediación editorial, difusión y traducción de la literatura latinoamericana en Francia (MEDET LAT) en la Escuela Normal Superior de París.

Idun Heir Senstad es doctoranda del Departamento de Archivística, Bibliotecología y Ciencia de la Información de la Universidad Metropolitana de Oslo (OsloMet), donde está finalizando su tesis sobre la traducción de literatura cubana contemporánea en Noruega. Tiene amplios intereses investigativos dentro de las áreas de los estudios de la traducción y la sociología de la literatura. También tiene un máster de lengua española de la Universidad de Oslo.

Ignacio M. Sánchez Prado ocupa la cátedra Jarvis Thurston and Mona van Duyn en las Humanidades en Washington University en St. Louis. Es autor de El canon y sus formas. La reinvención de Harold Bloom y sus lecturas hispanoamericanas (2002); Naciones intelectuales. Las fundaciones de la modernidad literaria mexicana (1917-1959) (2009), con el que obtuvo el premio LASA México 2010 a Mejor Libro en Humanidades; Intermitencias americanistas. Ensayos académicos y literarios (2004-2010) (2012); Screening Neoliberalism: Transforming Mexican Cinema 1988-2012 (2014), Strategic Occidentalism. On Mexican Fiction, The Neoliberal Book Market and the Question of World Literature (2018), e Intermitencias alfonsinas. Estudios y otros textos (2004-2018) (2019). Ha editado trece colecciones críticas, las más recientes de las cuales son A History of Mexican Literature (con Anna Nogar y José Ramón Ruisánchez, 2016), Mexican Literature in Theory (2018) y Pierre Bourdieu in Hispanic Literature and Culture (2018). Es también autor de más de cien artículos académicos sobre cuestiones de literatura, cultura y cine mexicanos, así como de teoría cultural latinoamericana. 
Ilse Logie es doctora en Filología hispánica por la Universidad de Amberes y profesora titular de Literatura hispanoamericana en la Universidad de Gante. Sus publicaciones se centran en la narrativa rioplatense y en la traducción literaria. Ha trabajado la representación de la violencia en la literatura conosureña contemporánea y actualmente dirige el proyecto de investigación "Vidas en traducción. Las paradojas de la escritura autobiográfica multilingüe hispanoamericana 1980-2015”. Entre sus publicaciones se pueden mencionar, además de numerosos artículos, volúmenes como La omnipresencia de la mímesis en la obra de Manuel Puig (Rodopi, 2001); Juan José Saer. La construcción de una obra (ed.; Universidad de Sevilla, 2013); Imaginarios apocalípticos en la literatura hispanoamericana contemporánea (coedición con Geneviève Fabry y Pablo Decock. Peter Lang, 2010).

Jorge J. Locane es licenciado en Letras por la Universidad de Buenos Aires y doctor por la Universidad Libre de Berlín. Su tesis doctoral fue reconocida con el premio alemán ADLAF y publicada bajo el título Miradas locales en tiempos globales por Iberoamericana/Vervuert (2016). En los últimos años se ha desempeñado como investigador posdoctoral en el proyecto ERC Reading Global. Constructions of World Literature and Latin America, alojado en la Universidad de Colonia. De este proyecto, surgieron su monografía De la literatura latinoamericana a la literatura (latinoamericana) mundial (De Gruyter, 2019) y, entre otros, el volumen colectivo, editado junto con Gesine Müller y Benjamin Loy, Re-mapping World Literature. Writing, Book Markets and Epistemologies between Latin America and the Global South (De Gruyter). También editó, con Daniel Nemrava, Experiencias límite en la ficción latinoamericana (literatura, cine, teatro) (Iberoamericana/Vervuert, 2019). Sus intereses de investigación se concentran en la traducción, las políticas editoriales, la poesía, la teoría cultural y literaria, la recepción y las transferencias Sur/Sur. Actualmente, es parte del Global Literary Studies Research Group de la Universitat Oberta de Catalunya con un trabajo dedicado a las relaciones culturales y literarias entre América Latina y China.

Judith Illerhaus entre 2015 y 2019 formó parte del proyecto de investigación Reading Global. Constructions of World Literature and Latin America (financiado por el Consejo Europeo de Investigación) en la Universidad de Colonia. Su proyecto de doctorado investiga los premios literarios y su impacto en la circulación de novelas latinoamericanas centrándose en el Premio Biblioteca Breve. Su publicación está prevista para 2020.

Liset Díaz Martínez es doctora en Ciencias del Lenguaje de la Universidad Cergy-Pontoise (Francia) y es miembro del laboratorio Lexiques, Textes, Discours, Dictionnaires de esa institución. Sus estudios se focalizan principalmente en la dialectología, la lexicografía y la metalexicografía. Se ocupa del análisis de la variación del español y actualmente integra en sus trabajos la literatura hispanoamericana, la traductología y las humanidades digitales, adhiriendo a la filosofía de la ciencia abierta y aplicando principios FAIR. Es redactora asociada de la revista ELA (Estudios de Lingüística Aplicada) y hace parte del equipo editorial del Museo virtual de los diccionarios franceses. Ha publicado recientemente un diccionario escolar (Paris, 2018, redacción colectiva).

Maarten Steenmeijer es catedrático de literatura y cultura españolas y latinoamericanas modernas en Radboud University (Nijmegen, Países Bajos), crítico literario en de Volkskrant y traductor literario (Clarín, Borges, Onetti, Paz, Sábato y otros). Es especialista en estudios de recepción y traducción. Sus últimas publicaciones incluyen libros como Moderne Spaanse en 
Spaans-Amerikaanse literatuur. Een geschiedenis (2009), Alli donde uno diría que ya no puede haber nada. Tu rostro mañana de Javier Marías (2009) (editado con Alexis Grohmann) y Schrijven als een ander. Over het vertalen van literatuur (2015). En 2020 va a publicar El nuevo capital de la literatura española en Europa.

Matías Moscardi es doctor en Letras por la Universidad Nacional de Mar del Plata. Se desempeña como profesor adjunto de la materia Taller de oralidad y escritura. Es autor del libro La máquina de hacer libritos. Poesía argentina y editoriales interdependientes en la década de los noventa (EDUVIM, 2019). Forma parte del consejo editor del sitio Bazar Americano y de la revista El jardín de los poetas.

Sara Carini consiguió el título de Ph.D en Literatura Hispanoamericana en la Universidad Católica de Milán y, actualmente, es becaria de investigación en esa misma universidad. Sus intereses de investigación abarcan la narrativa centroamericana y latinoamericana contemporánea. En particular, sus últimos temas de investigación se centran en el análisis de la narración del cuerpo y de su representación en el texto literario y en la temática de la representación de la esclavitud en la literatura del área centroamericana y caribeña. Se ha dedicado también al estudio de la recepción de la literatura latinoamericana en Italia desde el punto de vista de la mediación editorial y con motivo de esta investigación ha propuesto análisis de este tópico a partir de documentos encontrados en los archivos editoriales de las editoriales Mondadori y Einaudi. Ha hecho también una primera reconstrucción de las relaciones entre la editorial Feltrinelli y América Latina a través del análisis de series políticas publicadas alrededor de los años 70 .

Silja Helber es licenciada en IberoCultura (Lengua, Literatura y Cultura Española) y Portugués por la Universidad de Friburgo (Alemania). Realizó una Maestría en Estudios Latinoamericanos Interdisciplinarios en la Universidad Libre de Berlín, especializándose en Estudios de Género. De 2015 a 2018 formó parte del proyecto de investigación Reading Global. Constructions of World Literature and Latin America (financiado por el Consejo Europeo de Investigación) en la Universidad de Colonia en cuyo marco está escribiendo su tesis doctoral sobre la mundialización de escritores latinoamericanos contemporáneos.

Yehua Chen es licenciada en Filología Hispánica por la Universidad de Estudios Extranjeros de Tianjin y recibió su título de Máster en Estudios de Traducción en la Universidad Pompeu Fabra. De 2015 a 2018 formó parte del grupo de investigación Reading Global. Constructions of World Literature and Latin America (financiado por el Consejo Europeo de Investigación) en la Universidad de Colonia. Actualmente, está preparando la edición de su tesis doctoral titulada "Tan lejos, tan cerca: la traducción y circulación de la literatura latinoamericana en China”. Ha publicado artículos sobre traducción literaria e historia de la traducción. 